\title{
Reactivity and Structure of Complexes of Small Molecules: Dinitrogen
}

\section{Nicolas Mézailles}

Laboratoire Hétérochimie Fondamentale et Appliquée, Université Paul Sabatier, CNRS, 118 Route de Narbonne, 31062 Toulouse, France

mezailles@chimie.ups-tlse.fr 


\section{Introduction}

1. Group 3 and actinide transition metal-dinitrogen complexes

2. Group 4 transition metal-dinitrogen complexes

3. Group 5 transition metal-dinitrogen complexes

4. Group 6 transition metal-dinitrogen complexes

5. Group 7 transition metal-dinitrogen complexes

6. Group 8 transition metal-dinitrogen complexes

7. Group 9 transition metal-dinitrogen complexes

8. Group 10 transition metal-dinitrogen complexes

9. Group 11 transition metal-dinitrogen complexes

Conclusion and perspectives

References 


\section{Abstract}

In this contribution, a comprehensive review of the coordination chemistry of dinitrogen since 2003 is presented. Tremendous advances have been achieved during this time frame on the activation and functionalization of dinitrogen, i.e. fixation, by metal centers. An emphasis is made on these cases. Mechanistic aspects pertaining to functionalization of $\mathrm{N}_{2}$ are presented.

\section{Keywords}

Dinitrogen, reduction, N2-to-NH3 catalysis, N2-to-N(SiMe3)3 catalysis, mechanisms

\section{Introduction}

This chapter, dedicated to the coordination chemistry of $\mathrm{N}_{2}$ follows the one from Comprehensive Coordination Chemistry II, and aims to be comprehensive presenting the results obtained since 2003. However, the chapter written in CCCII mainly focused on "Nature's solution to the nitrogen fixation problem, describing our understanding (up to the end of 2002) of the metal cluster of the nitrogenase enzymes". We will therefore include in the present review some results that date back from before 2003, which were crucial for the subsequent developments of the $\mathrm{N}_{2}$ coordination and functionalization.

\section{Group 3 and actinide transition metal-dinitrogen complexes}

In 1909, Haber patented uranium nitride as heterogeneous catalyst, active enough to be industrial candidates for the $\mathrm{N}_{2}$-to- $\mathrm{NH}_{3}$ process. ${ }^{1},{ }^{2}$ Bosch, Mittasch and co-workers patented later the use of Fe based catalysts and showed that $\mathrm{Y}, \mathrm{La}, \mathrm{Ce}, \mathrm{Th}$ and $\mathrm{U}$ in combination with other metals were also active. ${ }^{3}$ In 1985, Evans reported the first $\mathrm{N}_{2}$ 
complex of an f-block element $\left[\left(\mathrm{Cp}_{2}{ }_{2} \mathrm{Sm}\right)_{2}\left(\mu-\eta^{2}: \eta^{2}-\mathrm{N}_{2}\right)\right]^{4}$, which crystal structure was obtained in $1988 .{ }^{5}$ In 1986, Shur showed that several lanthanide complexes reacted with $\mathrm{N}_{2}$ (atm pressure, room temp) in the presence of excess of $\mathrm{Na} /$ naphthalenide, and that hydrolysis of the reaction medium would generate sub-stoichiometric amounts of $\mathrm{NH}_{3}{ }^{6}$ Since then, dozens of complexes of rare-earth or actinide $\mathrm{N}_{2}$ complexes have been reported, with an increase in the number of reports in the past decade, yet their reactivity remains unexplored.

\subsection{Preparation of Rare Earth (RE : group 3 and}

\section{Lanthanides) metal-dinitrogen complexes}

The overwhelming coordination mode of $\mathrm{N}_{2}$ at rare earth metals is side-on between two metals. It is interesting to note that the chemistry of dinitrogen complexes of RE metals is intimately linked to the search for stable RE complexes at the +II oxidation state. ${ }^{7}$ Only a limited number of anionic ligands have been used successfully in this chemistry: $\mathrm{Cp}$ derivatives, $\mathrm{N}\left(\mathrm{SiMe}_{3}\right)_{2}$, bulky $\mathrm{OAr}, \mathrm{Tp}$ (tris-pyrazolylborate) and calix[4]pyrrole. ${ }^{8},{ }^{9}$ The most common synthetic procedure for the $\mathrm{M}\left(\mathrm{N}_{2}\right)(\mathrm{M}=\mathrm{RE})$ complexes involves reduction under atmospheric pressure of $\mathrm{N}_{2}$ of a chosen precursor in the $+\mathrm{III}$ oxidation state with stoichiometric amounts of strong reducing agents $\left(\mathrm{KC}_{8}\right.$, $\mathrm{NaK}, \mathrm{Li}, \mathrm{Na} \ldots$...). In these cases, THF is classically used as solvent, and its coordination in the final complex depends on the size of the $\mathrm{M}$ center. 


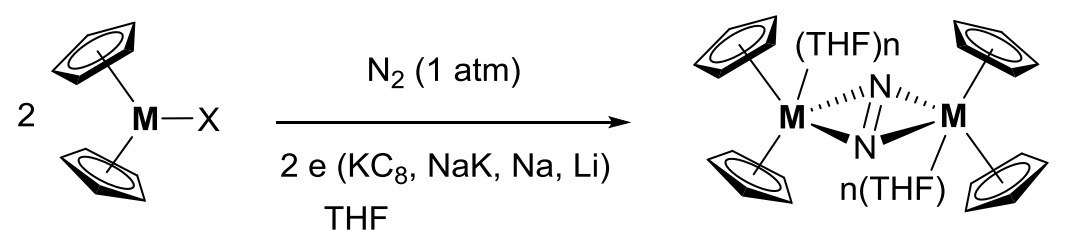

with
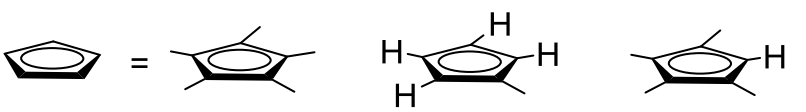

$\mathrm{n}=0-1$<smiles>[18FH]</smiles>

$\mathrm{Cp}$

$\mathrm{Cp} "$
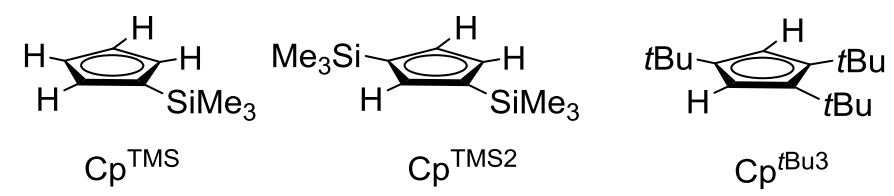

$\mathrm{X}=\mathrm{Cp}$ ', Cp", CpTMS, $\mathrm{BH}_{4}, \mathrm{BPh}_{4}, \mathrm{H}, \mathrm{I}$

$\mathbf{M}=\mathrm{Sc}, \mathrm{Y}, \mathrm{La}, \mathrm{Ce}, \mathrm{Pr}, \mathrm{Nd}, \mathrm{Sm}, \mathrm{Gd}, \mathrm{Tb}, \mathrm{Dy}, \mathrm{Tm}, \mathrm{Lu}$

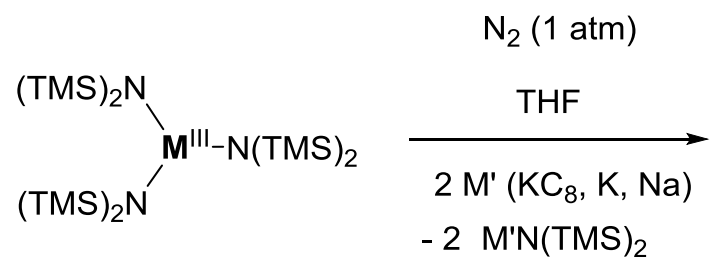

$\mathbf{M}=\mathrm{Sc}, \mathrm{Y}, \mathrm{La}, \mathrm{Ce}, \mathrm{Pr}, \mathrm{Nd}$,

Gd, Tb, Dy, Ho, Er, Tm, Lu

Gr3-Scheme 1

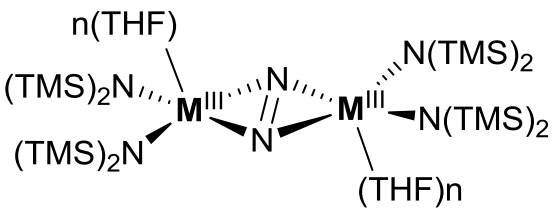

L

Scheme 1

Following equation 1 , scheme 1 , $\left[\left\{(“ C p ")_{2} \mathbf{M}\right\}_{2}\left(\mu-\eta^{2}: \eta^{2}-\mathrm{N}_{2}\right)\right]$ complexes have been

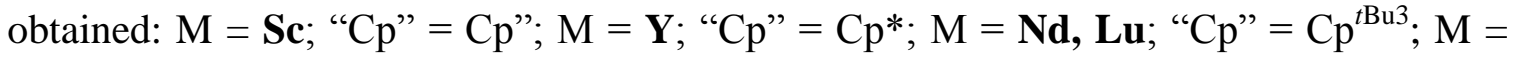
Gd, $\mathbf{T b}, \mathbf{L u}$; "Cp" = Cp*; $\mathrm{M}=\mathbf{L u}$; "Cp" = $\mathrm{Cp}{ }^{*} \mathrm{Cp}$ ". With other combinations of "Cp" ligands and M, solvated complexes are formed, $\left[\left\{(“ \mathrm{Cp} \text { ” })_{2}(\mathrm{THF}) \mathbf{M}\right\}_{2}\left(\mu-\eta^{2}: \eta^{2}-\mathrm{N}_{2}\right)\right]: \mathbf{M}=$ 


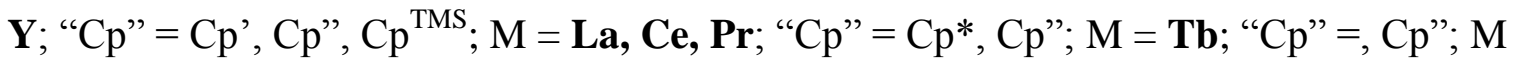

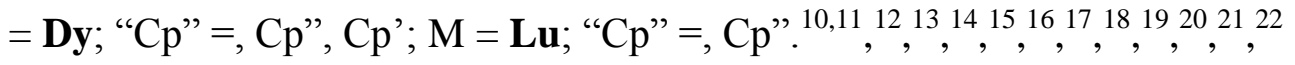

With the bissilylamido ligand $\mathrm{N}(\mathrm{TMS})_{2},\left[\left\{\left(\mathrm{NTMS}_{2}\right)_{2}(\mathrm{THF}) \mathbf{M}\right\}_{2}\left(\mu-\eta^{2}: \eta^{2}-\mathrm{N}_{2}\right)\right]\left(\mathrm{M}=\mathrm{Y},{ }^{23}\right.$ $\mathrm{La}, \mathrm{Nd}, \mathrm{Tb},{ }^{24}$ complexes were obtained following equation 2 , scheme 1 .

Bulky aryloxy complexes of $\left[\left\{(\mathrm{OAr})_{2}(\mathrm{THF}) \mathbf{M}\right\}_{2}\left(\mu-\eta^{2}: \eta^{2}-\mathrm{N}_{2}\right)\right] \quad(\mathrm{Ar}=2,6-\operatorname{dit} \mathrm{BuPh}, \mathbf{M}=$ Dy, Nd) have been synthesized according to two different strategies. The first one is similar to the one presented above, ${ }^{25}$ while the second relies on the accessibility to the $\mathrm{M}^{\mathrm{II}} \mathrm{I}_{2}$ precursors $\left(\mathrm{M}=\mathrm{Nd}\right.$, Dy), and substitution of $\mathrm{I}^{-}$(Scheme 2$) .{ }^{26}{ }^{27}$ In addition to these expected complexes, small amounts of one electron reduced complexes were formed (vide infra).

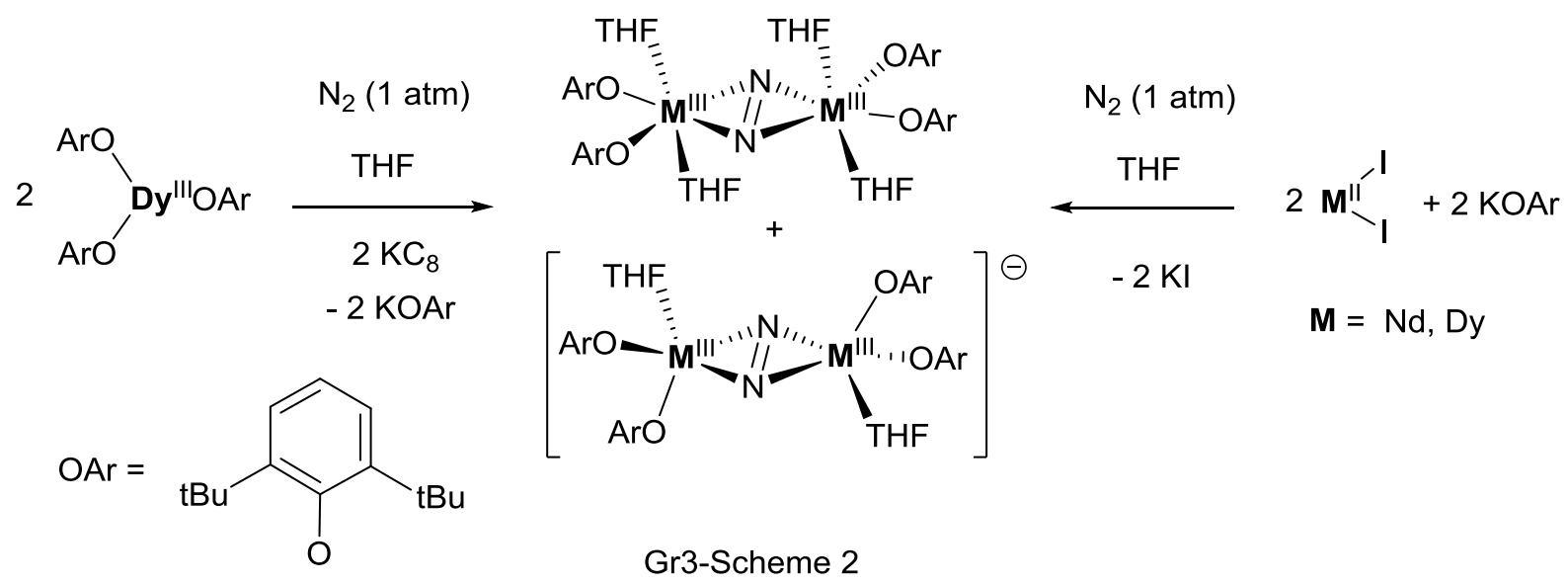

Scheme 2

In fact, this strategy precedes the one involving reduction of the $\mathrm{M}^{\mathrm{III}}$ precursor for the synthesis of several of the bis amide complexes. ${ }^{27}$ The group of Takats reported in 2008 the formation of a $\mathrm{Tm}^{(\mathrm{III})}$-dinitrogen $\left[\left(\mathrm{Tp} \mathrm{p}^{\prime}\right) \mathrm{Tm}(\mathrm{NHR})\right]\left(\mu-\eta^{2}: \eta^{2}-\mathrm{N}_{2}\right)\left(\mathrm{Tp} \mathrm{p}^{\prime}=\right.$ hydrotris(3-tBu-5-Me-pyrazolyl)borate, $\mathrm{R}=2,5-t \mathrm{Bu}_{2}-\mathrm{C}_{5} \mathrm{H}_{3}$ ) complex while attempting to synthesize the primary imido derivative (Tp') $\mathrm{Tm}^{(\mathrm{II})}(\mathrm{NHR})$.

A third strategy has been discovered in 2013. It is based on the observation that 
$\left[\left(\mathrm{Cp}^{*}\right)(\mathrm{Cp} ")_{2} \mathrm{Lu}\right]$ and $\left[\left(\mathrm{Cp}^{*}\right)_{2}(\mathrm{Cp} ") \mathrm{Y}\right]$ react slowly with $\mathrm{N}_{2}$ (3 weeks) to form the known $\left\{\left[\left(\mathrm{Cp}^{*}\right)(\mathrm{Cp} ") \mathrm{Lu}\right]_{2}\left(\mu-\eta^{2}: \eta^{2}-\mathrm{N}_{2}\right)\right\}$ and $\left\{\left[(\mathrm{Cp} *)_{2} \mathrm{Y}\right]\left(\mu-\eta^{2}: \eta^{2}-\mathrm{N}_{2}\right)\right\}$. In the sterically crowded precursors the Cp" ligand in fact coordinates as $\left(\eta^{3}-\mathrm{C}_{5} \mathrm{Me}_{4} \mathrm{H}\right)^{-}$ligand, which elimination as the radical can be photoactivated, leaving an excited d1 metal fragment that can reduce $\mathrm{N}_{2}{ }^{28}{ }^{29}$

All the dinitrogen ligands bridging two rare earth metals presented above contain the diazenido $\mathrm{N}_{2}{ }^{2-}$ ligand, in light of the N-N bond distances measured between 1.17 and $1.31 \AA$ (compare to $\mathrm{N}=\mathrm{N}$ bond of trans-diazene $1.247 \AA$ ). These complexes thus feature a NN double bond.

As mentioned above Evans initially observed the formation of the one electron reduced derivatives $\left[\mathrm{K}(\text { thf })_{6}\right]\left[\left\{\left(2,6-t \mathrm{Bu}_{2} \mathrm{C}_{6} \mathrm{H}_{3} \mathrm{O}\right)_{2}(\text { thf }) \text { Dy }\right\}_{2}\left(\mu-\eta^{2}: \eta^{2}-\mathrm{N}_{2}\right)\right]$ and $\quad[\{(2,6-$ $\left.t \mathrm{Bu}_{2} \mathrm{C}_{6} \mathrm{H}_{3} \mathrm{O}\right)_{2}(\text { thf)Dy }\}_{2}\left(\mu_{3}-\eta^{2}: \eta^{2}: \eta^{2}-\mathrm{N}_{2}\right) \mathrm{K}($ thf $\left.)\right]$ as well as $\left.\left[\mathrm{K}(\mathrm{thf})_{6}\right]\left[\left\{(\mathrm{NTMS})_{2}\right)_{2}(\mathrm{THF}) \mathrm{Y}\right\}_{2}\left(\mu-\eta^{2}: \eta^{2}-\mathrm{N}_{2}\right)\right]$ and $\left[\left\{\left(\mathrm{NTMS}_{2}\right)_{2}(\mathrm{THF}) \mathrm{Y}\right\}_{2}\left(\mu_{3}-\eta^{2}: \eta^{2}: \eta^{2}-\right.\right.$ $\left.\mathrm{N}_{2}\right) \mathrm{K}($ thf)] as byproducts. It was however a very significant discovery and the $\mathrm{N}-\mathrm{N}$ bond distance of $1.40 \AA$, as well as EPR and Raman characterization showed that the $\mathrm{N}_{2}{ }^{2-}$ moiety could be further reduced to the trianionic radical hydrazido(3-) ligand, $\mathrm{N}_{2}{ }^{3-}$. Alternatively the $\left[\left\{\left(\mathrm{NTMS}_{2}\right)_{2}(\mathrm{THF}) \mathrm{M}\right\}_{2}\left(\mu_{3}-\eta^{2}: \eta^{2}: \eta^{2}-\mathrm{N}_{2}\right) \mathrm{K}(\right.$ thf $\left.)\right](\mathrm{M}=\mathrm{Y}, \mathrm{Gd}, \mathrm{Tb}, \mathrm{Dy})$ complexes could be synthesized by the one electron reduction of the corresponding $\left[\left\{\left(\mathrm{NTMS}_{2}\right)_{2}(\mathrm{THF}) \mathrm{M}\right\}_{2}\left(\mu-\eta^{2}: \eta^{2}-\mathrm{N}_{2}\right)\right]$ complexes. ${ }^{25},{ }^{30}$ In these complexes, the $\mathrm{K}$ is bound to the side-on $\mathrm{N}_{2}$ moiety. This coordination can be prevented by using $\mathrm{Na}$ as reducing agent, cryptands of $\mathrm{K}$, or if $\mathrm{K}(\mathrm{THF})_{6}{ }^{+}$is formed. ${ }^{25}$ In terms of reactivity, the first successful example of protonation to form the $\left(\mathrm{N}_{2} \mathrm{H}_{2}\right)^{2-}$ bridging ligand was given with the anionic Y complex (Scheme 3). ${ }^{31}$ Indeed, none of the neutral rare earth related 
complexes (thus featuring $\mathrm{N}_{2}{ }^{2-}$ bridging moiety) showed this type of reactivity, and rather released $\mathrm{N}_{2}$ upon protonation. In this reaction, the radical $\mathrm{N}_{2}{ }^{3-}$ apparently dismutates into $\mathrm{N}_{2}{ }^{2-}$ and $\mathrm{N}_{2}{ }^{4-}$, the latter being protonated. The related $\mathrm{Gd}\left(\mathrm{N}_{2} \mathrm{H}_{2}\right)^{2-}$ complex could be synthesized from the sequence involving reduction of the neutral $\left[\left\{\left(\mathrm{NTMS}_{2}\right)_{2}(\mathrm{THF}) \mathrm{Gd}\right\}_{2}\left(\mu-\eta^{2}: \eta^{2}-\mathrm{N}_{2}\right)\right]$ by $\mathrm{KC}_{8}$, followed by treatment with $\mathrm{NEt}_{3} \mathrm{H}^{+}$. ${ }^{31}$
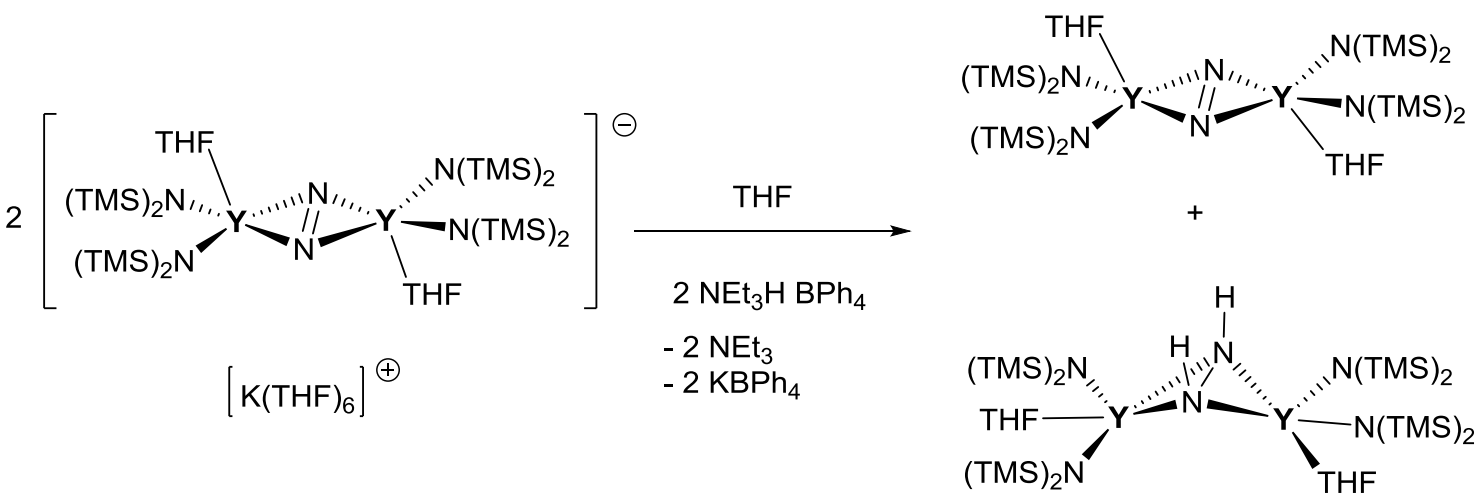

Scheme 3

The chemistry of $\mathrm{N}_{2}{ }^{3-}$ was subsequently developed with the Cp" derivatives. ${ }^{32,33}$ Most notably, the use of the radical trianion of side-on $\mathrm{N}_{2}$ ligand is shown to allow coupling between two lanthanide ions, promoting strong axial magnetic anisotropy leading to single molecule magnets. ${ }^{20}$

Further reduction of $\mathrm{N}_{2}$ to $\mathrm{N}_{2}^{4-}$ with rare earth metals was evidenced. Indeed, starting in 1994, Gambarotta reported the coordination of calix[4]pyrrolide(4-) ligand to $\mathrm{Sm}^{\text {(II) }}$ and $\mathrm{Sm}^{\text {(III) }}$. Coordination of $\mathrm{N}_{2}$ to the $\mathrm{Sm}$ (II) complex formed a dimeric complex in which $\mathrm{N}_{2}$ is surprisingly not reduced when the reaction is done in $\mathrm{THF} / \mathrm{hexane}$, while a trinuclear " $\mathrm{Sm}^{(\mathrm{III})}{ }_{3}\left(\mathrm{~N}_{2}{ }^{4-}\right)$ " complex is formed in $\mathrm{THF}^{8}$ They also used dipyrrolyl coordination to $\mathrm{Sm}(\mathrm{II})$ to promote electron transfer to $\mathrm{N}_{2} \cdot{ }^{34},{ }^{35},{ }^{36}$ In these cases dinitrogen bridged tetrasamarium complexes $\left[(\text { dipyrr })_{4}\{(\mathrm{THF}) \mathrm{Sm}\}_{2} \operatorname{Sm}_{2}\left(\mu_{4}-\eta^{1}: \eta^{1}: \eta^{2}: \eta^{2}-\mathrm{N}_{2}\right)\right]$ are formed, in which $\mathrm{N}_{2}$ is coordinated to two Sm centers end-on and to the two others side- 
on, with overall four $\mathrm{Sm}^{\mathrm{III}}$ and $\mathrm{N}_{2}{ }^{4-}$ moieties.

In 2017, $c a$ almost 30 years after the first report of side-on bridging $\mathrm{N}_{2}$ complexes of rare earth metals, Evans presented the first example of end-on $\mathrm{N}_{2}$ coordination in $\left[\left\{\left(\mathrm{NTMS}_{2}\right)_{3} \mathrm{Sc}\right\}_{2}\left(\mu-\eta^{1}: \eta^{1}-\mathrm{N}_{2}\right)\right][\mathrm{K}(\mathrm{crypt})]_{2}$ (crypt $=2.2 .2$-cryptand) (Scheme 4). Although the $\left[\mathrm{Sc}\left(\mathrm{NTMS}_{2}\right)_{3}\right][\mathrm{K}(\mathrm{crypt})]$ complex does not appear to react with $\mathrm{N}_{2}$ at room temperature, treatment at low temperature $\left(-35^{\circ} \mathrm{C}\right)$ in the absence of light, allowed the synthesis of the bridging $\mathrm{N}_{2}$ complex. DFT calculations of the paramagnetic complex shows two degenerate HOMOs mainly $\mathrm{N}_{2} \pi^{*}$ in character but also with significant $\mathrm{Sc}-\mathrm{N}_{2}-$ Sc $\pi$ bonding character, and thus features a triplet $\mathrm{N}_{2}{ }^{2-}$ ligand (N-N distance of 1.221(3) $\AA$ ). ${ }^{37}$ Irradiation of the complex under Ar liberates $\mathrm{N}_{2}$ and reforms the $\left[\operatorname{Sc}\left(\mathrm{NTMS}_{2}\right)_{3}\right][\mathrm{K}(\mathrm{crypt})]$ starting species. It is proposed that the small size and high Lewis acidity of $\mathrm{Sc}^{3+}$ is responsible for the presence of three anionic amide ligands per metal, and therefore an important steric crowding at the metal favoring the unprecedented end-on coordination in bridging $\mathrm{N}_{2}$ complexes of rare earth metals.

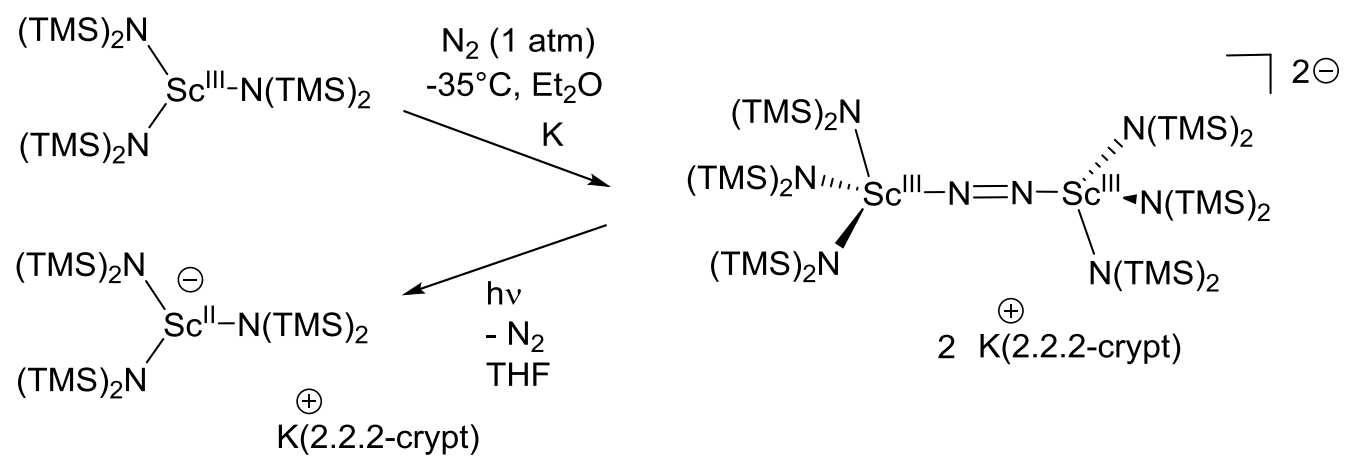

Gr3-Scheme 1

Scheme 4

In 2019, the group of Zhang and Xi reported a novel ligand platform at Sc to activate and functionalize $\mathrm{N}_{2} \cdot{ }^{38}$ It involves $\mathrm{Cp}^{*}$ and amidinate (Scheme 5). Reduction of the $\mathrm{Sc}^{\mathrm{III}}$ precursor with stoichiometric amounts of $\mathrm{K}$ formed the $\mathrm{N}_{2}{ }^{2-}$ side-on bridging 
complex, while reduction with an excess of $K$ in the presence of cryptand [2.2.2] formed the paramagnetic $\mathrm{N}_{2}{ }^{3-}$ bridging complex featuring an elongated $\mathrm{NN}$ bond distance (1.3963(16)Å) (between single and double). Most interestingly, only the anionic complex reacted with MeOTf. In the latter complex, the $\left(\mathrm{N}_{2} \mathrm{Me}_{2}\right)^{2-}$ fragment possesses a nucleophilic character, and several hydrazine derivatives were obtained in good yield upon reaction with activated electrophiles. Reaction with $\mathrm{CO}$ yielded an unsymmetrical dimer in excellent yield via $\mathrm{N}-\mathrm{C}$ bond formation.

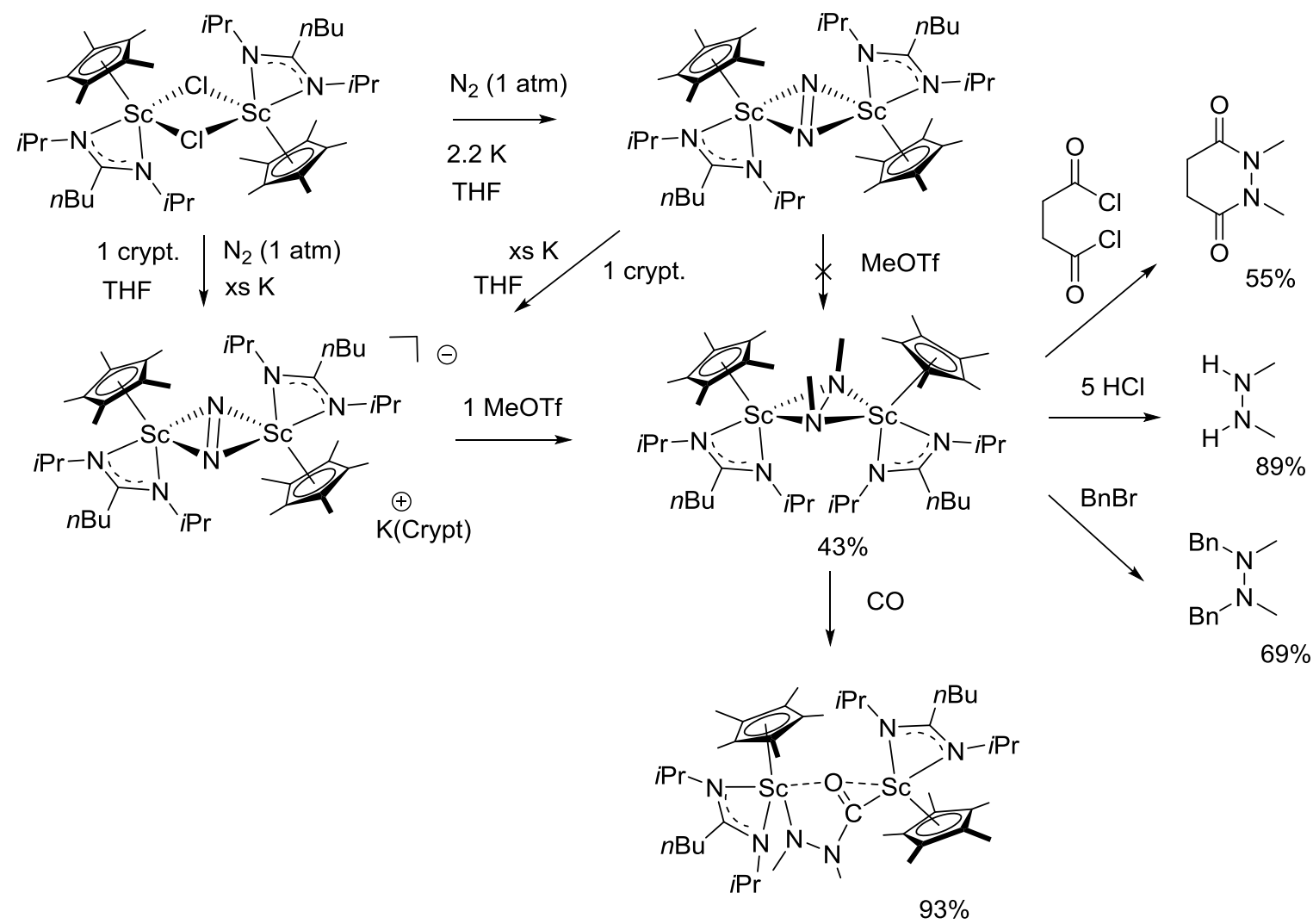

Scheme 5

\subsection{Preparation of Uranium metal-dinitrogen complexes}

In 1998, Roussel and Scott reported the first actinide- $\mathrm{N}_{2}$ complex using a bulky trisamido-amine ligand. ${ }^{39}$ Coordination of $\mathrm{N}_{2}$, in side-on fashion, proved to be reversible 
and the short NN bond distance (1.109(7) $\AA$ ) suggests that the " $U\left(\mathrm{NN}_{3}{ }_{3}\right)$ " fragment acts as a potent Lewis acid, preventing back donation and formal $\mathrm{N}_{2}$ reduction. The same year, Cummins reported the end-on coordination of $\mathrm{N}_{2}$ between a $\mathrm{U}^{\mathrm{III}}$ and a $\mathrm{Mo}^{\mathrm{III}}$ trisamide complexes. ${ }^{40}$ A double electron transfer occurs to form the $\mathrm{U}^{\mathrm{IV}}-\left(\mathrm{N}_{2}{ }^{2-}\right)-\mathrm{Mo}^{\mathrm{IV}}$ complex. In 2002, Cloke and Hitchcock provided the second example of side-on bridging coordination of $\mathrm{N}_{2}$ at $\mathrm{U}^{\mathrm{III}}$, using bulky $\mathrm{Cp}^{*}$ and pentalene ligands. ${ }^{41}$ In that case, magnetic susceptibility and $\mathrm{NN}$ bond distance of $1.232(10) \AA$ consistent with $\mathrm{N}_{2}{ }^{2-}$, point to reduction of $\mathrm{N}_{2}$ by the two $\mathrm{U}^{\mathrm{III}}$ centers, leading to two $\mathrm{U}^{\mathrm{IV}}$ centers. Despite the stronger activation of $\mathrm{N}_{2}$ in this complex, $\mathrm{N}_{2}$ is readily lost in the solid state or in solution. The same year, Gambarotta reported that the reduction of a $\mathrm{U}^{\mathrm{III}}$ tetrapyrrole complex by potassium naphthalenide under $\mathrm{N}_{2}$ resulted in the formation of the bridging dinitrido $\mathrm{U}^{\mathrm{IV}} / \mathrm{U}^{\mathrm{V}}$ complex, in which the $\mathrm{NN}$ triple bond has been split. ${ }^{42}$ In 2003 , the only mononuclear rare earth or actinide $\mathrm{N}_{2}$ complex featuring end-on coordination was reported by Evans. Exposure of [UCp* ${ }_{3}$ ] to $c a 5$ atm of $\mathrm{N}_{2}$ afforded the $\mathrm{U}^{\mathrm{III}}-\mathrm{N}_{2}$ complex, which readily releases $\mathrm{N}_{2}$ upon lowering the pressure (Scheme 7; top). ${ }^{43}$

It is worth noting here that Gambarotta evidenced the formation of parent amido $\mathrm{NH}_{2}$ fragment upon the reduction of a Th complex under $\mathrm{N}_{2}$, although an intermediate $\mathrm{N}_{2}$ complex was not isolated. ${ }^{44}$ This is the first and sole example of functionalization of $\mathrm{N}_{2}$ into terminal amide $\mathrm{NH}_{2}$ in rare earth and actinide complexes (Scheme 6).
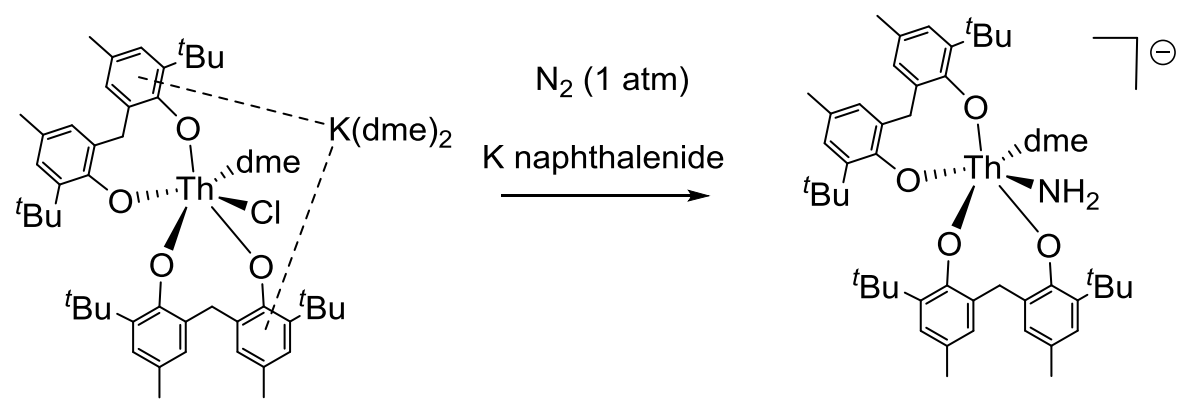
Scheme 6

In 2011, Arnold reported the coordination of $\mathrm{N}_{2}$ at $\mathrm{U}^{\mathrm{III}}\left[\mathrm{U}(\mathrm{OR})_{3}\right]$ complexes $(\mathrm{R}=$ 2,6-di-tert-butylphenoxide, 2,4,6-tri-tert-butylphenoxide, Si(Mes) $)_{3}$, Scheme 7, bottom), and that the analytical data points the $\mathrm{U}^{\mathrm{IV}}-\mathrm{N}_{2}{ }^{2-}-\mathrm{U}^{\mathrm{IV}}$ structures. ${ }^{45}$ The OSi(Mes) 3 dinitrogen complex is remarkably thermally stable. ${ }^{46}$

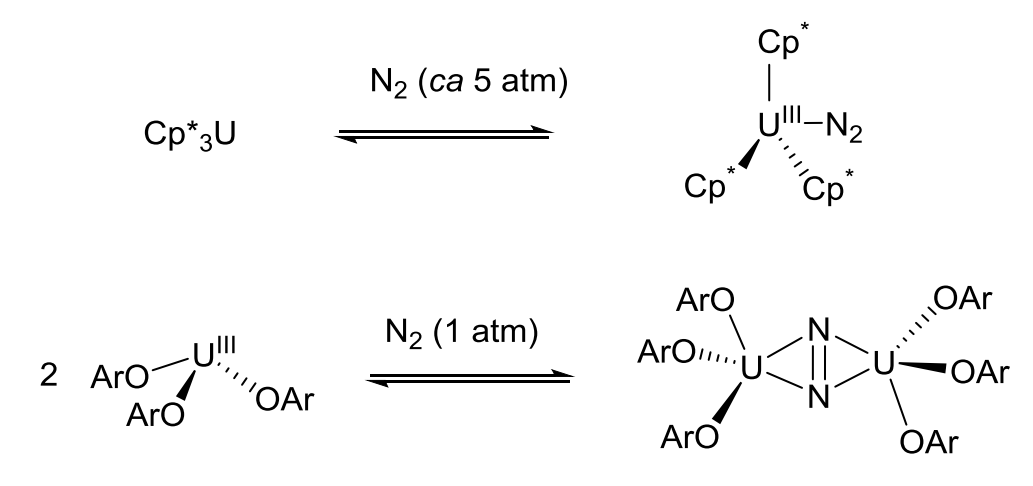

Scheme 7

In 2013, Mazzanti showed that the $\left[\mathrm{U}\left\{\mathrm{OSi}(\mathrm{OtBu})_{3}\right\}\right][\mathrm{K}(18-\mathrm{C}-6)]$ reacted with organic azides to form the corresponding imido complexes. The reaction of $\left[\mathrm{U}\left(\mathrm{OSi}(\mathrm{OtBu})_{3}\right)_{2}(\mu-\right.$ $\left.\left.\mathrm{OSi}(\mathrm{OtBu})_{3}\right)\right]_{2}$ with $\mathrm{CsN}_{3}$ at low temperature resulted in the formation of the $\mathrm{U}^{\mathrm{IV}} / \mathrm{U}^{\mathrm{IV}}$ bridging nitride $\mathrm{Cs}\left\{(\mu-\mathrm{N})\left[\mathrm{U}\left(\mathrm{OSi}-(\mathrm{OtBu})_{3}\right)_{3}\right]_{2}\right\} .{ }^{47}$ The reactivity of the latter complex was subsequently studied. Its reduction by $\mathrm{KC}_{8}$ results in the formation of $\left[\mathrm{K}_{3}\left\{\left[\mathrm{U}(\mathrm{OR})_{3}\right]_{2}(\mu-\right.\right.$ $N)\}]$ which does react with $N_{2}$ to form the $\left[K_{3}\left(\mu_{4}-\eta^{1}: \eta^{1}: \eta^{1}: \eta^{1}-N\right)\left(\mu_{3}-\eta^{2}: \eta^{2}: \eta^{2}-\right.\right.$ $\left.\left.\mathrm{N}_{2}\right)\left(\mathrm{U}\left\{\mathrm{OSi}(\mathrm{O} t \mathrm{Bu})_{3}\right\}_{3}\right)_{2}\right]$ complex, in which the side-on $\mathrm{N}_{2}$ moiety is $\mathrm{N}_{2}{ }^{4-}$ (Scheme 8). ${ }^{48}$ Protonation of the complex under sub-stoichiometric conditions allowed isolation of the parent imido-dinitrogen complex, while with two equiv. of $\mathrm{H}^{+}$, the dinitrogen moiety is protonated to form the bis-bridging imido complex. Most interestingly, reaction with excess $\mathrm{H}+$ source under $\mathrm{H}_{2}$ resulted in $77 \%$ formation of $\mathrm{NH}_{3}$, whereas without $\mathrm{H}_{2}$ a lower yield of $\mathrm{NH}_{3}$ is found. 

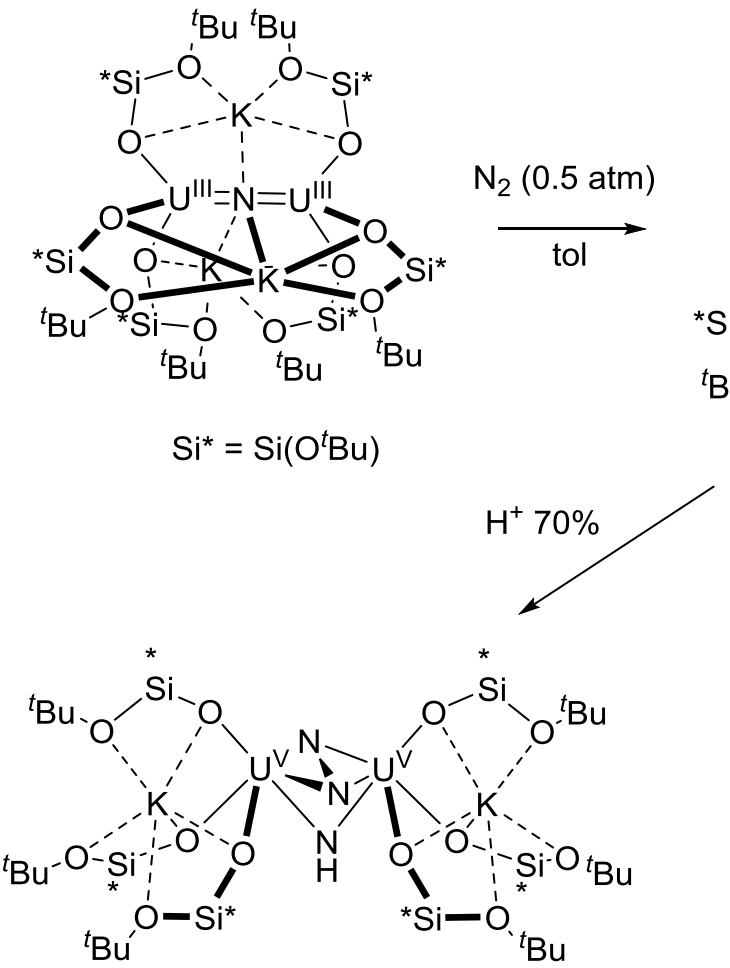
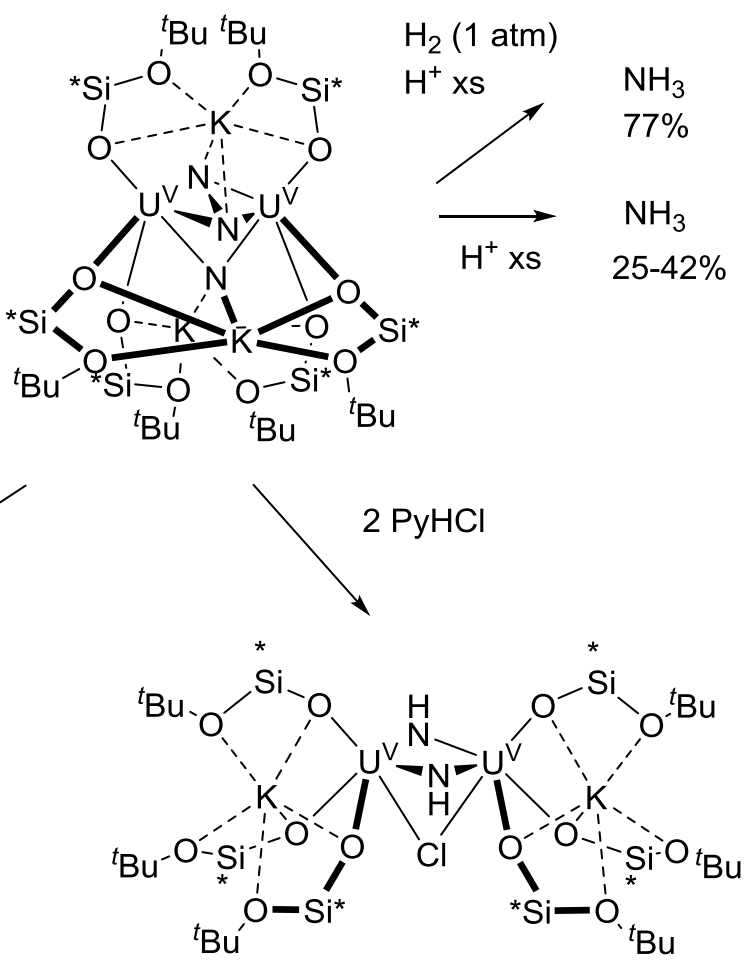

Scheme 8

In 2019 , the same group studied the reactivity of a diuranium $\mathrm{U}^{\mathrm{III}}-\mathrm{O}-\mathrm{U}^{\mathrm{III}}$ complex toward $\mathrm{N}_{2}$ (Scheme 9). ${ }^{49}$ In this case also a bridging hydrazido 4- is formed, which strong nucleophilic character was evidenced by its reactivity toward excess $\mathrm{CO}$. A cyanamido $\mathrm{NCN}^{2-}$ bridged complex is formed resulting from $\mathrm{NC}$ bond formation and $\mathrm{CO}$ bond breaking. Addition of excess $\mathrm{CO}$ to isolated cyanamide complex promotes a slow reduction of the diuranium(V) complex into a bis-oxo diuranium(IV) complex. Unfortunately, the fate of the $\mathrm{N}$ containing product could not be identified. Rather surprisingly, protonation of the hydrazido 4- moiety did not result in $\mathrm{NH}_{3}$ formation but rather in $\mathrm{N}_{2}$ liberation. 

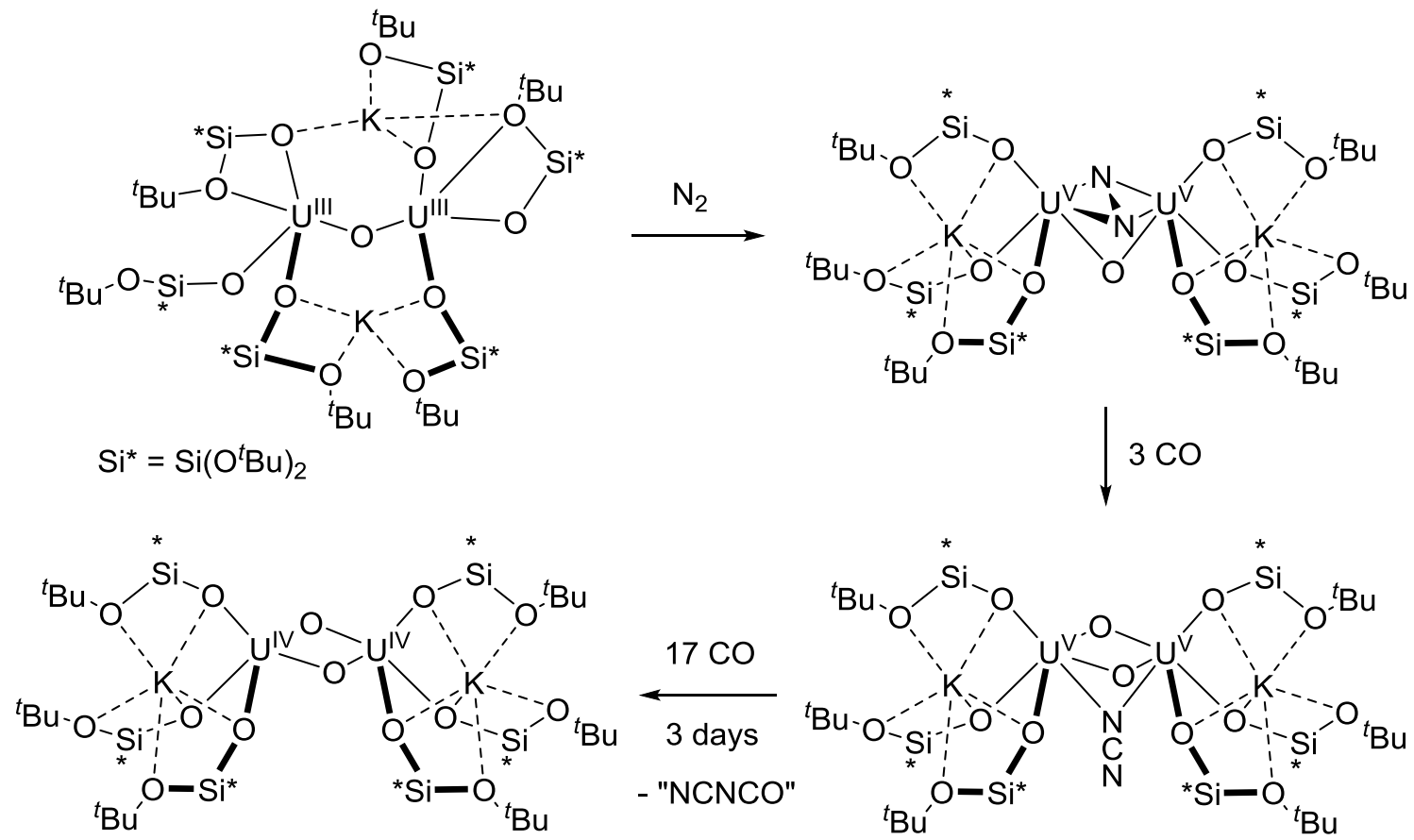

Scheme 9

In conclusion, rare earth and actinide complexes of dinitrogen have been reported quite recently, and their reactivity has not been studied extensively yet. However, first trends can be seen. In the rare earth complexes, it appears that the nucleophilic or basic character of the $\mathrm{N}$ atoms of the bridging $\mathrm{N}_{2}{ }^{2-}$ is rather weak, and $\mathrm{N}_{2}$ is typically liberated rather than functionalized. On the other hand, the one electron reduced species, featuring $\mathrm{N}_{2}{ }^{3-}$ is readily protonated or alkylated, forming the corresponding $\left(\mathrm{N}_{2} \mathrm{H}_{2}\right)^{2-}$ and $\left(\mathrm{N}_{2} \mathrm{Me}_{2}\right)^{2-}$ bridging species, opening ways to further functionalize dinitrogen. Recent developments at $\mathrm{U}$ centers also evidenced the need for strongly reduced $\mathrm{N}_{2}{ }^{4-}$ moiety for subsequent functionalization. 


\section{Group 4 transition metal-dinitrogen complexes}

\subsection{Ti complexes: synthesis and reactivity}

Major developments of the coordination chemistry of $\mathrm{N}_{2}$ obtained in the 2000s are based on the early works by Vol'pin and Shur, Shilov, and Bercaw. The latter group introduced the $\mathrm{Cp}^{*}$ (pentamethylcyclopentadienyl) ligand in the titanocene chemistry, synthesized $\mathrm{N}_{2}$ complexes and demonstrated reversible end-on coordination depending on the temperature (Scheme 10, top). ${ }^{50,51}$ Teuben, Mach and coworkers have used the less sterically demanding $\eta^{5}-\mathrm{C}_{5} \mathrm{Me}_{4} \mathrm{H}$ ligand and reported that unlike the $\mathrm{Cp}$ * derivative, the Ti-H complex reacts instantaneously with $\mathrm{N}_{2}$ to form the bridging end-on $\left[\left\{\left(\eta^{5}-\right.\right.\right.$ $\left.\left.\left.\mathrm{Me}_{4} \mathrm{C}_{5} \mathrm{H}\right)_{2} \mathrm{Ti}\right\}_{2}\left(\mu-\eta^{1}: \eta^{1}-\mathrm{N}_{2}\right)\right] .{ }^{52}$ The group of Chirik studied the effect of systematic modification of the substitution pattern of the $\mathrm{Cp}$ ring. They observed changes in both the stability of the $\mathrm{N}_{2}$ adducts (decreased stability with increasing bulk), and in its coordination mode. Indeed, if the end-on coordination is favored with bulky $\mathrm{Cp}$ rings and ansa derivative, ${ }^{53}$ the side-on coordination is observed in $\left[\left\{\left(\eta^{5}-1,2,4-\mathrm{Me}_{3} \mathrm{C}_{5} \mathrm{H}_{2}\right)_{2} \mathrm{Ti}\right\}_{2}(\mu-\right.$ $\left.\left.\eta^{2}: \eta^{2}-\mathrm{N}_{2}\right)\right]$ (Scheme 10, middle). ${ }^{53}$ This coordination results in a significant $\mathrm{N}-\mathrm{N}$ bond elongation to $1.216(3) \AA$, indicating a two electron reduction to $\mathrm{N}_{2}{ }^{2-}$. Reduction of the bond order was classically associated with increased reactivity at the $\mathrm{N}_{2}$ fragment, yet reaction with $\mathrm{H}_{2}$ liberated $\mathrm{N}_{2}$ and formed the dihydride complex. When the steric bulk was reduced further, a trimetallic Ti complex was formed in which the $\mathrm{N}_{2}$ binds in a $\mu_{3^{-}}$ $\eta^{1}: \eta^{2}: \eta^{1}$ fashion. It features the longest $\mathrm{N}-\mathrm{N}$ bond in titanocene complexes $(1.320(3) \AA)$ (Scheme 10, bottom left). ${ }^{54}$ 


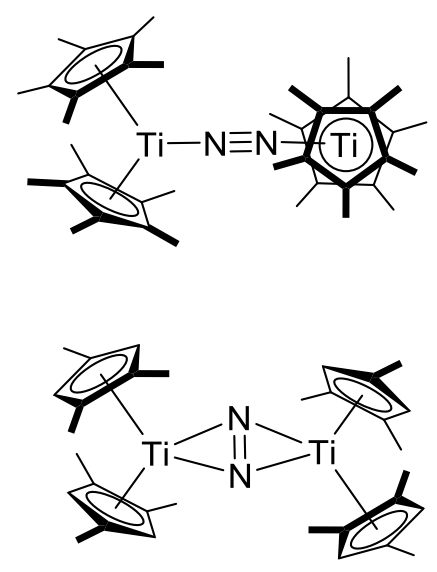

$\mathrm{d}(\mathrm{N}-\mathrm{N})$ 1.216(3) A

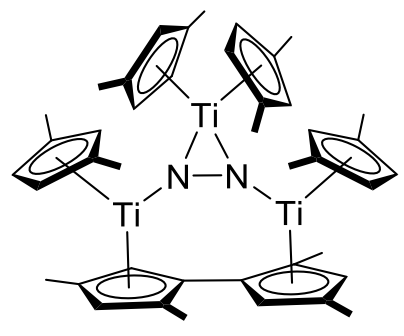

$d(N-N) 1.320(3) A$
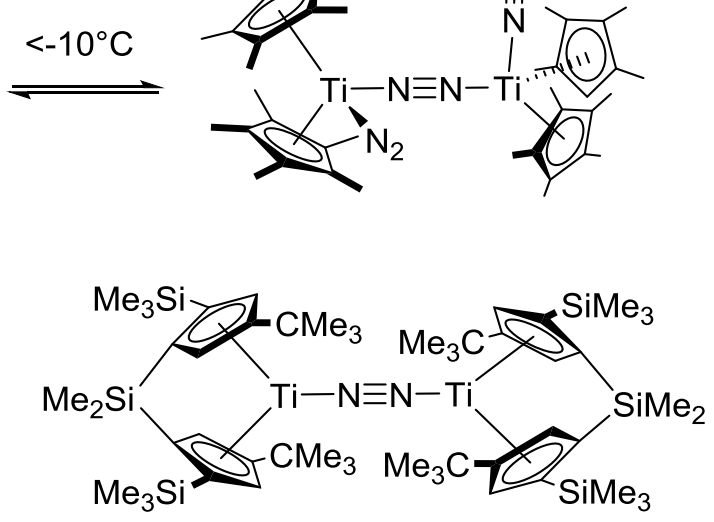

$d(N-N) 1.174(3) A$

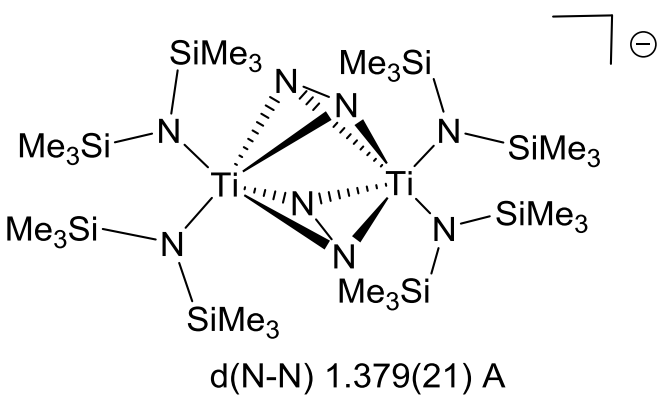

Scheme 10

Reduction of $\mathrm{Cp}^{*} \mathrm{TiCl}_{3}$ under $\mathrm{N}_{2}$ in the presence of fulvene derivatives resulted in the formation of related end-on complexes. ${ }^{55}$

Simple bis-silylamide ligands were shown by Gambarotta to stabilize reduced $\mathrm{Ti}$ complexes bearing strongly activated $\mathrm{N}_{2}$ moieties. ${ }^{56}$ Indeed, N-N bonds of $1.379(21) \AA$ and 1.263(7) $\AA$ are measured in the anionic mixed valent complex $\left[\mathrm{Li}(\right.$ tmeda) $)\left[\left\{\left[\left(\mathrm{Me}_{3} \mathrm{Si}\right)_{2} \mathrm{~N}\right]_{2} \mathrm{Ti}\right\}_{2}\left(\mu-\eta^{2}: \eta^{2}-\mathrm{N}_{2}\right)_{2}\right] \quad($ Scheme 10, bottom right $)$ and $\left[\left\{\left[\left(\mathrm{Me}_{3} \mathrm{Si}\right)_{2} \mathrm{~N}\right]_{2} \mathrm{TiCl}(\text { tmeda })\right\}_{2}\left(\mu-\eta^{1}: \eta^{1}-\mathrm{N}_{2}\right)\right]$ respectively. The same group then reported the use of tridentate ligands featuring pyrrolide moieties. Reduction of a $\mathrm{Ti}^{\mathrm{III}}$ precursor LTiCl ( $\left.\mathrm{L}=2,5-\left\{\left(\mathrm{C}_{4} \mathrm{H}_{3} \mathrm{~N}\right) \mathrm{CPh}_{2}\right\}_{2} \mathrm{C}_{4} \mathrm{H}_{2} \mathrm{~N}(\mathrm{Me})\right)$ under $\mathrm{N}_{2}$ with various amounts of $\mathrm{Na} / \mathrm{Hg}$ in DME resulted in N-N bond splitting in the coordination sphere of Ti (Scheme 11). Using 
THF as crystallization solvent resulted in protonation of one of the two bridging nitride moieties, and reaction with $\mathrm{SiMe}_{3} \mathrm{Cl}$ yielded the imido complex [LTiNTMS].
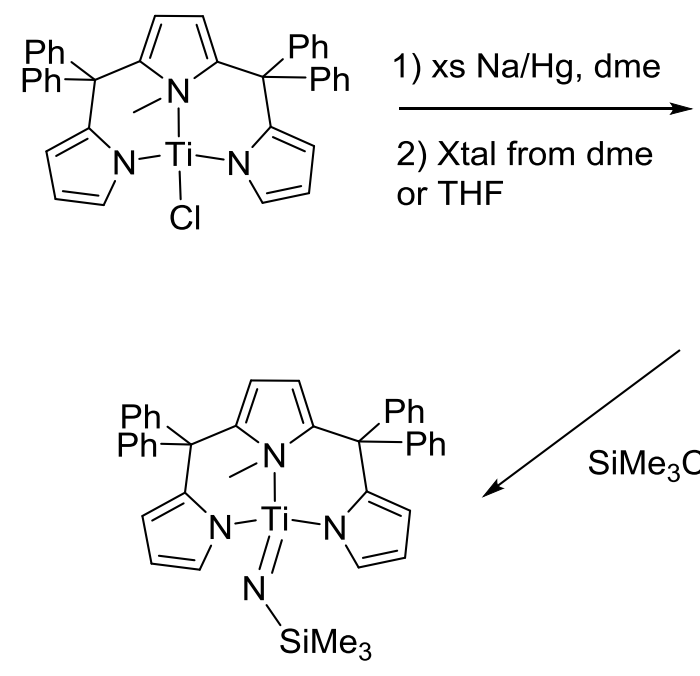

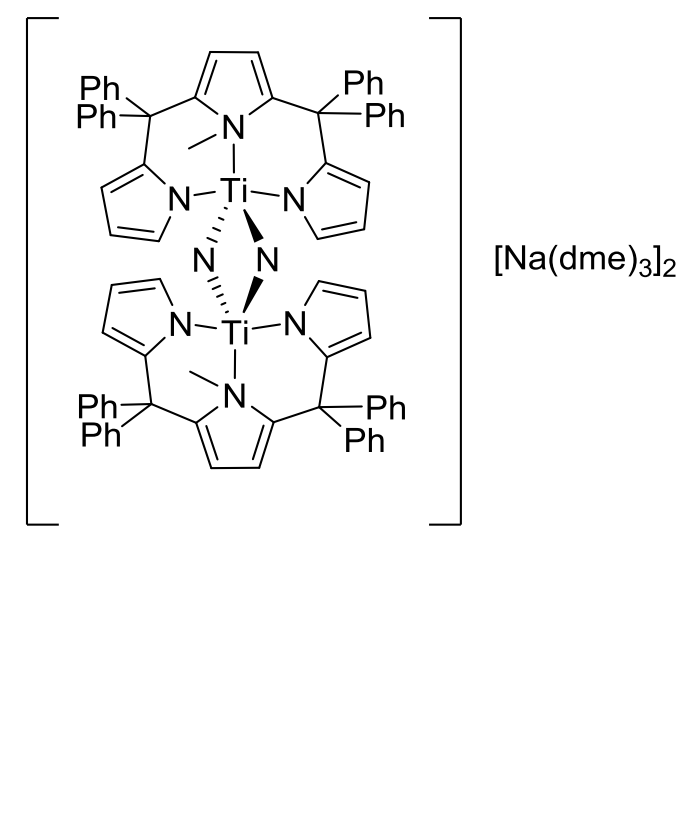

Scheme 11

A bis-guanidinate titanium dichloride complex was reduced with $\mathrm{Mg}$ under $\mathrm{N}_{2}$ to yield the end-on $\mu-\eta^{1}: \eta^{1}-\mathrm{N}_{2}$ bridging complex. The N-N bond of 1.28(1) $\AA$ is significantly longer than in the related end-on $\mathrm{Cp}$ derivatives, which explains its stability under reduced pressure. The reported reactivity of the complex however shows facile displacement of $\mathrm{N}_{2}$, and no functionalization at $\mathrm{N}^{57}$ The group of Liddle obtained a major achievement in 2018, using a tetradentate tris-amido-amine. The stepwise reduction of the $\mathrm{Ti}^{\mathrm{IV}}$ precursor was studied, and the end-on $\left[\left\{\left(\operatorname{Tren}^{\mathrm{TMS}}\right) \mathrm{Ti}^{\mathrm{III}}\right\}_{2}\left(\mu-\eta^{1}: \eta^{1}-\right.\right.$ $\left.\left.\mathrm{N}_{2}\right)\right]$ and $\left[\left\{\left(\operatorname{Tren}^{\mathrm{TMS}}\right) \mathrm{Ti}^{\mathrm{IV}}\right\}_{2}\left(\mu_{4}-\eta^{1}: \eta^{1}: \eta^{2}: \eta^{2}-\mathrm{N}_{2} \mathrm{~K}_{2}\right)\right]$ complexes were thus synthesized (Scheme 12). In the latter complex, the $\mathrm{K}$ cations are bound to the $\mathrm{N}_{2}$ moiety and the $\mathrm{N}-\mathrm{N}$ bond is highly elongated to $1.315(3) \AA$ compared to $1.121(6) \AA$ in the $\mathrm{Ti}^{\mathrm{III}}$ complex. Addition of cryptant resulted in charge separation and further N-N bond elongation 
(1.461(7) $\AA$ ), suggesting Ti-imido character. However, Raman stretch which is a better indicator of $\mathrm{N}_{2}$ activation, suggests a reduced activation in the latter complex. Most interestingly, the authors showed that the $\left[\left\{\left(\operatorname{Tren}^{\mathrm{TMS}}\right) \mathrm{Ti}^{\mathrm{IV}}\right\}_{2}\left(\mu_{4}-\eta^{1}: \eta^{1}: \eta^{2}: \eta^{2}-\mathrm{N}_{2} \mathrm{~K}_{2}\right)\right]$ complex catalyzes the production of up to 18 equivalents of $\mathrm{NH}_{3}$, making this complex the only homogeneous $\mathrm{Ti}$ species competent for catalytic reduction of $\mathrm{N}_{2}$ into $\mathrm{NH}_{3} .{ }^{58}$
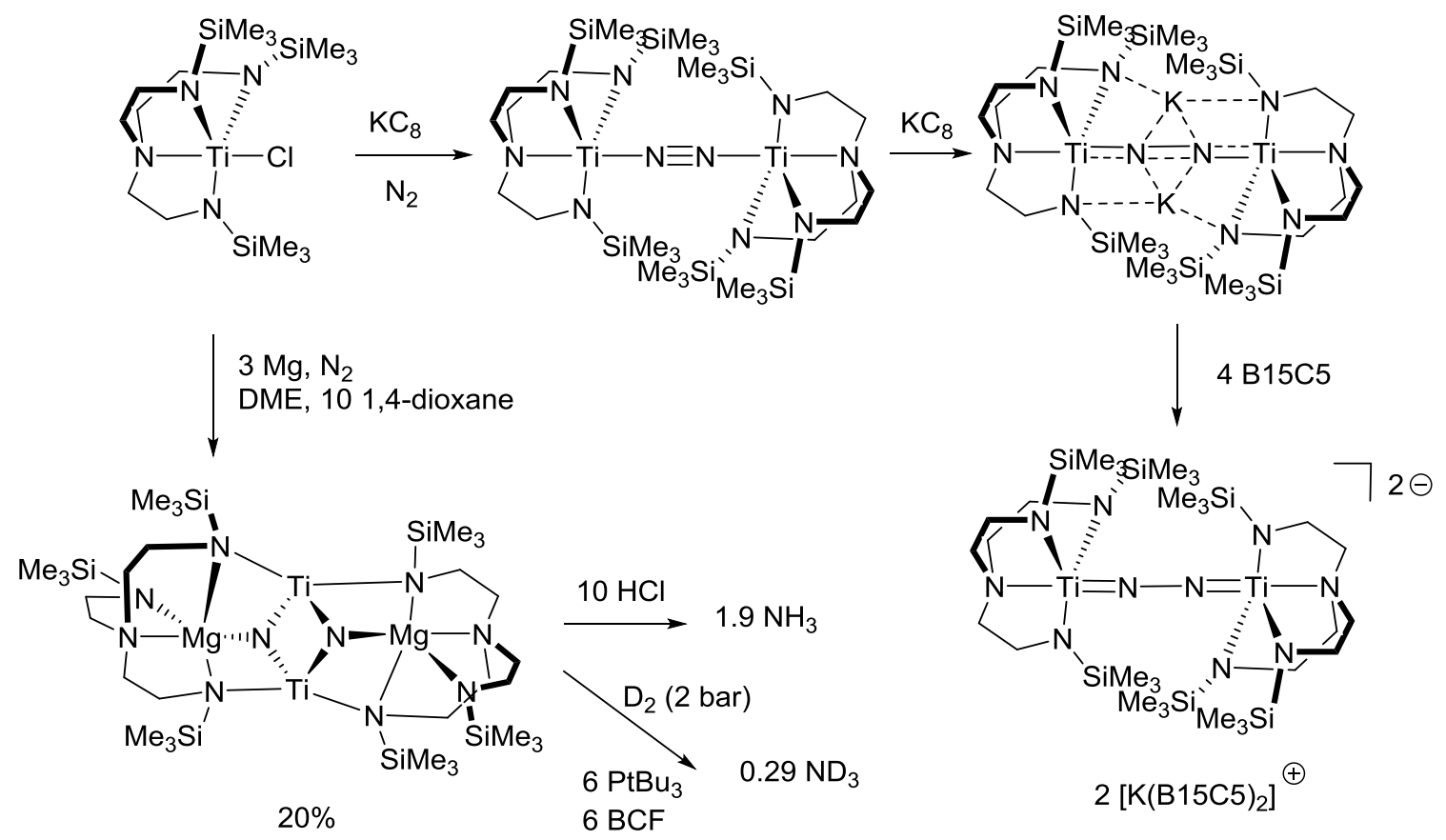

Scheme 12

In 2019, the same group reported a Haber-Bosch like approach to stoichiometric $\mathrm{N}_{2}$ functionalization. ${ }^{59}$ Indeed, they evidenced a homogeneous reductive cleavage of $\mathrm{N}_{2}$ to $\mathrm{N}^{3-}$ by a Ti-Mg complex, as well as conversion to $\mathrm{NH}_{3}$ using $\mathrm{H}_{2}$, split by a frustrated Lewis pair (FLP). Starting from the $\left[\mathrm{Ti}\left(\operatorname{Tren}^{\mathrm{TMS}}\right) \mathrm{Cl}\right]$ complex, reduction by excess $\mathrm{Mg}$ over 3 days resulted in the formation of the bis- $\mu^{3}$-nitrido complex $\left[\{\mathrm{Mg}(\operatorname{TrenTMS})\}_{2}\left\{\left(\mu_{3}-\mathrm{N}\right)_{2}(\mathrm{Ti})_{2}\right\}\right]$ in $20 \%$ yield. Major ligand rearrangement is observed during this reaction. It is interesting to note that $\mathrm{N}_{2}$ is reduced to the $\mathrm{N}^{3-}$ state in this case, whereas it was reduced to $\mathrm{N}_{2}{ }^{4-}$ with $\mathrm{KC}_{8}$, despite $\mathrm{Mg}\left(\mathrm{E}^{\circ}=-2.37 \mathrm{~V}\right)$ being a weaker 
reducing agent compared to $\mathrm{K}\left(\mathrm{E}^{\circ}=-2.92 \mathrm{~V}\right)$. The authors suggest that the cooperative combination of $\mathrm{Ti}$ and $\mathrm{Mg}$ for the six electron reduction of $\mathrm{N}_{2}$. Subsequent hydrolysis produced near quantitative amounts of $\mathrm{NH}_{3}$, whereas treatment with $\mathrm{D}_{2}$ and $\mathrm{PtBu}_{3} / \mathrm{BCF}$ (6 equiv.) formed 0.29 equiv. of $\mathrm{ND}_{3}$.

As an alternative strategy to activate and functionalize $\mathrm{N}_{2}$, Hou and coworkers reacted the mixed valent $\mathrm{Ti}^{\mathrm{III}} / \mathrm{Ti}^{\mathrm{IV}}$ bridging hydride trimetallic complex $\left[\left\{\left(\eta^{5}-\mathrm{C}_{5} \mathrm{Me}_{4} \mathrm{SiMe}_{3}\right) \mathrm{Ti}\right\}_{3}\left(\mu_{3}-\right.\right.$ $\mathrm{H})\left(\mu_{2}-\mathrm{H}\right)_{6}$ ] with $\mathrm{N}_{2}$. Several intermediates along the path of $\mathrm{N}_{2}$ funtionalization were characterized, proving the $\mathrm{NH}$ bond formation from both bridging nitride and hydride (Scheme 13, top). ${ }^{60}$ In 2016, the same group reported the synthesis of a mixed amide/nitride tetranuclear Ti complex as well as the subsequent functionalization of the four $\mathrm{N}$ atoms with a variety of acid chlorides (alkyl and aryl) to yield nitrile derivatives in good to excellent yields (60 to $84 \%$ ) (Scheme 13, middle). ${ }^{61}$ Hydrogenolysis of a (PNP)Ti $\left(\mathrm{CH}_{2} \mathrm{SiMe}_{3}\right)_{2} \mathrm{Ti}^{\mathrm{III}}$ complex under a mixture of $\mathrm{H}_{2} / \mathrm{N}_{2}$ afforded the binuclear $\left\{[(\mathrm{PNP}) \mathrm{Ti}]_{2}\left(\mu_{2}, \eta^{1}, \eta^{2}-\mathrm{N}_{2}\right)(\mu-\mathrm{H})_{2}\right\} \quad$ complex $\quad($ Scheme $13, \quad$ bottom). Subsequent hydrogenation under mild conditions $\left(1 \mathrm{~atm}, 60^{\circ} \mathrm{C}\right)$, allowed $\mathrm{N}-\mathrm{H}$ bond formation and NN bond splitting, ${ }^{62}$ a reactivity observed previously by Fryzuk et al. at $\mathrm{Zr}$ (vide infra). 


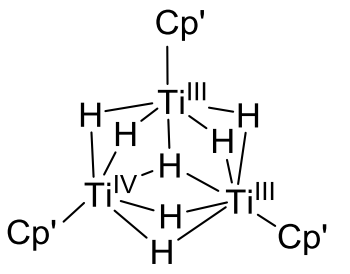

$\mathbf{N}_{2}$, rt, 12h, hexane

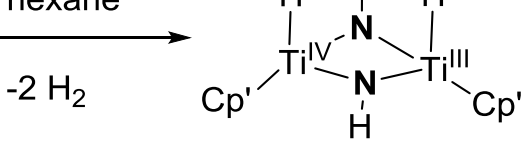

$91 \%$

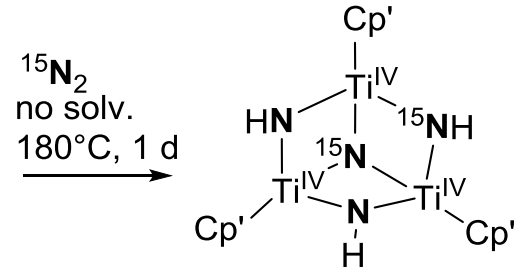

conv $65 \%$

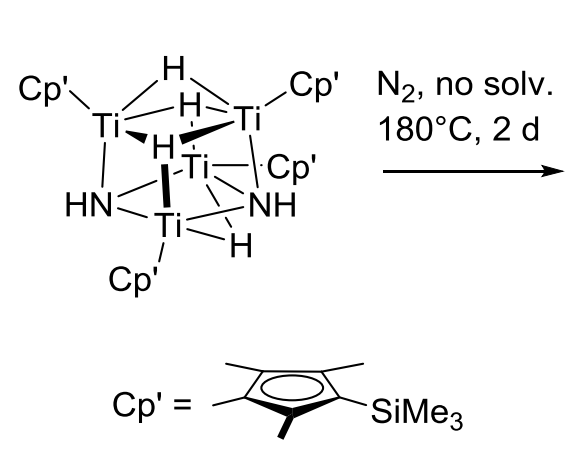

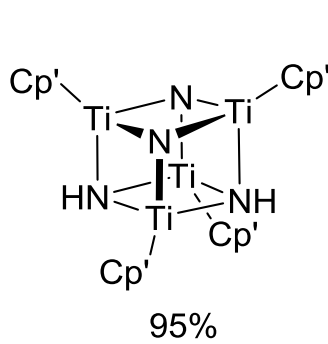

$\mathrm{RCOCl}$<smiles>[R]C#N</smiles>

$\mathbf{H}_{2}$ (100 atm) $180^{\circ} \mathrm{C}, 2 \mathrm{~d}$

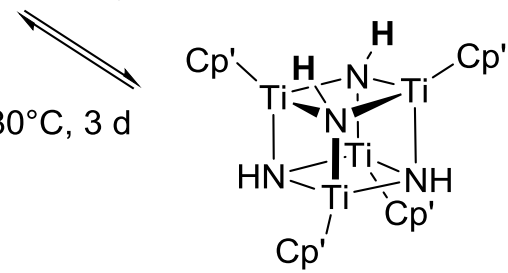

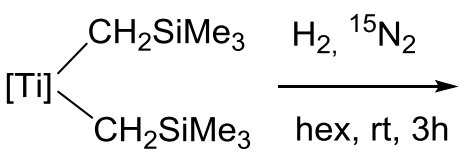

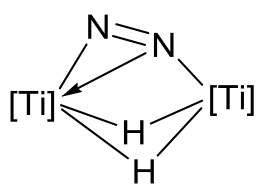

$69 \%$

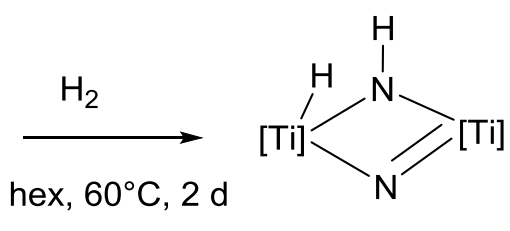

$76 \%$

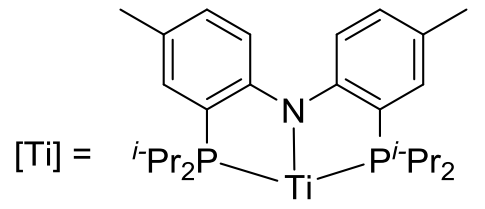

scheme Gr4Ti4

Scheme 13

\section{2. $\mathrm{Zr}$ and $\mathrm{Hf}$ complexes: synthesis and reactivity}

The group of Fryzuk has studied for ca 30 years the polydentate (poly-)anionic ligands featuring phosphine and amido donors. The reduction of the $\left[(\mathrm{PNP}) \mathrm{ZrCl}_{3}\right]$ under $\mathrm{N}_{2}$ provided the first $\mathrm{Zr}$ side-on coordinated $\left[\{(\mathrm{PNP}) \mathrm{ZrCl}\}_{2}\left(\mu-\eta^{2}: \eta^{2}-\mathrm{N}_{2}\right)\right]$ complex, featuring an activated $\mathrm{N}_{2}$ unit, as shown by the very long $\mathrm{N}-\mathrm{N}$ bond of $1.548(7) \AA$ (Scheme 14). ${ }^{63}$ This discovery was the starting point of their extensive work dealing with 
$\mathrm{N}_{2}$ activation and functionalization. ${ }^{64}$ The PNP complex proved too reactive toward $\mathrm{H}_{2}$ or silane, likely because of phosphine dissociation, which prompted the development of the macrocyclic $\mathrm{P}_{2} \mathrm{~N}_{2}$ dianionic ligand. Reduction of the corresponding $\mathrm{Zr}^{\mathrm{IV}}$ complex resulted in the formation of the bimetallic side-on bound $\mathrm{N}_{2}$ complex $\left[\left\{\left(\mathrm{P}_{2} \mathrm{~N}_{2}\right) \mathrm{Zr}\right\}_{2}\left(\mu-\eta^{2}: \eta^{2}-\mathrm{N}_{2}\right)\right]$. Hydrogenation of the side-on $\mathrm{N}_{2}$ with $\mathrm{H}_{2}$ resulted in the formation of $\left[\left\{\left(\mathrm{P}_{2} \mathrm{~N}_{2}\right) \mathrm{Zr}\right\}_{2}(\mu-\right.$ $\left.\left.\eta^{2}: \eta^{2}-\mathrm{N}_{2} \mathrm{H}\right)(\mu-\mathrm{H})\right]$, while the addition of Si-H bond formed the related $\left[\left\{\left(\mathrm{P}_{2} \mathrm{~N}_{2}\right) \mathrm{Zr}\right\}_{2}(\mu-\right.$ $\left.\left.\eta^{2}: \eta^{2}-\mathrm{N}_{2} \mathrm{SiH}_{2} \mathrm{Bu}\right)(\mu-\mathrm{H})\right]$. Most notably, the NH bond formation was the first case of hydrogenation of coordinated $\mathrm{N}_{2} \cdot{ }^{65} \mathrm{CN}$ bond formation was also demonstrated through alkyne addition. The reaction involves a [2+2] cycloaddition between $\mathrm{Zr}-\mathrm{N}$ and the $\mathrm{C} \equiv \mathrm{C}$ bond, followed by protonation of the $\mathrm{Zr}-\mathrm{C}$ bond by the terminal alkyne. ${ }^{66}$ 

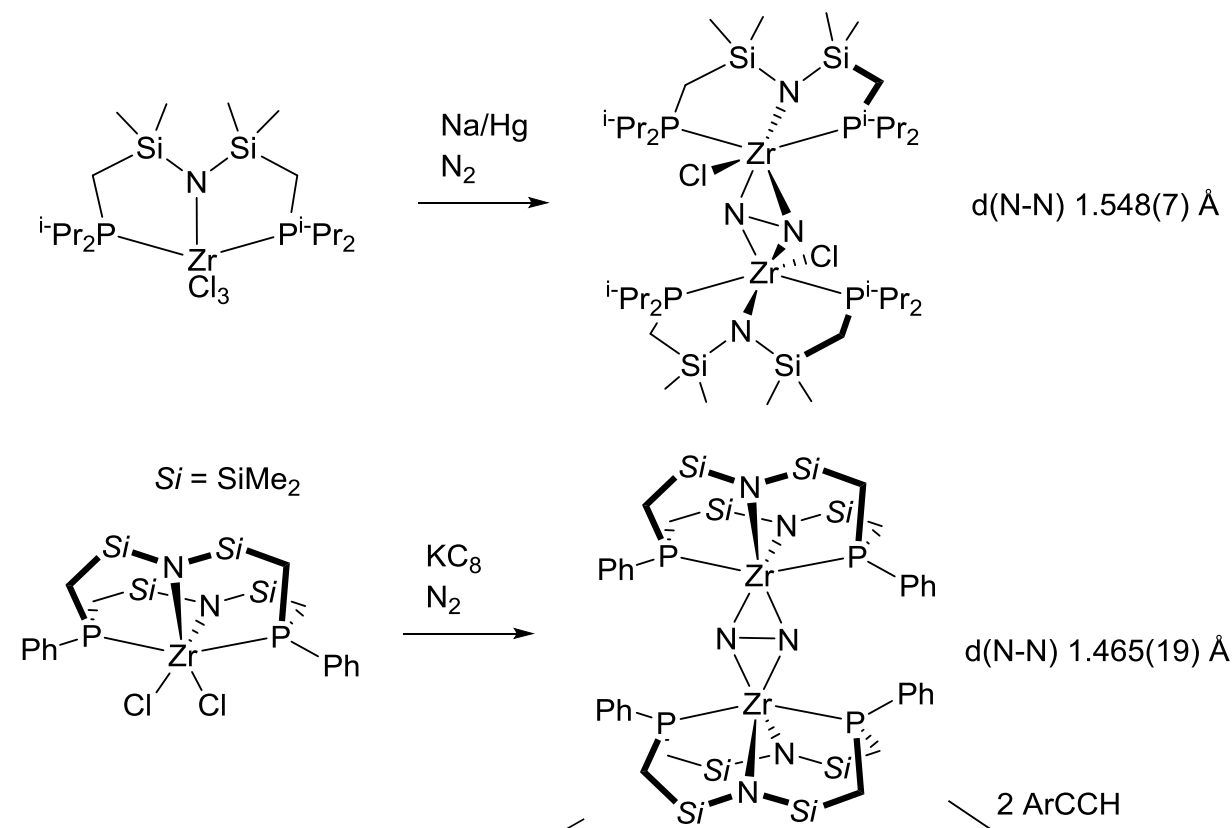

$\mathrm{d}(\mathrm{N}-\mathrm{N}) 1.465(19) \AA$
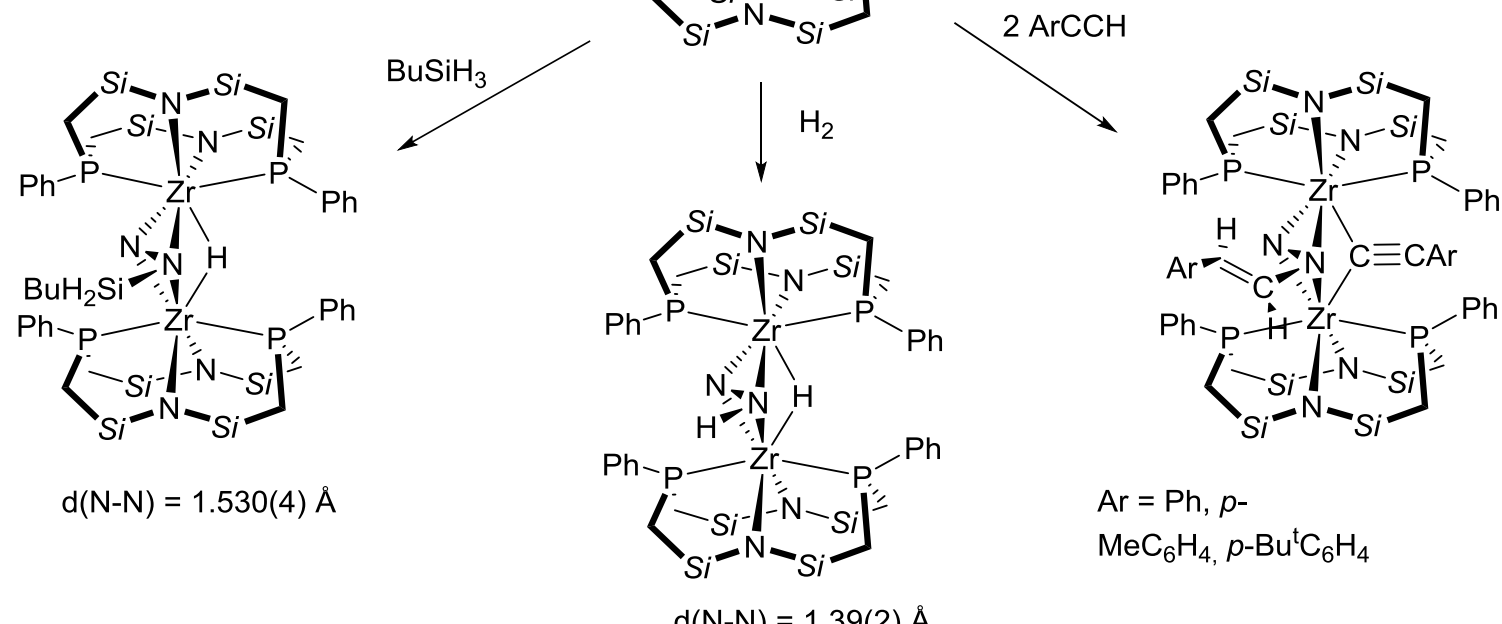

Scheme 14

$\mathrm{d}(\mathrm{N}-\mathrm{N})=1.39(2) \AA$

$\mathrm{Ar}=\mathrm{Ph}, p-$

$\mathrm{MeC}_{6} \mathrm{H}_{4}, p-\mathrm{Bu}^{\mathrm{t}} \mathrm{C}_{6} \mathrm{H}_{4}$

Because side-on coordination of $\mathrm{N}_{2}$ in these complexes appeared key to its reactivity, the group of Chirik studied the effect of substitution pattern of $\mathrm{Cp}$ ligands in zirconocene and hafnocene complexes of $\mathrm{N}_{2}$. Sodium amalgam reduction of $\left[\left(\eta^{5}-\mathrm{C}_{5} \mathrm{Me}_{4} \mathrm{H}\right)_{2} \mathrm{ZrCl}_{2}\right]$ under $\mathrm{N}_{2}$ furnished the $\left[\left\{\left(\eta^{5}-\mathrm{C}_{5} \mathrm{Me} \mathrm{e}_{4} \mathrm{H}\right)_{2} \mathrm{Zr}\right\}_{2}\left(\mu-\eta^{2}: \eta^{2}-\mathrm{N}_{2}\right)\right]$ with side-on coordination (featuring $\mathrm{N}_{2}{ }^{4-}$ moiety) (scheme 15). ${ }^{67}$ The solution behavior however pointed equilibrium between the end-on and side-on complexes (10-15\% of the end-on). Synthesis of the Hf congener revealed only side-on coordination. ${ }^{68}$ 


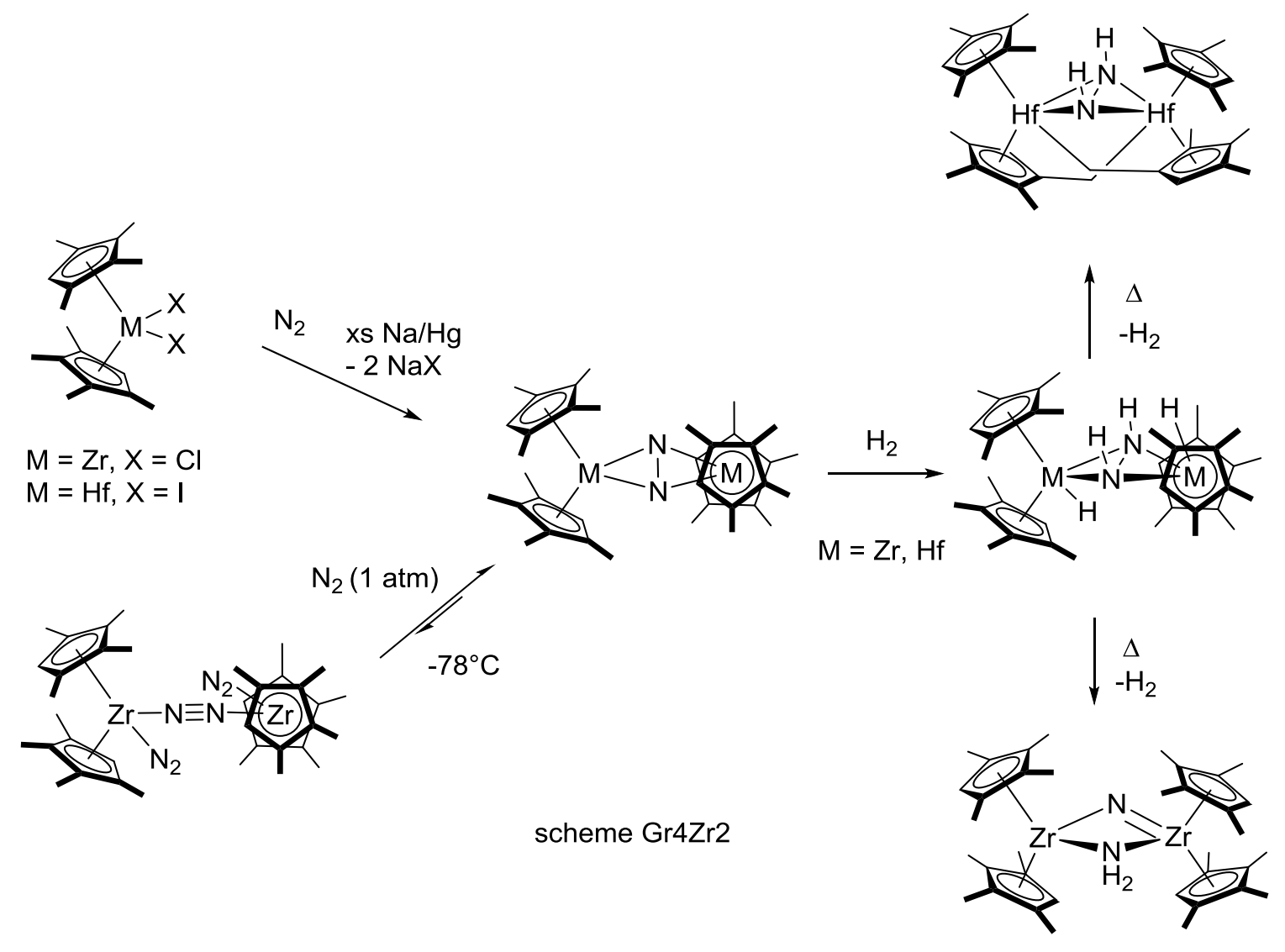

Scheme 15

These activated $\mathrm{N}_{2}$ complexes react with $\mathrm{H}_{2}$ to form the corresponding dihydride diazenido derivatives $\left[\left\{\left(\eta^{5}-\mathrm{C}_{5} \mathrm{Me}{ }_{4} \mathrm{H}\right)_{2} \mathrm{M}(\mathrm{H})\right\}_{2}\left(\mu-\eta^{1}: \eta^{1}-\mathrm{N}_{2} \mathrm{H}_{2}\right)\right]$, with the Hf complex being ca four times faster than the $\mathrm{Zr}$ analogue. ${ }^{69}$ A detailed kinetic study, involving isotopic labeling, of the $\mathrm{H}_{2}$ addition lead to a mechanistic proposal in which the $\mathrm{H}_{2}$ 1,2-addition on $\mathrm{Zr}-\mathrm{N}$ is rate determining. The corresponding transition state involves simultaneous $\mathrm{H}-$ $\mathrm{H}$ bond breaking and $\mathrm{Zr}-\mathrm{H}$ and $\mathrm{N}-\mathrm{H}$ bond formation. ${ }^{67} \mathrm{DFT}$ calculations supported this mechanism. ${ }^{70}$ The outcome of thermolysis of the $\mathrm{Zr}$ and $\mathrm{Hf}\left[\left\{\left(\eta^{5}-\mathrm{C}_{5} \mathrm{Me}_{4} \mathrm{H}\right)_{2} \mathrm{M}(\mathrm{H})\right\}_{2}(\mu-\right.$ $\left.\left.\eta^{1}: \eta^{1}-\mathrm{N}_{2} \mathrm{H}_{2}\right)\right]$ complexes differed drastically. Indeed, if $\mathrm{H}_{2}$ loss was observed in both cases, N-N bond breaking occurred in the $\mathrm{Zr}$ complex, leading to $\mu$-nitrido, $\mu-\mathrm{NH}_{2}$ 
moieties, whereas $\mathrm{CH}$ activation of the ligand was seen in the $\mathrm{Hf}$ complex. ${ }^{68}$ If the thermal treatment of the $\mathrm{Zr}$ complex is done under $\mathrm{H}_{2}$, formation of the $\mathrm{Zr}$ dihydride is observed together with the elimination of $\mathrm{NH}_{3}$ from the coordination sphere of the $\mathrm{Zr}^{71}$ The reactivity of the coordinated $\mathrm{N}_{2}{ }^{4-}$ moiety toward various sources of protons was then studied. Protonation by $\mathrm{H}_{2} \mathrm{O}$ or EtOH liberates hydrazine from the $\mathrm{Zr}$, whereas addition of amines or terminal alkynes left " $\mathrm{N}_{2} \mathrm{H}_{2}$ " moiety in the coordination sphere (scheme $16)^{72}$

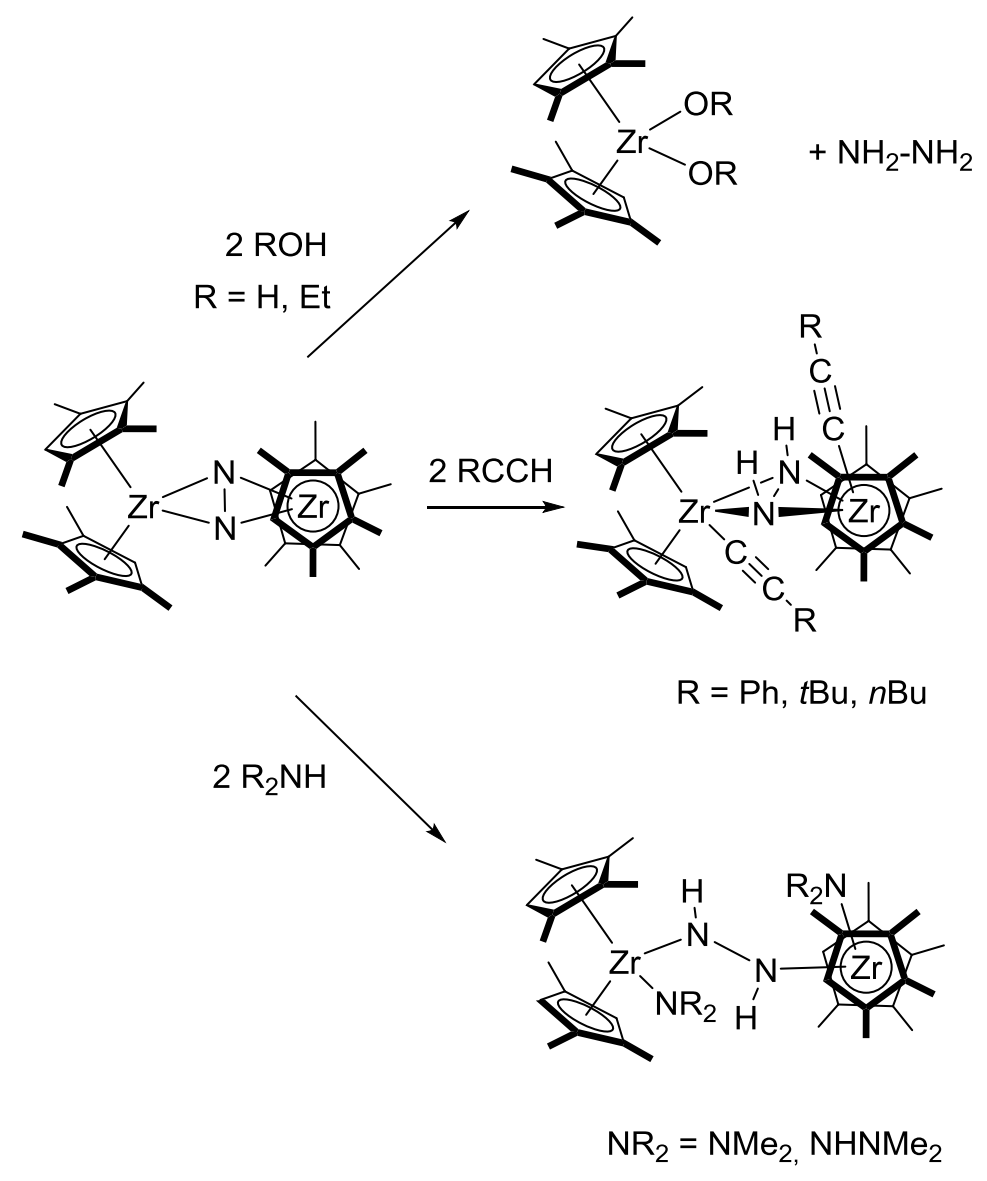

Scheme 16

When one cyclopentadienyl ligand was changed to an indenyl ligand, the presence of the arene ring resulted in markedly different $\mathrm{N}_{2}$ complexes. ${ }^{73}$ It is to be noted that at least two alkyl groups are to be present on the Cp moiety of the indenyl for the success of the 
reduction of the $\mathrm{Zr}^{\mathrm{IV}}$ precursor (scheme 17). Reduction under Ar leads to $\eta^{5}: \eta^{4}$ coordination of the indenyl at a single $\mathrm{Zr}$ center. When this species is exposed to an $\mathrm{N}_{2}$ atmosphere, a bimetallic complex featuring a $\mu-\eta^{1}: \eta^{1}$ end on $N_{2}$ ligand is formed. On the other hand, when the reduction was performed under $\mathrm{N}_{2}$, a bimetallic complex with a end-on side-on $\mathrm{N}_{2}$ ligand is preferably formed. With two indenyl ligands, reduction of the $\mathrm{Zr}^{\mathrm{IV}}$ precursor under $\mathrm{N}_{2}$ resulted in the inclusion of one equivalent of the salt $(\mathrm{NaX})$ per $\mathrm{Zr}$ center in addition to the expected coordination/reduction of $\mathrm{N}_{2} \cdot{ }^{74}$ Most interestingly, hydrogenation of this complex resulted in the double $\mathrm{NH}$ bond formation, proving that end on coordinated $\mathrm{N}_{2}$ could also undergo 1,2 additions of $\mathrm{H}_{2}$.

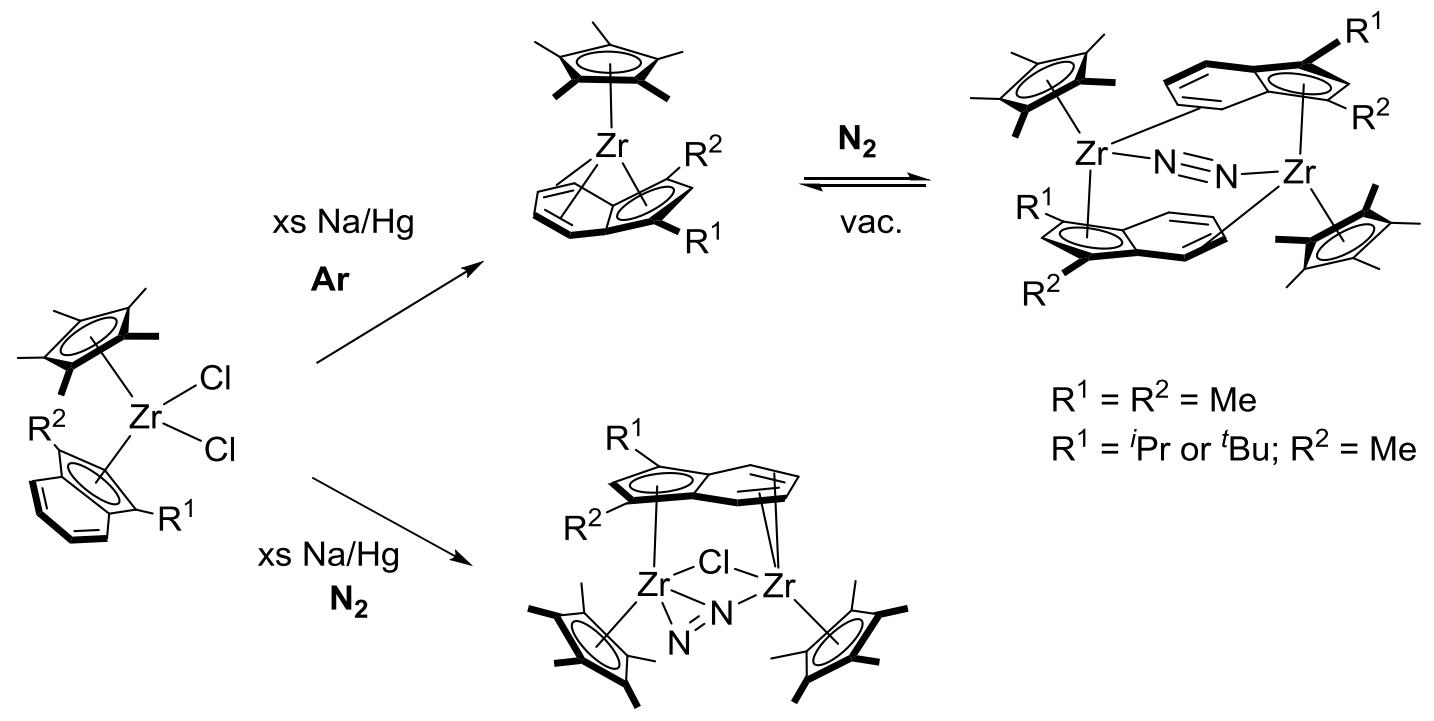

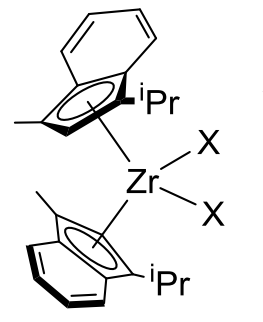

+ rac-isomer

$\mathrm{X}=\mathrm{Cl}, \mathrm{Br}$, I

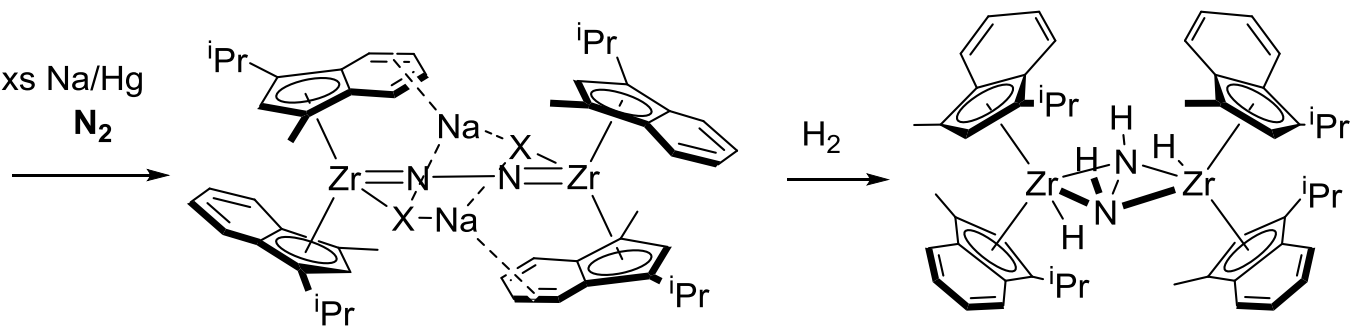

scheme Gr4Zr4

Scheme 17 
Finally, the $\mathrm{N}_{2}$ coordinated ansa-zirconocene complex $\left[\mathrm{K}\left\{\mathrm{Me}_{2} \mathrm{Si}\left(\mathrm{C}_{5} \mathrm{Me}_{4}\right)_{2} \mathrm{Zr}(\mu-\mathrm{Cl}-\right.\right.$ $\left.1 \kappa, 2 \kappa)\}_{2}\left(\mu-\eta^{1}: \eta^{1}-\mathrm{N}_{2}\right)\right]$ proved to undergo reversible end-on to side-on switch upon one electron redox process (scheme 18). ${ }^{75}$
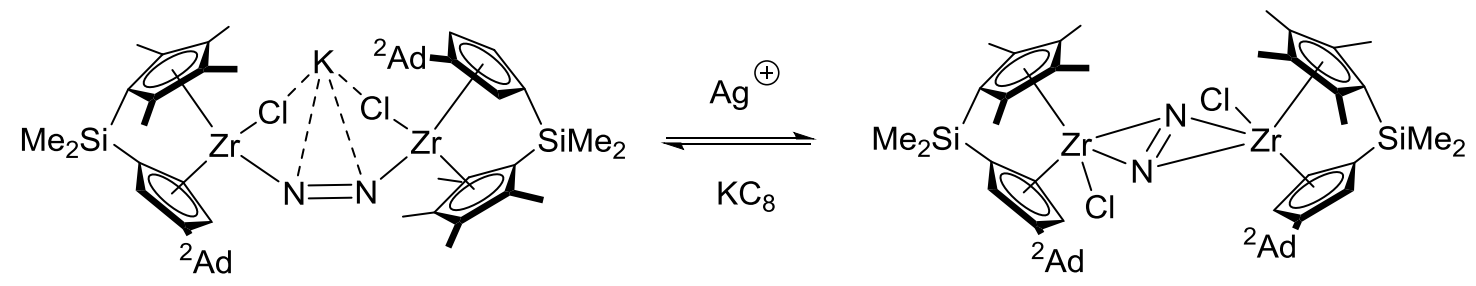

Scheme 18

The authors reinvestigated the coordination of $\mathrm{N}_{2}$ in the complex resulting from the reduction of $\left[\mathrm{Cp}_{2} \mathrm{Zr}\left(\mathrm{CH}_{2}\left(\mathrm{SiMe}_{3}\right)_{2}\right) \mathrm{Cl}\right]$. Lappert initially proposed the formation of the monomeric complex $\left[\mathrm{Cp}_{2} \mathrm{Zr}\left(\mathrm{CH}_{2}\left(\mathrm{SiMe}_{3}\right)_{2}\right)\left(\mathrm{N}_{2}\right)\right]$ favoring a side-on rather than the end-on coordination. When the solid was kept under vacuum, dimerization occurred as shown by crystallization from toluene, and bridging end-on was proposed, ${ }^{76}, 77$ later proved by Chirik.

The same group further studied the reactivity of the Hf complex $\left[\left\{\left(\eta^{5}-\mathrm{C}_{5} \mathrm{Me}_{4} \mathrm{H}\right)_{2} \mathrm{Hf}\right\}_{2}(\mu-\right.$ $\left.\left.\eta^{2}: \eta^{2}-\mathrm{N}_{2}\right)\right]$ toward polar electrophiles, such as $\mathrm{CO}_{2}$ and $\mathrm{PhNCO},{ }^{78}$ and observed $\mathrm{N}-\mathrm{C}$ bond formations. Elimination of a hydrazine derivative could be achieved (scheme 19). ${ }^{79}$ 


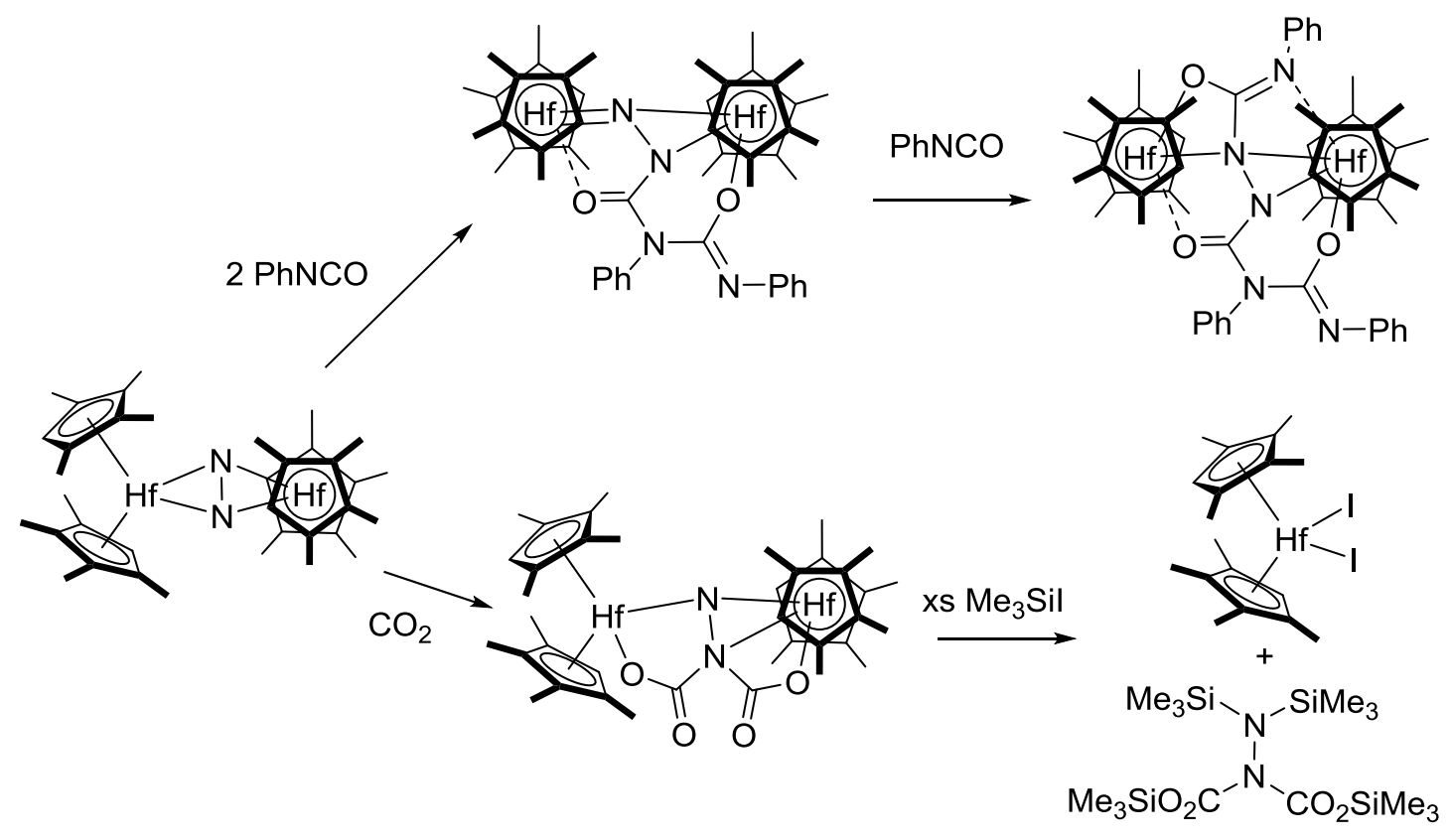

Scheme 19

Related chemistry involving cyclopentadienyl steric and electronic tuning was subsequently developed, and significant changes in the reactivity at $\mathrm{N}$ were observed proving the richness of this chemistry. The reactivity of the $\left[\left\{\left(\eta^{5}-\mathrm{C}_{5} \mathrm{Me}_{3} \mathrm{H}_{2}\right)_{2} \mathrm{Hf}\right\}_{2}(\mu-\right.$ $\left.\left.\eta^{2}: \eta^{2}-\mathrm{N}_{2}\right)\right]$ is particularly rich, showing successive $\mathrm{N}-\mathrm{C}, \mathrm{N}-\mathrm{B}$ and $\mathrm{N}-\mathrm{Si}^{80}$ bond formations (scheme 20). ${ }^{81}$ The isocyanato $\mu$-nitrido complex $\left[\left\{\left(\eta^{5}-\mathrm{C}_{5} \mathrm{Me}_{3} \mathrm{H}_{2}\right)_{2} \mathrm{Hf}\right\}_{2}(\mu-\mathrm{N})(\mathrm{NCO})\right]$ obtained upon reaction with $\mathrm{CO}^{82}$ demonstrated a versatile reactivity of the bridging nitride. Indeed, reactions with nitrile, isocyanate, $\mathrm{CO}_{2}$ as well as allenes and activated alkyne was observed. ${ }^{83}$ 


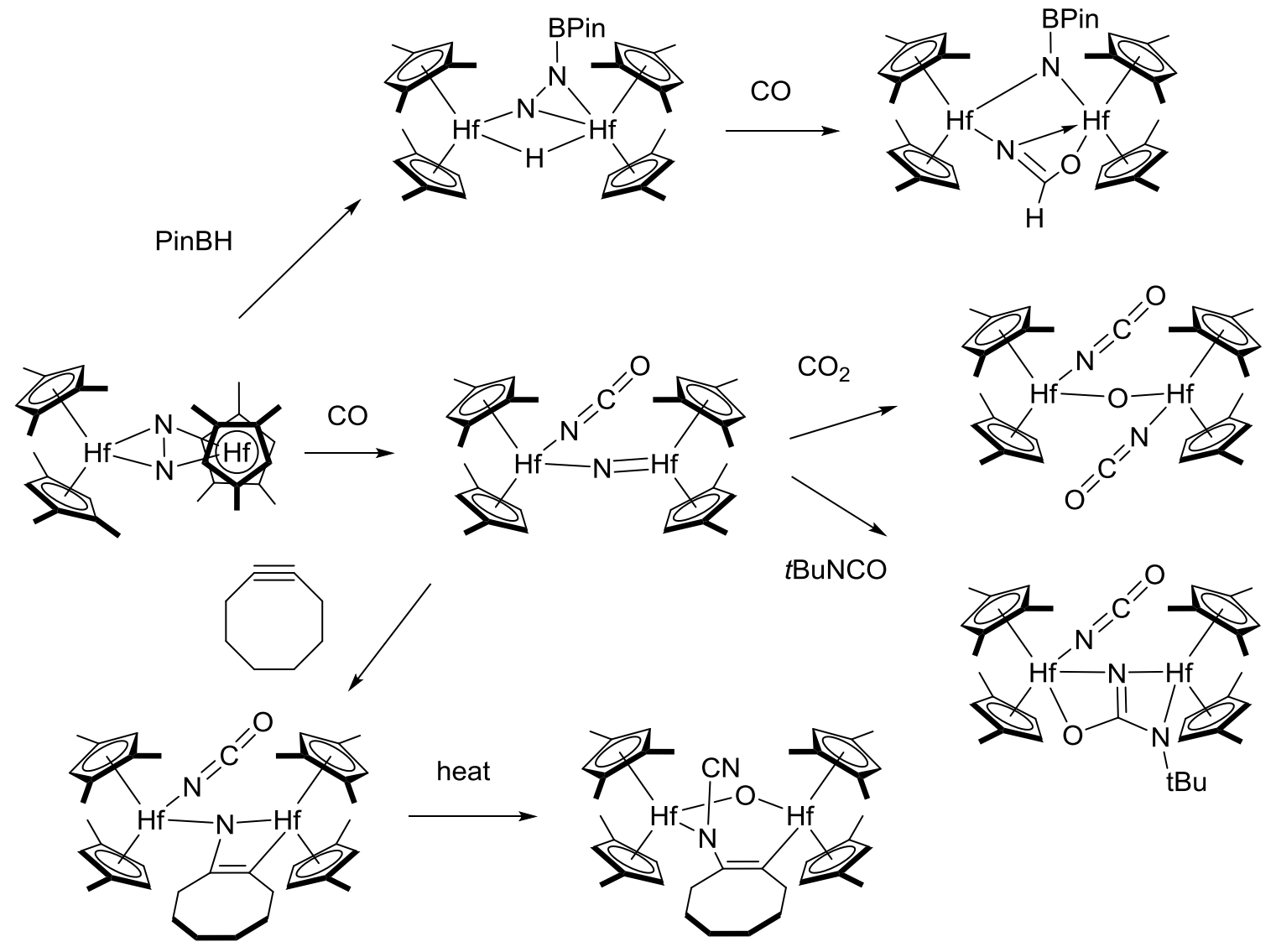

Scheme 20

The chemistry of ansa-hafnocene complex $\left[\left\{\mathrm{Me}_{2} \mathrm{Si}\left(\mathrm{C}_{5} \mathrm{Me}_{4}\right)\left(\mathrm{C}_{5} \mathrm{H}_{3} t \mathrm{Bu}\right) \mathrm{Zr}\right\}\left(\mu-\eta^{2}: \eta^{2}-\mathrm{N}_{2}\right)\right]$ was studied simultaneously. ${ }^{84}$ In this case, reaction with one equiv. of CO leads to NN splitting, as above, followed by $\mathrm{CH}$ activation of a tBu group of a ligand by the bridging nitride. Alternatively, double $\mathrm{CO}$ addition to form a $\left(\mathrm{N}_{2} \mathrm{C}_{2} \mathrm{O}_{2}\right)^{4-}$ ligand was observed under 1 atm. of CO (scheme 21). 


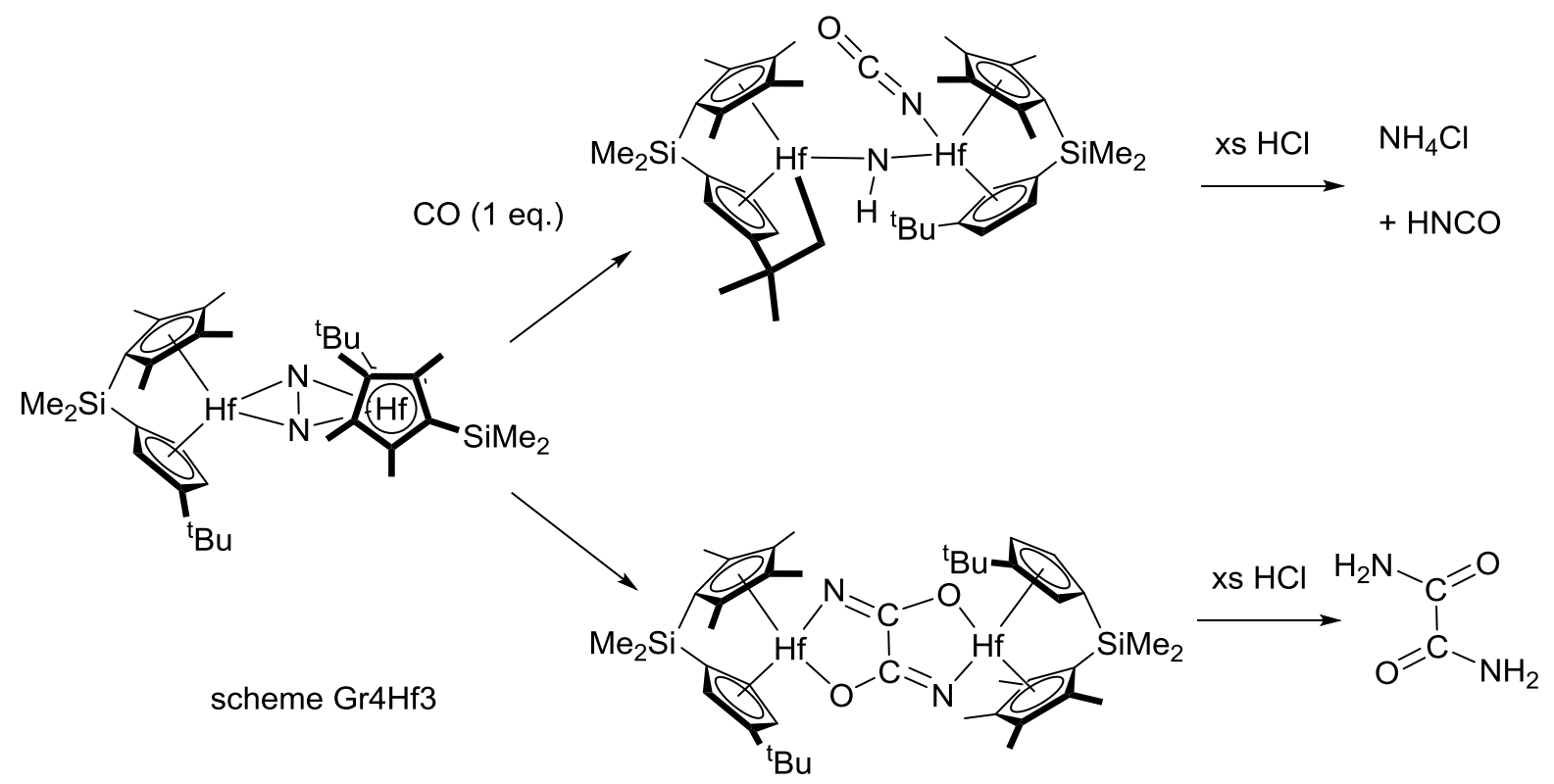

Scheme 21

\section{Group 5 transition metal-dinitrogen complexes}

Despite the fact that one type of nitrogenase enzyme contains a vanadium center, the dinitrogen chemistry of group 5 metals has been developed rather late compared to discoveries of $\mathrm{M}-\mathrm{N}_{2}$ complexes in the 60s. Indeed, the first dinitrogen complex of group 5, a Ta complex, was reported in 1980 by Schrock and co-workers. ${ }^{85}$ Only a few reports precede 2003, and therefore will be included in this chapter for the sake of providing a historical perspective.

\subsection{Vanadium complexes: synthesis and reactivity}

The first vanadium $\mathrm{N}_{2}$ complex was obtained in 1989 by Gambarotta more than twenty years after the discovery of the first $\mathrm{Ru}-\mathrm{N}_{2}$ complex by Allen and Senoff. It was obtained from the reaction between trans-(TMEDA) $)_{2} \mathrm{VCl}_{2}$ with two equivalents of an anionic ligand $\left.\left[\mathrm{o}-\left(\mathrm{CH}_{3}\right)_{2} \mathrm{NCH}_{2}\right) \mathrm{C}_{6} \mathrm{H}_{4}\right] \mathrm{Li}$ under $\mathrm{N}_{2}$. The bimetallic complex featured an 
end-on bridging $\mathrm{N}_{2}$ ligand, for which a NN bond distance of 1.228(4) $\AA$ was measured suggesting a reduced $\mathrm{N}_{2}{ }^{2-}$ ligand. Magnetic susceptibility on the other hand supports two formal $\mathrm{V}^{\mathrm{II}}$ centers, and thus marginally reduced $\mathrm{N}_{2}$ ligand, also in accord with facile displacement by pyridine ${ }^{86}$ This example already points that in group 5 , as in all other groups, the elongation of the $\mathrm{NN}$ bond distance compared to free $\mathrm{N}_{2}$ is a poor indicator of $\mathrm{NN}$ bond reduction upon coordination, as well as a poor guide for $\mathrm{N}$ functionalization. Three years later, in 1992, Rehder reported the $\mathrm{V}$ anionic analogue $\left[\mathrm{V}(\mathrm{dppe})_{2}\left(\mathrm{~N}_{2}\right)_{2}\right][\mathrm{Na}(\mathrm{THF})]$ of the extensively studied $\left[\mathrm{Mo}(\mathrm{dppe})_{2}\left(\mathrm{~N}_{2}\right)_{2}\right]$, synthesized in 1969. This complex is a rare example featuring a terminal end-on $\mathrm{N}_{2}$ ligand at group 5 metals. It is obtained by reduction of $\mathrm{VCl}_{3}$ with $\mathrm{Na}$ sand in the presence of dppe, under $\mathrm{N}_{2}{ }^{87}$ The complex decomposes in solution within days and hydrolysis with excess $\mathrm{HBr}$ generates $\mathrm{NH}_{4}{ }^{+}$(one equiv. per complex). The dmpe analogue was reported in $1994 .{ }^{88} \mathrm{In}$ the following years, the group of Gambarotta studied $\mathrm{N}$ based ligands to obtain $\mathrm{V}-\mathrm{N}_{2}$ complexes, such as amide, polydentate amides ${ }^{89}$ and amidinate. ${ }^{90}$ In 1995 , the same group synthesized an anionic V-nitride dimer $\left[\left(\left(\mathrm{SiMe}_{3}\right)_{2} \mathrm{~N}\right)_{2} \mathrm{~V}(\mu-\mathrm{N})\right]_{2}{ }^{-}$via hydrogenolysis of a vanadacyclobutane complex under $\mathrm{N}_{2}, \mathrm{~N}_{2}$ being the source of the bridging nitride ligands. ${ }^{91}$ Few years later, in 1999 , Cloke also observed direct $\mathrm{N}_{2}$ cleavage upon reduction of a $\mathrm{V}^{\mathrm{III}}$ complex featuring a tridentate diamidoamine ligand (scheme 22). Reduction by two electrons yielded the paramagnetic anionic complex with symmetrical $\mathrm{V}-\mu \mathrm{N}$ bond distances. The 15 line EPR spectrum at $293 \mathrm{~K}$ in toluene is consistent with the unpaired electron of the $\mathrm{d} 1 \mathrm{~V}^{\mathrm{V}}-\mathrm{V}^{\mathrm{IV}}$ dimer being delocalized in solution. ${ }^{92}$ Oxidation with $\mathrm{Ag}$ + forms the doubly nitride-bridged $\mathrm{V}^{(\mathrm{V})}-\mathrm{V}^{(\mathrm{V})}$ dimer, as a diamagnetic complex. The VN bond distances are unsymmetrical, 1.769(10) $\AA$ and 1.862(10) $\AA$ in this dimer. 


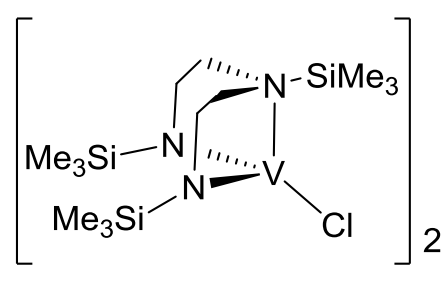

$$
\mathrm{KC}_{8}
$$

$\mathrm{N}_{2}$

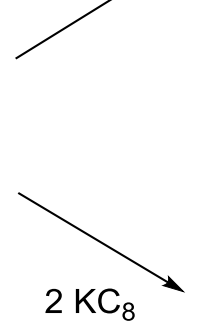

$\mathrm{N}_{2}$

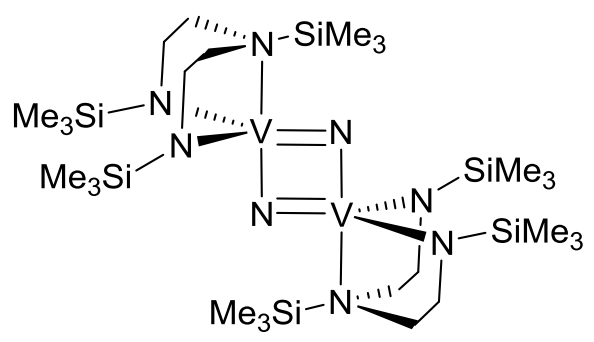

$$
\mathrm{AgBPh}_{4} \| \mathrm{KC}_{8}
$$

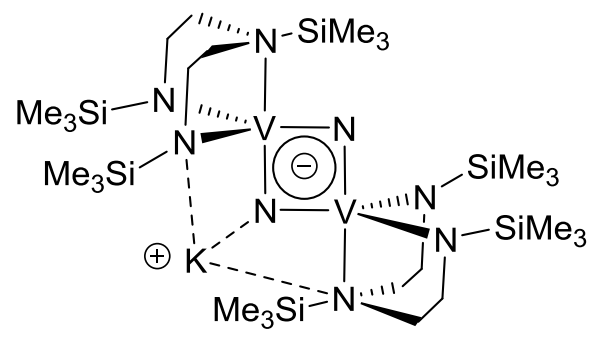

Scheme 22

In 2005, Gambarotta showed that a tridentate [NNN] Pyridine-bis-imine ligand could be non-innocent and either accept or give electron from or to the metal center (scheme 23). ${ }^{93}$ DFT calculations on simplified models (Me instead of 2,6- $\left.\left(\mathrm{iPr}_{2}\right) \mathrm{C}_{6} \mathrm{H}_{3}\right)$ point that $S=0$ and $S=1$ are close in energy and provide very similar geometries. In 2012, Chirik prepared a related bisimino-pyridine ligand $(\mathrm{R}=\mathrm{Ph})$, and observed a similar complex featuring a reduced dianionic tridentate ligand. ${ }^{94}$ In 2006 , Schrock reported the second example of monometallic terminal end-on $\mathrm{N}_{2}$ complex of $\mathrm{V},\left[\mathrm{V}\left(\mathrm{HIPTN} \mathrm{N}_{3} \mathrm{~N}\right)\left(\mathrm{N}_{2}\right)\right] \mathrm{K}$ supported by the very bulky tetrapodal, trianionic $\left(\mathrm{HIPTN}_{3} \mathrm{~N}\right)^{3-}$ ligand. ${ }^{95}$ It was obtained by reduction of the $\left[\mathrm{V}\left(\mathrm{HIPTN}{ }_{3} \mathrm{~N}\right)(\mathrm{THF})\right]$ complex under $\mathrm{N}_{2}$, and is stable at room temperature, although $\mathrm{N}_{2}$ can reversibly dissociate under these conditions. 
2

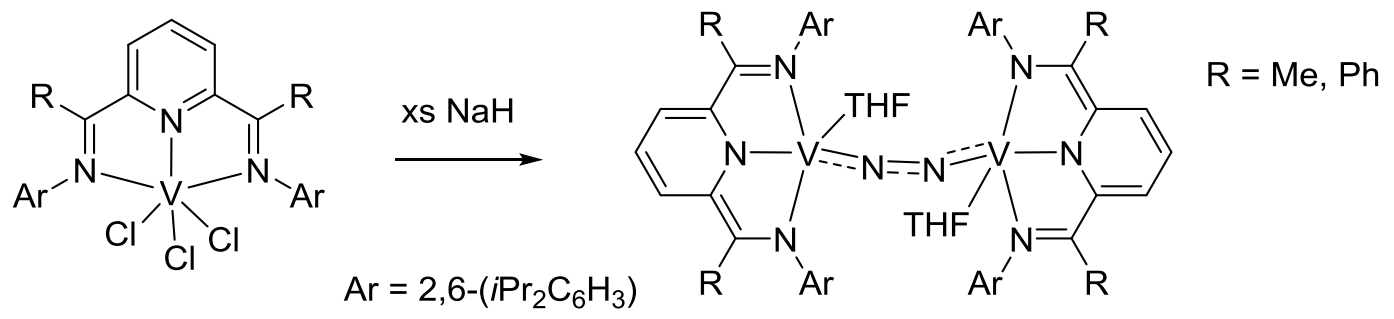

2
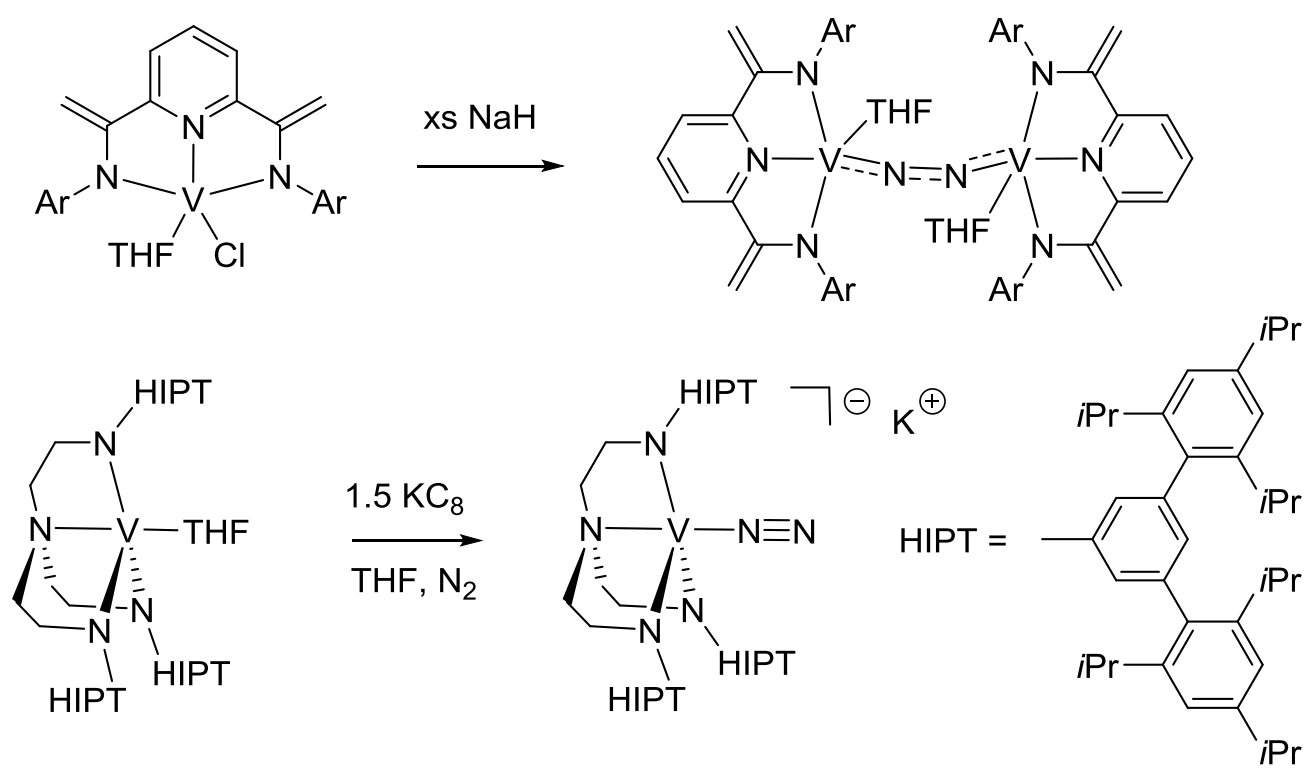

Scheme 23

In 2007, the dipyrrolide-pyrrole dianionic $[\mathrm{NNN}]^{2-}$ ligand was designed to provide variable $\sigma$ and $\pi$ donation. Reduction of the $\mathrm{V}^{\mathrm{III}}$ precursor yielded the mononuclear $\mathrm{V}^{\mathrm{II}}$ complex, and coordination of $\mathrm{N}_{2}$ could only be achieved upon THF abstraction by $\mathrm{AlMe}_{3}$ in toluene under $\mathrm{N}_{2}$ (scheme 24). The magnetic moment measurement shows the two $\mathrm{V}$ centers in $\mathrm{V}^{\mathrm{II}}$ oxidation state, in accord with modest $\mathrm{NN}$ bond distance elongation (1.248(5) $\AA$ ), as well as easy displacement by THF. Interestingly, this complex could be reduced to induce $\mathrm{NN}$ bond cleavage. Thus, upon reaction with $\mathrm{KC}_{8}$ ( 2 equiv.), the mixed-valent $\mathrm{V}^{\mathrm{III}}, \mathrm{V}^{\mathrm{IV}} \mu$-nitrido was formed as primary product, following an unknown mechanism. Reaction with the ${ }^{15} \mathrm{~N}$ isotopomer nonetheless proved the nitride $\mathrm{N}$ atom to result from $\mathrm{N}_{2}$ cleavage. $^{96}$ 


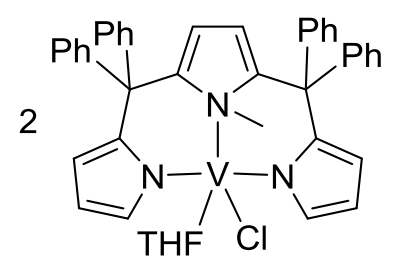

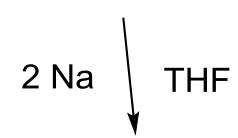<smiles></smiles>

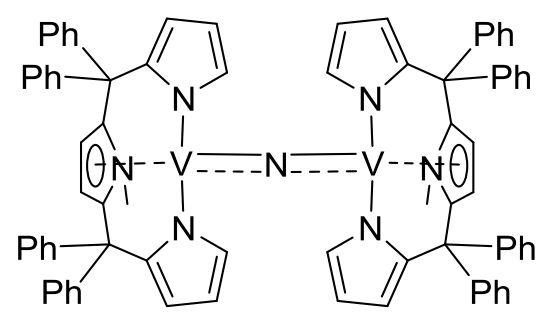<smiles>[R][13CH3]</smiles>
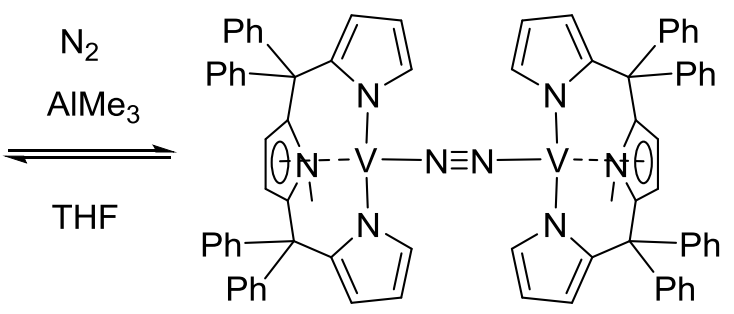

Scheme 24

Mindiola reported that an anionic tridentate $[\mathrm{PNP}]^{-}$ligand supported the formation of the diamagnetic divanadium $\mu-\mathrm{N}_{2}$ complex, $[[\mathrm{PNP}] \mathrm{V}(t \mathrm{BuCH})]_{2}\left(\mu-\eta^{1}: \eta^{1}-\mathrm{N}_{2}\right)$, with a short $\mathrm{NN}$ bond distance of $1.246(6) \AA$, as well as short imide VN bond (1.757(3) $\AA$ ). $.^{97},{ }^{98}$ The lack of $\mathrm{N}_{2}$ displacement by tBuCN is consistent with the proposal of $\mathrm{V}^{\mathrm{V}}$ centers. The same group later showed that $\mathrm{N}_{2}$ can coordinate a $\mathrm{V}^{\mathrm{II}}$ complex featuring bulky $\mathrm{NacNac}$ and $\mathrm{ArO}^{-}$ ligands, leading to two antiferromagnetically coupled $\mathrm{V}^{\mathrm{III}}$ centers bridged by the reduced end-on $\mathrm{N}_{2}$ ligand (scheme 25). DFT calculations rationalize the reluctance of the dimer to split $\mathrm{N}_{2}$ to form the corresponding V-nitride (barrier of $>80 \mathrm{kcal} / \mathrm{mol}$ ). ${ }^{99}$ Nocera reported the coordination of $\mathrm{N}_{2}$ at $\mathrm{V}^{\mathrm{III}}$ stabilized by a bulky alkoxy ligand $(t \mathrm{Bu})_{2}\left(\mathrm{CH}_{3}\right) \mathrm{CO}^{-}$, following THF dissociation. Here also, the $\left[\mathrm{V}^{\mathrm{III}}, \mathrm{V}^{\mathrm{III}}\right]$ bridging $\mathrm{N}_{2}$ complex readily loses $\mathrm{N}_{2}$ in solution. ${ }^{100}$ 
2<smiles></smiles>

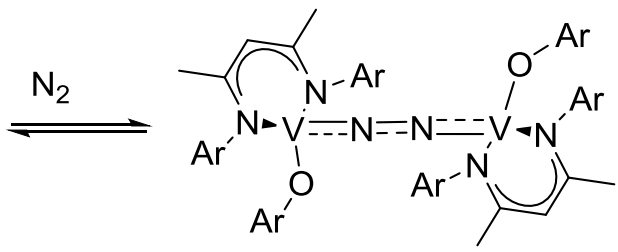

$\mathrm{Ar}=2,6-\left(\mathrm{Pr}_{2} \mathrm{C}_{6} \mathrm{H}_{3}\right)$

2

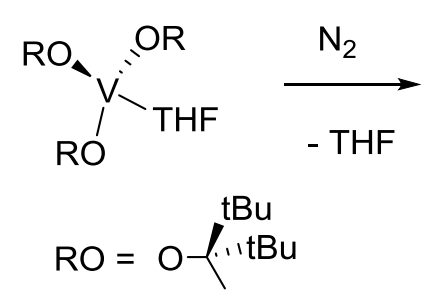<smiles></smiles>

Scheme 25

Cummins reported in 2014 the $\mathrm{V}-\left(\mu-\mathrm{N}_{2}\right)-$ Mo heterobimetallic complex to be formed by the reaction between $\left.\left[\mathrm{Mo}\left(\mathrm{N}(t \mathrm{Bu})-3,5-\mathrm{Me}_{2}\right) \mathrm{C}_{6} \mathrm{H}_{3}\right)_{3}\right]$ and $\left[\mathrm{V}\left(\mathrm{N}(t \mathrm{Bu})-2-\left(\mathrm{NMe}_{2}\right)-5-\right.\right.$ $\left.(\mathrm{Me}) \mathrm{C}_{6} \mathrm{H}_{3}\right)_{2}$ ] under $\mathrm{N}_{2}$. Unlike what is observed with the homobimetallic Mo complex, vide infra, this complex does not split $\mathrm{N}_{2} \cdot{ }^{101}$ Also in 2014, Kawaguchi synthesized the $[[\mathrm{ONO}] \mathrm{V}(\mathrm{THF})]$ complex featuring a $[\mathrm{ONO}]^{3-}$ ligand, 2,6-(3- $\left.t \mathrm{Bu}-5-\mathrm{Me}-2-\mathrm{OC}_{6} \mathrm{H}_{2} \mathrm{CH}_{2}\right)_{2}-$ 4-tBu-(p-tolyl) $\left.\mathrm{NC}_{6} \mathrm{H}_{4}\right)_{2}$. Reaction with $\mathrm{KH}$ under $\mathrm{N}_{2}$ resulted in $\mathrm{H}_{2}$ elimination and formation of $\left[\{[\mathrm{ONO}] \mathrm{V}(\mu-\mathrm{N})\}\{\mathrm{K}(\mathrm{DME})\}_{2}\right]_{2}$, a paramagnetic $\left[\mathrm{V}^{\mathrm{IV}}, \mathrm{V}^{\mathrm{IV}}\right]$ bis $(\mu-\mathrm{N})$ complex (scheme 26). The absence of NN bond is evidenced by the NN distance of 2.550(3) $\AA$ for the $\mathrm{V}_{2} \mathrm{~N}_{2}$ core. Two electron oxidation results in significant ligand reorganization, back to $\kappa 3[\mathrm{ONO}]$ coordination at $\mathrm{V}$, forming the $\mathrm{V}^{\mathrm{V}}$ nitride dimer, $[[\mathrm{ONO}] \mathrm{V}(\mathrm{N})(\mu-\mathrm{K}(\mathrm{DME}))]_{2} \cdot{ }^{102}$ 


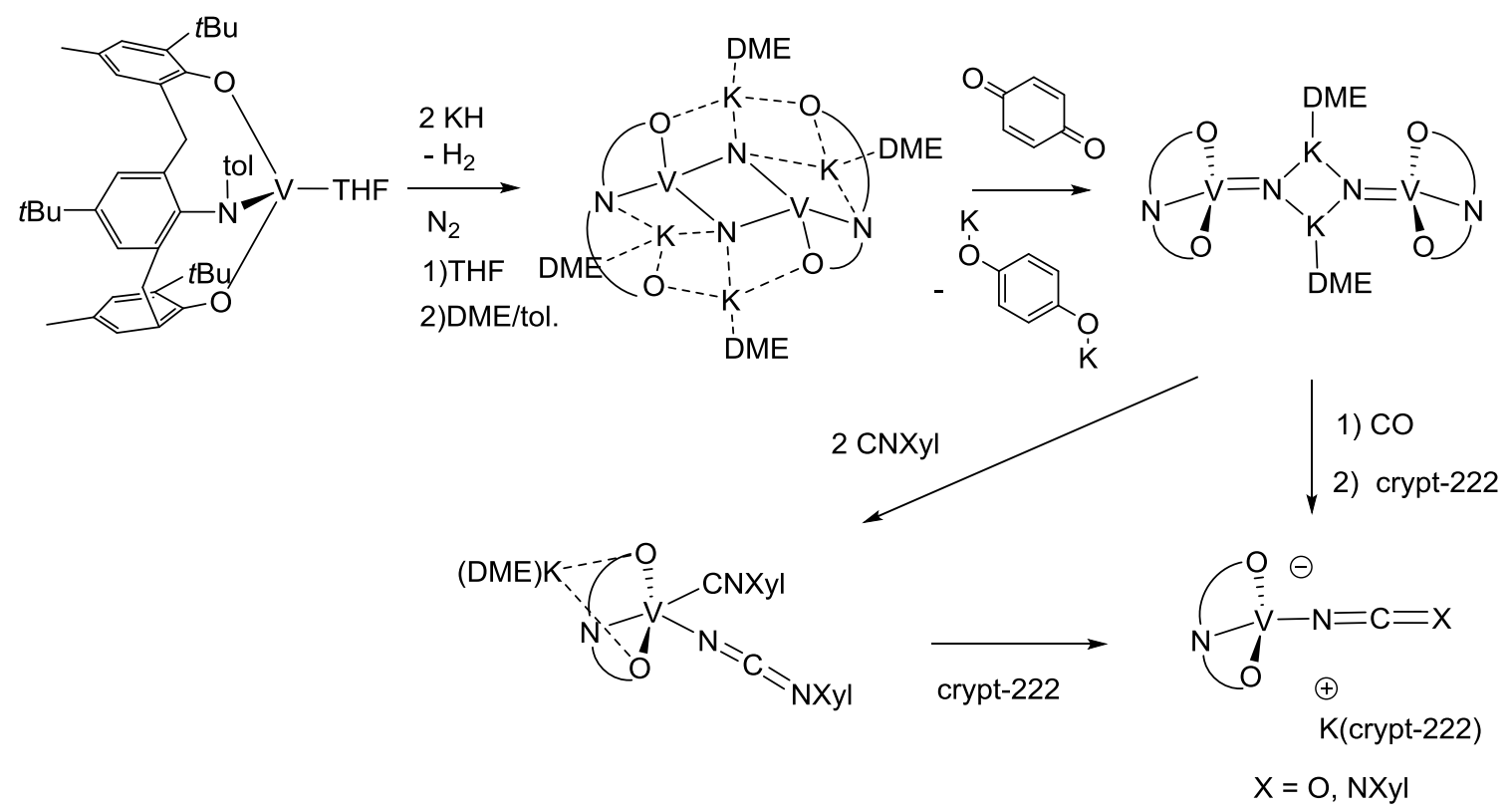

Scheme 26

Functionalization of the nitride was achieved with $\mathrm{CO}$ and $\mathrm{CNXyl}$, leading to cyanate and carbodiimide complexes respectively. Most interestingly, addition of 2-butyne on the cyanate complex in toluene allowed for $\mathrm{KNCO}$ elimination (because of its precipitation in this solvent) from the coordination sphere and formation of the [[ONO]V( $\eta^{2}$-butyne $\left.)\right]$ complex. The alkyne can be displaced by THF, regenerating the starting complex. Unfortunately, elimination of KNCO by THF is not feasible because of its solubility in this solvent, which precluded development of a catalytic cycle.

\subsection{Niobium dinitrogen complexes: synthesis, $\mathrm{NN}$ bond cleavage and functionalization}

The first niobium $\mathrm{N}_{2}$ complex was obtained in the mid-90s by Gambarotta. The diamagnetic $\left[\mathrm{Nb}\left(\mathrm{NCy}_{2}\right)_{3}\right]_{2}\left(\mu-\eta^{1}: \eta^{1}-\mathrm{N}_{2}\right)$ complex was obtained through reduction of the $\mathrm{Nb}^{\mathrm{IV}}$ precursor under $\mathrm{N}_{2}$ (scheme 27 , top). The complex is thermally robust in solution, and $\mathrm{N}_{2}$ was not readily displaced by classical strong $\sigma$ donors. ${ }^{103}$ 

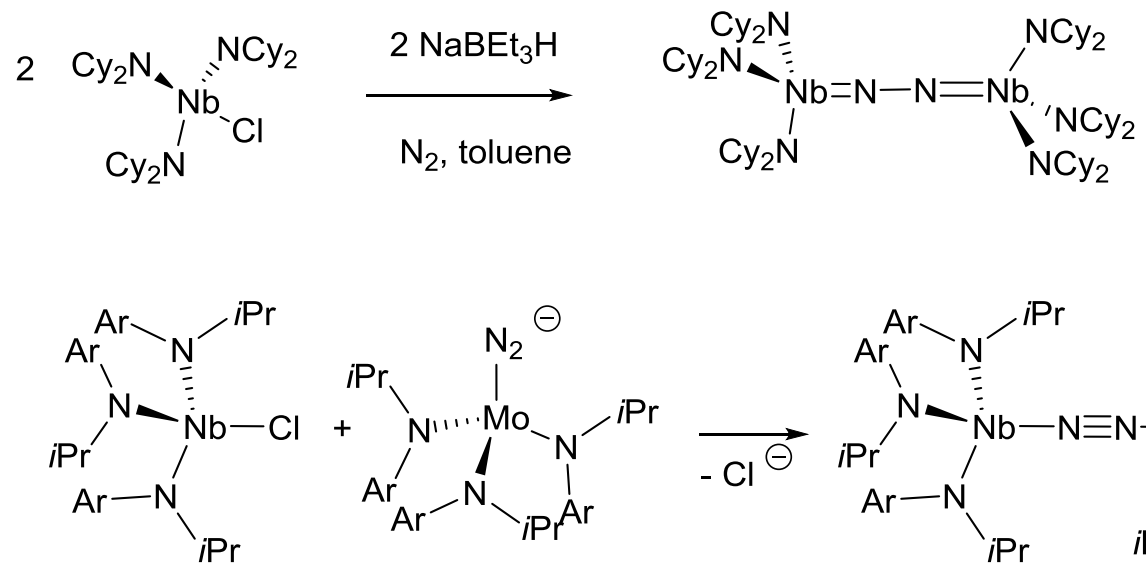<smiles>CC(C)N(C(C)C)[N+]1(N(C(C)C)C(C)C)C(C)N1C(C)C</smiles><smiles>CC(C)N[Al]N(N(C(C)C)C(C)C)N([Al])N(C(C)C)C(C)C</smiles><smiles>[206Po]</smiles>

$\mathrm{KC}_{8}$, crytpand-222

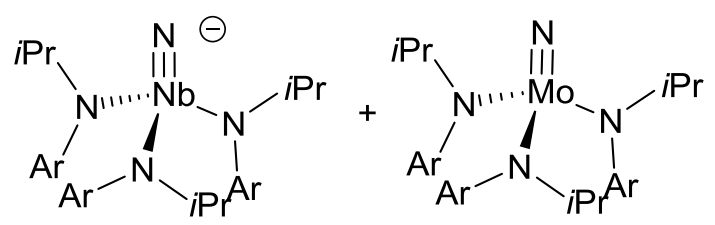

Scheme 27

Cummins et al. synthesized a neutral, paramagnetic $\mathrm{Nb}-\left(\mu-\mathrm{N}_{2}\right)-\mathrm{Mo}$ heterobimetallic complex in 2000 (scheme 27, bottom). ${ }^{104}$ Electrochemistry suggested that the one electron reduction of the complex would result in $\mathrm{NN}$ bond splitting, which was confirmed chemically. When the anionic $\mathrm{Nb}$ nitride complex was oxidized, a cyclic trimer $\left[\mathrm{Nb}(\mathrm{N}(\mathrm{iPr}) \mathrm{Ar})_{2}(\mu-\mathrm{N})\right]_{3}$ was obtained. A complete synthetic cycle was achieved based on this system. Reaction of the anionic nitride intermediate with acylchlorides $(\mathrm{R}=$ tBu, $\mathrm{Ph}, \mathrm{Me}$, 1-adamantyl, vinyl) generates the desired nitriles and the $\left[\mathrm{Nb}(\mathrm{N}(\mathrm{iPr}) \mathrm{Ar})_{2}(\mathrm{O})\right]$ complex. Transformation into the bis-triflate followed by one electron reduction closes the synthetic cycle. ${ }^{105}$ 


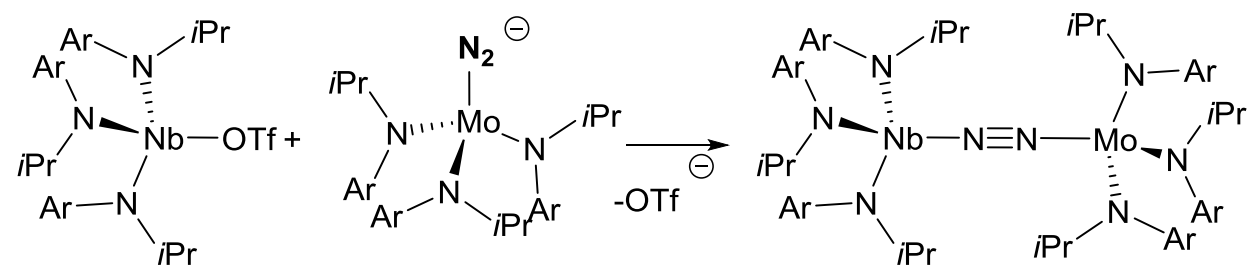<smiles>CCCCCCC(=O)O[Na]</smiles><smiles></smiles>
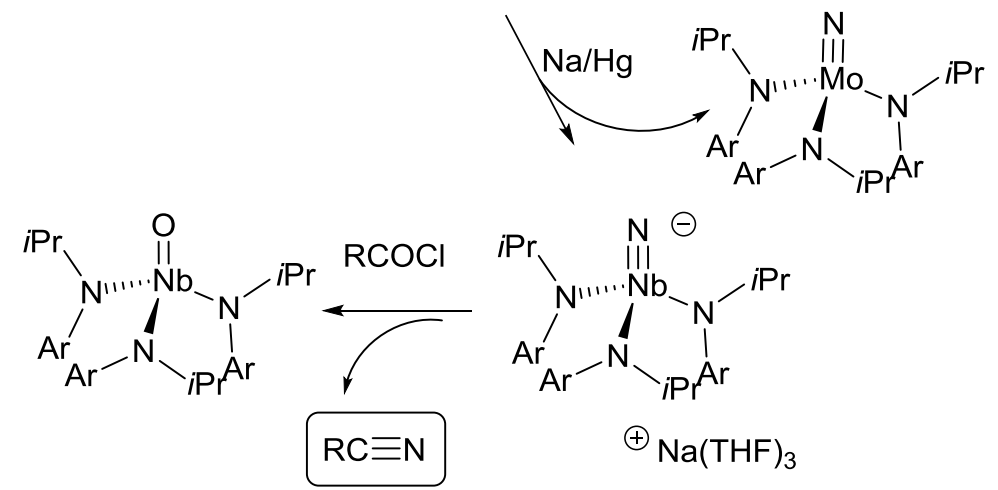

Scheme 28

Floriani reported the use of $\mathrm{p}-(\mathrm{tBu})$-calix[4]arene, "calix", as precursor to tetraanionic $\mathrm{O}$ ligand. The reduction of the $\left[(\right.$ calix $) \mathrm{NbCl}_{2}$ dimer by four electron under Ar leads to the formation of $[(\text { calix }) \mathrm{Nb}]_{2} \mathrm{Na}_{2}(\mathrm{THF})_{6}$ which subsequently reacts with $\mathrm{N}_{2}$ to form the $\left[[(\text { calix }) \mathrm{Nb}]_{2}\left(\mu-\eta^{1}: \eta^{1}-\mathrm{N}_{2}\right)\right]^{2-}$ dianion which crystal structure was obtained from diglyme as the ion pair with $\left[\mathrm{Na}(\text { diglyme })_{2}\right]^{+}$as counter ion (scheme 29$) .{ }^{106}$ In this complex, the remarkably long $\mathrm{NN}$ bond distance of $1.390(17) \AA$ and the long $\mathrm{NbN}$ bond distance (1.748(12) $\AA$ ) support the presence of $\mathrm{N}_{2}^{4-}$ hydrazido bridging moiety. It is to be noted that calculations were performed to explain this unusually long NN bond distance. Although all other metrical parameters were reproduced, the calculated NN bond distance fall within the range 1.26-1.30 $\AA^{107}$ Anyhow, further reduction of the dimer by two electrons resulted in NN bond splitting and formation of the nitride dimer, featuring a planar $\mathrm{Nb}_{2} \mathrm{~N}_{2}$ core with $\mathrm{N}_{+++} \mathrm{N}$ separation of $2.598(8) \AA .{ }^{108}$ 

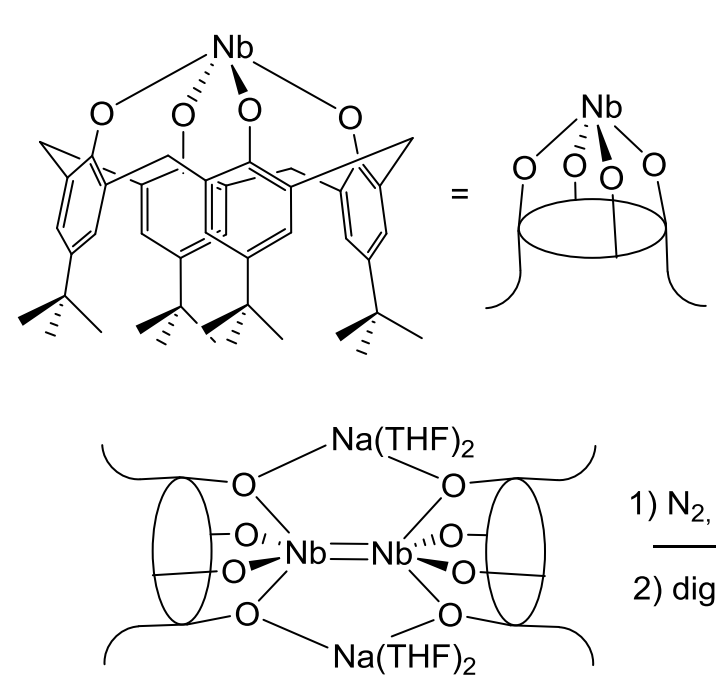

1) $\underset{\mathrm{N}_{2}, \mathrm{THF}}{\stackrel{\mathrm{diglyme}}{\longrightarrow}}$

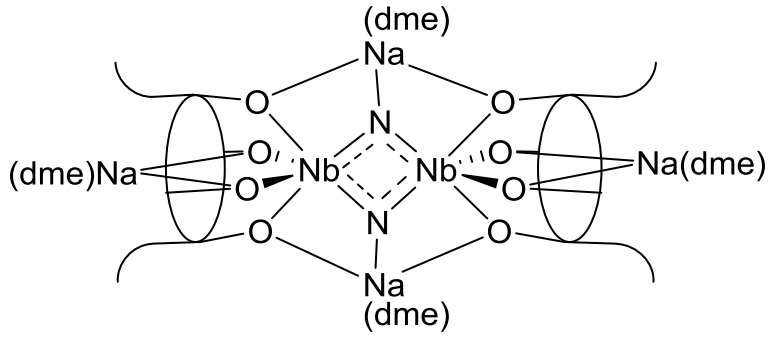

1) $2 \mathrm{Na}, \mathrm{THF}$

2) dme

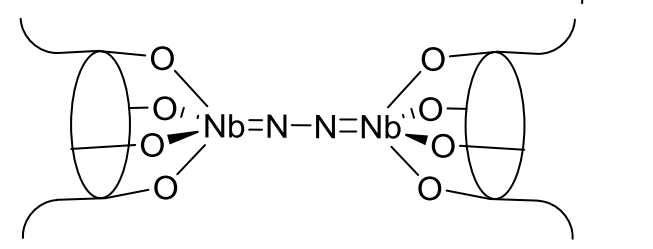

$2 \mathrm{Na}$ (diglyme) ${ }_{2}$

Scheme 29

A related, tris-aryloxy $[\mathrm{OOO}]^{3-}$ trianionic ligand system was reported by Kawaguchi. The reaction of the $\left[[\mathrm{OOO}] \mathrm{NbCl}_{2}\right]_{2}$ precursor with $\mathrm{LiBEt}_{3} \mathrm{H}$ under $\mathrm{N}_{2}$ formed the $[[\mathrm{OOO}] \mathrm{Nb}(\mu-\mathrm{N}) \mathrm{Li}(\text { thf })]_{2}$ complex (scheme 30, top). ${ }^{109}$ The ${ }^{15} \mathrm{~N}$ NMR spectrum of the complex synthesized under ${ }^{15} \mathrm{~N}_{2}$ showed a signal at $312 \mathrm{ppm}$. The crystal structure showed the two bridging nitride to be arranged in an unsymmetrical fashion ( $\mathrm{Nb}-\mathrm{N}$ of $1.892(3)$ and $1.935(3) \AA)$. In this case also, the $\mathrm{N}_{+++} \mathrm{N}$ separation of $2.569(5) \AA$ indicates full $\mathrm{NN}$ bond cleavage. With another tris-aryloxy $[\mathrm{OOO}]^{3-}$ trianionic ligand, the same group later reported that the tetrahydride complex $\left[\left(\mathrm{CH}\left(3,5-(t \mathrm{Bu}) 2-2-\mathrm{OC}_{6} \mathrm{H}_{2}\right)_{3}\right) \mathrm{Nb}(\mu-\right.$ $\left.\mathrm{H})_{2}\right]_{2}{ }^{2-} 2[\mathrm{~K}(\mathrm{DME})]+$ reacts with $\mathrm{N}_{2}$ to form the corresponding dianionic $\left[\mathrm{Nb}^{\mathrm{V}}, \mathrm{Nb}^{\mathrm{V}}\right]$ bis( $\mu$-nitrido) complex, without the need for external reducing agent (scheme 30, bottom). Here also, the long NN distance of $2.589(5) \AA$ indicates NN cleavage. ${ }^{110}$ The mechanisms of the NN bond cleavage in these two cases have been evaluated by DFT. ${ }^{111}$ Alkylation of the nitrido was achieved with MeI. After reaction with pyridine, the 
terminal methylimido complex was reacted with $\mathrm{CO}_{2}$ to generate a mixture of bridging oxo and dianionic dimethylurea complexes.

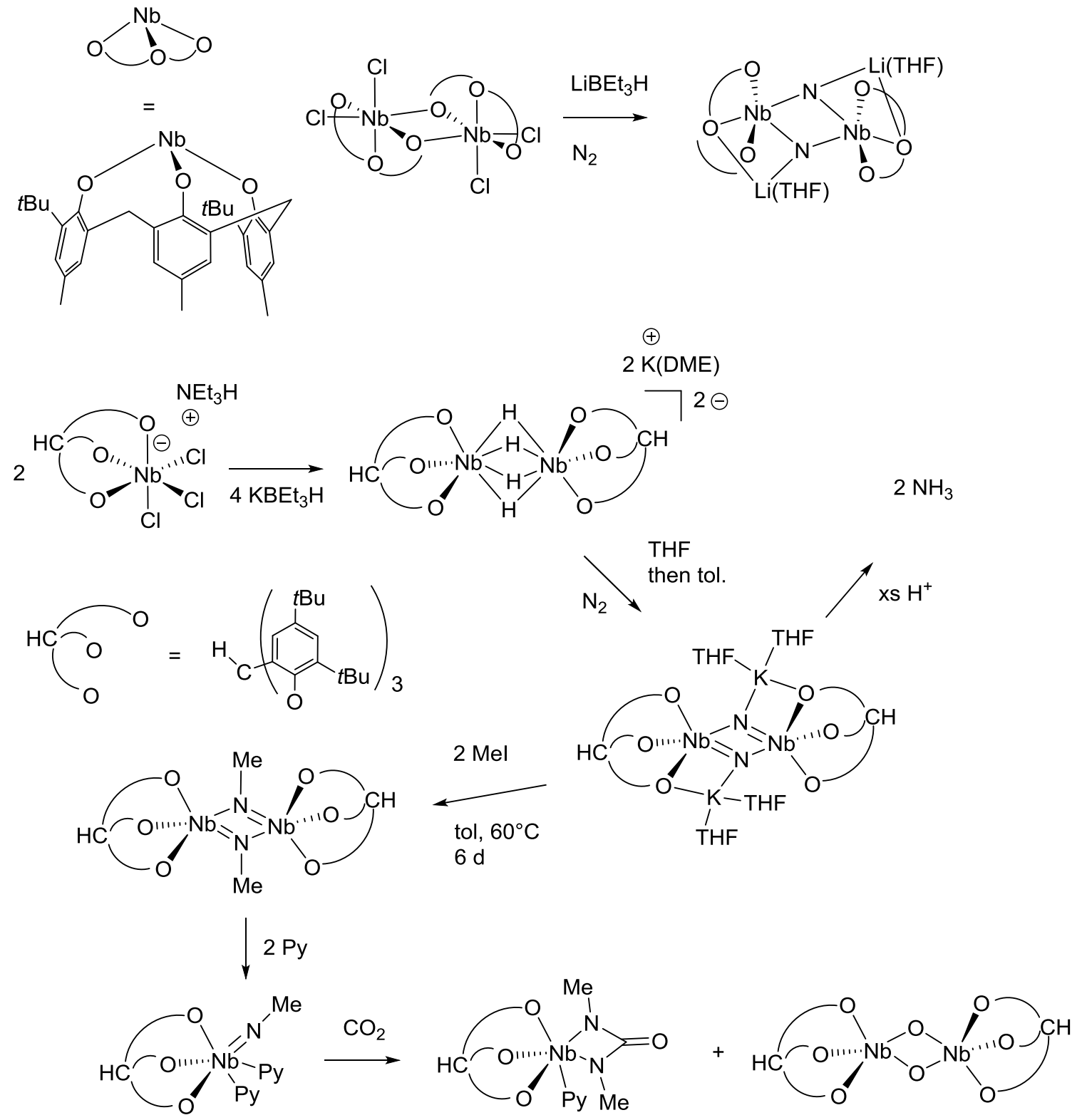

Scheme 30

In 2015, the group of Mindiola used a very bulky aryloxy ligand to achieve NN bond splitting at $\mathrm{Nb}$. Reduction of the $\left[(\mathrm{ArO})_{2} \mathrm{Nb}(\mu-\mathrm{Cl}) \mathrm{Cl}_{2}\right]_{2}$ complex $(\mathrm{ArO}=4-\mathrm{tBu}-2,6-$ $\left.\left(\mathrm{CHPh}_{2}\right)_{2} \mathrm{C}_{6} \mathrm{H}_{2} \mathrm{O}\right)$ by six electrons under $\mathrm{N}_{2}$ generates the formal $\left[\mathrm{Nb}^{\mathrm{V}}, \mathrm{Nb}^{\mathrm{V}}\right]$ bis $(\mu$-nitrido) complex, $\left[(\mathrm{ArO})_{2} \mathrm{Nb}(\mu-\mathrm{N})\right]_{2}$ (scheme 31). The mechanism involves formation of a low 
valent $\mathrm{Nb}^{\mathrm{II}}$ intermediate, which coordinates a $\mathrm{N}_{2}$ molecule to which six electrons are transferred resulting in NN bond splitting (NN distance of $2.56 \AA$ ). ${ }^{112}$ The bis $(\mu-\mathrm{N})$ complex can be reversibly reduced by one electron to form the formal mixed valent $\left[\mathrm{Nb}^{\mathrm{IV}}, \mathrm{Nb}^{\mathrm{V}}\right]$ bis( $\mu$-nitrido), which EPR spectrum at room temperature validates a delocalized electron over the $\mathrm{Nb}_{2} \mathrm{~N}_{2}$ core. Treatment of both of these complexes with excess acid indicated stoichiometric $\mathrm{NH}_{4}{ }^{+}$production.

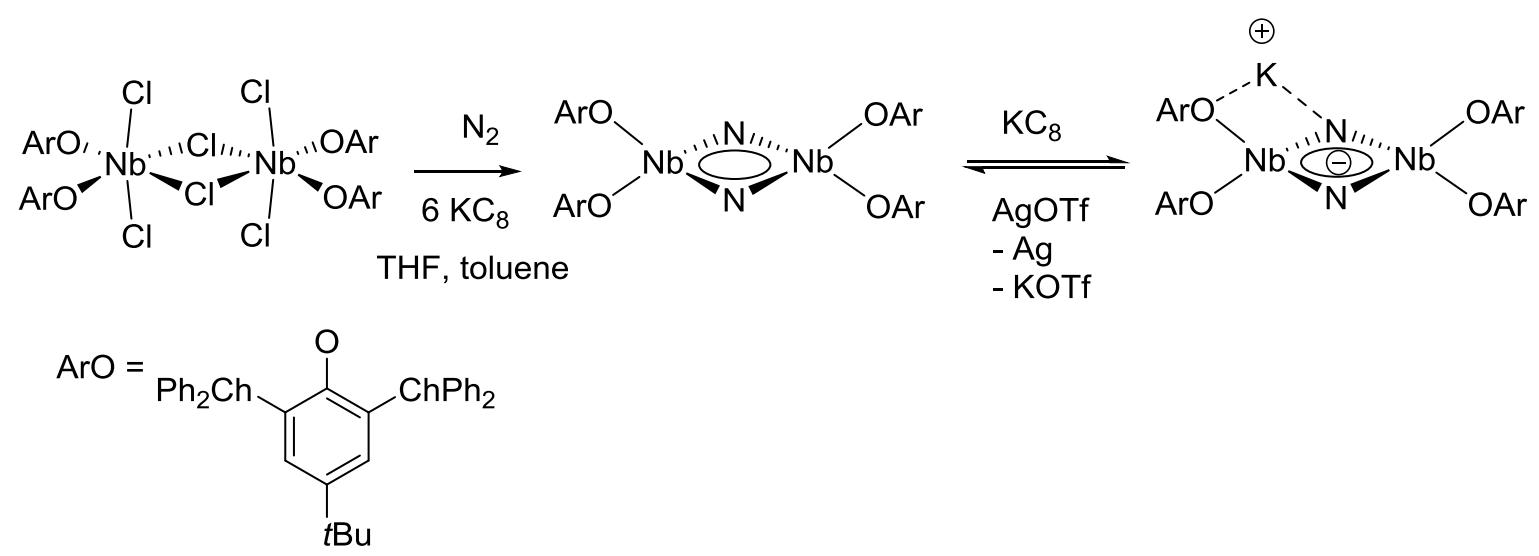

Scheme 31

In the late $90 \mathrm{~s}$, Fryzuk designed dianionic tripodal $[\mathrm{NPN}]^{2-}$ and tetrapodal $\left[\mathrm{P}_{2} \mathrm{~N}_{2}\right]^{2-}$ ligands for the stabilization of $\mathrm{M}$-dinitrogen complexes. The first $\mathrm{Nb}$ complex, $[(\mathrm{NPN}) \mathrm{NbCl}]_{2}\left(\mu-\eta^{1}: \eta^{1}-\mathrm{N}_{2}\right)$, reported in 2001 , features a bridging $\mathrm{N}_{2}$ with a solid state bond distance of 1.237(4) $\AA$, and is proposed to formally have two $\mathrm{Nb}^{\mathrm{V}}$ centers (scheme 32). ${ }^{113}$ The paramagnetic $\left[\left(\mathrm{P}^{\mathrm{Ph}}{ }_{2} \mathrm{~N}_{2}\right) \mathrm{Nb}\right]_{2}\left(\mu-\eta^{1}: \eta^{1}-\mathrm{N}_{2}\right)$ complex was synthesized by reduction of the $\mathrm{Nb}^{\mathrm{III}} \mathrm{Cl}$ precursor with $\mathrm{KC}_{8}$ under $\mathrm{N}_{2}$. Variable temperature magnetic studies and EPR data concur to propose two $\mathrm{Nb}^{\mathrm{IV}}$ centers coupled antiferromagnetically through the bridging hydrazido $\mathrm{N}_{2}{ }^{4-}$ moiety. ${ }^{114}$ Thermolysis of this complex at $110^{\circ} \mathrm{C}$ results in $\mathrm{NN}$ bond cleavage and single bridging nitride formation. The second $\mathrm{N}$ atom appears to have inserted into the backbone of one of the $\left[\mathrm{P}_{2} \mathrm{~N}_{2}\right]$ ligand, provoking a 
rearrangement. Methylation of the $\left[\left(\mathrm{P}^{\mathrm{R}}{ }_{2} \mathrm{~N}_{2}\right) \mathrm{NbCl}\right](\mathrm{R}=\mathrm{Ph}, \mathrm{Cy})$ precursor induces reversible $\mathrm{N}_{2}$ coordination and dimer formation. ${ }^{115}$
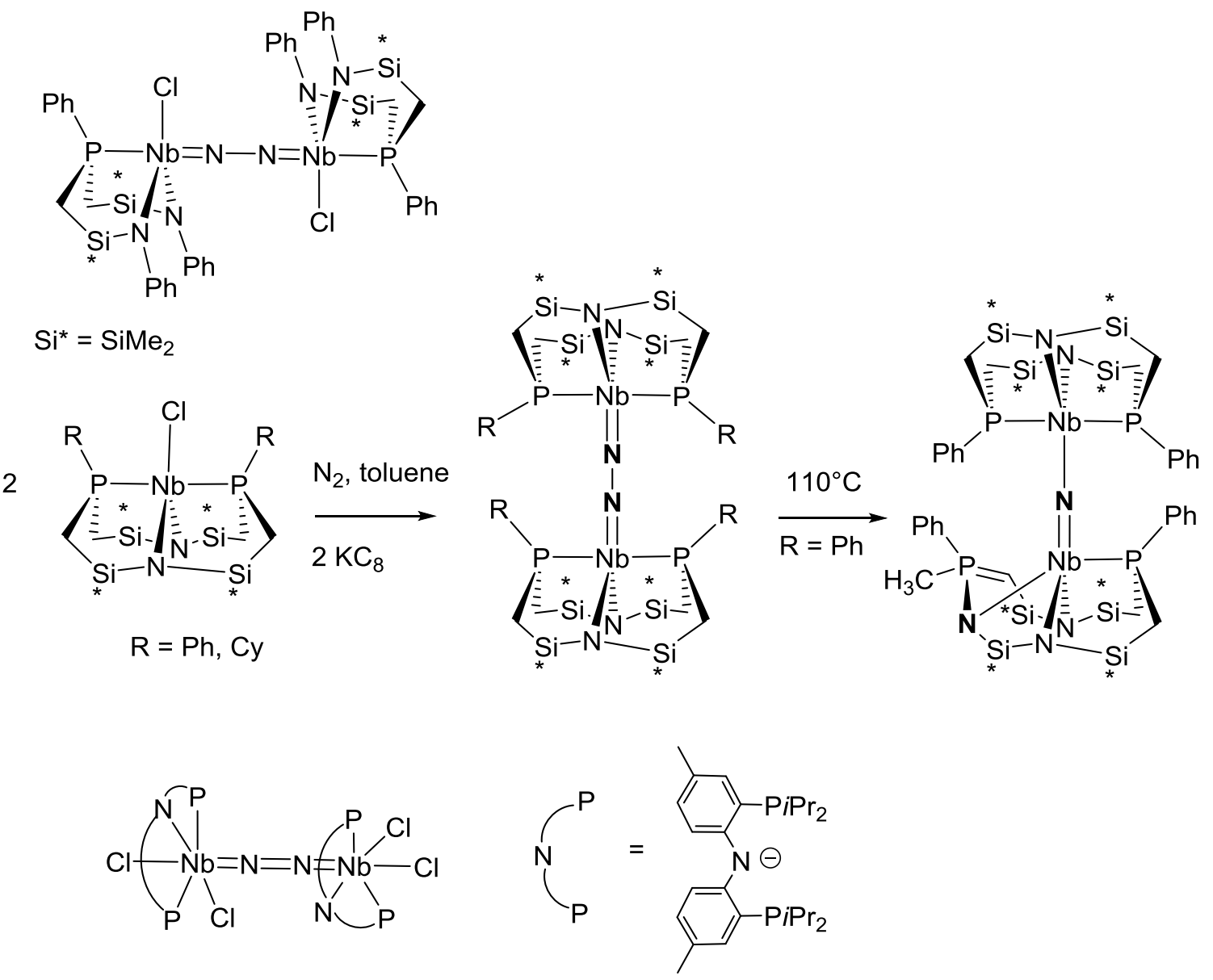

Scheme 32

In addition to the $\mathrm{V}$ complex, Mindiola reported the synthesis of $\left[[\mathrm{PNP}] \mathrm{NbCl}_{2}\right]_{2}\left(\mu-\eta^{1}: \eta^{1}-\right.$ $\left.\mathrm{N}_{2}\right)\left([\mathrm{PNP}]=\left[\mathrm{N}\left(2-\mathrm{P}(\mathrm{iPr})_{2}-4-\left(\mathrm{CH}_{3}\right) \mathrm{C}_{6} \mathrm{H}_{3}\right)_{2}\right]\right)$ from the reduction of the [[PNP]NbCl $\left.\mathrm{N}_{3}\right]$ precursor, forming the $\left[[\mathrm{PNP}] \mathrm{NbCl}_{2}\right]$ as intermediate. ${ }^{116}$ The short $\mathrm{NbN}$ and elongated NN bond distances (1.851(3) $\AA$ and $1.277(6) \AA$ respectively), together with DFT calculations point a bonding of the core between $\mathrm{Nb}=\mathrm{N}-\mathrm{N}=\mathrm{Nb}$ and $\mathrm{Nb}=\mathrm{N}=\mathrm{N}=\mathrm{Nb}$.

\subsection{Tantalum dinitrogen complexes: synthesis and reactivity}

The first tantalum $\mathrm{N}_{2}$ complex was obtained as early as 1980 by Schrock. ${ }^{85}$ Reduction of 
the $\mathrm{Ta}^{\mathrm{V}}$ alkylidene $\left[\mathrm{Ta}\left(\mathrm{PMe}_{3}\right)_{2}\left(\mathrm{Me}_{3} \mathrm{CCH}\right) \mathrm{Cl}_{3}\right]$ by $\mathrm{Na} / \mathrm{Hg}$ under $\mathrm{N}_{2}$ in the presence of additional $\mathrm{PMe}_{3}$ yielded the $\left[\mathrm{Ta}\left(\mathrm{PMe}_{3}\right)_{2}\left(\left(\mathrm{CH}_{3}\right)_{3} \mathrm{CCH}_{2}\right) \mathrm{Cl}\right]_{2}\left(\mu-\eta^{1}: \eta^{1}-\mathrm{N}_{2}\right)$. Presence of bridging $\mathrm{N}_{2}$ was confirmed by reaction with $\mathrm{HCl}$ and acetone. Furthermore, alkylation of this complex with $\mathrm{RLi}(\mathrm{R}=\mathrm{Np}$ or $\mathrm{Me})$ formed the corresponding $\left[\mathrm{Ta}\left(\mathrm{PMe}_{3}\right)_{2}\left(\left(\mathrm{CH}_{3}\right)_{3} \mathrm{CCH}_{2}\right) \mathrm{R}\right]_{2}\left(\mu-\eta^{1}: \eta^{1}-\mathrm{N}_{2}\right)$ complexes, and crystal structure was obtained for $\mathrm{R}=\mathrm{Np}$ ). Diamagnetism, long NN bond (1.298(12) $)$, relatively short TaN bond (1.840 av.) support the $\mathrm{Ta}=\mathrm{N}-\mathrm{N}=\mathrm{Ta}$ structure with two $\mathrm{Ta}^{\mathrm{V}}$ centers and $\mathrm{N}_{2}{ }^{4-}$ bridge. ${ }^{117} \mathrm{~A}$ related bimetallic $\mathrm{Ta}^{\mathrm{III}}\left(\mu-\eta^{1}: \eta^{1}-\mathrm{N}_{2}\right)$ complex is obtained by the reduction of $\left[\mathrm{Ta}\left(\mathrm{C}_{2} \mathrm{H}_{4}\right)\left(\mathrm{PMe}_{3}\right)_{3} \mathrm{Cl}_{3}\right]$ under $\mathrm{N}_{2}{ }^{117}$

In 1998, as stated by Fryzuk, they "serendipitously discovered a simple way to prepare a new dinitrogen complex". ${ }^{118}$ It relied on the reaction of the bimetallic $\mathrm{Ta}^{\mathrm{IV}}, \mathrm{Ta}^{\mathrm{IV}}$ bridging tetrahydride complex $\left[\left[\mathrm{NP}^{\mathrm{Ph}} \mathrm{N}\right] \mathrm{Ta}\right]_{2}(\mu-\mathrm{H})_{4}$ with $\mathrm{N}_{2}$, which readily eliminated $\mathrm{H}_{2}$ to yield the formal $\mathrm{Ta}^{\mathrm{V}}, \mathrm{Ta}^{\mathrm{V}}$ end-on, side-on bridged $\mathrm{N}_{2}$ complex $\left[\left[\mathrm{NP}^{\mathrm{Ph}} \mathrm{N}\right] \mathrm{Ta}\right]_{2}\left(\mu-\eta^{1}: \eta^{2}-\mathrm{N}_{2}\right)(\mu-\mathrm{H})_{2}$ (scheme 33). ${ }^{113},{ }^{119}$ This complex is remarkable because of the strongly elongated NN bond $(1.319(6) \AA)$ as well as by the end-on, side-on coordination, which disymmetrizes the $\mathrm{NN}$ fragment. In 2015, the same group developed a similar complex with the [ $\mathrm{NP}^{\mathrm{Cy}} \mathrm{N}$ ] ligand. ${ }^{120} \mathrm{~A}$ wealth of reactivity has been discovered with this complex. ${ }^{121}$, Focusing on the reactivity of the bridging $\mathrm{NN}$, the nucleophilic character of the "terminal" $\mathrm{N}$ is evidenced first by reaction with electrophiles such as $\mathrm{PhCH}_{2} \mathrm{Br}^{113}$ or $\mathrm{X}=\mathrm{C}=\mathrm{X}^{\prime}\left(\mathrm{X}, \mathrm{X}^{\prime}=\mathrm{S}\right.$ or $\mathrm{NPh}){ }^{122}$ 

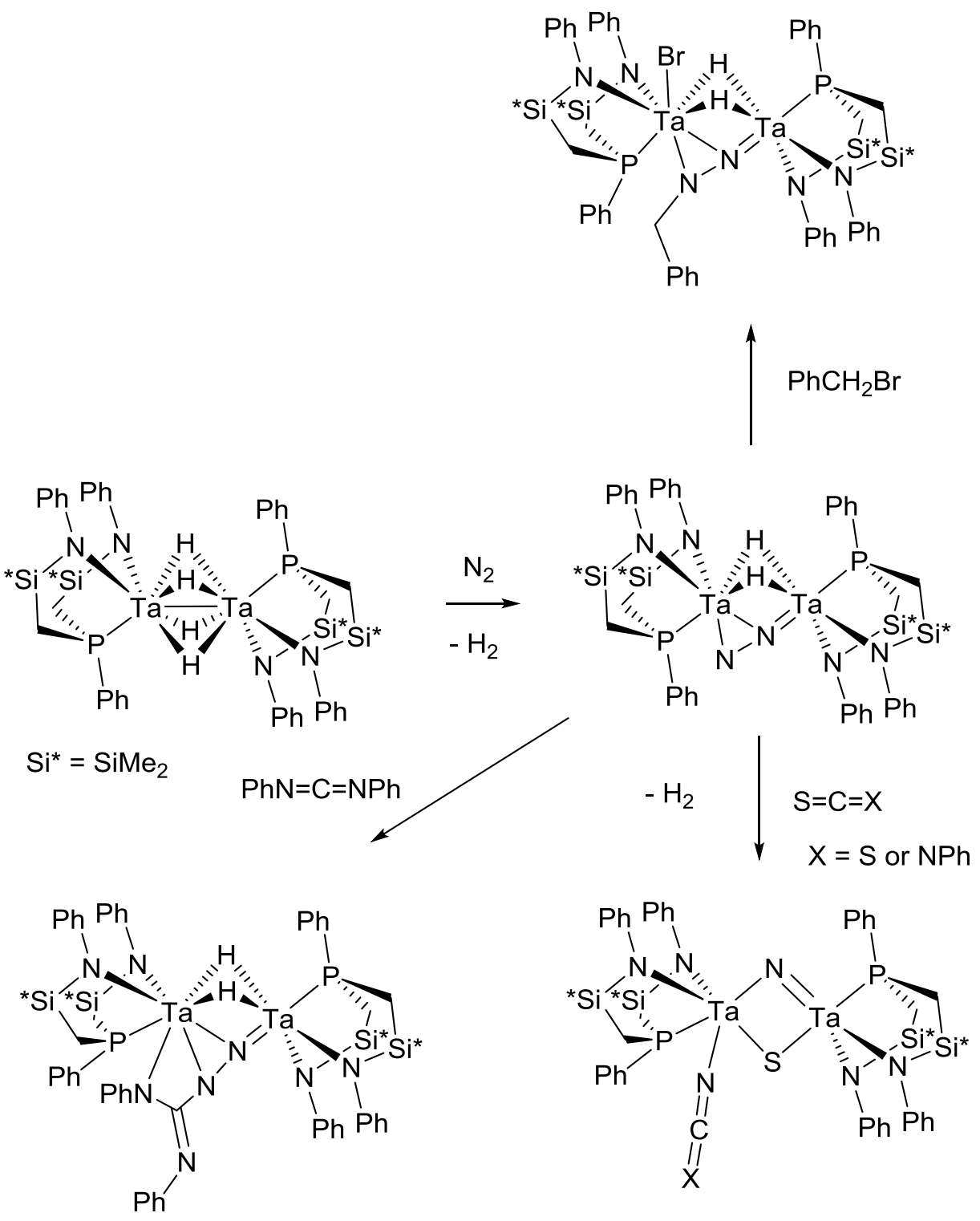

\section{Scheme 33}

The complex also reacts with several E-H bonds (B-H, Si-H, Al-H) to form N-E and Ta$\mathrm{H}$ bonds as initial steps, followed in general by $\mathrm{H}_{2}$ elimination. This elimination is necessary for $\mathrm{NN}$ bond cleavage and subsequent functionalization, as it provides the required additional two electrons. ${ }^{123}$ In the case of boranes $\mathrm{R}_{2} \mathrm{BH}(9-\mathrm{BBN}=9$ borobicyclononane, $\left.\mathrm{Cy}_{2} \mathrm{BH}, \mathrm{HB}\left(\mathrm{C}_{6} \mathrm{~F}_{5}\right)_{2}\right)$ or $\mathrm{RBH}_{2}$ (thexylborane $=\mathrm{H}_{2} \mathrm{BCMe}_{2} \mathrm{CHMe}_{2}$ ), several cases were observed (scheme 34). ${ }^{124}$ In the case of 9-BBN the final bimetallic Ta 
complex features a bridging nitride, an imide resulting from $\mathrm{N}$ functionalization by $\mathrm{B}$, as well as a bridging imide resulting from ligand rearrangement. ${ }^{125}$ Reaction with DIBAL (diisobutylaluminum hydride) also results in ligand rearrangement. One of the amide arm coordinates the $\mathrm{Al}$ center in the final complex, which features two bridging nitrides. ${ }^{126}$ 


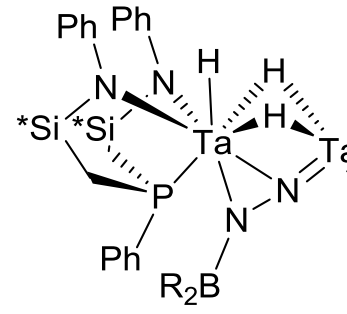

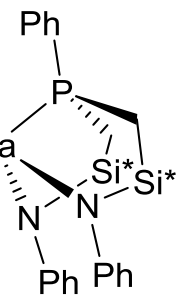
$9-B B N=R_{2} B H$
$-\mathrm{H}_{2}$

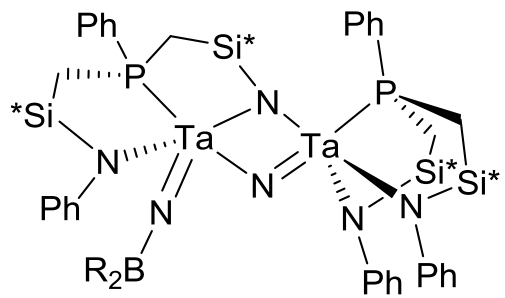

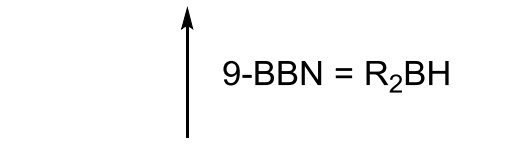

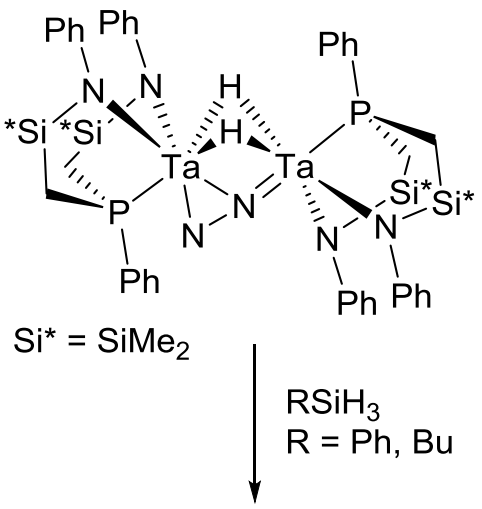

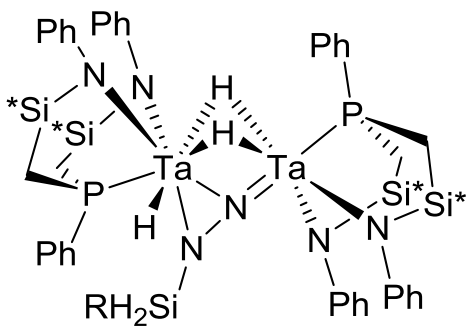

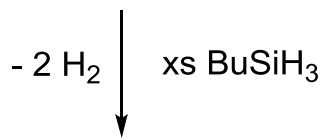

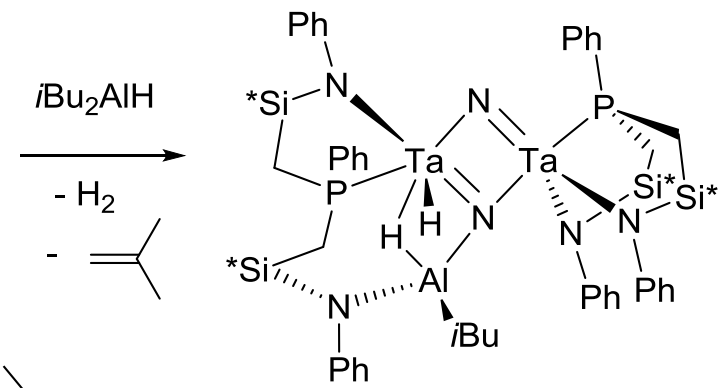

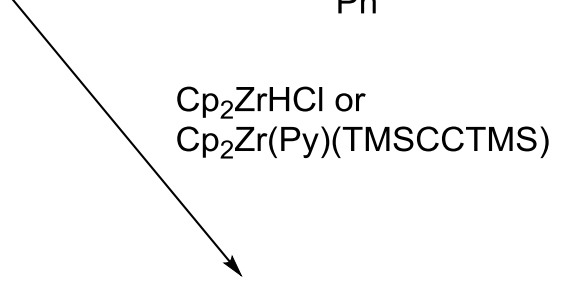

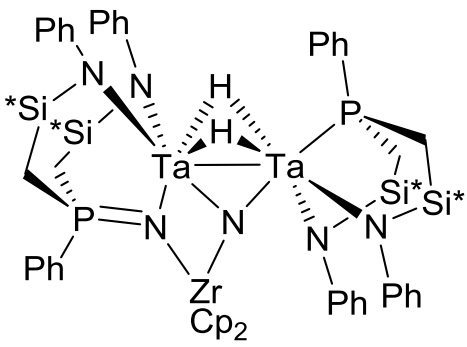

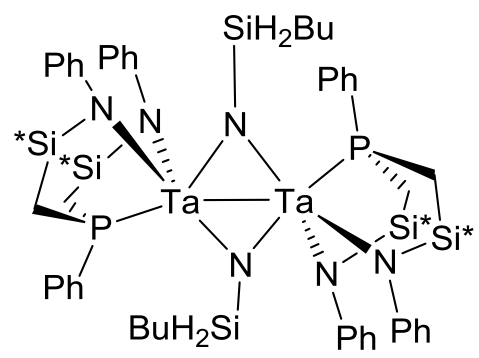

Scheme 34

Reaction with silanes were also very interesting. ${ }^{127},{ }^{128}$ The complexes resulting from the first $\mathrm{Si}-\mathrm{H}$ bond addition across the TaN bond could be isolated. When an excess of 
$\mathrm{BuSiH}_{3}$ is reacted, the elimination of $\mathrm{H}_{2}$ is seen, which results in $\mathrm{NN}$ bond splitting and subsequent functionalization of the intermediate bridging nitride. Finally, a second equivalent of $\mathrm{H}_{2}$ is released to form the bis silylimide bridging complex. ${ }^{128}$

Reaction with Schwartz reagent $\mathrm{Cp}_{2} \mathrm{ZrHCl}$ was intriguing as neither $\mathrm{H}$ nor $\mathrm{Cl}$ were found in the final product. A much higher yield of the trimetallic " $\mathrm{Ta}_{2} \mathrm{Zr}$ " complex was obtained when the zirconocene precursor $\mathrm{Cp}_{2} \mathrm{Zr}(\mathrm{Py})(\mathrm{TMSCCTMS})$ was used. ${ }^{123}$

Cyclopentadienyl ligands have also been used to stabilize Ta-dinitrogen complexes. Thus, reduction of $\mathrm{Cp}_{2}{ }_{2} \mathrm{TaCl}_{2}$ by $\mathrm{Na} / \mathrm{Hg}$ under $\mathrm{N}_{2}$ in $\mathrm{THF}$ forms the $\left[\mathrm{Cp}{ }_{2}{ }_{2} \mathrm{TaCl}\right]_{2}\left(\mu-\eta^{1}: \eta^{1}-\mathrm{N}_{2}\right)$ with $\mathrm{NN}$ bond of $1.235(13) \AA{ }^{129}$ while the one of $\left[\left(\eta^{5}-\right.\right.$ $\left.\mathrm{C}_{5} \mathrm{Me}_{4} \mathrm{R}\right) \mathrm{TaCl}_{4}$ forms $\left[\left(\eta^{5}-\mathrm{C}_{5} \mathrm{Me}_{4} \mathrm{R}\right) \mathrm{TaCl}_{2}\right]_{2}\left(\mu-\eta^{1}: \eta^{1}-\mathrm{N}_{2}\right)(\mathrm{R}=\mathrm{Me}$, Et $)$ with $\mathrm{NN}$ bond of $1.280(6) \AA$ A suggesting stronger reduction of the $\mathrm{N}_{2}$ bridge in the latter (scheme 35 , top). ${ }^{130}$ The chloride ligands could be substituted to synthesize the amidate complexes, with elongated $\mathrm{NN}$ bond $(1.292(4) \AA) .{ }^{131}$ Alternatively, reduction of the $\mathrm{Cp}^{*} \mathrm{TaCl}_{4}$ with an excess of $\mathrm{KC}_{8}$ (5 equiv.) under $\mathrm{N}_{2}$ in the presence of ArS-SAr provided the $\mathrm{Ta}^{\mathrm{V}}, \mathrm{Ta}^{\mathrm{V}}$ complex $\quad\left[\mathrm{Cp} * \mathrm{Ta}\left(\mathrm{S}-4-\left(\mathrm{MeC}_{6} \mathrm{H}_{4}\right)_{2}\right)\right]_{2}\left(\mu-\eta^{1}: \eta^{1}-\mathrm{N}_{2}\right) \quad(d(\mathrm{NN}) \quad 1.281(7) \AA) \quad($ scheme 35 , bottom). ${ }^{132}$ The thiolate ligands were subsequently shown to act as bridging ligands between Ta and $\mathrm{M}\left(\mathrm{M}=\mathrm{Cr}\right.$, Mo) upon photolysis of $\mathrm{M}(\mathrm{CO})_{6}$ in the presence of the $\mathrm{N}_{2}$ complex. Prolonged photolysis was studied to promote NN bond cleavage, but rather resulted in elimination of one $\mathrm{M}(\mathrm{CO})_{4}$ fragment. 


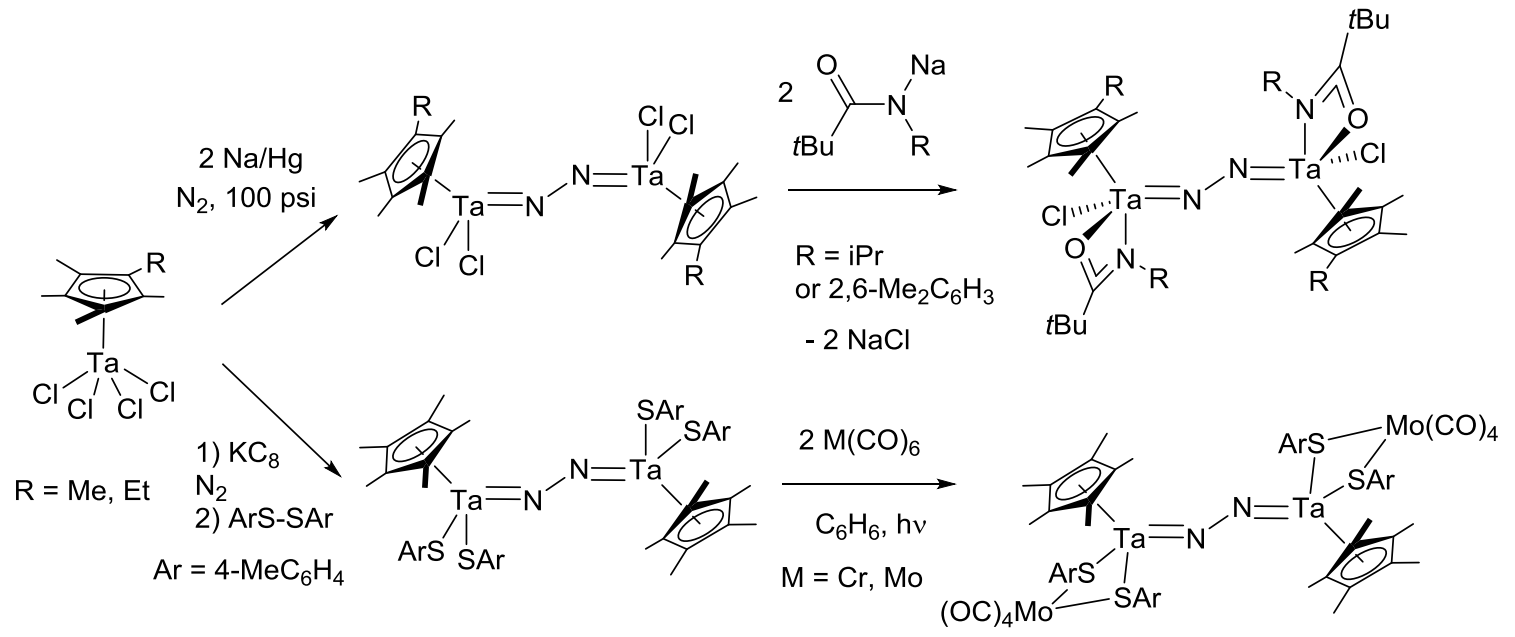

Scheme 35

\subsection{Cp*-amidinate group 5 dinitrogen complexes: synthesis and reactivity}

The group of Sita has studied a family of dinitrogen complexes featuring the fragment $\mathrm{Cp}^{*} /$ amidinate/M, $\mathrm{M}=$ group 4, 5 and 6 transition metal complexes. Thus, they have obtained a large number of isostructural $\left[\left(\eta^{5}-C_{5} M_{5}\right)\left(N\left(R^{1}\right) C\left(R^{2}\right) N\left(R^{1}\right)\right) M\right]_{2}(\mu-$ $\left.\eta^{1}: \eta^{1}-\mathrm{N}_{2}\right)$ complexes $(\mathrm{M}=\mathrm{Ti}, \mathrm{Zr}, \mathrm{Hf}, \mathrm{V}, \mathrm{Nb}, \mathrm{Ta}, \mathrm{Mo}$, and $\mathrm{W})$ which allow a meaningful comparison of the structure/ $\mathrm{d}^{\mathrm{n}}$ electron count/reactivity at $\mathrm{N}_{2}$ relationship. 


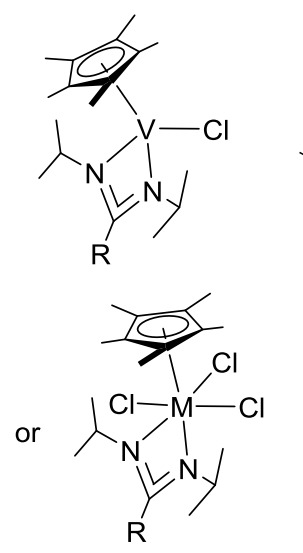

$\mathrm{M}=\mathrm{Nb} ; \mathrm{R}=\mathrm{Me}, \mathrm{Ph}$

$\mathrm{M}=\mathrm{Ta} ; \mathrm{R}=\mathrm{Me}, \mathrm{Ph}, \mathrm{NMe}_{2}$
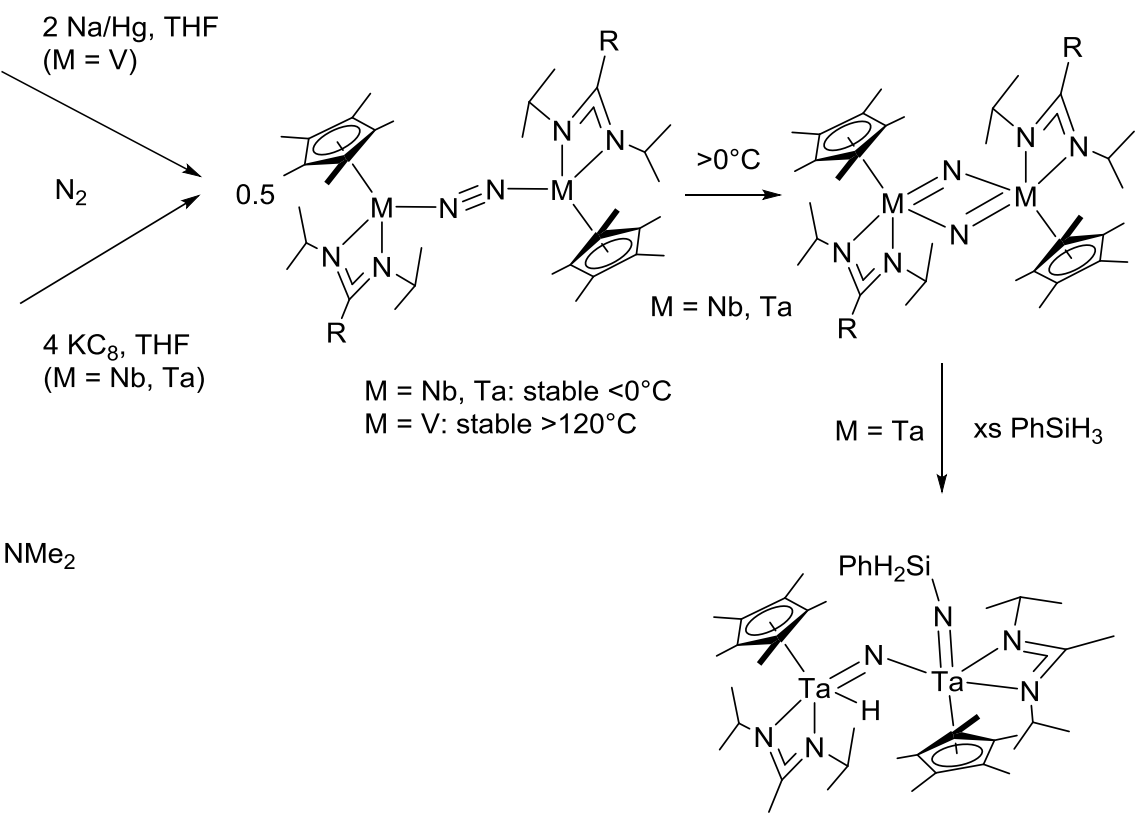

Scheme 36

As shown, reduction of the $\mathrm{V}^{\mathrm{III}}$ or $\mathrm{Nb}^{\mathrm{V}}$ and $\mathrm{Ta}^{\mathrm{V}}$ precursors led to the desired $\mathrm{N}_{2}$ complexes (scheme 36). ${ }^{133},{ }^{134}$ The $\mathrm{V}$ dimer is obtained as a paramagnetic [ $\mathrm{V}^{\mathrm{II}}, \mathrm{V}^{\mathrm{II}}$ ] complex, thermally stable in solution even at $120^{\circ} \mathrm{C}$. It features a short $\mathrm{NN}$ bond distance of $1.225(2) \AA$. On the other hand, the $\mathrm{Nb}$ and $\mathrm{Ta}$ complexes are kinetically unstable in solution depending on the nature of the metal center and the $\mathrm{R}$ group of the amidinate ligand. Apart from the $\mathrm{Nb}$ complex with $\mathrm{R}=\mathrm{Me}$, all other complexes were crystallized and characterized in solution, below $0^{\circ} \mathrm{C}$. The NN bond distances higher than $1.300 \AA$ (1.300(3) $\AA$ to $1.313(4) \AA)$ in these complexes point to $\left[\mathrm{M}^{\mathrm{IV}}, \mathrm{M}^{\mathrm{IV}}\right](\mathrm{M}=\mathrm{Nb}, \mathrm{Ta})$ complexes, and thus a reduced $\mathrm{N}_{2}{ }^{4-}$ bridging moiety. Interestingly, they evolve quantitatively to the diamagnetic $\left[\left(\eta^{5}-\mathrm{C}_{5} \mathrm{Me}_{5}\right)\left(\mathrm{N}\left(\mathrm{R}^{1}\right) \mathrm{C}\left(\mathrm{R}^{2}\right) \mathrm{N}\left(\mathrm{R}^{1}\right)\right) \mathrm{M}(\mu-\mathrm{N})\right]_{2}$ complexes $\left(\left[\mathrm{M}^{\mathrm{V}}, \mathrm{M}^{\mathrm{V}}\right]\right.$ dimer). This thermal process is accompanied by a marked increase in the $\mathrm{NN}$ bond distance, now above $2.55 \AA$, confirming the NN bond splitting. Kinetic data as well as crossover experiments support the rate-determining intramolecular $\mu-\eta^{1}: \eta^{1}-\mathrm{N}_{2}$ to $\mu$ - 
$\eta^{2}: \eta^{2}-\mathrm{N}_{2}$ isomerization prior $\mu$-nitride formation.

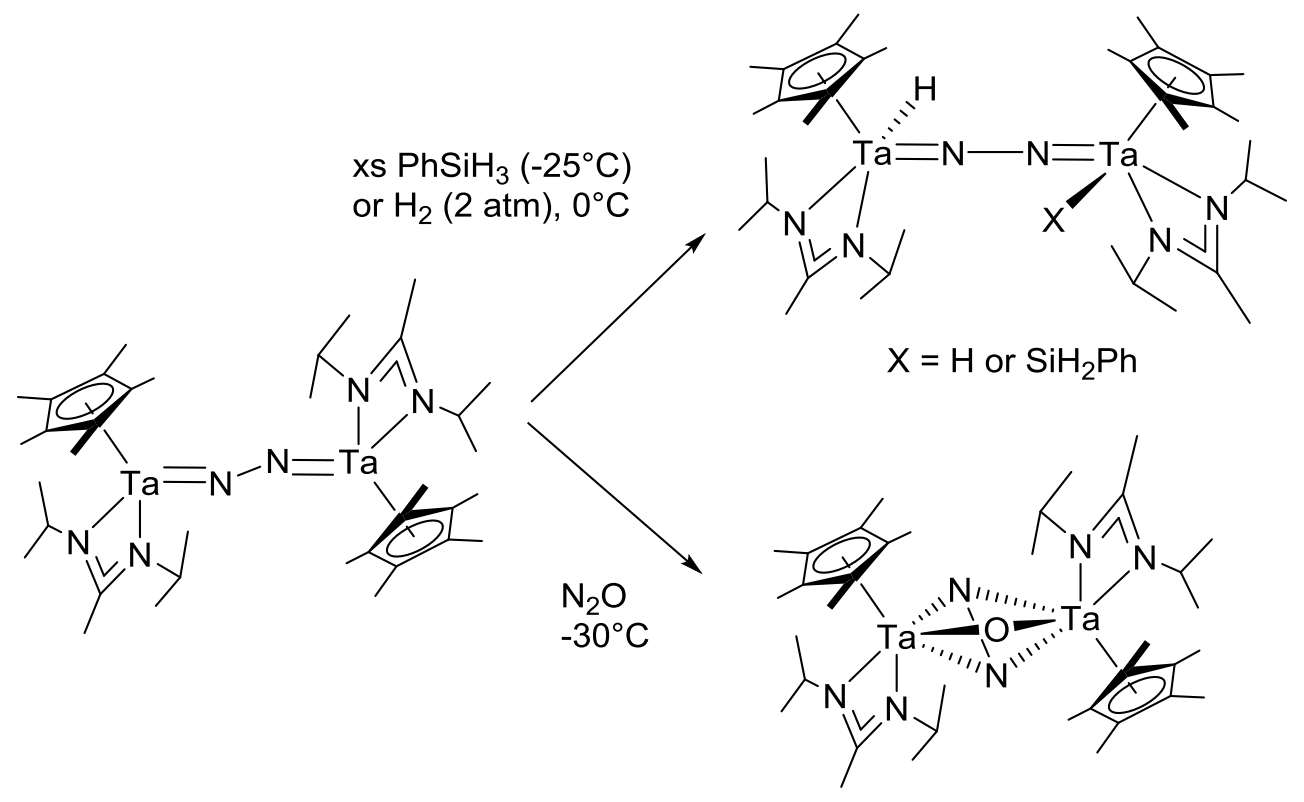

Scheme 37

commentaire

\section{Group 6 transition metal-dinitrogen complexes}

\subsection{Cr complexes: synthesis and reactivity}

After the reported activity of $\mathrm{CrCl}_{3}$ as catalyst in the $\mathrm{N}\left(\mathrm{SiMe}_{3}\right)_{3}$ formation from $\mathrm{N}_{2} / \mathrm{SiMe}_{3} \mathrm{Cl} / \mathrm{Li}$ by Shiina in 1972 followed by first syntheses of $\mathrm{N}_{2}$ complexes of chromium in 1977 , i.e. the thermally unstable $\left[\mathrm{Cr}\left(\mathrm{PMe}_{3}\right)_{4}\left(\mathrm{~N}_{2}\right)_{2}\right]^{135}$ complex and $\left[\mathrm{Cr}(\mathrm{dppe})_{2}\right]_{2}\left(\mu-\mathrm{N}_{2}\right)^{136}$, little attention was paid to $\mathrm{Cr}$ for $\mathrm{N}_{2}$ activation in the next thirty years. In 2007, Budzelaar proposed the use of a tridentate [NNN] pyridine-bis-imine (PDI) ligand to stabilize a bridged $\mathrm{N}_{2}$ complex obtained via the one electron reduction of the $\left(\mathrm{PDI}^{\circ}\right) \mathrm{Cr}^{\mathrm{II}}$ precursor under $\mathrm{N}_{2}$ (scheme 38). ${ }^{137}$ Electron transfer from the in situ generated $\mathrm{Cr}^{0}$ to the end on bridging $\mathrm{N}_{2}$ moiety results in $\mathrm{N}_{2}{ }^{2-}$ formation $(\mathrm{NN}$ bond distance of $1.241(6) \AA$ ). Further addition of $\mathrm{NaH}$ allowed reduction and functionalization 
of $\mathrm{N}_{2}$ and $\mathrm{NN}$ splitting. Protonation of the anionic imido complex released ammonium. The electron acceptor capacity of the PDI ligand appears to be important in the sequence of reactions leading to $\mathrm{N}_{2}$ functionalization. The same year, Theopold reported the synthesis of $\left[\left(\left(i-\mathrm{Pr}_{2} \mathrm{Ph}\right)_{2} \text { nacnac }\right) \mathrm{Cr}\right]_{2}\left(\mu-\eta^{2}: \eta^{2}-\mathrm{N}_{2}\right)$ by reduction of the corresponding $\mathrm{Cr}(\mathrm{II})$ precursor. ${ }^{138}$ Changing the $\beta$-diketiminate ligand by a tris-pyrazolylborate ligand favored the coordination of $\mathrm{N}_{2}$ in an end-on fashion rather than side on. In these two cases, a significant $\mathrm{N}-\mathrm{N}$ bond elongation is observed compared to free $\mathrm{N}_{2}(1.249(5) \AA$ and

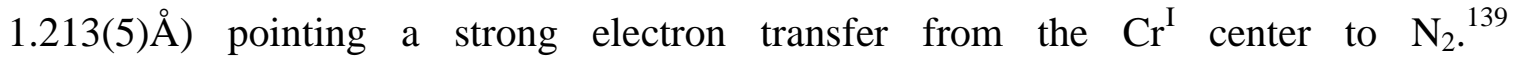
Functionalization of the coordinated $\mathrm{N}_{2}$ was nevertheless not attempted.

2

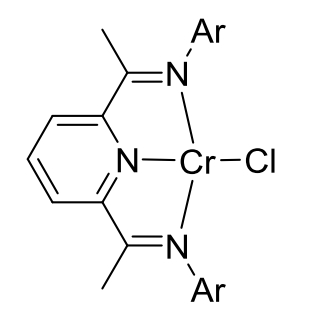<smiles>N#[W]N</smiles>

$\stackrel{\mathrm{xs} \mathrm{NaH}}{\underset{\mathrm{N}_{2}}{\longrightarrow}} 2$<smiles></smiles><smiles>CCCC1=NC2(NC)CCCC12N</smiles>

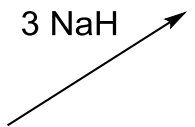<smiles>C1C[In]C1</smiles>
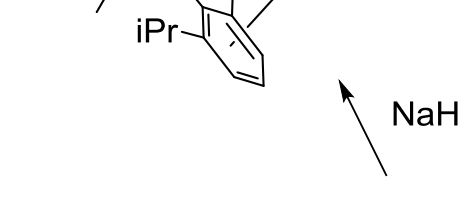

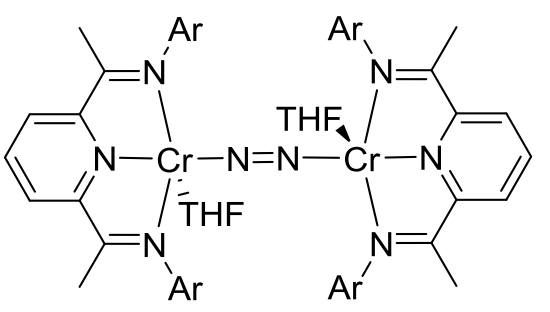

$2 \mathrm{NaH}$

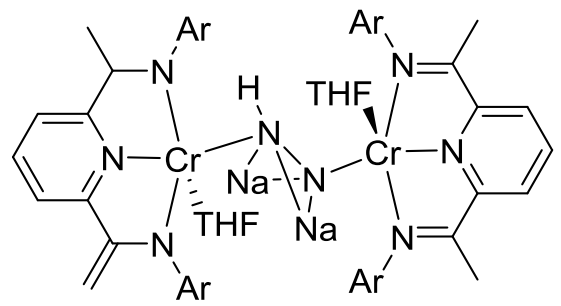

Scheme 38

Since 2011, the group of Mock has focused on low valent $\mathrm{Cr}$ dinitrogen complexes stabilized by neutral macrocyclic ligands " $\mathrm{P}_{\mathrm{n}} \mathrm{N}_{\mathrm{n}}$ " (8-16 membered rings), for which the ligands are bound solely via the phosphines. ${ }^{140}$ With the diphosphine $\mathrm{P}^{\mathrm{Ph}}{ }_{2} \mathrm{~N}^{\mathrm{Bn}}{ }_{2}$ both the cis (ca 15\% yield) and trans isomers could be obtained, depending on the reduction conditions of the $\mathrm{Cr}^{\mathrm{III}}$ precursor (Scheme 39). ${ }^{140}$ 


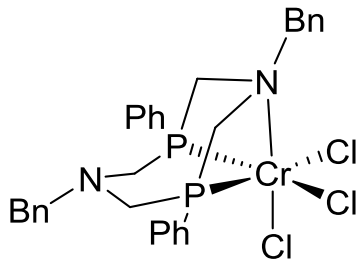

$$
\begin{gathered}
\mathrm{P}_{2}{ }_{2} \mathrm{~N}^{\mathrm{Bn}}{ }_{2} \\
\mathrm{Mg}, \mathrm{N}_{2}
\end{gathered}
$$
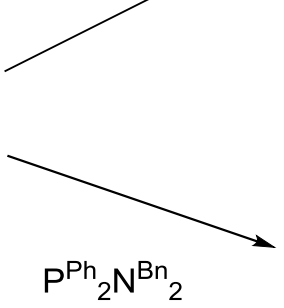

$\mathrm{KC}_{8}, \mathrm{~N}_{2}$

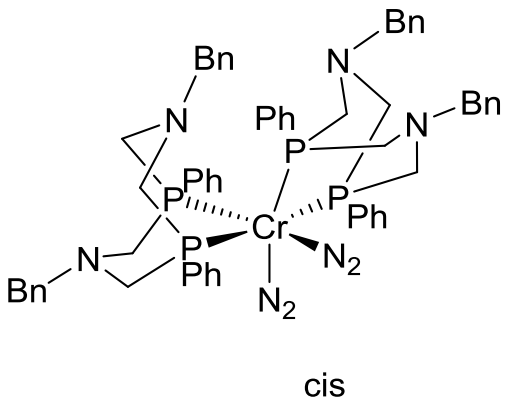

cis +

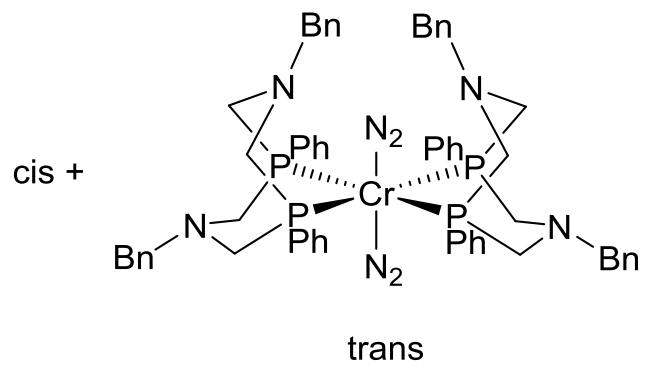

Scheme 39

In 2013, they showed that the macrocyclic diphosphine ligand $\mathrm{P}^{\mathrm{Ph}}{ }_{2} \mathrm{~N}^{\mathrm{Bn}}{ }_{2}$ rearranges to the $12\left(\mathrm{P}^{\mathrm{Ph}}{ }_{3} \mathrm{~N}^{\mathrm{Bn}}{ }_{3}\right)$ and $16\left(\mathrm{P}^{\mathrm{Ph}}{ }_{4} \mathrm{~N}^{\mathrm{Bn}}{ }_{4}\right)$ membered macrocycles upon coordination to $\mathrm{Cr}^{\mathrm{II}}$. Reduction of $\left[\left(\mathrm{P}^{\mathrm{Ph}}{ }_{4} \mathrm{~N}^{\mathrm{Bn}}{ }_{4}\right) \mathrm{CrCl}_{2}\right]$ by $\mathrm{Mg}$ under $\mathrm{N}_{2}$ formed the trans $\left[\left(\mathrm{P}^{\mathrm{Ph}}{ }_{4} \mathrm{~N}^{\mathrm{Bn}}{ }_{4}\right) \mathrm{Cr}\left(\mathrm{N}_{2}\right)_{2}\right]$ in good yield (63\%). X-ray diffraction and IR spectroscopy (strong and weak $v_{\mathrm{NN}}$ bands at $1918 \mathrm{~cm}^{-1}$ and at $2072 \mathrm{~cm}^{-1}$ respectively) proved the trans geometry (scheme 40). ${ }^{141}$ Protonation at room temperature resulted in $\mathrm{N}_{2}$ and phosphine loss and produced no reduced $\mathrm{N}_{2}$ products. If phosphine loss is also observed at $-50^{\circ} \mathrm{C}$, protonation at $\mathrm{N}$ moieties to form hydrazinium $\mathrm{N}_{2} \mathrm{H}_{5}{ }^{+}$was observed as the major $\mathrm{N}$ containing species rather than $\mathrm{NH}_{4}{ }^{+}$(traces). DFT calculations were carried out and suggest protonation of the ligand at the pending $\mathrm{NBn}$, followed by transfer to the $\beta \mathrm{N}$ of $\mathrm{N}_{2}$. Note that the electrons needed for the reduction of $\mathrm{N}_{2}$ are provided by the metal center in the absence of external electron source. 

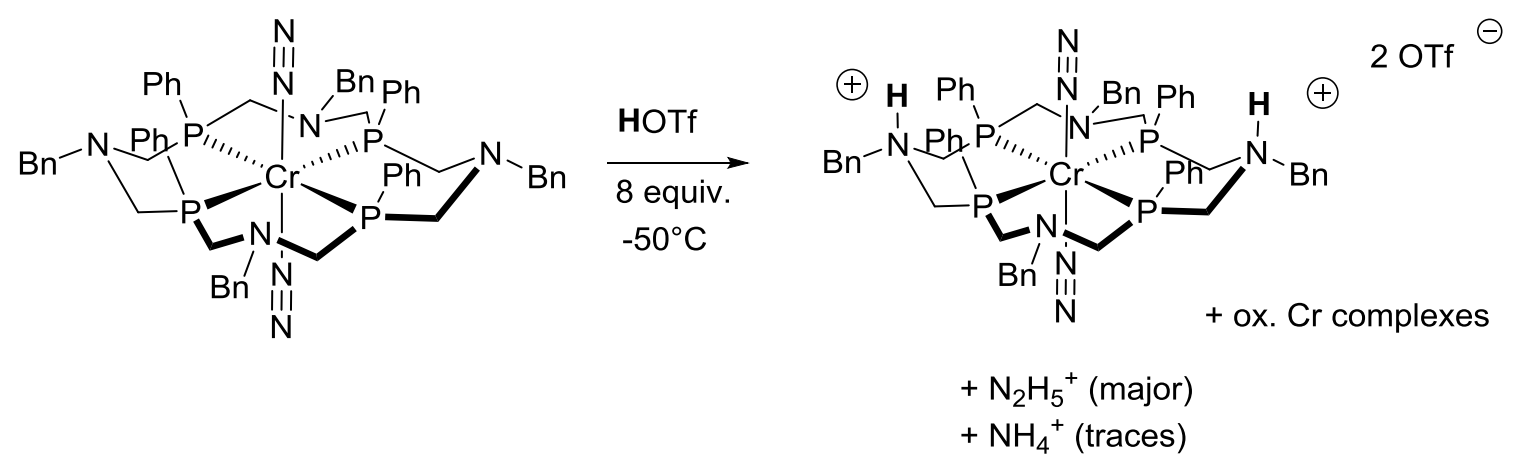

Scheme 40

In a subsequent study, in 2015 , the reduction of $f a c-\left[\left(\mathrm{P}^{\mathrm{Ph}}{ }_{3} \mathrm{~N}_{3}{ }_{3}\right) \mathrm{CrCl}_{3}\right]$ by $\mathrm{Mg}$ under $\mathrm{N}_{2}$ in the presence of dmpe was reported. ${ }^{142}$ Protonation of the electron rich $\mathrm{Cr}^{0}$ complex was studied. Reaction with $\mathrm{HBArF}$ (12 equiv.) at $-78^{\circ} \mathrm{C}$ resulted in immediate and quantitative protonation at $\mathrm{Cr}$ consistent with the formation of only traces of $\mathrm{NH}_{4}{ }^{+}$in addition to free $\mathrm{N}_{2}$. In 2016, the same group reported a family of group 6 dinitrogen $(\mathrm{Cr}$, Mo, W) complexes featuring bidentate phosphine ligands. They evidenced a strong metal dependence on the reduction of coordinated $\mathrm{N}_{2}$, and $\mathrm{NH}_{4}{ }^{+}$(0.08 eq.) and $\mathrm{N}_{2} \mathrm{H}_{5}{ }^{+}(0.22$ eq. $)$ were only observed with the Cr complex (scheme 41$).{ }^{143}$

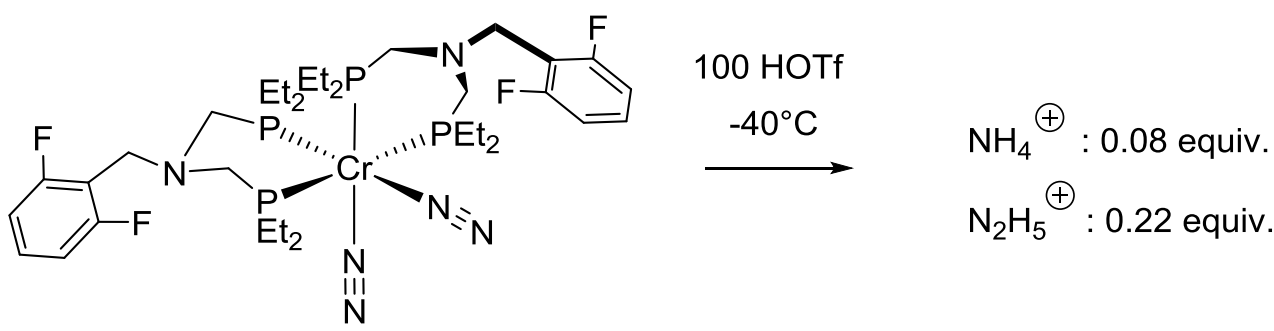

Scheme 41

In 2018, they reported a systematic study involving Cr complexes as catalysts of the $\mathrm{N}_{2}$-to- $\mathrm{N}\left(\mathrm{SiMe}_{3}\right)_{3}$ transformation. ${ }^{144}$ Between 4.8 and 6.8 equiv. of $\mathrm{N}\left(\mathrm{SiMe}_{3}\right)_{3}$ were obtained for the Cr-dinitrogen complexes with bidentate and tridentate ligands (100 equiv. $\mathrm{Na}$ and $\mathrm{SiMe}_{3} \mathrm{Cl}, 1$ atm $\left.\mathrm{N}_{2}, 23^{\circ} \mathrm{C}, 16 \mathrm{~h}, \mathrm{THF}\right)$. The tetraphosphine " $\mathrm{P}_{4} \mathrm{~N}_{4}$ " ligand, 
featuring the 16 membered macrocycle provided the best results (10.6 equiv. $\mathrm{NH}_{4}{ }^{+}$), and proved catalytically active after reloading (maximum 34.1 equiv. $\mathrm{NH}_{4}^{+}$), pointing resistance of the " $\mathrm{P}_{4} \mathrm{Cr}$ " fragment to ligand dissociation and catalyst deactivation. Interestingly, reaction under 90 atm $\mathrm{N}_{2}$ failed to increase the efficiency, suggesting that a five coordinate " $\mathrm{P}_{4} \mathrm{Cr}^{0}\left(\mathrm{~N}_{2}\right)$ " complex is a prerequisite for catalysis. Finally, in 2019, the group of $\mathrm{Xi}$ proposed a novel $\mathrm{Cp}$-phosphine ligand capable of stabilizing low valent $\mathrm{Cr}$ $\mathrm{N}_{2}$ complexes (neutral $\mathrm{Cr}^{\mathrm{I}}$ and anionic $\mathrm{Cr}^{0}$ ) (scheme 42). They showed that even if the $\mathrm{NN}$ bond distance is very similar in the $\mathrm{Cr}^{\mathrm{I}}(1.05-1.17 \AA)$ and $\mathrm{Cr}^{0}(1.141 \AA)$, the N-N stretching frequencies show much stronger activation for the reduced complexes. The best catalytic efficiency in the $\mathrm{N}_{2}$-to- $\mathrm{N}\left(\mathrm{SiMe}_{3}\right)_{3}$ reaction was found to be 26.0 eq of $\mathrm{NTMS}_{3}$ per Cr complex. Mechanistic investigation showed that the hydrazido complex $\mathrm{Cr}=\mathrm{N}-\mathrm{N}\left(\mathrm{SiMe}_{3}\right)_{3}$ could be formed from the anionic $\mathrm{Cr}^{0}$ complex.

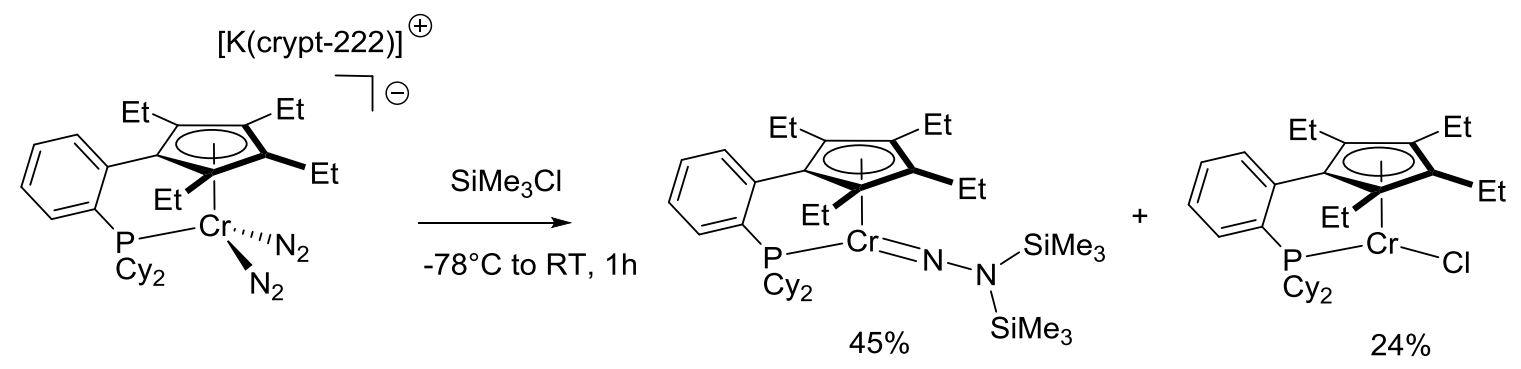

Scheme 42

\subsection{Mo and $W$ complexes}

Together with $\mathrm{Fe}$, Mo is most intensively studied in the context of $\mathrm{N}_{2}$ activation. This fact takes its origin in their presence in the most common as well as most efficient nitrogenase enzyme. Seminal works by Hidai and Chatt at the end of the 1960s and in the 1970s have focused on the synthesis of $\mathrm{M}^{0}$ bis-dinitrogen $(\mathrm{M}=\mathrm{Mo}, \mathrm{W})$ with mono or bidentate phosphines and their subsequent reactivity. ${ }^{145}$ A large body of work has 
subsequently focused on phosphine variation with the long time goal of developing a catalytic process. Two synthetic strategies for the low valent metal complexes $\mathrm{N}_{2}$ are classically used. A high valent precursor is reduced under $\mathrm{N}_{2}$ in the presence of the chosen ligand, or the high valent ligand-metal complex is synthesized prior to its reduction under $\mathrm{N}_{2}$. Monodentate phosphine displacement by bidentate ones has also been reported. In 2008, Nishibayashi reported a series of $\left[\mathrm{M}(\mathrm{PP})_{2}\left(\mathrm{~N}_{2}\right)_{2}\right](\mathrm{M}=\mathrm{Mo}$ and W) where "PP" is a bidentate phosphine featuring a metallocene (ferrocenyl, ruthenocenyl, or chromobenzene) backbone (vide infra). ${ }^{146},{ }^{147},{ }^{148}$

Tridentate ligands, [PEP] (with $\mathrm{P}=\mathrm{R}_{2} \mathrm{P}, \mathrm{R}=\mathrm{Ar}$ or alkyl; $\mathrm{E}=\mathrm{O}, \mathrm{NH}, \mathrm{S}, \mathrm{PR}$ ) have also been used as platforms to stabilize low valent $\mathrm{M}-\mathrm{N}_{2}$ complexes. The stability of the complexes strongly depends on the nature of the "P" ligand. In the case of $\mathrm{PPh}_{2}$, an additional donor ligand has to be added to stabilize the $\mathrm{Mo}^{0}$ oxidation state (Scheme 43, top). ${ }^{149},{ }^{150},{ }^{151}$, Similar requirements are found for [PNN] ligands. ${ }^{152}$ On the other hand, with $\mathrm{P}(\mathrm{alkyl})_{2}$ moieties,${ }^{153}$ the $\mathrm{Mo}^{0}$ complex can be stable in the absence of additional phosphine and several complexes featuring bridging end-on $\mathrm{N}_{2}$ ligand have been synthesized which have proved relevant to $\mathrm{N}_{2}$ functionalization in recent years (vide infra) (Scheme 43, middle). ${ }^{154},{ }_{155},{ }^{156},{ }_{157},{ }^{158}$ Tripodal, ${ }^{159},{ }^{160}$ Tetradentate ${ }^{161},{ }^{162},{ }^{163}$ and pentadentate ${ }^{164},{ }^{165}$ phosphine ligands have been designed to favor coordination of either one or two $\mathrm{N}_{2}$ ligands at the $\mathrm{Mo}^{0}$ center.

Tridentate [NNN] ligand pyridine-di-imine (PDI) has been used by Chirik to stabilize efficiently the $\left[(\mathrm{PDI}) \mathrm{Mo}\left(\mathrm{N}_{2}\right)\right]_{2}\left(\mu-\mathrm{N}_{2}\right)$ complex (Scheme 43, bottom). Subsequent attempts of $\mathrm{N}_{2}$ functionalization were unsuccessful, resulting in $\mathrm{N}_{2}$ displacement by $\mathrm{H}_{2}$, or C-N bond breaking in the ligand backbone (imine moiety) upon reaction with $\mathrm{NH}$ moieties. ${ }^{166}$ 
[PEP]

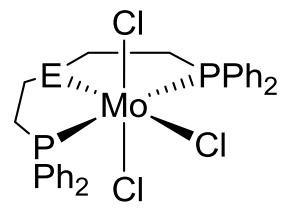

$\mathrm{E}=\mathrm{PPh}, \mathrm{O}, \mathrm{NH}$

2

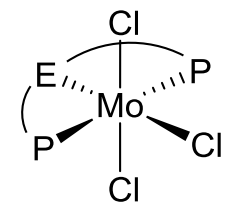

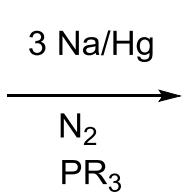

$\mathrm{PR}_{3}=\mathrm{PPh}_{3}, \mathrm{PMePh}_{2}, \mathrm{PMe}_{2} \mathrm{Ph}$

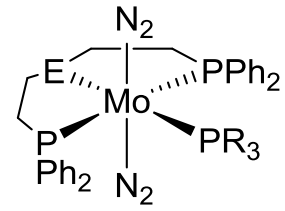

$3 \mathrm{Na} / \mathrm{Hg}$

$\mathrm{N}_{2}$

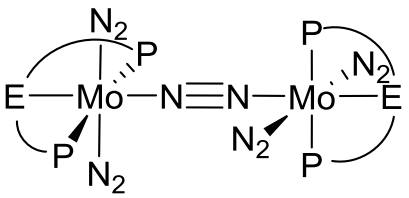<smiles>[R16]Cc1cc([R])cc(CPCCCC)n1</smiles>

$\mathrm{R}^{\prime}=\mathrm{H}, \mathrm{Me} \mathrm{Ph}, \mathrm{tBu}$,

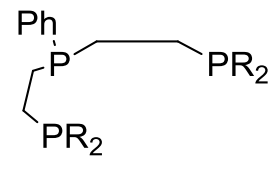

$\mathrm{R}=\mathrm{tBu}, \mathrm{Cy}$

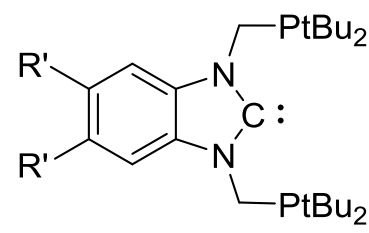

$\mathrm{R}^{\prime}=\mathrm{H}, \mathrm{Me}$
$[N N N]=P D I$

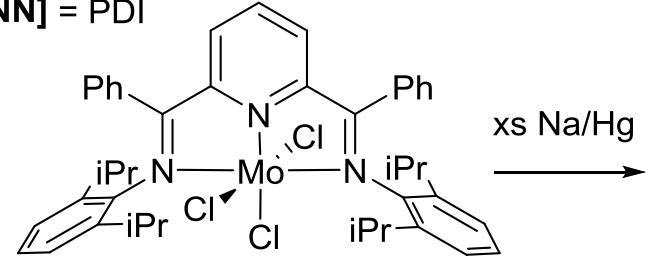

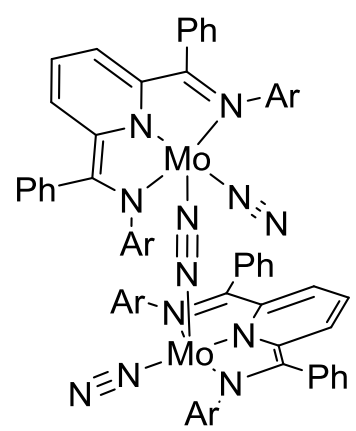

Scheme 43

\subsection{From end-on bridging complexes to $\mathrm{NN}$ bond splitting}

As exemplified previously, formation of bridging $\mathrm{N}_{2}$ complexes can result in significant electron transfer from the metal center to $\mathrm{N}_{2}$, thereby potentially weakening the bond and favoring its subsequent functionalization. These complexes can be synthesized using two strategies. Firstly, a stable " $\mathrm{M}-\mathrm{N}_{2}$ " complex can be used as a ligand for the second fragment, opening ways to heterobimetallic (or polymetallic) 
complexes. Secondly, the bridging $\mathrm{N}_{2}$ ligand can be installed upon reduction of a metalhalogen bond. The first strategy was reported as early as 1975 using $\left[\operatorname{Re}(\mathrm{Cl})\left(\mathrm{PMe}_{2} \mathrm{Ph}\right)_{4}\left(\mathrm{~N}_{2}\right)\right]$ as a "ligand" for $\mathrm{Mo}^{\mathrm{IV}}$ to form the $\mathrm{N}_{2}$ bridging dimer $\left[\operatorname{ReCl}\left(\mathrm{PMe}_{2} \mathrm{Ph}\right)_{4}\left(\mu-\mathrm{N}_{2}\right) \mathrm{MoCl}_{4}(\mathrm{MeOH})\right] .{ }^{167}$ From 1997, Schrock used the " $\left[\mathrm{N}_{3} \mathrm{~N}\right] \mathrm{Mo}$ $\mathrm{N}=\mathrm{N}^{-”}$ anion of $\left[\left[\mathrm{N}_{3} \mathrm{~N}\right] \mathrm{Mo}-\mathrm{N}=\mathrm{N}-\mathrm{Mg}(\mathrm{THF})_{2}\right]$ as an $\mathrm{X}$ type ligand to generate the heteropolymetallic complexes $\quad\left[\left\{\left[\mathrm{N}_{3} \mathrm{~N}\right] \mathrm{Mo}\left(\mu-\eta^{1}-\eta^{1}: \mathrm{N}=\mathrm{N}\right)\right\}_{3} \mathrm{Fe}\right], \quad\left[\left\{\left[\mathrm{N}_{3} \mathrm{~N}\right] \mathrm{Mo}\left(\mu-\eta^{1}-\right.\right.\right.$ $\left.\left.\left.\eta^{1}: \mathrm{N}=\mathrm{N}\right)\right\}_{2} \mathrm{VCl}(\mathrm{THF})\right]$ and $\left[\left\{\left[\mathrm{N}_{3} \mathrm{~N}\right] \mathrm{Mo}\left(\mu-\eta^{1}-\eta^{1}: \mathrm{N}=\mathrm{N}\right)\right\}_{2} \mathrm{ZrCl}_{2}\right]$ (scheme 44, top) ${ }^{168}{ }^{169}$ At the same time, the $\left[\mathrm{W}\left(\mathrm{PMe}{ }_{2} \mathrm{Ph}\right)_{4}\left(\mathrm{~N}_{2}\right)_{2}\right]$ complex was used by Hidai to synthesize the several examples of $\mathrm{W}-\mathrm{N}_{2}-\mathrm{M}(\mathrm{M}=$ group 4 or 13 metal $)$ complexes that result formally from the addition of $\mathrm{M}-\mathrm{Cl}$ across the $\mathrm{W}-\mathrm{N}_{2}$ moiety (scheme 44 , bottom), a reactivity reminiscent to other R-X additions (vide infra). ${ }^{170},{ }^{171}$ 


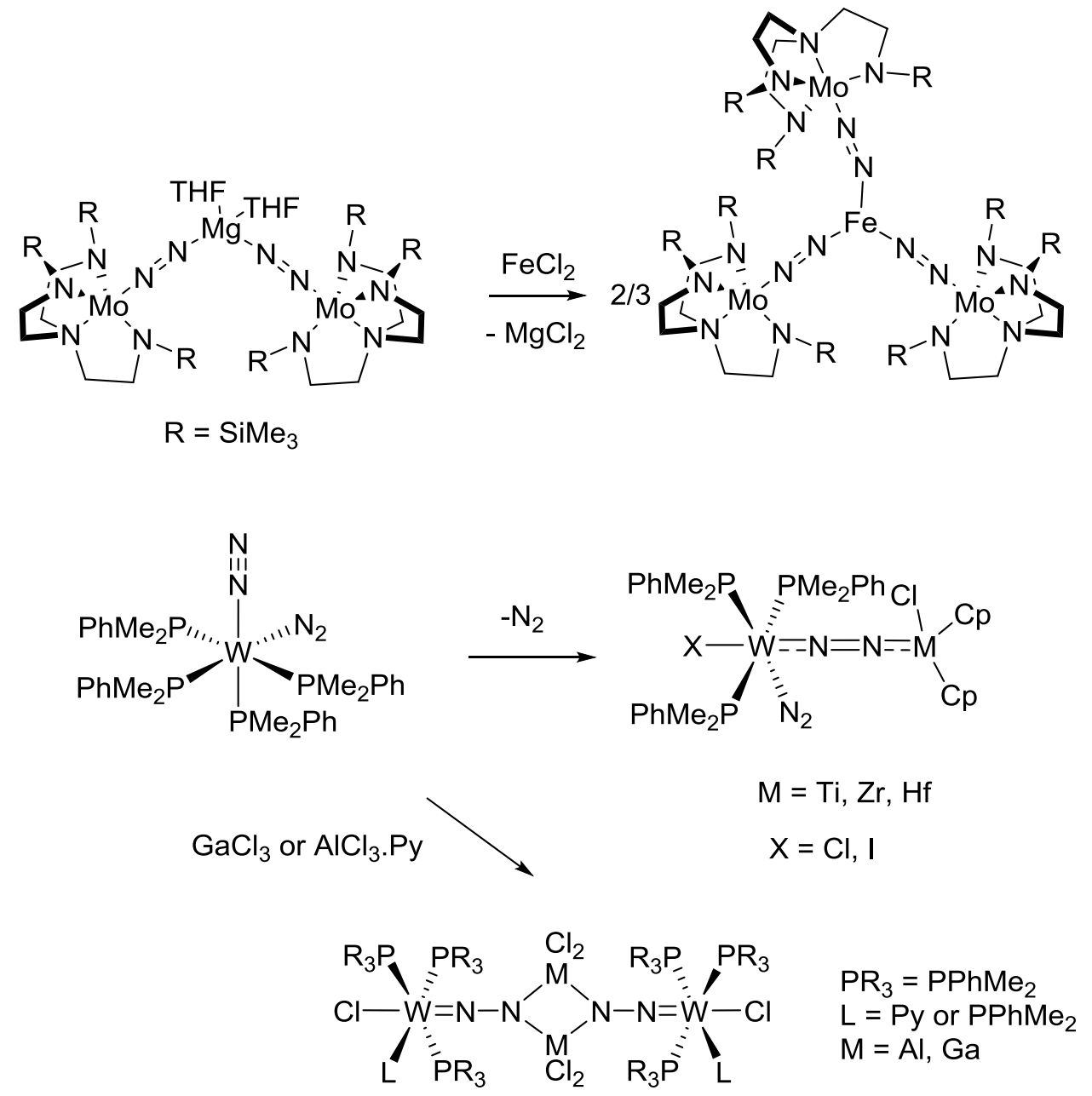

Scheme 44

Schrock and coworkers also studied the activation of $\mathrm{N}_{2}$ at high valent $\mathrm{W}$ and $\mathrm{Mo}$ complexes. Reduction of $\left[\mathrm{W}\left(\mathrm{Cp}^{*}\right)(\mathrm{Me})_{3}(\mathrm{OTf})\right]$ by one electron yields the bridging endon $\mathrm{N}_{2} \mathrm{~W}$ complexes $\left[\mathrm{W}\left(\mathrm{Cp}^{*}\right)(\mathrm{Me})_{3}\right]_{2}\left(\mu-\mathrm{N}_{2}\right)$, in which the NN Bond distance of ca $1.27 \AA$ is consistent with a $\mathrm{N}_{2}{ }^{2-}$ moiety. ${ }^{172}$ Functionalization of $\mathrm{N}_{2}$ by acid was attempted but reactivity at $\mathrm{M}_{-} \mathrm{CH}_{3}$ was only observed. The analogous homo-bimetallic $\left[\mathrm{Mo}\left(\mathrm{Cp}^{*}\right)(\mathrm{Me})_{3}\right]_{2}\left(\mu-\mathrm{N}_{2}\right)$ and hetero-bimetallic $\left[\mathrm{W}\left(\mathrm{Cp}^{\prime}\right)(\mathrm{Me})_{3}\right]\left(\mu-\mathrm{N}_{2}\right)\left[\mathrm{Mo}\left(\mathrm{Cp}^{*}\right)(\mathrm{Me})_{3}\right]$ were made. ${ }^{173}$

Sita and co-workers studied the reduction under $\mathrm{N}_{2}$ of related $\mathrm{Mo}^{\mathrm{IV}}, \mathrm{Mo}^{\mathrm{V}}$ and $\mathrm{W}^{\mathrm{V}}$ complexes featuring $\mathrm{Cp}^{*}$ and amidinate (or guanidinate) ligands in 2010. The bridging 
end-on complexes were obtained in excellent yields (scheme 45). ${ }^{174}$

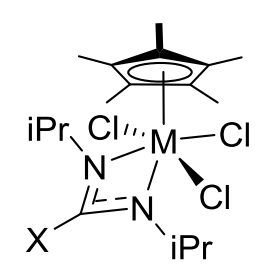

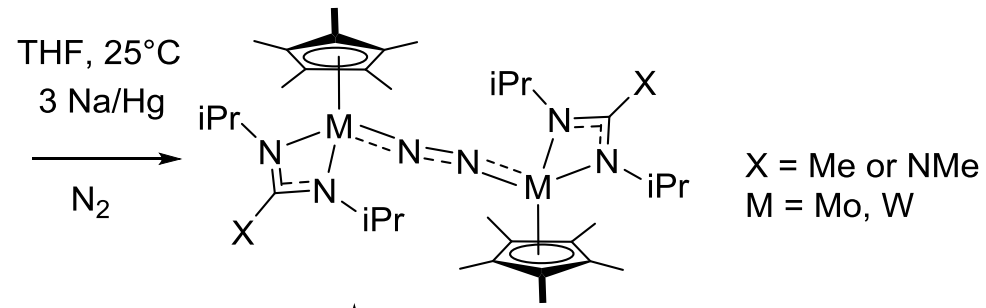

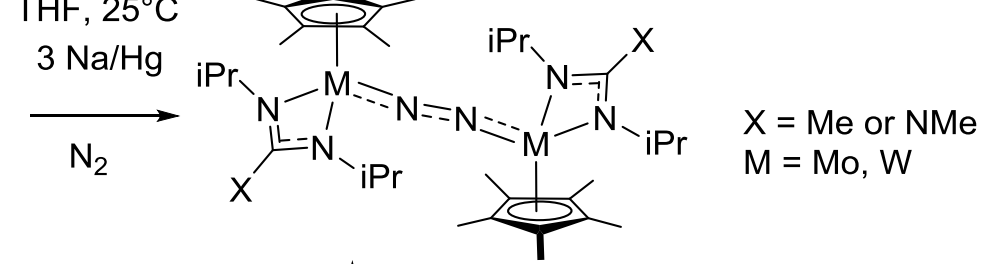<smiles>CCC[Se]</smiles>
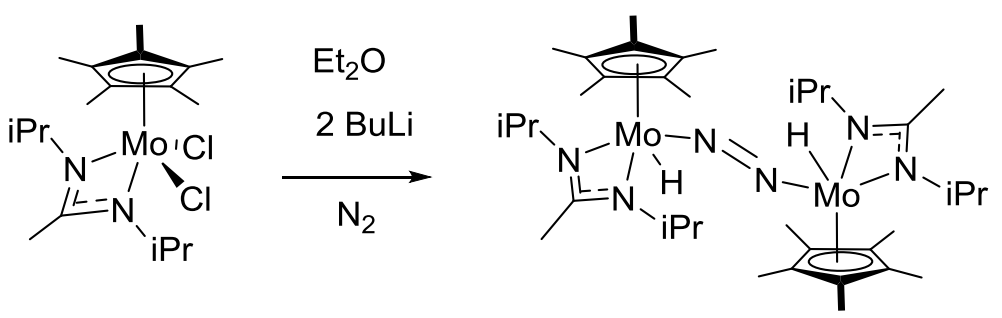

Scheme 45

In these end-on bridging complexes, although an activation of $\mathrm{N}_{2}$ is observed, it is not sufficient to promote the splitting between the two metal centers. This requires the transfer of a total of six electrons into the $\pi^{*}$ and $\sigma^{*}$ manifold of $\mathrm{N}_{2}$. Cummins and coworkers reported in 1995 that the coordinatively unsaturated $\mathrm{Mo}^{\text {III }}$ complex $\left[\mathrm{Mo}(\mathrm{N}(\mathrm{R}) \mathrm{Ar})_{3}\right]\left(\mathrm{R}=\mathrm{C}\left(\mathrm{CD}_{3}\right)_{2} \mathrm{CH}_{3}, \mathrm{Ar}=3,5-\mathrm{Me}_{2}-\mathrm{C}_{6} \mathrm{H}_{3}\right)$ reacts with $\mathrm{N}_{2}$ to eventually form the terminal nitrido complex $\left[\mathrm{Mo}(\mathrm{N})(\mathrm{N}(\mathrm{R}) \mathrm{Ar})_{3}\right] .{ }^{175}$ Impressively, all the intermediates of the process have been observed. Thus, the $\left[\mathrm{Mo}(\mathrm{N}(\mathrm{R}) \mathrm{Ar})_{3}\right]$ complex forms first a monometallic complex at $-35^{\circ} \mathrm{C}$, which dimerizes to $\left[\mathrm{Mo}(\mathrm{N}(\mathrm{R}) \mathrm{Ar})_{3}\right]\left(\mu-\mathrm{N}_{2}\right)($ scheme 46$)$. This latter complex evolves to the nitrido species at $30^{\circ} \mathrm{C}\left(1 / 2\right.$ life of 35 minutes at $\left.30^{\circ} \mathrm{C}\right)$, via a zig-zag transition state, required for the electron flow from a $\pi$ symmetry orbital (in the linear geometry) into the $\sigma$ symmetry orbital (N-N antibonding, in the zig-zag geometry). ${ }^{176}$ In a subsequent article, they showed that both the coordination of $\mathrm{N}_{2}$ and 
the splitting can be accelerated by addition of reducing agent. ${ }^{177}$ Functionalization of the nitride moiety was then demonstrated (vide infra).

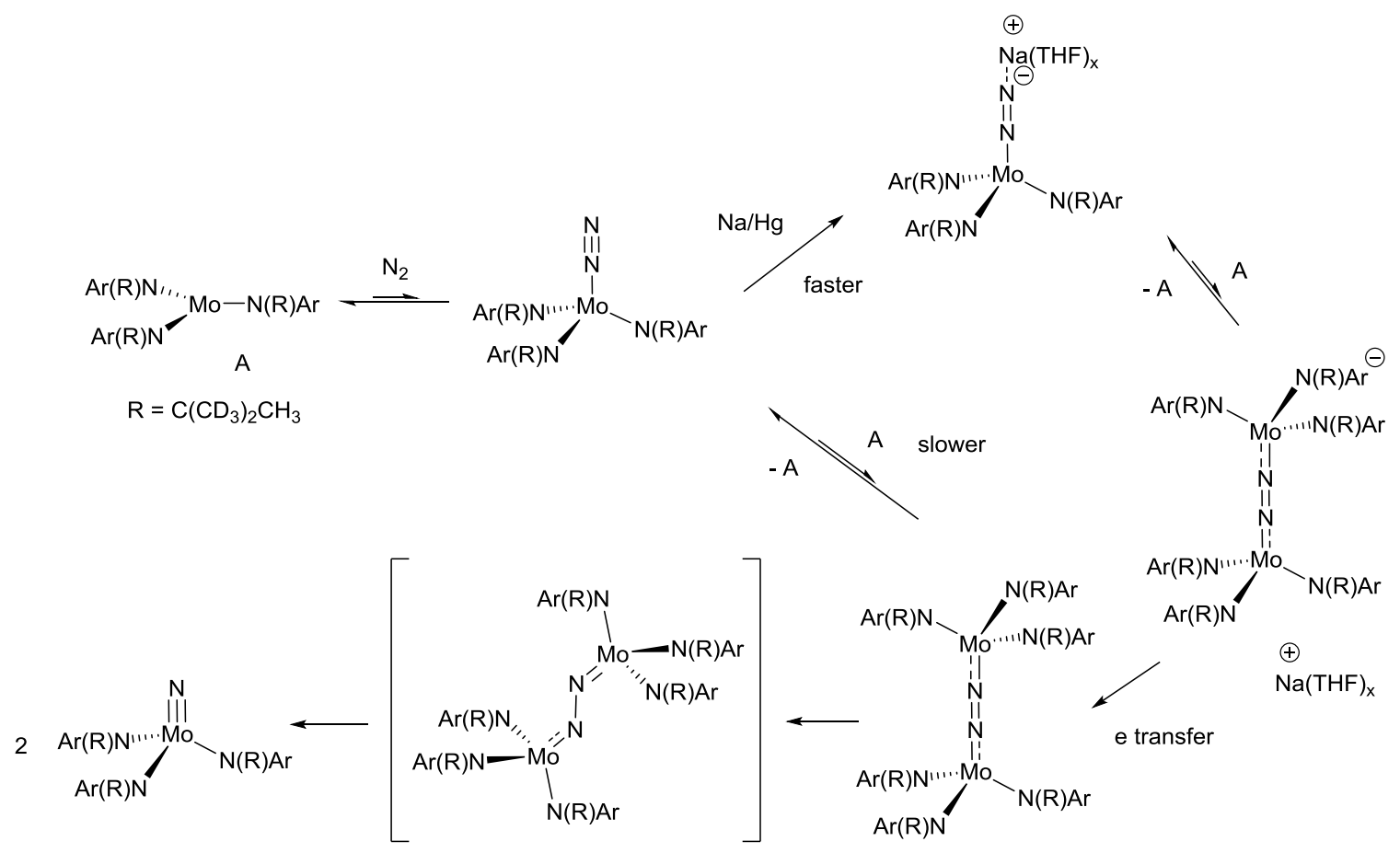

Scheme 46

This seminal study prompted several groups to search for conditions that favored $\mathrm{N}_{2}$ splitting. In 2001, Floriani and co-workers reported the synthesis of $\left[\mathrm{Mo}(\mathrm{Mes})_{3}\right]_{2}\left(\mu-\mathrm{N}_{2}\right)$ by the reaction between $\mathrm{MoCl}_{4}$. $\mathrm{DME}$ and $\mathrm{MesMgBr}$ under $\mathrm{N}_{2}$. Although this complex is thermally stable, irradiation with UV light results in $\mathrm{N}_{2}$ splitting, leading to the mixed valent nitrido dimer $\left[\left\{\mathrm{Mo}(\mathrm{Mes})_{3}\right\}(\mu-\mathrm{N})\right]$. The authors propose that the intermediate terminal nitrido complex is formed and reacts with the starting complex $\left[\mathrm{Mo}(\mathrm{Mes})_{3}\right]_{2}(\mu-$ $\mathrm{N}_{2}$ ) to generate a tetra Mo complex which breaks apart by $\mathrm{N}_{2}$ elimination. ${ }^{178}$

In 2012, Schrock and co-workers synthesized the $[\mathrm{Mo}[\mathrm{PCP}](\mathrm{N})(\mathrm{I})]^{-}$complex by the two electron reduction of the $\left[\mathrm{Mo}[\mathrm{PCP}](\mathrm{I})_{2}\right]$ pincer complex $\left([\mathrm{PCP}]=\mathrm{C}_{6} \mathrm{H}_{3}-1,3-\left[\mathrm{OP}(t-\mathrm{Bu})_{2}\right]_{2}\right)$ 
(scheme 47). ${ }^{179}$ Protonation of the anionic nitrido complex did not yield the expected parent imido species but provide a rare example of a bridging $\mathrm{H}$ between Mo and $\mathrm{P}$.

2

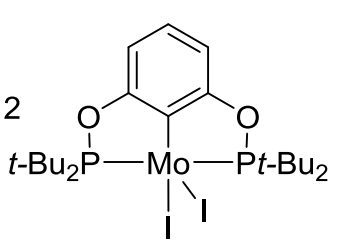

Scheme 47

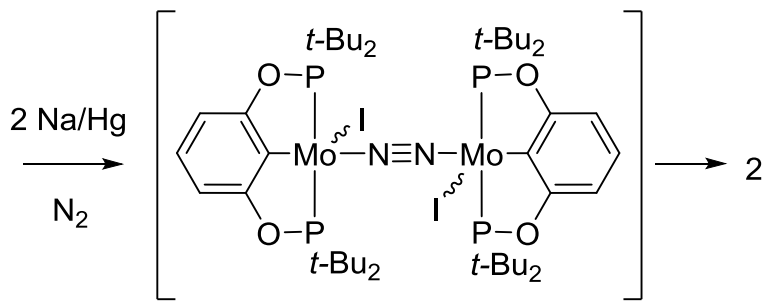

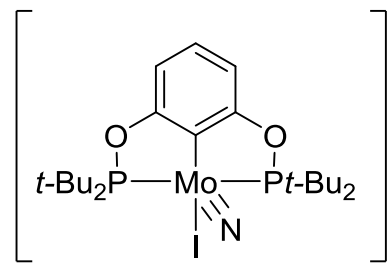
$2 \mathrm{Na} / \mathrm{Hg}$<smiles>CC=[O+]NCC</smiles><smiles>CCCCOP(=N)(Oc1ccccc1)Oc1cccc2c1OP(C(C)(C)C)N(C)C2</smiles>

In 2014, the group of Nishibayashi has used the depf, diethylphosphinoferrocene, ligand, in conjunction to the bulky $\mathrm{Cp}^{*}$ ligand to study the activation of end-on bridging $\mathrm{N}_{2}$ Mo complex depending on the oxidation state at the metal. ${ }^{180},{ }^{181}$ Irradiation of the neutral complex resulted in the NN splitting giving the Mo ${ }^{\mathrm{IV}}$ nitride complex, although in low yield, which oxidation allowed NN reformation (scheme 48).
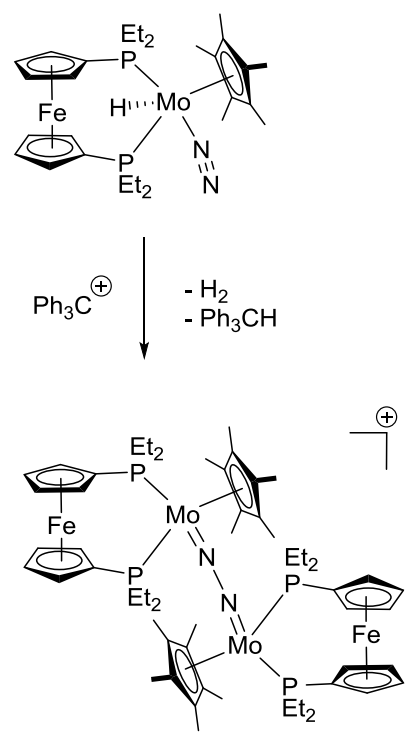
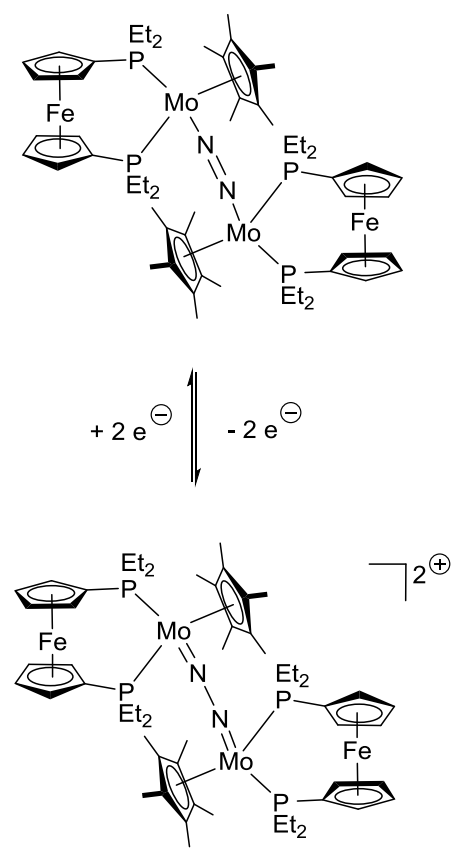

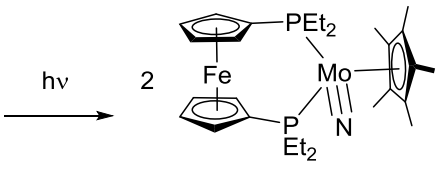

$33 \%$ 
Scheme 48

Sita and co-workers reported in 2015 the photochemical $\mathrm{N}_{2}$ splitting form $\left[\mathrm{M}\left(\mathrm{Cp}^{*}\right)\left(\mathrm{N}(i \mathrm{Pr}) \mathrm{C}\left(\mathrm{CH}_{3}\right) \mathrm{N}(i \mathrm{Pr})\right)\right]_{2}\left(\mu-\mathrm{N}_{2}\right)(\mathrm{M}=\mathrm{Mo}, \mathrm{W})$ complexes. In the case of Mo, a mixture of bridging nitrido complexes, the $\mathrm{Mo}^{\mathrm{V}}-\mathrm{Mo}^{\mathrm{V}}$ $\left[\mathrm{Mo}\left(\mathrm{Cp}^{*}\right)\left(\mathrm{N}(i \mathrm{Pr}) \mathrm{C}\left(\mathrm{CH}_{3}\right) \mathrm{N}(i \mathrm{Pr})\right)\right]_{2}(\mu-\mathrm{N}) \quad$ and $\quad$ the $\mathrm{Mo}^{\mathrm{III}}-\mathrm{Mo}^{\mathrm{IV}}$ $\left[\mathrm{Mo}\left(\mathrm{Cp}^{*}\right)\left(\mathrm{N}(i \mathrm{Pr}) \mathrm{C}\left(\mathrm{CH}_{3}\right) \mathrm{N}(i \operatorname{Pr})\right)(\mu-\mathrm{N})\right]_{2}$ complexes was obtained (scheme 49$) .{ }^{182}$ In the case of $\mathrm{W}$, the reaction is slower but cleaner, forming the $\left[\mathrm{W}\left(\mathrm{Cp}^{*}\right)\left(\mathrm{N}(i \mathrm{Pr}) \mathrm{C}\left(\mathrm{CH}_{3}\right) \mathrm{N}(i \mathrm{Pr})\right)(\mu-\mathrm{N})\right]_{2} \quad$ complex. In 2016, they showed that decreasing the steric crowding at the amidinate ligand (Me instead of $i$ Pr) allowed the thermal $\mathrm{N}_{2}$ splitting process forming the bridging nitrido complexes in excellent isolated yields (Mo $=80 \% ; \mathrm{W}=77 \%$ ), opening ways for further functionalization (vide infra). ${ }^{183}$

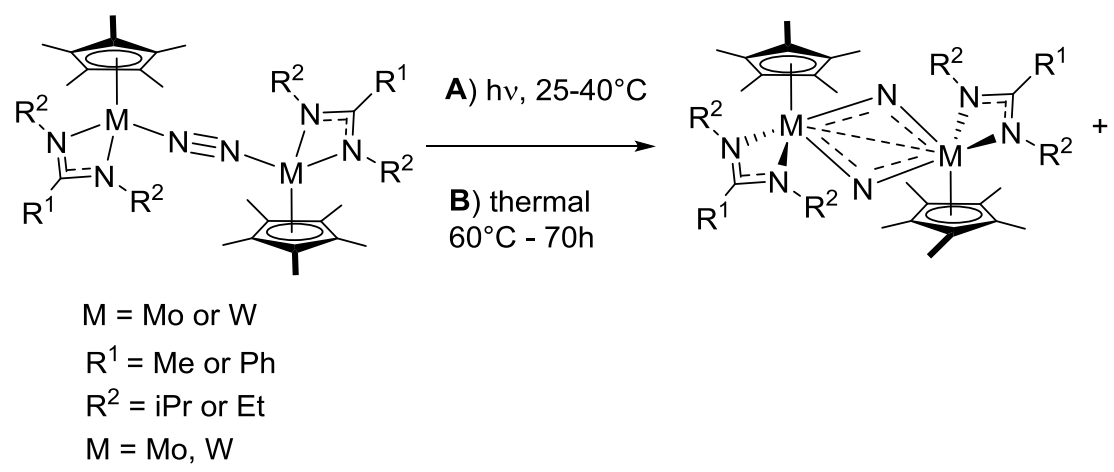

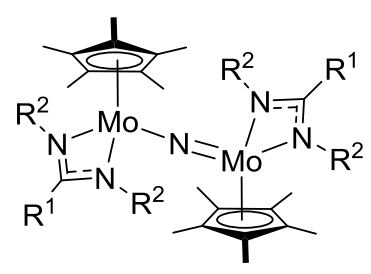

observed path $\mathbf{A}$

\section{Scheme 49}

Also in 2016, Mézailles and co-workers studied the two electron reduction of the $\left[\mathrm{Mo}\left(\mathrm{P}^{\mathrm{Cy}} \mathrm{P}^{\mathrm{Ph}} \mathrm{P}^{\mathrm{Cy}}\right)(\mathrm{Cl})_{3}\right]$ complex in the presence of NaI. The nitrido complex $\left[\mathrm{Mo}\left(\mathrm{P}^{\mathrm{Cy}} \mathrm{P}^{\mathrm{Ph}} \mathrm{P}^{\mathrm{Cy}}\right)(\mathrm{N})(\mathrm{I})\right]$ is formed in good $60 \%$ yield $(80 \% \mathrm{NMR})$ (Scheme 50) via the proposed splitting of $\mathrm{N}_{2}$ between two equivalents of the unobserved unsaturated Mo ${ }^{\mathrm{I}}$ intermediate. $^{184}$ 
2

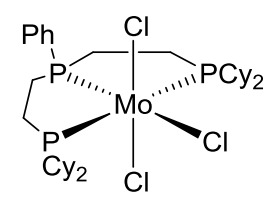

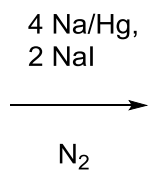

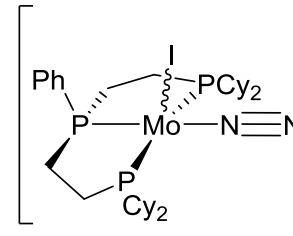

管

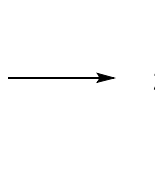

$60 \%$

Scheme 50

In 2017, Schneider and co-workers reported the reduction of $\left[\mathrm{Mo}(\mathrm{PNP}) \mathrm{Cl}_{3}\right]$ complex $\left(\mathrm{PNP}=\mathrm{N}\left(\mathrm{CH}_{2} \mathrm{CH}_{2} \mathrm{P} t \mathrm{Bu}_{2}\right)_{2}\right)$ by two electrons $(\mathrm{Na} / \mathrm{Hg})$ to form the thermally stable bridged dimer $[\mathrm{Mo}(\mathrm{PNP})]_{2}\left(\mu-\mathrm{N}_{2}\right)$ in $70 \%$ yield (Scheme 51$) .{ }^{185}$ Double protonation at the amido $\mathrm{N}$ centers of the ligands triggered the $\mathrm{N}_{2}$ cleavage, and the $\left[\mathrm{Mo}\left(\mathrm{PN}^{\mathrm{H}} \mathrm{P}\right)(\mathrm{N})(\mathrm{Cl})\right]^{+} \mathrm{X}^{-}(\mathrm{X}=$ OTf, $\mathrm{BAr}_{4}{ }_{4}$ ) complex was obtained in $80 \%$ yield. The mechanism of the proton induced $\mathrm{N}_{2}$ splitting was probed experimentally and by DFT calculations, and linked to changes in ground state multiplicity between the neutral, protonated and doubly protonated complexes.
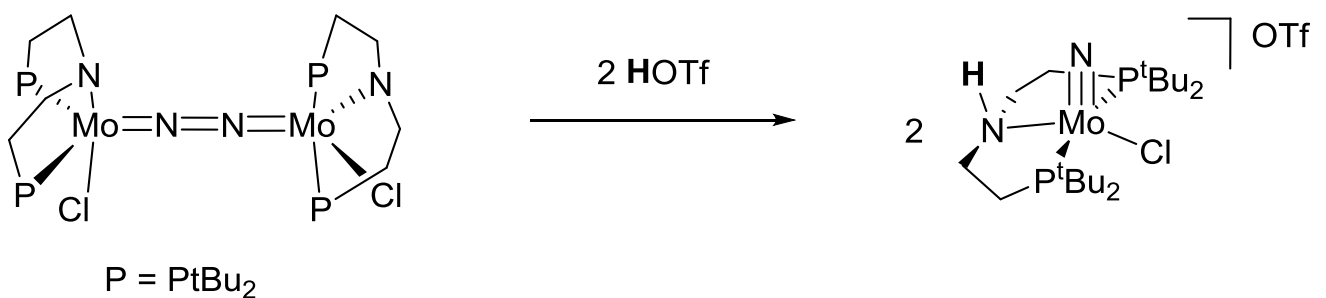

Scheme 51

\subsection{Stoichiometric reactions of $\mathrm{M}-\mathrm{N}_{2}$}

It is important here to recall the seminal reports by Chatt and co-workers in the early 1970s who studied the protonation at Mo and W coordinated dinitrogen. They showed that protonation of the $\mathrm{N}_{2}$ ligand occurs in a stepwise manner, accompanied by electron transfer from the metal center. Protonation with $\mathrm{H}_{2} \mathrm{SO}_{4}$ in $\mathrm{MeOH}$ provided the best results $\left(90 \%\right.$ of $\mathrm{NH}_{3}$ for the $\left[\mathrm{W}\left(\mathrm{PMePh}_{2}\right)_{4}\left(\mathrm{~N}_{2}\right)_{2}\right]$ complex vs $36 \%$ for the Mo 
complex). ${ }^{186}$ Chatt has demonstrated that the sequence of $\mathrm{N}_{2}$ reduction involves diazenido $(\mathrm{MNNH})$, hydrazido $\left(^{2-}\right)\left(\mathrm{MNNH}_{2}\right)$, hydrazinium $\left(\mathrm{MNNH}_{3}{ }^{+}\right)^{187}$ and nitrido (MN) intermediates. These form the basis of the Chatt cycle of catalytic $\mathrm{N}_{2}$-to- $\mathrm{NH}_{3}$ process. The protonation of complexes featuring dppe classically stopped at the hydrazido(2-) stage (scheme 52) ${ }^{188,189},{ }^{190,191}$ and further functionalization of the $\mathrm{M}=\mathrm{N}-\mathrm{NH}_{2}$ proved very rewarding (vide infra). The protonation of the complexes by inorganic acids to release $\mathrm{NH}_{4}{ }^{+}$or $\mathrm{N}_{2} \mathrm{H}_{5}{ }^{+}$is now used as a benchmark reaction.

Starting from 2012, Mock and Bullock have studied the influence of a N moiety as pendant ligand in bidentate phosphine ligands in the outcome of the protonation of the corresponding Mo-dinitrogen complexes (scheme 52, bottom). ${ }^{192},{ }^{193},{ }^{194}$ These studies highlighted the strong influence of electronics and sterics of the ligand on the site of protonation and the eventual efficiency of $\mathrm{NH}_{4}{ }^{+}$production. In addition, they found out that poor yields of ammonia were indirectly correlated to the stability of the hydrazido $\mathrm{Mo}=\mathrm{N}-\mathrm{NH}_{2}$ complexes, showing that external source of electron is likely required to achieve further conversion of the hydrazido moiety. 

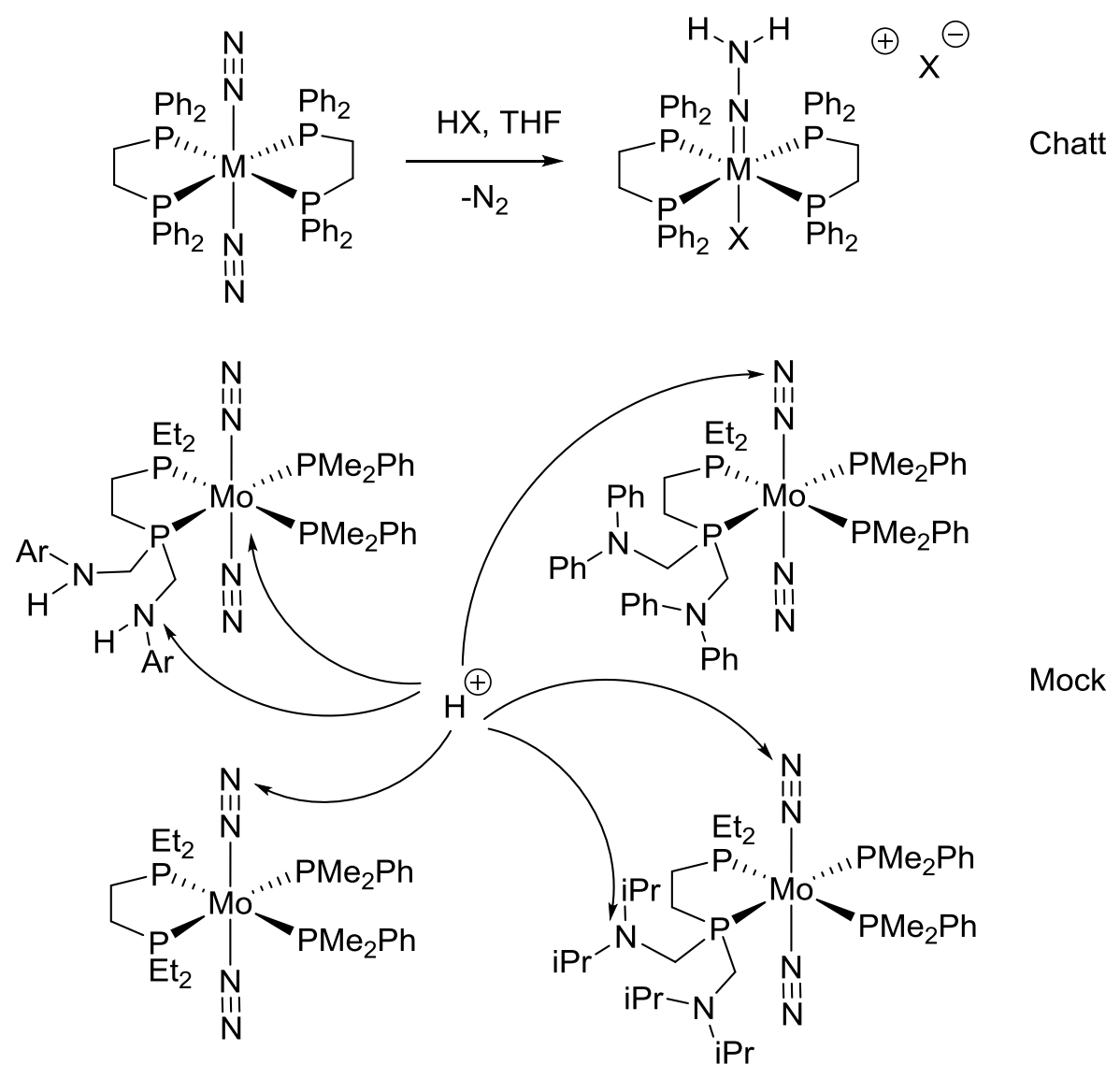

Scheme 52

Functionalization of coordinated $\mathrm{N}_{2}$ with $\mathrm{H}_{2}$ was also envisaged. The bis dinitrogen complexes of Mo and $\mathrm{W}$ being stable toward $\mathrm{H}_{2}$, the groups of Morris and Hidai relied on the acidic character of coordinated $\mathrm{H}_{2}$ in $\left[\mathrm{Ru}(\mathrm{Cp})(\mathrm{PP})\left(\mathrm{H}_{2}\right)\right]^{195}$ and $\left[\mathrm{Ru}(\mathrm{dppp})(\mathrm{Cl})\left(\eta^{2}-\mathrm{H}_{2}\right)\right] \mathrm{X}$ respectively to efficiently protonate trans- $\left[\mathrm{W}(\mathrm{dppe})_{2}\left(\mathrm{~N}_{2}\right)_{2}\right]^{196}$ to form the corresponding hydrazido(2-) derivative. Starting with the cis[W $\left(\mathrm{PMe}_{2} \mathrm{Ph}\right)_{4}\left(\mathrm{~N}_{2}\right)_{2}$ ] complex, the reaction leads to $\mathrm{NH}_{3}$ formation (55\% yield) (Scheme 53, top). ${ }^{196}$ No reaction was observed with the analogous Mo complexes, in which the terminal $\mathrm{N}$ center is less basic. Hidai further extended this concept to the use of hydrosulfido complexes as sources of proton, which mimic the postulated mode of action of enzymes. These can be used directly or generated in situ from $\mathrm{H}_{2}$. Thus, reaction 
between cis-[W( $\left.\left(\mathrm{PMe}_{2} \mathrm{Ph}\right)_{4}\left(\mathrm{~N}_{2}\right)_{2}\right]$ and 10 equiv. of $\left[(\mathrm{CpMo})_{2}\left(\mu-\mathrm{S}_{2} \mathrm{CH}_{2}\right)(\mu-\mathrm{S})(\mu-\mathrm{SH})\right][\mathrm{OTf}]$ under $\mathrm{H}_{2}$ produced ammonia in $38 \%$ yield. Starting from the corresponding hydrazido(2-) complex near quantitative yield of $\mathrm{NH}_{3}$ is formed. With the dppe analogue, the hydrazido(2-) complex $\mathrm{Mo}=\mathrm{NNH}_{2}{ }^{+}$is observed as the final species. ${ }^{197}$ Subsequent work was dedicated to changing the bridging hydrosulfido complexes (Mo, Ru, Rh and Ir) as proton donors, with the Ir complex being the most efficient ( $78 \%$ yield of $\mathrm{NH}_{3}$ per W). ${ }^{198}$
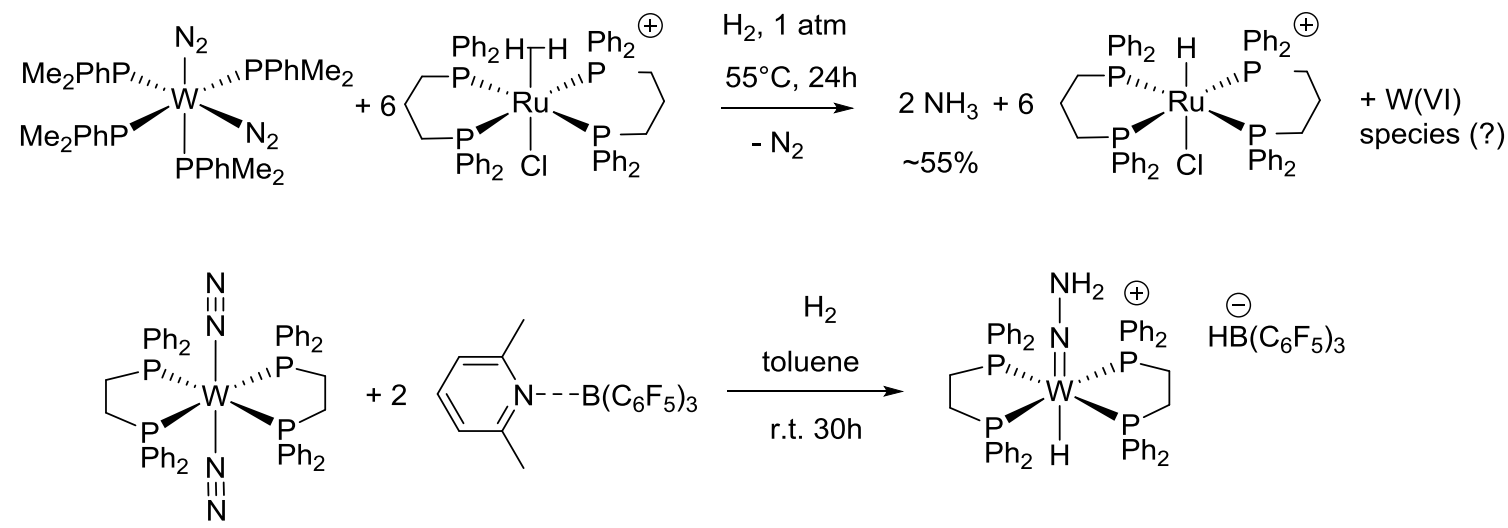

Scheme 53

In 2017, Sivasankar used a frustrated Lewis Pair to activate $\mathrm{H}_{2}$ into the corresponding pyridinium borohydride and efficiently doubly protonate terminal $\mathrm{N}_{2}$ of trans-[W(dppe $\left.)_{2}\left(\mathrm{~N}_{2}\right)_{2}\right]$ to form the trans-[(H)W(dppe $\left.)_{2}\left(\mathrm{~N}_{2} \mathrm{H}_{2}\right)\right]\left[\mathrm{HB}\left(\mathrm{C}_{6} \mathrm{~F}_{5}\right)_{3}\right]$ complex (Scheme 53, bottom). ${ }^{199}$

\section{5 $\mathrm{N}_{2}$-to- $\mathrm{NH}_{3}$ Catalytic Transformation}

In 2003, Yandulov and Schrock reported the first catalytic $\mathrm{N}_{2}$ reduction to $\mathrm{NH}_{3}$ involving well-defined molecular complex. ${ }^{200}$ The $\mathrm{Mo}^{\mathrm{III}}$ precursor features a sterically highly demanding ligand $\quad\left[\mathrm{HIPTN}_{3} \mathrm{~N}\right] \quad\left(\left[\mathrm{HIPTN}_{3} \mathrm{~N}\right]=\{3,5-(2,4,6-\right.$ $\left.\left.\left.\left.{ }_{i} \operatorname{Pr}_{3} \mathrm{C}_{6} \mathrm{H}_{2}\right)_{2} \mathrm{C}_{6} \mathrm{H}_{3}\right) \mathrm{NCH}_{2} \mathrm{CH}_{2}\right\}_{3} \mathrm{~N}\right]^{3-}$ ), crucial as it prevents formation of bimetallic Mo- $\mathrm{N}_{2-}$ Mo complex as well as provides good solubility in nonpolar solvents. A careful 
optimization of the nature of the proton source and reducing agent was done, resulting in the use of sparingly soluble in heptane $[\mathrm{LutH}]\left[\mathrm{BAr}_{4}^{\mathrm{F}}\right]$ proton source, and decamethylcobaltocene $\mathrm{Cp}^{*}{ }_{2} \mathrm{Co}\left(\mathrm{Cp}^{*}=\eta^{5}-\mathrm{C}_{5} \mathrm{Me}_{5}\right)$ as reducing agent. Moreover, slow addition (via syringe pump) of the reducing agent was used to reduce the amount of $\mathrm{H}_{2}$ formed. Under optimized conditions (48 equiv. of [LutH][BAr$\left.{ }_{4}{ }_{4}\right]$ and 36 equiv. of $\mathrm{Cp}^{*}{ }_{2} \mathrm{Co}$ ) ca 8 equiv of $\mathrm{NH}_{3}$ (ca $65 \%$ efficiency) were obtained per equiv. of $\left[\left[\mathrm{HIPTN} \mathrm{N}_{3} \mathrm{~N}\right] \mathrm{Mo}\left(\mathrm{N}_{2}\right)\right]$ complex under an $\mathrm{N}_{2}$ atmosphere. The mechanism of the transformation was evaluated by stepwise electron and proton additions, and several intermediates have been isolated (in black in the scheme). These have been subsequently shown to perform nearly identically in the catalytic process. ${ }^{201-205}$ The corresponding catalytic cycle was later also corroborated by DFT calculations (Scheme 54). ${ }^{206-209}$ 
<smiles>[R]C1N([R])CN2CN([R])C([R])N1N2[R]</smiles>

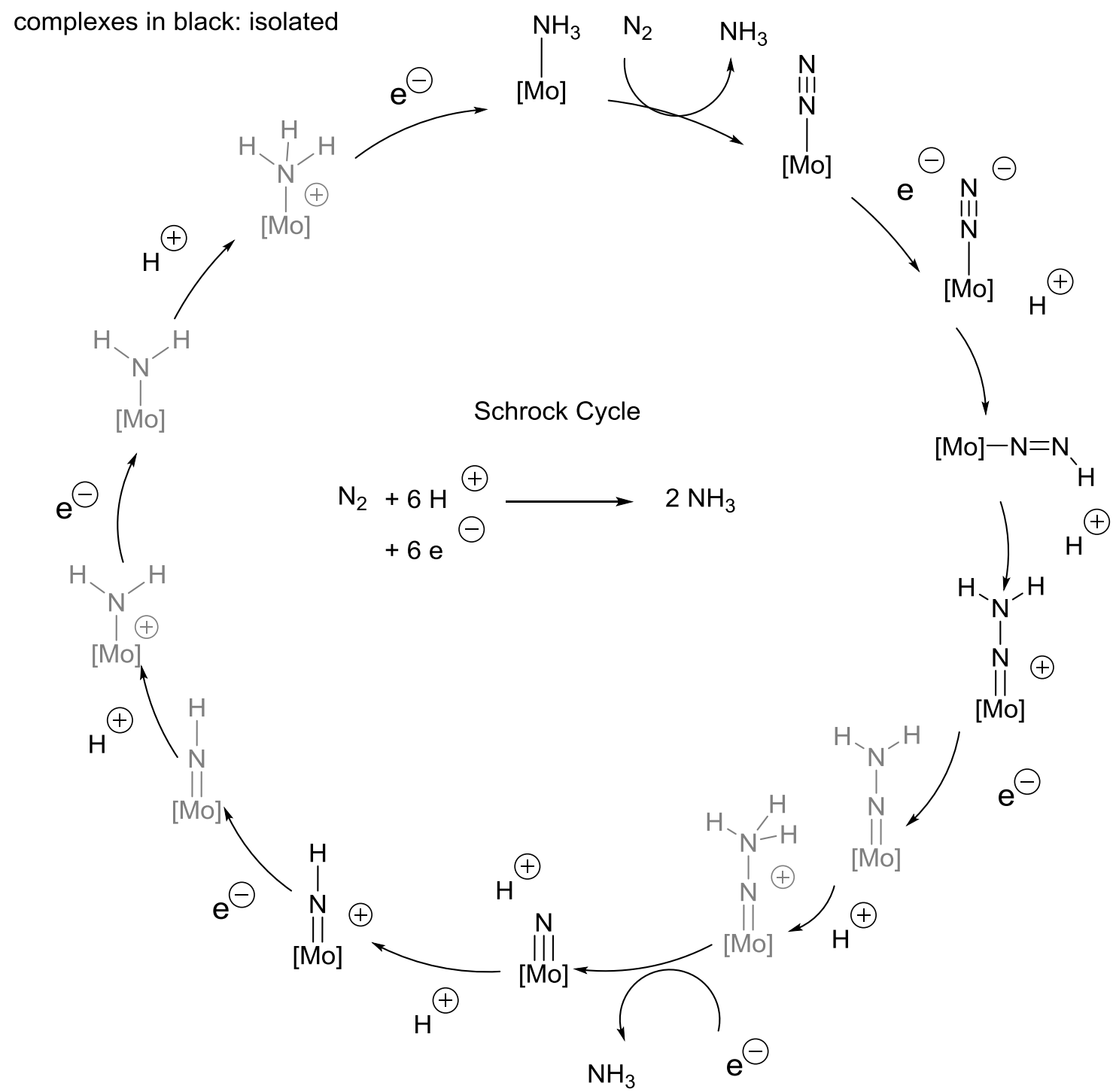

\section{Scheme 54}

Competitive protonation of the amide moiety of the ligand has been shown to be the cause of the limited activity of the catalyst as it leads to catalyst decomposition. Many efforts have been dedicated to catalyst improvement via ligand tuning (sterics and electronics), which were not successful. ${ }^{210-212}$ The group of Nishibayashi reported in 
2011 the catalyst $\left[\left[\mathrm{P}^{t \mathrm{Bu}} \mathrm{NP}^{t \mathrm{Bu}}\right] \mathrm{Mo}\left(\mathrm{N}_{2}\right)_{2}\right]_{2}\left(\mu-\mathrm{N}_{2}\right)$ (with $\left[\mathrm{P}^{t \mathrm{Bu}} \mathrm{NP}^{t \mathrm{Bu}}\right]=2,6$-bis$[($ di-tertbutylphosphino)methyl] pyridine) bearing a less basic neutral tridentate ligand scaffold which led to improved yields (Scheme 55). Under optimized conditions (288 equiv. [LutH][OTf] as poorly soluble proton source, 216 equiv. $\mathrm{CoCp}_{2}$ as reducing agent under slow addition, $1 \mathrm{~atm} \mathrm{~N}_{2}$ ), a maximum of 23 equiv. of ammonia were obtained. ${ }^{154}$ The presence of both the bridging and terminal $\mathrm{N}_{2}$ moieties is crucial for the catalytic process as the related complexes $\left[\left[\mathrm{P}^{t \mathrm{Bu}} \mathrm{NP}^{t \mathrm{Bu}}\right] \mathrm{Mo}(\mathrm{CO})_{2}\right]_{2}\left(\mu-\mathrm{N}_{2}\right)$ or $\left[\left[\mathrm{P}^{\mathrm{tBu}} \mathrm{NP}^{t \mathrm{Bu}}\right] \mathrm{Mo}\left(\mathrm{PMe}{ }_{2} \mathrm{Ph}\right)\left(\mathrm{N}_{2}\right)_{2}\right]$, did only provide 0.4 and 0.2 equiv. of $\mathrm{NH}_{3}$ under the same experimental conditions, whereas $\left[\left[\mathrm{P}^{\mathrm{tBu}} \mathrm{NP}^{t \mathrm{Bu}}\right] \mathrm{MoCl}_{2}\right]_{2}\left(\mu-\mathrm{N}_{2}\right)$ and $\left[\left[\mathrm{P}^{\mathrm{tBu}} \mathrm{NP}^{\mathrm{tBu}}\right] \mathrm{W}\left(\mathrm{PMe}{ }_{2} \mathrm{Ph}\right)\left(\mathrm{N}_{2}\right)_{2}\right]$ did not give any $\mathrm{NH}_{3}{ }^{213},{ }^{157}$ In subsequent works, the authors attempted to improve the process by $\mathrm{P}^{\mathrm{R}} \mathrm{NP}^{\mathrm{R}}$ (where $\mathrm{R}=\mathrm{Ph},{ }^{\mathrm{i}} \mathrm{Pr}$, Ad and $\mathrm{Cy}$ ) ligand tuning or using the softer $\mathrm{As}^{{ }^{\mathrm{BBu}}} \mathrm{NAs}^{{ }^{\mathrm{B} u}}$ ligand. ${ }^{214}$ Only the ligand with the bulky adamantyl moiety allowed a moderate improvement of the catalytic performance, while the others showed a drastic decrease (between 1 and 3 equiv. $\left.\mathrm{NH}_{3}\right){ }^{215}$ A series of Mo-nitrido complexes, postulated intermediates in the

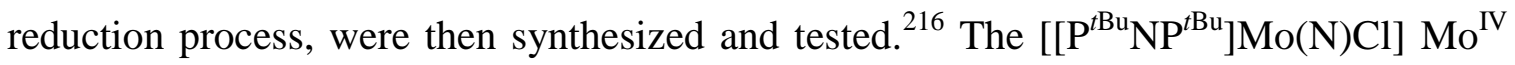
and cationic $\left[\left[\mathrm{P}^{t \mathrm{Bu}} \mathrm{NP}^{t \mathrm{Bu}}\right] \mathrm{Mo}(\mathrm{N}) \mathrm{Cl}\right]^{+} \mathrm{Mo}^{\mathrm{V}}$ complexes are as efficient as the $\mathrm{Mo}^{0}$ dinitrogen dimer (6.8-7.1 equiv. $\mathrm{NH}_{3}$ vs 5.9). Rather surprisingly, $\left.\left[{ }^{t \mathrm{tBu}} \mathrm{NP}^{t \mathrm{Bu}}\right] \mathrm{Mo}(\mathrm{N}) \mathrm{Cl}_{2}\right]$ and $\left[\left[\mathrm{P}^{\mathrm{Ad}} \mathrm{NP}^{\mathrm{Ad}}\right] \mathrm{Mo}(\mathrm{N}) \mathrm{Cl}\right]^{+} \mathrm{Mo}^{\mathrm{V}}$ complexes performed poorly (1.2 and 1.8 equiv. $\mathrm{NH}_{3}$ resp.). Other changes in the ligand backbone also resulted in drastic decrease in catalytic activity. 


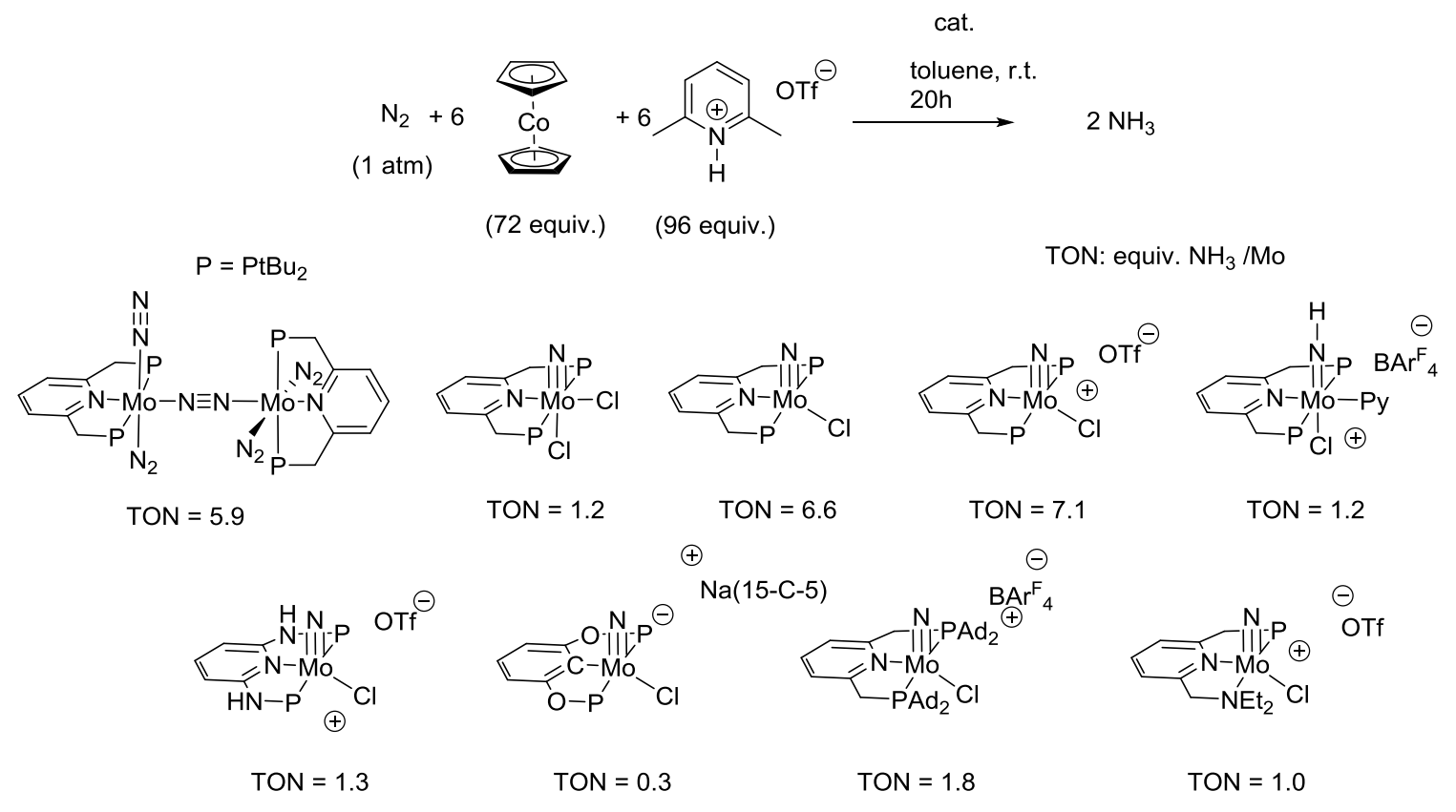

Scheme 55

DFT calculations rationalizing the experimental facts were carried out independently by Nishibayashi, Yoshizawa and co-corkers and Batista and coworkers. $^{216,217}$ The most important result is that although $\left[\left[\mathrm{P}^{t \mathrm{Bu}} \mathrm{NP}^{t \mathrm{Bu}}\right] \mathrm{Mo}\left(\mathrm{N}_{2}\right)_{2}\right]_{2}\left(\mu-\mathrm{N}_{2}\right)$ and the monomer $\left[\left[\mathrm{P}^{t \mathrm{Bu}} \mathrm{NP}^{t \mathrm{Bu}}\right] \mathrm{Mo}\left(\mathrm{N}_{2}\right)_{3}\right]$ can be in equilibrium in solution, the double protonation at terminal $\mathrm{N}_{2}$ to form the hydrazido intermediate is only exergonic for the former. It appears that in the dimer, the Mo fragment [PNP]Mo( $\left.\mathrm{N}_{2}\right)_{3}$ acts as intramolecular (via $\mathrm{N}_{2}$ bridge) electron donor to stabilize the hydrazido fragment, and therefore provides a strong kinetic preference for the pathway involving the dimeric species. Addition of $\mathrm{a} \mathrm{H}^{+}$and an electron to the hydrazido derivative leads to the $\mathrm{NN}$ bond splitting and formation of the first equivalent of $\mathrm{NH}_{3}$ together with the nitrido intermediate. Nishibayashi and Yoshizawa propose that the dimer splits into the Monitrido complex and the monomeric $\operatorname{Mo}\left(\mathrm{N}_{2}\right)_{3}$ complex. Functionalization of monometallic nitrido then leads to the second equivalent of $\mathrm{NH}_{3}$, in accord with the fact 
that isolated monometallic nitrido complexes are as efficient as the Mo dinitrogen dimer. ${ }^{216}$ Batista proposes that the integrity of the dimer is retained till the end of the functionalization. ${ }^{217}$ Overall, a catalytic scheme consistent with the experiments can be proposed (scheme 56).

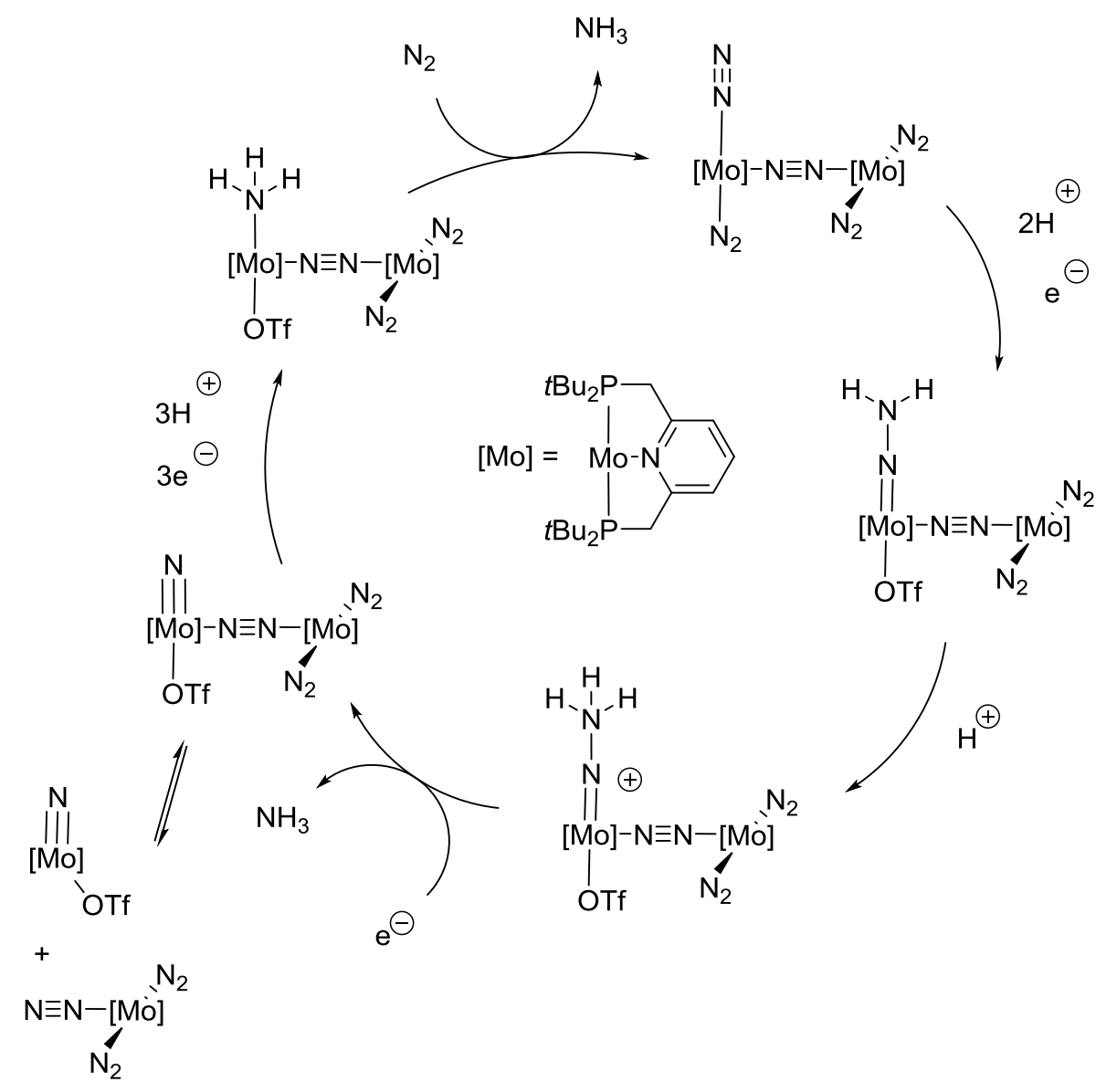

Scheme 56

Based on this precise mechanistic understanding, the group of Nishibayashi has evaluated experimentally the influence of the $[\mathrm{PEP}](\mathrm{E}=$ pyridine ring, phosphine, carbene moiety) neutral tridentate ligand on the efficiency of the catalysis. First, electron donating substituents at the para position of the pyridine increased the yield of $\mathrm{NH}_{3}$ up to 34 equiv. (for $\mathrm{R}=\mathrm{OMe} v s 23$ for $\mathrm{H}$ ). ${ }^{155}$ Non innocent moieties (in a redox sense), such as ferrocene or ruthenocene moieties were tested and the ferrocene substituent was shown to 
be the fastest catalyst (rate for the $1^{\text {st }}$ hour) as well as slightly more efficient (conditions: $\mathrm{N}_{2}, 216$ equiv. $\mathrm{Cp}_{2} \mathrm{Co}$ and 288 equiv of LutHOTf in toluene for $20 \mathrm{~h}$ : TON 37 equiv. $\mathrm{NH}_{3}$; max TON 53). ${ }^{218}$ With the $\left[\mathrm{P}^{t \mathrm{Bu}} \mathrm{P}^{\mathrm{Ph}} \mathrm{P}^{t \mathrm{Bu}}\right]$ tridentate phosphine ligand, the $\mathrm{Mo}^{0}$ dinitrogen dimer was not isolated because of a weak Mo- $\mathrm{N}_{2}-\mathrm{Mo}$ bond, although it was clearly observed by IR. Alternatively, the $\mathrm{Mo}^{\mathrm{V}}$ cationic nitrido complex $\left[\left[\mathrm{P}^{t \mathrm{Bu}} \mathrm{P}^{\mathrm{Ph}} \mathrm{P}^{t \mathrm{Bu}}\right] \mathrm{Mo}(\mathrm{N}) \mathrm{Cl}\right]^{+}$as well as the $\left[\left[\mathrm{P}^{t \mathrm{Bu}} \mathrm{P}^{\mathrm{Ph}} \mathrm{P}^{t \mathrm{Bu}}\right] \mathrm{MoCl}_{3}\right]$ precursor were used as catalysts, and proved to be more efficient with a maximum of 63 equiv. of $\mathrm{NH}_{3}{ }^{156} \mathrm{In}$ 2017, the P-carbene-P ligand was developed and the corresponding catalyst provided up to 230 equiv. $\mathrm{NH}_{3}{ }^{158}$ In 2017 also, Nishibayashi studied the catalytic behavior of the $\left[\mathrm{Mo}[\mathrm{PNP}] \mathrm{I}_{3}\right]$ complex in the $\mathrm{N}_{2}$-to- $\mathrm{NH}_{3}$ reaction. Most interestingly, starting from this precursor instead of the reduced $\mathrm{Mo}^{0}$ dinitrogen complex, the efficiency of the transformation is drastically improved, with 415 equiv. of $\mathrm{NH}_{3}(2880$ [ColH]OTf / 2160 $\left.\mathrm{CoCp}_{2}\right)\left(\mathrm{ColH}\right.$ is $\left.2,4,6-\mathrm{Me}_{3} \mathrm{C}_{5} \mathrm{H}_{2} \mathrm{NH}\right)$ vs 23 equiv. at best for the dimer as well as very little $\mathrm{H}_{2}$ formation. Also, dramatic halide effect was observed as only 12 equiv. $\mathrm{NH}_{3}$ are formed with the $\left[\mathrm{Mo}[\mathrm{PNP}] \mathrm{Cl}_{3}\right]$ pre-catalyst under the same conditions. ${ }^{219}$ They showed that the $[\mathrm{Mo}[\mathrm{PNP}](\mathrm{N}) \mathrm{X}]$ nitrido complexes are key intermediates in this process and therefore proposed a novel catalytic cycle, corroborated by DFT calculations (scheme $57)$. 


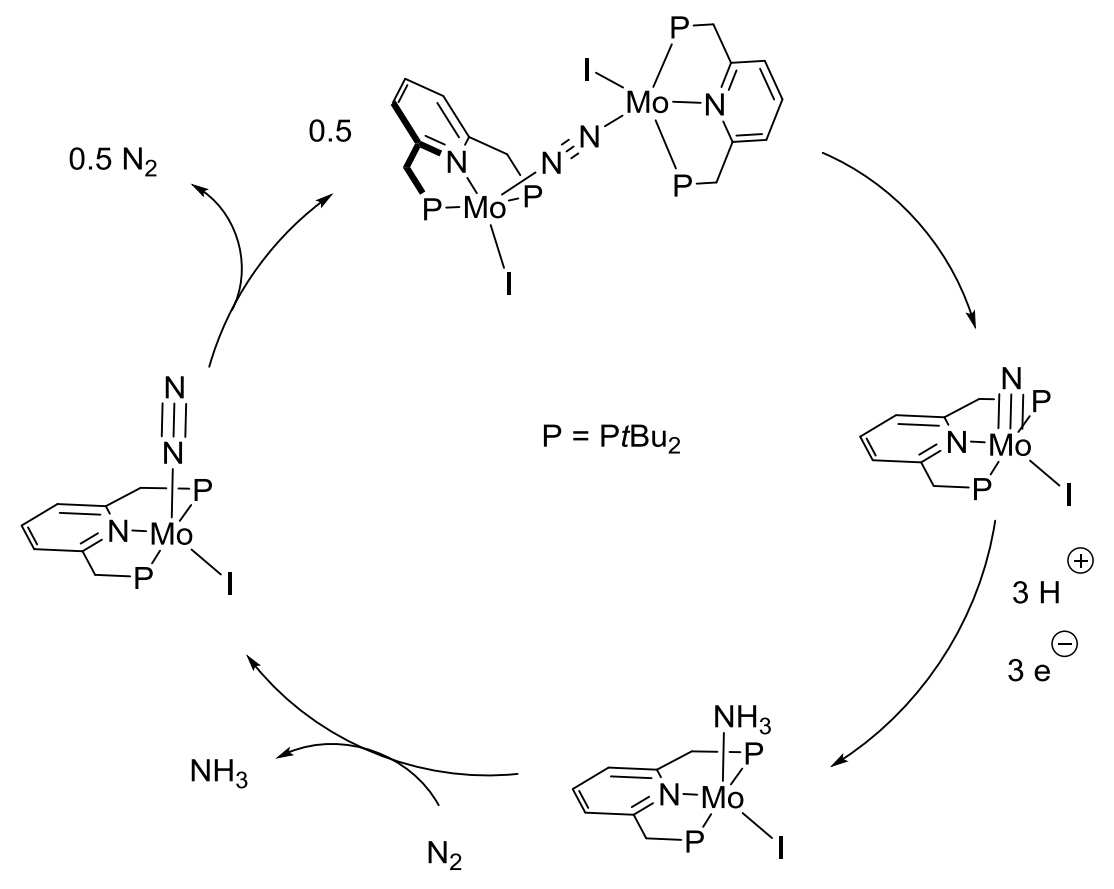

Scheme 57

In 2017, Schrock reported that $\mathrm{Mo}^{\mathrm{VI}}$ nitrido complexes, $\left[\left[\mathrm{N}_{2} \mathrm{~N}\right] \mathrm{Mo}(\mathrm{N}) \mathrm{X}\right]$ where $\left[\mathrm{N}_{2} \mathrm{~N}\right]$ is a diamido-pyridine ligand and $\mathrm{X}$ is an alkoxide or chloride ligand, were catalytically competent for the reduction of $\mathrm{N}_{2}$ into $\mathrm{NH}_{3}$, producing up to 10.3 equivalents of ammonia under optimized conditions (108 equiv. of $\mathrm{Cp}^{*}{ }_{2} \mathrm{Co}$ and 140 equiv. of $\mathrm{Ph}_{2} \mathrm{NH}_{2} \mathrm{OTf}$ ). ${ }^{220}$ In the catalyzed $\mathrm{N}_{2}$ to $\mathrm{NH}_{3}$ reaction, the optimization of the sources of reducing agent and proton has to be done for each complex. In 2019, Nishibayashi has shown for the first time that alcohols or even $\mathrm{H}_{2} \mathrm{O}$ can be used as source of proton if $\mathrm{SmI}_{2}$ is used as the reducing agent. $^{221}$ Under these conditions, several of their previously reported catalytically competent complexes performed much more efficiently. ${ }^{222}$ They could even show that starting from a Mo-oxo complex was not detrimental to the reaction as the oxo is transformed into the nitrido upon reduction by $\mathrm{SmI}_{2}$ under $\mathrm{N}_{2}$. The yield of $\mathrm{NH}_{3}$ reaches $92 \%$ in the best case, almost suppressing the side reaction making $\mathrm{H}_{2}$. The 
maximum TON of 4350 is truly impressive, and the best TOF of ca $117 \mathrm{~min}^{-1}$ is similar to what is measured in nitrogenase enzymes $\left(40-120 \mathrm{~min}^{-1}\right)$.

\subsection{N-C bond formation}

$\mathrm{N}-\mathrm{C}$ bond formation studies have been initiated by the groups of Chatt and George in the 70s. The reactivity relies on the nucleophilic character of the terminal $\mathrm{N}$ atom of the coordinated $\mathrm{N}_{2}$ ligand. It is thus limited to Mo and $\mathrm{W}$ complexes featuring bidentate phosphine and polydentate thioether ligands. With alkyl halides, the first $\mathrm{N}-\mathrm{C}$ bond creation requires irradiation and is proposed to occur via $\mathrm{C}$ radical intermediate. The second N-C at the same $\mathrm{N}$ center involves $\mathrm{S}_{\mathrm{N}} 2$ mechanism. ${ }^{223,224}$ In 1989 , Yoshida and Hidai showed the Mo tetra-thioether complex to be much more reactive, without the need for irradiation, toward $\mathrm{MeI}, \mathrm{PhCH}_{2} \mathrm{Br}$ and even $\mathrm{ArX}^{225}$ Subsequent functionalization of the dialkylhydrazido complexes, apart from hydrolysis to the hydrazine derivatives, has not been reported since. On the other hand, Hidai has studied to large extent the $\mathrm{N}-\mathrm{C}$ bond formation from the $\mathrm{M}=\mathrm{N}-\mathrm{NH}_{2}$ hydrazido derivatives, as the terminal $\mathrm{NH}_{2}$ reacts similarly to amines in condensation reactions with carbonyl derivatives (scheme 58). Various nitrogen containing derivatives, such as pyrazoles and phtalimidines, have been synthesized in stoichiometric fashion from $\mathrm{N}_{2}{ }^{226}, 227,228,229$ 


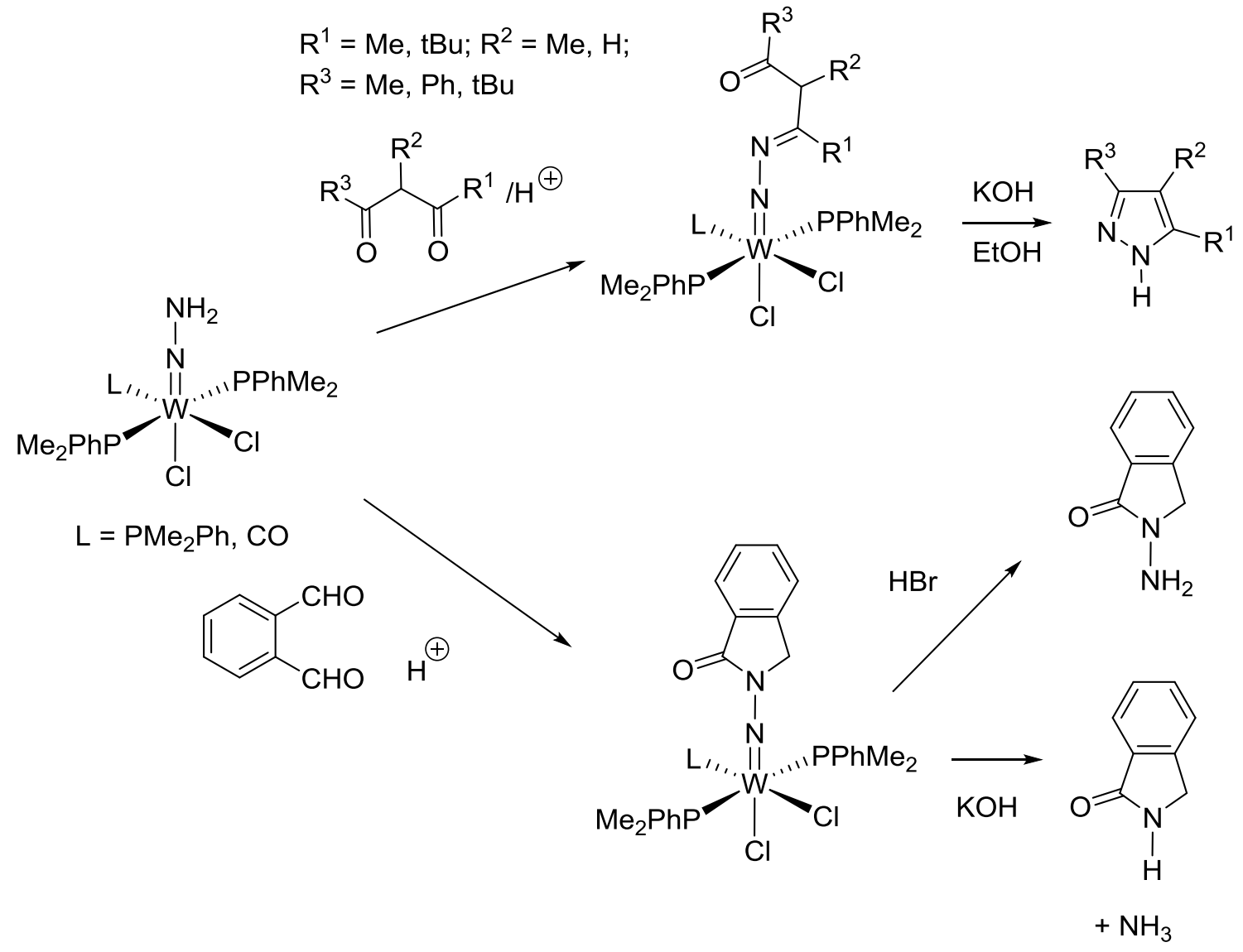

Scheme 58

More recently, Cummins has developed a synthetic method toward nitriles via functionalization of the $\mathrm{N}$ atom of the $\left[\left(\mathrm{N}^{*}\right)_{3} \mathrm{Mo}(\mathrm{N})\right] \mathrm{Mo}^{\mathrm{VI}}$ complex $\left(\mathrm{N}^{*}=\mathrm{N}(t \mathrm{Bu})(3,5-\right.$ $\mathrm{Me}_{2} \mathrm{Ph}$ )) they obtained by $\mathrm{N}_{2}$ splitting. They showed that the $\mathrm{N}$ atom is weakly nucleophilic, and could only react once with strongly activated substrates, such as $\mathrm{RCO}(\mathrm{OTf}), \mathrm{SiMe}_{3} \mathrm{OTf}$ or $\mathrm{MeI}$ to yield the corresponding imido complexes (scheme $59)^{230}$ 


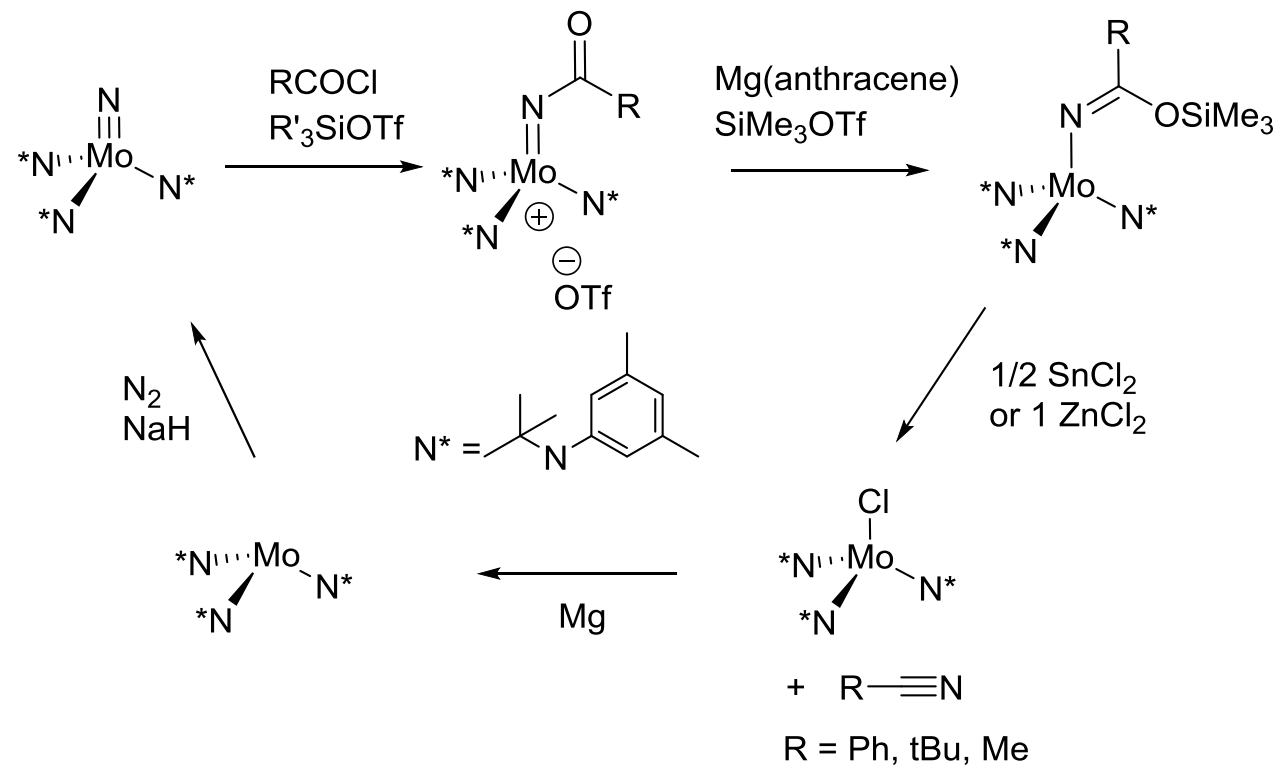

scheme 59

\subsection{N-E bond formation: Stoichiometric and catalytic processes.}

A large number of studies have been dedicated in the recent years on the creation of N-Si and N-B bonds. These have found grounds on seminal works by the group of Hidai who showed reactivity at terminal $\mathrm{N}$ of coordinated $\mathrm{N}_{2}$ with $\mathrm{Si}-\mathrm{Cl}$ moieties as well as $\mathrm{BH}$ bond. Here again, the nucleophilic character of the terminal $\mathrm{N}$ center of the trans$\left[\mathrm{M}\left(\mathrm{N}_{2}\right)_{2}(\mathrm{dppe})_{2}\right]$ and $c i s-\left[\mathrm{M}\left(\mathrm{N}_{2}\right)_{2}\left(\mathrm{PMe}{ }_{2} \mathrm{Ph}\right)_{4}\right]$ is evidenced through silylation reactions to form the corresponding diazenido complexes trans-[M(I)(PMe $\left.\left.{ }_{2} \mathrm{Ph}\right)_{4}\left(\mathrm{~N}_{2} \mathrm{SiR}_{3}\right)\right]$ and trans$\left[\mathrm{M}(\mathrm{I})(\mathrm{dppe})_{2}\left(\mathrm{~N}_{2} \mathrm{SiR}_{3}\right)\right] \quad(\mathrm{M}=\mathrm{Mo}, \mathrm{W}) .{ }^{231}$ The double N-Si bond formation can occur to form the hydrazido(2-) "M=N-N($\left(\mathrm{SiR}_{3}\right)_{2} "$ complex using the $\mathrm{ClSiMe}_{2} \mathrm{CH}_{2} \mathrm{CH}_{2} \mathrm{SiMe}_{2} \mathrm{Cl} / 2 \mathrm{NaI}$ couple (Scheme 60). Most importantly, reduction of the diazenido complex trans-[M(I)(PMe $\left.2 \mathrm{Ph})_{4}\left(\mathrm{~N}_{2} \mathrm{SiR}_{3}\right)\right]$ with $\mathrm{Na}$ was shown to give mixtures of silylamines, which was the basis for the first efficient catalytic process of $\mathrm{N}_{2}$ reduction, $\mathrm{N}_{2}$-to- $\mathrm{N}\left(\mathrm{SiMe}_{3}\right)_{3}$ (vide infra). With cis-[Mo(PMe $\left.\left.2 \mathrm{Ph}\right)_{4}\left(\mathrm{~N}_{2}\right)_{2}\right]$, they reported a TON of 24 
( $\mathrm{Na}$ dispersion as reducing agent) for the silylamine, while the $\mathrm{W}$ analogue and trans$\left[\mathrm{Mo}(\mathrm{dppe})_{2}\left(\mathrm{~N}_{2}\right)_{2}\right]$ only provided "stoichiometric" amounts of silylamine (3 and 1 equiv. resp.). ${ }^{232}$
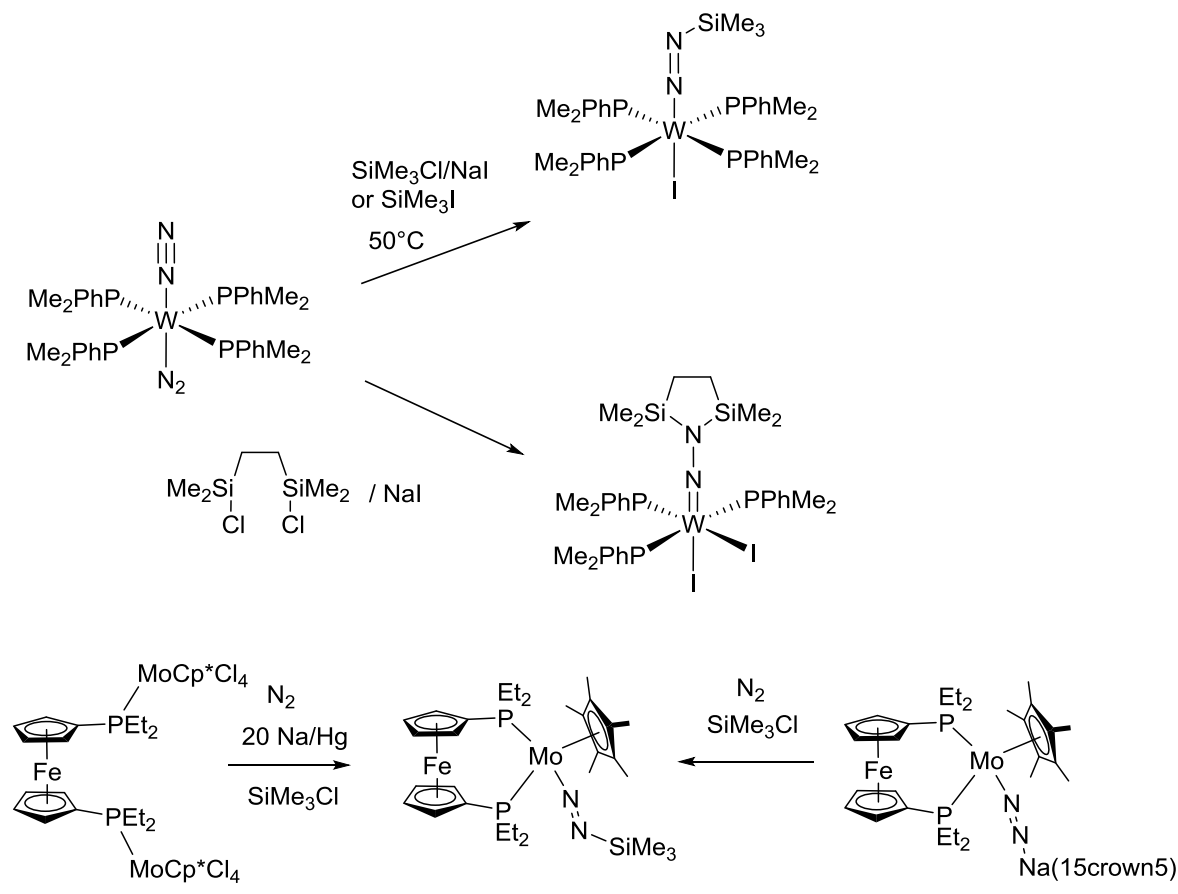

Scheme 60

In 2011, Nishibayashi has reported the silylation of neutral and anionic dinitrogen complexes featuring depf ligand, yielding the silyldiazenido complex (Scheme 60, bottom), the first intermediate in the $\mathrm{N}_{2}$-to- $\mathrm{N}\left(\mathrm{SiMe}_{3}\right)_{3}$ catalytic process. ${ }^{180,233}$ The efficiency of the trans-[Mo(depf $\left.)_{2}\left(\mathrm{~N}_{2}\right)_{2}\right]$ complex is impressive with up to 226 equiv. of $\mathrm{N}\left(\mathrm{SiMe}_{3}\right)_{3}$ produced. ${ }^{233}$ Other complexes featuring the same depf ligand, trans$\left[\mathrm{Mo}(\mathrm{depf})\left(\mathrm{PMe}_{2} \mathrm{Ph}\right)_{2}\left(\mathrm{~N}_{2}\right)_{2}\right]$ and trans-[W(depf $\left.)_{2}\left(\mathrm{~N}_{2}\right)_{2}\right]$ were also competent catalysts (TON of 54 and 60 resp.). The same authors reported in 2014 that the anionic complex $\left[\mathrm{Cp} * \mathrm{Mo}\left(\mu-\mathrm{N}_{2}\right)\{\mathrm{Na}(15 \text {-crown-5) }\}(\mathrm{depf})]^{-}\right.$was less efficient $(\mathrm{TON}=22){ }^{234} \mathrm{DFT}$ calculations have been used to propose a catalytic cycle consistent with experimental data (Scheme 61), postulating the active species to be $\mathrm{SiMe}_{3}$ radical. 


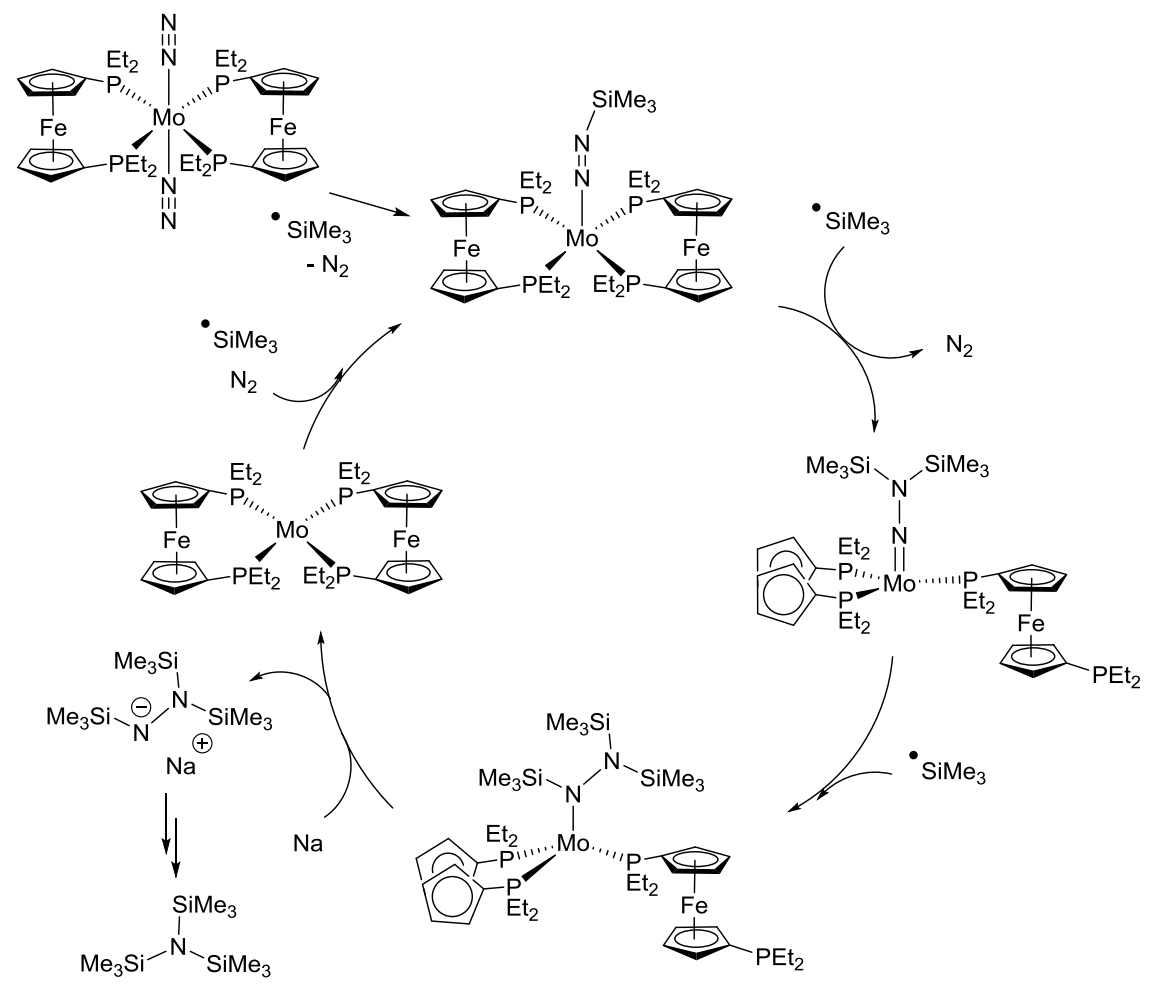

Scheme 61

A key feature of the depf-Mo system lies in the capacity of the ligand to adopt flexible bonding modes (mono and bidentate coordination) to Mo in addition to their bulkiness and electron richness. It is proposed that the N-N bond splitting occurs outside the coordination sphere.

In 2013, Masuda and co-corkers have reported several Mo- $\mathrm{N}_{2}$ complexes featuring various bidentate bis(diphenylphosphino)amine $\mathrm{RN}\left(\mathrm{PPh}_{2}\right)_{2}$ ligands, as well as their behavior in the same silylamine catalytic formation. Unfortunately, the performances of the catalysts were quite limited as 0.3-4.0 equiv. of $\mathrm{N}\left(\mathrm{SiMe}_{3}\right)_{3}$ were obtained (by GC/MS). ${ }^{235}$

In 2014, Mézailles studied the stepwise silylation/reduction of a terminal $\mathrm{N}_{2}$ complex generated in situ by reduction of the Mo ${ }^{\text {II }}$ precursor, featuring a tetradentate phosphine $\left[\mathrm{PP}_{3}\right]$ ligand. They have isolated the silylhydrazido(2-) and imido complexes, 
and showed them to be catalytically competent (200 equiv. $\mathrm{K}$ and $\mathrm{SiMe}_{3} \mathrm{Cl}, 50^{\circ} \mathrm{C}, 2$ days, TON 12-15) (Scheme 62). ${ }^{236}$
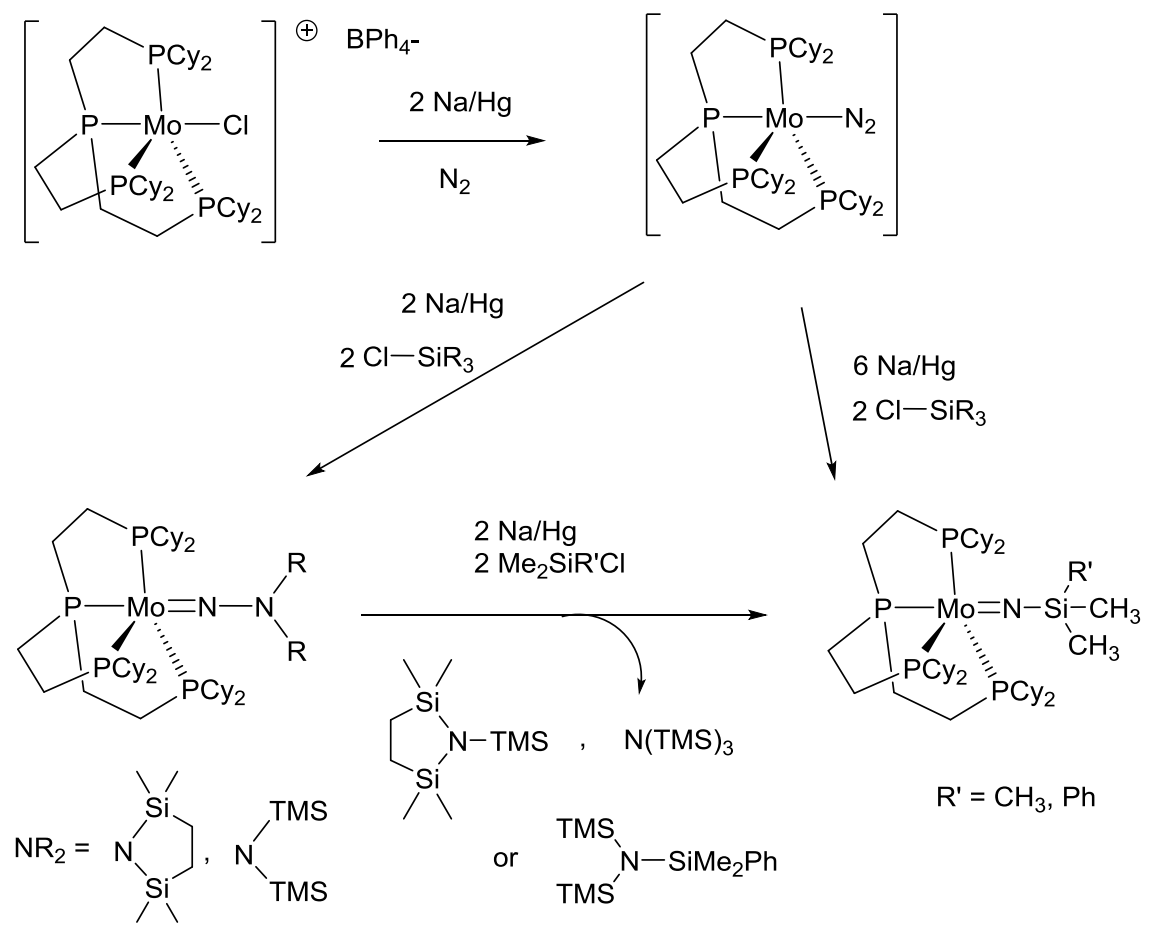
$\mathrm{R}^{\prime}=\mathrm{CH}_{3}, \mathrm{Ph}$

\section{Scheme 62}

In a subsequent study, the stepwise reduction of a mixture of $\left[\mathrm{Mo}\left[\mathrm{P}^{\mathrm{Cy}} \mathrm{P}^{\mathrm{Ph}} \mathrm{P}^{\mathrm{Cy}}\right]\left(\mathrm{N}_{2}\right)_{\mathrm{x}}\right](\mathrm{x}=2,3)$ complexes allowed isolation of the silylhydrazido(2-), the nitrido and the silylimido complexes (Scheme 63). ${ }^{237}$ These complexes perform equally well in catalysis with TON of 33-39 (400 equiv. $\mathrm{K}, 200$ equiv. $\left(\mathrm{CH}_{2} \mathrm{SiMe}_{2} \mathrm{Cl}\right)_{2}, 50^{\circ} \mathrm{C}, 2$ days). In addition to being reactive toward $\mathrm{Si}-\mathrm{Cl}$ bond, the nitrido complex reacted with $\mathrm{Si}-\mathrm{H}$ bonds under mild conditions providing a synthesis of bis-silylamine. ${ }^{184}$ 


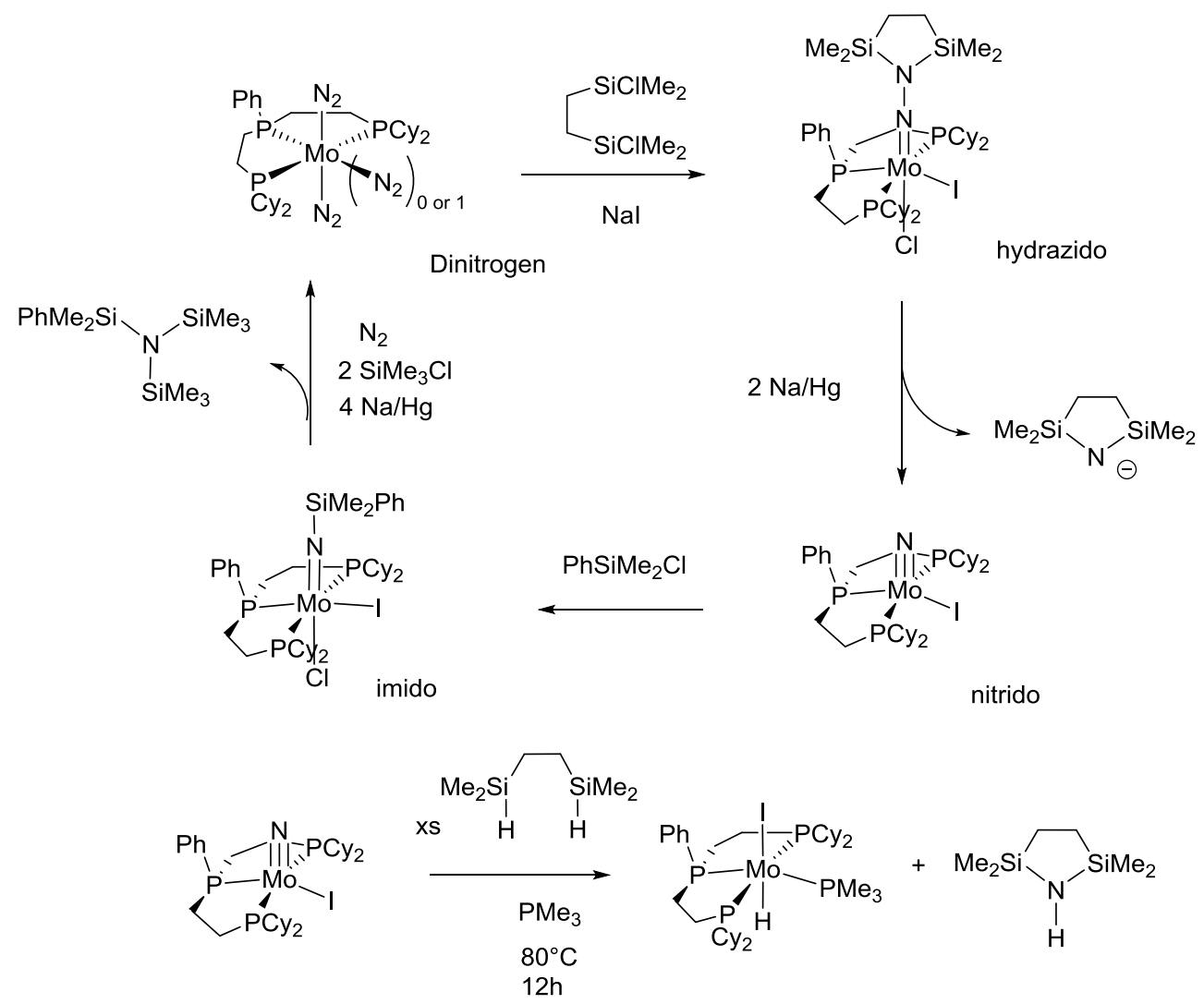

Scheme 63

Using the mixed $\mathrm{Cp}^{*} /$ amidinate complexes presented above, Sita and co-workers reported in 2015 a synthetic cycle to produce $\mathrm{SiMe}_{3} \mathrm{NCO},{ }^{182}$ or $\left(\mathrm{SiMe}_{3}\right)_{2} \mathrm{NH}^{238}$ based on the reactivity of the nitrido derivative. Photolytic or thermal $\mathrm{N}_{2}$ splitting is followed by functionalization of the nitrido intermediate with $\mathrm{SiMe}_{3} \mathrm{Cl}$ (scheme 64). 


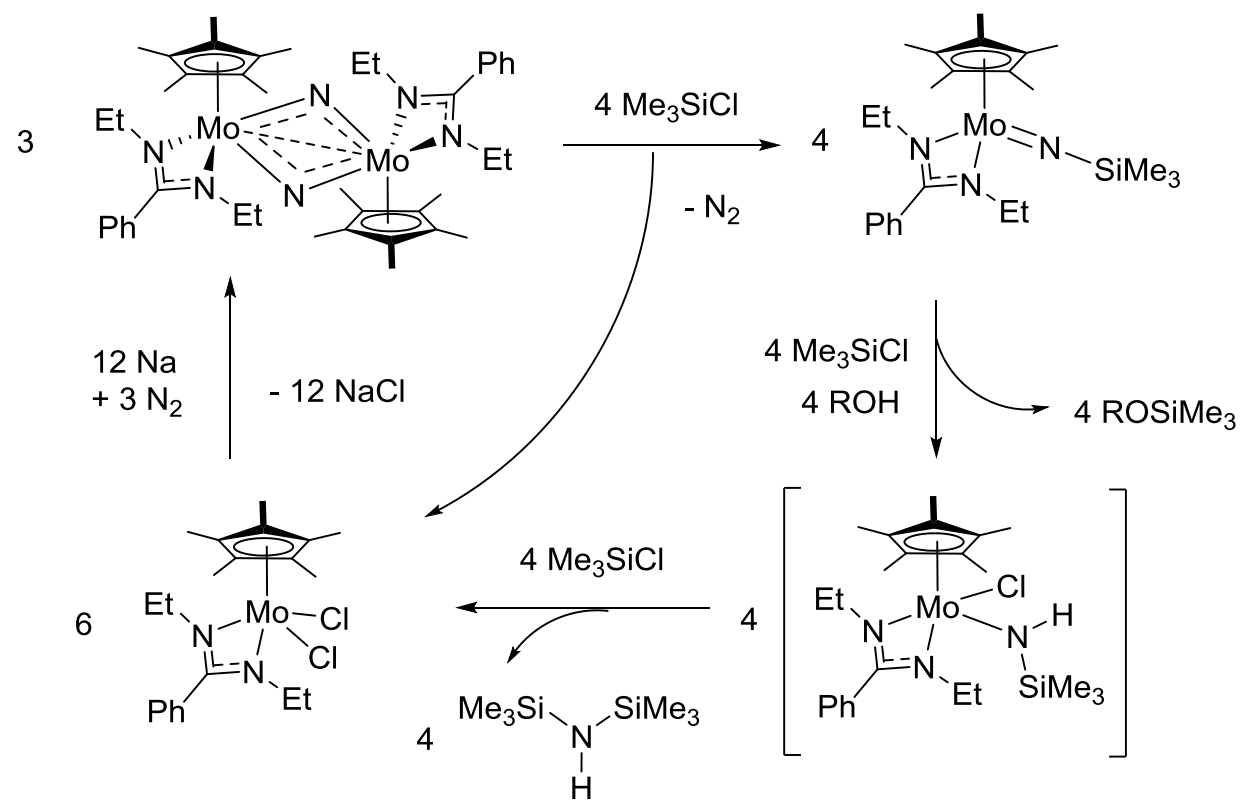

Scheme 64

In 1998, the reaction between $\mathrm{RBH}_{2}$ and an anionic $\mathrm{W}^{0}$ complex, activated by $\mathrm{N}_{2}$ substitution by an electron donating $\mathrm{NCS}^{-}$, was reported by Hidai. ${ }^{239}$ In 2017, Simonneau used BCF (tris-pentafluorophenyl borane) to activate coordinated $\mathrm{N}_{2}$ toward $\mathrm{BH}$ functionalization with $\mathrm{HB}\left(\mathrm{C}_{6} \mathrm{~F}_{5}\right)_{2}$ (scheme 65). ${ }^{240}$ In 2019, the same group reported on the 1,3 addition of $\mathrm{BH}$ across the $\mathrm{W}-\mathrm{N} \equiv \mathrm{N}$ moiety, to form $\mathrm{H}-\mathrm{W}-\mathrm{N}=\mathrm{NB}\left(\mathrm{C}_{6} \mathrm{~F}_{5}\right)_{2}$ fragments. ${ }^{241}$ In 2018, Mézailles showed that stepwise functionalization of the $\left[\left[\mathrm{P}^{\mathrm{Cy}} \mathrm{P}^{\mathrm{Ph}} \mathrm{P}^{\mathrm{Cy}}\right] \mathrm{Mo}(\mathrm{N}) \mathrm{I}\right]$ nitrido complex with PinBH does lead to borylamine formation, via borylamido-hydride and (bis-boryl)amido-bis-hydride intermediate complexes (scheme 66). 


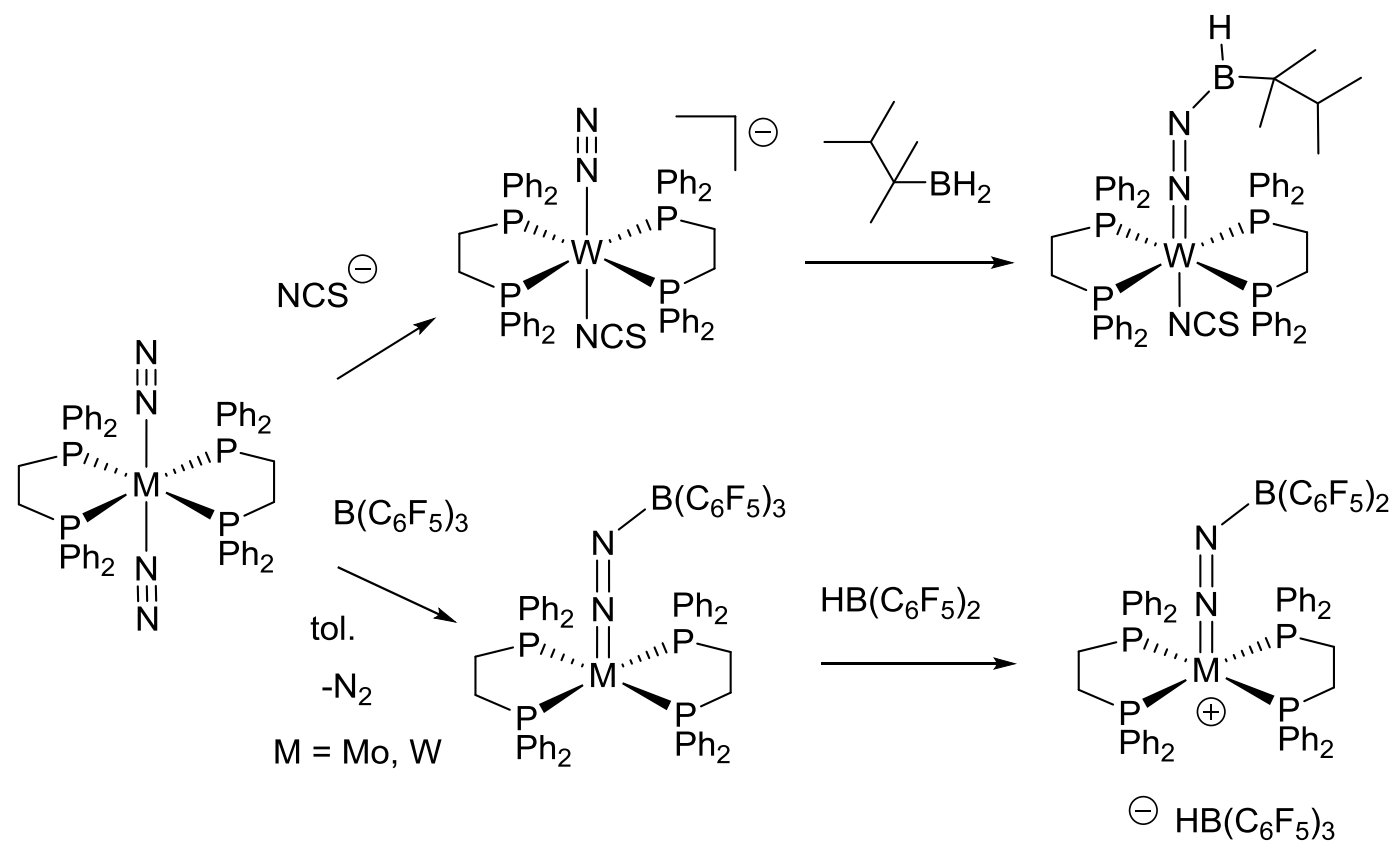

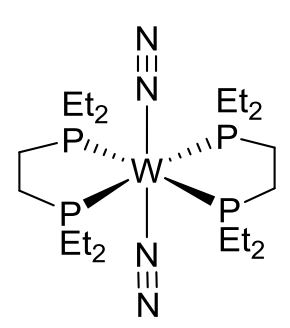

$3 \mathrm{HB}\left(\mathrm{C}_{6} \mathrm{~F}_{5}\right)_{2}$

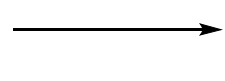

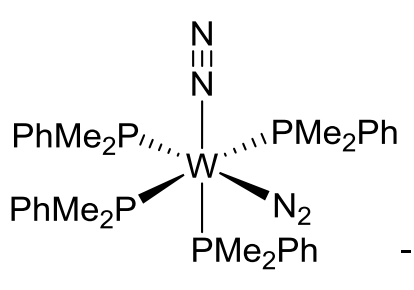

Scheme 65

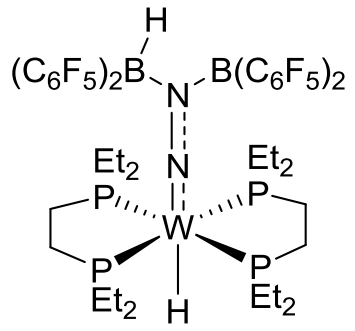

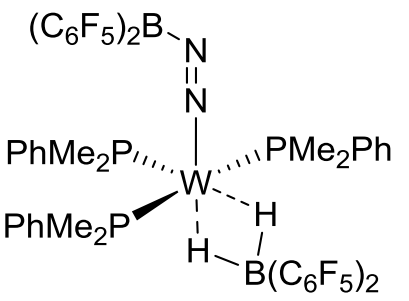




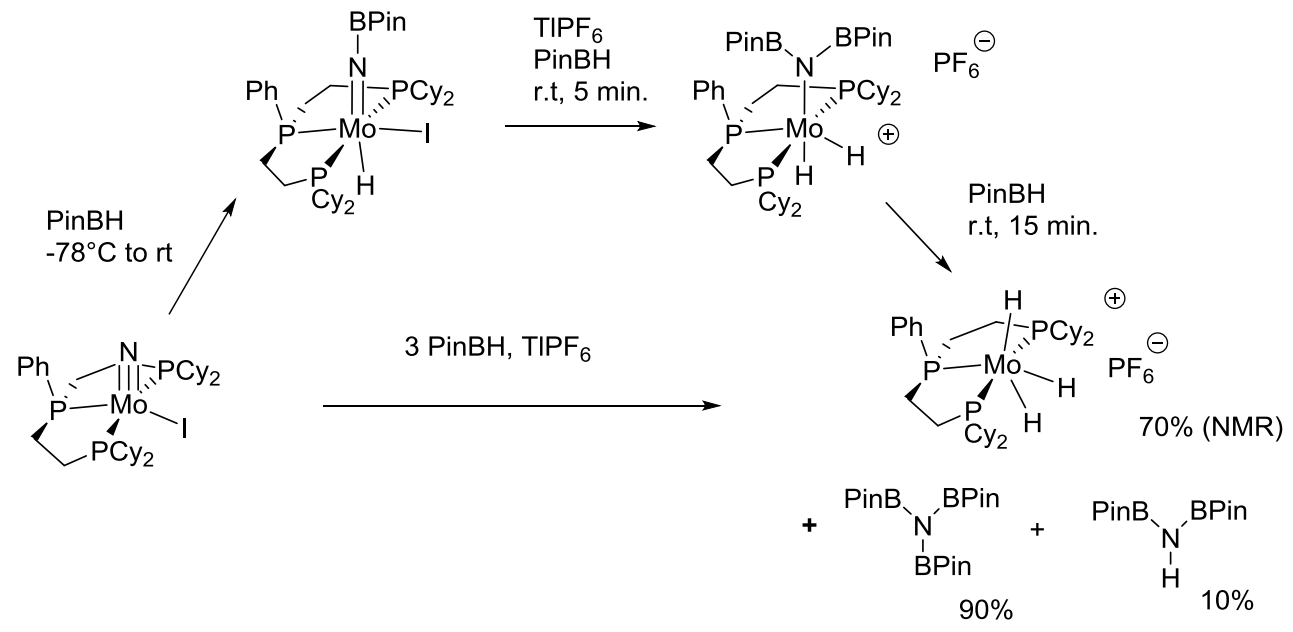

Scheme 66

\section{Group 7 transition metal-dinitrogen complexes}

The chemistry of group 7 metals pertaining to $\mathrm{N}_{2}$ is very limited compared to its direct group 6 and 8 neighbors. Early work has focused on the synthesis of the $\mathrm{N}_{2}$ complexes via two different strategies, i.e. the classical reduction of the halide precursor and the degradation of benzoyldiazenido complex (scheme 67). ${ }^{242},{ }^{243},{ }^{244}$

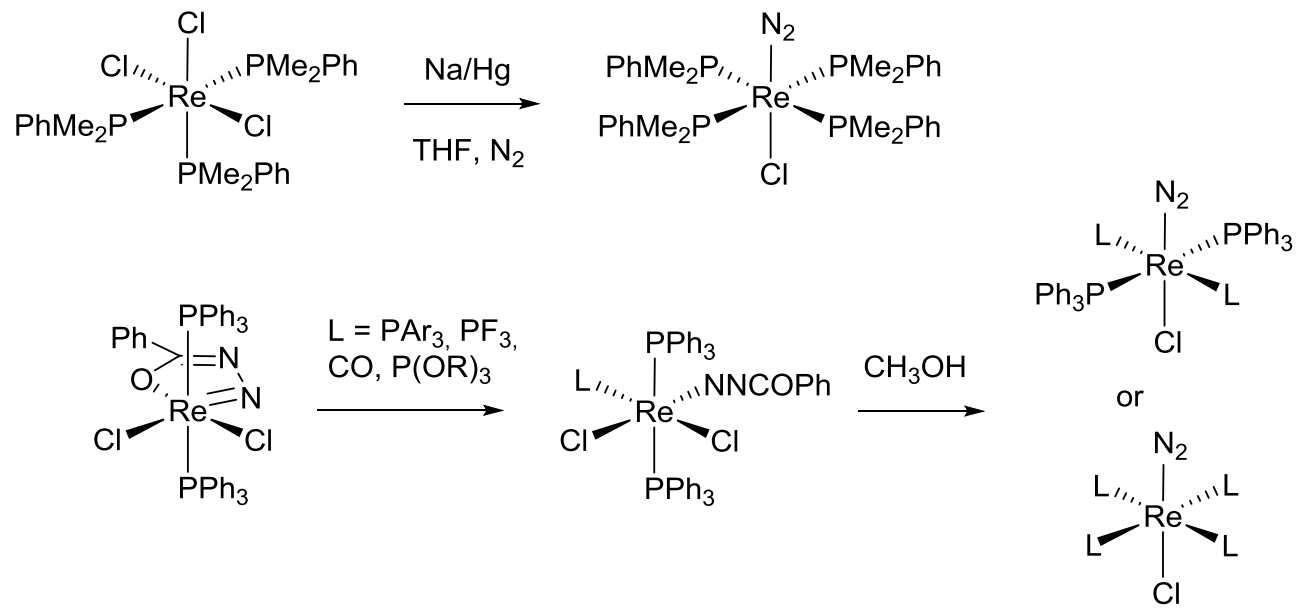

Scheme 67

Since 2003, only a handful of publications, summarized below, have been 
dedicated to these metal centers dinitrogen complexes. In 2006, Pombeiro showed that $\mathrm{CO}$ and $\mathrm{Cl}^{-}$ligands can be displaced from a Re center while keeping the $\mathrm{N}_{2}$ coordinated, leading to the formation of a picolinate Re- $\mathrm{N}_{2}$ complex. ${ }^{245}$ The $\mathrm{dNN}$ at $1.169(4) \AA$ is only marginally elongated from free $\mathrm{N}_{2}(1.0976 \AA$ ). Following the known strategy based on benzoyldiazenido decomposition, the same group reported the synthesis of a water soluble Re- $\mathrm{N}_{2}$ complex, using the 1,3,5-triaza-7-phosphaadamantane as ligand. ${ }^{246}$

Chatt showed as early as 1969 that Re- $\mathrm{N}_{2}$ complexes could be used to synthesize bridged $\mathrm{N}_{2}$ heterobimetallic complexes. In fact, they proposed such Re-NN-Mo complex as model to understand the function of Mo in nitrogenase enzyme. ${ }^{247}$ This strategy was followed in 2006 by Brown to obtain another Re-NN-Mo heterobimetallic complex (scheme 68 ). ${ }^{248}$ The goal was to probe the NN bond cleavage between two different metal centers. They therefore also prepared the corresponding nitrido complexes of both Re and Mo to evaluate the microscopic reverse NN bond forming process.

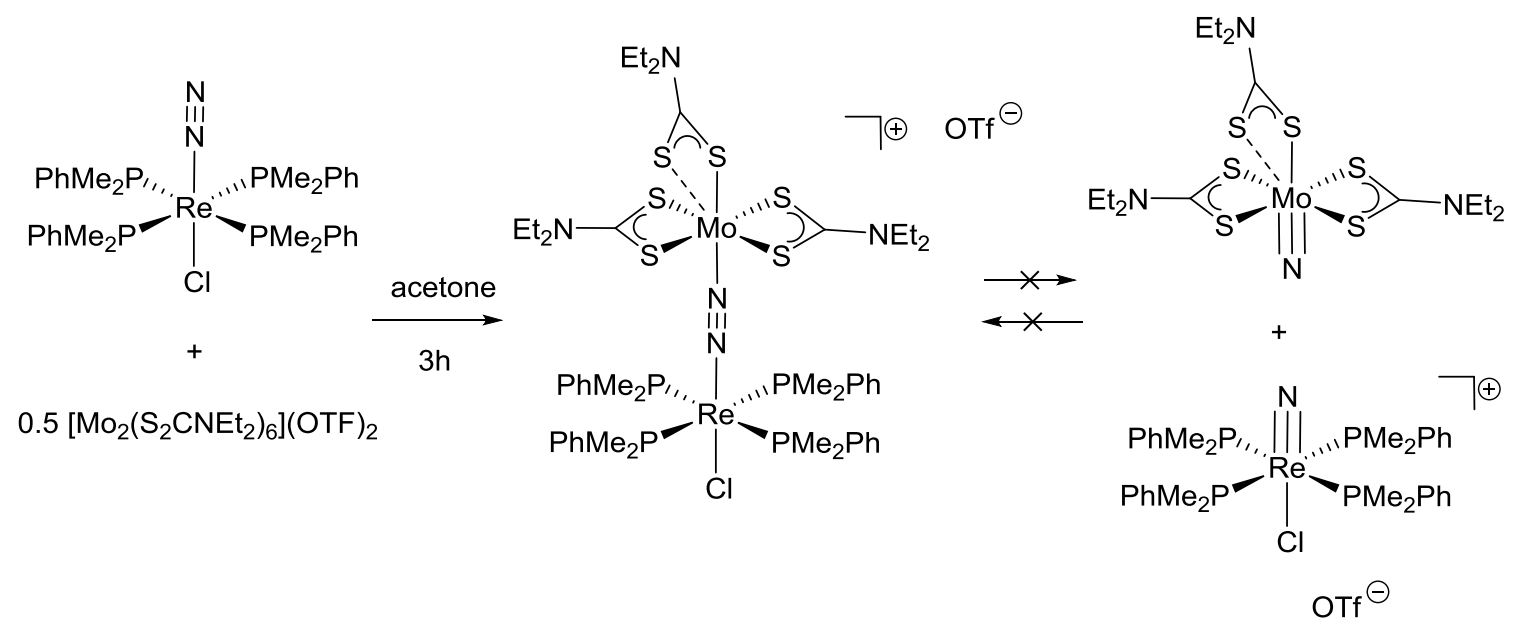

Scheme 68

Unfortunately, the NN bond cleavage could not be observed under various conditions, including reduction, heating or photolysis, which only led to $\mathrm{Re}-\mathrm{N}_{2}$ complex and/or 
several unidentified complexes. The $\mathrm{N}_{2}$ formation from the two nitride complexes did not occur either, but the reaction formed the "(N)Re-N-Mo" $\mu$-nitrido complex instead. The authors conclude that kinetic factors rather than thermodynamic ones govern the stability of the $\mathrm{N}_{2}$ bimetallic complex.

In 2007 and 2009, Arnold reported the use of an anionic $\left[\mathrm{N}_{2} \mathrm{P}_{2}\right]^{-}$ligand, acting as tridentate ligand, to form the $\left[\left[\mathrm{N}_{2} \mathrm{P}_{2}\right] \mathrm{Mn}\right]_{2}\left(\mu-\eta^{1}: \eta^{1}-\mathrm{N}_{2}\right)$ complex, although in poor yield. The solution magnetic moment $\left(8.7 \mu_{\mathrm{B}}\right)$, being close to the spin only value for eight unpaired electrons, is consistent two $\mathrm{Mn}^{\mathrm{I}}$ high spin centers (scheme 69). ${ }^{249,250}$
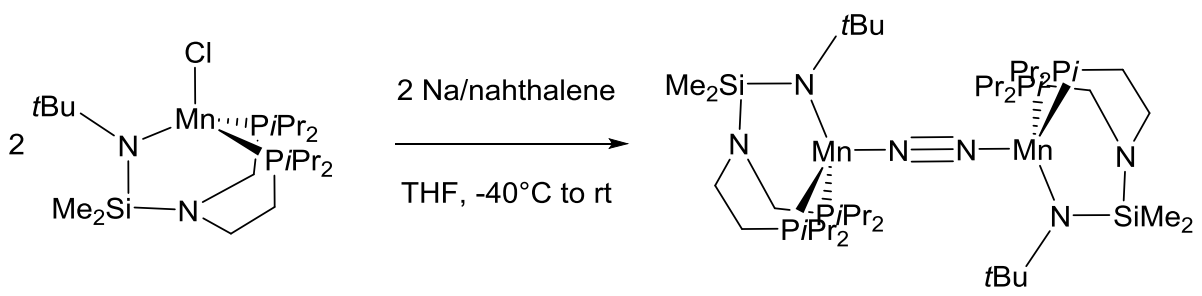

Scheme 69

The most advanced system pertaining to $\mathrm{N}_{2}$ functionalization with group 7 metals has been proposed by Schneider since 2014. In a first report, reduction of the $\left[\mathrm{Re}\left[\mathrm{PNP} \mathrm{Cl}_{2}\right]\right.$ complex (where $\left.[\mathrm{PNP}]=\mathrm{N}\left(\mathrm{CH}_{2} \mathrm{CH}_{2} \mathrm{P} t \mathrm{Bu}_{2}\right)_{2}\right)$ by one electron $\left(\mathrm{Na} / \mathrm{Hg}\right.$ or $\left.\mathrm{Cp}_{2}{ }_{2} \mathrm{Co}\right)$ under $\mathrm{N}_{2}$ led to isolation of the $\operatorname{Re}^{\mathrm{V}}$ nitride complex [[PNP]Re(N)Cl] in excellent yield, resulting from $\mathrm{N}_{2}$ cleavage (scheme 70). ${ }^{251}$ In a subsequent study, the mechanism for this process was studied. Performing the reduction at lower temperature, they were able to characterize the bimetallic bridging $\mathrm{N}_{2}$ complex, including by X-ray diffraction. In parallel, a very thorough electrochemical study of the reduction, coupled to DFT calculations was performed. The mechanism for the NN cleavage thus follows a $\mathrm{EC}^{\mathrm{N} 2} \mathrm{C}^{\mathrm{Cl}} \mathrm{EC}^{\mathrm{dim}}$ pathway $\left(\mathrm{E}=\right.$ electrochemical, $\mathrm{C}=$ chemical; $\mathrm{C}^{\mathrm{N} 2}: \mathrm{N}_{2}$ coordination, $\mathrm{C}^{\mathrm{Cl}}$ :

$\mathrm{Cl}^{-}$dissociation, $\mathrm{C}^{\mathrm{dim}}$ : dimerization). The rate determining step occurs after dimerization, 
and implies an in plane zigzag transition state with a NN distance of $1.59 \AA$.

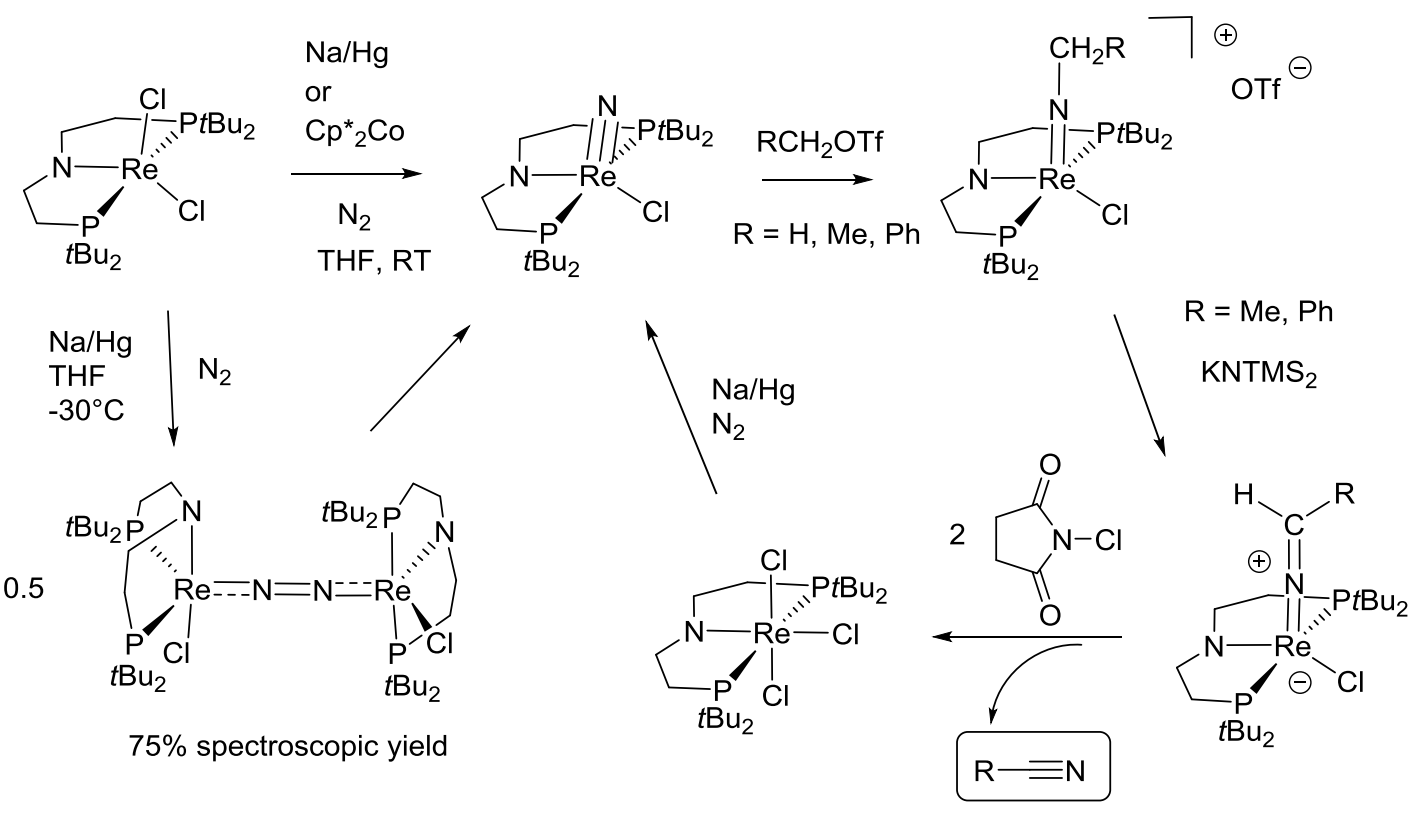

Scheme 70

Schneider's group then studied the functionalization of the nitrido complex. ${ }^{252,253}$ They devised a multistep process based on alkylation, deprotonation and subsequent oxidation to generate two nitrile derivatives, $\mathrm{PhCN}$ and $\mathrm{MeCN}$. Interestingly, the $[[\mathrm{PNP}] \mathrm{Re}(\mathrm{N}) \mathrm{Cl}]$ complex can be regenerated closing a synthetic cycle for nitrile synthesis from atmospheric $\mathrm{N}_{2}$.

In 2019, they reported a modified platform that splits $\mathrm{N}_{2}$ under photolytic conditions (scheme 71). The corresponding $\operatorname{Re}^{\mathrm{V}}$ nitrido complex [[PNP]Re(N)Cl$\left.{ }_{2}\right]$ further reacted with benzoylchloride to form mixtures of $\mathrm{PhCONH}_{2}(30 \%), \mathrm{PhCN}(64 \%)$ as well as $\mathrm{PhCOOH}(64 \%)$. This process necessitates the participation of the ligand as a $2 \mathrm{e}^{-} / 2 \mathrm{H}^{+}$ donor, forming an imine moiety. A subsequent reaction of this intermediate with hydride then proton sources regenerated the starting complex, closing a four step synthetic cycle. Finally, an electrochemical process was also presented for this synthetic cycle. ${ }^{254}$ 


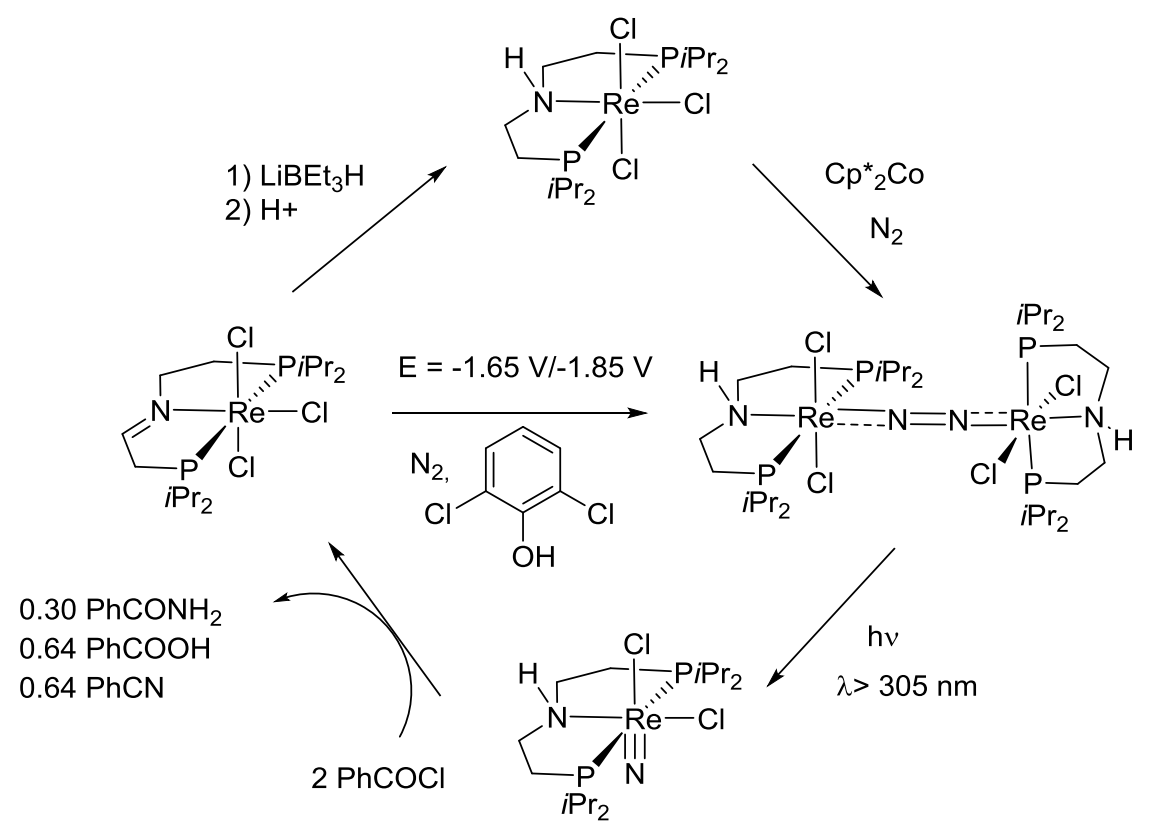

Scheme 71

\section{Preparation of group 8 transition metal-dinitrogen}

\section{complexes}

The vast majority of group 8 metal dinitrogen complexes are known with Fe. Thus, this chapter will be presented according to ligand classes instead of metal centers. A plethora of ligands have been shown to allow the synthesis of group $8 \mathrm{M}-\mathrm{N}_{2}$ complexes, and most of them contain phosphine ligands. As will be seen below several complexes are efficient in the $\mathrm{N}_{2}$ reduction processes $\left(\mathrm{N}_{2}\right.$-to- $\mathrm{NH}_{3}$ and $\mathrm{N}_{2}$-to- $\left.\mathrm{N}\left(\mathrm{SiMe}_{3}\right)_{3}\right)$.

\subsection{Fe- $\mathrm{N}_{2}$ complexes: synthesis and stoichiometric reactivity}

\subsubsection{P containing ligands}

Most of the known Fe- $\mathrm{N}_{2}$ complexes contain phosphine ligands. Following seminal work by Leigh, ${ }^{255}$ with donating bidentate phosphines, Tyler synthesized 
$\left[[\mathrm{PP}]_{2} \mathrm{Fe}\left(\mathrm{H}_{2}\right)(\mathrm{H})\right]^{+}([\mathrm{PP}]=1,2$-bis(bis-(methoxypropyl)phosphino)ethane, a water soluble ligand $)^{256}$ and showed that $\mathrm{H}_{2}$ could be displaced by $\mathrm{N}_{2}$ to form $\left[[\mathrm{PP}]_{2} \mathrm{Fe}\left(\mathrm{N}_{2}\right)(\mathrm{H})\right]^{+}$, featuring a minimally activated $\mathrm{N}_{2}$ moiety $\left(v_{\mathrm{NN}}\right.$ of $2088 \mathrm{~cm}^{-1}, \mathrm{NN}$ distance $\left.1.112 \AA\right)$ (scheme 72 ). ${ }^{257,258}$ Dinitrogen is readily displaced in this type of complexes. In particular, coordination of $\mathrm{NH}_{3}, \mathrm{NH}_{2} \mathrm{NH}_{2}$ and $\mathrm{NH}=\mathrm{NH}$ was studied in light of their possible intermediacy in the $\mathrm{N}_{2}$ reduction process. ${ }^{259}$ Subsequent deprotonation of $\left[[\mathrm{PP}]_{2} \mathrm{Fe}\left(\mathrm{N}_{2}\right)(\mathrm{H})\right]^{+}$yields the $\mathrm{Fe}^{0}$ complex $\left[[\mathrm{PP}]_{2} \mathrm{Fe}\left(\mathrm{N}_{2}\right)\right]$, showing increased $\mathrm{N}_{2}$ activation ( $v_{\mathrm{NN}}$ of $1966 \mathrm{~cm}^{-1}$ ), and $\mathrm{NH}_{3}(15 \%)$ and $\mathrm{N}_{2} \mathrm{H}_{4}(2 \%)$ were both obtained upon acid treatment (triflic acid). DFT calculations were carried out to rationalize the formation of $\mathrm{NH}_{3}$ and hydrazine. ${ }^{260}$ Notably, the analogous complex $\left[\mathrm{Fe}(\mathrm{depe})_{2}\left(\mathrm{~N}_{2}\right)\right]$ did not yield any $\mathrm{NH}_{3}$ upon protonation. ${ }^{261}$ Field has demonstrated in 2015 that starting from isolated $\left[\mathrm{Fe}(\mathrm{dmpe})_{2}\left(\mathrm{~N}_{2}\right)\right]$, no $\mathrm{NH}_{3}$ is formed upon acid treatment, ${ }^{262}$ in contrast with initial reports by Leigh $\left(20 \% \mathrm{NH}_{3}\right.$, protonation with $\mathrm{HCl}$ at low temp using crude mixture containing the Fe- $\mathrm{N}_{2}$ complex). Rather, protonation at the $\mathrm{Fe}$ center was observed, leading to $\mathrm{Fe}^{\mathrm{II}}$ hydride complex. For the synthesis of $\left[\mathrm{Fe}(\mathrm{dmpe})_{2}\left(\mathrm{~N}_{2}\right)\right]$, Field followed the reduction procedure from the dichloride they developed to isolate the related $\left[\mathrm{Fe}(\mathrm{dmpe})_{2}(\mathrm{NH}=\mathrm{NH})\right]$ complex. ${ }^{263}$ Interestingly, deprotonation of the diazene derivative with strong base regenerates the $\left[\mathrm{Fe}(\mathrm{dmpe})_{2}\left(\mathrm{~N}_{2}\right)\right]$ complex. ${ }^{264}$ Related chemistry was studied in parallel by Field with ruthenium. ${ }^{265}$ 


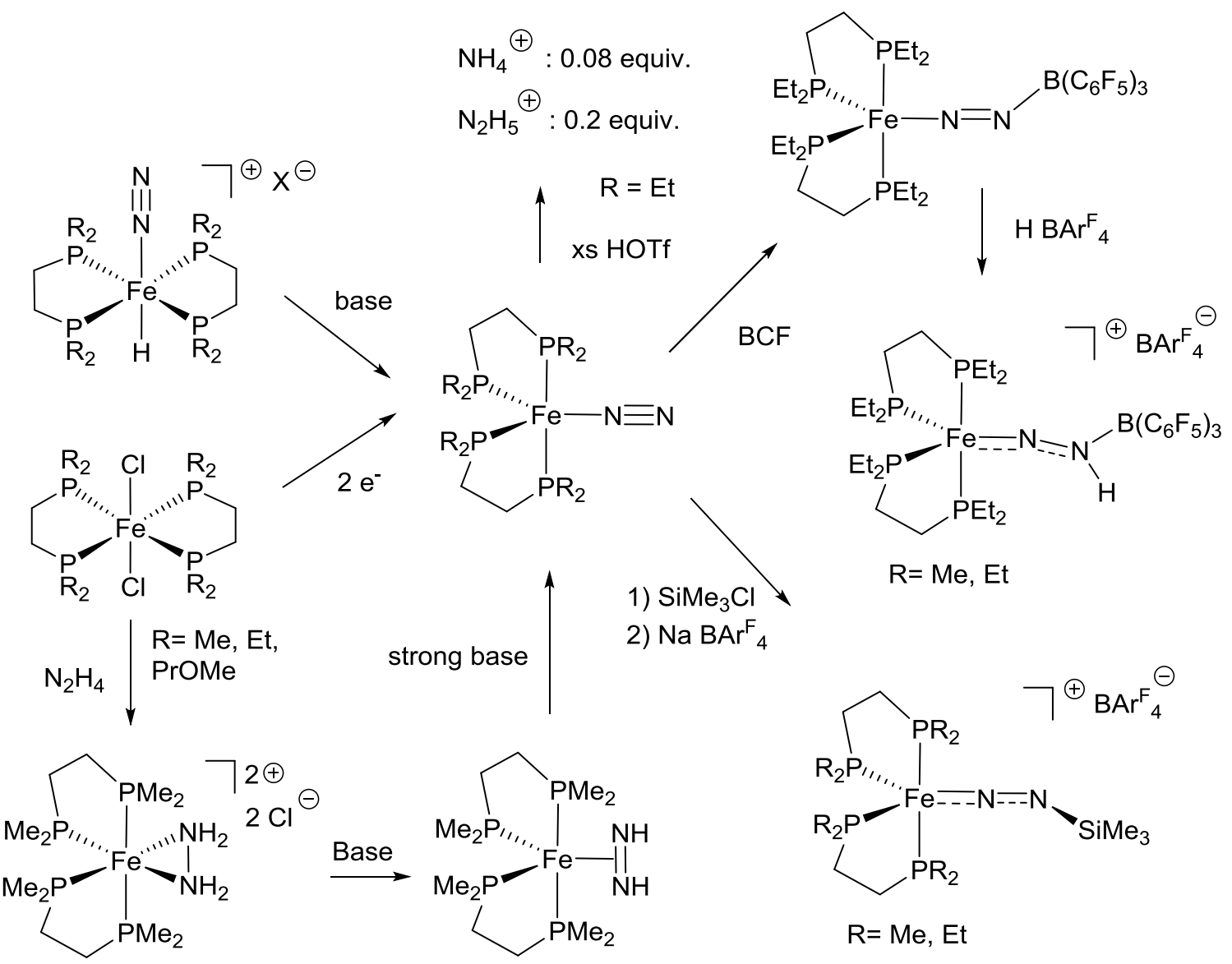

Scheme 72

In 2016, Ashley also studied the $\left[[\mathrm{PP}]_{2} \mathrm{Fe}\left(\mathrm{N}_{2}\right)\right]$ complexes $([\mathrm{PP}]=$ dmpe, depe $),{ }^{266}$ and showed that the dimeric $\left[\mathrm{Fe}(\mathrm{dmpe})_{2}\right]_{2}\left(\mu-\eta^{1}: \eta^{1} \mathrm{~N}_{2}\right)$ complex is obtained from the monomer upon vacuum treatment and crystallization. They also discovered that reaction with TfOH produced appreciable amounts of $\mathrm{N}_{2} \mathrm{H}_{4}$ and $\mathrm{NH}_{3}$, with depe complex (ca $20 \% \mathrm{~N}_{2} \mathrm{H}_{4}, 8 \% \mathrm{NH}_{3}$ ) being more efficient than dmpe one (ca $9 \% \mathrm{~N}_{2} \mathrm{H}_{4}, 0 \% \mathrm{NH}_{3}$ ). Moreover, the significant proportion of hydrazine vs $\mathrm{NH}_{3}$ suggests that the latter may be generated from the intermediacy of the hydrazine complex. The authors have studied the catalytic functionalization (vide infra). In parallel, they have also evaluated the addition of Si electrophile on the $\mathrm{N}_{2}$ in the $\left[\mathrm{Fe}(\mathrm{dmpe})_{2}\left(\mathrm{~N}_{2}\right)\right]$ and $\left[\mathrm{Fe}(\mathrm{depe})_{2}\left(\mathrm{~N}_{2}\right)\right]$ complexes. Thus, addition of $\mathrm{TMSCl}$ and a chloride abstractor allowed the first isolation of a silyldiazenido 
derivative of $\mathrm{Fe}$, showing an acute NNSi bond angle of $c a 130^{\circ} \cdot{ }^{267}$ DFT calculations were carried out and confirm a significant $\mathrm{FeN} \pi$ interaction as well as population of a $\mathrm{NN} \pi^{*}$ orbital, consistent with the observed $v_{\mathrm{NN}}$ stretches at 1732 and $1727 \mathrm{~cm}^{-1}$ (depe and dmpe complexes respectively). In 2017, Szymczak showed that an increase in the $\mathrm{NN}$ bond polarization could favor protonation at $\mathrm{N}$ rather than at Fe. ${ }^{268}$ This could be achieved by coordination of various Lewis acids to $\left[\mathrm{Fe}(\mathrm{depe})_{2}\left(\mathrm{~N}_{2}\right)\right]$ and the extent of $\mathrm{N}_{2}$ activation evaluated by IR spectroscopy (decrease in the $v_{\mathrm{NN}}$ frequency by $129 \mathrm{~cm}^{-1}$, at $\left.1830 \mathrm{~cm}^{-1}\right)$. The $\mathrm{BCF}$ adduct was crystallized, as well as the $[\mathrm{Fe}(\mathrm{depe})(\mathrm{N}=\mathrm{NH}(\mathrm{BCF}))]^{+}$ complex.

In 2013 and 2014, Mock reported the synthesis of $\mathrm{Fe}^{\mathrm{II}}$-hydride-dinitrogen complexes, featuring bidentate phosphines with a pendant amine moiety $\left(\left[\mathrm{P}^{\mathrm{N}} \mathrm{P}\right]\right.$ ligand), and studied the effect of this pendant $\mathrm{N}$ ligand on the protonation/electron events (scheme 73) ${ }^{269}$ In the case of the $\left[[\mathrm{PNP}] \mathrm{Fe}(\mathrm{H})\left(\mathrm{N}_{2}\right)\right]^{+}$complex, protonation reactions did not result in functionalization at $\mathrm{N}$ or at $\mathrm{Fe}$, but at the pendant $\mathrm{N}$ moiety, leading ultimately to the tricationic species with two ammonium moieties. ${ }^{270}$ Reduction then triggers a sequence of $\mathrm{N}_{2}$ decoordination, intermolecular proton and electron transfers, to eventually favor again $\mathrm{N}_{2}$ coordination at $\mathrm{Fe}^{\mathrm{II}}$.

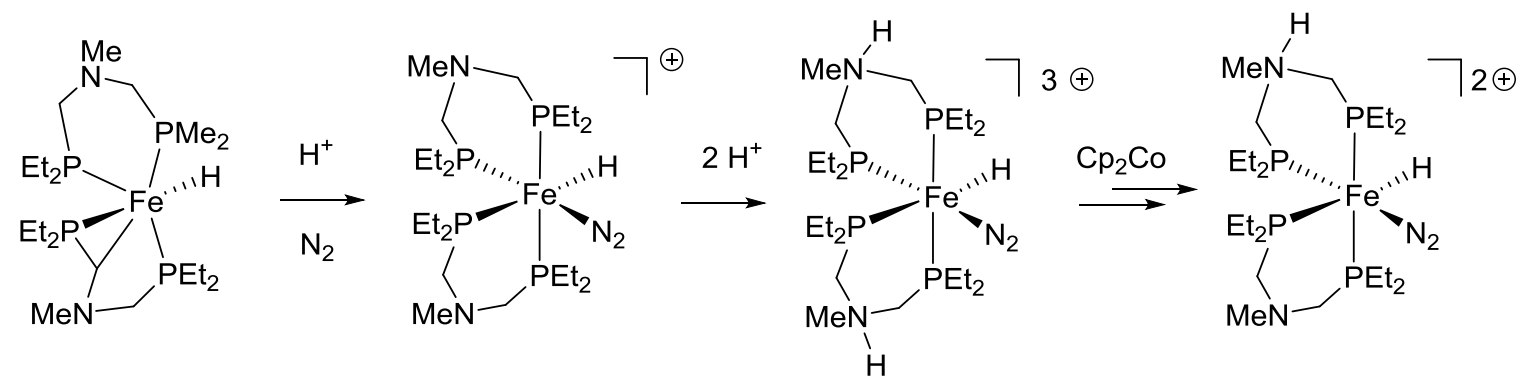

Scheme 73

Bidentate phosphine ligands have been shown to support piano-stool $\mathrm{Ru}-\mathrm{N}_{2}$ complexes. ${ }^{271}$ 
Tridentate ligands featuring phosphines can be separated in two families, the neutral and anionic type ligands. Whittlesey has reported in 2010 the synthesis of $\left[[\mathrm{POP}] \mathrm{Ru}(\mathrm{H})\left(\mathrm{PPh}_{3}\right)\left(\mathrm{N}_{2}\right)\right]\left[\mathrm{BAr}_{4}{ }_{4}\right]$ complexes, with $[\mathrm{POP}]$ being $\left(\mathrm{Ph}_{2} \mathrm{PCH}_{2} \mathrm{CH}_{2}\right)_{2} \mathrm{O}$, xanthphos and DPEphos, thus featuring an ether and two diphenylphosphino moieties. ${ }^{272}$ The neutral tridentate [PPP] type ligands have been surprisingly studied only quite recently. Indeed, Peters reported in 2017 the synthesis of the $[[\mathrm{PPP}] \mathrm{Fe}(\mathrm{H})]_{2}\left(\mu-\eta^{1}: \eta^{1}-\mathrm{N}_{2}\right)$

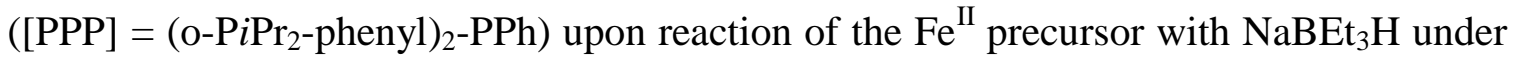
$\mathrm{N}_{2}$ (scheme 74, left). ${ }^{273}$ The complex is in equilibrium with the monomeric $\left[[\mathrm{PPP}] \mathrm{Fe}(\mathrm{H})\left(\mathrm{N}_{2}\right)\right]$ complex, present in minor amounts in solution. The $\left[[\mathrm{PPP}] \mathrm{Fe}(\mathrm{H})_{2}\left(\mathrm{~N}_{2}\right)\right]$ complex could be obtained upon protonation/e transfer. Both the $\mathrm{Fe}^{\mathrm{I}}$ dimer and the $\mathrm{Fe}^{\mathrm{II}}$ complexes are active catalysts in the $\mathrm{N}_{2}$-to- $\mathrm{NH}_{3}$ process with respectively up to 24.6 equiv of $\mathrm{NH}_{3}$ (per Fe center) (3000 eq. $\mathrm{HBAr}_{4}^{\mathrm{F}}, 3600 \mathrm{KC}_{8}$, THF, $-80^{\circ} \mathrm{C}, 1 \mathrm{~h}$ ) and 2.6 equiv of $\mathrm{NH}_{3}$ (150 eq. $\mathrm{HBAr}_{4}^{\mathrm{F}}, 180 \mathrm{KC}_{8}, \mathrm{THF},-80^{\circ} \mathrm{C}, 1 \mathrm{~h}$ ). The authors showed that photolysis during catalysis did provide more active intermediates, from the $\mathrm{Fe}^{\mathrm{I}}$ dimer resulting in most significant improvement of the efficiency (up to 66.7 equiv. $\mathrm{NH}_{3}$ ). In 2018, Mézailles reported the synthesis of the [[PPP]Fe $\left.\left(\mathrm{N}_{2}\right)_{2}\right]\left(v_{\mathrm{NN}} 2048,1981 \mathrm{~cm}^{-1}\right)$ and $\left[[\mathrm{PPP}] \mathrm{Fe}\left(\mathrm{N}_{2}\right)(\mathrm{H})_{2}\right]\left(v_{\mathrm{NN}} 2092 \mathrm{~cm}^{-1}\right)$ complexes $\left([\mathrm{PPP}]=\mathrm{RP}\left(\mathrm{CH}_{2} \mathrm{CH}_{2} \mathrm{PCy}_{2}\right)_{2}, \mathrm{R}=\mathrm{Ph}, t \mathrm{Bu}\right)$ and their poor efficiency in the same $\mathrm{N}_{2}$-to- $\mathrm{NH}_{3}$ catalysis (3.6 and 2.7 equiv. $\mathrm{NH}_{3}$ respect.; 200 eq. $\operatorname{HBAr}_{4}^{\mathrm{F}}, 200 \mathrm{KC}_{8}, \mathrm{THF},-80^{\circ} \mathrm{C}, 1 \mathrm{~h}$ ) (scheme 74, right). ${ }^{274}$ Interestingly, in sharp contrast with Peters' results, with these different [PPP] ligands, the authors report the instability of the $\left[[\mathrm{PPP}] \mathrm{Fe}\left(\mathrm{N}_{2}\right)(\mathrm{H})\right]$ toward dismutation into the known $\mathrm{Fe}^{\mathrm{II}}$ $\left[[\mathrm{PPP}] \mathrm{Fe}\left(\mathrm{N}_{2}\right)(\mathrm{H})_{2}\right]$ and unknown $\mathrm{Fe}^{0}$ complexes. In a follow up study, Peters isolated the [[PPP]Fe( $\left.\left(\mathrm{N}_{2}\right)_{2}\right]$ complex $\left(v_{\mathrm{NN}} 2065,2009 \mathrm{~cm}^{-1}\right)$ as well as its one electron and most 
impressively the two electron reduction derivatives $\left[[\mathrm{PPP}] \mathrm{Fe}\left(\mathrm{N}_{2}\right)_{2}\right][\mathrm{K}(18-\mathrm{C} 6)]\left(v_{\mathrm{NN}} 1872\right.$ $\left.\mathrm{cm}^{-1}\right)$ and $\left[[\mathrm{PPP}] \mathrm{Fe}\left(\mathrm{N}_{2}\right)_{2}\right]\left[\mathrm{K}_{2}(\mathrm{THF})_{3}\right]\left(v_{\mathrm{NN}} 1677 \mathrm{~cm}^{-1}\right) .{ }^{275}$ Stoichiometric functionalization by $\mathrm{H}^{+}$and $\mathrm{Si}^{+}$was studied, showing that an anionic state of the system is required for effective functionalization at $\mathrm{N}$.

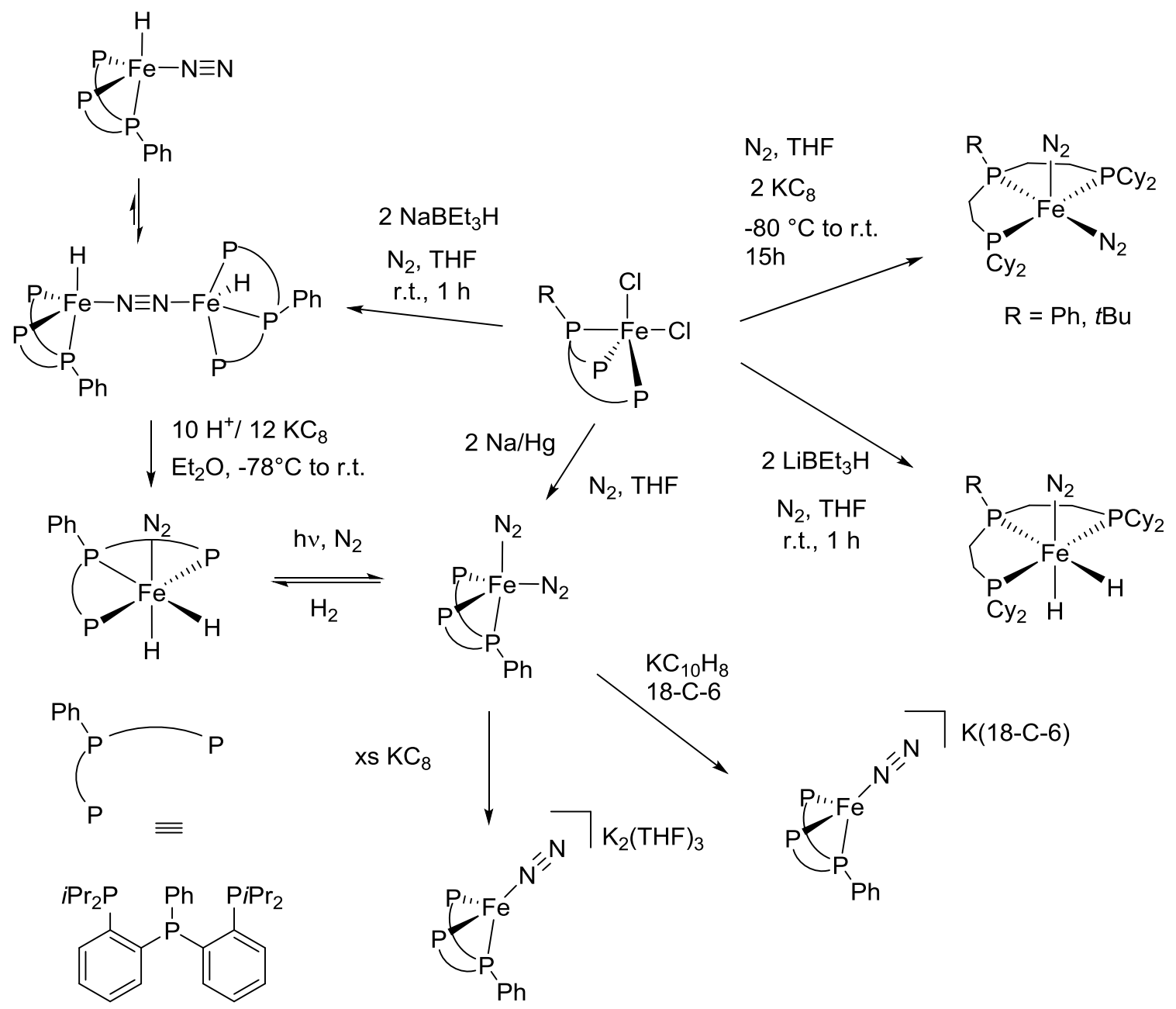

Scheme 74

Prior to these neutral [PPP] ligands, Peters had reported the use of anionic [PPP] ligands, $\left(\left[\mathrm{BP}_{3}\right]=\mathrm{PhB}\left(\mathrm{CH}_{2} \mathrm{PPh}_{2}\right)_{3}{ }^{-}\right)$to support Fe dinitrogen complexes. Thus, reduction of the $\left.\left[\mathrm{BP}_{3}\right] \mathrm{FeCl}\right] \mathrm{Fe}^{\mathrm{II}}$ precursor by $\mathrm{Na} / \mathrm{Hg}$ resulted in the formation of the neutral $\mathrm{Fe}^{\mathrm{I}}$ bridging dimer $\left[\left(\left[\mathrm{BP}_{3}\right] \mathrm{Fe}\right)_{2}\left(\mu-\eta^{1}: \eta^{1}-\mathrm{N}_{2}\right)\right]$ as well as the formal $\mathrm{Fe}^{0.5} \operatorname{dimer}\left[\left(\left[\mathrm{BP}_{3}\right] \mathrm{Fe}\right)_{2}(\mu\right.$ - 
$\left.\left.\eta^{1}: \eta^{1}-\mathrm{N}_{2}\right)\right]\left[\mathrm{Na}(\mathrm{THF})_{6}\right]$ upon addition of a second equivalent of $\mathrm{Na} / \mathrm{Hg}$ (scheme 75). ${ }^{276}$ Alternatively, the anionic $\mathrm{Fe}^{0}$ complex $\left[\left[\mathrm{PhBP}_{3}\right] \mathrm{Fe}\left(\mathrm{N}_{2}\right)\right]\left[\mathrm{MgCl}(\mathrm{THF})_{2}\right]\left(v_{\mathrm{NN}} 1872 \mathrm{~cm}^{-1}\right)$ was obtained from the Mg reduction. Functionalization with MeOTf yielded the high spin diazenido $\left[\left[\mathrm{BP}_{3}\right] \mathrm{Fe}\left(\mathrm{N}_{2} \mathrm{Me}\right)\right]$ with $v_{\mathrm{NN}}\left({ }^{15} \mathrm{~N}_{2}\right)$ vibration at $1597(1538) \mathrm{cm}^{-1}$. Synthesis of the $\mathrm{Fe}^{\mathrm{I}}$ dimer was subsequently shown to be achieved from the in situ generated $\mathrm{Fe}^{\mathrm{IV}}$ nitride. ${ }^{277}$ Indeed, although stable and characterized at $-35^{\circ} \mathrm{C}$, this species cleanly evolved to the dinitrogen complex at room temperature.

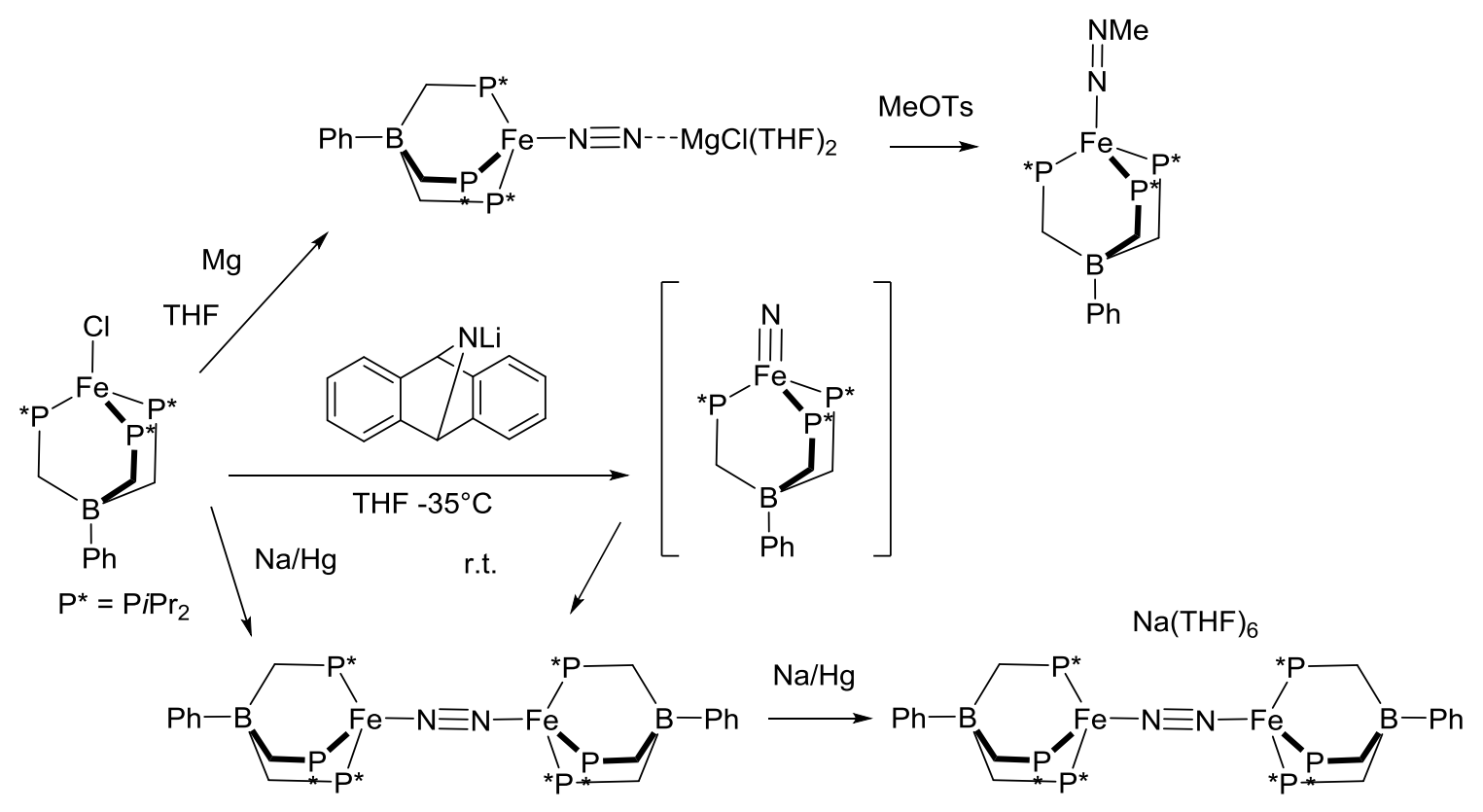

Scheme 75

In 2011, the same group utilized a similar platform to study the coordination/interconversion of $\mathrm{N}_{\mathrm{x}} \mathrm{H}_{\mathrm{y}}$ ligands at $\mathrm{Fe} .{ }^{278}$ They discovered that the $\mu-\mathrm{N}_{2} \mathrm{H}_{4}$ and $\mu-\mathrm{N}_{2} \mathrm{H}_{2}$ complexes react with free hydrazine reducing the latter to $\mathrm{NH}_{3}$ as the former is oxidized (scheme 76). 


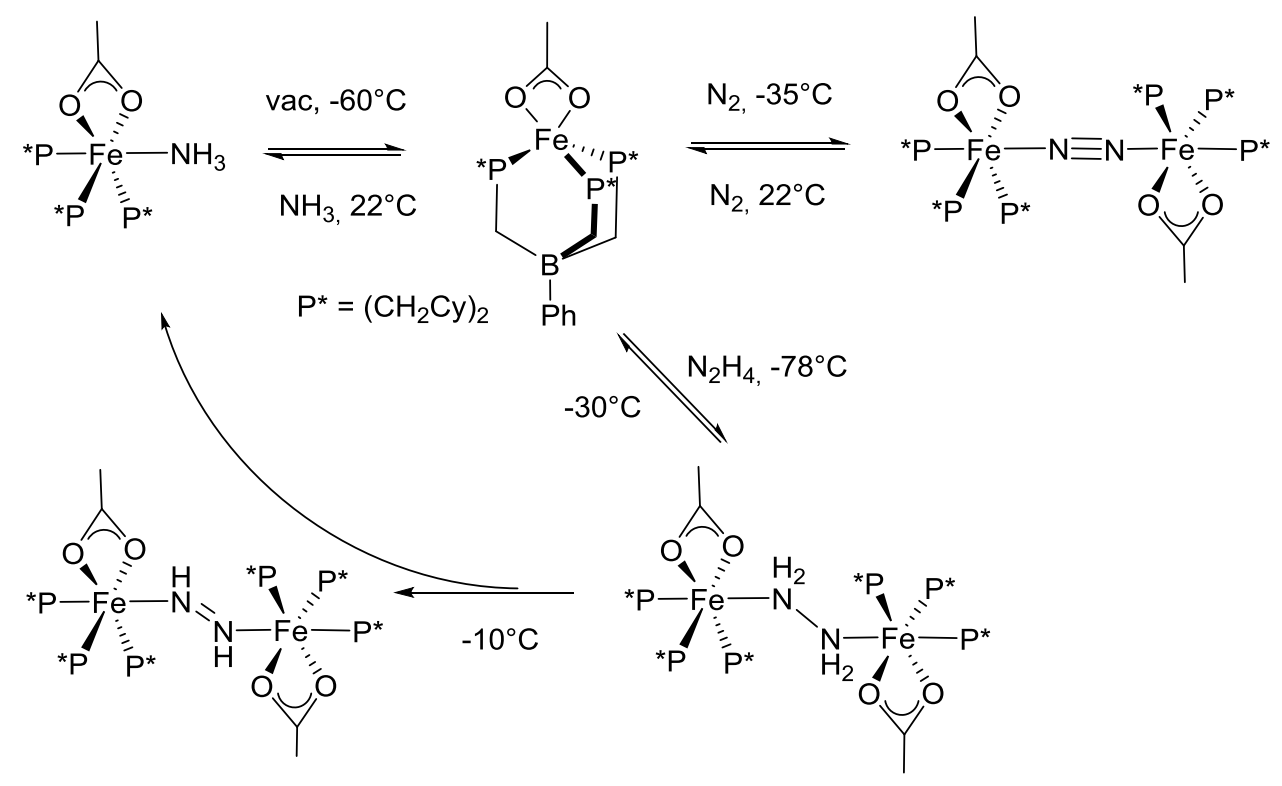

Scheme 76

This tripodal anionic $\left[\mathrm{BP}_{3}\right]^{-}$ligand has led to the development of related families of tetrapodal neutral $\left[\mathrm{BP}_{3}\right]$ and anionic $\left[\mathrm{CP}_{3}\right]^{-}$and $\left[\mathrm{SiP}_{3}\right]^{-}$ligands by the group of Peters. Both the $\mathrm{C}^{-}$and $\mathrm{Si}^{-}$moieties exert a strong trans influence on the coordinated $\mathrm{N}_{2}$. With the $\left[\mathrm{SiP}_{3}^{\mathrm{R}}\right]^{-}$ligand $\left(\mathrm{P}^{\mathrm{R}}=\mathrm{PPh}_{2}\right.$ and $\left.\mathrm{PiPr}_{2}\right)$, the neutral $\mathrm{Fe}^{\mathrm{I}}-\mathrm{N}_{2}$ complexes were synthesized (scheme 77). ${ }^{279,280}$ The $\left[\mathrm{SiP}_{3}^{i \mathrm{Pr}}\right]^{-}$ligand being more electron rich than the corresponding $\left[\mathrm{SiP}_{3}^{\mathrm{Ph}}\right]^{-}$one, the $\mathrm{NN}$ stretch is logically found at lower energy. In the latter case, addition of excess $\mathrm{H}^{+}$only resulted in the formation of sub-stoichiometric amounts of hydrazine (0.17 equiv.) while the addition of $\mathrm{H}^{+}$and electrons increased the yield up to 0.47 equiv. The neutral $\mathrm{Fe}-\mathrm{N}_{2}$ complexes could be further reduced to the anionic $\mathrm{Fe}^{0}-\mathrm{N}_{2}$ derivatives. Protonation of the $\left[\left[\mathrm{SiP}_{3}^{\mathrm{iPr}}\right] \mathrm{Fe}\left(\mathrm{N}_{2}\right)\right]^{-}$at $-78^{\circ} \mathrm{C}$ did not result in $\mathrm{NH}$ bond formation but rather in reduction to the $\left[\left[\mathrm{SiP}_{3}{ }_{3}^{\mathrm{Pr}}\right] \mathrm{Fe}\left(\mathrm{N}_{2}\right)\right]$ complex, via competitive $\mathrm{H}_{2}$ production. On the other hand, $\mathrm{N}-\mathrm{Si}$ bond formation occurred efficiently yielding $\left[\left[\mathrm{SiP}_{3}^{i \mathrm{Pr}}{ }_{3}\right] \mathrm{Fe}\left(\mathrm{NNSiR}_{3}\right)\right]$ $(\mathrm{R}=\mathrm{Me}, \mathrm{Ph}, i \mathrm{Pr}) .{ }^{281}$ Mössbauer and DFT calculations concur to define the complex as a $\mathrm{Fe}^{0}$ center with strong back donation to the $\pi^{*}$ system of $\mathrm{N}_{2} \mathrm{SiR}_{3}{ }^{+}$. The $\left[\left[\mathrm{SiP}_{3}^{\mathrm{iPr}}\right] \mathrm{Fe}\left(\mathrm{N}_{2}\right)\right]$ 
complex was used as pre-catalyst for the catalytic NN coupling of azides into azoarene. ${ }^{282}$ The first step of the transformation involves $\mathrm{N}_{2}$ displacement by arylazide prior to imide formation. In the absence of arylazide, under $\mathrm{N}_{2}$, the imide evolves back to the $\mathrm{Fe}-\mathrm{N}_{2}$ complex via ArNNAr formation.

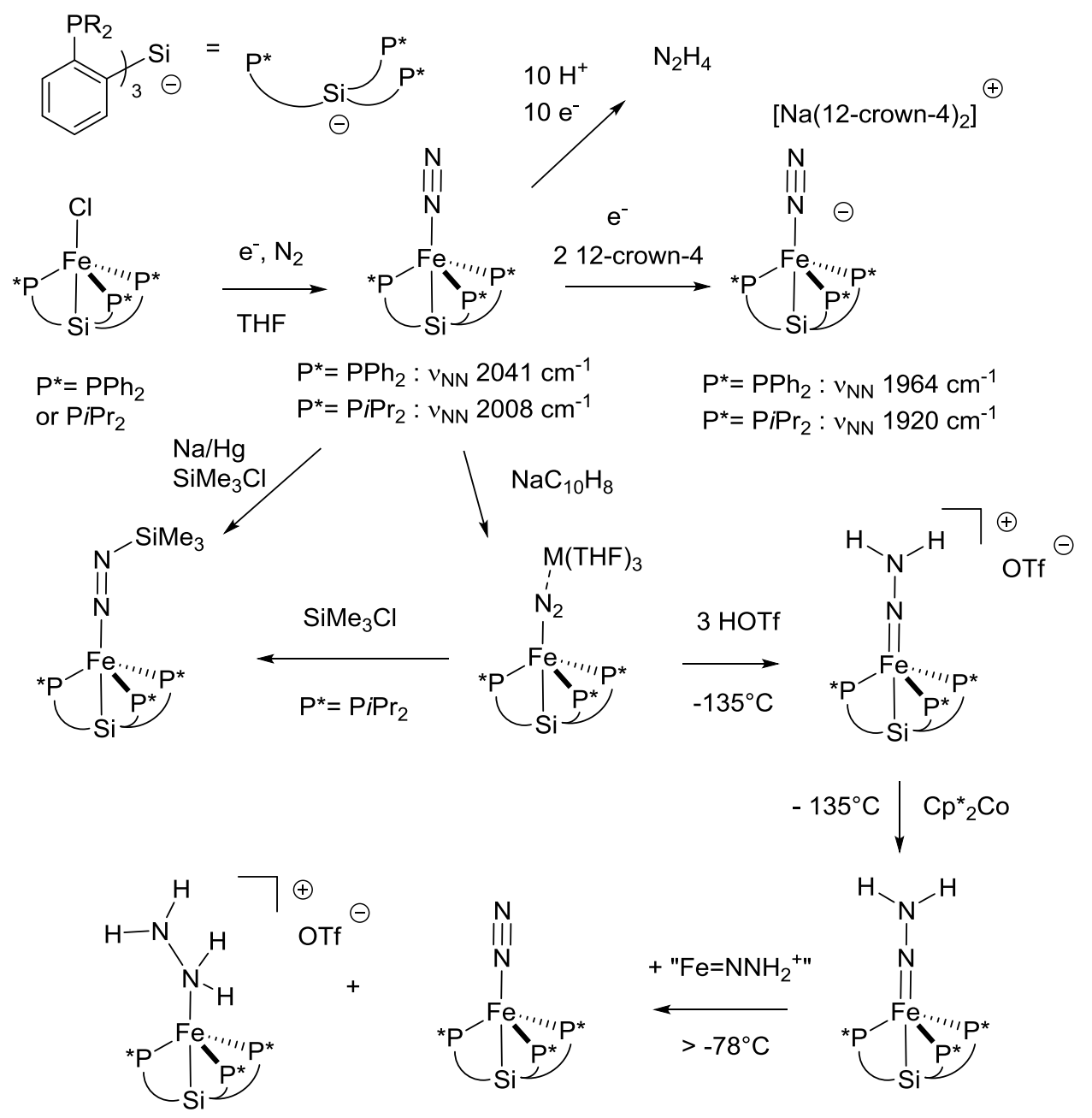

Scheme 77

In subsequent studies, conditions to favor $\mathrm{NH}$ bond formation related to catalytic $\mathrm{NH}_{3}$ production as well as NC bond formation were evaluated. Protonation of the $\left[\left[\mathrm{SiP}_{3}^{i \mathrm{Pr}}\right] \mathrm{Fe}\left(\mathrm{N}_{2}\right)\right] \mathrm{K}(\mathrm{THF}) \mathrm{x}$ at very low temperature $\left(-135^{\circ} \mathrm{C}\right)$ with excess $\mathrm{H}^{+}$sources was required to yield the desired $\left[\left[\mathrm{SiP}_{3}^{i \mathrm{Pr}}\right] \mathrm{Fe}\left(=\mathrm{NNH}_{2}\right)\right]^{+}$complex while alkylation with 
MeOTf to form $\left[\left[\mathrm{SiP}_{3}{ }_{3}^{i \mathrm{Pr}}\right] \mathrm{Fe}\left(=\mathrm{NNMe}_{2}\right)\right]^{+}$was successful at $-78^{\circ} \mathrm{C}^{283}$ Both complexes could be reduced by one electron to form the corresponding $\left[\left[\mathrm{SiP}_{3}^{i \mathrm{Pr}}{ }_{3}\right] \mathrm{Fe}\left(=\mathrm{NNR}_{2}\right)\right]$ derivatives $(\mathrm{R}=\mathrm{H}, \mathrm{Me})$. The $\left[\left[\mathrm{SiP}^{i \mathrm{iPr}}{ }_{3}\right] \mathrm{Fe}\left(=\mathrm{NNH}_{2}\right)\right]$ complex, synthesized at $-135^{\circ} \mathrm{C}$ and characterized at low temperature by EPR spectroscopy, reacts readily at $-78^{\circ} \mathrm{C}$ with $\left[\left[\mathrm{SiP}_{3}^{\mathrm{Pr}}\right] \mathrm{Fe}\left(=\mathrm{NNH}_{2}\right)\right]^{+}$via $\mathrm{H}^{\circ} / \mathrm{H}+$ transfer to form the $\left[\left[\mathrm{SiP}_{3}^{i \mathrm{Pr}}{ }_{3}\right] \mathrm{Fe}\left(\mathrm{NH}_{2} \mathrm{NH}_{2}\right)\right]^{+}$hydrazine and $\left[\left[\mathrm{SiP}_{3}^{i \mathrm{Pr}}\right] \mathrm{Fe}\left(\mathrm{N}_{2}\right)\right]$ complexes. Overall, these studies provide a very precise understanding on the sequence of protonation/reduction of $\mathrm{N}_{2}$ at the $\left[\mathrm{SiP}_{3}^{\mathrm{iPr}}\right] \mathrm{Fe}$ fragment, where a distal intermediate " $\mathrm{Fe}=\mathrm{NNH}_{2}$ " is formed first, followed by reduction/disproportionation to an alternating derivative " $\mathrm{Fe}\left(\mathrm{NH}_{2} \mathrm{NH}_{2}\right)$ " that finally serves as a source of $\mathrm{NH}_{3}$ via late stage $\mathrm{NN}$ bond cleavage. ${ }^{281}$ Notably, the same ligand was studied in the frame of cyanide reduction, $\mathrm{CN}^{-}$being isoelectronic to $\mathrm{N}_{2} \cdot{ }^{284,285} \mathrm{In}$ 2017, additional $\mathrm{N}$ donor moieties (amines) were incorporated in the " $\mathrm{SiP}_{3}$ " ligand in order to evaluate secondary-sphere interactions in the catalytic $\mathrm{N}_{2}$ fixation. It did not prove efficient because of kinetically facile $\mathrm{Fe}-\mathrm{H}$ formation. ${ }^{286}$ In parallel to studies dedicated to $\mathrm{Fe}$, the coordination to $\mathrm{Ru}$ and $\mathrm{Os}$ was evaluated. Thus, the $\left.\left[\mathrm{SiP}_{3}^{i \mathrm{Pr}}\right] \mathrm{M}\left(\mathrm{N}_{2}\right)\right]$ $(\mathrm{M}=\mathrm{Ru}, \mathrm{Os}) \mathrm{M}^{\mathrm{I}}$ complexes were synthesized via the one electron reduction of the $\mathrm{M}^{\mathrm{II}}$ precursor. ${ }^{287}$ They featured NN stretches at 2088 and $2052 \mathrm{~cm}^{-1}$. The Ru complex could be oxidized and reduced by one electron to $\mathrm{Ru}^{\mathrm{II}}$ and $\mathrm{Ru}^{0}$, while the Os could be reduced to $\mathrm{Os}^{0}$. The $\left[\left[\mathrm{SiP}_{3}^{i \mathrm{Pr}}\right] \mathrm{Ru}\left(\mathrm{N}_{2}\right)\right]$ complex is a catalyst in the N-N coupling of arylazides to form azoarenes. ${ }^{288}$ Mechanistic studies point a different pathway than with $\mathrm{Fe}$, with formation of free arylnitrene during catalysis. The $\mathrm{M}^{0}\left[\left[\mathrm{SiP}_{3}^{i \mathrm{Pr}}\right] \mathrm{M}\left(\mathrm{N}_{2}\right)\right]^{-}$complexes were tested in 2017 in the $\mathrm{N}_{2}$ reduction reaction. Using knowledge gained with the $\left[\mathrm{BP}_{3}\right]$ ligand system, vide infra, anilinium/ $\mathrm{Cp}^{*}{ }_{2} \mathrm{Co}$ couple was shown to be optimal and up to 
120 equiv. of $\mathrm{NH}_{3}$ per Os center were produced (1500 equiv. acid, 1800 equiv. reductant) exceeding the best results with Fe catalysts. ${ }^{289}$

The group of Peters also developed tetradentate $\left[\mathrm{CP}_{3}\right]^{-}$to probe $\mathrm{Fe}-\mathrm{N}_{2}$ functionalization. With $\left[\mathrm{C}^{\mathrm{Si}} \mathrm{P}_{3}\right]^{-}$, the diamagnetic $\left[\left[\mathrm{C}^{\mathrm{Si}} \mathrm{P}_{3}^{\mathrm{Ph}}{ }_{3}\right] \mathrm{Fe}\left(\mathrm{N}_{2}\right)\right][\mathrm{K}$ (benzo-15-C-5) $]$ complex $\left(v_{\mathrm{NN}} 1927 \mathrm{~cm}^{-1}\right)$ was obtained from the reduction of the $\left[\left[\mathrm{C}^{\mathrm{Si}} \mathrm{P}^{\mathrm{Ph}}{ }_{3}\right] \mathrm{Fe}\right] \mathrm{Fe}^{\mathrm{I}}$ complex (scheme 78). Functionalization of $\mathrm{N}_{2}$ at the terminal position required the use of a highly encumbered silylating agent, $\operatorname{Si}\left(i \operatorname{Pr}_{3}\right) \mathrm{OTf}$ at $-78{ }^{\circ} \mathrm{C}$, resulting in one phosphine arm decoordination. The diazenido ligand features an elongated NN bond length of 1.203(2) $\AA^{290}$ Similar chemistry was carried out with the $\mathrm{C}$ analogue of the $\left[\mathrm{SiP}_{3}\right]^{-}$ ligand. Thus, reduction of the $\left[\left[\mathrm{CP}_{3}^{i \mathrm{Pr}}\right] \mathrm{FeCl}\right]$ complex over $\mathrm{Na}$ mirror yielded the neutral $\left[\left[\mathrm{CP}_{3}^{i \mathrm{Pr}}\right] \mathrm{Fe}\left(\mathrm{N}_{2}\right)\right] \mathrm{Fe}^{\mathrm{I}}$ complex, while reaction with an excess of $\mathrm{KC}_{8}$ produced the $\mathrm{Fe}^{0}$ complex $\left[\left[\mathrm{CP}_{3}^{i \mathrm{Pr}}\right] \mathrm{Fe}\left(\mathrm{N}_{2}\right)\right]\left[\mathrm{K}\left(\mathrm{OEt}_{2}\right)_{3}\right]$. The silyl diazenido complex $\left[\left[\mathrm{CP}_{3}^{\mathrm{iPr}}\right] \mathrm{Fe}\left(\mathrm{N}_{2} \mathrm{SiMe}_{3}\right)\right]$ was obtained by trapping of the anionic complex, and impressively, treatment of the same complex at $-78^{\circ} \mathrm{C}$ with an excess of electron and proton sources (40 equiv $\mathrm{KC}_{8}$ and 38 equiv $\left.\left[\mathrm{H}\left(\mathrm{Et}_{2} \mathrm{O}\right)_{2}\right]\left[\mathrm{BAr}_{4}{ }_{4}\right]\right)$ provided the second case of a catalytic $\mathrm{N}_{2}$ reduction, with 4.6 equiv. of $\mathrm{NH}_{3}$ produced. ${ }^{291}$ 


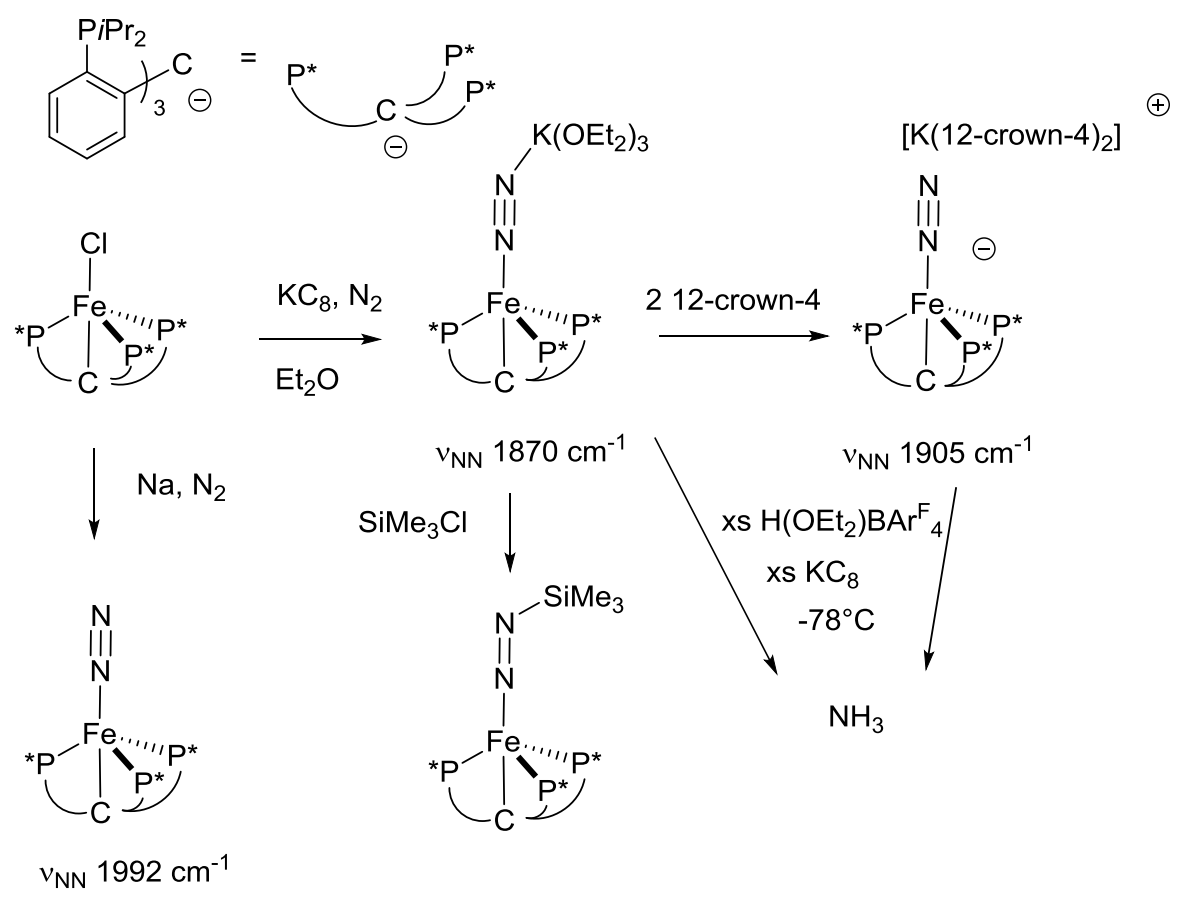

Scheme 78

Modification of the ligand scaffold to replace the anionic Si or C moieties by neutral B center was achieved. The corresponding " $\left[\mathrm{BP}_{3}\right] \mathrm{Fe}$ " system is probably the most studied in the frame of $\mathrm{N}_{2}$ functionalization. Thus, in 2011, Moret and Peters reported the synthesis of the $\mathrm{Fe}^{\mathrm{I}}$ complex $\left[\left[\mathrm{BP}_{3}\right] \mathrm{FeBr}\right]$ and its reduction to the neutral and anionic $\mathrm{N}_{2}$ complexes $\left[\left[\mathrm{BP}_{3}\right] \mathrm{Fe}\left(\mathrm{N}_{2}\right)\right]$ and $\left[\left[\mathrm{BP}_{3}\right] \mathrm{Fe}\left(\mathrm{N}_{2}\right)\right] \mathrm{Na}($ Scheme 79$) .{ }^{292,293}$ The latter features a stretching band at $1879 \mathrm{~cm}^{-1}$ in the solid state, while in solution a mixture of $\mathrm{Na}$ coordinated and ion pair species are seen $\left(v_{\mathrm{NN}}\right.$ at 1877 and $\left.1918 \mathrm{~cm}^{-1}\right)$. Trapping of the anionic complex with $\mathrm{SiMe}_{3} \mathrm{Cl}$ resulted in the formation of the silyldiazenido derivative $\left[\left[\mathrm{BP}_{3}\right] \mathrm{Fe}\left(\mathrm{NNSiMe}_{3}\right)\right]$ which could be further reduced to $\left[\left[\mathrm{BP}_{3}\right] \mathrm{Fe}\left(\mathrm{NNSiMe}_{3}\right)\right] \mathrm{Na}$. In that case, decoordination of a phosphine moiety is evidenced. If the anion is reacted with a bis-chlorosilane, then the bissilylhydrazido $\mathrm{Fe}^{\mathrm{II}}$ derivative is synthesized. Notably, in that case, the FeB bond elongates significantly, which illustrates the flexibility of the ligand in terms of electron acceptor capacity. Upon addition of tBuNC, a phosphine arm 
dissociates, which provokes a slow NN bond breaking process, resulting in N-B and N-P bond formation, as well as Fe-bissilylamido generation.
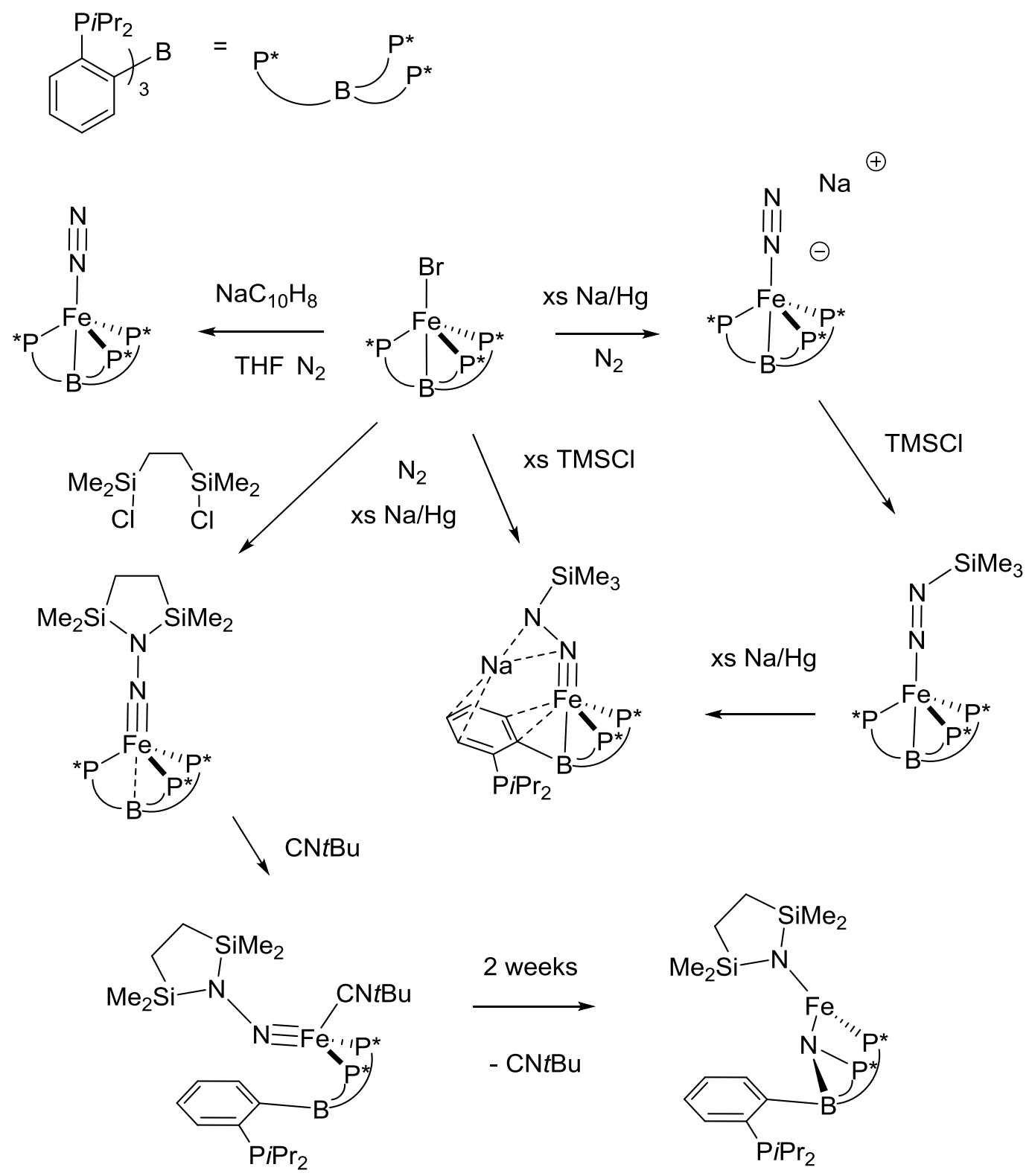

Scheme 79

In 2013, the same group discovered that the anionic Fe complex $\left[\left[\mathrm{BP}_{3}\right] \mathrm{Fe}\left(\mathrm{N}_{2}\right)\right][\mathrm{Na}(12-$ crown-4) $)_{2}$ is a catalyst for the reduction of $\mathrm{N}_{2}$ into $\mathrm{NH}_{3} \cdot{ }^{294}$ The catalytic performance is very sensitive to the nature of proton source $\left(\mathrm{HBAr}^{\mathrm{F}}{ }_{4}\right.$ required), reducing agent $\left(\mathrm{KC}_{8}\right.$ required) as well as temperature ( 7.0 equiv. per Fe complex at $\left.-78^{\circ} \mathrm{C}\right)$. Most notably, the 
complexes $\left[\left[\mathrm{BP}_{3}\right] \mathrm{Fe}\right]^{+},\left[\left[\mathrm{BP}_{3}\right] \mathrm{Fe}\left(\mathrm{NH}_{3}\right)\right]^{+}$and $\left[\left[\mathrm{BP}_{3}\right] \mathrm{Fe}\left(\mathrm{N}_{2} \mathrm{H}_{4}\right)\right]^{+}$all produce 6 equivalents of $\mathrm{NH}_{3}$ under the same catalytic conditions, demonstrating that they are likely intermediates in the catalytic cycle of $\mathrm{N}_{2}$ functionalization. ${ }^{295}$ Moreover, the complex $\left[\left[\mathrm{BP}_{3}\right] \mathrm{Fe}\left(\mathrm{NNH}_{2}\right)\right]^{+}$, was characterized at low temperature $\left(-135^{\circ} \mathrm{C}\right)$ from the double protonation of the anionic complex $\left[\left[\mathrm{BP}_{3}\right] \mathrm{Fe}\left(\mathrm{N}_{2}\right)\right]\left[\mathrm{Na}(12 \text {-crown-4) })_{2}\right] .{ }^{296}$ It was later shown that at least some of the catalyst $\left[\left[\mathrm{BP}_{3}\right] \mathrm{Fe}\left(\mathrm{N}_{2}\right)\right]\left[\mathrm{Na}(12 \text {-crown-4) })_{2}\right]$ was stable at low temperature, allowing significant increase of the $\mathrm{NH}_{3}$ yield upon successive reloading of substrates (up to 64 equiv. $\mathrm{NH}_{3}$ per Fe center at 1500 equiv. acid loading). ${ }^{297}$ Based on these results Peters presented a catalytic cycle for the $\mathrm{N}_{2}$-to- $\mathrm{NH}_{3}$ transformation using the " $\left[\mathrm{BP}_{3}\right] \mathrm{Fe}$ " system (scheme 80 ). ${ }^{297}$ In 2018, the same group evaluated by DFT calculations the competitive HER (hydrogen evolution reaction) and $\mathrm{N}_{2} \mathrm{RR}$ (nitrogen reduction reaction) with the three "[ $\left.\mathrm{EP}_{3}\right] \mathrm{Fe}$ " $(\mathrm{E}=\mathrm{B}, \mathrm{C}, \mathrm{Si})$ systems. ${ }^{298}$ They conclude that the comparative stability of the $\left[\mathrm{EP}_{3}\right] \mathrm{Fe}\left(\mathrm{NNH}_{2}\right)^{\mathrm{n}+}$ intermediates is one of the important factors in determining the selectivity for the $\mathrm{N}_{2} \mathrm{RR}$ versus HER. Recent developments have focused on improving the selectivity at lower driving force using other $\mathrm{H}^{+}$/electron sources. ${ }^{299}$ Anilinium/metallocenes provide PCET (proton coupled electron transfer) pathways whose efficiencies are linked to the pKa of the acid. ${ }^{300}$ 


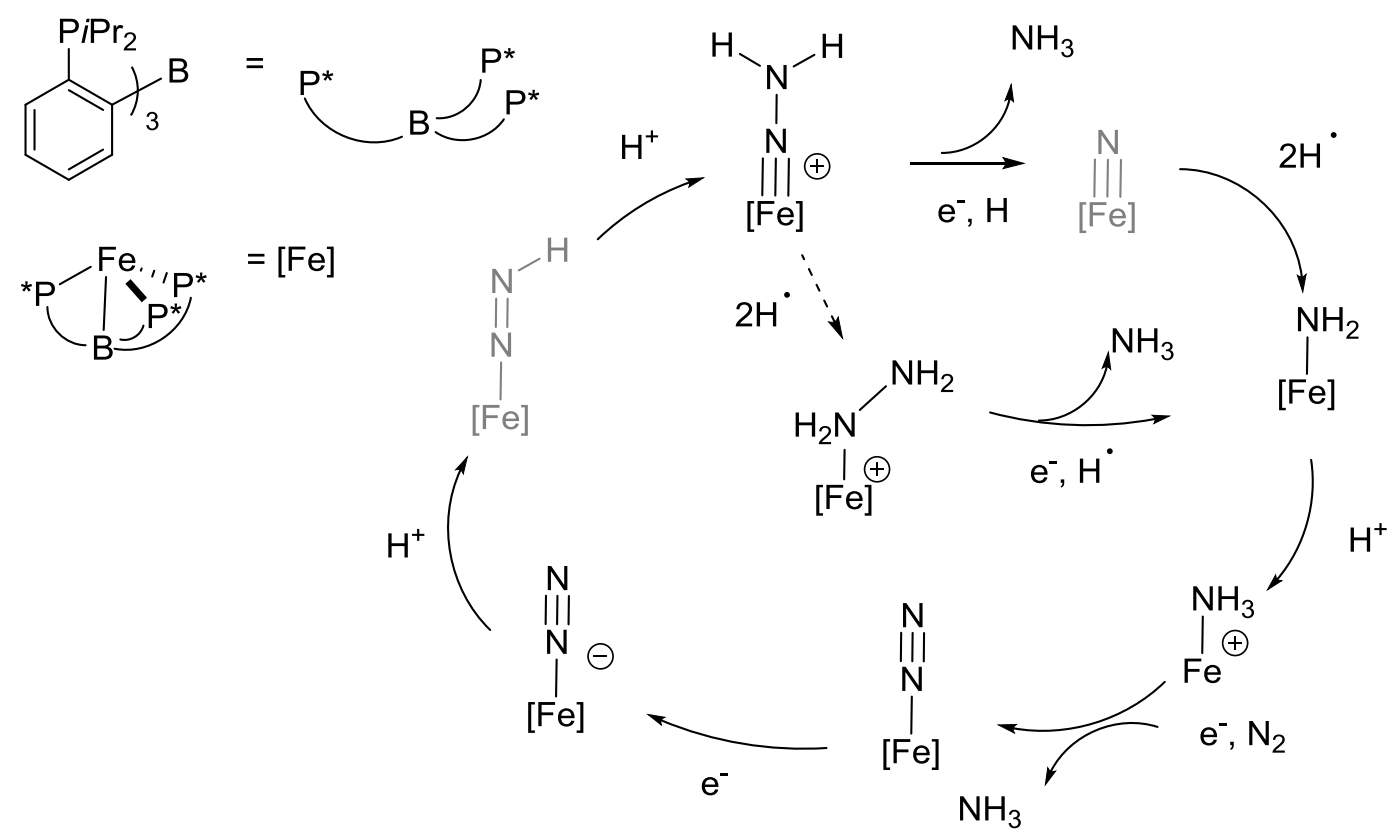

Scheme 80

The group of $\mathrm{Lu}$ has introduced in 2011 a trisphosphino-(triamido)amine $\left[\mathrm{NN}_{3} \mathrm{P}_{3}\right]^{3-}$ ligand capable to enforce M-M' interaction. Coordination of "Altraphos" to Fe ${ }^{\mathrm{II}}$ followed by reduction under $\mathrm{N}_{2}$ allowed the synthesis of $\mathrm{Fe}^{0}-\mathrm{N}_{2}$ complex $\left[\left[\mathrm{NN}_{3} \mathrm{P}_{3}\right] \mathrm{AlFe}\left(\mathrm{N}_{2}\right)\right]$, in equilibrium with its dimeric form via $\mathrm{N}_{2}$ bridging (scheme 81 ). ${ }^{301}$ One electron reduction can be achieved, which further activates $\mathrm{N}_{2}$ and trapping with a bis-chlorosilane results in the isolation of the diamagnetic, low-spin $\mathrm{Fe}^{\mathrm{II}}$ disilyl-hydrazido complex, "FeNN $\left(\mathrm{SiMe}_{2} \mathrm{CH}_{2}\right)_{2} "$. 302 

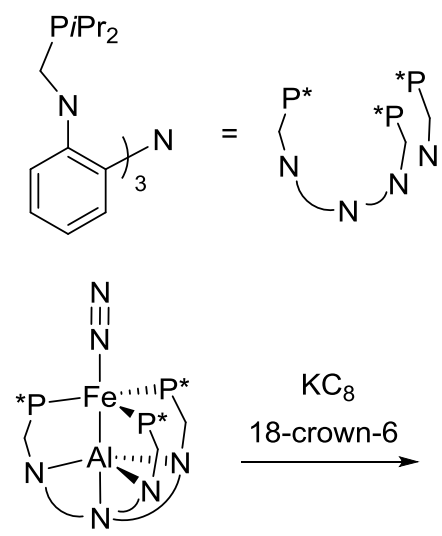

$v_{\mathrm{NN}} 2010 \mathrm{~cm}^{-1}$

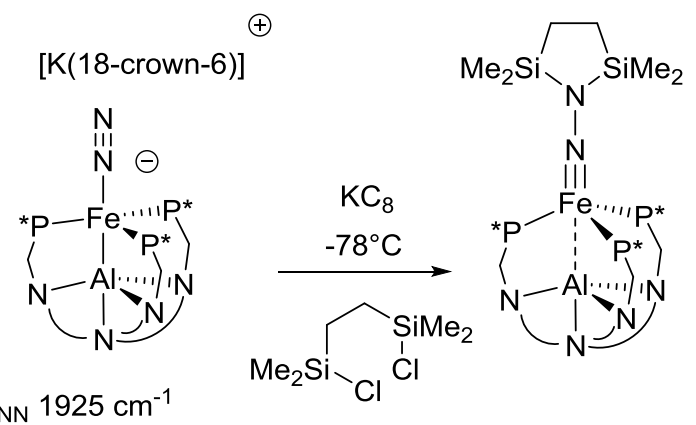

Scheme 81

Ligands based on related scaffolds, designed to favor bimetallic systems and/or incorporate $\mathrm{S}$ binding moieties were developed by the group of Peters (scheme 82). ${ }^{303,304,305,306}$ If the desired Fe- $\mathrm{N}_{2}$ complexes could be synthesized, the successes in functionalization was limited. 
<smiles>[R]Sc1ccccc1[Si](C)C[PH3+]</smiles>

$\mathrm{R}=\mathrm{Ad}, \mathrm{iPr}$

2011, 2018

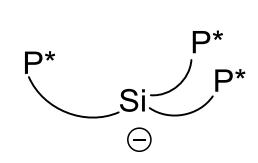

$=\gamma_{3}^{\mathrm{Si}} \Theta$

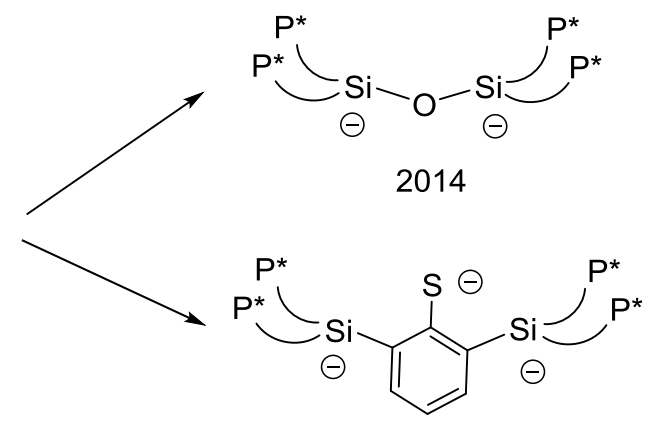

2015

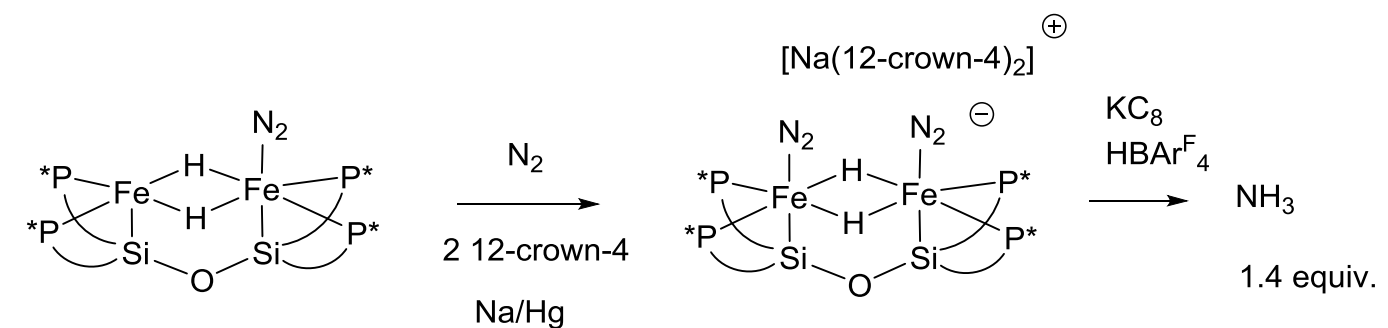

$\mathrm{Na} / \mathrm{Hg}$

[Na(12-crown-4) $)_{2}{ }^{\oplus}$

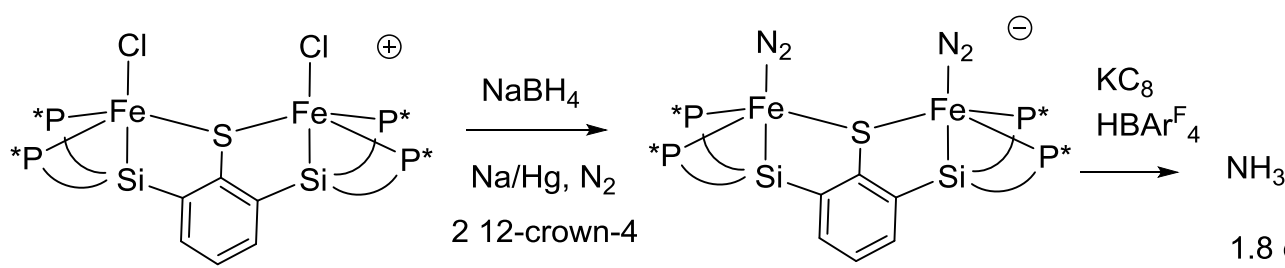

1.8 equiv.

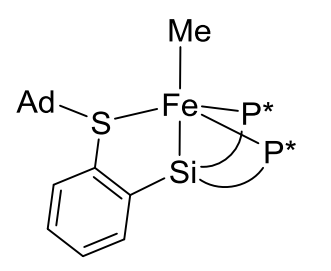<smiles>[123I-]</smiles>

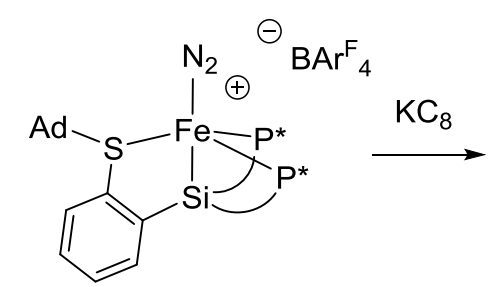

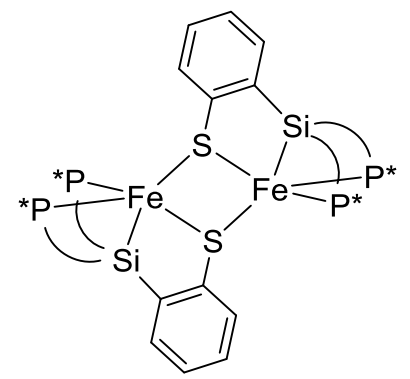<smiles>CC(C)Sc1c(-c2ccccc2)cccc1[Si](C[PH2+])(C[PH3+])C[PH3+]</smiles>
0.5

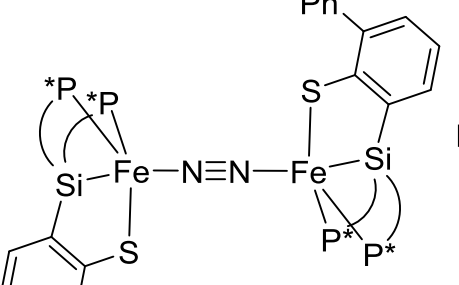<smiles>CCCCCCC</smiles>

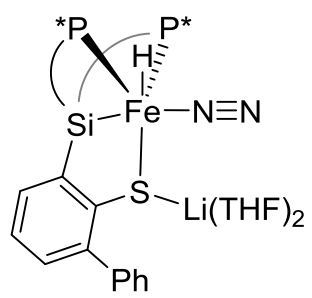

Scheme 82

Iron complexes of tridentate anionic $\left[\mathrm{SiP}_{2}\right]^{-}$ligand were studied in 2017 by Nishibayashi, in link with the possible involvement of $\left[(\mathrm{THF}) \mathrm{Fe}\left(\mathrm{SiMe}_{3}\right)_{2}\left(\mathrm{~N}_{2}\right)\right]$ as intermediate in the $\mathrm{N}_{2}$ 
to $\mathrm{N}\left(\mathrm{SiMe}_{3}\right)_{3}$ reduction by $\mathrm{Cp}_{2} \mathrm{Fe}$ or $\mathrm{Fe}(\mathrm{CO})_{5} .{ }^{307}$ Thus, $\left[\left[\mathrm{Si}^{\mathrm{R}} \mathrm{P}_{2}\right] \mathrm{Fe}(\mathrm{H})\left(\mathrm{PMe}_{3}\right)\left(\mathrm{N}_{2}\right)\right]$ complexes were synthesized and evaluated as catalysts (scheme 83). ${ }^{308}$

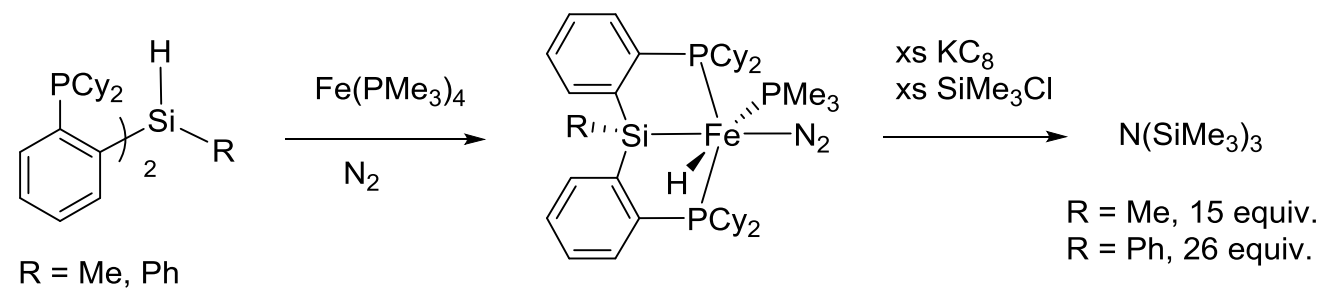

Scheme 83

Iron dinitrogen complexes of anionic tridentate ligands featuring both amido and phosphine moieties have been studied recently. In 2015, Mindiola reported that minor amounts of a heterobimetallic FeMg- $\mathrm{N}_{2}$ complex are formed when an excess of $\mathrm{EtMgCl}$ is reacted with [[PNP] $\mathrm{FeCl}]$ under $\mathrm{N}_{2}$ (scheme 84 ).
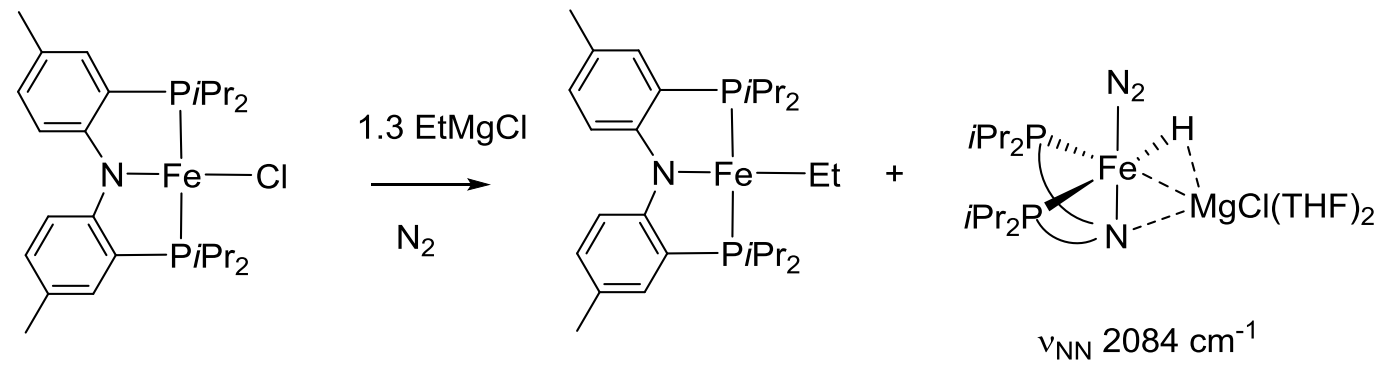

Scheme 84

In 2016, the group of Nishibayashi expanded the chemistry of [PNP] pincer ligands with a central pyrrolide moiety toward $\mathrm{Fe}$ (scheme 85 ). ${ }^{309}$ They obtained $\mathrm{Fe}^{\mathrm{I}}-\mathrm{N}_{2}$ complex upon reduction of the $[[\mathrm{PNP}] \mathrm{FeCl}]\left(\left[\mathrm{PN}^{\mathrm{R}} \mathrm{P}\right]=2,5\right.$-bis(di- $t \mathrm{Bu}-$ phosphinomethyl)pyrrolide $)$, or by protonation of the hydride or methyl derivative followed by reduction. A $v_{\mathrm{NN}}$ band at $1964 \mathrm{~cm}^{-1}$ assignable to terminal $\mathrm{N}_{2}$ was found in the IR spectrum. This complex is a competent catalyst in $\mathrm{NH}_{3}$ synthesis only when $\left[\mathrm{H}\left(\mathrm{OEt}_{2}\right)_{2}\right] \mathrm{BAr}_{4}^{\mathrm{F}}$ and $\mathrm{KC} 8$ were used as proton source and reducing agent, at low temperature $\left(-78^{\circ} \mathrm{C}\right)$. Under optimized conditions, up to 14.3 equivalents of $\mathrm{NH}_{3}$ are formed together with 1.8 equivalent of 
hydrazine. In a subsequent study, they evaluated the effect of the electronics of the pyrrolide ligand on the efficiency of the catalysis. ${ }^{310}$ They found out that more electron rich ligand increased the yield of $\mathrm{NH}_{3}$ by $50 \%$ (up to 22.7 equiv for dimethylpyrrolide $v \mathrm{~s}$ 14.3 for pyrrolide). In light of the facile protonation at the pyrrolide moiety, the same authors modified the ligand structure to incorporate a carbazole ring. ${ }^{311}$ However, the corresponding $\mathrm{Fe}-\mathrm{N}_{2}$ complex did not prove efficient (0.5 equiv. $\left.\mathrm{NH}_{3}\right)$. The corresponding $\quad\left[\left[\mathrm{PN}^{\mathrm{R}} \mathrm{P}\right] \mathrm{FeMe}\right] \quad\left(\left[\mathrm{PN}^{\mathrm{R}} \mathrm{P}\right]=2,5\right.$-bis $(\mathrm{di}-t \mathrm{Bu}-$ phosphinomethyl $)(3,6$-di$t \mathrm{Bu}$ )carbazole) did produce up to 3.2 equiv. $\mathrm{NH}_{3}$ (80 equiv. $\mathrm{KC}_{8}, 78$ equiv. $\mathrm{HBAr}_{4}^{\mathrm{F}}$, $\left.78^{\circ} \mathrm{C}, \mathrm{Et}_{2} \mathrm{O}\right)$

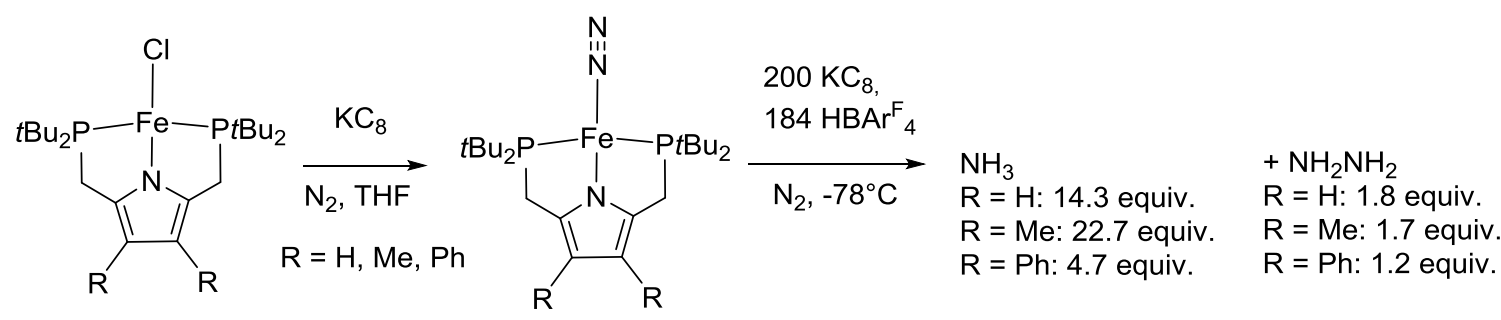

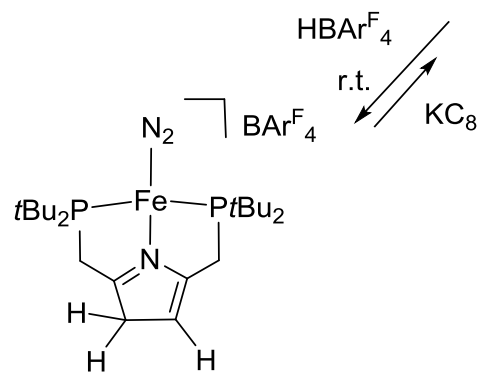

poor catalyst

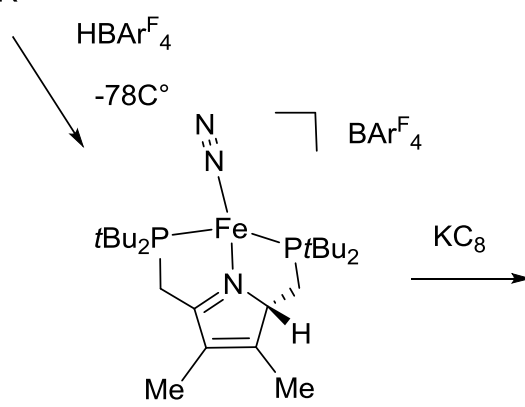

Me

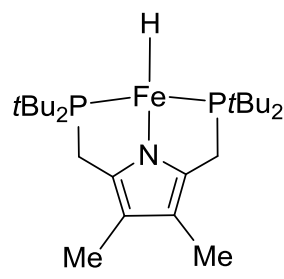

$52 \%$

Scheme 85

Caulton reported in 2007 the hydrogenation of $\mathrm{N}_{2} \mathrm{O}$ by the [[PNP]Os $\left.(\mathrm{H})_{3}\right]([\mathrm{PNP}]$ $\left.=\mathrm{N}\left(\mathrm{SiMe}_{2} \mathrm{CH}_{2} \mathrm{P}_{\mathrm{Bu}}\right)_{2}\right)$ complex. ${ }^{312}$ In addition to water, the reaction yielded the $\left[[\mathrm{PNP}] \mathrm{Os}(\mathrm{H})\left(\mathrm{N}_{2}\right)\right]$ complex, characterized by a high field hydride $(-34.8 \mathrm{ppm})$ in ${ }^{1} \mathrm{H}$ NMR, as well as a $v_{\mathrm{NN}}$ stretch at $2003 \mathrm{~cm}^{-1}$ in the IR spectrum. 
Fryzuk, Masuda and coworkers developed an anionic [PNN] ligand that features an iminophosphorane unit $\left(\mathrm{R}_{3} \mathrm{P}=\mathrm{N}-\mathrm{R}\right)$, an electron-rich phosphine, and an amide (scheme 86). They reported that the reduction of the corresponding $\mathrm{Fe}^{\mathrm{II}}$ complex $[[\mathrm{PNN}] \mathrm{FeBr}]$ under $\mathrm{N}_{2}$ yielded the $\mathrm{N}_{2}$ bridging dimer. ${ }^{313}$ The $\mathrm{NN}$ bond distance is elongated to $1.184(6) \AA$ and the $v_{\mathrm{NN}}$ stretch is found at $1755 \mathrm{~cm}^{-1}$ in the Raman spectrum, at lower energy compared to the Nacnac complexes reported by Holland (vide infra). The solution-state magnetic moment indicates six unpaired electrons, while the Mössbauer is consistent with $\mathrm{Fe}^{\mathrm{II}}$ centers. Together, these data support antiferromagnetic coupling between $\mathrm{N}_{2}{ }^{2-}$ and the two $\mathrm{Fe}^{\mathrm{II}}$ centers.

2

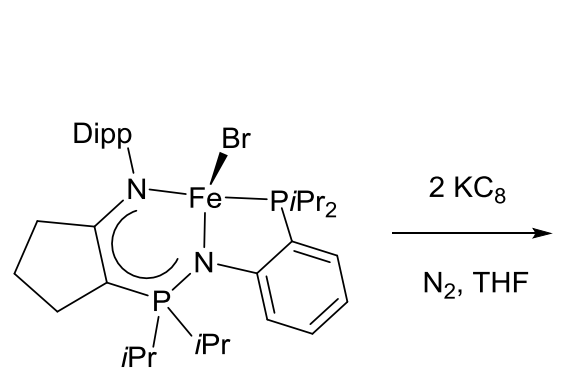

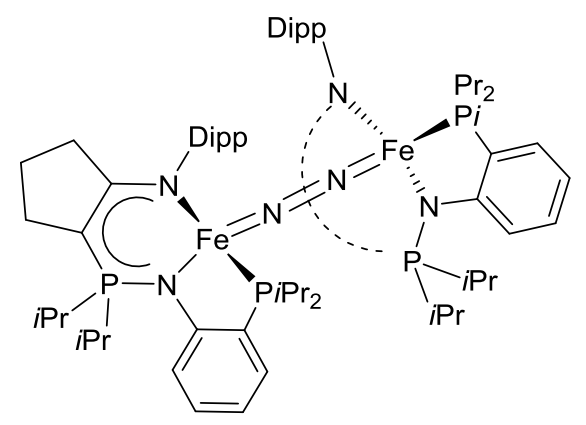

Scheme 86

The coordination chemistry of tetradentate phosphine based ligands, $\left[\mathrm{NP}_{3}\right]$ and $\left[\mathrm{PP}_{3}\right]$ toward group 8 metals date back to Sacconi's work in the mid 70s. In 2005, Peters has reported novel, bulky examples of $\left[\mathrm{NP}_{3}\right]$ ligands and their coordination to $\mathrm{Fe}^{\mathrm{II}}$. Following a similar route, the $\left[\left[\mathrm{NP}_{3}^{i \mathrm{Pr}}\right] \mathrm{Fe}\left(\mathrm{N}_{2}\right)(\mathrm{H})\right]\left[\mathrm{PF}_{6}\right]$ complex could be obtained. ${ }^{314}$ Coordination of bulky tetradentate $\left[\mathrm{PP}_{3}\right]$ ligands to $\mathrm{Fe}^{\mathrm{II}}$ and $\mathrm{Ru}^{\mathrm{II}}$ centers was studied by Field, as well as their reduction under $\mathrm{N}_{2}$ (scheme 87). ${ }^{315}$ The diamagnetic, trigonal bipyramidal, $\left[\left[\mathrm{PP}_{3}^{\mathrm{R}}\right] \mathrm{M}\left(\mathrm{N}_{2}\right)\right]$ complexes were fully characterized. Functionalization of $\mathrm{N}_{2}$ was attempted with mildly acidic lutidinium, but the metal-hydride- $\mathrm{N}_{2}$ complexes were observed instead. Deprotonation regenerated the $\mathrm{M}(0)$ complexes. ${ }^{316}$ Deprotonation of 
the cationic hydrazine complex $\left[\left[\mathrm{PP}_{3}^{i \mathrm{Pr}}\right] \mathrm{Ru}\left(\mathrm{NH}_{2} \mathrm{NH}_{2}\right) \mathrm{Cl}\right]^{+}$provides another synthetic pathway to the $\mathrm{Ru}^{0}-\mathrm{N}_{2}$ complex, although it generates stoichiometric amounts of the $\mathrm{Ru}(\mathrm{H})_{2}$ derivative. ${ }^{317}$ Notably, when the more bulky $\left[\mathrm{PP}_{3}^{\mathrm{tBu}}{ }_{3}\right]$ ligand was used, only tridentate coordination was observed. ${ }^{318}$

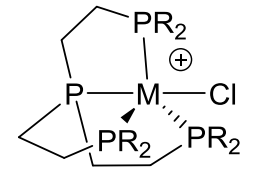

$M=F e, T B P$ $M=R u, S P$

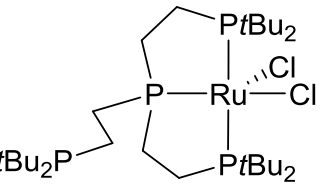

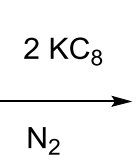

$\mathrm{R}=\mathrm{iPr}, \mathrm{Cy}$

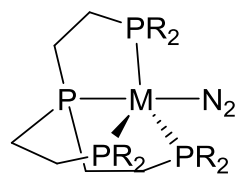

$M=F e, R u T B P$

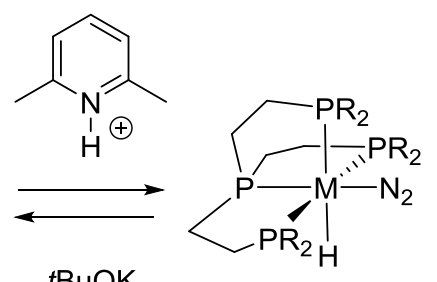

tBuOK
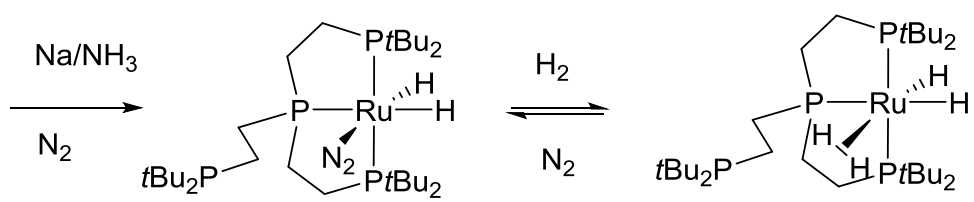

Scheme 87

In 2017, Dzik, de Bruin, Reetz and coworkers studied the coordination of a novel $\left[\mathrm{PP}^{\mathrm{Ph}}{ }_{3}\right]$ ligand, based on indole ring, to $\mathrm{Ru}$. Stepwise reduction of the $\left[\left[\mathrm{PP}_{3}^{\mathrm{Ph}}\right] \mathrm{RuCl}_{2}\right]$ yielded the $\mathrm{Ru}^{\mathrm{I}}$ and $\mathrm{Ru}^{0}-\mathrm{N}_{2}$ complexes, featuring a $v_{\mathrm{NN}}$ at $2125 \mathrm{~cm}^{-1}$. 319

Also in 2017, Mock reported a series of Fe complexes bearing a rigid tetraphosphine ligand $\left[\mathrm{P}_{4} \mathrm{~N}_{2}\right]$, and in particular the first example of a square pyramidal complex $\left[\left[\mathrm{P}_{4} \mathrm{~N}_{2}\right] \mathrm{Fe}\left(\mathrm{N}_{2}\right)\right]\left(v_{\mathrm{NN}}\right.$ at $\left.2003 \mathrm{~cm}^{-1}\right)$ (scheme 88$) .{ }^{320}$ They quantified the affinity of $\mathrm{N}_{2}$

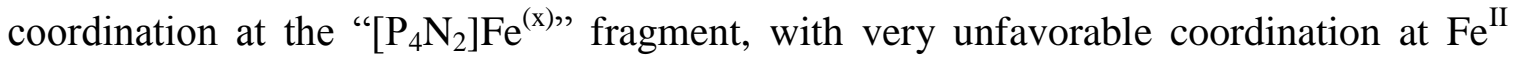
(>30 kcal $/ \mathrm{mol})$, favorable at $\mathrm{Fe}^{0}(-7 \mathrm{kcal} / \mathrm{mol})$ and reversible at $\mathrm{Fe}^{\mathrm{I}}(0.4 \mathrm{kcal} / \mathrm{mol})$. Under a high pressure of $\mathrm{N}_{2}(100 \mathrm{~atm})$, the $\left[\left[\mathrm{P}_{4} \mathrm{~N}_{2}\right] \mathrm{Fe}\left(\mathrm{N}_{2}\right)\right]$ complex is a competent catalyst in the $\mathrm{N}_{2}$ to $\mathrm{N}\left(\mathrm{SiMe}_{3}\right)_{3}$ transformation (up to 65 equiv. $\left.\mathrm{N}\left(\mathrm{SiMe}_{3}\right)_{3}\right)$. 


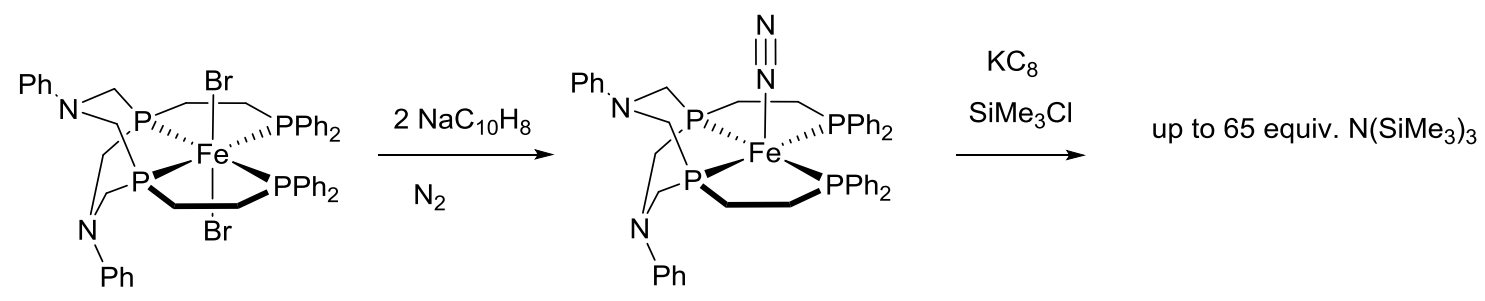

Scheme 88

The use of monodentate phosphines for the stabilization of group 8-dinitrogen complexes has been seldom reported. In fact, phosphine stabilized " $\mathrm{Fe}_{4}$ " and " $\mathrm{Fe}_{6}$ " clusters featuring bridging hydrides have been reported to be impressive catalysts in the $\mathrm{N}_{2}$ to $\mathrm{N}\left(\mathrm{SiMe}_{3}\right)_{3}$ transformation (up to 183 equiv. for the "Fe 6 " cluster). ${ }^{321}$ It is to be noted however that no intermediate with $\mathrm{Fe}-\mathrm{N}_{2}$ has been observed in these cases. Ruthenium complex $\left[\mathrm{Ru}(\mathrm{H})_{2}\left(\mathrm{PCy}_{3}\right)_{2}\left(\mathrm{~N}_{2}\right)_{2}\right]$ has been used to achieve $\mathrm{CH}$ and $\mathrm{CO}$ activation under mild conditions, thanks to easy $\mathrm{N}_{2}$ dissociation. ${ }^{322}$

\subsection{2 $\mathrm{N}$ based ligands}

The chemistry of $\mathrm{Fe}-\mathrm{N}_{2}$ complexes with " $\mathrm{N}$ based ligands" has been most extensively studied with two families, the neutral $[\mathrm{NNN}]$ and the anionic $[\mathrm{NN}]^{-}$ligands. The neutral [NNN] pyridine-diimine (PDI) ligands have been reported to stabilize $\mathrm{Fe}-\mathrm{N}_{2}$ by Chirik in 2004. Thus, reduction of the $\left[\mathrm{Fe}\left({ }^{i \mathrm{Pr}} \mathrm{PDI}\right) \mathrm{X}_{2}\right]\left({ }^{i \mathrm{Pr}} \mathrm{PDI}=2,6-\{\mathrm{MeC}=\mathrm{N}(2,6-i-\right.$ $\left.\left.\operatorname{Pr}_{2} \mathrm{C}_{6} \mathrm{H}_{3}\right)\right\}_{2} \mathrm{C}_{5} \mathrm{H}_{3} \mathrm{~N}$ ) under $\mathrm{N}_{2}$ resulted in the formation of the highly unusual paramagnetic formally $\mathrm{Fe}^{0}$ bis- $\mathrm{N}_{2}$ complex $\left[\mathrm{Fe}\left({ }^{i \mathrm{Pr}} \mathrm{PDI}\right)\left(\mathrm{N}_{2}\right)_{2}\right]$ (scheme 89$) .{ }^{323}$ The complex crystallized as distorted square based pyramid, and present minimal activation of the $\mathrm{N}_{2}$ ligands (by

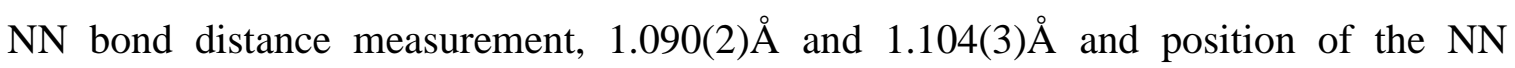
stretching bands in IR, at 2122 and $2058 \mathrm{~cm}^{-1}$ ) by the $\mathrm{d}^{8} \mathrm{Fe}$ center. Subsequent combined spectroscopic, structural, and computational studies have resulted in a comprehensive 
picture of the electronic structure of the complex, involving reduction of the PDI ligand to a dianionic $[\mathrm{PDI}]^{2-}$ fragment complexed to an intermediate spin ferrous ion, $\mathrm{Fe}^{\mathrm{II}}{ }^{324}$ In terms of reactivity, the two $\mathrm{N}_{2}$ ligands are readily displaced and the $\left[\mathrm{Fe}\left({ }^{i \mathrm{iPr}} \mathrm{PDI}\right)\left(\mathrm{N}_{2}\right)_{2}\right]$ complex acts as a masked unsaturated " $\mathrm{Fe}\left({ }^{i \mathrm{Pr}} \mathrm{PDI}\right)$ " fragment in many significant transformations. ${ }^{325}, 326,327,328,329,330,330,331,332,333,334,335,336,337338,339,340$

Budzelaar,

Gambarotta and coworkers showed in 2008 that reaction of the same $\left[\mathrm{Fe}\left({ }^{i \mathrm{Pr}} \mathrm{PDI}\right) \mathrm{Cl}_{2}\right]$ complex with excess $\mathrm{NaH}$ did form several reduced Fe- $\mathrm{N}_{2}$ complexes (scheme 89, bottom). ${ }^{341}$

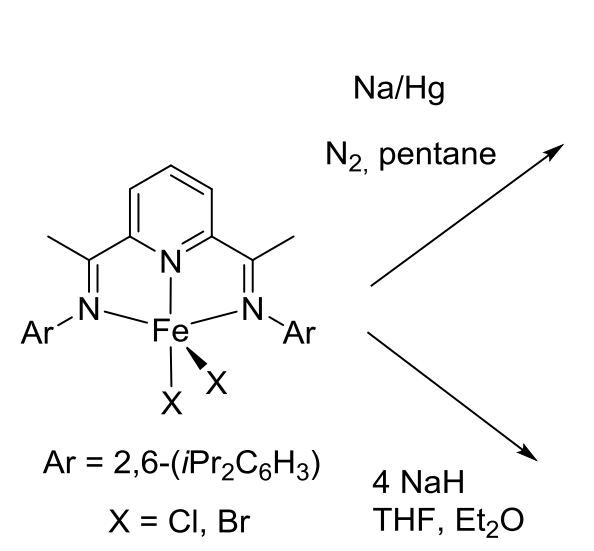

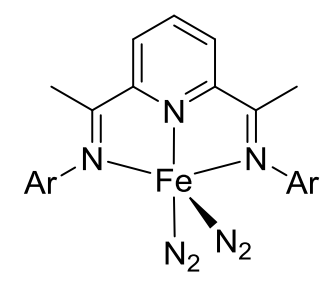

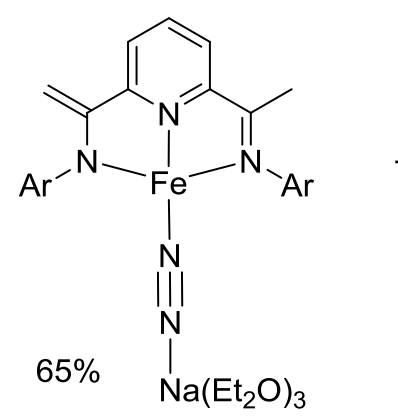
$20 \%$

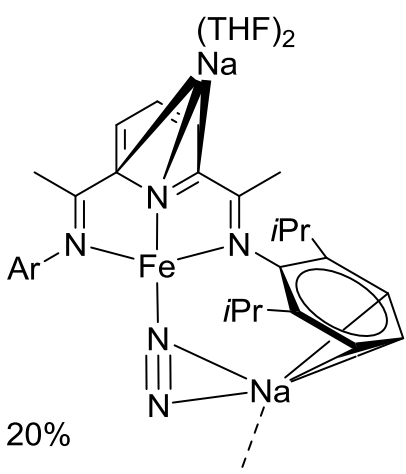

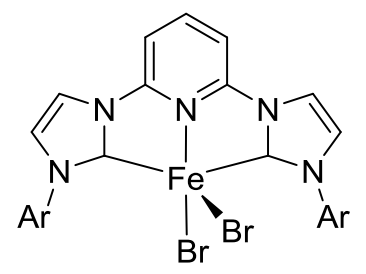<smiles>N#[W]N</smiles>

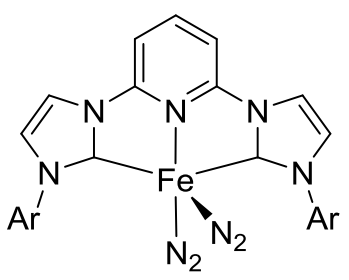

$$
\mathrm{Ar}=2,6-\left(\mathrm{Pr}_{2} \mathrm{C}_{6} \mathrm{H}_{3}\right)
$$

Scheme 89

At the same time Chirik reported the synthesis of the $\left[\mathrm{Fe}\left({ }^{i \mathrm{Pr}} \mathrm{PDI}\right)\left(\mathrm{N}_{2}\right)_{2}\right]$ complex, Danopoulos synthesized the related $\left[[\mathrm{CNC}] \mathrm{Fe}\left(\mathrm{N}_{2}\right)_{2}\right]$ complex $([\mathrm{CNC}]$ is a pyridine-bis- 
NHC ligand). ${ }^{342}$ In this case, because of the presence of the two NHC ligands, the complex is diamagnetic, and the $\mathrm{NN}$ stretching frequencies are measured at slightly lower wavelengths as expected $\left(2109\right.$ and $\left.2031 \mathrm{~cm}^{-1}\right)$. Electronic and steric ligand tuning was achieved from 2012 by Chirik, and the corresponding [[CNC] $\left.\mathrm{Fe}\left(\mathrm{N}_{2}\right)_{2}\right]$ are extremely active hydrogenation pre-catalysts. ${ }^{333},{ }^{343}$ In 2017 , the saturated version of the NHC ligand was reported, and the $\mathrm{Fe}-\mathrm{N}_{2}$ complex enables oxidative addition of $\mathrm{H}_{2}$ to $\mathrm{Fe}^{0}{ }^{344}$

High oxidation state "Os-Nitride" complexes of neutral $[\mathrm{NNN}]([\mathrm{NNN}]=$ terpy or tris-pyrrazolylmethane) have been studied by Meyer and Huynh from 1999 (scheme 90). ${ }^{345} \mathrm{~N}-\mathrm{N}$ bond formation to form $\mathrm{N}_{2}$ as ligand was demonstrated in a variety of reactions between the $\left[[\mathrm{NNN}] \mathrm{Os}(\mathrm{Cl})_{2}(\mathrm{~N})\right]^{+}$complexes and hydroxylamines $\left(\mathrm{H}_{2} \mathrm{NOH}\right.$ and $\mathrm{MeHNOH})$ and methoxylamines $\left(\mathrm{H}_{2} \mathrm{NOMe}\right.$ and $\left.\mathrm{MeHNOMe}\right)$ in $\mathrm{MeOH}$ at room temperature. ${ }^{346}$ A four electron reduction of the metal center occurs in this transformation. Intermediates featuring $\mathrm{NN}$ bonds have been observed during the transformations. Although not using polydentate ligands, the studies by Vogler need to be presented at this point, as they are related to the $\mathrm{NN}$ bond cleavage/formation at Os. Indeed, photolytic splitting of $\mathrm{N}_{2}$ in $\left[\left(\mathrm{NH}_{3}\right)_{5} \mathrm{Os}\left(\mu-\mathrm{N}_{2}\right) \mathrm{Os}\left(\mathrm{NH}_{3}\right)_{5}\right]^{5+}$ was achieved in aqueous medium. ${ }^{347}$ The mechanism involves an intramolecular photoredox process.

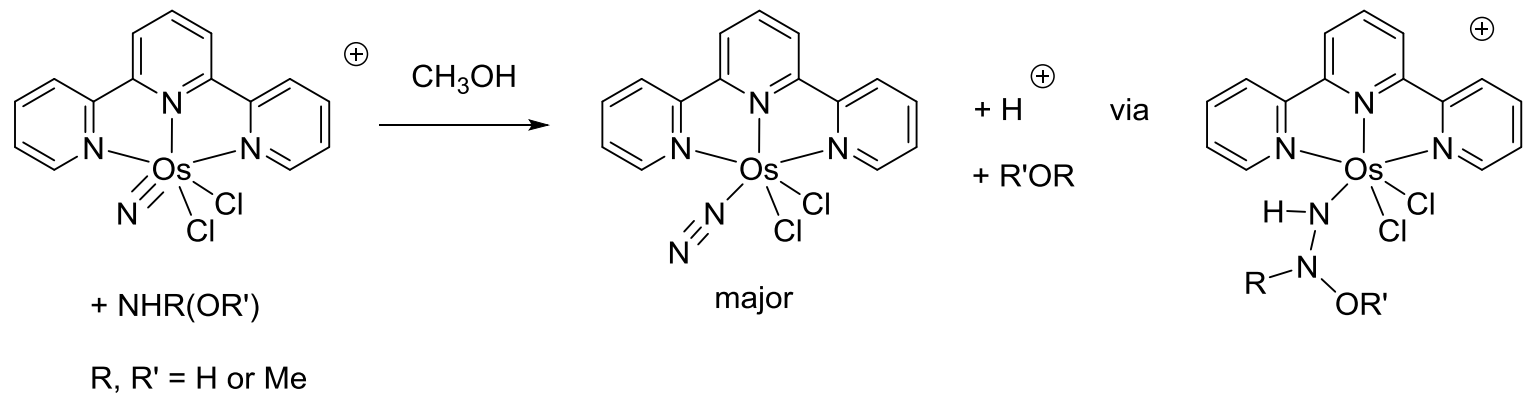
Scheme 90

In 2014, dinitrogen has been shown to displace $\mathrm{H}_{2}$ in dinuclear $\mathrm{Ru}^{\text {II }}$ polyhydride cationic 
complexes featuring the neutral [NNN] ligand 1,4,7-trimethyl-1,4,7-triazacyclononane. ${ }^{348}$

The other class of $\mathrm{N}$ ligands extensively studied in the frame of $\mathrm{N}_{2}$ fixation is the anionic $[\mathrm{NN}]^{-}$ligand $\beta$-diketiminate $\left(\mathrm{L}^{t \mathrm{Bu} \text {,dipp }}=\mathrm{CH}\left\{\mathrm{C}(t-\mathrm{Bu}) \mathrm{N}\left(2,6-i-\mathrm{Pr}_{2} \mathrm{C}_{6} \mathrm{H}_{3}\right)\right\}_{2}{ }^{-}\right)$, also known as Nacnac ligands. In 2001, Holland reported the reduction of $\left[\mathrm{Fe}\left(\mathrm{L}^{t \mathrm{Bu} \text {,dipp }}\right) \mathrm{Cl}\right]$ by one electron under $\mathrm{N}_{2}$ yielded the bimetallic bridging end-on complex $\left[\left\{\mathrm{Fe}\left(\mathrm{L}^{t \mathrm{Bu}, \mathrm{dipp}}\right)\right\}_{2}(\mu-\right.$ $\left.\left.\eta^{1}: \eta^{1}-\mathrm{N}_{2}\right)\right]\left(v_{\mathrm{NN}}=1778 \mathrm{~cm}^{-1}\right)$ shown to feature elongated $\mathrm{NN}$ bond $(1.182(5) \AA)($ scheme 91). ${ }^{349}$ The $\mathrm{N}_{2}$ ligand is readily displaced in these complexes. ${ }^{350}$ In particular, it can be used as precursor for $\mathrm{CO}_{2}$ reduction into $\mathrm{CO} .{ }^{351}$ Reduction by two electrons per Fe center to the formal $\mathrm{Fe}(0)$ was also achieved, forming the $\left[\left\{\mathrm{Fe}\left(\mathrm{L}^{t \mathrm{Bu}, \mathrm{dipp}}\right)\right\}_{2}\left(\mu-\eta^{1}: \eta^{1}-\mathrm{N}_{2}\right)\right] \mathrm{M}_{2}(\mathrm{M}=$ $\mathrm{Na}, \mathrm{K})\left(v_{\mathrm{NN}}=1589 \mathrm{~cm}^{-1}, \mathrm{M}=\mathrm{K}\right) \cdot{ }^{349}$ In that case, the $\mathrm{NN}$ bond distance is elongated to $1.24 \AA$, in the range of $\mathrm{N}_{2}{ }^{2-}$ moieties. In subsequent studies, ligand electronics and sterics were modulated. With $\mathrm{Me}$ in place of $\mathrm{t}-\mathrm{Bu}$, similar $\mathrm{Fe}-\mathrm{N}_{2}$ complexes were obtained. ${ }^{352}$ When the ligand $\mathrm{L}^{\mathrm{Me}, \mathrm{Me} \text {,dipp }}=\mathrm{CMe}\left\{\mathrm{C}(\mathrm{Me}) \mathrm{N}\left(2,6-i-\mathrm{Pr}_{2} \mathrm{C}_{6} \mathrm{H}_{3}\right)\right\}_{2}{ }^{-}$was used, full $\mathrm{N}_{2}$ splitting was achieved upon reduction (scheme 92). DFT calculations rationalized the necessity of having both multiple Fe centers as well as $\mathrm{K}^{+}$coordination to allow nitride formation. ${ }^{353}$

2

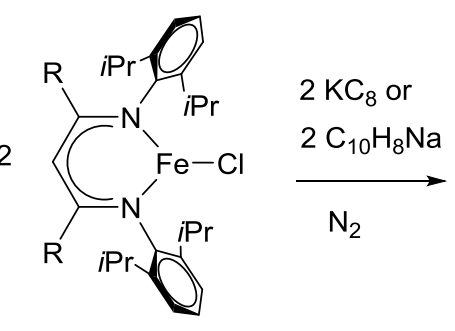

$\mathrm{R}=\mathrm{Me}, t-\mathrm{Bu}$
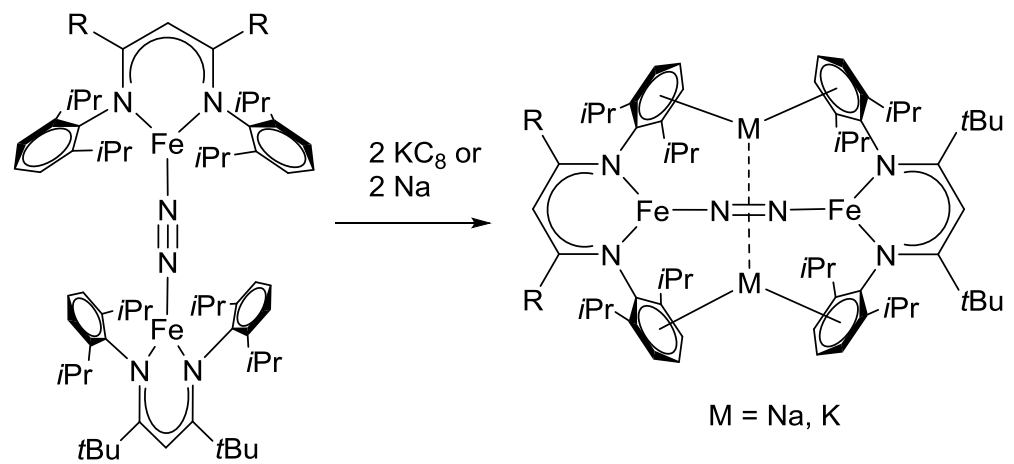

Scheme 91

The authors further evaluated the effect of counter ion, and showed that with the smaller $\mathrm{Na}^{+}$, a trimetallic complex, with bridging nitrides, is obtained. ${ }^{354}$ On the other hand, with 
Cs+, $N_{2}$ is not split, and a trinuclear complex with two $\mu, \eta^{1}, \eta^{1}-\mathrm{N}_{2}$ bridging is formed. ${ }^{355}$ Finally, when $\mathrm{Mg}$ was used as reducing agent, metastable complexes consistent with the formulation $\left[\left\{\mathrm{Fe}\left(\mathrm{L}^{\mathrm{R}, \mathrm{dipp}}\right)\right\}_{2}\left(\mu-\eta^{1}: \eta^{1}-\mathrm{N}_{2}\right)\right]_{2}\left[\mathrm{Mg}(\mathrm{THF})_{4}\right]$ were obtained. ${ }^{356}$ When 18-crown-6 was added to the tetranuclear Fe complex, $\mathrm{K}^{+}$was sequestered which resulted in $\mathrm{NH}$ bond formation and $\mathrm{CH}$ bond activation of the ligand backbone, likely via the intermediacy of the anionic nitride complex. ${ }^{357}$

2
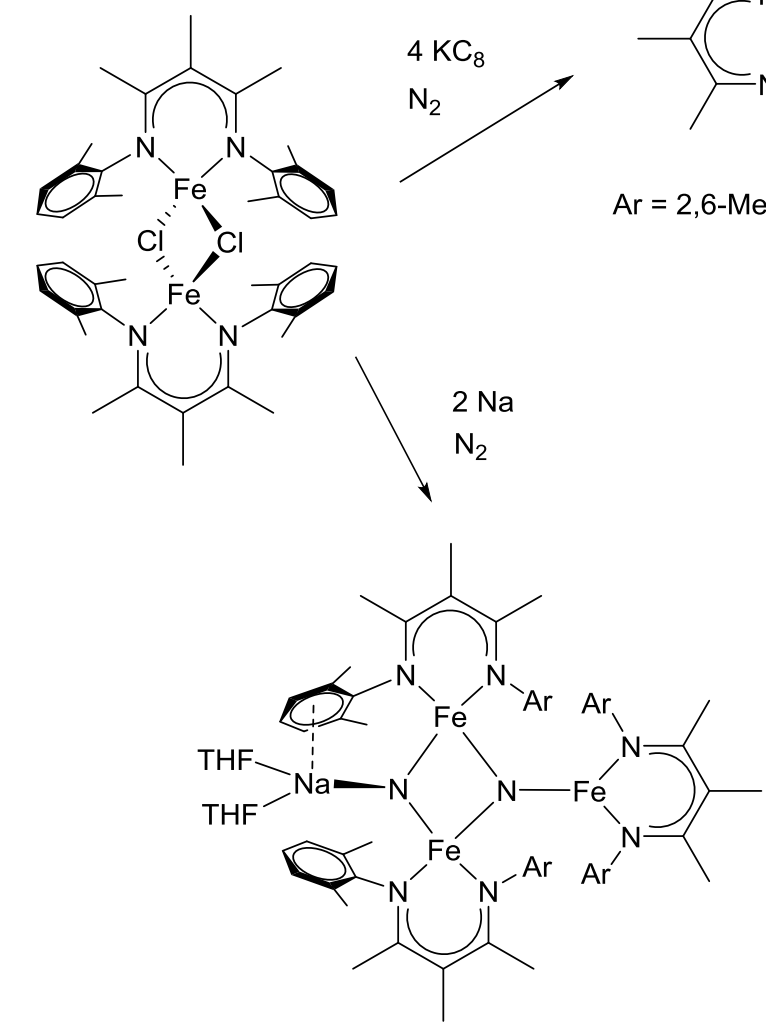

$4 \mathrm{KC}_{8}$

$\mathrm{N}_{2}$

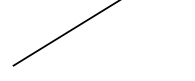

$\mathrm{Ar}=2,6-\mathrm{Me}_{2} \mathrm{C}_{6} \mathrm{H}_{3}$
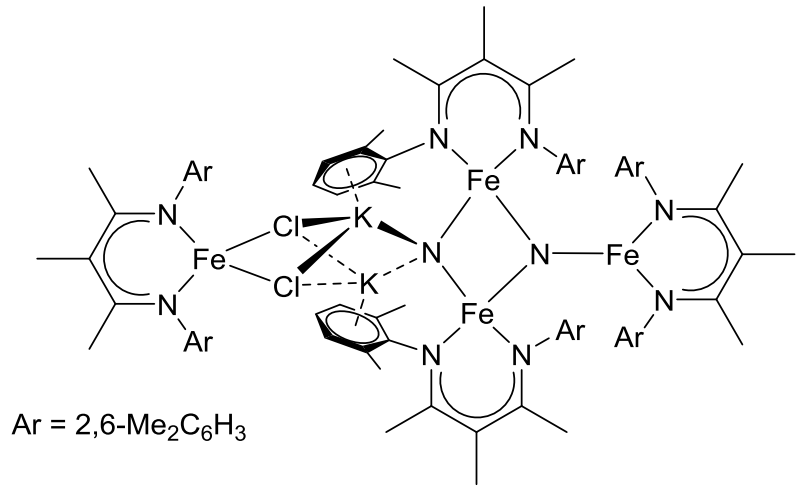

2 18-crown-6

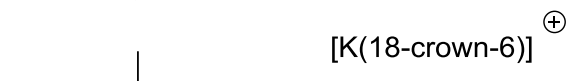

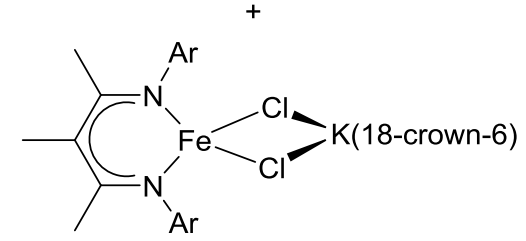

Scheme 92

Most significantly, protonation with excess $\mathrm{HCl}$ of the tetranuclear $\mathrm{Fe}$ bis nitride complex 
resulted in the formation of $82 \%$ of $\mathrm{NH}_{4} \mathrm{Cl}^{358}$ In 2016 , an exhaustive protonation study was done, revealing no link between the $\mathrm{pKa}$ of the acid and the quantity of ammonia produced. In fact, high yields of ammonia are often found for weak acids, and even with water $\left(96 \%\right.$ yield). ${ }^{359}$ Stepwise functionalizations of the nitrido moieties by protons and electrons (stepwise or coupled proton/electron transfer) were achieved. Impressively, several intermediates were isolated and/or spectroscopically characterized (scheme 93). The bridging imido/nitrido $(\mathrm{NH} / \mathrm{N})$, amido/nitrido $\left(\mathrm{NH}_{2} / \mathrm{N}\right)$, bis amido $\left(\mathrm{NH}_{2} / \mathrm{NH}_{2}\right)$ complexes were isolated while anionic imido/nitrido $(\mathrm{NH} / \mathrm{N})$, and amido $\left(\mathrm{NH}_{2}\right)$ complexes were spectroscopically characterized. Despite the fact that the $\mathrm{N}_{2}$ is fully split with this system, it appears that the reversible reaction is kinetically accessible. Indeed, addition of two electron donors $\mathrm{CO}, 2,6-\left(\mathrm{CH}_{3}\right)_{2} \mathrm{C}_{6} \mathrm{H}_{3} \mathrm{CN}$, or catalytic pyridine in benzene induced $\mathrm{N}_{2}$ elimination and efficient synthesis of the $\mathrm{Fe}^{\mathrm{I}}$ complexes. ${ }^{360}$ 


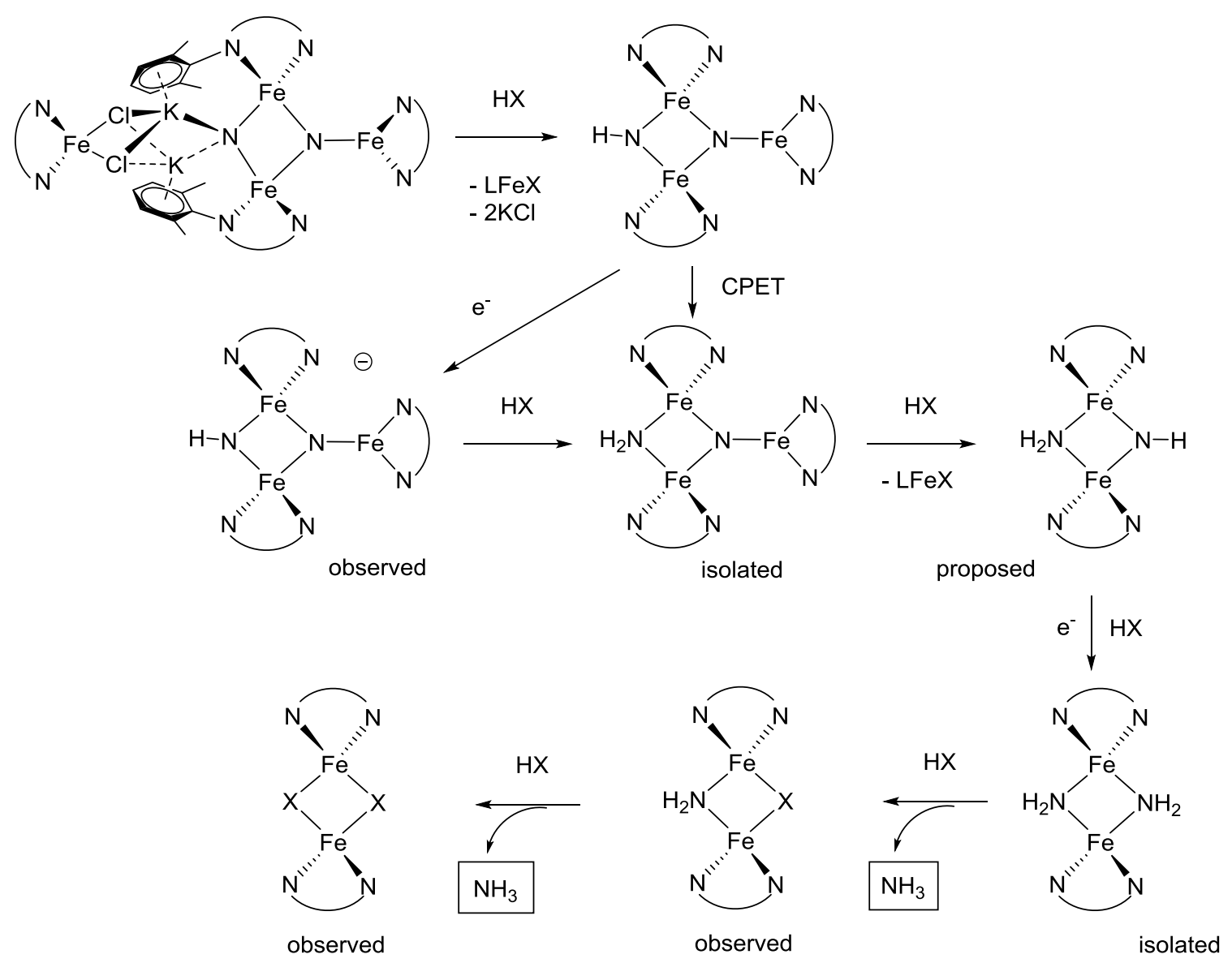

Scheme 93

In 2015, Murray developed a tris- $\beta$-diketiminate, linked via aromatic rings. ${ }^{361}$ This ligand favored trimetallic $\mathrm{Fe}^{\mathrm{II}}$ complex formation. Subsequent reduction by six electrons under $\mathrm{N}_{2}$ resulted in $\mathrm{N} \equiv \mathrm{N}$ splitting and protonation (scheme 94 ). Based on this ligand platform, this group reported in 2018 the Fe catalyzed $\mathrm{N}_{2}$ conversion to $\mathrm{N}\left(\mathrm{SiMe}_{3}\right)_{3} \cdot{ }^{362}$ Several precatalysts $\left[(\mathrm{Ligand}) \mathrm{Fe}_{3} \mathrm{X}_{3}\right](\mathrm{X}=\mathrm{Br}, \mathrm{Cl}, \mathrm{F}, \mathrm{H}, \mathrm{O}, \mathrm{S})$ and $\left[(\mathrm{Ligand}) \mathrm{Fe}_{3}(\mathrm{Br})_{2}\left(\mu_{3}-\mathrm{N}\right)\right]$ and $\left[(\right.$ Ligand $\left.) \mathrm{Fe}_{3}\left(\mu_{3}-\mathrm{N}\right)\right]$ were tested. The yields obtained (i.e. $\left.\mathrm{N}\left(\mathrm{SiMe}_{3}\right)_{3} / \mathrm{Fe}_{3}\right)$ for a reaction between 500 equiv. $\mathrm{KC}_{8}$ and $\mathrm{SiMe}_{3} \mathrm{Cl}$ at room temperature for $24 \mathrm{~h}$ are for most of them higher than 50, with the highest at $64(\mathrm{X}=\mathrm{F})$. If the reaction is performed at $-34^{\circ} \mathrm{C}$ for 96h, the best yield is $83(\mathrm{X}=\mathrm{Br})$, which makes this system the most effective one for this transformation (50\% yield based on reducing equivalents). Interestingly, the $\mu_{3}-\mathrm{N}$ 
complexes are slightly less efficient, consistent with the fact that $\left[(\right.$ Ligand $\left.) \mathrm{Fe}_{3}\left(\mu_{3}-\mathrm{N}\right)\right]$ is stable under reducing conditions.

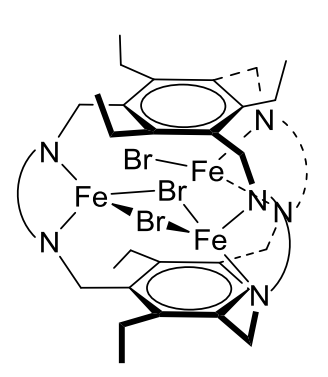

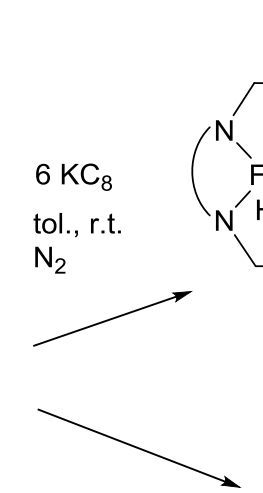

$\mathrm{Et}_{2} \mathrm{O} /$ tol. $9 / 1$

Scheme 94

Also in the family of anionic $\mathrm{N}$ based ligands, one finds the weak field ligands trispyrazolylborates. In light of the weak field ligand sulfide found in nitrogenase, the Tp ligands are interesting models for $\mathrm{N}_{2}$ coordination to high spin Fe. Harman reported in 2015 that reduction of the $\mathrm{Fe}^{\mathrm{II}}$ precursors $\left[\left(\mathrm{Tp}^{\mathrm{R}, \mathrm{Me}}\right) \mathrm{FeCl}\right](\mathrm{R}=\mathrm{Ph}, \mathrm{Ad})$ results in the formation of $\left[\left(\mathrm{Tp}^{\mathrm{Ph}, \mathrm{Me}}\right) \mathrm{Fe}\right]_{2}\left(\mu-\eta^{1}: \eta^{1}-\mathrm{N}_{2}\right)$ and $\left[\left(\mathrm{Tp}^{\mathrm{Ad}, \mathrm{Me}}\right) \mathrm{Fe}\left(\mathrm{N}_{2}\right)\right]$, the latter being the first terminal high-spin $\mathrm{Fe}^{(\mathrm{I})}-\mathrm{N}_{2}$ complex $(\mathrm{S}=3 / 2)$ as proved by EPR, magnetic measurements and substantiated by DFT calculations. ${ }^{363}$ With the slightly less bulky $\mathrm{Tp}^{\mathrm{tBu}, \mathrm{Me}}$ ligand, the bridging dimer $\left[\left(\mathrm{Tp}^{t \mathrm{Bu}, \mathrm{Me}}\right) \mathrm{Fe}\right]_{2}\left(\mu-\eta^{1}: \eta^{1}-\mathrm{N}_{2}\right)$ was obtained. ${ }^{364}$

Neutral $[\mathrm{NN}]$ ligands of the type 4,5-diazafluorene can be deprotonated from $\left[\mathrm{Ru}(\mathrm{H})(\mathrm{Cl})(\mathrm{LH})\left(\mathrm{PPh}_{3}\right)_{2}\right] \quad(\mathrm{LH}=\quad 4,5$-diazafluorene $) \quad$ under $\quad \mathrm{N}_{2}$ to form the $\left[\mathrm{Ru}(\mathrm{H})(\mathrm{L})\left(\mathrm{PPh}_{3}\right)_{2}\left(\mathrm{~N}_{2}\right)\right]$ complex. ${ }^{365}$ This complex reacts with $\mathrm{CO}_{2}$ reversibly via insertion in a $\mathrm{CH}$ bond of the ligand. ${ }^{366}$

Finally concerning the $\mathrm{N}$ based ligand, a Ru complex featuring a macrocyclic [NNNN] ligand was designed as sensor for $\mathrm{N}_{2}$ in water at different $\mathrm{pH}$. It is based on the 
dissociation of $\mathrm{OH}^{-}$from the complex at high $\mathrm{pH}^{367}$

\subsection{3 $\mathrm{S}$ based ligands}

Prior to 2003, the group of Sellmann has studied many polydentate ligands featuring thiolate moieties to develop functional models of nitrogenase. ${ }^{368}$ Relevant to the more recent literature is the dianionic $[\mathrm{SNNS}]^{2-}$ ligand, 1,2-ethanediamine-N,N'dimethyl-N,N'-bis(2-benzenethiolate) ${ }^{2-}$. In $2001, \quad$ the corresponding $\left[[\mathrm{SNNS}] \mathrm{Ru}\left(\mathrm{PiPr}_{3}\right)\left(\mathrm{N}_{2}\right)\right]$ terminal $\mathrm{Ru}^{\mathrm{II}}-\mathrm{N}_{2}$ complex was synthesized. ${ }^{369}$ The [[SNNS]Ru(PiPr 3$\left.)\left(\mathrm{NH}_{3}\right)\right]$ complex was later obtained and $\mathrm{NH}_{3}$ shown to be labile and readily displaced by $\mathrm{N}_{2}$ at room temperature (scheme 95$) .{ }^{370}$ The viability of diazene and hydrazine complexes as intermediates in the $\mathrm{N}_{2}$ reduction upon $\mathrm{H}^{+} / \mathrm{e}^{-}$transfers was studied with this metal fragment. Interestingly, reaction with hydrazine resulted in the slow formation of the diazene complex following a dismutation process from the $\mathrm{N}_{2} \mathrm{H}_{4}$ intermediate. 


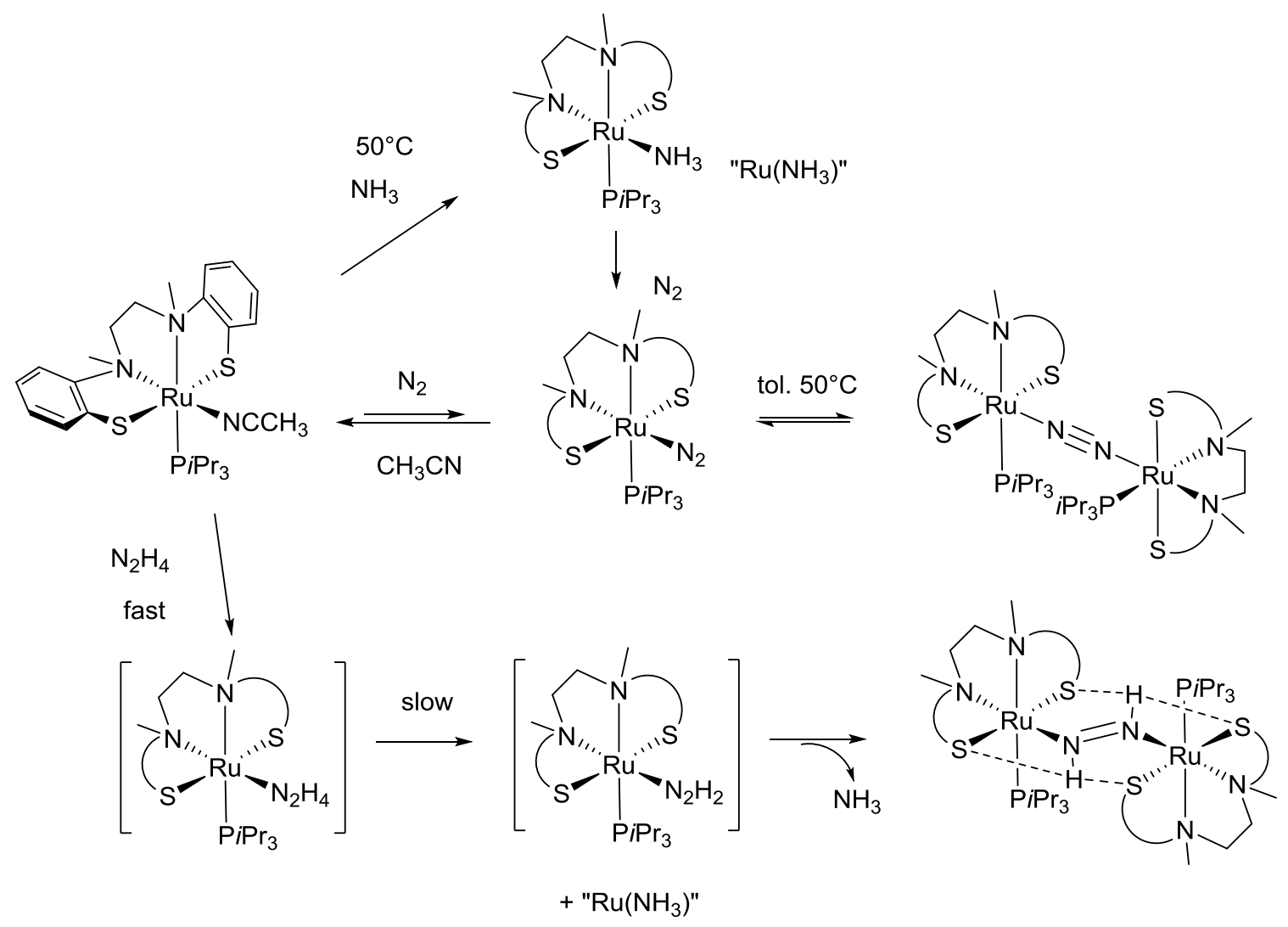

Scheme 95

In 2015, Holland designed a bis-thiolate ligand [SArS $]^{2-}$ which offers only $\mathrm{S}$ and $\mathrm{C}$ coordination sites. ${ }^{371}$ Reduction of the $\left[[\mathrm{SArS}] \mathrm{Fe}(\mathrm{THF})_{2}\right]$ complex by two electrons at low temperature under $\mathrm{N}_{2}$ allowed the isolation of the thermally sensitive complex $\left[[\mathrm{SArS}] \mathrm{Fe}\left(\mathrm{N}_{2}\right)\right]^{2-}$, in which the $\mathrm{Fe}$ center is pseudo-tetracoordinated. Infrared spectroscopy analysis of single crystals of the complex showed a $\mathrm{N}-\mathrm{N}$ stretching band at $1880 \mathrm{~cm}^{-1}$. 


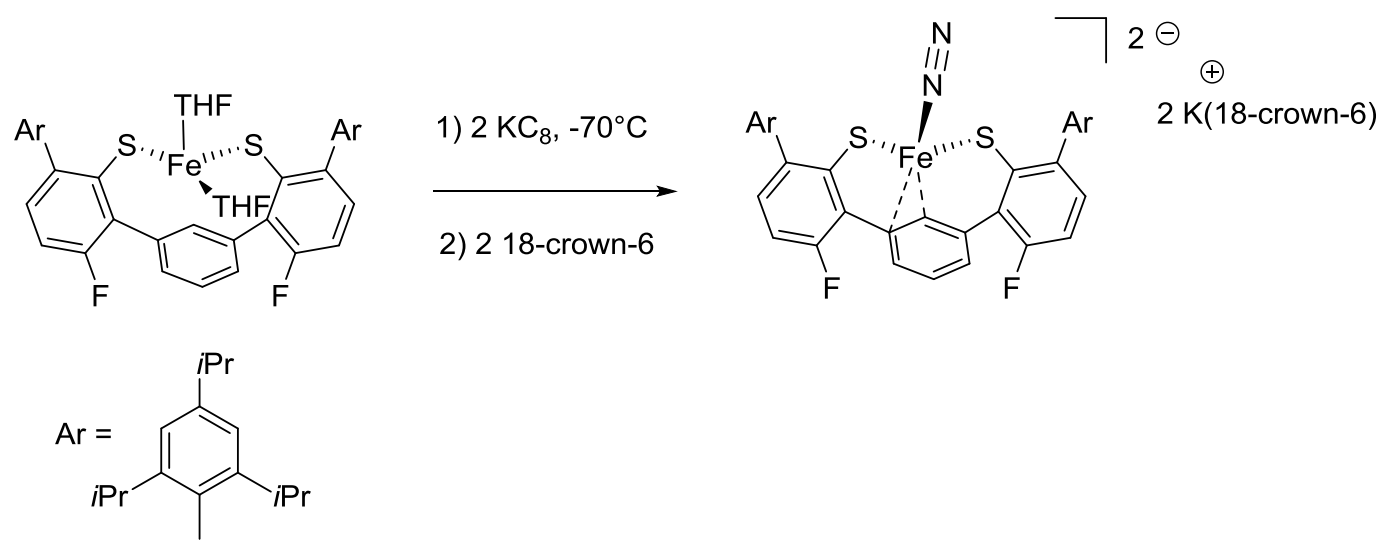

Scheme 96

In 2017, a bridging $\mathrm{Fe}^{\mathrm{II}}-\mathrm{N}_{2}$ complex featuring an anionic thiolate-phosphine $[\mathrm{SP}]^{-}$ligand was reported to act as catalyst in the hydroboration of arenes. ${ }^{372}$ The mechanism implies $\mathrm{N}_{2}$ displacement by the substrate.

\subsubsection{C and Si based ligands}

In 2010, Sunada reported the synthesis of a dinuclear Fe complex with bridging $\mathrm{N}_{2}{ }^{373}$ The reaction between $\left[\mathrm{Fe}(\text { mesityl) })_{2}\right.$ and 1,2-bis(dimethyl-silyl)benzene in aromatic solvents yielded $\left[\left(\eta^{6} \text {-arene }\right) \mathrm{Fe}\left(\mathrm{Me}_{2} \mathrm{SiC}_{6} \mathrm{H}_{4} \mathrm{SiMe}_{2}\right)\right]_{2}\left(\mu-\eta^{1}: \eta^{1}-\mathrm{N}_{2}\right) \quad$ (arene = benzene or toluene). In these complexes, the $\mathrm{N}_{2}$ ligand is readily displaced by $\mathrm{CO}, \mathrm{PPh}_{3}$ or $\mathrm{H}_{2}$.

Carbene ligands have been introduced in group 8- $\mathrm{N}_{2}$ chemistry rather recently. Whittlesey, MacGregor and Pregosin reported in 2009 the $\left[\mathrm{Ru}(\mathrm{NHC})_{4}(\mathrm{H})\left(\mathrm{N}_{2}\right)\right] \mathrm{BAr}{ }_{4}$ complexes $\left(\mathrm{NHC}=\mathrm{I} i \mathrm{Pr}_{2} \mathrm{Me}_{2}\right.$, and $\left.\mathrm{IEt}_{2} \mathrm{Me}_{2}\right)$ with hydride and $\mathrm{N}_{2}$ ligands in trans position. ${ }^{374}$ The $\mathrm{N}_{2}$ ligand is weakly coordinated and here also readily displaced by CO. In the reaction between $\left[(\mathrm{p}\right.$-cymene $\left.) \mathrm{Ru}(\mu-\mathrm{Cl})_{3} \mathrm{RuCl}\left(\mathrm{C}_{2} \mathrm{H}_{4}\right)(\mathrm{IMes})\right]$ and $\mathrm{N}_{2} \mathrm{O}$, Severin observed the formation of $\left[(\mathrm{p}\right.$-cymene $\left.) \mathrm{Ru}(\mu-\mathrm{Cl})_{3} \mathrm{RuCl}\left(\mathrm{N}_{2}\right)(\mathrm{IMes})\right]$ which gradually disappeared to the benefit of a complex featuring a $\mu$-alkoxy ligand derived from 
oxidation of one of the o-Me group of the IMes ligand. ${ }^{375}$ The coordination of PicolylNHC (Py-NHC) ligands at Fe and Ru has been studied by the groups of Puerta, Valerga and Song. A weak coordination of $\mathrm{N}_{2}$ was observed at the "M(Py-NHC)(X)+" cationic fragment $\left(\mathrm{M}=\mathrm{Fe}, \mathrm{Ru}, \mathrm{X}=\mathrm{Cp} *{ }^{376} \mathrm{M}=\mathrm{Ru}, \mathrm{X}=\mathrm{Tp}{ }^{377}\right)$. In 2015, Peters reported that the two coordinate $\left[\mathrm{Fe}(\mathrm{CAAC})_{2}\right]$ does only bind $\mathrm{N}_{2}$ at low temperature $\left(<-80^{\circ} \mathrm{C}\right)$ to form the $\left[\mathrm{Fe}(\mathrm{CAAC})_{2}\left(\mathrm{~N}_{2}\right)\right] \mathrm{Fe}^{0}$ complex (scheme 97$) .{ }^{378}$ This complex can be reduced at $-95^{\circ} \mathrm{C}$ by $\mathrm{KC}_{8}$ in the presence of 18 -crown- 6 to form $\left[\mathrm{Fe}(\mathrm{CAAC})_{2}\left(\mathrm{~N}_{2}\right)\right][\mathrm{K}(18$-crown-6)], which features a $v_{\mathrm{NN}}$ stretch at $1850 \mathrm{~cm}^{-1}$.
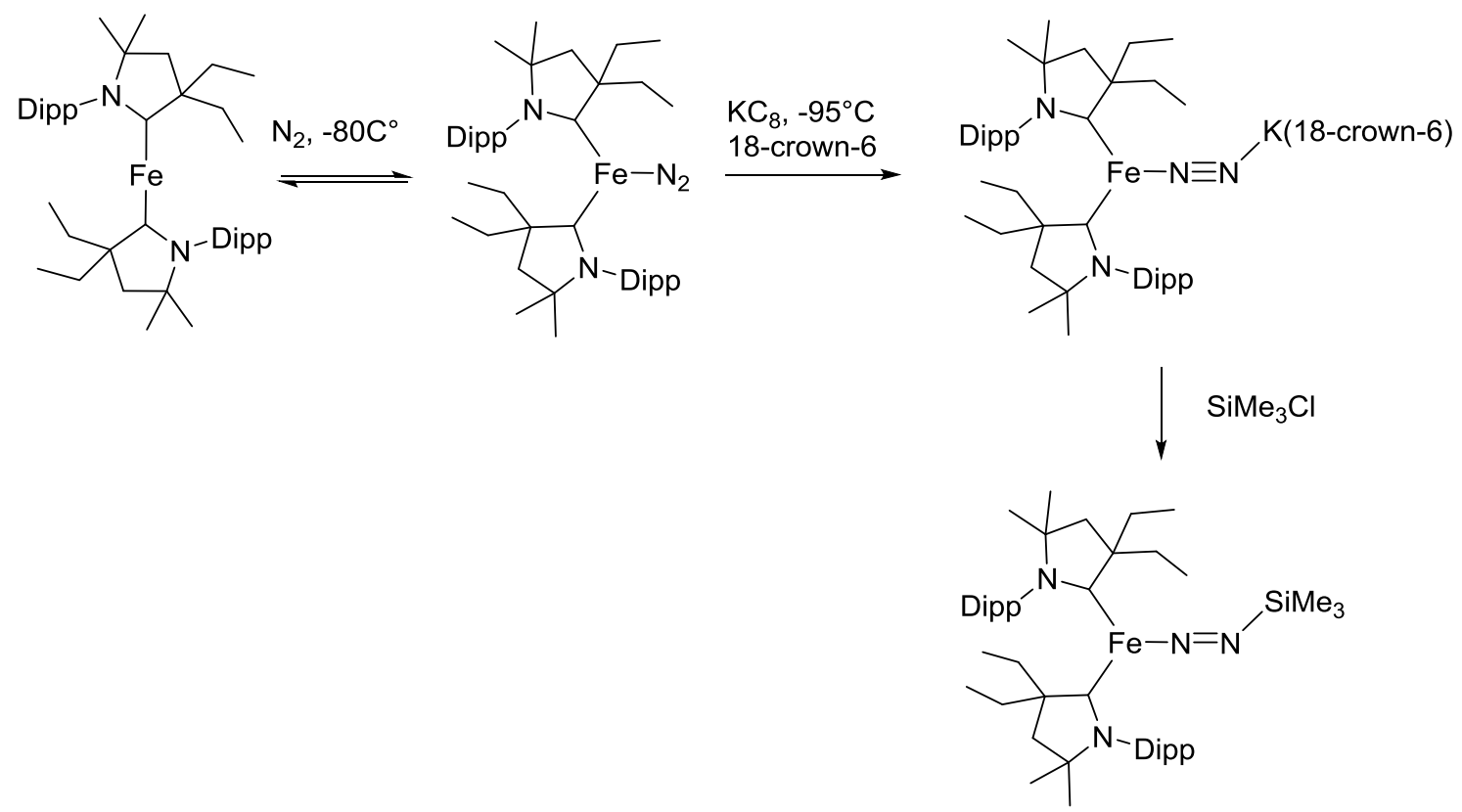

Scheme 97

At this temperature, these complexes are catalysts of the $\mathrm{NH}_{3}$ synthesis (3.3 and 2.6 equiv. respectively) using $\operatorname{HBAr}_{4}^{\mathrm{F}}$ and $\mathrm{KC}_{8}$ (50 equiv.). The anionic complex was reacted with $\mathrm{R}_{3} \mathrm{SiCl}(\mathrm{R}=\mathrm{Me}, \mathrm{Et})$, and the diazenido $\left[(\mathrm{CAAC})_{2} \mathrm{Fe}\left(\mathrm{N}_{2} \mathrm{SiR}_{3}\right)\right]$ isolated. The $\left[\mathrm{Fe}(\mathrm{CAAC})_{2}\left(\mathrm{~N}_{2}\right)\right]$ complex proved to be a competent catalyst for the formation of $\mathrm{N}\left(\mathrm{SiMe}_{3}\right)_{3}$ (24.4 equiv. for a reaction with 600 equiv. of $\mathrm{SiMe}_{3} \mathrm{Cl}$ and $\mathrm{KC}_{8}$, room temp). 
Finally, dinitrogen complexes of $\mathrm{Fe}^{0}, \mathrm{Fe}^{\mathrm{I}}$ and $\mathrm{Fe}^{\mathrm{II}}$ have been reported by Deng, with a bulky NHC supporting ligand (ICy) (scheme 98). ${ }^{379}$ Thus, reduction of the $\left[\mathrm{Fe}(\mathrm{ICy})_{3}\left(\mathrm{~N}_{2}\right)\right]^{+}$complex by $\mathrm{KC}_{8}$ at very low temperature (from $-118^{\circ} \mathrm{C}$ to $-80^{\circ} \mathrm{C}$ ) yielded the expected $\left[\mathrm{Fe}(\mathrm{ICy})_{3}\left(\mathrm{~N}_{2}\right)\right] \mathrm{Fe}^{0}$ complex. They feature a strong $v_{\mathrm{NN}}$ stretch at $1967 \mathrm{~cm}^{-1}$ and two $v_{\mathrm{NN}}$ stretches at 1853 and $1841 \mathrm{~cm}^{-1}$ respectively. In solution, the $\mathrm{Fe}^{0}$ complex is in equilibrium with the $\mathrm{Fe}^{\mathrm{II}}$-hydride-dinitrogen complex that results from $\mathrm{CH}$ bond insertion into the Cy moiety of the ligand.

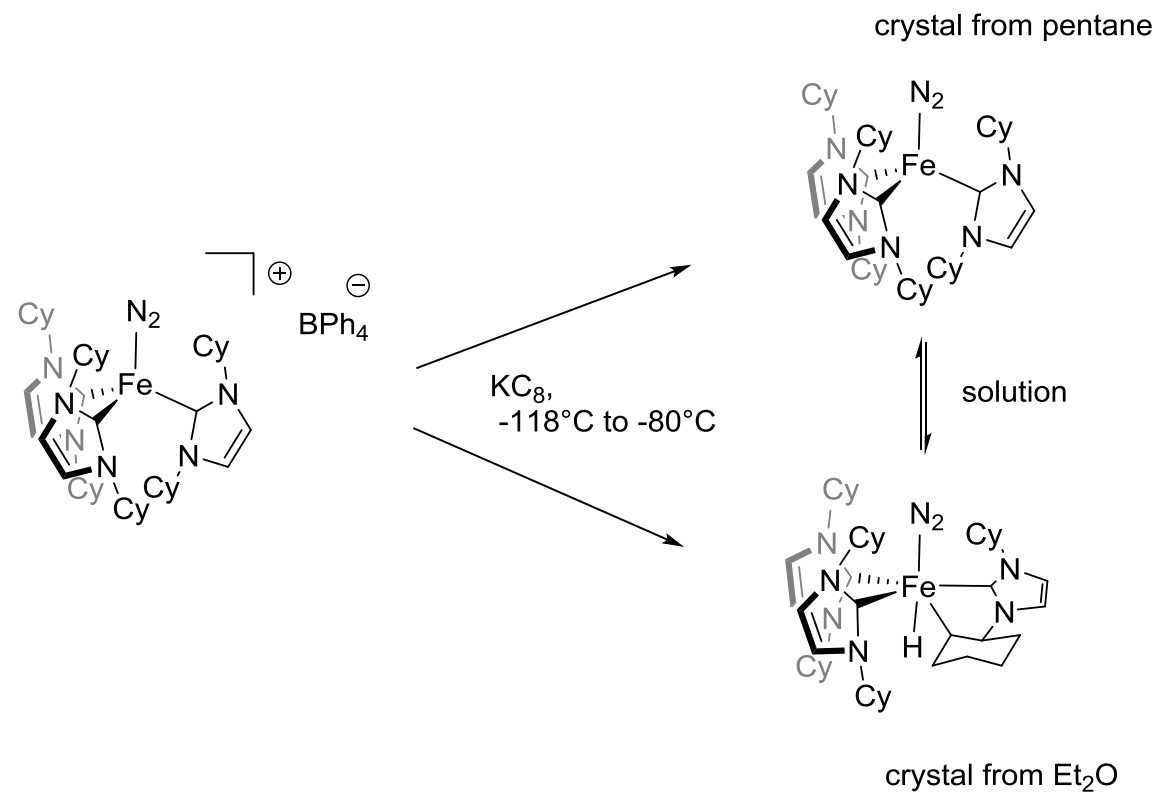

Scheme 98

\section{Group 9 transition metal-dinitrogen complexes}

\subsection{Cobalt complexes}

\subsubsection{P containing ligands}

The first Co- $\mathrm{N}_{2}$ complex $\left[\mathrm{Co}(\mathrm{H})\left(\mathrm{PPh}_{3}\right)_{3}\left(\mathrm{~N}_{2}\right)\right]$ was synthesized in 1967, and subsequent years have witnessed studies using monodentate phosphine ligands to stabilize such Co- $\mathrm{N}_{2}$ moieties. Much like for other metal centers, it has been common 
belief that "activation of $\mathrm{N}_{2}$ ", identified by $\mathrm{NN}$ bond lengthening and $v_{\mathrm{NN}}$ stretching frequency lowering, would translate into enhanced reactivity at $\mathrm{N}$, thereby eventually allowing for $\mathrm{N}$ incorporation into valuable molecules, i.e. $\mathrm{NH}_{3}, \mathrm{~N}\left(\mathrm{SiMe}_{3}\right)_{3}$. The recent efficient $\mathrm{N}_{2}$ functionalization by selected Co complexes prove that the problem is much more complex, and that looking at the $\mathrm{M}-\mathrm{N}_{2}$ reagent does not tell much about the subsequent energy profile linked to $\mathrm{N}$ functionalization.

In an early important report, Yamamoto et al. showed that reduction of the $\left[\mathrm{Co}(\mathrm{H})\left(\mathrm{PPh}_{3}\right)_{3}\left(\mathrm{~N}_{2}\right)\right]$ complex into $\left[\mathrm{Co}\left(\mathrm{PPh}_{3}\right)_{3}\left(\mathrm{~N}_{2}\right)\right]\left[\mathrm{Li}(\mathrm{solv})_{3}\right]\left(\right.$ solv $=\mathrm{Et}_{2} \mathrm{O}$ or $\left.\mathrm{THF}\right)$, allowed $\mathrm{NH}_{3}$ and/or hydrazine formation from $\mathrm{N}_{2}$ upon hydrolysis (20-30\% of initial $\mathrm{N}_{2}$ ligand is reduced), while the rest of $\mathrm{N}_{2}$ is liberated. ${ }^{380}$

Starting from 1985, polydentate ligands were used to synthesize Co- $\mathrm{N}_{2}$ complexes. ${ }^{381}$ In 2003, Peters reported the use of a tripodal anionic $\left[\mathrm{BP}_{3}\right]^{-}$ $\left(\left[\mathrm{PhB}\left(\mathrm{CH}_{2} \mathrm{PiPr}_{2}\right)_{3}\right]^{-}\right)$ligand for the stabilization of $\mathrm{Co}^{0}$ and $\mathrm{Co}^{\mathrm{I}} \mathrm{N}_{2}$ complexes. Stepwise reduction of the $\mathrm{Co}^{\mathrm{II}}$ precursor by $\mathrm{Na} / \mathrm{Hg}$ in $\mathrm{THF}$ allowed isolation of the $\mathrm{Co}^{\mathrm{I}}$ bridging dimer $\left[\left(\left[\mathrm{BP}_{3}\right] \mathrm{Co}\right)_{2}\left(\mu-\eta^{1}: \eta^{1}-\mathrm{N}_{2}\right)\right]$, as well as the formal $\mathrm{Co}^{0.5}$ dimer $\left[\left(\left[\mathrm{BP}_{3}\right] \mathrm{Co}\right)_{2}\left(\mu-\eta^{1}: \eta^{1}-\right.\right.$ $\left.\left.\mathrm{N}_{2}\right)\right]\left[\mathrm{Na}(\mathrm{THF})_{6}\right]$ (scheme 99). ${ }^{276}$ Alternatively, reduction by $\mathrm{Mg}$ formed the dianionic $\mathrm{Co}^{0}$ dimer $\left[\left(\left[\mathrm{BP}{ }_{3}\right] \mathrm{Co}\right)_{2}\left(\mu-\eta^{1}: \eta^{1}-\mathrm{N}_{2}\right)\right]\left[\mathrm{Mg}(\mathrm{THF})_{4}\right]$. Functionalization of the bridging $\mathrm{N}_{2}$ in the latter complex with either TMSCl or MeOTs was reported to yield the corresponding diazenido complexes (low spin $\mathrm{Co}^{\mathrm{II}}$ ). 


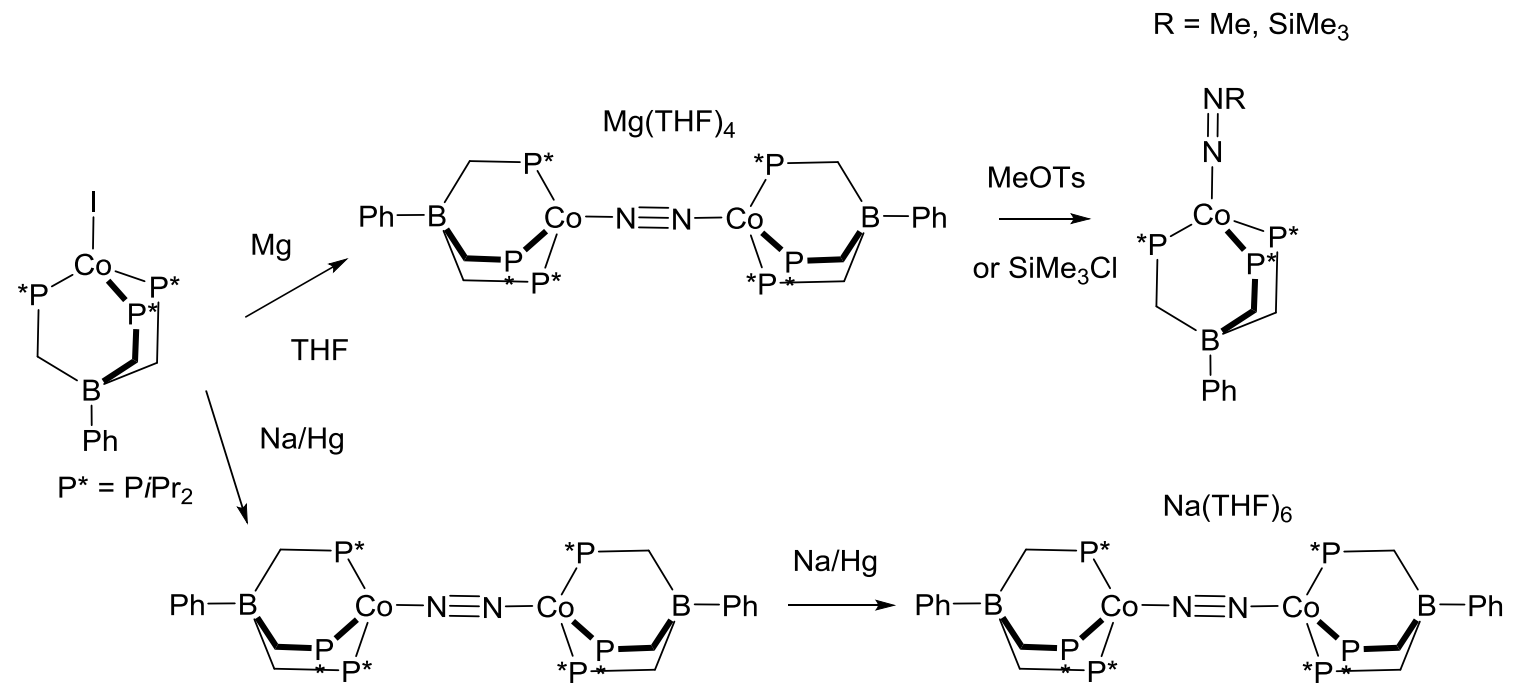

Scheme 99

The same group then synthesized a series of $\mathrm{CoN}_{2}$ complexes featuring tetrapodal $\left[\mathrm{EP}_{3}\right]$ ligands, where $\mathrm{E}=\mathrm{B}, \mathrm{Si}$ and $\mathrm{C}$ following the same strategy, i.e. reduction of the $\mathrm{Co}^{\mathrm{I}}(\mathrm{E}=\mathrm{B})$ and $\mathrm{Co}^{\mathrm{II}}(\mathrm{E}=\mathrm{Si}, \mathrm{C})$ precursors (scheme 100). In these complexes, the ligand trans to $\mathrm{N}_{2}$ differs, as well as the charge, which allowed a systematic comparison of the extent of $\mathrm{N}_{2}$ activation. ${ }^{280}, 382,383$ 


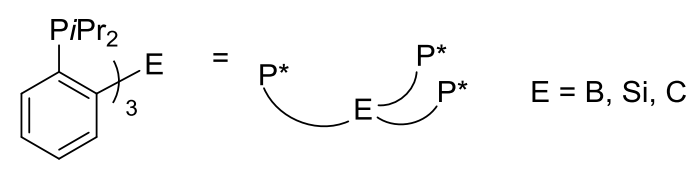

$$
\left[\mathrm{Na}(12 \text {-crown-4) })^{\oplus}\right.
$$<smiles>BrP1[Pb]2CP3[P-]P(C2)C31Br</smiles>

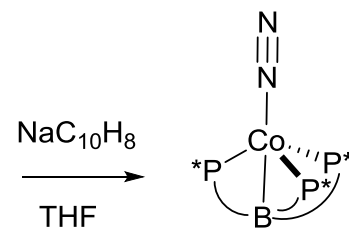

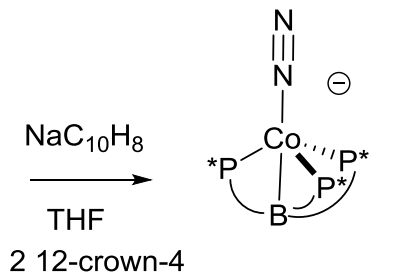

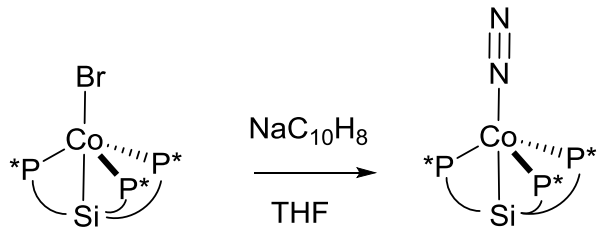

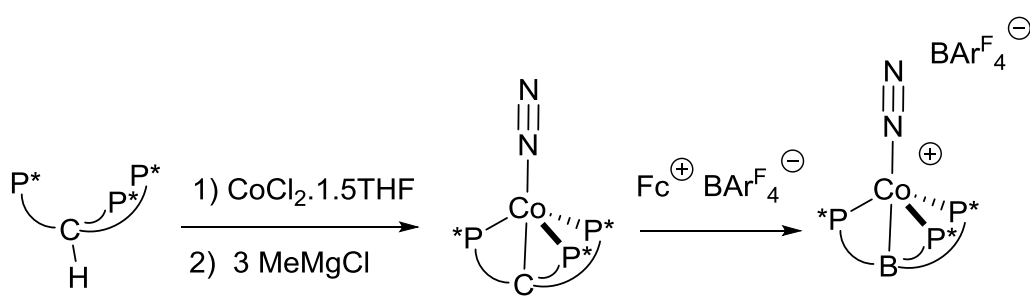

Scheme 100

The $\left[\mathrm{BP}_{3}\right]$ ligand allowed both $\mathrm{Co}^{0}$ and $\mathrm{Co}^{-1} \mathrm{~N}_{2}$ complexes to be made, the latter being diamagnetic. The neutral $\mathrm{Co}^{\mathrm{I}}$ can be obtained for the $\left[\mathrm{SiP}_{3}\right]$ and $\left[\mathrm{CP}_{3}\right]$ derivatives, and the cationic $\mathrm{Co}^{\mathrm{II}}$ for the latter. Measures of the $v_{\mathrm{NN}}$ stretching frequencies in these complexes point that, as one expects, more electron rich Co center (low oxidation state, more negative charge) results in greater $\mathrm{N}_{2}$ activation. The authors evaluated these complexes, as well as several others, in the $\mathrm{N}_{2}$-to- $\mathrm{NH}_{3}$ reduction. The standard conditions involve reaction at $-78^{\circ} \mathrm{C}$ between suspension of $\left[\mathrm{H}\left(\mathrm{Et}_{2} \mathrm{O}\right)_{2}\right]\left[\mathrm{BAr}_{4}^{\mathrm{F}}\right]$ (47 equiv) and $\mathrm{KC}_{8}(60$ equiv) for one hour. Only the complexes featuring the $\left[\mathrm{BP}_{3}\right]$ ligand proved active, with the anionic complex $\left[\left[\mathrm{BP}_{3}\right] \mathrm{Co}\left(\mathrm{N}_{2}\right)\right]^{-}$yielding 2.4 equivalents of $\mathrm{NH}_{3}$, while the neutral one $\left[\left[\mathrm{BP}_{3}\right] \mathrm{Co}\left(\mathrm{N}_{2}\right)\right]$ produced 0.8 equivalents. The $\mathrm{Co}^{\mathrm{I}}$ precursors $\left[\left[\mathrm{BP}_{3}\right] \mathrm{CoBr}\right]$ and $\left[\left[\mathrm{BP}_{3}\right] \mathrm{Co}\right]^{+}$yielded 0.7 and 1.6 equivalents respectively. 
In a related approach, in 2011, the group of Lu reported the synthesis of a ligand trisphosphino-(triamido)amine $\left[\mathrm{NN}_{3} \mathrm{P}_{3}\right]^{3-}$ capable to enforce M-M' interaction (scheme 101). ${ }^{301}$ With this ligand, bimetallic $\mathrm{M}$-Co complexes $\left(\mathrm{M}=\mathrm{Al}\right.$, Co) were obtained. ${ }^{302},{ }^{384}$

In the case of $\mathrm{M}=\mathrm{Co}$, cyclic voltammetry showed an irreversible one electron reduction under $\mathrm{N}_{2}$, which suggested coordination of $\mathrm{N}_{2}$ upon reduction. Chemical reduction under $\mathrm{N}_{2}$ with $\mathrm{KC}_{8}$ in the presence of 2.2.2-cryptand allowed isolation of the expected $\left[\left[\mathrm{NN}_{3} \mathrm{P}_{3}\right] \mathrm{CoCo}\left(\mathrm{N}_{2}\right)\right]\left[\mathrm{K}\left(\right.\right.$ crypt-222)]. Similarly, reduction of the $\left[\left[\mathrm{NN}_{3} \mathrm{P}_{3}\right] \mathrm{AlCo}\left(\mathrm{N}_{2}\right)\right]$ complex by one electron formed the $\left[\left[\mathrm{NN}_{3} \mathrm{P}_{3}\right] \mathrm{AlCo}\left(\mathrm{N}_{2}\right)\right][\mathrm{K}($ crypt-222)] species. Most interestingly, the reduction potential for the CoCo and AlCo complexes and the $v_{\mathrm{NN}}$ stretching frequencies of the reduced $\mathrm{MCoN}_{2}{ }^{-}$complexes are nearly identical, although the $\mathrm{M}$ center is trans to $\mathrm{N}_{2}$ and would be expected to have a significant influence. The three complexes $\left[\left[\mathrm{NN}_{3} \mathrm{P}_{3}\right] \mathrm{AlCo}\left(\mathrm{N}_{2}\right)\right]$, $\left[\left[\mathrm{NN}_{3} \mathrm{P}_{3}\right] \mathrm{CoCo}\right]$ and $\left[\left[\mathrm{NN}_{3} \mathrm{P}_{3}\right] \mathrm{CoCo}\left(\mathrm{N}_{2}\right)\right]^{-}$were tested as catalysts in the $\mathrm{N}_{2}$-to-NTMS 3 reduction ( 1 atm $\mathrm{N}_{2}, 2000$ eq. TMSCl, $2000 \mathrm{KC}_{8}$, r.t, THF, 12h), and compared to other Co species. The "AlCo" complex did provide 30 equiv. of $\mathrm{NTMS}_{3}$, which is less than what was obtained with $\left[\mathrm{Co}\left(\mathrm{PPh}_{3}\right)_{3} \mathrm{Cl}\right]$ (TON: 44) or derivatives obtained by mixing $\mathrm{CoCl}_{2}$ and monophosphines (TON: ca 90 equiv.). On the other hand, the neutral and anionic "CoCo" complexes proved highly active, generating 195 and 178 equivalents of the silylamine respectively. Even more impressively, when a second batch of chlorosilane and $\mathrm{KC}_{8}$ was added, a total of 326 equiv. of $\mathrm{NTMS}_{3}$ was produced. In 2015 , the same group further extended the family of $\left[\left[\mathrm{NN}_{3} \mathrm{P}_{3}\right] \mathrm{MCo}\right]$ complexes $(\mathrm{M}=\mathrm{Ti}, \mathrm{V}, \mathrm{Cr})$. Reduction of the $\mathrm{VCo}$ and $\mathrm{CrCo}$ complexes under $\mathrm{N}_{2}$ also resulted in the formation of the anionic $\mathrm{N}_{2}$ derivatives $\left[\left[\mathrm{NN}_{3} \mathrm{P}_{3}\right] \mathrm{MCo}\left(\mathrm{N}_{2}\right)\right]^{-}$A thorough DFT analysis revealed that the CoCo derivative is unique in the series. Indeed, the 
$(\mathrm{MCo})^{2+}$ core features a $\mathrm{M}^{\mathrm{III}} \mathrm{Co}^{-\mathrm{I}}$ oxidation state for $\mathrm{M}=\mathrm{Al}, \mathrm{Ti}, \mathrm{V}$ and $\mathrm{Cr}$, while it is $\mathrm{Co}^{\mathrm{II}} \mathrm{Co}^{0}$ in the dicobalt anion. ${ }^{385}$

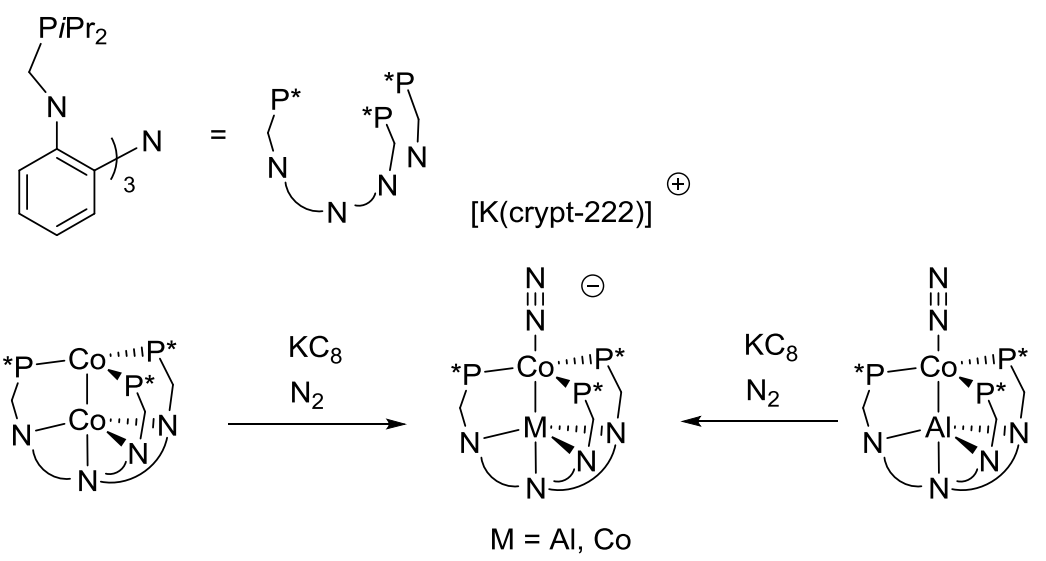

Scheme 101

The group of Peters also evaluated the tridentate $\left[\mathrm{BP}_{2}\right]$ ligand, and in this case, the Co center uses the BPh moiety as ligand (scheme 102). ${ }^{386}$ Reduction of the $\mathrm{Co}^{\mathrm{II}}$ precursor lead to formation of the $\mathrm{Co}^{0}-\mathrm{N}_{2}$ complex $\left[\left[\mathrm{BP}_{2}\right] \mathrm{Co}\left(\mathrm{N}_{2}\right)\right]$, as the major species in solution, as attested by the $\mathrm{N}_{2}$ stretch at $2098 \mathrm{~cm}^{-1}$. However, in the crystal, both the end-on and the bridging $\mathrm{N}_{2}$ complexes are found. As mentioned above, each Co center is pentacoordinated because of the interaction with the ispo carbon of the phenyl ring.

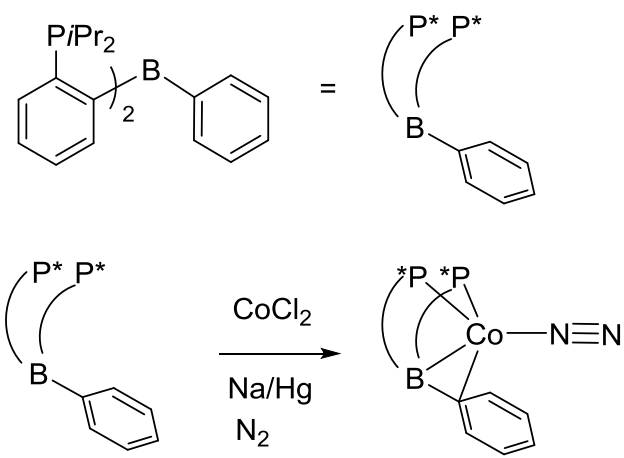

Scheme 102

Starting from 2009, the group of Thomas has developed the use of phosphino-amide ligands to stabilize $\mathrm{M}$-Co heterobimetallic $\left(\mathrm{M}=\mathrm{Zr}\right.$, Hf) edifices. ${ }^{387}$, ${ }^{388}$ Reduction of the 
precursors under $\mathrm{N}_{2}$ by an excess of $\mathrm{Na} / \mathrm{Hg}$ resulted in the formation of "MCo- $\mathrm{N}_{2}$ " complexes in which $\mathrm{N}_{2}$ is bound to Co (scheme 103). Depending on the nature of the substituents at $\mathrm{P}$ and $\mathrm{N}$, the $\mathrm{Na}^{+}$cation remains coordinated to either $\mathrm{N}_{2}$ or the $\mathrm{X}-\mathrm{M}$ fragment. $\mathrm{Co}$ and $\mathrm{Zr} \mathrm{K}$-edge XANES data indicates that the reduced $\mathrm{ZrCoN}_{2}$ derivatives are best described as $\mathrm{Zr}^{\mathrm{IV}} \mathrm{Co}^{-\mathrm{I}}$. ${ }^{389}$ The Thomas group utilized the [(MesNPiPr $)_{3} \mathrm{ZrCoN}_{2}$ ] complex in a range of stoichiometric and catalytic transformations, ${ }^{390,391,392,393,394,395,396}$ all involving the $\mathrm{Zr}$ center, but did not report successful $\mathrm{N}_{2}$ functionalization.

In 2015, successful synthesis of the related $\mathrm{TiCoN}_{2}$ complex could be achieved with less sterically demanding ligand $\mathrm{RNP} \operatorname{Pr}_{2}\left(\mathrm{R}=3\right.$,5-dimethylphenyl). In this case, the $\mathrm{N}_{2}$ is so weakly bound to Co that it readily dissociates under vacuum or under Ar. This is corroborated by the high $v_{\mathrm{N} 2}$ stretch at $2084 \mathrm{~cm}^{-1}$ (compared to $2045 \mathrm{~cm}^{-1}$ for the $\mathrm{Zr}$ analogue) showing much poorer back donation from Co, linked to increased donation toward the more Lewis acidic center $\mathrm{Ti}^{397}$ Most interestingly, the "TiCoN 2 " complex catalyzes the disproportionation of hydrazine into $\mathrm{NH}_{3}$ and $\mathrm{N}_{2}$. Unfortunately, the complexes are decomposed in the presence of excess $\mathrm{NH}_{3}$ which limits the catalyst efficiency. 

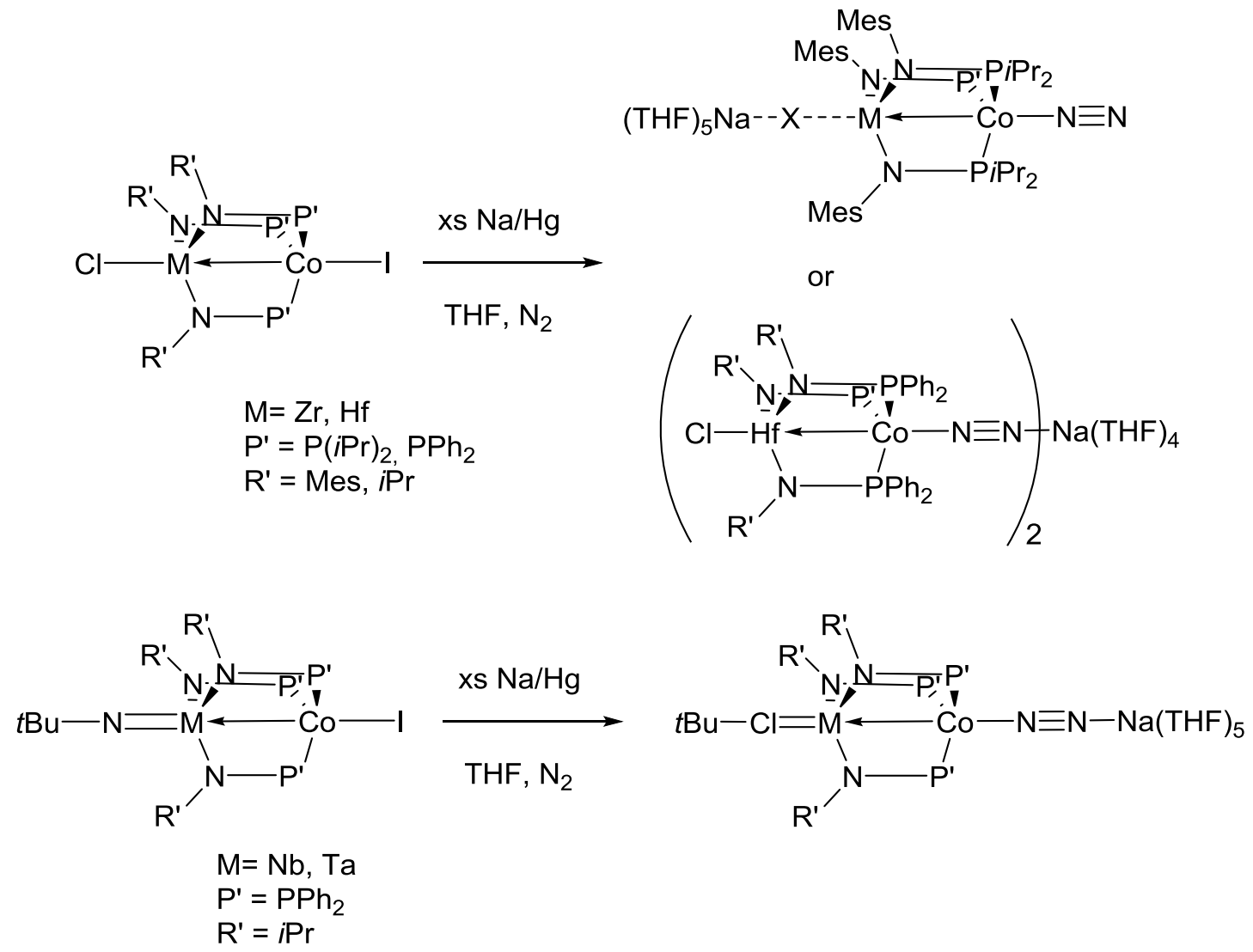

Scheme 103

In 2012, this group also reported the synthesis of the $\mathrm{M}-\mathrm{Co}-\mathrm{N}_{2}(\mathrm{M}=\mathrm{Nb}$, Ta) complexes with the $\mathrm{Ph}_{2} \mathrm{PNiPr}_{2}$ ligand, following the same reductive strategy. In this case, the group 5 imido complexes are used as precursors. ${ }^{398}$

Bis-phosphino pyridine [PNP] ligands were also shown to stabilize Co- $\mathrm{N}_{2}$ fragments. ${ }^{399}$ Thus, synthesis of [[PNP]Co(BPin) $\left.\left(\mathrm{N}_{2}\right)\right]$ complexes $\left([\mathrm{PNP}]=2,6-\left(i \mathrm{Pr}_{2} \mathrm{PCH}_{2}\right)_{2}-4-\mathrm{R}-\mathrm{Py}\right), \mathrm{R}$ $=\mathrm{H}, \mathrm{Me}, \mathrm{BPin}$, Pyrrole) was reported by Chirik in the frame of Co catalyzed borylation reactions. Only the complex with 4-pyrrole derivative is stable toward $\mathrm{N}_{2}$ loss under vacuum. Catalysis involves $\mathrm{N}_{2}$ dissociation to generate the active [[PNP]Co(BPin)] species. 


\subsubsection{N Based ligands}

Bulky $\beta$-diketiminate ligands have been used in the Co- $\mathrm{N}_{2}$ chemistry by Holland.

Thus, reduction of the $\left[\mathrm{Co}\left(\mathrm{L}^{t \mathrm{Bu}, \mathrm{dipp}}\right) \mathrm{Cl}\right]\left(\mathrm{L}^{t \mathrm{Bu}, \mathrm{dipp}}=\mathrm{CH}\left\{\mathrm{C}(t-\mathrm{Bu}) \mathrm{N}\left(2,6-i-\mathrm{Pr}_{2} \mathrm{C}_{6} \mathrm{H}_{3}\right)\right\}_{2}{ }^{-}\right)$by one electron yielded the bimetallic bridging end-on complex $\left[\left\{\operatorname{Co}\left(\mathrm{L}^{t \mathrm{Bu} \text {,dipp }}\right)\right\}_{2}\left(\mu-\eta^{1}: \eta^{1}-\right.\right.$ $\mathrm{N}_{2}$ )], shown to feature two $\mathrm{Co}^{\mathrm{I}}$ centers, ferromagnetically coupled (scheme 104). ${ }^{400}$ Reduction by two electrons to the formal $\mathrm{Co}^{0}$ was also achieved, forming the $\left[\left\{\mathrm{Co}\left(\mathrm{L}^{t \mathrm{Bu}, \mathrm{dipp}}\right)\right\}_{2}\left(\mu-\eta^{1}: \eta^{1}-\mathrm{N}_{2}\right)\right] \mathrm{M}_{2}(\mathrm{M}=\mathrm{Na}, \mathrm{K})$. In that case, the $\mathrm{NN}$ bond distance is elongated to $1.21-1.22 \AA$ (vs $1.139(2) \AA$ in the neutral complex), in the range of $\mathrm{N}_{2}{ }^{2-}$ moieties ( $\mathrm{N}=\mathrm{N}$ double bond), also confirmed by the $\mathrm{N}-\mathrm{N}$ vibration band at $1599 \mathrm{~cm}^{-1}$ in the Raman spectrum. DFT calculations revealed that the extent of bond lengthening is due both to the reduction and alkali metal coordination. Similar reactivity was recently observed by Scheer with the ligand $\mathrm{L}^{\mathrm{Me}, \mathrm{dipp}}=\mathrm{CH}\left\{\mathrm{C}(\mathrm{Me}) \mathrm{N}\left(2,6-i-\mathrm{Pr}_{2} \mathrm{C}_{6} \mathrm{H}_{3}\right)\right\}_{2}{ }^{-} \cdot{ }^{401}$
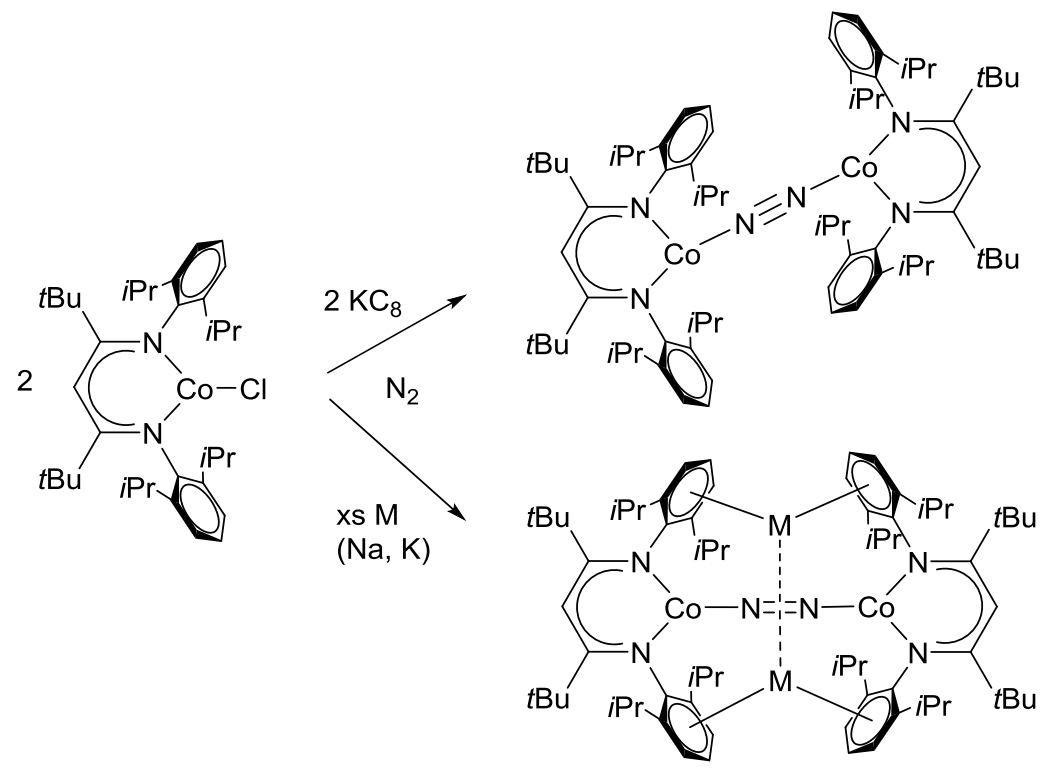

Scheme 104

In 2001, Gibson synthesized the $\left[\mathrm{Co}\left({ }^{i \mathrm{Pr}} \mathrm{PDI}\right)\left(\mathrm{N}_{2}\right)\right]^{+}\left({ }^{i \mathrm{Pr}} \mathrm{PDI}=2,6-\{\mathrm{MeC}=\mathrm{N}(2,6-i-\right.$ $\left.\left.\operatorname{Pr}_{2} \mathrm{C}_{6} \mathrm{H}_{3}\right)\right\}_{2} \mathrm{C}_{5} \mathrm{H}_{3} \mathrm{~N}$ ) complex by abstraction of a $\mathrm{CH}_{3}$ moiety under $\mathrm{N}_{2}$. In 2010 and 2013, 
Chirik reported the reduction of this complex by one and two electrons, and evidenced the non-innocence of the PDI ligands in the process. Thus, in the complexes, the Co center remains at the $+\mathrm{I}$ oxidation state and the $\mathrm{N}_{2}$ is only moderately affected by the reduction as shown by $v_{\mathrm{NN}}$ stretching frequencies (from 2184 to 2093 to $2046 \mathrm{~cm}^{-1}$ ) (scheme 105). ${ }^{402,403}$

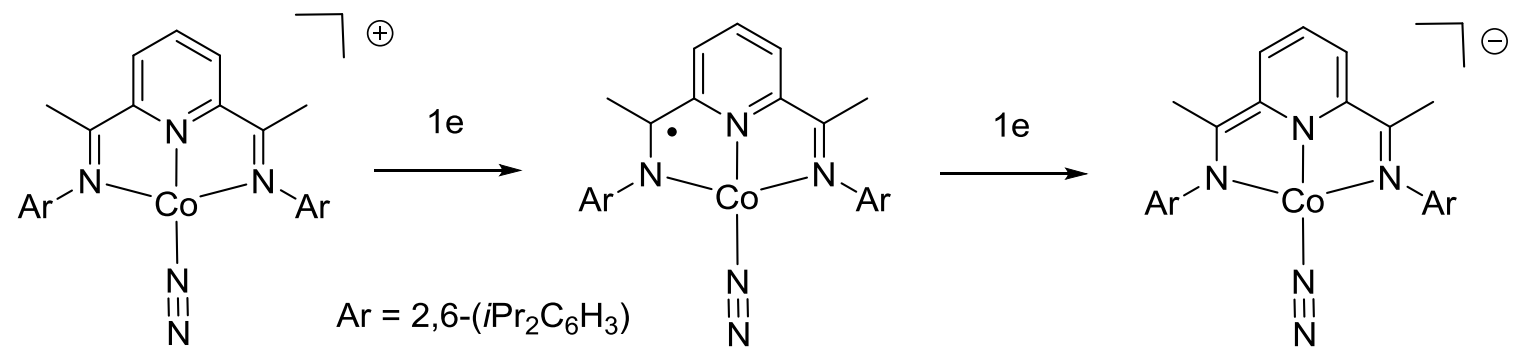

Scheme 105

\subsubsection{Carbon Based ligands: carbenes and isocyanides}

Surprisingly, NHC ligands (N Heterocyclic Carbene) have only been used recently in the Co- $\mathrm{N}_{2}$ chemistry. Deng reported in 2012 first studies using the IMes (1,3dimesitylimidazol-2-ylidene) ligand. Despite being unsaturated, coordination of $\mathrm{N}_{2}$ at the $\left[\mathrm{Co}(\mathrm{IMes})_{2}\right]^{+}$complex was not evidenced. Reduction of the $\left[\mathrm{Co}(\mathrm{IMes})_{2} \mathrm{Cl}\right]$ complex with $\mathrm{Na} / \mathrm{Hg}$ resulted in the double $\mathrm{CH}$ bond insertion in the ligand, but reaction with MeLi did yield a $\left[\mathrm{Co}(\mathrm{IMes})(\mathrm{IMes})^{\prime}\left(\mathrm{N}_{2}\right)\right]$ complex, concomitant with $\mathrm{CH}_{4}$ elimination (scheme 106). ${ }^{404}$ The complex is thus a $\mathrm{Co}^{\mathrm{I}}$ diamagnetic species. In a subsequent study, the same group studied the coordination of 1,3-dicyclohexylimidazol-2-ylidene (ICy). ${ }^{405}$ In this case, reduction of $\left[\mathrm{Co}(\mathrm{ICy})_{3} \mathrm{Cl}\right]$ by $\mathrm{KC}_{8}$ in THF yielded the $\mathrm{Co}^{0}$ complex $\left[\mathrm{Co}(\mathrm{ICy})_{3}\left(\mathrm{~N}_{2}\right)\right]$. Cyclic voltammetry studies revealed that this complex could be reduced further at $-2.10 \mathrm{~V}$ vs SCE. Chemical reduction with $\mathrm{M}(\mathrm{M}=\mathrm{K}, \mathrm{Rb}, \mathrm{Cs})$ was thus done, leading to 
$\left[\mathrm{Co}(\mathrm{ICy})_{2}\left(\mathrm{~N}_{2}\right)_{2}\right] \mathrm{M}$ complexes, featuring terminally bound $\mathrm{N}_{2}$ to $\mathrm{Co}$, while the interaction with $M$ can be either $\eta^{1}$ or $\eta^{2}$. Functionalization of the coordinated $N_{2}$ was then studied. Treatment of the $\left[\mathrm{Co}(\mathrm{ICy})_{3}\left(\mathrm{~N}_{2}\right)\right]$ and $\left[\mathrm{Co}(\mathrm{ICy})_{2}\left(\mathrm{~N}_{2}\right)_{2}\right]^{-}$complexes with excess strong acid resulted in quantification of significant amounts of hydrazine (5\% and 23-31\% respectively). Addition of $\mathrm{SiCl}$ bonds to $\left[\mathrm{Co}(\mathrm{ICy})_{2}\left(\mathrm{~N}_{2}\right)_{2}\right]^{-}$resulted in the formation of the disilyl diazene complex $\left[\mathrm{Co}(\mathrm{ICy})_{2}\left(\eta^{2}-\mathrm{R}_{3} \mathrm{SiNNSiR}_{3}\right)_{2}\right]$. The $\mathrm{NN}$ bond distance of 1.457(3) $\AA$ is consistent with a single bond. In light of the stoichiometric functionalization of $\mathrm{N}_{2}$ with chlorosilane, the authors tested the catalyzed formation of $\mathrm{N}\left(\mathrm{SiMe}_{3}\right)_{3}$ using the neutral, anionic and diazene complexes. Thus, reaction of $\mathrm{N}_{2}$ with 2000 equivalents of $\mathrm{SiMe}_{3} \mathrm{Cl}$ and $\mathrm{KC}_{8}$ per complex, in THF, yielded 103-125 equiv. of silylamine.

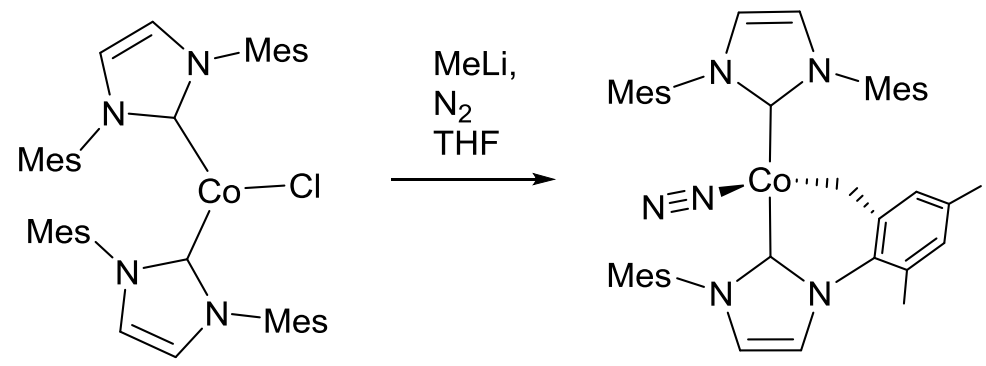

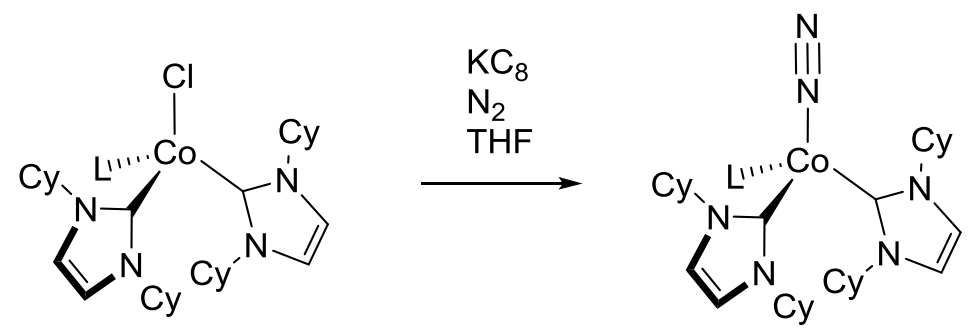

$L=I C y$

$$
M=K, \text { Rb, Cs } \mid \begin{aligned}
& M \\
& N_{2} \\
& \text { THF }
\end{aligned}
$$

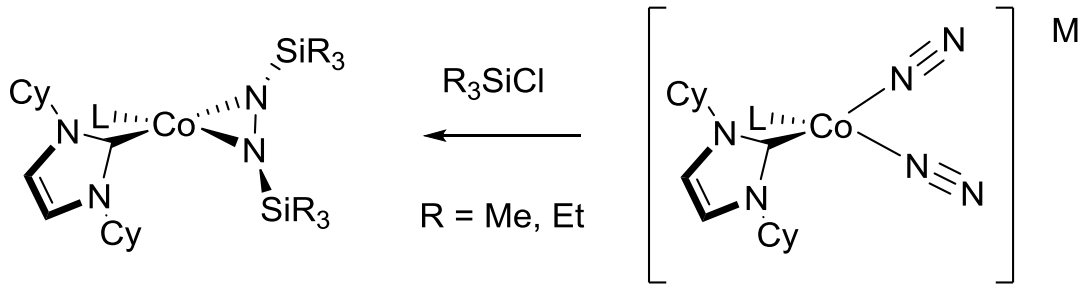


Scheme 106

In 2013, Chirik reported Co complexes featuring the pyridine-bis carbene ligand [CNC] in a study dedicated to catalytic hydrogenation (scheme 107). ${ }^{406}$ The sequence of Co- $\mathrm{N}_{2}$ formation is quite unusual. It involves migration of a hydride ligand from the Co to the para position of the Py ligand, which therefore acts as a non-innocent ligand. If the reaction is carried out in the presence of 1,1-diphenylethylene, migration of the alkyl moiety formed after insertion is observed.

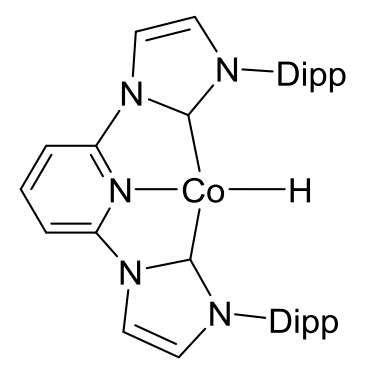

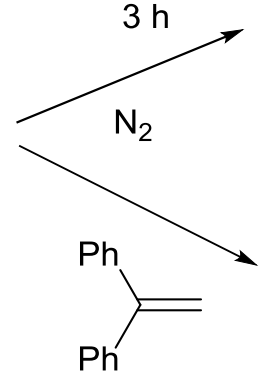

minutes
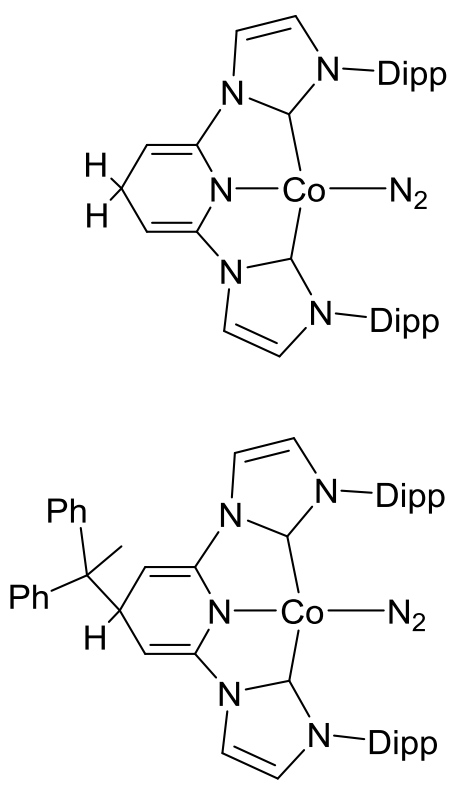

Scheme 107

A related tridentate ligand, [PNC] phosphine-pyridine-carbene, was reported in 2016 by Braunstein, Danopoulos and coworker. ${ }^{407}$ Reaction of the imidazolium precursor with $\left[\mathrm{Co}\left(\mathrm{NTMS}_{2}\right)_{2}\right]$ formed the $[[\mathrm{PNC}] \mathrm{CoBr}] \mathrm{Co}^{\mathrm{II}}$ complex featuring dearomatized anionic PNC ligand. Subsequent reduction of this complex by $\mathrm{KC}_{8}$ yielded the diamagnetic $\mathrm{Co}^{\mathrm{I}}-$ $\mathrm{N}_{2}$ complex [[PNC]Co($\left.\left(\mathrm{N}_{2}\right)\right]$. In this complex, a NN bond distance of $0.987(3) \AA$ was measured, shorter than the distance in free $\mathrm{N}_{2}(1.098 \AA)$, apparently incompatible with the 
$v_{\mathrm{NN}}$ at $2057 \mathrm{~cm}^{-1}$ which shows some activation via back bonding, and thus which should lead to elongation.

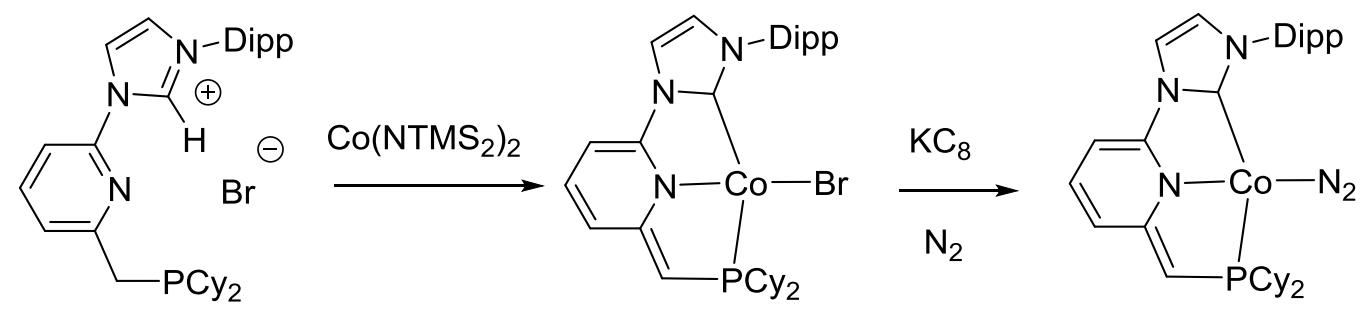

Scheme 108

Bulky isocyanide ligands have enabled synthesis of $\mathrm{Co}^{\mathrm{I}}-\mathrm{N}_{2}$ complexes. Starting from the $\left[\mathrm{Co}\left(\mathrm{CNAr}^{\mathrm{Mes} 2}\right)_{3}\right]^{-}$anion, the $\left[\mathrm{Co}\left(\mathrm{CNAr}^{\mathrm{Mes} 2}\right)_{3}\left(\mathrm{SiMe}_{3}\right)\left(\mathrm{N}_{2}\right)\right]$ complex was obtained by Figueroa's group upon addition of $\mathrm{SiMe}_{3} \mathrm{Cl}$ under $\mathrm{N}_{2}$ (scheme 109). ${ }^{408}$ In this complex the $\mathrm{N}_{2}$ moiety is trans to the $\mathrm{SiMe}_{3}$ group. The presence of strong $\pi$ acceptor isocyanide ligands deplete the $\mathrm{Co}^{\mathrm{I}}$ center from electron density which translates to the highest vibrational band for $\mathrm{NN}$ at $2231 \mathrm{~cm}^{-1}$. The same group then evaluated the addition of strong donor ligands, $\mathrm{Cp}$ derivatives. ${ }^{409}$ In the case of the $\left[\mathrm{CpCo}\left(\mathrm{CNAr}^{\mathrm{Dipp} 2}\right) \mathrm{I}_{2}\right]$, reduction did not lead to formation of a $\mathrm{Co}-\mathrm{N}_{2}$ complex, but on dimerization. With the more donating and sterically encumbered, the desired $\left[\mathrm{Cp} * \mathrm{Co}\left(\mathrm{CNAr}^{\mathrm{Dipp} 2}\right)\left(\mathrm{N}_{2}\right)\right]$ complex was obtained. However, it is not stable under vacuum, and ligand rearrangement was observed. 


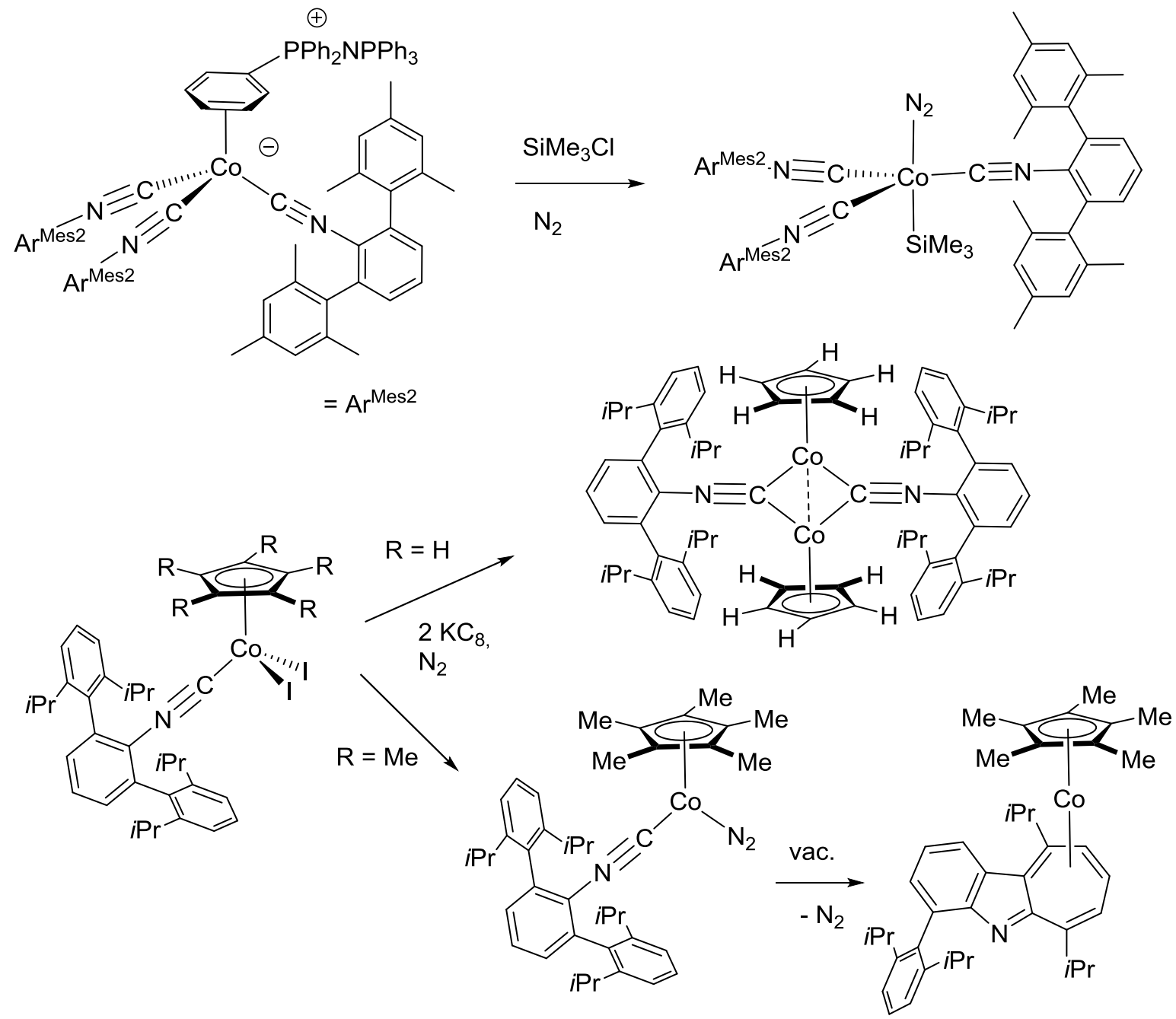

Scheme 109

\subsubsection{Pincer ligands}

A variety of pincer, tridentate anionic, ligands favoring meridional coordination at the metal center have been used to stabilize $\mathrm{Co}-\mathrm{N}_{2}$ fragments.

In 2006, the group of Mindiola studied the reduction of the [[PNP]CoCl] complex where $[\mathrm{PNP}]$ is $\left[\mathrm{N}\left\{2-\mathrm{PiPr}_{2}-4-\mathrm{MeC}_{6} \mathrm{H}_{3}\right\}_{2}\right]^{-}$(scheme 110). ${ }^{410}$ Under $\mathrm{N}_{2}$, reaction with tBuLi formed the $\mathrm{Co}^{\mathrm{I}} \mathrm{Co}^{\mathrm{I}}$ dimer $[[\mathrm{PNP}] \mathrm{Co}]_{2}\left(\mu-\mathrm{N}_{2}\right)$, featuring two square planar Co centers. At this oxidation state the $\mathrm{N}_{2}$ binds reversibly to the Co center. Reduction with 
an excess of $\mathrm{Na}$ /naphthalene yielded the diamagnetic dianionic $\mathrm{Co}^{-\mathrm{I}}$ complex $\left[[\operatorname{PNP}] \mathrm{Co}\left(\mathrm{N}_{2}\right)\right]^{2-}$. The X-ray structure $\left[[\mathrm{PNP}] \mathrm{Co}\left(\mu-\mathrm{N}_{2}\right) \mathrm{Na}_{2}(\mathrm{THF})_{3}\right]_{2}$ is rather complex, with highly distorted tetrahedral geometry at Co. Despite the formal highly reduced Co center, the $v_{\mathrm{NN}}$ at $1784 \mathrm{~cm}^{-1}$ indicates a moderate $\mathrm{N}_{2}$ activation.
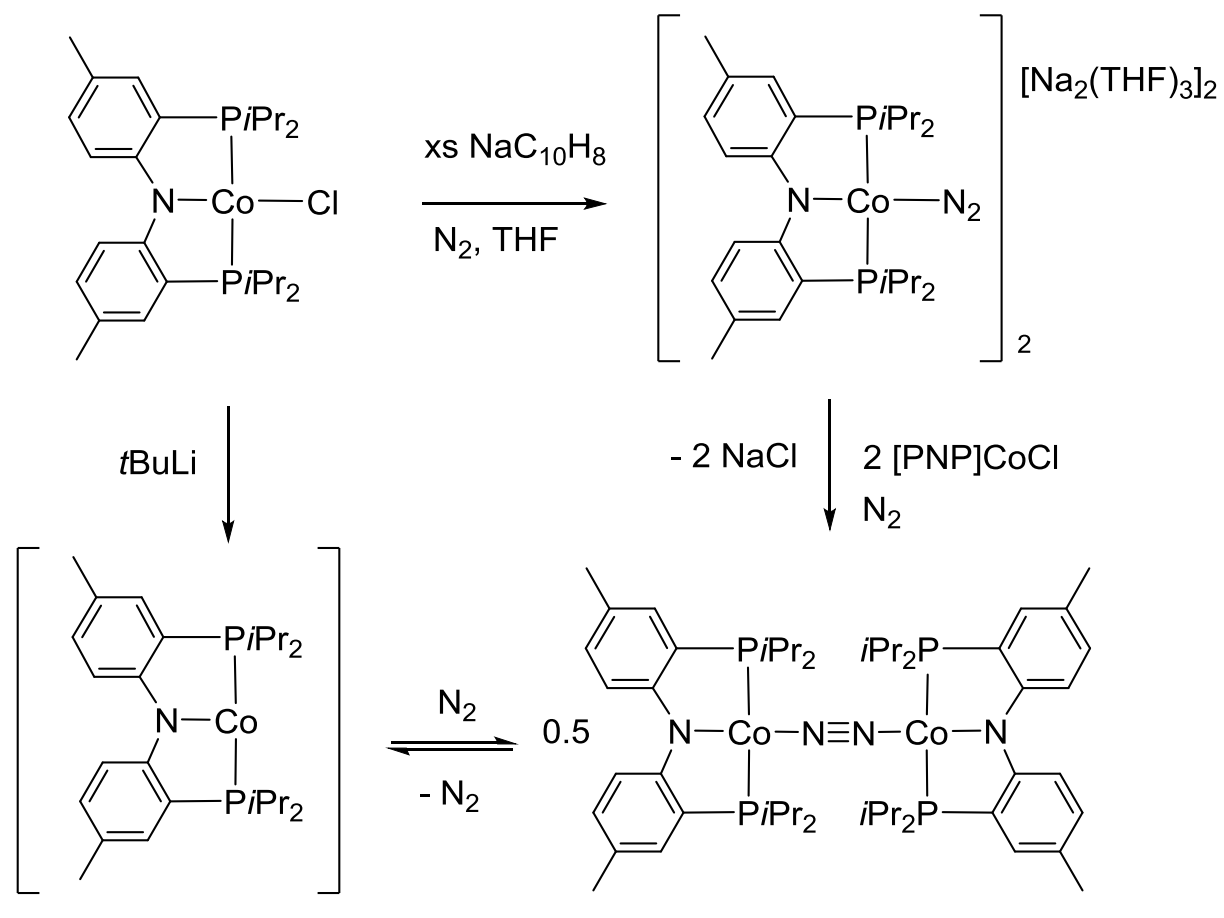

Scheme 110

Similar reversible coordination of $\mathrm{N}_{2}$ was observed the same year by Caulton with another [PNP] pincer ligand, $\left(t \mathrm{Bu}_{2} \mathrm{PCH}_{2} \mathrm{SiMe}_{2}\right)_{2} \mathrm{~N}^{-411}$ The group of Arnold reported in 2013 the use of a stronger donor pincer ligand, $\left(i \mathrm{Pr}_{2} \mathrm{PCH}_{2} \mathrm{CH}_{2}\right)_{2} \mathrm{~N}^{-412}$ In that case, reduction of the $\mathrm{CoCl}$ precursor with $\mathrm{KC}_{8}$ under $\mathrm{N}_{2}$ yielded the desired [[PNP]Co( $\left.\left.\mathrm{N}_{2}\right)\right]$ complex, as a diamagnetic species. As above, it readily loses $\mathrm{N}_{2}$ even in the solid state in an $\mathrm{N}_{2}$ filled glovebox. In 2016, the group of Nishibayashi further expanded the chemistry of [PNP] pincer ligands toward Co, with the pyrrolide derivative (scheme 111, top). ${ }^{413}$ They also obtained diamagnetic $\mathrm{Co}^{\mathrm{I}}-\mathrm{N}_{2}$ complexes upon reduction of the [[PNP]CoCl] $([\mathrm{PNP}]=2,5$-bis(dialkyl-phosphinomethyl)pyrrolide). Most interestingly, these 
complexes are catalysts of the $\mathrm{N}_{2}$-to- $\mathrm{NH}_{3}$ reduction, using $\left[\mathrm{H}\left(\mathrm{OEt}_{2}\right)_{2}\right]\left[\mathrm{BAr}_{4}^{\mathrm{F}}\right]$ as proton source and $\mathrm{KC}_{8}$ as reducing agent. Under carefully optimized conditions, i.e. $-78^{\circ} \mathrm{C}, \mathrm{Et}_{2} \mathrm{O}$ as solvent, 1 h, 200 eq. $\mathrm{KC} 8$ and 184 eq. $\mathrm{H}^{+}$source, up to 15.9 equivalents of $\mathrm{NH}_{3}$ are formed together with 1.0 equivalent of hydrazine.

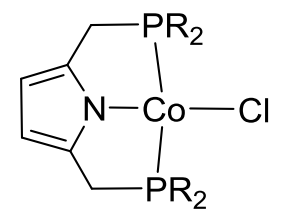

$\mathrm{R}=t \mathrm{Bu}, \mathrm{Cy}$

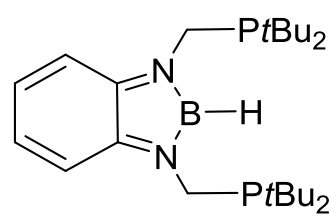

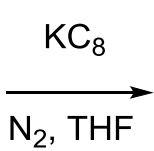

1) $\mathrm{CoBr}_{2}$

2) $2 \mathrm{Na} / \mathrm{Hg}$

$\mathrm{N}_{2}, \mathrm{THF}$
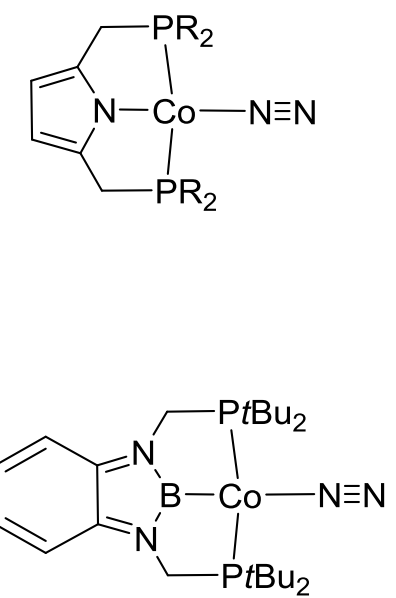

Scheme 111

A diazaborole [PBP] pincer ligand was reported by Peters to allow the formation of the $\left[[\mathrm{PBP}] \mathrm{Co}\left(\mathrm{N}_{2}\right)\right]$ complex upon reduction under $\mathrm{N}_{2}$ with $\mathrm{Na} / \mathrm{Hg}$ (scheme 111, bottom) ${ }^{414}$ It appears that the strongly $\sigma$ donor boryl and the $\pi$ basic amido are similarly (poorly) effective in $\mathrm{N}_{2}$ activation ( $v_{\mathrm{NN}}$ values of $2013 \mathrm{~cm}^{-1}$ and 2024 to 1999 respectively).

The group of Fryzuk and Masuda developed a novel pincer $\left[\mathrm{N}^{\mathrm{P}} \mathrm{NP}\right]^{-}$ligand which $\mathrm{N}^{\mathrm{P}} \mathrm{N}$ anionic part bears resemblance to $\beta$-diketiminate ligand. ${ }^{415}$ Reduction of the $\mathrm{Co}^{\mathrm{II}}$ precursor by $\mathrm{KC}_{8}$ generated the paramagnetic $(\mathrm{S}=1)$ complex $\left[\left[\mathrm{N}^{\mathrm{P}} \mathrm{NP}\right] \mathrm{Co}\right]$, which exists in solution in equilibrium with a small amount of the dinitrogen complex $\left[\left[\mathrm{N}^{\mathrm{P}} \mathrm{NP}\right] \mathrm{Co}\left(\mathrm{N}_{2}\right)\right]$ (scheme 112). Crystals incorporating both complexes could be grown. Most interestingly, the mixture catalyzed the $\mathrm{N}_{2}$-to-NTMS 3 reduction. Under optimized 
conditions $\left(-40^{\circ} \mathrm{C}\right.$, THF, $1500 \mathrm{KC}_{8}, 2000 \mathrm{SiMe}_{3} \mathrm{Cl}, 10$ days $), 200$ equiv. of $\mathrm{N}\left(\mathrm{SiMe}_{3}\right)_{3}$ were formed.
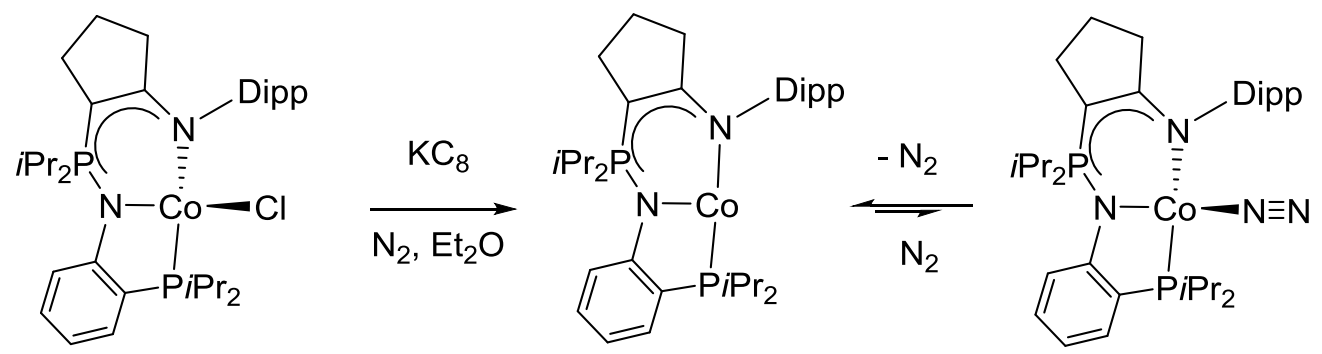

Scheme 112

Pincer $\left[{ }^{\mathrm{R}} \mathrm{CCC}\right]^{-}(\mathrm{R}=$ Dipp, Mes) ligands featuring two carbenes and an aryl moiety was used by Fout to synthesize Co- $\mathrm{N}_{2}$ complexes via reduction of the $\mathrm{Co}^{\mathrm{II}}$ precursor at low temperature (scheme 113). ${ }^{416},{ }^{417}$ Like most of the $\mathrm{Co}^{\mathrm{I}}-\mathrm{N}_{2}$ complexes, they are diamagnetic with a square planar geometry at Co and present a weakly activated $\mathrm{N}_{2}$. Addition of a phosphine yielded the square base pyramid complexes, also diamagnetic, with $\mathrm{N}_{2}$ in the equatorial plane. The $\left[\left[{ }^{\text {Dipp }} \mathrm{CCC}\right] \mathrm{Co}\left(\mathrm{N}_{2}\right)\right]$ complex was used as catalyst in hydrosilylation of alkene reactions. ${ }^{418}$

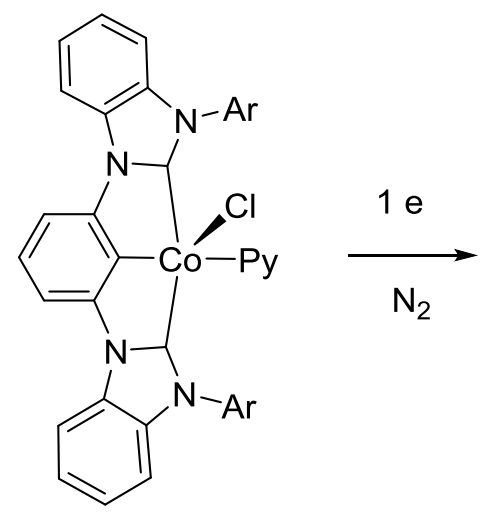

$\mathrm{Ar}=\mathrm{Dipp}$, Mes

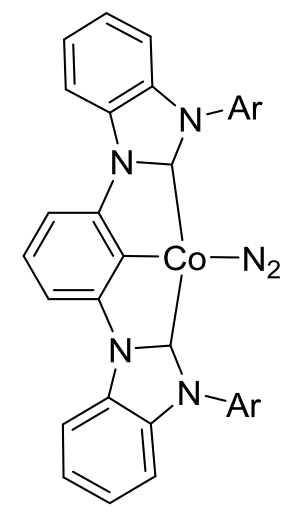

$\mathrm{PR}_{3}$

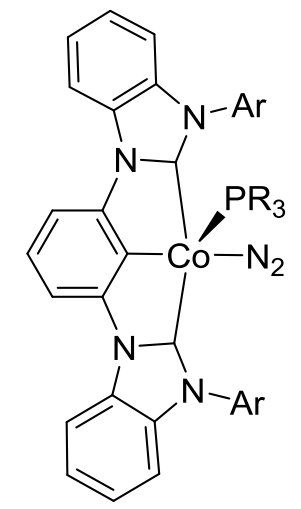

$\mathrm{Ar}=\mathrm{Dipp}, \mathrm{R}=\mathrm{Ph}$

$\mathrm{Ar}=\mathrm{Mes}, \mathrm{R}=\mathrm{Me}$

Scheme 113 
The group of Deng synthesized a pincer $[\mathrm{CSiC}]^{-}$anionic ligand featuring two carbene moieties in the coordination sphere of Co (scheme 114). ${ }^{419}$ Subsequent reaction of the $\mathrm{Co}^{\mathrm{III}}\left[[\mathrm{CSiC}] \mathrm{Co}(\mathrm{H})\left(\mathrm{OEt}_{2}\right)\right]\left[\mathrm{BPh}_{4}\right]$ complex with hydride source under $\mathrm{N}_{2}$ resulted in the formation of the $\left[[\mathrm{CSiC}] \mathrm{Co}\left(\mathrm{N}_{2}\right)\right]$ species, which presents a strongly distorted square planar geometry at $\mathrm{Co}\left(\mathrm{SiCoN}\right.$ angle of $\left.131^{\circ}\right)$. Despite this, the complex is diamagnetic in solution. IR data collected both in solution and solid state show nearly identical frequencies $\left(v_{\mathrm{NN}}: 2004 \mathrm{~cm}^{-1}\right.$ for ${ }^{14} \mathrm{~N}$ complex in the solid, $1943 \mathrm{~cm}^{-1}$ and 1937 $\mathrm{cm}^{-1}$ for ${ }^{15} \mathrm{~N}$ complex in the solid and in solution respectively).
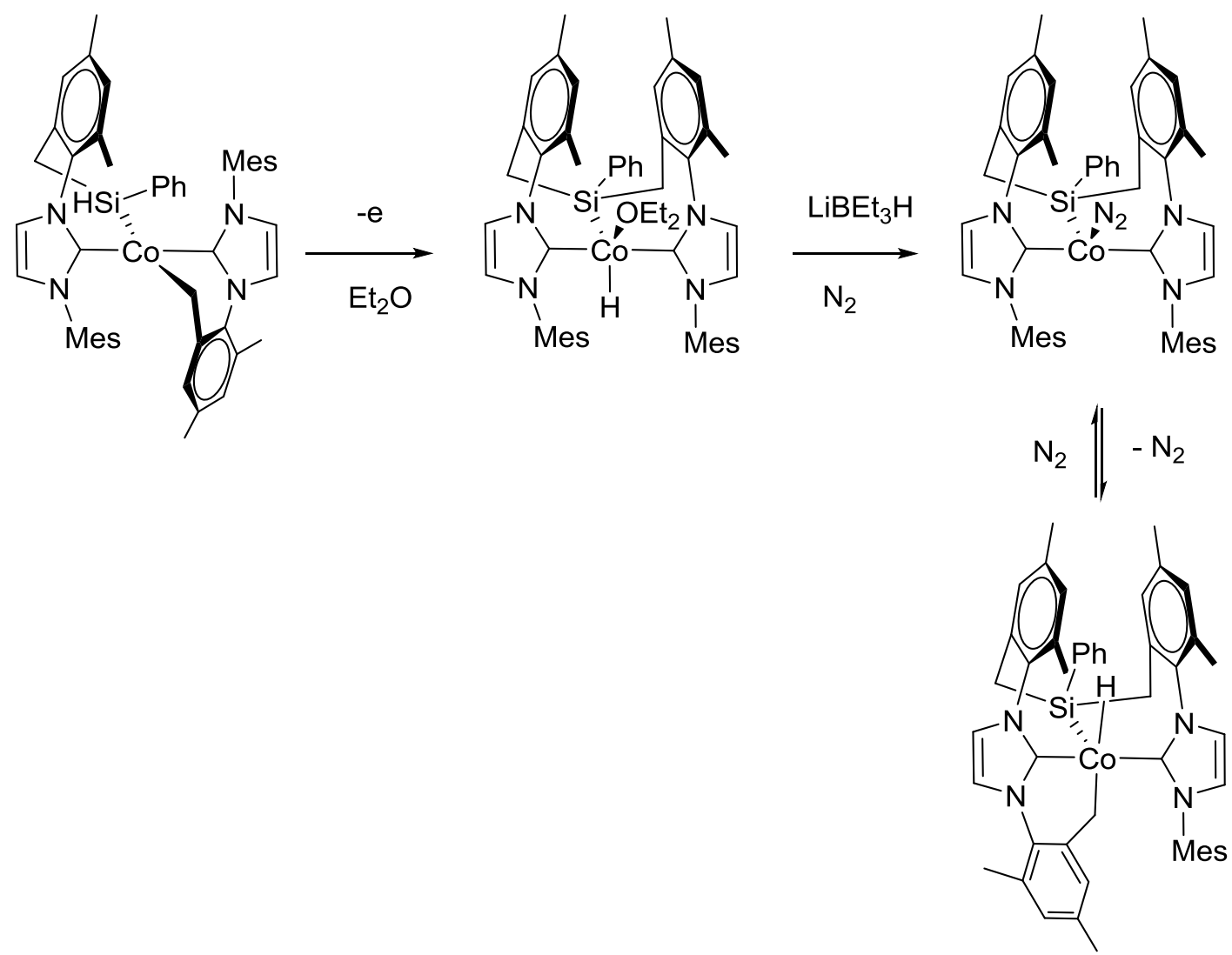

Scheme 114 


\subsection{Rh complexes}

As will be seen below, no $\mathrm{Rh}$ and $\mathrm{Ir}$ complexes are known for $\mathrm{N}_{2}$ functionalization, either in a stoichiometric or catalytic way. They thus differ markedly from Co complexes for which N-H and N-Si bond formations have been reported.

\subsection{1 $P$ and $N$ containing neutral ligands}

Even if the first crystal structure of a $\mathrm{Rh}-\mathrm{N}_{2}$ complex was obtained in 1976 using phosphine ligands, $\left[\mathrm{Rh}(\mathrm{H})\left(\mathrm{N}_{2}\right)\left(\mathrm{P} t \mathrm{Bu}_{2} \mathrm{Ph}\right)_{2}\right],{ }^{420}$ little work has been reported since 2003 using such ligands. In a work related to studies on the formation of Rh-vinylidenes, Werner and coworkers studied the coordination of diazoalkanes to $\left[\mathrm{Rh}(\mathrm{PiPr})_{2} \mathrm{Cl}\right]_{2} .{ }^{421} \mathrm{In}$ most cases, simple coordination via terminal $\mathrm{N}$ of the diazo occurs, without $\mathrm{NC}$ bond breaking, leading to $\left[\mathrm{Rh}\left(\mathrm{PiPr}_{3}\right)_{2}\left(\mathrm{R}_{2} \mathrm{CN}_{2}\right) \mathrm{Cl}\right]$ complexes. Only in the case of $\mathrm{CH}\left(\mathrm{CO}_{2} \mathrm{Et}\right) \mathrm{N}_{2}$ does the $\left[\mathrm{Rh}\left(\mathrm{P} i \mathrm{Pr}_{3}\right)_{2}\left(\mathrm{~N}_{2}\right) \mathrm{Cl}\right]$ complex forms. Neutral tridentate ligand featuring phosphines or phosphites, such as $[\mathrm{PNP}]$, where $\mathrm{N}$ is a pyridine moiety have been reported to stabilize square planar $\mathrm{Rh}^{\mathrm{I}}-\mathrm{N}_{2}$ complexes. ${ }^{422},{ }^{423}$ Upon deprotonation, the ligand becomes [PNP] ${ }^{-}$anionic, and metal-ligand cooperation has been reported. ${ }^{424}$

The group of Burger has used bis-(imino)pyridine $\left[\mathrm{N}^{\mathrm{R}} \mathrm{NN}^{\mathrm{R}}\right](\mathrm{R}=$ Mes or Dipp) ligands to study the synthesis and reactivity of $\mathrm{M} \equiv \mathrm{N}$ nitrido complexes $(\mathrm{M}=\mathrm{Rh}, \mathrm{Ir})$ (scheme 115). ${ }^{425}$ In order to study the dimerization process, they independently synthesized the Rh- $\mathrm{N}_{2}$ by reduction of the $\left[\left[\mathrm{N}^{\mathrm{R}} \mathrm{NN}^{\mathrm{R}}\right] \mathrm{RhCl}\right]$ precursors. In the case of $\mathrm{R}=$ Mes, a bridging $\mathrm{N}_{2}$ complex is formed while the terminal end-on complex is obtained for the more bulky Dipp ligand. In fact, the $\mathrm{N}_{2}$ complex does not form upon irradiation of the azide derivative $\left[\left[\mathrm{N}^{\text {Dipp }} \mathrm{NN} \mathrm{N}^{\text {Dipp }}\right] \mathrm{Rh}\left(\mathrm{N}_{3}\right)\right]$ because of the high reactivity of the generated nitride $\left[\left[\mathrm{N}^{\text {Dipp }} \mathrm{NN}^{\text {Dipp }}\right] \mathrm{Rh}(\mathrm{N})\right]$. Instead, multiple $\mathrm{CH}$ bond insertions into the ligand are observed. 


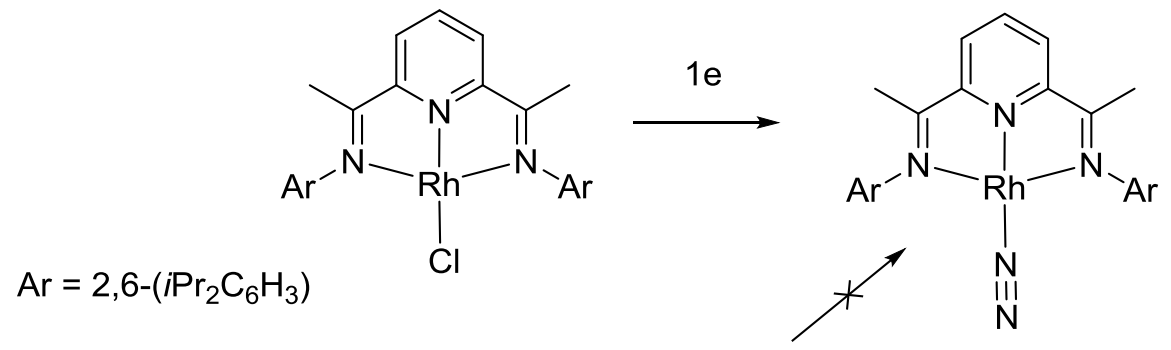

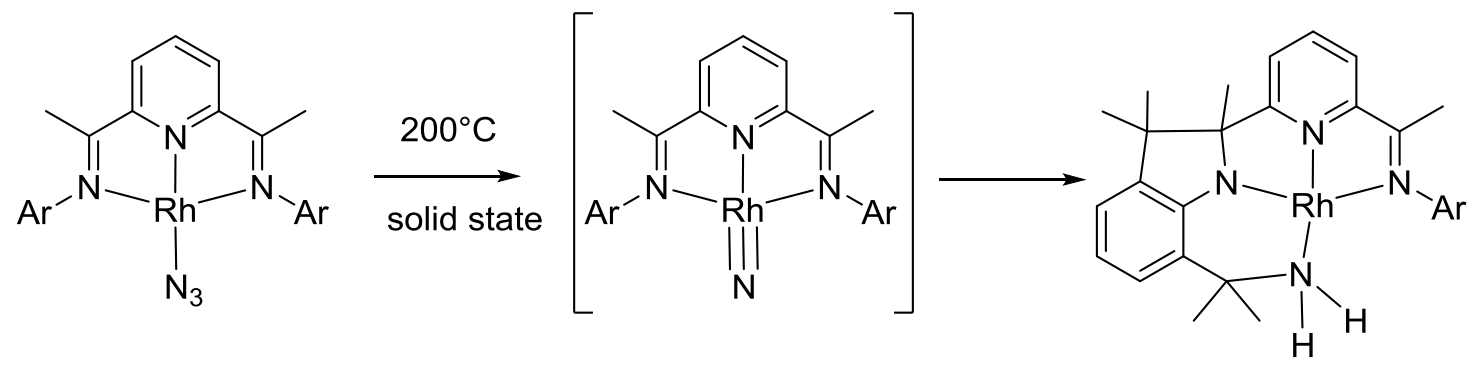

Scheme 115

\subsection{2 $P$ and $N$ containing anionic ligands}

Anionic $[\mathrm{PCP}]^{-}$ligands have been used to a large extent to provide robust platforms "M[PCP]" for many catalytic applications. Accordingly, coordination of $\mathrm{N}_{2}$ at these fragments is sufficient to allow isolation of the 16 electron complexes, yet $\mathrm{N}_{2}$ is readily displaced by many two electron donors en route to catalysis. ${ }^{426},{ }^{427}$ An equilibrium between terminal and bridging end-on complexes has been observed (scheme 116). ${ }^{428}$ Unlike what was presented above, reaction of $\mathrm{PhCHN}_{2}$ formed a stable adduct only at low temperature. Above $-30^{\circ} \mathrm{C}$, the diazo is transformed into the carbene complex. 

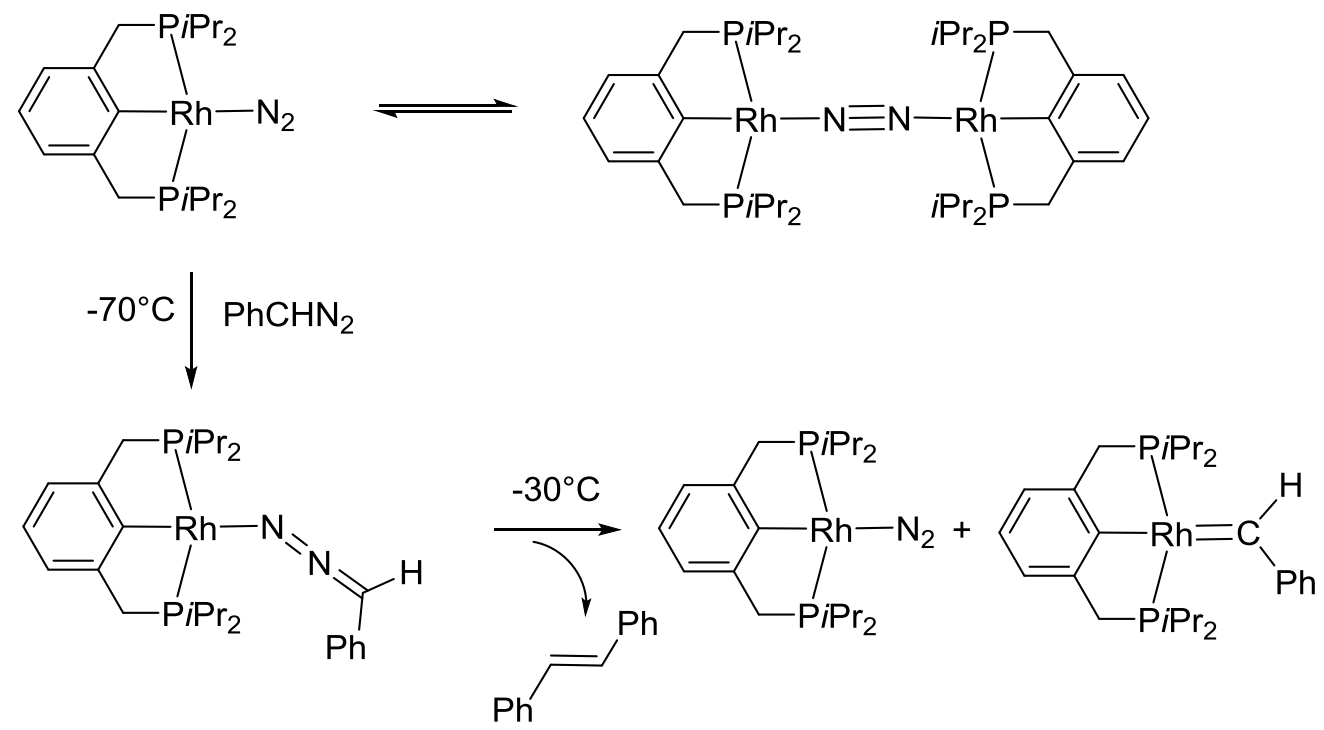

Scheme 116

Related properties have been observed with anionic $[\mathrm{PNP}]^{-}$ligands, i.e. weak coordination of $\mathrm{N}_{2}$ at $\mathrm{Rh}^{4}{ }^{429},{ }^{430}$ In 2013, Schneider, de Bruin and coworkers reported the synthesis of $\left[[\mathrm{PNP}] \mathrm{Rh}\left(\mathrm{N}_{2}\right)\right]$ and $[[\mathrm{PNP}] \mathrm{Rh}]\left(\mu-\mathrm{N}_{2}\right)\left([\mathrm{PNP}]=\left[\mathrm{N}\left(\mathrm{CH}=\mathrm{CHP} t \mathrm{Bu}_{2}\right)_{2}\right]\right)$ via coupling of the unstable $[[\mathrm{PNP}] \mathrm{Rh}(\mathrm{N})] \mathrm{Rh}^{\mathrm{IV}}$ nitride derivative (scheme 117$) .{ }^{431}$ Thus, irradiation of the azide precursor in frozen solution generated the nitride which was characterized by in situ IR and EPR spectroscopies. Upon warming, dimerization occurs followed by formation of the terminal $\mathrm{N}_{2}$ complex.

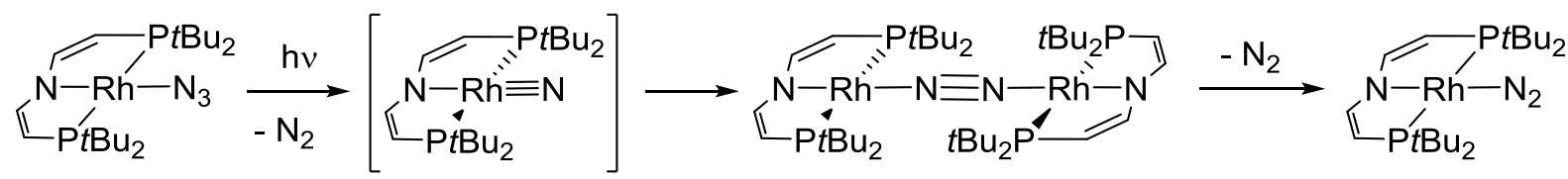

Scheme 117

Yamashita, Nozaki and coworkers reported the use of [PBP]diazaborolide/phosphine pincer ligand to stabilize unsaturated [[PBP]Rh] fragment. ${ }^{432}$ Indeed, this $\mathrm{T}$ shaped fragment is only stabilized in the crystal structure by a $\sigma \mathrm{CH}$ bond of the benzene moiety of another ligand. In solution, coordination of $\mathrm{N}_{2}$ is favorable and leads to the expected square planar $\mathrm{Rh}^{\mathrm{I}}$ derivative. 


\subsubsection{NHC ligands}

The group of Crudden has studied the coordination of the bulky NHC ligands (IPr and SIPr) as alternative to phosphines. The $\left[\mathrm{Rh}(\operatorname{IPr})_{2} \mathrm{Cl}\left(\mathrm{N}_{2}\right)\right]$ and $\left[\mathrm{Rh}(\mathrm{SIPr})_{2} \mathrm{Cl}\left(\mathrm{N}_{2}\right)\right]$ complexes feature coordinated $\mathrm{N}_{2}$ ligand, also readily displaced, even in the crystal by $\mathrm{O}_{2}$ and $\mathrm{CO}^{433,434}$

\subsection{Ir complexes}

\subsubsection{Neutral ligands}

Using the bulky monodentate phosphine $\mathrm{P} \mathrm{Pr}_{2} \mathrm{Ad}$, Figueroa observed the reversible $\mathrm{N}_{2}$ coordination at $\left[\operatorname{Ir}\left(\operatorname{PiPr}_{2} \mathrm{Ad}\right)_{2}(\mathrm{H})\left(\mathrm{N}_{2}\right)\right]$ and $\mathrm{CH}$ bond insertion into the ligand at room temperature (scheme 118). ${ }^{435}$
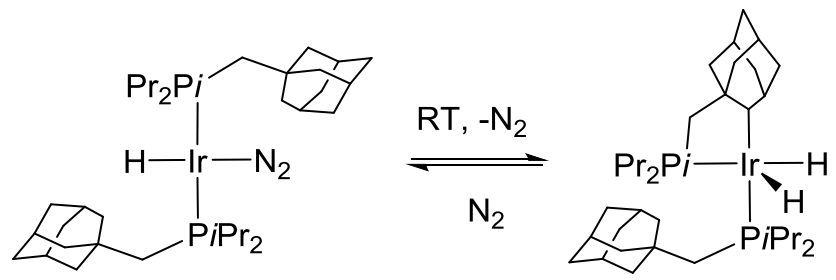

Scheme 118

Also in 2010, Aldridge reported the first example of a bis- $\mathrm{N}_{2}$ complex of $\mathrm{Ir}$, [ $\left.\operatorname{Ir}(\mathrm{IMes})_{2}\left(\mathrm{~N}_{2}\right)_{2}\right] \mathrm{BAr}_{4}{ }_{4}$, in which the $\mathrm{N}_{2}$ ligands are trans to each other. ${ }^{436}$ One of the $\mathrm{N}_{2}$ ligand is readily displaced by THF. Here, as above, the NN bond distance of $1.109(8) \AA$ shows minimal elongation compared to free $\mathrm{N}_{2}$, although the IR stretch are found at $c a$ $1985 \mathrm{~cm}^{-1}$. The same group also prepared the $\left[\operatorname{Ir}(\mathrm{IMes})(\mathrm{Cl})\left(\mathrm{N}_{2}\right)(\mathrm{COE})\right]$ complex, as precursor to $\left[\operatorname{Ir}(\mathrm{IMes})_{2}(\mathrm{Cl})(\mathrm{COE})\right]^{437}$

In 2013, Bohle and coworkers used the labile character of $\mathrm{N}_{2}$ in $\left[\operatorname{Ir}\left(\mathrm{PPh}_{3}\right)_{2} \mathrm{Cl}\left(\mathrm{N}_{2}\right)\right]$ to trap the azo form of the azo-triazole equilibrium (scheme 119). ${ }^{438}$ 
<smiles>[N-]=Nc1ccccc1NS(=O)(=O)OC(F)(F)F</smiles>

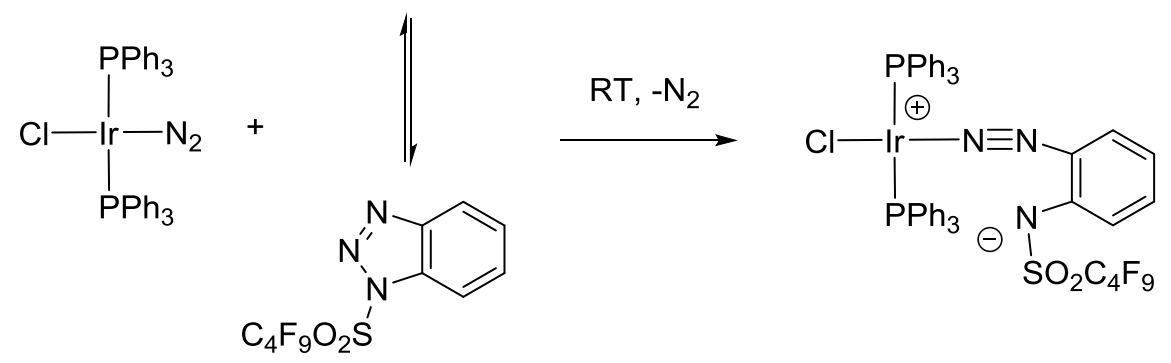

Scheme 119

\subsubsection{Anionic ligands}

In search for luminescent Ir complexes, the group of Zhang and Ding discovered serendipitously an $\mathrm{Ir}^{\mathrm{II}} / \mathrm{Ir}^{\mathrm{II}}$ metal-metal-bonded complex featuring a single end-on $\mathrm{N}_{2}$ ligand. The two metal centers are coordinated by three cyclometalated phenylquinolyl ligands in total. ${ }^{439}$

The tetradentate $\left[\mathrm{SiP}_{3}\right]^{-}$was utilized to stabilize trigonal bipyramidal $\operatorname{Ir}^{\mathrm{I}}$ [[SiP $\left.] \operatorname{Ir}\left(\mathrm{N}_{2}\right)\right]$, similarly to $\mathrm{Co}^{280}$ The $\mathrm{N}_{2}$ ligand, trans to the strong $\sigma$-donor silyl, is weakly coordinated and shows a stretching frequency at $2122 \mathrm{~cm}^{-1}, 59 \mathrm{~cm}^{-1}$ higher than the Co analogue. It is readily removed under vacuum.

Like for the $\mathrm{Rh}$ complexes, anionic $[\mathrm{PCP}]^{-}$ligands have been used to provide robust platforms "Ir[PCP]" for catalytic applications, ${ }^{440},{ }^{441}$ such as alkane dehydrogenation. ${ }^{42}$ In these cases, the $\mathrm{N}_{2}$ complexes can inhibit the reactivity, but in general $\mathrm{N}_{2}$ is readily displaced by even poor sigma donors. Brookhart has even showed that $\mathrm{N}_{2}$ can be displaced and that reactions could subsequently occur in single crystals. ${ }^{443}$

Shimada reported the synthesis of a [PSiP] $^{-}$pincer ligand by insertion of an $\operatorname{Ir}(\mathrm{I})$ 
precursor into the $\mathrm{SiH}$ bond of the $[\mathrm{PSiHP}]$ ligand. Subsequent reaction of the $[[\mathrm{PSiP}] \operatorname{Ir}(\mathrm{H})(\mathrm{Cl})]$ with hydride sources lead to mer (major, $85-90 \%)$ and $\mathrm{fac}$ (minor) dihydride complexes [[PSiP] $\left.\operatorname{Ir}(\mathrm{H})_{2}\left(\mathrm{~N}_{2}\right)\right]$. In the mer isomer, the $\mathrm{N}_{2}$ ligand is trans to a hydride while in the $f a c$, it is trans to Si with the N-N stretching frequencies are at 2091 $\mathrm{cm}^{-1}$ and $1926 \mathrm{~cm}^{-1}$ respectively. ${ }^{444}$

Tris-pyrazolyl borates have also been shown to support $\mathrm{N}_{2}$ coordination at Ir. Carmona and coworkers irradiated the $\operatorname{Ir}(\mathrm{I})\left[\left(\mathrm{Tp}^{\mathrm{tol}}\right) \operatorname{Ir}(\right.$ isoprene $\left.)\right]$ complex in $\mathrm{C}_{6} \mathrm{H}_{6}$ under $\mathrm{N}_{2}$. The isoprene loss resulted in both intra (in the tolyl substituent) and inter (in $\mathrm{C}_{6} \mathrm{H}_{6}$ ) $\mathrm{CH}$ bond activations yielding an $\mathrm{Ir}(\mathrm{III})-\mathrm{N}_{2}$ complex. ${ }^{445}$

In 2004, Chirik showed that $\left[\operatorname{Ir}\left(\mathrm{L}^{\mathrm{Me}, \mathrm{dipp}}\right)\left(\mathrm{N}_{2}\right)(\mathrm{COE})\right]\left(\mathrm{L}^{\mathrm{Me}, \mathrm{dipp}}=\mathrm{CH}\{\mathrm{CMeN}(2,6-i-\right.$ $\left.\left.\mathrm{Pr}_{2} \mathrm{C}_{6} \mathrm{H}_{3}\right)\right\}_{2}{ }^{-}$) can be used as precursor for $\mathrm{H}_{2}$ and $\mathrm{CH}$ bond activation. ${ }^{446}$

In 2008, Grubbs reported the use of a [[PNP]Ir( $\left.\left(\mathrm{N}_{2}\right)\right]$ complex as catalyst for the oxidation of $t \mathrm{BuMeO}$ by organic azide to produce $\mathrm{HC}=\mathrm{NR}(\mathrm{O} t \mathrm{Bu})($ scheme 120$) .{ }^{447}$ The Ir- $\mathrm{N}_{2}$ moiety is generated from the reaction between the $\mathrm{Ir}=\mathrm{CHO} t \mathrm{Bu}$ Fischer carbene intermediate and nucleophilic azide. The reaction requires the use of NBE (norbornene) as sacrificial $\mathrm{H}_{2}$ acceptor.

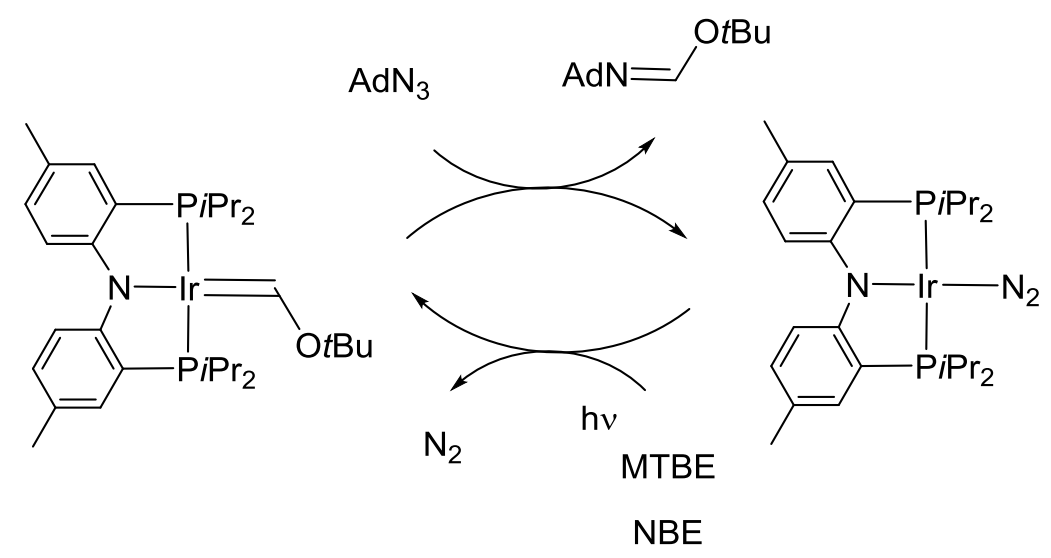

Scheme 120 
The groups of Schneider and de Bruin have studied in greatest details the chemistry of the "[PNP]Ir" fragment $\left([\mathrm{PNP}]=\left(\mathrm{N}\left(\mathrm{CHCHP} t \mathrm{Bu}_{2}\right)_{2}\right)\right.$, in parallel to the one of Rh presented above. They do bear some similarities. In particular, photolysis of the $\operatorname{Ir}^{\mathrm{II}}$ azide precursor generates the nitride $\operatorname{Ir}^{\mathrm{IV}}$ complex, unstable at room temperature which eventually leads to the bridging $\mathrm{N}_{2}$ dimer (scheme 121). On the other hand, oxidation by one electron yields the stable $\operatorname{Ir}^{\mathrm{V}}$ nitride cationic species. ${ }^{448}$ This is explained by the nitridyl $\mathrm{N}^{\circ}$ character of the neutral $v s$ closed shell nature of the cation. Alternatively, the bridging $\mathrm{N}_{2}$ dimer can be obtained upon one electron reduction of the cation and the mechanism was studied. ${ }^{449}$ Although the nitride is not obtained from $\mathrm{N}_{2}$, understanding its functionalization is important.

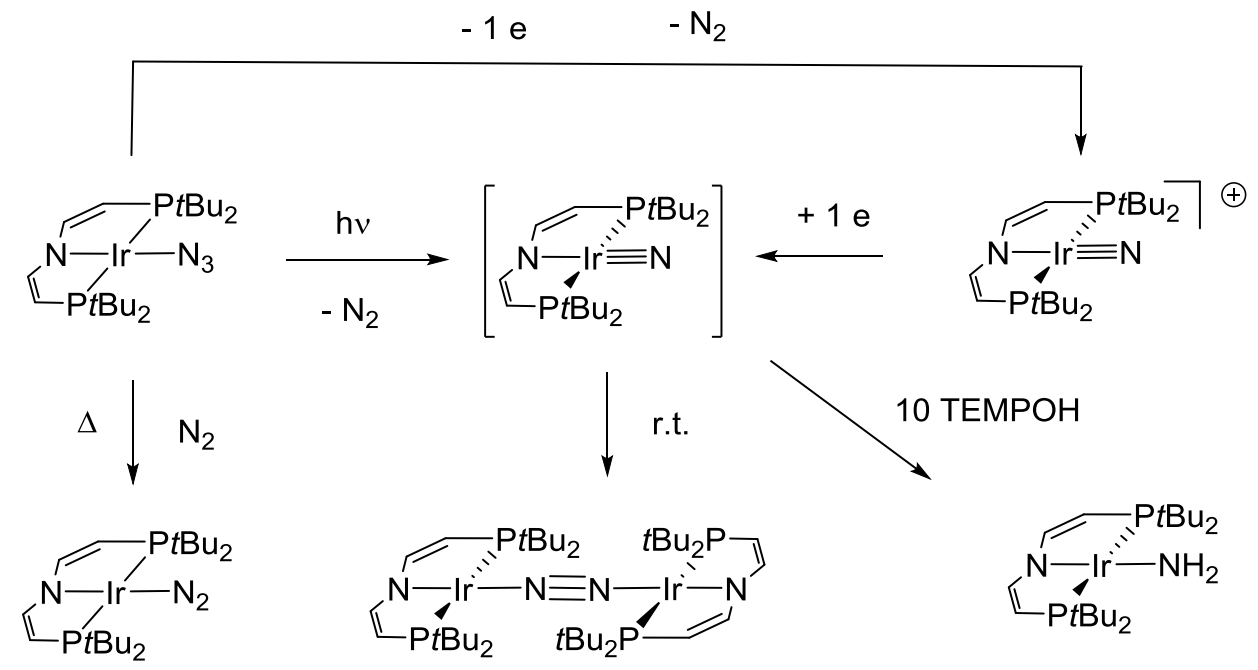

Scheme 121

$\mathrm{H}$ atom transfer to form the amido complex was studied experimentally and computationally. Protonation of the amido finally generates the $\mathrm{Ir}_{-} \mathrm{NH}_{3}$ complex. ${ }^{450}$

\section{Group 10 and 11 transition metal-dinitrogen complexes}

Jonas made a seminal report on the synthesis and structural characterization of the 
$\mathrm{Ni}-\mathrm{N}_{2}$ complex $\left[\mathrm{Ni}\left(\mathrm{PCy}_{3}\right)_{2}\left(\mathrm{~N}_{2}\right)\right]$ in 1968. An equilibrium between the mononuclear complex and the $\mu-\eta^{1}: \eta^{1}-\mathrm{N}_{2}$ bridged dinuclear complex was evidenced. Johnson proposed a different synthetic approach to the $\left[\mathrm{Ni}\left(\mathrm{PiPr}_{3}\right)_{2}\right]_{2}\left(\mu-\eta^{1}: \eta^{1}-\mathrm{N}_{2}\right)$ complex, relying on the reduction of the $\left[\mathrm{Ni}\left(\mathrm{PiPr}_{3}\right)_{2} \mathrm{Cl}\right] \mathrm{Ni}^{\mathrm{I}}$ precursor with $\mathrm{Mg}$ in $\mathrm{THF}$ (scheme 122). ${ }^{451}$ Interestingly, the complex features a NN stretching frequency at $1908 \mathrm{~cm}^{-1}$ in the Raman spectrum, a very low value compared to other Ni complexes, which can be linked to the geometry of the complex favoring the orbital overlap with the $\pi^{*}$ orbitals of $\mathrm{N}_{2}$.

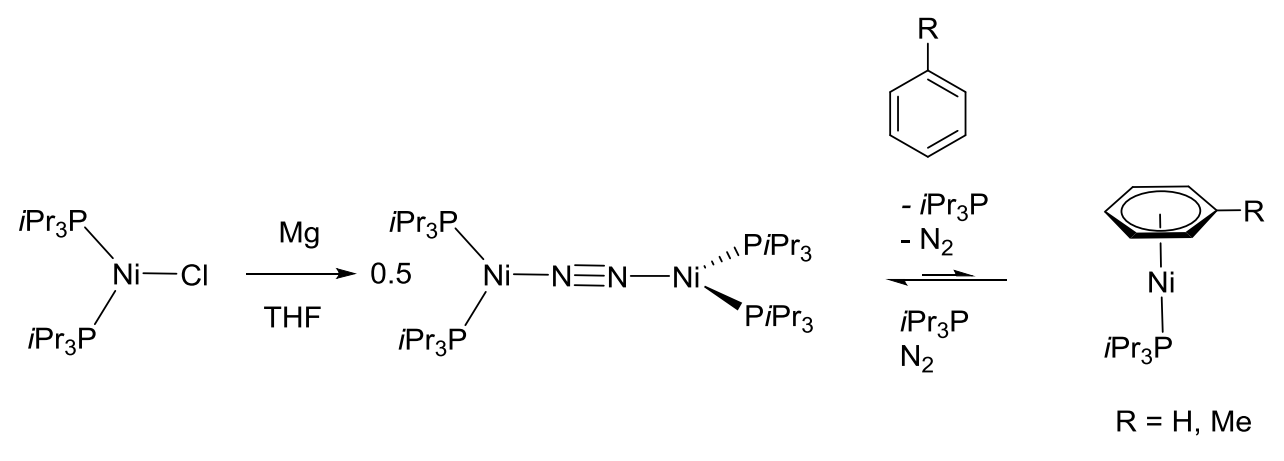

Scheme 122

Waterman and Hillhouse reported the synthesis of the pseudo tetrahedral $\mathrm{Ni}^{0}$ complex $\left[\mathrm{Ni}(\mathrm{dtbpe})\left(\mathrm{PPh}_{3}\right)\left(\mathrm{N}_{2}\right)\right]$ from the reaction of $[\mathrm{Ni}(\mathrm{dtbpe})]_{2}\left(\mu, \eta^{2}: \eta^{2} \mathrm{C}_{6} \mathrm{H}_{6}\right)$ with $\mathrm{PPh}_{3}$ under $\mathrm{N}_{2}{ }^{452}$ Starting from 2014 Lee and coworkers developed tridentate phosphine/Ni platforms that support $\mathrm{N}_{2}$ coordination. In a first study, the neutral [[PPP]Ni( $\left.\left.\mathrm{N}_{2}\right)\right] \mathrm{Ni}^{0}$

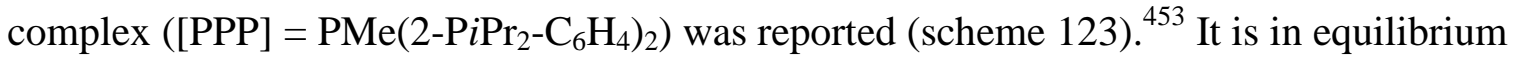
with the $\mathrm{N}_{2}$ bridged dimer. $\mathrm{N}_{2}$ is reversibly displaced by $\mathrm{CO}_{2}$, pointing a weak coordination of both ligands to Ni. 


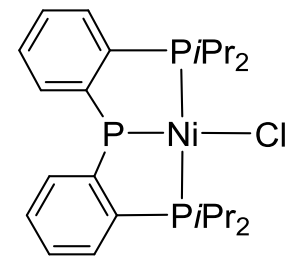

\begin{tabular}{l|l}
$\mathrm{R}^{\prime}=\mathrm{Me}$, & $\mathrm{R}^{\prime} \mathrm{O}^{-}$ \\
$\mathrm{iPr}$ & $\mathrm{N}_{2}$
\end{tabular}

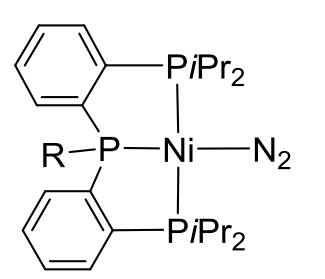

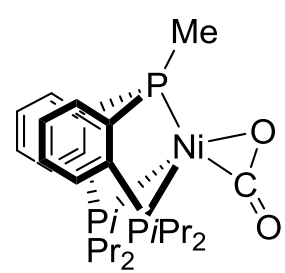

$\mathrm{CO}_{2} \| \begin{aligned} & \mathrm{N}_{2} \\ & \mathrm{R}=\mathrm{Me}\end{aligned}$
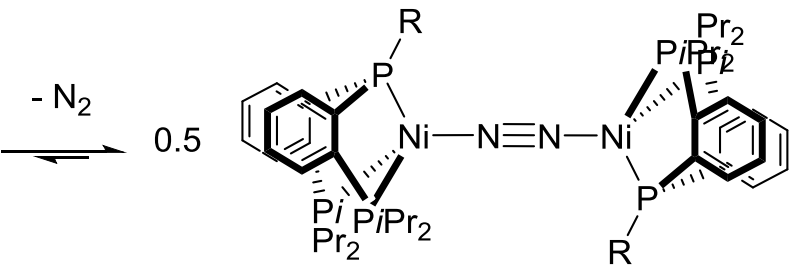

$\mathrm{R}=\mathrm{Me}, \mathrm{OMe}, \mathrm{OiPr}$

Scheme 123

The same group found out that the related phosphide $\mathrm{Ni}^{\mathrm{II}}$ complex reacted with alkoxide sources under $\mathrm{N}_{2}$ to form the $\mathrm{Ni}^{0}$ [[PPP]Ni( $\left.\left.\mathrm{N}_{2}\right)\right]$ complexes via a formal reductive elimination of the P-OR' moiety. ${ }^{454},{ }^{455}$ If the reaction is carried out under Ar, the reduction of the Ni center does not occur, and the ligand remains the anionic $[\mathrm{PPP}]^{-}$ ligand featuring a central phosphide.

The groups of Balcells and Hazari observed a related reactivity with an anionic [PSiP] ${ }^{-}$ ligand $\left([\mathrm{PSiP}]=\mathrm{SiMe}\left(2-\mathrm{PCy}_{2}-\mathrm{C}_{6} \mathrm{H}_{4}\right)_{2}\right)$. Thus, upon reaction of the $[[\mathrm{PSiP}] \mathrm{NiH}]$ complex with $\mathrm{N}_{2}$, reductive elimination of $\mathrm{SiH}$ was evidenced (scheme 124). The coordination sphere of the $\mathrm{Ni}^{0}$ formed is completed by an agostic interaction with the $\mathrm{Si}-\mathrm{H}$ bond. ${ }^{456}$

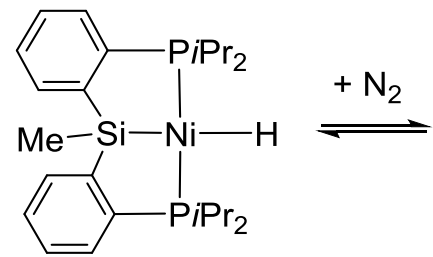

$[[\mathrm{PSiP}] \mathrm{NiH}]$

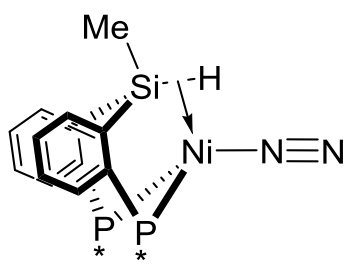

$\mathrm{P}^{*}=\mathrm{PiPr}_{2}$
[[PSiP] NiH]

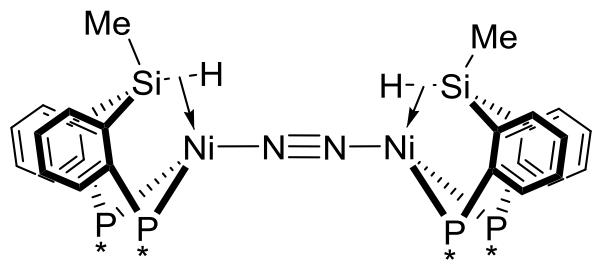




\section{Scheme 124}

The group of Peters evidenced tridentate coordination of the neutral $\left[\mathrm{BP}_{2}\right]$ ligand, via the $\mathrm{BPh}$ moiety as well as phosphines, in the $\left[\left[\mathrm{BP}_{2}\right] \mathrm{Ni}\left(\mathrm{N}_{2}\right)\right] \mathrm{Ni}^{0}$ complex, obtained by $\mathrm{Na} / \mathrm{Hg}$ reduction of the $\mathrm{Ni}^{\mathrm{I}}$ precursor (scheme 125). ${ }^{457}$ In the solid state structure, both the monomer and the end on $\mathrm{N}_{2}$ bridging dimer are present. The complex reacts with $\mathrm{H}_{2}$ to release $\mathrm{N}_{2}$ and form first the dihydrogen adduct, followed by $\mathrm{H}-\mathrm{H}$ cleavage and insertion into the $\mathrm{NiB}$ bond.
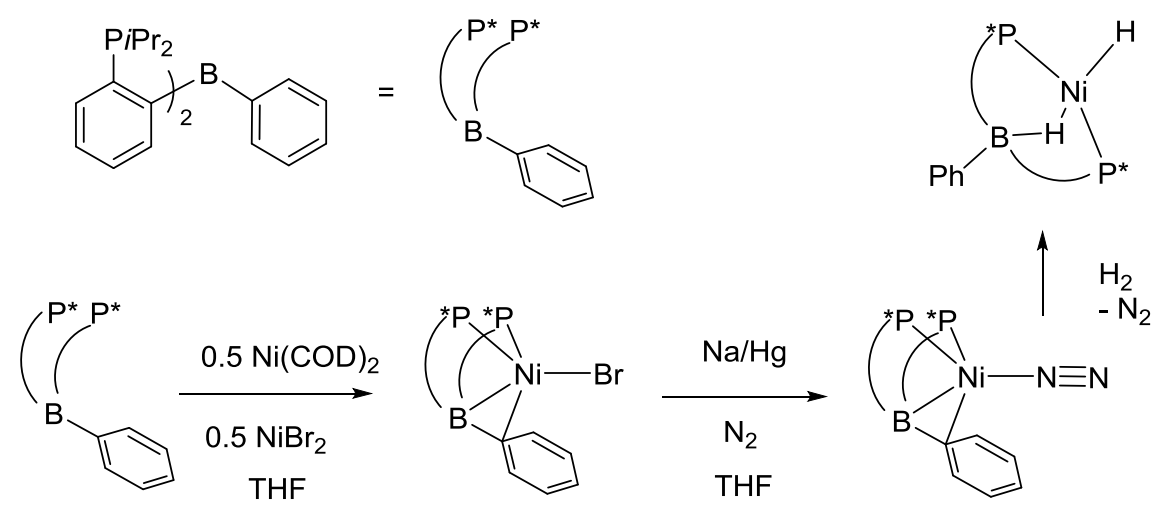

Scheme 125

Coordination of another tridentate neutral [PPP] ligand featuring a ferrocenyl moiety $\left([\mathrm{PPP}]=\left[\mathrm{Fe}\left(\eta^{5}-\mathrm{C}_{5} \mathrm{H}_{4} \mathrm{PPh}_{2}\right)\left(\eta^{5}-\mathrm{C}_{5} \mathrm{H}_{4} \mathrm{P} t \mathrm{Bu}-2-\mathrm{PPh}_{2} \mathrm{C}_{6} \mathrm{H}_{4}\right)\right]\right)$ to $\mathrm{Ni}^{0}$ under $\mathrm{N}_{2}$ also yielded a binuclear complex with bridging dinitrogen $[[\mathrm{PPP}] \mathrm{Ni}]_{2}\left(\mu-\eta^{1}: \eta^{1}-\mathrm{N}_{2}\right)$ (scheme 126). ${ }^{458}$ If the $\mathrm{PPh}_{2}$ moiety is replaced by a $\mathrm{BPh}_{2}$ moiety, its coordination is observed rather than $\mathrm{N}_{2}$ coordination, much like for the $\left[\mathrm{BP}_{2}\right]$ ligand presented above. 


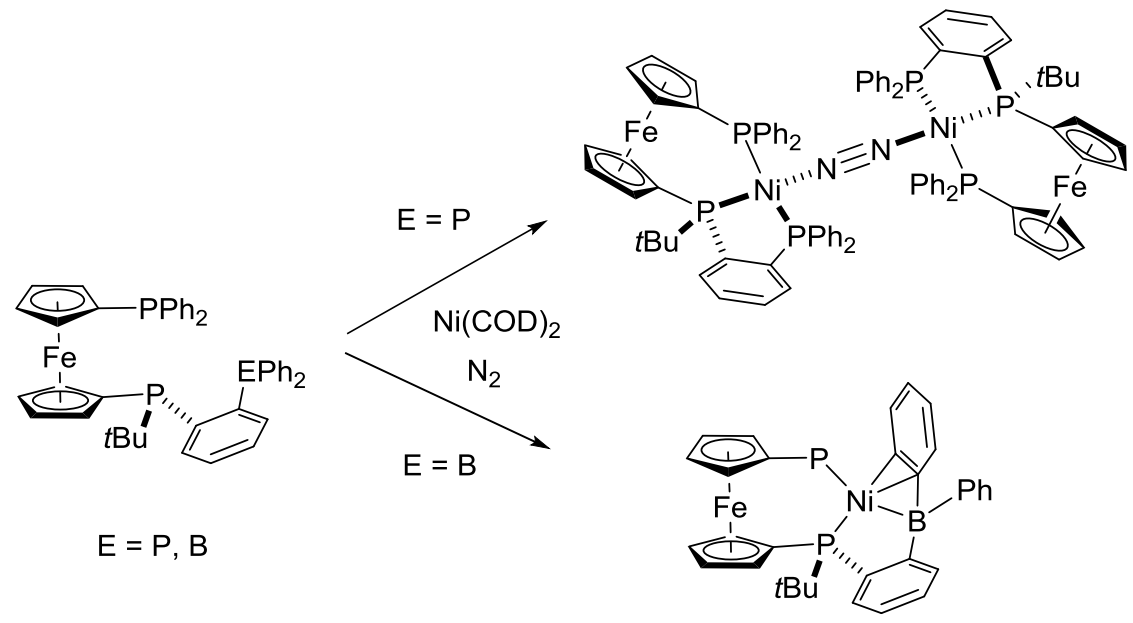

Scheme 126

Tetrapodal ligands have also been used for the stabilization of $\mathrm{Ni}-\mathrm{N}_{2}$ complexes. Upon protonation of the $\left[\left[\mathrm{SiP}_{3}\right] \mathrm{Ni}\left(\mathrm{CH}_{3}\right)\right] \mathrm{Ni}$ complexes under $\mathrm{N}_{2}$, Peters isolated the corresponding cationic $\mathrm{N}_{2}$ complex $\left[\left[\mathrm{SiP}_{3}\right] \mathrm{Ni}\left(\mathrm{N}_{2}\right)\right]^{+}$, in which the $\mathrm{N}_{2}$ ligand is minimally activated, as attested by the NN bond distance and the very high stretching frequency (2223 and $2234 \mathrm{~cm}^{-1}$ for the complexes with iPr and Ph substituents at P) (scheme 127, top). ${ }^{459}$ Exposition of the bimetallic $\mathrm{In}^{\mathrm{III}}-\mathrm{Ni}^{0}$ complex supported by a $\left[\mathrm{N}_{4} \mathrm{P}_{3}\right]$ ligand to $\mathrm{N}_{2}$ allowed $\mathrm{Lu}$ to isolate the corresponding thermally stable $\left[\left[\mathrm{N}_{4} \mathrm{P}_{3}\right] \operatorname{InNi}\left(\mathrm{N}_{2}\right)\right]$ complex (scheme 127 , bottom). ${ }^{460}$ Synthesis of the related $\mathrm{Al}^{\mathrm{III}}$ and $\mathrm{Ga}^{\mathrm{III}}\left[\left[\mathrm{N}_{4} \mathrm{P}_{3}\right] \mathrm{MNi}\right]$ analogues was done but these complexes do not coordinate $\mathrm{N}_{2}{ }^{301}$

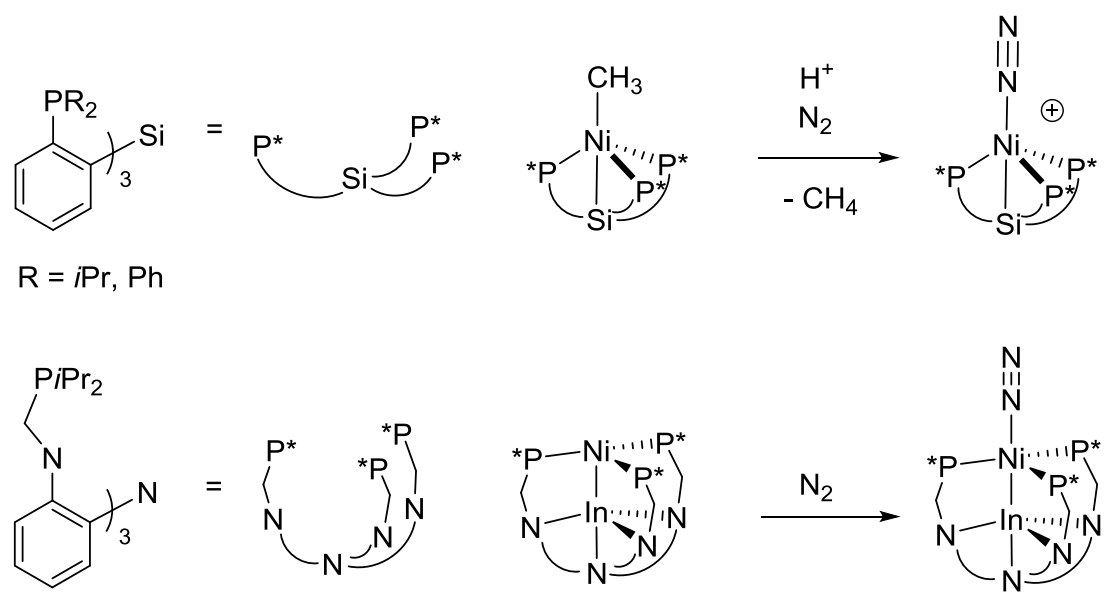


Scheme 127

Like for many other metal centers, beta diketiminates have permitted stabilization of Ni$\mathrm{N}_{2}$ complexes. Thus, as shown by Limberg, reduction of the $\left[\left(\mathrm{L}^{t \mathrm{Bu}, \mathrm{dipp}}\right) \mathrm{NiBr}\right]\left(\mathrm{L}^{t \mathrm{Bu}, \mathrm{dipp}}=\right.$ $\left.\mathrm{CH}\left\{\mathrm{C}(t-\mathrm{Bu}) \mathrm{N}\left(2,6-i-\mathrm{Pr}_{2} \mathrm{C}_{6} \mathrm{H}_{3}\right)\right\}_{2}{ }^{-}\right)$complex resulted in the formation of the $\mathrm{Ni}^{\mathrm{I}}$ end-on $\mathrm{N}_{2}$ dimer $\left[\left\{\mathrm{Ni}\left(\mathrm{L}^{t \mathrm{Bu}, \mathrm{dipp}}\right)\right\}_{2}\left(\mu-\eta^{1}: \eta^{1}-\mathrm{N}_{2}\right)\right]$ via the proposed intermediate $\left[\mathrm{Ni}\left(\mathrm{L}^{t \mathrm{Bu}, \mathrm{dipp}}\right) \mathrm{H}\right]_{2}$ (scheme 128). ${ }^{461}$ Alternatively, the complex can be obtained by the $\mathrm{KC}_{8}$ reduction. This complex, featuring two Ni centers in T shaped geometry, is a triplet of spin consistent with two uncoupled $\mathrm{Ni}^{\mathrm{I}}$ ions. Most interestingly, upon further reductions by $\mathrm{KC}_{8}$, both the mono and di-reduced complexes could be isolated and characterized. In these complexes, the $\mathrm{K}^{+}$cations coordinate the aryl groups as well as the $\mathrm{N}_{2}$ ligand in a side on fashion. $\mathrm{X}$ ray structure analyses of the " $\mathrm{Ni}_{2} \mathrm{~N}_{2}$ ", " $\mathrm{Ni}_{2} \mathrm{~N}_{2} \mathrm{~K}$ " and " $\mathrm{Ni}_{2} \mathrm{~N}_{2} \mathrm{~K}_{2}$ " complexes evidenced stepwise reduction of the $\mathrm{N}_{2}$ fragment ( $\mathrm{NN}$ bond distances of 1.120(4), 1.143(8) and $1.185(8) \AA$ respectively) also corroborated by the systematic decrease of the $\nu_{\mathrm{N}-\mathrm{N}}$ stretching frequencies from 2164 to 1825 to $1696 \mathrm{~cm}^{-1}$ respectively. The same group reported the reduction of the " $\mathrm{Ni}_{2} \mathrm{~N}_{2}$ ", " $\mathrm{Ni}_{2} \mathrm{~N}_{2} \mathrm{~K}$ " complexes by $\mathrm{Na}$ instead of $\mathrm{KC}_{8}$ to form the related " $\mathrm{Ni}_{2} \mathrm{~N}_{2} \mathrm{Na}_{2}$ " and " $\mathrm{Ni}_{2} \mathrm{~N}_{2} \mathrm{KNa"} \mathrm{complexes.} \mathrm{A} \mathrm{similar} \mathrm{side} \mathrm{on} \mathrm{coordination} \mathrm{of} \mathrm{N}_{2}$ to $\mathrm{Na}$ was also evidenced. ${ }^{462}$ Despite a formal reduction of the $\mathrm{N}_{2}$ fragment in the $\mathrm{Ni}^{(0)}$ complexes, it is readily displaced by $\mathrm{CO}$. The complex also reacts with extremely inert $\mathrm{SF}_{6}$ gas first via redox process followed by S-F bond breaking. ${ }^{463}$ 


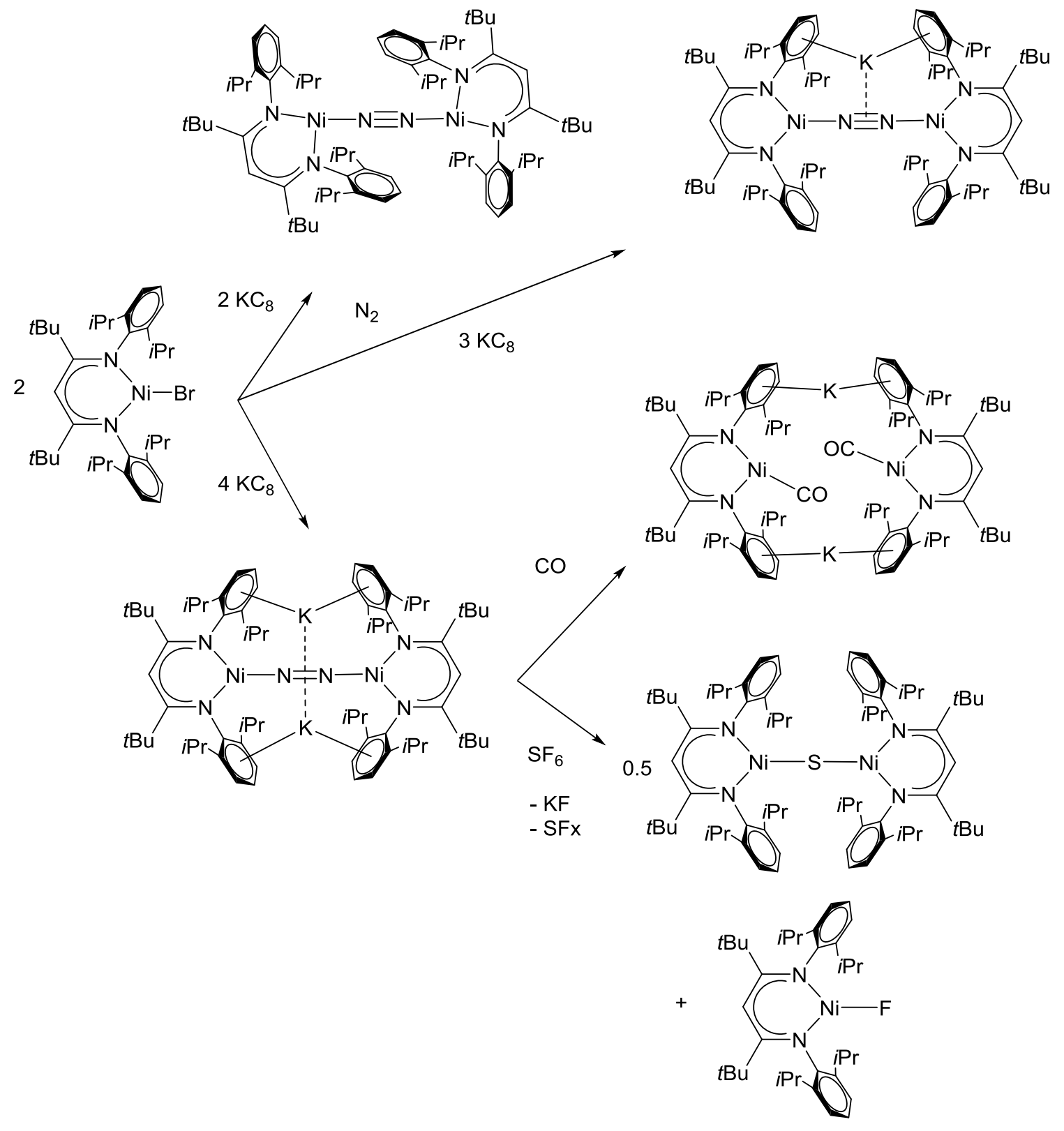

Scheme 128

Even if it does not concern molecular complexes, it is pertinent to cite here the work of Bordiga who has measured the adsorption enthalpy of $\mathrm{N}_{2}$ on a five coordinate $\mathrm{Ni}^{\mathrm{II}}$ site of the MOF CPO-27-Ni to be $-17 \mathrm{~kJ} / \mathrm{mol}^{464}$ It is expectedly much weaker than coordination of both $\mathrm{CO}$ and $\mathrm{NO}(-50$ and $-90 \mathrm{~kJ} / \mathrm{mol}$ respectively).

Finally, there are no Pd or Pt complexes of $\mathrm{N}_{2}$ to date. 


\section{Group 11 transition metal-dinitrogen complexes}

The first $\mathrm{Cu}$ complex of $\mathrm{N}_{2}$ was isolated as recently as 2014 by the group of Murray. They carefully designed a macrocyclic tris( $\beta$-diketimine) ligand which upon deprotonation favors coordination of three $\mathrm{Cu}^{\mathrm{I}}$ centers as well as a $\mathrm{N}_{2}$ molecule, making a " $\mathrm{Cu}_{3} \mathrm{~N}_{2}{ }^{3+"}$ central core (scheme 129). ${ }^{465}$ In the crystal structure, the position of $\mathrm{N}_{2}$ is disordered with a major component (75\%) presenting a $\mu-\eta^{1}: \eta^{2}: \eta^{1}-\mathrm{N}_{2}$ coordination and a distance of $1.0956(1) \AA$. In the minor component (25\%) the $\mathrm{N}_{2}$ ligand presents only $\eta 1$ coordination mode with the two $\mathrm{N}$ atoms acting as $\mu^{1,1}$ and $\mu^{1,2}$ bridging respectively. The NN stretching frequency in the Raman spectrum is found at $1952 \mathrm{~cm}^{-1}$, pointing a relatively activated $\mathrm{N}_{2}$ fragment. DFT calculations on truncated models reveal that subtle changes in the ligand have a large influence on the activation of $\mathrm{N}_{2}$ in this environment. If the reaction is done with $\mathrm{CuCl}$ instead of CuOTf, the complex featuring a $\mu^{3}-\mathrm{Cl}$ is obtained. ${ }^{466}$

2

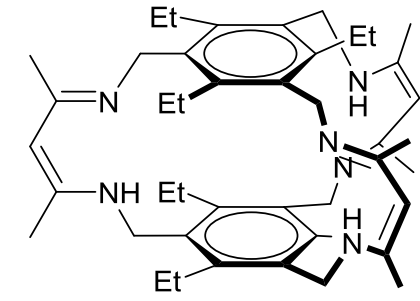

1) $3 \mathrm{BnK}$

2) 3 CuOTf
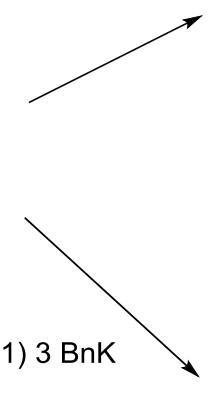

2) 3 CuOTf
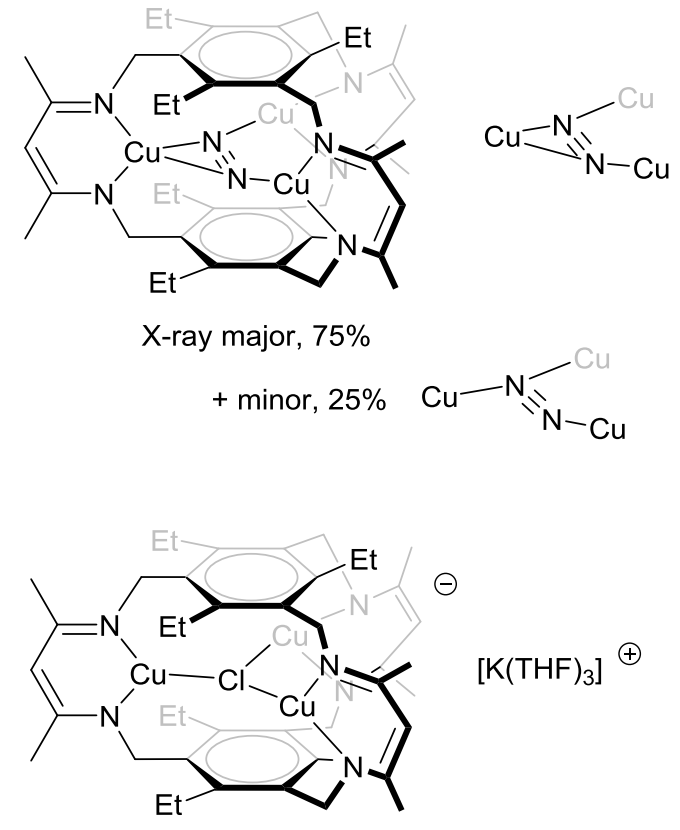

Scheme 129 
Cundari, Warren and coworkers showed that the tris-pyrazolylborate ligand ${ }^{i \mathrm{Pr} 2} \mathrm{Tp}$ allows $\mathrm{Cu}^{\mathrm{I}}-\mathrm{N}_{2}-\mathrm{Cu}^{\mathrm{I}}$ formation. ${ }^{467}$ Thus, reaction of the $\left[\left({ }^{i \mathrm{Pr} 2} \mathrm{Tp}\right) \mathrm{Cu}{ }^{\mathrm{II}}(\mathrm{OH})\right]_{2}$ precursor with two equivalents of $\mathrm{Ph}_{3} \mathrm{SiH}$ at $-20^{\circ} \mathrm{C}$ led to several color changes, ultimately forming colorless crystals of $\left[\left({ }^{i \mathrm{Pr} 2} \mathrm{Tp}\right) \mathrm{Cu}\right]_{2}\left(\mu-\eta^{1}: \eta^{1}-\mathrm{N}_{2}\right)$ in $38 \%$ yield. Impressively, the authors were able to isolate and crystallize a purple intermediate, only stable at low temperature (below $\left.-20^{\circ} \mathrm{C}\right)\left[\left({ }^{\mathrm{iP} 2} \mathrm{Tp}\right) \mathrm{Cu}\right]_{2}(\mu-\mathrm{H})$, a mixed valence dicopper hydride complex. The dinitrogen complex $\left.\left[{ }^{i \mathrm{Pr} 2} \mathrm{Tp}\right) \mathrm{Cu}\right]_{2}\left(\mu-\eta^{1}: \eta^{1}-\mathrm{N}_{2}\right)$ presents modest thermal stability and $\mathrm{N}_{2}$ is readily displaced by two electron donors, such as nitriles or isonitriles to form the corresponding monometallic $\mathrm{Cu}^{\mathrm{I}}$ complexes.

Chen and coworkers studied the in situ generated formamidinate ligands coordination to $\mathrm{Cu}^{\mathrm{II}}$ acetate under solvothermal conditions (scheme 130). ${ }^{468}$ The ligand $\left(N, N^{\prime}-\right.$ bis(pyridine-n-ylmethyl)formamidinate), made from either 3 or 4-aminomethylpyridine, acts as building block for coordination polymers together with $\mathrm{N}_{2}$. Presence of $\mathrm{N}_{2}$ was evidenced by the differences in the IR spectra obtained using ${ }^{14} \mathrm{~N}_{2}$ and ${ }^{15} \mathrm{~N}_{2}$ gases. The $\mathrm{NN}$ stretching frequency at $1575 \mathrm{~cm}^{-1}$ is consistent with a $\mathrm{N}_{2}^{-}$moiety.

8<smiles>NCc1cccnc1</smiles>

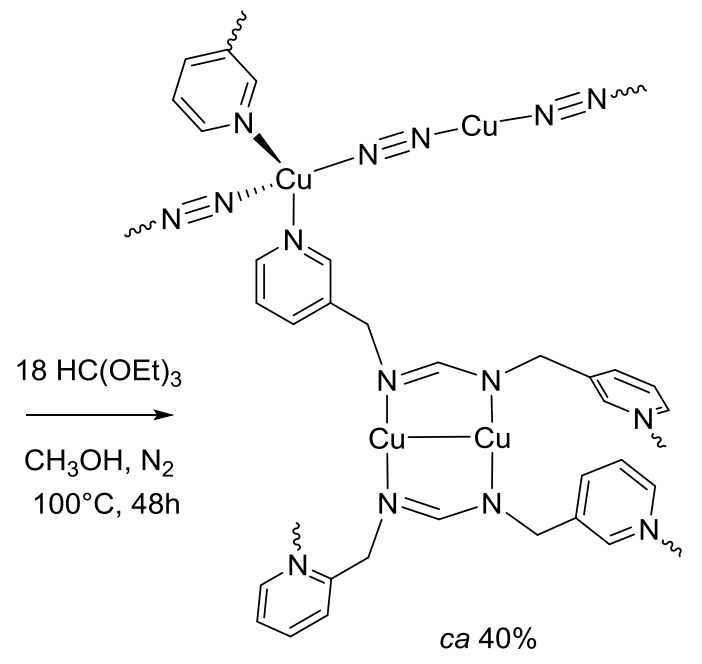

Scheme 130 
There has been no report of molecular $\mathrm{N}_{2}$ complexes of Ag and Au since 2003.

\section{Conclusion and perspectives}

It is quite obvious in light of the large body of works presented in this review that tremendous progresses have been made in the coordination chemistry of $\mathrm{N}_{2}$ since 2003. In fact, the domain goes far beyond simple coordination of $\mathrm{N}_{2}$ to metal fragments. It is well understood that functionalization of $\mathrm{N}_{2}$ requires "activation", i.e. electron transfer from the metal center to $\mathrm{N}_{2}$. It has been a standard practice to evaluate such activation, or degree of N-N bond order reduction, by comparing crystallographically determined NN bond distance in a complex with the one of free $\mathrm{N}_{2}$. As we now know a vast number of metal complexes of $\mathrm{N}_{2}$, it appears that the $\mathrm{NN}$ bond distance is neither useful in terms of predicting complex stability, reactivity at $\mathrm{N}_{2}$, nor helpful to assign oxidation state at metal within bimetallic complexes.

In terms of $\mathrm{N}_{2}$ coordination, activation and functionalization, three cases can be put forward.

First, activation of $\mathrm{N}_{2}$ between two metals is classically observed with metallic fragments featuring metal centers in low oxidation state. Multiple electron transfers from the metals to $\mathrm{N}_{2}$ result in reduction to formal $\mathrm{N}_{2}{ }^{\mathrm{x}-}$ moiety. It would seem enough to transfer two electrons to $\mathrm{N}_{2}$ to enhance nucleophilicity at $\mathrm{N}$ and enable functionalization under mild conditions. A representative example is given by recent work of $\mathrm{Xi}$ and Zhang. Indeed functionalization of a " $\mathrm{Sc}_{2} \mathrm{~N}_{2}$ " complex, featuring $\mathrm{N}_{2}{ }^{2-}$ fragment, was not observed, while the one additional electron complex, featuring the reduced $\mathrm{N}_{2}{ }^{3-}$ fragment, reacted with the strong electrophile MeOTf. Accordingly, most significant achievements have been witnessed with formal $\mathrm{N}_{2}^{4-}$ fragment stabilized by group 4 metals by the 
groups of Fryzuk and Chirik. In particular, reactivity with $\mathrm{H}_{2}$, silanes ( $\left.\mathrm{Si}-\mathrm{H}\right)$, boranes (B$\mathrm{H})$ and $\mathrm{CO}$ have allowed $\mathrm{N}-\mathrm{E}(\mathrm{E}=\mathrm{H}, \mathrm{Si}, \mathrm{B}, \mathrm{C})$ bond formation under neutral conditions.

A second case is found when enough electrons are found at metal centers to favor a six-electron transfer to $\pi^{*}$ and $\sigma^{*}$ orbitals of $\mathrm{N}_{2}$. This transfer, also implying appropriate orbital symmetry overlap, results in $\mathrm{N} \equiv \mathrm{N}$ bond splitting and nitride (bridging or terminal) formation. Bridging nitrides are obtained for example from a $\mathrm{Ti}_{3}$ hydride cluster or from two group 5 " $\mathrm{M}^{\mathrm{II}}$ (amidinate) $\left(\mathrm{Cp}^{*}\right)$ " fragments, or from two " $\mathrm{Fe}^{0}$ (Nacnac)" fragments, while terminal nitride was first obtained by Cummins using a "Mo $\left.\mathrm{MoI}_{\text {(amide) }}\right)^{\mathrm{II}}$ fragment. Subsequent functionalization of the terminal nitride has led to stoichiometric synthesis of $\mathrm{N}$ derivatives (nitriles by Cummins and Schneider, silylamine by Sita, silylamine and borylamine by Mézailles, cyanate by Kawaguchi).

The third case concerns mid to late transition metals, for which terminal $\mathrm{M}-\mathrm{N}_{2}$ are classical, sometimes needing that bulky ligands are used to prevent end-on bridging dimer formation. In that case, functionalization of $\mathrm{N}_{2}$ requires significant nucleophilic or basic character of the terminal $\mathrm{N}$ center, and competition with alkylation/protonation at the metal center can be a major issue. Seminal works by Chatt and Hidai in the seventies illustrate favorable reactivity at $\mathrm{N}$ for group $6 \mathrm{M}^{0}$ centers, while many other $\mathrm{M}-\mathrm{N}_{2}$ metal complexes require reduction (by one or two electrons) prior to functionalization (works of Schrock, Peters to achieve NH bond formation, or Nishibayashi, Peters, Lu, Fryzuk and Masuda for N-Si bond formation).

Notably, these principles of $\mathrm{N}_{2}$ activation/functionalization have been extended most recently to main group metals. Braunschweig reported in 2018 that the generation of an electron rich borylene fragment allowed the first trapping of $\mathrm{N}_{2}$ between two $\mathrm{B}$ 
centers, ${ }^{469}$ and in 2019 the coupling between two $\mathrm{N}_{2}$ molecules. ${ }^{470}$ Subsequent protonation created two NH bonds. In 2019, Berben showed that controlled potential electrolysis (-1.16V vs SCE in THF) of a cationic $\mathrm{Al}^{\mathrm{III}}$ complex under $\mathrm{N}_{2}$, in the presence of a proton source yielded $21 \%$ of $\mathrm{NH}_{3} \cdot{ }^{471}$ Although no $\mathrm{N}_{2}$ complex was observed, isotope labelling demonstrated it to be the source of $\mathrm{NH}_{3}$.

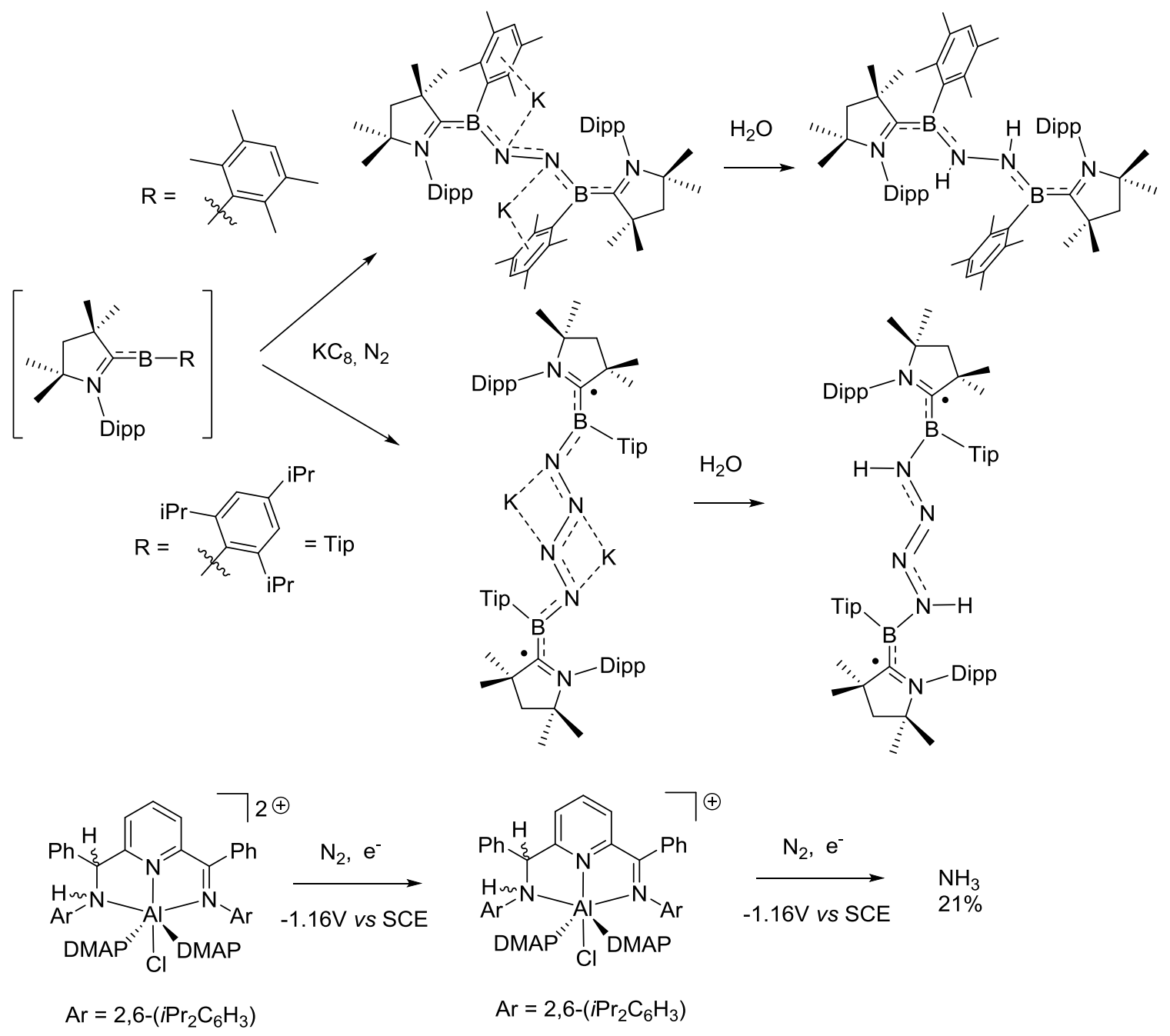

The studies dealing with stoichiometric functionalization of $\mathrm{N}_{2}$ have allowed the development of the two known catalytic reductions of $\mathrm{N}_{2}$ : the $\mathrm{N}_{2}$-to- $\mathrm{N}\left(\mathrm{SiMe}_{3}\right)_{3}$ and the $\mathrm{N}_{2}$-to- $\mathrm{NH}_{3}$ processes. Hidai reported in 1989 that a $\mathrm{Mo}^{0}$ complex is a competent catalyst 
(TON ca 20) for the $\mathrm{N}_{2}$-to- $\mathrm{N}\left(\mathrm{SiMe}_{3}\right)_{3}$ reaction, and catalysts based on Mo (Nishibayashi), Co (Lu, Masuda and Fryzuk) and Fe (Ashley) have been reported in the last decade to achieve TONs of $c a$ 200, 200 and 120 respectively. This process is proposed to involve $\mathrm{SiMe}_{3}$ radicals. Several complexes that are catalytic intermediates (hydrazido, nitrido, imido) have been isolated from stepwise functionalization of Mo- $\mathrm{N}_{2}$ by Mézailles.

Schrock reported the first catalyzed $\mathrm{N}_{2}$-to- $\mathrm{NH}_{3}$ process in 2003 , using a trisamidoamine Mo complex, and characterized many catalytic intermediates. Nishibayashi has presented several Mo complexes, among which a Mo-nitride, with improved efficiency and TONs (up to $c a 400$ equiv. $\mathrm{NH}_{3}$ ). In 2019, this group reported the use of $\mathrm{SmI}_{2}$ as reductant in combination with protic solvents, leading to unprecedented efficiency $(91 \%)$, TON of 4350 equiv. of $\mathrm{NH}_{3}$ (from 14400 equiv. $\mathrm{SmI}_{2}$ and $\mathrm{H}_{2} \mathrm{O}$ ) and turnover frequency of $117 \mathrm{~min}^{-1}$. Among the other metals active in this catalysis, Fe occupies an important place. Several catalysts have been developed by the groups of Peters and Nishibayashi. Most importantly, detailed mechanistic investigations have been carried out by Peters allowing characterization of many intermediates in $\mathrm{N}-\mathrm{H}$ bond formation especially for their $\left[\mathrm{BP}_{3}\right] \mathrm{Fe}$ system. Moreover, this group has recently demonstrated improved performance at lower driving force (i.e. use of $\left[\mathrm{Ph}_{2} \mathrm{NH}_{2}\right] \mathrm{OTf} / \mathrm{Cp}^{*}{ }_{2} \mathrm{Co}$ couple vs $\mathrm{HBAr}^{\mathrm{F}}{ }_{4} / \mathrm{KC}_{8}$ ), which highlights the importance of optimizing the proton source/reductant couple. In terms of mechanism, in addition to stepwise electron transfer (ET)-proton transfer (PT) or PT-ET pathways, PCET steps have been discussed in the past years.

To the catalytic systems involving these two metals, one needs to add the first examples of Ti by Liddle, $\mathrm{V}$ by Nishibayashi, Ru and Os by Peters, and Co by Peters and Nishibayashi in the past six years. These result demonstrate that catalysis for $\mathrm{N}_{2}$ 
reduction is not limited to the metal complexes found in nitrogenase enzymes (especially Mo and Fe), and pave the way for further developments.

\section{References}

(1) Haber, F. Verfahren Zur Herstellung von Ammoniak Durch Katalytische Vereinigung von Stickstoff Un Wasserstoff, Zwekmässig Unter Hohem Druck., 1909.

(2) Haber, F. No Title. Z. Angew. Chem 1914, 27, 473-477.

(3) Mittasch, A.; Frankenburger, W. The Historical Development and Theory of Ammonia Synthesis. J. Chem. Educ. 1929, 6 (12), 2097-2098. https://doi.org/10.1021/ed006p2097.

(4) Evans, W. J.; Bloom, I.; Hunter, W. E.; Atwood, J. L. Metal Vapor Synthesis of (C5Me52Sm(THF)2and (C5Me4Et)2Sm(THF)2and Their Reactivity with Organomercurial Reagents. Synthesis and X-Ray Structural Analysis of (C5Me52Sm(C6H5)(THF). Organometallics 1985, 4 (1), 112-119. https://doi.org/10.1021/om00120a019.

(5) Evans, W. J.; Ulibarri, T. A.; Ziller, J. W. Isolation and X-Ray Crystal Structure of the First Dinitrogen Complex of an f-Element Metal, [(C5Me5)2Sm]2N2. J. Am. Chem. Soc. 1988, 110 (20), 6877-6879. https://doi.org/10.1021/ja00228a043.

(6) Bochkarev, M. N.; Trifonov, A. A.; Razuvaev, G. A.; Ilatovskaya, M. A.; Shur, V. B. FIXATION OF MOLECULAR NITROGEN BY RARE-EARTH METAL COMPOUNDS. Bull. Acad. Sci. USSR, Div. Chem. Sci. (Engl. Transl.) 1986, 35, $1726-1728$. 
(7) Evans, W. J. Tutorial on the Role of Cyclopentadienyl Ligands in the Discovery of Molecular Complexes of the Rare-Earth and Actinide Metals in New Oxidation States136†. Organometallics 2016, 35 (18), 3088-3100. https://doi.org/10.1021/acs.organomet.6b00466.

(8) Guan, J.; Dube, T.; Gambarotta, S.; Yap, G. P. A. Dinitrogen Labile Coordination versus Four-Electron Reduction, THF Cleavage, and Fragmentation Promoted by a (Calix-Tetrapyrrole)Sm(II) Complex. Organometallics 2000, 19 (23), 4820-4827. https://doi.org/10.1021/om000698p.

(9) Jubb, J.; Gambarotta, S. Dinitrogen Reduction Operated by a Samarium Macrocyclic Complex. Encapsulation of Dinitrogen into a Sm2Li4 Metallic Cage. J. Am. Chem. Soc. 1994, 116 (10), 4477-4478.

https://doi.org/10.1021/ja00089a047.

(10) Demir, S.; Siladke, N. A.; Ziller, J. W.; Evans, W. J. Scandium and Yttrium Metallocene Borohydride Complexes: Comparisons of (BH 4) 1-vs. (BPh 4) 1Coordination and Reactivity. Dalt. Trans. 2012, 41 (32), 9659-9666.

https://doi.org/10.1039/c2dt30861d.

(11) Demir, S.; Lorenz, S. E.; Fang, M.; Furche, F.; Meyer, G.; Ziller, J. W.; Evans, W. J. Synthesis, Structure, and Density Functional Theory Analysis of a Scandium Dinitrogen Complex, [(C5Me4H)2Sc] 2( $\mu-\mathrm{H} 2$ : H2-N2). J. Am. Chem. Soc. 2010, 132 (32), 11151-11158. https://doi.org/10.1021/ja102681w.

(12) Mueller, T. J.; Fieser, M. E.; Ziller, J. W.; Evans, W. J. (C5Me4H)1--Based Reduction of Dinitrogen by the Mixed Ligand Tris(Polyalkylcyclopentadienyl) Lutetium and Yttrium Complexes, (C5Me5)3-x(C5Me 4H)XLn. Chem. Sci. 2011, 
2 (10), 1992-1996. https://doi.org/10.1039/c1sc00139f.

(13) Schmiege, B. M.; Ziller, J. W.; Evans, W. J. Reduction of Dinitrogen with an Yttrium Metallocene Hydride Precursor, [(C5Me5)2YH]2. Inorg. Chem. 2010, 49 (22), 10506-10511. https://doi.org/10.1021/ic101558e.

(14) Fieser, M. E.; Woen, D. H.; Corbey, J. F.; Mueller, T. J.; Ziller, J. W.; Evans, W. J. Raman Spectroscopy of the N-N Bond in Rare Earth Dinitrogen Complexes. Dalt. Trans. 2016, 45 (37), 14634-14644. https://doi.org/10.1039/c5dt04547a.

(15) Lorenz, S. E.; Schmiege, B. M.; Lee, D. S.; Ziller, J. W.; Evans, W. J. Synthesis and Reactivity of Bis(Tetramethylcyclopentadienyl) Yttrium Metallocenes Including the Reduction of Me $3 \mathrm{SiN} 3$ to $[(\mathrm{Me} 3 \mathrm{Si}) 2 \mathrm{~N}]-$ with $[(\mathrm{C} 5 \mathrm{Me} 4 \mathrm{H}) 2$ $\mathrm{Y}(\mathrm{THF})] 2$ ( $\mu-\eta 2$ :ๆ 2 -N 2 ). Inorg. Chem. 2010, 49 (14), 6655-6663. https://doi.org/10.1021/ic100682d.

(16) MacDonald, M. R.; Ziller, J. W.; Evans, W. J. Synthesis of a Crystalline Molecular Complex of Y2+, [(18-Crown-6)K][(C5H4SiMe3)3Y]. J. Am. Chem. Soc. 2011, 133 (40), 15914-15917. https://doi.org/10.1021/ja207151y.

(17) Evans, W. J.; Lee, D. S.; Lie, C.; Ziller, J. W. Expanding the LnZ3/Alkali-Metal Reduction System to Organometallic and Heteroleptic Precursors: Formation of Dinitrogen Derivatives of Lanthanum. Angew. Chem. Int. Ed. 2004, 43 (41), 55175519. https://doi.org/10.1002/anie.200461170.

(18) Evans, W. J.; Rego, D. B.; Ziller, J. W. Synthesis, Structure, and 15N NMR Studies of Paramagnetic Lanthanide Complexes Obtained by Reduction of Dinitrogen. Inorg. Chem. 2006, 45 (26), 10790-10798. https://doi.org/10.1021/ic061485g. 
(19) Jaroschik, F.; Momin, A.; Nief, F.; Le Goff, X. F.; Deacon, G. B.; Junk, P. C.

Dinitrogen Reduction and C-H Activation by the Divalent Organoneodymium Complex $[(\mathrm{C} 5 \mathrm{H} 2 \mathrm{tBu} 3) 2 \mathrm{Nd}(\mu-\mathrm{I}) \mathrm{K}([18]$ Crown-6)]. Angew. Chem. Int. Ed. 2009, 48 (6), 1117-1121. https://doi.org/10.1002/anie.200804934.

(20) Demir, S.; Gonzalez, M. I.; Darago, L. E.; Evans, W. J.; Long, J. R. Giant Coercivity and High Magnetic Blocking Temperatures for N23- Radical-Bridged Dilanthanide Complexes upon Ligand Dissociation /639/638/263/406 /639/638/911 /639/638/298/920 Article. Nat. Commun. 2017, 8 (1), 1-9. https://doi.org/10.1038/s41467-017-01553-w.

(21) Evans, W. J.; Allen, N. T.; Ziller, J. W. Expanding Divalent Organolanthanide Chemistry: The First Organothulium(II) Complex and the in Situ Organodysprosium(II) Reduction of Dinitrogen. Angew. Chem. Int. Ed. 2002, 41 (2), 359-361. https://doi.org/10.1002/1521-3773(20020118)41:2<359::AIDANIE359>3.0.CO;2-A.

(22) Evans, W. J.; Lee, D. S.; Johnston, M. A.; Ziller, J. W. The Elusive (C 5Me 4H) 3Lu: Its Synthesis and LnZ 3/K/N 2 Reactivity. Organometallics 2005, 24 (26), 6393-6397. https://doi.org/10.1021/om050709k.

(23) Evans, W. J.; Lee, D. S.; Ziller, J. W. Reduction of Dinitrogen to Planar Bimetallic M2(N2) Complexes of Y, Ho, Tm, and Lu Using the K/Ln[N(SiMe3)2]3 Reduction SystemEvans, W. J., Lee, D. S., \& Ziller, J. W. (2004). Reduction of Dinitrogen to Planar Bimetallic M2(??-?? 2:??2-N2) Com. J. Am. Chem. Soc. 2004, 126 (2), 454-455. https://doi.org/10.1021/ja036923m.

(24) Evans, W. J.; Lee, D. S.; Rego, D. B.; Perotti, J. M.; Kozimor, S. A.; Moore, E. K.; 
Ziller, J. W. Expanding Dinitrogen Reduction Chemistry to Trivalent Lanthanides via the LnZ3/Alkali Metal Reduction System: Evaluation of the Generality of Forming Ln2( $\mu-\mathrm{H} 2: \mathrm{H} 2-\mathrm{N} 2)$ Complexes via LnZ3/K. J. Am. Chem. Soc. 2004, 126 (44), 14574-14582. https://doi.org/10.1021/ja046047s.

(25) Fang, M.; Bates, J. E.; Lorenz, S. E.; Lee, D. S.; Rego, D. B.; Ziller, J. W.; Furche, F.; Evans, W. J. (N2)3- Radical Chemistry via Trivalent Lanthanide Salt/Alkali Metal Reduction of Dinitrogen: New Syntheses and Examples of (N 2)2- and (N2)3- Complexes and Density Functional Theory Comparisons of Closed Shell Sc3+, Y 3+, and Lu3+ versus 4f9 Dy3+. Inorg. Chem. 2011, 50 (4), 1459-1469. https://doi.org/10.1021/ic102016k.

(26) Evans, W. J.; Fang, M.; Zucchi, G. L.; Furche, F.; Ziller, J. W.; Hoekstra, R. M.; Zink, J. I. Isolation of Dysprosium and Yttrium Complexes of a Three-Electron Reduction Product in the Activation of Dinitrogen, the (N2)3- Radical. J. Am. Chem. Soc. 2009, 131 (31), 11195-11202. https://doi.org/10.1021/ja9036753.

(27) Evans, W. J.; Zucchi, G.; Ziller, J. W. Dinitrogen Reduction by Tm(II), Dy(II), and $\mathrm{Nd}$ (II) with Simple Amide and Aryloxide Ligands. J. Am. Chem. Soc. 2003, 125 (1), 10-11. https://doi.org/10.1021/ja0211712.

(28) Fieser, M. E.; Bates, J. E.; Ziller, J. W.; Furche, F.; Evans, W. J. Dinitrogen Reduction via Photochemical Activation of Heteroleptic Tris(Cyclopentadienyl) Rare-Earth Complexes. J. Am. Chem. Soc. 2013, 135 (10), 3804-3807. https://doi.org/10.1021/ja400664s.

(29) Fieser, M. E.; Johnson, C. W.; Bates, J. E.; Ziller, J. W.; Furche, F.; Evans, W. J. Dinitrogen Reduction, Sulfur Reduction, and Isoprene Polymerization via 
Photochemical Activation of Trivalent Bis(Cyclopentadienyl) Rare-Earth-Metal Allyl Complexes. Organometallics 2015, 34 (17), 4387-4393.

https://doi.org/10.1021/acs.organomet.5b00613.

(30) Meihaus, K. R.; Corbey, J. F.; Fang, M.; Ziller, J. W.; Long, J. R.; Evans, W. J. Influence of an Inner-Sphere K+ Ion on the Magnetic Behavior of N23- RadicalBridged Dilanthanide Complexes Isolated Using an External Magnetic Field. Inorg. Chem. 2014, 53 (6), 3099-3107. https://doi.org/10.1021/ic4030102.

(31) Fang, M.; Lee, D. S.; Ziller, J. W.; Doedens, R. J.; Bates, J. E.; Furche, F.; Evans, W. J. Synthesis of the (N2)3- Radical from Y2+ and Its Protonolysis Reactivity to Form (N2H2) 2- via the Y[N(SiMe3)2]3/KC 8 Reduction System. J. Am. Chem. Soc. 2011, 133 (11), 3784-3787. https://doi.org/10.1021/ja1116827.

(32) Rinehart, J. D.; Fang, M.; Evans, W. J.; Long, J. R. Strong Exchange and Magnetic Blocking in N23-- Radical-Bridged Lanthanide Complexes. Nat. Chem. 2011, 3 (7), 538-542. https://doi.org/10.1038/nchem.1063.

(33) Rinehart, J. D.; Fang, M.; Evans, W. J.; Long, J. R. A N23- Radical-Bridged Terbium Complex Exhibiting Magnetic Hysteresis at 14 K. J. Am. Chem. Soc. 2011, 133 (36), 14236-14239. https://doi.org/10.1021/ja206286h.

(34) Dubé, T.; Conoci, S.; Gambarotta, S.; Yap, G. P. A.; Vasapollo, G. Tetrametallic Reduction of Dinitrogen: Formation of a Tetranuclear Samarium Dinitrogen Complex. Angew. Chem. Int. Ed. 1999, 38 (24), 3657-3659. https://doi.org/10.1002/(SICI)1521-3773(19991216)38:24<3657::AIDANIE3657>3.0.CO;2-A.

(35) Dube', T.; Ganesan, S.; Conoci, S.; Gambarotta, S.; Yap, G. P. A. Tetrametallic 
Divalent Samarium Cluster Hydride and Dinitrogen Complexes. Organometallics 2000, 19 (18), 3716-3721. https://doi.org/10.1021/om0005021.

(36) Ganesan, M.; Gambarotta, S.; Yap, G. P. A. Highly Reactive SmII Macrocyclic Clusters: Precursors to N2 Reduction. Angew. Chem. Int. Ed. 2001, 40 (4), 766769. https://doi.org/10.1002/1521-3773(20010216)40:4<766::AIDANIE7660>3.0.CO;2-H.

(37) Woen, D. H.; Chen, G. P.; Ziller, J. W.; Boyle, T. J.; Furche, F.; Evans, W. J. EndOn Bridging Dinitrogen Complex of Scandium. J. Am. Chem. Soc. 2017, 139 (42), 14861-14864. https://doi.org/10.1021/jacs.7b08456.

(38) Lv, Z. J.; Huang, Z.; Zhang, W. X.; Xi, Z. Scandium-Promoted Direct Conversion of Dinitrogen into Hydrazine Derivatives via N-C Bond Formation. J. Am. Chem. Soc. 2019, 141 (22), 8773-8777. https://doi.org/10.1021/jacs.9b04293.

(39) Roussel, P.; Scott, P. Complex of Dinitrogen with Trivalent Uranium. J. Am.

Chem. Soc. 1998, 120, 1070-1071. https://doi.org/10.1021/ja972933+.

(40) Odom, A. L.; Arnold, P. L.; Cummins, C. C. Heterodinuclear Uranium/Molybdenum Dinitrogen Complexes [16]. J. Am. Chem. Soc. 1998, 120 (23), 5836-5837. https://doi.org/10.1021/ja980095t.

(41) Cloke, F. G. N.; Hitchcock, P. B. Reversible Binding and Reduction of Dinitrogen by a Uranium(III) Pentalene Complex. J. Am. Chem. Soc. 2002, 124 (32), 93529353. https://doi.org/10.1021/ja027000e.

(42) Korobkov, I.; Gambarotta, S.; Yap, G. P. A. A Highly Reactive Uranium Complex Supported by the Calix[4]Tetrapyrrole Tetraanion Affording Dinitrogen Cleavage, Solvent Deoxygenation, and Polysilanol Depolymerization. Angew. Chem. Int. Ed. 
2002, No. 18, 3433-3436.

(43) Evans, W. J.; Kozimor, S. A.; Ziller, J. W. A Monometallic f Element Complex of Dinitrogen: (C5Me 5)3U(H1-N2). J. Am. Chem. Soc. 2003, 125 (47), 1426414265. https://doi.org/10.1021/ja037647e.

(44) Korobkov, I.; Gambarotta, S.; Yap, G. P. A. Amide from Dinitrogen by In Situ Cleavage and Partial Hydrogenation Promoted by a Transient Zero-Valent Thorium Synthon. Angew. Chem. Int. Ed. 2003, 42 (40), 4958-4961. https://doi.org/10.1002/anie.200352205.

(45) Mansell, S. M.; Kaltsoyannis, N.; Arnold, P. L. Small Molecule Activation by Uranium Tris(Aryloxides): Experimental and Computational Studies of Binding of $\mathrm{N} 2$, Coupling of $\mathrm{CO}$, and Deoxygenation Insertion of $\mathrm{CO} 2$ under Ambient Conditions. J. Am. Chem. Soc. 2011, 133 (23), 9036-9051. https://doi.org/10.1021/ja2019492.

(46) Mansell, S. M.; Farnaby, J. H.; Germeroth, A. I.; Arnold, P. L. Thermally Stable Uranium Dinitrogen Complex with Siloxide Supporting Ligands. Organometallics 2013, 32 (15), 4214-4222. https://doi.org/10.1021/om4003957.

(47) Camp, C.; Pécaut, J.; Mazzanti, M. Tuning Uranium-Nitrogen Multiple Bond Formation with Ancillary Siloxide Ligands. J. Am. Chem. Soc. 2013, 135 (32), 12101-12111. https://doi.org/10.1021/ja405815b.

(48) Falcone, M.; Chatelain, L.; Scopelliti, R.; Živković, I.; Mazzanti, M. Nitrogen Reduction and Functionalization by a Multimetallic Uranium Nitride Complex. Nature 2017, 547 (7663), 332-335. https://doi.org/10.1038/nature23279.

(49) Falcone, M.; Barluzzi, L.; Andrez, J.; Fadaei Tirani, F.; Zivkovic, I.; Fabrizio, A.; 
Corminboeuf, C.; Severin, K.; Mazzanti, M. The Role of Bridging Ligands in Dinitrogen Reduction and Functionalization by Uranium Multimetallic Complexes. Nat. Chem. 2019, 11 (2), 154-160. https://doi.org/10.1038/s41557018-0167-8.

(50) Bercaw, J. E.; Brintzinger, H. H.

Bis(Pentamethylcyclopentadienyl)Titanium(II).Isolation and Reactions with Hydrogen, Nitrogen, and Carbon Monoxide. J. Am. Chem. Soc. 1971, 93 (8), 2045-2046. https://doi.org/10.1021/ja00737a033.

(51) Bercaw, J. E. Bis(Pentamethylcyclopentadienyl)Titanium(II) and Its Complexes with Molecular Nitrogen. J. Am. Chem. Soc. 1974, 96 (16), 5087-5095. https://doi.org/10.1021/ja00823a012.

(52) de Wolf, J. M.; Blaauw, R.; Meetsma, A.; Teuben, J. H.; Gyepes, R.; Varga, V.; Mach, K.; Veldman, N.; Spek, A. L. Bis(Tetramethylcyclopentadienyl)Titanium Chemistry. Molecular Structures of [(C 5 HMe 4$)(\mu-\eta 1$ :ๆ 5 -C 5 Me 4 )Ti] 2 and [(C 5 HMe 4 ) 2 Ti] 2 N 2. Organometallics 1996, 15 (23), 4977-4983. https://doi.org/10.1021/om960509w.

(53) Hanna, T. E.; Bernskoetter, W. H.; Bouwkamp, M. W.; Lobkovsky, E.; Chirik, P. J. Bis(Cyclopentadienyl) Titanium Dinitrogen Chemistry: Synthesis and Characterization of a Side-on Bound Haptomer. Organometallics 2007, 26 (9), 2431-2438. https://doi.org/10.1021/om0611913.

(54) Semproni, S. P.; Milsmann, C.; Chirik, P. J. Side-on Dinitrogen Complexes of Titanocenes with Disubstituted Cyclopentadienyl Ligands: Synthesis, Structure, and Spectroscopic Characterization. Organometallics 2012, 31 (9), 3672-3682. 
https://doi.org/10.1021/om300156z.

(55) Scherer, A.; Kollak, K.; Lützen, A.; Friedemann, M.; Haase, D.; Saak, W.;

Beckhaus, R. Low-Valent Titanium-Pentafulvene Complexes - Formation of

Dinuclear Titanium-Nitrogen Complexes. Eur. J. Inorg. Chem. 2005, No. 6, 10031010. https://doi.org/10.1002/ejic.200400938.

(56)

Duchateau, R.; Gambarotta, S.; Beydoun, N.; Bensimon, C. Side-On versus EndOn Coordination of Dinitrogen to Titanium (II) and Mixed-Valence

Titanium(I)/Titaniuni(II) Amido Complexes. J. Am. Chem. Soc. 1991, 113 (23), 8986-8988. https://doi.org/10.1021/ja00023a080.

Mullins, S. M.; Duncan, A. P.; Bergman, R. G.; Arnold, J. Reactivity of a Titanium Dinitrogen Complex Supported by Guanidinate Ligands: Investigation of Solution Behavior and a Novel Rearrangement of Guanidinate Ligands. Inorg. Chem. 2001, 40 (27), 6952-6963. https://doi.org/10.1021/ic010631+.

(58) Doyle, L. R.; Wooles, A. J.; Jenkins, L. C.; Tuna, F.; McInnes, E. J. L.; Liddle, S. T. Catalytic Dinitrogen Reduction to Ammonia at a Triamidoamine-Titanium Complex. Angew. Chem. Int. Ed. 2018, 57 (21), 6314-6318. https://doi.org/10.1002/anie.201802576.

Doyle, L. R.; Wooles, A. J.; Liddle, S. T. Bimetallic Cooperative Cleavage of Dinitrogen to Nitride and Tandem Frustrated Lewis Pair Hydrogenation to Ammonia. Angew. Chem. Int. Ed. 2019, 58 (20), 6674-6677. https://doi.org/10.1002/anie.201902195.

(60) Shima, T.; Hu, S.; Luo, G.; Kang, X.; Luo, Y. Y.; Hou, Z. Dinitrogen Cleavage and Hydrogenation by a Trinuclear Titanium Polyhydride Complex. Science (80-. 
). 2013, 340 (6140), 1549-1552. https://doi.org/10.1126/science.1238663.

(61) Guru, M. M.; Shima, T.; Hou, Z. Conversion of Dinitrogen to Nitriles at a Multinuclear Titanium Framework. Angew. Chem. Int. Ed. 2016, 55 (40), 1231612320. https://doi.org/10.1002/anie.201607426.

(62) Wang, B.; Luo, G.; Nishiura, M.; Hu, S.; Shima, T.; Luo, Y.; Hou, Z. Dinitrogen Activation by Dihydrogen and a PNP-Ligated Titanium Complex. J. Am. Chem. Soc. 2017, 139 (5), 1818-1821. https://doi.org/10.1021/jacs.6b13323.

(63) Fryzuk, M. D.; Haddad, T. S.; Rettig, S. J. Reduction of Dinitrogen by a Zirconium Phosphine Complex To Form a Side-On-Bridging N2 Ligand. Crystal Structure of $\{[(\mathrm{PrI} 2 \mathrm{PCH} 2 \mathrm{SiMe} 2) 2 \mathrm{~N}] \mathrm{ZrCl}\} 2(\mu-\mathrm{H} 2: \mathrm{H} 2-\mathrm{N} 2)$. J. Am. Chem. Soc. 1990, 112 (22), 8185-8186. https://doi.org/10.1021/ja00178a063.

(64) Burford, R. J.; Yeo, A.; Fryzuk, M. D. Dinitrogen Activation by Group 4 and Group 5 Metal Complexes Supported by Phosphine-Amido Containing Ligand Manifolds. Coord. Chem. Rev. 2017, 334, 84-99. https://doi.org/10.1016/j.ccr.2016.06.015.

(65) Fryzuk, M. D.; Love, J. B.; Rettig, S. J.; Young, V. G. Transformation of Coordinated Dinitrogen by Reaction with Dihydrogen and Primary Silanes. Science (80-. ). 1997, 275 (5305), 1445-1447. https://doi.org/10.1126/science.275.5305.1445.

(66) Morello, L.; Love, J. B.; Patrick, B. O.; Fryzuk, M. D. Carbon-Nitrogen Bond Formation via the Reaction of Terminal Alkynes with a Dinuclear Side-on Dinitrogen Complex. J. Am. Chem. Soc. 2004, 126 (31), 9480-9481. https://doi.org/10.1021/ja049490b. 
(67) Bernskoetter, W. H.; Lobkovsky, E.; Chirik, P. J. Kinetics and Mechanism of N2 Hydrogenation in Bis(Cyclopentadienyl) Zirconium Complexes and Dinitrogen Functionalization by 1,2-Addition of a Saturated C-H Bond. J. Am. Chem. Soc. 2005, 127 (40), 14051-14061. https://doi.org/10.1021/ja0538841.

(68) Bernskoetter, W. H.; Olmos, A. V.; Lobkovsky, E.; Chirik, P. J. N 2 Hydrogenation Promoted by a Side-on Bound Hafnocene Dinitrogen Complex. Organometallics 2006, 25 (4), 1021-1027. https://doi.org/10.1021/om0509037.

(69) Pool, J. A.; Bernskoetter, W. H.; Chirik, P. J. On the Origin of Dinitrogen Hydrogenation Promoted by [(H5- C5Me4H)2Zr]2(M2, H2,H2-N2). J. Am. Chem. Soc. 2004, 126 (44), 14326-14327. https://doi.org/10.1021/ja045566s.

(70) Miyachi, H.; Shigeta, Y.; Hirao, K. Theoretical Study of the Mechanism of Hydrogenation of Side-on Coordinated Dinitrogen Activated by Zr Binuclear

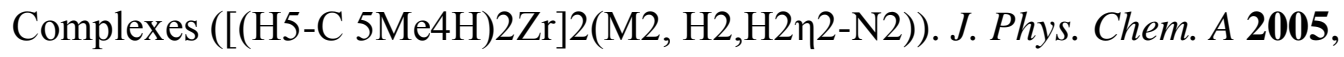
109 (39), 8800-8808. https://doi.org/10.1021/jp053308r.

(71) Pool, J. A.; Lobkovsky, E.; Chirik, P. J. Hydrogenation and Cleavage of Dinitrogen to Ammonia with a Zirconium Complex. Nature 2004, 427 (6974), 527-530. https://doi.org/10.1038/nature02274.

(72) Bernskoetter, W. H.; Pool, J. A.; Lobkovsky, E.; Chirik, P. J. Dinitrogen Functionalization with Terminal Alkynes, Amines, and Hydrazines Promoted by [(H5-C5Me4H) 2Zr]2(M2,H2, H2-N2): Observation of Side-on and End-on Diazenido Complexes in the Reduction of N2 to Hydrazine. J. Am. Chem. Soc. 2005, 127 (21), 7901-7911. https://doi.org/10.1021/ja050387b.

(73) Pun, D.; Lobkovsky, E.; Chirik, P. J. Indenyl Zirconium Dinitrogen Chemistry: N2 
Coordination to an Isolated Zirconium Sandwich and Synthesis of Side-on, End-on Dinitrogen Compounds. J. Am. Chem. Soc. 2008, 130 (18), 6047-6054. https://doi.org/10.1021/ja801021w.

(74) Pun, D.; Bradley, C. A.; Lobkovsky, E.; Keresztes, I.; Chirik, P. J. N2

Hydrogenation from Activated End-on Bis(Indenyl) Zirconium Dinitrogen

Complexes. J. Am. Chem. Soc. 2008, 130 (43), 14046-14047.

https://doi.org/10.1021/ja8048332.

(75) Semproni, S. P.; Knobloch, D. J.; Milsmann, C.; Chirik, P. J. Redox-Induced N2 Hapticity Switching in Zirconocene Dinitrogen Complexes. Angew. Chem. Int. Ed. 2013, 52 (20), 5372-5376. https://doi.org/10.1002/anie.201301800.

(76) Gynane, M. J. S.; Jeffery, J.; Lappert, M. F. Organozirconium(II1)-Dinitrogen Complexes : Evidence for (Q2-N,)-Metal Bonding in [Zr(q-CsH,),(N2)(R)] [R = $\mathrm{Me}, \mathrm{Si}), \mathrm{CH}]$. J.C.S. Chem. Comm. 1978, 34-36.

(77) Jeffery, J.; Lappert, M. F.; Riley, P. I. ORGANOZIRCOINIUM DINITROGEN COMPLEXES [Zr(e-C5H,R')2(E2-N2)R] AND [\{Zr(e-C5H4R')2N2R] [R = (Me2Si)2CH, R' = H OR Me]. 1979, 181, 25-36.

(78) Bernskoetter, W. H.; Olmos, A. V.; Pool, J. A.; Lobkovsky, E.; Chirik, P. J. N-C Bond Formation Promoted by a Hafnocene Dinitrogen Complex: Comparison of Zirconium and Hafnium Congeners. J. Am. Chem. Soc. 2006, 128 (33), 1069610697. https://doi.org/10.1021/ja064163k.

(79) Bernskoetter, W. H.; Lobkovsky, E.; Chirik, P. J. Nitrogen-Carbon Bond Formation from N2 and CO2 Promoted by a Hafnocene Dinitrogen Complex Yields a Substituted Hydrazine. Angew. Chem. Int. Ed. 2007, 46 (16), 2858-2861. 
https://doi.org/10.1002/anie.200604099.

(80) Semproni, S. P.; Lobkovsky, E.; Chirik, P. J. Dinitrogen Silylation and Cleavage with a Hafnocene Complex. J. Am. Chem. Soc. 2011, 133 (27), 10406-10409. https://doi.org/10.1021/ja2042595.

(81) Semproni, S. P.; Chirik, P. J. Dinitrogen Borylation with Group 4 Metallocene Complexes. Eur. J. Inorg. Chem. 2013, 2 (22-23), 3907-3915. https://doi.org/10.1002/ejic.201300046.

(82) Semproni, S. P.; Milsmann, C.; Chirik, P. J. Structure and Reactivity of a Hafnocene $\mu$-Nitrido Prepared from Dinitrogen Cleavage. Angew. Chem. Int. Ed. 2012, 51 (21), 5213-5216. https://doi.org/10.1002/anie.201201361.

(83) Semproni, S. P.; Chirik, P. J. Synthesis of a Base-Free Hafnium Nitride from N2 Cleavage: A Versatile Platform for Dinitrogen Functionalization. J. Am. Chem. Soc. 2013, 135 (30), 11373-11383. https://doi.org/10.1021/ja405477m.

(84) Knobloch, D. J.; Lobkovsky, E.; Chirik, P. J. Dinitrogen Cleavage and Functionalization by Carbon Monoxide Promoted by a Hafnium Complex. Nat. Chem. 2010, 2 (1), 30-35. https://doi.org/10.1038/nchem.477.

(85) Turner, H. W.; Fellmann, J. D.; Rocklage, S. M.; Schrock, R. R.; Churchill, M. R.; Wasserman, H. J. Tantalum Complexes Containing Diimido Bridging Dinitrogen Ligands. J. Am. Chem. Soc. 1980, 102 (26), 7809-7811. https://doi.org/10.1021/ja00546a044.

(86) Edema, J. J. H.; Meetsma, A.; Gambarotta, S. Divalent Vanadium and Dinitrogen Fixation: The Preparation and X-Ray Structure of $(\mu-\mathrm{N} 2)\{[(0-$ Me2NCH2)C6H4]2V(Py)\}2(THF)2. J. Am. Chem. Soc. 1989, 111 (17), 6878- 
6880. https://doi.org/10.1021/ja00199a079.

(87) Rehder, D.; Woitha, C.; Priebsch, W.; Gailus, H. Trans-

[Na(Thf)][V(N2)2(Ph2PCH2CH2PPh2)2]: Structural Characterization of a

Dinitrogenvanadium Complex, a Functional Model for Vanadiumnitrogenase.

J.C.S. Chem. Comm. 1992, 28, 364-365.

(88) Gailus, H.; Woitha, C.; Rehder, D. Dinitrogenvanadates(- I): Synthesis, Reactions and Conditions for Their Stability. J. Chem. Soc. Dalt. Trans. 1994, 3471-3477.

(89) Song, J. I.; Berno, P.; Gambarotta, S. Dinitrogen Fixation, Ligand

Dehydrogenation, and Cyclometalation in the Chemistry of Vanadium(III)

Amides. J. Am. Chem. Soc. 1994, 116 (15), 6927-6928.

https://doi.org/10.1021/ja00094a054.

(90) Desmangles, N.; Jenkins, H.; Ruppa, K. B.; Gambarotta, S. Preparation and Characterization of a Vanadium (III) Dinitrogen Complex Supported by a Tripodal Anionic Amide Ligand. Inorganica Chim. Acta 1996, 250 (1-2 PART I), 1-4.

(91) Berno, P.; Gambarotta, S. Reaction of a Vanadium(Ir1) Amide with H, : Isolation and Characterization of a Polynuclear Mixed-Valence Polyhydrido -Nitrido Complex. 1995, 34, 922-924.

(92) Clentsmith, G. K. B.; Bates, V. M. E.; Hitchcock, P. B.; Cloke, F. G. N. Reductive Cleavage of Dinitrogen by a Vanadium Diamidoamine Complex: The Molecular Structures of $[\mathrm{V}(\mathrm{Me} 3 \mathrm{SiN}\{\mathrm{CH} 2 \mathrm{CH} 2 \mathrm{NSiMe} 3\} 2)(\mu-\mathrm{N})] 2$ and K[V(Me3SiN $\{\mathrm{CH} 2 \mathrm{CH} 2 \mathrm{NSiMe} 3\} 2)(\mu-\mathrm{N})] 2$ [15]. J. Am. Chem. Soc. 1999, 121 (44), 10444-10445. https://doi.org/10.1021/ja9921219.

(93) Vidyaratne, I.; Gambarotta, S.; Korobkov, I.; Budzelaar, P. H. M. Dinitrogen 
Partial Reduction by Formally Zero- and Divalent Vanadium Complexes

Supported by the Bis-Iminopyridine System. Inorg. Chem. 2005, 44 (5), $1187-$

1189. https://doi.org/10.1021/ic048358+.

(94) Milsmann, C.; Semproni, S. P.; Chirik, P. J. N-N Bond Cleavage of 1,2-

Diarylhydrazines and N-H Bond Formation via H-Atom Transfer in Vanadium

Complexes Supported by a Redox-Active Ligand. J. Am. Chem. Soc. 2014, 136

(34), 12099-12107. https://doi.org/10.1021/ja5062196.

(95) Smythe, N. C.; Schrock, R. R.; Müller, P.; Weare, W. W. Synthesis of [(HIPTNCH

$2 \mathrm{CH} 2$ ) 3 N]V Compounds (HIPT = 3,5-(2,4,6- i -Pr 3 C 6 H 2 ) 2 C 6 H 3 ) and

an Evaluation of Vanadium for the Reduction of Dinitrogen to Ammonia. Inorg.

Chem. 2006, 45 (23), 9197-9205. https://doi.org/10.1021/ic061554r.

(96) Vidyaratne, I.; Crewdson, P.; Lefebvre, E.; Gambarotta, S. Dinitrogen

Coordination and Cleavage Promoted by a Vanadium Complex of a $\sigma, \pi, \sigma$-Donor

Ligand. Inorg. Chem. 2007, 46 (21), 8836-8842.

https://doi.org/10.1021/ic701219h.

(97) Kilgore, U. J.; Sengelaub, C. A.; Pink, M.; Fout, A. R.; Mindiola, D. J. A Transient VIII-Alkylidene Complex: Oxidation Chemistry Including the Activation of N2 to Afford a Highly Porous Honeycomb-Like Framework. Angew. Chem. Int. Ed.

2008, 47 (20), 3769-3772. https://doi.org/10.1002/anie.200705931.

(98) Kilgore, U. J.; Sengelaub, C. A.; Fan, H.; Tomaszewski, J.; Karty, J. A.; Baik, M. H.; Mindiola, D. J. A Transient Vanadium(III) Neopentylidene Complex. Redox Chemistry and Reactivity of the V=CH TBu Functionality. Organometallics 2009, 28 (3), 843-852. https://doi.org/10.1021/om800800g. 
(99) Tran, B. L.; Pinter, B.; Nichols, A. J.; Konopka, F. T.; Thompson, R.; Chen, C. H.; Krzystek, J.; Ozarowski, A.; Telser, J.; Baik, M. H.; et al. A Planar ThreeCoordinate Vanadium(II) Complex and the Study of Terminal Vanadium Nitrides from N2: A Kinetic or Thermodynamic Impediment to N-N Bond Cleavage? J. Am. Chem. Soc. 2012, 134 (31), 13035-13045. https://doi.org/10.1021/ja303360v.

(100) Groysman, S.; Villagrán, D.; Freedman, D. E.; Nocera, D. G. Dinitrogen Binding at Vanadium in a Tris(Alkoxide) Ligand Environment. Chem. Commun. 2011, 47 (37), 10242-10244. https://doi.org/10.1039/c1cc13645c.

(101) Cozzolino, A. F.; Silvia, J. S.; Lopez, N.; Cummins, C. C. Experimental and Computational Studies on the Formation of Cyanate from Early Metal Terminal Nitrido Ligands and Carbon Monoxide. Dalt. Trans. 2014, 43 (12), 4639-4652. https://doi.org/10.1039/c3dt52738g.

(102) Ishida, Y.; Kawaguchi, H. Nitrogen Atom Transfer from a Dinitrogen-Derived Vanadium Nitride Complex to Carbon Monoxide and Isocyanide. J. Am. Chem. Soc. 2014, 136 (49), 16990-16993. https://doi.org/10.1021/ja510317h.

(103) Berno, P.; Gambarotta, S. Formation of a Metallaaziridine Ring and Dinitrogen Fixation Promoted by a Niobium Amide Complex. Organometallics 1995, 14 (5), 2159-2161. https://doi.org/10.1021/om00005a012.

(104) Mindiola, D. J.; Meyer, K.; Cherry, J. P. F.; Baker, T. A.; Cummins, C. C. Dinitrogen Cleavage Stemming from a Heterodinuclear Niobium/Molybdenum N2complex: New Nitridoniobium Systems Including a Niobazene Cyclic Trimer. Organometallics 2000, 19 (9), 1622-1624. https://doi.org/10.1021/om000159k. (105) Figueroa, J. S.; Piro, N. A.; Clough, C. R.; Cummins, C. C. A Nitridoniobium(V) 
Reagent That Effects Acid Chloride to Organic Nitrile Conversion: Synthesis via Heterodinuclear (Nb/Mo) Dinitrogen Cleavage, Mechanistic Insights, and Recycling. J. Am. Chem. Soc. 2006, 128 (3), 940-950.

https://doi.org/10.1021/ja056408j.

(106) Zanotti-Gerosa, A.; Solari, E.; Giannini, L.; Floriani, C.; Chiesi-Villa, A.; Rizzoli, C. Stepwise Reduction of Dinitrogen to Nitride Assisted by Niobium Bonded to Oxygen Donor Atoms: The Potential of Reduced Forms of Niobium Calix[4]Arene. J. Am. Chem. Soc. 1998, 120 (2), 437-438. https://doi.org/10.1021/ja9722584.

(107) Terrett, R.; Cavigliasso, G.; Stranger, R.; Yates, B. F. On the Unprecedented Level of Dinitrogen Activation in the Calix[4]Arene Complex of $\mathrm{Nb}($ Iii). Dalt. Trans. 2011, 40 (42), 11267. https://doi.org/10.1039/c1dt11091h.

(108) Caselli, A.; Solari, E.; Scopelliti, R.; Floriani, C.; Re, N.; Rizzoli, C.; Chiesi-Villa, A. Dinitrogen Rearranging over a Metal-Oxo Surface and Cleaving to Nitride: From the End-On to the Side-On Bonding Mode, to the Stepwise Cleavage of the N:N Bonds Assisted by Nb III -Calix[4]Arene. J. Am. Chem. Soc. 2000, 122 (15), 3652-3670. https://doi.org/10.1021/ja9943288.

(109) Kawaguchi, H.; Matsuo, T. Dinitrogen-Bond Cleavage in a Niobium Complex Supported by a Tridentate Aryloxide Ligand. Angew. Chem. Int. Ed. 2002, 41 (15), 2792-2794. https://doi.org/10.1002/1521-3773(20020802)41:15<2792::AIDANIE2792>3.0.CO;2-K.

(110) Akagi, F.; Matsuo, T.; Kawaguchi, H. Dinitrogen Cleavage by a Diniobium Tetrahydride Complex : Formation of a Nitride and Its Conversion into Imide 
Species **. 2007, 8778-8781. https://doi.org/10.1002/anie.200703336.

(111) Tanaka, H.; Shiota, Y.; Matsuo, T.; Kawaguchi, H.; Yoshizawa, K. DFT Study on N2 Activation by a Hydride-Bridged Diniobium Complex. $\mathrm{N} \equiv \mathrm{N}$ Bond Cleavage Accompanied by H2 Evolution. Inorg. Chem. 2009, 48 (8), 3875-3881. https://doi.org/10.1021/ic802377p.

(112) Searles, K.; Carroll, P. J.; Chen, C. H.; Pink, M.; Mindiola, D. J. Niobium-Nitrides Derived from Nitrogen Splitting. Chem. Commun. 2015, 51 (17), 3526-3528. https://doi.org/10.1039/c4cc09563d.

(113) Fryzuk, M. D.; Johnson, S. A.; Patrick, B. O.; Albinati, A.; Mason, S. A.; Koetzle, T. F. New Mode of Coordination for the Dinitrogen Ligand: Formation, Bonding, and Reactivity of a Tantalum Complex with a Bridging N2 Unit That Is Both Sideon and End-On. J. Am. Chem. Soc. 2001, 123 (17), 3960-3973. https://doi.org/10.1021/ja0041371.

(114) Fryzuk, M. D.; Kozak, C. M.; Bowdridge, M. R.; Patrick, B. O.; Rettig, S. J. Nitride Formation by Thermolysis of a Kinetically Stable Niobium Dinitrogen Complex. J. Am. Chem. Soc. 2002, 124 (28), 8389-8397. https://doi.org/10.1021/ja025997f.

(115) Fryzuk, M. D.; Kozak, C. M.; Patrick, B. O. Dinuclear Organometallic Dinitrogen Complexes of Niobium. Inorganica Chim. Acta 2003, 345, 53-62. https://doi.org/10.1016/S0020-1693(02)01305-1.

(116) Kilgore, U. J.; Yang, X.; Tomaszewski, J.; Huffman, J. C.; Mindiola, D. J. Activation of Atmospheric Nitrogen and Azobenzene $\mathrm{N}=\mathrm{N}$ Bond Cleavage by a Transient Nb(III) Complex. Inorg. Chem. 2006, 45 (26), 10712-10721. 
https://doi.org/10.1021/ic061642b.

(117) Rocklage, S. M.; Turner, H. W.; Fellmann, J. D.; Schrock, R. R. Preparation of Tantalum $\mu$-Dinitrogen Complexes from Molecular Nitrogen and Reduced Tantalum Complexes. Organometallics 1982, 1 (5), 703-707. https://doi.org/10.1021/om00065a006.

(118) Fryzuk, M. D. Side-on End-on Bound Dinitrogen: An Activated Bonding Mode That Facilitates Functionalizing Molecular Nitrogen. Acc. Chem. Res. 2009, 42 (1), 127-133. https://doi.org/10.1021/ar800061g.

(119) Fryzuk, M. D.; Johnson, S. A.; Rettig, S. J. New Mode of Coordination for the Dinitrogen Ligand: A Dinuclear Tantalum Complex with a Bridging N2 Unit That Is Both Side-on and End-on [25]. J. Am. Chem. Soc. 1998, 120 (42), 11024-11025. https://doi.org/10.1021/ja982377z.

(120) Yeo, A.; Shaver, M. P.; Fryzuk, M. D. A New Side-on End-On Ditantalum Dinitrogen Complex and Its Reaction with BuSiH 3. Zeitschrift für Anorg. und Allg. Chemie 2015, 641 (1), 123-127. https://doi.org/10.1002/zaac.201400167.

(121) Shaver, M. P.; Johnson, S. A.; Fryzuk, M. D. Activation and Cleavage of Alkynes by the Dinuclear Tantalum Complexes ([NPN]Ta) $2(\mu-\mathrm{H}) 4$ and $([\mathrm{NPN}] \mathrm{Ta}) 2(\mu-$ H1:H2-N2)( $\mu-\mathrm{H}) 2($ Where NPN $=$ PhP(CH2SiMe2NPh)2). Can. J. Chem. 2005, 83 (6-7), 652-660. https://doi.org/10.1139/v05-034.

(122) Ballmann, J.; Yeo, A.; Patrick, B. O.; Fryzuk, M. D. Carbon-Nitrogen Bond Formation by the Reaction of 1,2-Cumulenes with a Ditantalum Complex Containing Side-on- and End-on-Bound Dinitrogen. Angew. Chem. Int. Ed. 2011, 50 (2), 507-510. https://doi.org/10.1002/anie.201005704. 
(123) Spencer, L. P.; MacKay, B. A.; Patrick, B. O.; Fryzuk, M. D. Inner-Sphere TwoElectron Reduction Leads to Cleavage and Functionalization of Coordinated Dinitrogen. Proc. Natl. Acad. Sci. U. S. A. 2006, 103 (46), 17094-17098. https://doi.org/10.1073/pnas.0602132103.

(124) MacKay, B. A.; Johnson, S. A.; Patrick, B. O.; Fryzuk, M. D. Functionalization and Cleavage of Coordinated Dinitrogen via Hydroboration Using Primary and Secondary Boranes. Can. J. Chem. 2005, 83 (4), 315-323. https://doi.org/10.1139/v04-161.

(125) Fryzuk, M. D.; MacKay, B. A.; Johnson, S. A.; Patrick, B. O. Hydroboration of Coordinated Dinitrogen: A New Reaction for the N2 Ligand That Results in Its Functionalization and Cleavage. Angew. Chem. Int. Ed. 2002, 41 (19), 3709-3712. https://doi.org/10.1002/1521-3773(20021004)41:19<3709::AIDANIE3709>3.0.CO;2-U.

(126) MacKay, B. A.; Patrick, B. O.; Fryzuk, M. D. Hydroalumination of a Dinuclear Tantalum Dinitrogen Complex: N-N Bond Cleavage and Ancillary Ligand Rearrangement. Organometallics 2005, 24 (16), 3836-3841. https://doi.org/10.1021/om050208z.

(127) MacKay, B. A.; Munha, R. F.; Fryzuk, M. D. Substituent Effects in the Hydrosilylation of Coordinated Dinitrogen in a Ditantalum Complex: Cleavage and Functionalization of N2. J. Am. Chem. Soc. 2006, 128 (29), 9472-9483. https://doi.org/10.1021/ja061508q.

(128) Fryzuk, M. D.; MacKay, B. A.; Patrick, B. O. Hydrosilylation of a Dinuclear Tantalum Dinitrogen Complex: Cleavage of N2 and Functionalization of Both 
Nitrogen Atoms. J. Am. Chem. Soc. 2003, 125 (11), 3234-3235.

https://doi.org/10.1021/ja034303f.

(129) Bregel, D. C.; Oldham, S. M.; Lachicotte, R. J.; Eisenberg, R. A New Tantalum Dinitrogen Complex and a Parahydrogen-Induced Polarization Study of Its Reaction with Hydrogen. Inorg. Chem. 2002, 41 (17), 4371-4377. https://doi.org/10.1021/ic025578j.

(130) Lee, T. Y.; Wooten, A. J.; Luci, J. J.; Swenson, D. C.; Messerle, L. Four-Electron Reduction of Dinitrogen during Solution Disproportionation of the Organodimetallic $(\eta-\mathrm{C} 5 \mathrm{Me} 4 \mathrm{R}) 2 \mathrm{Ta} 2(\mu-\mathrm{Cl}) 4(\mathrm{R}=\mathrm{Me}, \mathrm{Et})$ to a New $\mu-\mathrm{H} 1, \mathrm{H} 1-\mathrm{N} 2$ Complex and Odd-Electron Organotrimetallic Cluster. Chem. Commun. 2005, 2 (43), 5444-5446. https://doi.org/10.1039/b508148c.

(131) Horrillo-Martinez, P.; Patrick, B. O.; Schafer, L. L.; Fryzuk, M. D. Oxygen Extrusion from Amidate Ligands to Generate Terminal TaO Units under Reducing Conditions. How to Successfully Use Amidate Ligands in Dinitrogen Coordination Chemistry. Dalt. Trans. 2012, 41 (5), 1609-1616. https://doi.org/10.1039/c1dt11595b.

(132) Takada, R.; Hirotsu, M.; Nishioka, T.; Hashimoto, H.; Kinoshita, I. Sulfur-Bridged Ta-M (M = Mo, Cr) Multinuclear Complexes Bearing a Four-Electron-Reduced Dinitrogen Ligand. Organometallics 2011, 30 (16), 4232-4235. https://doi.org/10.1021/om200596v.

(133) Hirotsu, M.; Fontaine, P. P.; Epshteyn, A.; Zavalij, P. Y.; Sita, L. R. Dinitrogen Activation at Ambient Temperatures: New Modes of $\mathrm{H} 2$ and $\mathrm{PhSiH} 3$ Additions for an "End-on-Bridged" [Ta(IV)] 2( $\mu-\mathrm{H} 1: \mathrm{H} 1-\mathrm{N} 2)$ Complex and for the Bis( $\mu$ - 
Nitrido) $[\mathrm{Ta}(\mathrm{V})(\mu-\mathrm{N})] 2$ Product Derived from Facile $\mathrm{N} \equiv \mathrm{N}$ Bond Cleavage. J. Am.

Chem. Soc. 2007, 129 (30), 9284-9285. https://doi.org/10.1021/ja072248v.

(134) Keane, A. J.; Yonke, B. L.; Hirotsu, M.; Zavalij, P. Y.; Sita, L. R. Fine-Tuning the Energy Barrier for Metal-Mediated Dinitrogen $\mathrm{N} \equiv \mathrm{N}$ Bond Cleavage. J. Am. Chem. Soc. 2014, 136 (28), 9906-9909. https://doi.org/10.1021/ja505309j.

(135) Karsch, H. H. CisBis(Dinitrogen)Tetrakis(Trimethylphosphane)Chromium. Angew. Chem. Int. Ed. Engl. 1977, 16 (1), 56-56. https://doi.org/10.1002/anie.197700561.

(136) Sobota, P.; Jezowska-Trzebiatowska, B. Fixation of Dinitrogen and Acetylene by the System CrCl2Mg. Isolation and Properties of Chromium Complexes with Fixed N2 and C2H2. J. Organomet. Chem. 1977, 131 (3), 341-345. https://doi.org/10.1016/S0022-328X(00)84409-5.

(137) Vidyaratne, I.; Scott, J.; Gambarotta, S.; Budzelaar, P. H. M. Dinitrogen Activation, Partial Reduction, and Formation of Coordinated Imide Promoted by a Chromium Diiminepyridine Complex. Inorg. Chem. 2007, 46 (17), 7040-7049. https://doi.org/10.1021/ic700810f.

(138) Monillas, W. H.; Yap, G. P. A.; MacAdams, L. A.; Theopold, K. H. Binding and Activation of Small Molecules by Three-Coordinate Cr(I). J. Am. Chem. Soc. 2007, 129 (26), 8090-8091. https://doi.org/10.1021/ja0725549.

(139) Akturk, E. S.; Yap, G. P. A.; Theopold, K. H. Mechanism-Based Design of Labile Precursors for Chromium(i) Chemistry. Chem. Commun. 2015, 51 (84), 1540215405. https://doi.org/10.1039/c5cc05993c.

(140) Mock, M. T.; Chen, S.; Rousseau, R.; O’Hagan, M. J.; Dougherty, W. G.; Kassel, 
W. S.; DuBois, D. L.; Bullock, R. M. A Rare Terminal Dinitrogen Complex of Chromium. Chem. Commun. 2011, 47 (44), 12212.

https://doi.org/10.1039/c1cc15430c.

(141) Mock, M. T.; Chen, S.; O’Hagan, M.; Rousseau, R.; Dougherty, W. G.; Kassel, W. S.; Bullock, R. M. Dinitrogen Reduction by a Chromium(0) Complex Supported by a 16-Membered Phosphorus Macrocycle. J. Am. Chem. Soc. 2013, 135 (31), 11493-11496. https://doi.org/10.1021/ja405668u.

(142) Mock, M. T.; Pierpont, A. W.; Egbert, J. D.; O’Hagan, M.; Chen, S.; Bullock, R. M.; Dougherty, W. G.; Kassel, W. S.; Rousseau, R. Protonation Studies of a Mono-Dinitrogen Complex of Chromium Supported by a 12-Membered Phosphorus Macrocycle Containing Pendant Amines. Inorg. Chem. 2015, 54 (10), 4827-4839. https://doi.org/10.1021/acs.inorgchem.5b00351.

(143) Egbert, J. D.; O’Hagan, M.; Wiedner, E. S.; Bullock, R. M.; Piro, N. A.; Kassel, W. S.; Mock, M. T. Putting Chromium on the Map for N2 Reduction: Production of Hydrazine and Ammonia. A Study of: Cis $-\mathrm{M}(\mathrm{N} 2) 2(\mathrm{M}=\mathrm{Cr}, \mathrm{Mo}, \mathrm{W})$ Bis(Diphosphine) Complexes. Chem. Commun. 2016, 52 (60), 9343-9346. https://doi.org/10.1039/c6cc03449g.

(144) Kendall, A. J.; Johnson, S. I.; Bullock, R. M.; Mock, M. T. Catalytic Silylation of N 2 and Synthesis of NH 3 and N 2 H 4 by Net Hydrogen Atom Transfer Reactions Using a Chromium P 4 Macrocycle. J. Am. Chem. Soc. 2018, 140 (7), 2528-2536. https://doi.org/10.1021/jacs.7b11132.

(145) Hidai, M.; Tominari, K.; Uchida, Y.; Misono, A. A Trans-Dinitrogen Complex of Molybdenum. J. Chem. Soc. D Chem. Commun. 1969, No. 23, 1392. 
https://doi.org/10.1039/C29690001392.

(146) Yuki, M.; Miyake, Y.; Nishibayashi, Y.; Wakiji, I.; Hidai, M. Synthesis and Reactivity of Tungsten- and Molybdenum-Dinitrogen Complexes Bearing Ferrocenyldiphosphines toward Protonolysis. Organometallics 2008, 27 (15), 3947-3953. https://doi.org/10.1021/om800327j.

(147) Yuki, M.; Midorikawa, T.; Miyake, Y.; Nishibayashi, Y. Synthesis and Protonolysis of Tungsten- and Molybdenum-Dinitrogen Complexes Bearing Ruthenocenyldiphosphines. Organometallics 2009, 28 (16), 4741-4746. https://doi.org/10.1021/om900298g.

(148) Yuki, M.; Miyake, Y.; Nishibayashi, Y. Preparation and Protonation of Tungstenand Molybdenum-Dinitrogen Complexes Bearing Bis(Dialkylphosphinobenzene)Chromiums as Auxiliary Ligands. Organometallics 2009, 28 (19), 5821-5827. https://doi.org/10.1021/om9006467.

(149) Broda, H.; Hinrichsen, S.; Tuczek, F. Molybdenum(0) Dinitrogen Complexes with Polydentate Phosphine Ligands for Synthetic Nitrogen Fixation: Geometric and Electronic Structure Contributions to Reactivity. Coord. Chem. Rev. 2013, 257 (2), 587-598. https://doi.org/10.1016/j.ccr.2012.05.010.

(150) Hinrichsen, S.; Schnoor, A. C.; Grund, K.; Flöser, B.; Schlimm, A.; Näther, C.; Krahmer, J.; Tuczek, F. Molybdenum Dinitrogen Complexes Facially Coordinated by Linear Tridentate PEP Ligands $(\mathrm{E}=\mathrm{N}$ or $\mathrm{P})$ : Impact of the Central e Donor in: Trans -Position to N2. Dalt. Trans. 2016, 45 (37), 14801-14813. https://doi.org/10.1039/c6dt02316a.

(151) Hanna, B. S.; Macintosh, A. D.; Ahn, S.; Tyler, B. T.; Palmore, G. T. R.; Williard, 
P. G.; Bernskoetter, W. H. Ancillary Ligand Effects on Carbon Dioxide-Ethylene Coupling at Zerovalent Molybdenum. Organometallics 2014, 33 (13), 3425-3432. https://doi.org/10.1021/om500324h.

(152) Arashiba, K.; Nakajima, K.; Nishibayashi, Y. Synthesis and Reactivity of Molybdenum-Dinitrogen Complexes Bearing PNN-Type Pincer Ligand. Zeitschrift fur Anorg. und Allg. Chemie 2015, 641 (1), 100-104. https://doi.org/10.1002/zaac.201400117.

(153) Dahlenbourg, L.; Pietsch, B. Mono- Und Bis(DistickstofQmolybdan(0)-Komplexe Des Dreizahnigen Chelat- Phosphans $\mathrm{MeP}(\mathrm{CH} 2 \mathrm{CH} 2 \mathrm{CH} 2 \mathrm{PMe} 2) 2$ : Synthesen, Strukturen Und Reaktionen Mit Kohlendioxid. Chem. Berichte 1989, 122, 20852090.

(154) Arashiba, K.; Miyake, Y.; Nishibayashi, Y. A Molybdenum Complex Bearing PNP-Type Pincer Ligands Leads to the Catalytic Reduction of Dinitrogen into Ammonia. Nat. Chem. 2011, 3 (2), 120-125. https://doi.org/10.1038/nchem.906.

(155) Kuriyama, S.; Arashiba, K.; Nakajima, K.; Tanaka, H.; Kamaru, N.; Yoshizawa, K.; Nishibayashi, Y. Catalytic Formation of Ammonia from Molecular Dinitrogen by Use of Dinitrogen-Bridged Dimolybdenum-Dinitrogen Complexes Bearing PNP-Pincer Ligands: Remarkable Effect of Substituent at PNP-Pincer Ligand. $J$. Am. Chem. Soc. 2014, 136 (27), 9719-9731. https://doi.org/10.1021/ja5044243.

(156) Arashiba, K.; Kinoshita, E.; Kuriyama, S.; Eizawa, A.; Nakajima, K.; Tanaka, H.; Yoshizawa, K.; Nishibayashi, Y. Catalytic Reduction of Dinitrogen to Ammonia by Use of Molybdenum-Nitride Complexes Bearing a Tridentate Triphosphine as Catalysts. J. Am. Chem. Soc. 2015, 137 (17), 5666-5669. 
https://doi.org/10.1021/jacs.5b02579.

(157) Arashiba, K.; Sasaki, K.; Kuriyama, S.; Miyake, Y.; Nakanishi, H.; Nishibayashi, Y. Synthesis and Protonation of Molybdenum-and Tungsten-Dinitrogen Complexes Bearing PNP-Type Pincer Ligands. Organometallics 2012, 31 (5), 2035-2041. https://doi.org/10.1021/om300011z.

(158) Eizawa, A.; Arashiba, K.; Tanaka, H.; Kuriyama, S.; Matsuo, Y.; Nakajima, K.; Yoshizawa, K.; Nishibayashi, Y. Remarkable Catalytic Activity of DinitrogenBridged Dimolybdenum Complexes Bearing NHC-Based PCP-Pincer Ligands toward Nitrogen Fixation. Nat. Commun. 2017, 8, 1-12. https://doi.org/10.1038/ncomms14874.

(159) Broda, H.; Hinrichsen, S.; Krahmer, J.; Näther, C.; Tuczek, F. Molybdenum Dinitrogen Complexes Supported by a Silicon-Centred Tripod Ligand and Dppm or Dmpm: Tuning the Activation of N2. Dalton Trans. 2014, 43 (5), 2007-2012. https://doi.org/10.1039/c3dt52965g.

(160) Söncksen, L.; Gradert, C.; Krahmer, J.; Näther, C.; Tuczek, F. Bonding and Activation of N2 in Mo(0) Complexes Supported by Hybrid Tripod Ligands with Mixed Dialkylphosphine/Diarylphosphine Donor Groups: Interplay of Steric and Electronic Factors. Inorg. Chem. 2013, 52 (11), 6576-6589. https://doi.org/10.1021/ic400582v.

(161) George, T. A.; Rose, D. J.; Chang, Y.; Chen, Q.; Zubieta, J. Reduction of Dinitrogen to Ammonia and Hydrazine in Iron(0) and Molybdenum(0) Complexes Containing the $\mathrm{N}(\mathrm{CH} 2 \mathrm{CH} 2 \mathrm{PPh} 2) 3$ Ligand. Crystal Structures of [FeH(L)(N(CH2CH2PPh2)3)][BPh4] ( $\mathrm{L}=\mathrm{N} 2$, $\mathrm{CO})$. Inorg. Chem. 1995, 34 (5), 
1295-1298. https://doi.org/10.1021/ic00109a046.

(162) Römer, R.; Stephan, G.; Habeck, C.; Hoberg, C.; Peters, G.; Näther, C.; Tuczek, F. Stereoselective Synthesis of the First Chatt-Type Bis(Dinitrogen)- Molybdenum(0) Complex with a Tetraphosphane Ligand. Eur. J. Inorg. Chem. 2008, No. 21, 32583263. https://doi.org/10.1002/ejic.200800417.

(163) Römer, R.; Gradert, C.; Bannwarth, A.; Peters, G.; Näther, C.; Tuczek, F. OneStep Synthesis of Mo(0) and W(0) Bis(Dinitrogen) Complexes with the Linear Tetraphosphine Ligand PrP4: Stereoselective Formation of Cis-[M(N2)2(RacPrP4)] and Trans-[M(N2)2(Meso-PrP4)]; M = Mo, W. Dalt. Trans. 2011, 40 (13), 3229. https://doi.org/10.1039/c0dt01646b.

(164) Stephan, G. C.; Peters, G.; Lehnert, N.; Habeck, G. M.; Näther, C.; Tuczek, F. Bonding, Activation, and Protonation of Dinitrogen on a Molybdenum Pentaphosphine Complex - Comparison to Trans-Bis(Dinitrogen) and -Nitrile Dinitrogen Complexes with Tetraphosphine Coordination. Can. J. Chem. 2005, 83 (4), 385-402. https://doi.org/10.1139/v05-015.

(165) Hinrichsen, S.; Kindjajev, A.; Adomeit, S.; Krahmer, J.; Näther, C.; Tuczek, F. Molybdenum(0) Dinitrogen Complexes Supported by Pentadentate Tetrapodal Phosphine Ligands: Structure, Synthesis, and Reactivity toward Acids. Inorg. Chem. 2016, 55 (17), 8712-8722. https://doi.org/10.1021/acs.inorgchem.6b01255.

(166) Margulieux, G. W.; Turner, Z. R.; Chirik, P. J. Synthesis and Ligand Modification Chemistry of a Molybdenum Dinitrogen Complex: Redox and Chemical Activity of a Bis-(Imino)Pyridine Ligand. Angew. Chem. Int. Ed. 2014, 53 (51), 1421114215. https://doi.org/10.1002/anie.201408725. 
(167) Cradwick, P. D.; Chatt, J.; Crabtree, R. H.; Richards, R. L. Preparation and X-Ray Structure of a Trinuclear Dinitrogen-Bridged Complex, Trans[MoCl4\{(N2)ReCl(PMe2Ph) 4\}2]. J. Chem. Soc. Chem. Commun. 1975, No. 9 , 351-352. https://doi.org/10.1039/C39750000351.

(168) Mösch-Zanetti, N. C.; Schrock, R. R.; Davis, W. M.; Wanninger, K.; Seidel, S. W.; O’Donoghue, M. B. Triamidoamine Complexes of Molybdenum and Tungsten That Contain Metal-E ( $\mathrm{E}=\mathrm{N}, \mathrm{P}$, and as) Single, Double, or Triple Bonds. J. Am. Chem. Soc. 1997, 119 (45), 11037-11048. https://doi.org/10.1021/ja971727z.

(169) O'Donoghue, M. B.; Davis, W. M.; Schrock, R. R.; Reiff, W. M. Heterobimetallic Dinitrogen Complexes That Contain the $\{[\mathrm{N} 3 \mathrm{~N}] \mathrm{Mo}-\mathrm{NN}\}$ - Ligand. Inorg. Chem. 1999, 38 (2), 243-252. https://doi.org/10.1021/ic9811188.

(170) Takagahara, K.; Ishino, H.; Ishii, Y.; Hidai, M. Synthesis and Molecular Structure of Tetranuclear Tungsten-Gallium Complexes with Bridging Dinitrogen Ligands. Chemistry Letters. 1998, pp 897-898. https://doi.org/10.1246/cl.1998.897.

(171) Ishino, H.; Nagano, T.; Kuwata, S.; Yokobayashi, Y.; Ishii, Y.; Hidai, M.; Mizobe, Y. Syntheses, Structures, and Reactivities of Heterobimetallic Bridging Dinitrogen Complexes Containing Group 6 and Group 4 or 5 Transition Metals 1. Organometallics 2001, 20 (1), 188-198. https://doi.org/10.1021/om000684j.

(172) O'Regan, M. B.; Liu, A. H.; Finch, W. C.; Schrock, R. R.; Davis, W. M. A Study of High-Oxidation-State Complexes of the Type [W(.Eta.5-C5Me5)Me2X]2(.Mu.N2), Including x-Ray Structures of [W(.Eta.5-C5Me5)Me2(OC6F5)]2(.Mu.-N2) and [W(.Eta.5-C5Me5)Me2(S-2,4,6-C6H2Me3)]2(.Mu.-N2). J. Am. Chem. Soc. 1990, 112 (11), 4331-4338. https://doi.org/10.1021/ja00167a033. 
(173) Schrock, R. R.; Kolodziej, R. M.; Liu, A. H.; Davis, W. M.; Vale, M. G. Preparation and Characterization of Two High Oxidation State Molybdenum Dinitrogen Complexes: [MoCp*Me3]2(.Mu.-N2) and [MoCp*Me3](.Mu.N2)[WCp'Me3]. J. Am. Chem. Soc. 1990, 112 (11), 4338-4345. https://doi.org/10.1021/ja00167a034.

(174) Fontaine, P. P.; Yonke, B. L.; Zavalij, P. Y.; Sita, L. R. Dinitrogen Complexation and Extent of NtN Activation within the Group 6 "End-On-Bridged" Dinuclear Complexes, $\{(\mathrm{H} 5-\mathrm{C} 5 \mathrm{Me} 5) \mathrm{M}[\mathrm{N}(\mathrm{i}-\mathrm{Pr}) \mathrm{C}(\mathrm{Me}) \mathrm{N}(\mathrm{i}-\mathrm{Pr})]\} 2(\mu-\mathrm{H} 1: \mathrm{H} 1-\mathrm{N} 2)(\mathrm{M}=\mathrm{Mo}$ and W). 2010, 20 (June), 159-161.

(175) Laplaza, C. E.; Cummins, C. C. Dinitrogen Cleavage by a Three-Coordinate Molybdenum(III) Complex. Science (80-. ). 1995, 268 (5212), 861-863. https://doi.org/10.1126/science.268.5212.861.

(176) Laplaza, C. E.; Johnson, M. J. A.; Peters, J. C.; Odom, A. L.; Kim, E.; Cummins, C. C.; George, G. N.; Pickering, I. J. Dinitrogen Cleavage by Three-Coordinate Molybdenum(III) Complexes: Mechanistic and Structural Data 1. J. Am. Chem. Soc. 1996, 118 (36), 8623-8638. https://doi.org/10.1021/ja960574x.

(177) Peters, J. C.; Cherry, J. P. F.; Thomas, J. C.; Baraldo, L.; Mindiola, D. J.; Davis, W. M.; Cummins, C. C. Redox-Catalyzed Binding of Dinitrogen by Molybdenum N-Tert- Hydrocarbylanilide Complexes: Implications for Dinitrogen Functionalization and Reductive Cleavage. J. Am. Chem. Soc. 1999, 121 (43), 10053-10067. https://doi.org/10.1021/ja991435t.

(178) Solari, E.; Da Silva, C.; Iacono, B.; Hesschenbrouck, J.; Rizzoli, C.; Scopelliti, R.; Floriani, C. Photochemical Activation of the N N Bond in Formation of a 
Molybdenum Nitride **. Angew. Chem. Int. Ed. 2001, 40, 3907-3909.

https://doi.org/10.1002/1521-3773(20011015)40:20<3907::AID-

ANIE3907>3.0.CO;2-\#.

(179) Hebden, T. J.; Schrock, R. R.; Takase, M. K.; Müller, P. Cleavage of Dinitrogen to Yield a (t-BuPOCOP)Molybdenum(Iv) Nitride. Chem. Commun. 2012, 48 (13), 1851. https://doi.org/10.1039/c2cc17634c.

(180) Miyazaki, T.; Tanabe, Y.; Yuki, M.; Miyake, Y.; Nakajima, K.; Nishibayashi, Y. Design and Preparation of Molybdenum-Dinitrogen Complexes with Ferrocenyldiphosphine and Pentamethylcyclopentadienyl Moieties as Auxiliary Ligands. Chem. - A Eur. J. 2013, 19 (36), 11874-11877. https://doi.org/10.1002/chem.201302700.

(181) Miyazaki, T.; Tanaka, H.; Tanabe, Y.; Yuki, M.; Nakajima, K.; Yoshizawa, K.; Nishibayashi, Y. Cleavage and Formation of Molecular Dinitrogen in a Single System Assisted by Molybdenum Complexes Bearing Ferrocenyldiphosphine. Angew. Chem. Int. Ed. 2014, 53 (43), 11488-11492.

https://doi.org/10.1002/anie.201405673.

(182) Keane, A. J.; Farrell, W. S.; Yonke, B. L.; Zavalij, P. Y.; Sita, L. R. MetalMediated Production of Isocyanates, $\mathrm{R}_{3} \mathrm{EN} \square \mathrm{C} \square \mathrm{O}$ from Dinitrogen, Carbon Dioxide, and $\mathrm{R}_{3}$ ECl. Angew. Chem. Int. Ed. 2015, 54 (35), 10220-10224. https://doi.org/10.1002/anie.201502293.

(183) Duman, L. M.; Farrell, W. S.; Zavalij, P. Y.; Sita, L. R. Steric Switching from Photochemical to Thermal Reaction Pathways for Enhanced Efficiency in MetalMediated Nitrogen Fixation. J. Am. Chem. Soc. 2016, 138 (45), 14856-14859. 
https://doi.org/10.1021/jacs.6b09789.

(184) Liao, Q.; Cavaillé, A.; Saffon-Merceron, N.; Mézailles, N. Direct Synthesis of Silylamine from N2and a Silane: Mediated by a Tridentate Phosphine Molybdenum Fragment. Angew. Chem. Int. Ed. 2016, 55 (37), 11212-11216. https://doi.org/10.1002/anie.201604812.

(185) Silantyev, G. A.; Förster, M.; Schluschaß, B.; Abbenseth, J.; Würtele, C.; Volkmann, C.; Holthausen, M. C.; Schneider, S. Dinitrogen Splitting Coupled to Protonation. Angew. Chem. Int. Ed. 2017, 56 (21), 5872-5876. https://doi.org/10.1002/anie.201701504.

(186) Chatt, J.; Pearman, A. J.; Richards, R. L. The Reduction of Mono-Coordinated Molecular Nitrogen to Ammonia in a Protic Environment. Nature 1975, 253 (39).

(187) Galindo, A.; Hills, A.; Hughes, D. L.; Richards, R. L.; Hughes, M.; Mason, J. Protonation Reactions of Dinitrogen Complexes of Molybdenum and Tungsten with PMe3 as Co-Ligand. X-Ray Structure of the Hydrazidium Complex [WCl(NNH3)(PMe3)4] Cl2. J. Chem. Soc. Dalt. Trans. 1990, No. 1, 283-288. https://doi.org/10.1039/DT9900000283.

(188) Chatt, J.; Heath, G. A.; Richards, R. L. Diazene-N-(Di-Imide) and Hydrazido-(2)N-(Aminoimido) Complexes: The Addition of Acids to Dinitrogen Complexes. $J$. Chem. Soc., Dalt. Trans. 1974, No. 19, 2074-2082. https://doi.org/10.1039/DT9740002074.

(189) Chatt, J.; Heath, G. A.; Richards, R. L. The Reduction of Ligating Dinitrogen to Yield a Ligating N2H2 Moiety. J. Chem. Soc. Chem. Commun. 1972, No. 18, 1010-1011. https://doi.org/10.1039/C39720001010. 
(190) Heath, G. A.; Mason, R.; Thomas, K. M. Reduction of Coordinated Dinitrogen to the Coordinated Hydrazido Dianion. The Structural Characterization of the 1- $\eta-$ Hydrazido(2-)Chlorobis[1,2-Bis(Diphenylphosphino)Ethane]Tungsten(IV)

Cation. J. Am. Chem. Soc. 1974, 96 (1), 259-260.

https://doi.org/10.1021/ja00808a048.

(191) Hidai, M.; Kodama, T.; Sato, M.; Harakawa, M.; Uchida, Y. Preparation and Properties of Dinitrogen-Molybdenum Complexes. 3.1 Preparation and Molecular Structure of 1-( $\eta$-Hydrazido(2-))Fluorobis[1,2-

Bis(Diphenylphosphino)Ethane]Molybdenum Tetrafluoroborate-Dichloromethane Solvate, [Mo(N2H2)F(Ph2PCH2CH2PPh2)2 [BF4]. Inorg. Chem. 1976, 15 (11), 2694-2697. https://doi.org/10.1021/ic50165a025.

(192) Labios, L. A.; Heiden, Z. M.; Mock, M. T. Electronic and Steric Influences of Pendant Amine Groups on the Protonation of Molybdenum Bis(Dinitrogen) Complexes. Inorg. Chem. 2015, 54 (9), 4409-4422. https://doi.org/10.1021/acs.inorgchem.5b00209.

(193) Weiss, C. J.; Groves, A. N.; Mock, M. T.; Dougherty, W. G.; Kassel, W. S.; Helm, M. L.; DuBois, D. L.; Bullock, R. M. Synthesis and Reactivity of Molybdenum and Tungsten Bis(Dinitrogen) Complexes Supported by Diphosphine Chelates Containing Pendant Amines. Dalt. Trans. 2012, 41 (15), 4517. https://doi.org/10.1039/c2dt12224c.

(194) Labios, L. A.; Weiss, C. J.; Egbert, J. D.; Lense, S.; Bullock, R. M.; Dougherty, W. G.; Kassel, W. S.; Mock, M. T. Synthesis and Protonation Studies of Molybdenum(0) Bis(Dinitrogen) Complexes Supported by Diphosphine Ligands 
Containing Pendant Amines. Zeitschrift fur Anorg. und Allg. Chemie 2015, 641

(1), 105-117. https://doi.org/10.1002/zaac.201400119.

(195) Jia, G.; Morris, R. H.; Schweitzer, C. T. An Acidic H2-Dihydrogen Complex Protonating Coordinated Dinitrogen. Inorg. Chem. 1991, 30 (4), 593-594. https://doi.org/10.1021/ic00004a001.

(196) Nishibayashi, Y. Bimetallic System for Nitrogen Fixation: Ruthenium-Assisted Protonation of Coordinated N2 on Tungsten with H2. Science (80-. ). 1998, 279 (5350), 540-542. https://doi.org/10.1126/science.279.5350.540.

(197) Nishibayashi, Y.; Wakiji, I.; Hirata, K.; DuBois, M. R.; Hidai, M. Protonation of Coordinated N2 on Tungsten with H2 Mediated by Sulfido-Bridged Dinuclear Molybdenum Complexes. Inorg. Chem. 2001, 40 (3), 578-580. https://doi.org/10.1021/ic000716v.

(198) Nishibayashi, Y.; Iwai, S.; Hidai, M. A Model for Protonation of Dinitrogen by Nitrogenase: Protonation of Coordinated Dinitrogen on Tungsten with Hydrosulfido-Bridged Dinuclear Complexes [9]. J. Am. Chem. Soc. 1998, 120 (40), 10559-10560. https://doi.org/10.1021/ja981223g.

(199) Tamizmani, M.; Sivasankar, C. Protonation of Coordinated Dinitrogen Using Protons Generated from Molecular Hydrogen. Eur. J. Inorg. Chem. 2017, 2017 (37), 4239-4245. https://doi.org/10.1002/ejic.201700784.

(200) Yandulov, D. V; Schrock, R. R. Catalytic Reduction of Dinitrogen to Ammonia at a Single Molybdenum Center. Science (80-. ). 2003, 301 (5629), 76-78. https://doi.org/10.1126/science.1085326.

(201) Yandulov, D. V.; Schrock, R. R. Reduction of Dinitrogen to Ammonia at a Well- 
Protected Reaction Site in a Molybdenum Triamidoamine Complex. J. Am. Chem.

Soc. 2002, 124 (22), 6252-6253. https://doi.org/10.1021/ja020186x.

(202) Weare, W. W.; Dai, X.; Byrnes, M. J.; Chin, J. M.; Schrock, R. R.; Müller, P. Catalytic Reduction of Dinitrogen to Ammonia at a Single Molybdenum Center. Proc. Natl. Acad. Sci. U. S. A. 2006, 103 (46), 17099-17106. https://doi.org/10.1073/pnas.0602778103.

(203) Yandulov, D. V.; Schrock, R. R. Studies Relevant to Catalytic Reduction of Dinitrogen to Ammonia by Molybdenum Triamidoamine Complexes. Inorg. Chem. 2005, 44 (4), 1103-1117. https://doi.org/10.1021/ic040095w.

(204) Hetterscheid, D. G. H.; Hanna, B. S.; Schrock, R. R. Molybdenum Triamidoamine Systems. Reactions Involving Dihydrogen Relevant to Catalytic Reduction of Dinitrogen. Inorg. Chem. 2009, 48 (17), 8569-8577. https://doi.org/10.1021/ic900468n.

(205) Kinney, R. A.; McNaughton, R. L.; Chin, J. M.; Schrock, R. R.; Hoffman, B. M. Protonation of the Dinitrogen-Reduction Catalyst [HIPTN3N] MoIII Investigated by ENDOR Spectroscopy. Inorg. Chem. 2011, 50 (2), 418-420. https://doi.org/10.1021/ic102127v.

(206) Schrock, R. R. Catalytic Reduction of Dinitrogen to Ammonia by Molybdenum: Theory versus Experiment. Angew. Chem. Int. Ed. 2008, 47 (30), 5512-5522. https://doi.org/10.1002/anie.200705246.

(207) Schenk, S.; Guennic, B. Le; Kirchner, B.; Reiher, M.; Schenk, S.; Guennic, B. Le; Kirchner, B.; Reiher, M. First-Principles Investigation of the Schrock Mechanism of Dinitrogen Reduction Employing the Full HIPTN N Ligand First-Principles 
Investigation of the Schrock Mechanism of Dinitrogen Reduction Employing the Full HIPTN 3 N Ligand. 2008, 47 (9), 3634-3650.

https://doi.org/10.1021/ic702083p.

(208) Schenk, S.; Kirchner, B.; Reiher, M. A Stable Six-Coordinate Intermediate in Ammonia-Dinitrogen Exchange at Schrock's Molybdenum Catalyst. Chem. - A Eur. J. 2009, 15 (20), 5073-5082. https://doi.org/10.1002/chem.200802438.

(209) Thimm, W.; Gradert, C.; Broda, H.; Wennmohs, F.; Neese, F.; Tuczek, F. Free Reaction Enthalpy Profile of the Schrock Cycle Derived from Density Functional Theory Calculations on the Full $\left[\mathrm{Mo}^{\mathrm{HIPT}} \mathrm{N}<\mathrm{inf}>3</ \mathrm{Inf}>\mathrm{N}\right]$ Catalyst. Inorg. Chem. 2015, 54 (19), 9248-9255. https://doi.org/10.1021/acs.inorgchem.5b00787.

(210) Ritleng, V.; Yandulov, D. V.; Weare, W. W.; Schrock, R. R.; Hock, A. S.; Davis, W. M. Molybdenum Triamidoamine Complexes That Contain Hexa-TertButylterphenyl, Hexamethylterphenyl, or p-Bromohexaisopropylterphenyl Substituents. An Examination of Some Catalyst Variations for the Catalytic Reduction of Dinitrogen. J. Am. Chem. Soc. 2004, 126 (19), 6150-6163. https://doi.org/10.1021/ja0306415.

(211) Weare, W. W.; Schrock, R. R.; Hock, A. S.; Müller, P. Synthesis of Molybdenum Complexes That Contain "Hybrid" Triamidoamine Ligands, [(Hexaisopropylterphenyl-NCH2CH 2)2NCH2CH2N-Aryl]3-, and Studies Relevant to Catalytic Reduction of Dinitrogen. Inorg. Chem. 2006, 45 (23), 91859196. https://doi.org/10.1021/ic0613457.

(212) Reithofer, M. R.; Schrock, R. R.; Müller, P. Synthesis of [(DPPNCH $\left.{ }_{2} \mathrm{CH}_{2}\right)_{3} \mathrm{~N}$ ] ${ }^{3-}$ Molybdenum Complexes (DPP = 3,5-(2,5-Diisopropylpyrrolyl) ${ }_{2} \mathrm{C}_{6} \mathrm{H}_{3}$ ) and 
Studies Relevant to Catalytic Reduction of Dinitrogen. J. Am. Chem. Soc. 2010, 132 (24), 8349-8358. https://doi.org/10.1021/ja1008213.

(213) Arashiba, K.; Kuriyama, S.; Nakajima, K.; Nishibayashi, Y. Preparation and Reactivity of a Dinitrogen-Bridged Dimolybdenum-Tetrachloride Complex. Chem. Commun. 2013, 49 (95), 11215-11217. https://doi.org/10.1039/c3cc46946h.

(214) Kinoshita, E.; Arashiba, K.; Kuriyama, S.; Miyake, Y.; Shimazaki, R.; Nakanishi, H.; Nishibayashi, Y. Synthesis and Catalytic Activity of Molybdenum-Dinitrogen Complexes Bearing Unsymmetric PNP-Type Pincer Ligands. Organometallics 2012, 31 (23), 8437-8443. https://doi.org/10.1021/om301046t.

(215) Tanabe, Y.; Kuriyama, S.; Arashiba, K.; Miyake, Y.; Nakajima, K.; Nishibayashi, Y. Preparation and Reactivity of Molybdenum-Dinitrogen Complexes Bearing an Arsenic-Containing ANA-Type Pincer Ligand. Chem. Commun. 2013, 49 (81), 9290-9292. https://doi.org/10.1039/c3cc45228j.

(216) Tanaka, H.; Arashiba, K.; Kuriyama, S.; Sasada, A.; Nakajima, K.; Yoshizawa, K.; Nishibayashi, Y. Unique Behaviour of Dinitrogen-Bridged Dimolybdenum Complexes Bearing Pincer Ligand towards Catalytic Formation of Ammonia. Nat. Commun. 2014, 5, 3737. https://doi.org/10.1038/ncomms4737.

(217) Tian, Y. H.; Pierpont, A. W.; Batista, E. R. How Does Nishibayashi’s Molybdenum Complex Catalyze Dinitrogen Reduction to Ammonia? Inorg. Chem. 2014, 53 (8), 4177-4183. https://doi.org/10.1021/ic500221n.

(218) Kuriyama, S.; Arashiba, K.; Nakajima, K.; Tanaka, H.; Yoshizawa, K.; Nishibayashi, Y. Nitrogen Fixation Catalyzed by Ferrocene-Substituted Dinitrogen-Bridged Dimolybdenum-Dinitrogen Complexes: Unique Behavior of 
Ferrocene Moiety as Redox Active Site. Chem. Sci. 2015, 6 (7), 3940-3951. https://doi.org/10.1039/C5SC00545K.

(219) Arashiba, K.; Eizawa, A.; Tanaka, H.; Nakajima, K.; Yoshizawa, K.; Nishibayashi, Y. Catalytic Nitrogen Fixation via Direct Cleavage of Nitrogen-Nitrogen Triple Bond of Molecular Dinitrogen under Ambient Reaction Conditions. Bull. Chem. Soc. Jpn. 2017, 90 (10), 1111-1118. https://doi.org/10.1246/bcsj.20170197.

(220) Wickramasinghe, L. A.; Ogawa, T.; Schrock, R. R.; Müller, P. Reduction of Dinitrogen to Ammonia Catalyzed by Molybdenum Diamido Complexes. J. Am. Chem. Soc. 2017, 139 (27), 9132-9135. https://doi.org/10.1021/jacs.7b04800.

(221) Ashida, Y.; Arashiba, K.; Nakajima, K.; Nishibayashi, Y. Molybdenum-Catalysed Ammonia Production with Samarium Diiodide and Alcohols or Water. Nature 2019, 568 (7753), 536-540. https://doi.org/10.1038/s41586-019-1134-2.

(222) Ashida, Y.; Arashiba, K.; Tanaka, H.; Egi, A.; Nakajima, K.; Yoshizawa, K.; Nishibayashi, Y. Molybdenum-Catalyzed Ammonia Formation Using Simple Monodentate and Bidentate Phosphines as Auxiliary Ligands. Inorg. Chem. 2019, 58 (14), 8927-8932. https://doi.org/10.1021/acs.inorgchem.9b01340.

(223) Bossard, G. E.; Busby, D. C.; Chang, M.; George, T. A.; Iske, S. D. A. Reactions of Coordinated Dinitrogen. 4. Reactions of Bromoalkanes with Bis(Dinitrogen)Bis[Ethylenebis(Diphenylphosphine)]Molybdenum. Formation of Ammonia and Amines. J. Am. Chem. Soc. 1980, 102 (3), 1001-1008. https://doi.org/10.1021/ja00523a016.

(224) Hussain, W.; Leigh, G. J.; Modh-Ali, H.; Pickett, C. J. Mechanism of Alkylation of Alkyldiazenido-Complexes of Molybdenum(II) and Tungsten(II): Influence of 
Metal and Co-Ligands on the Nucleophilicity of a Diazenido-Group. J. Chem. Soc.

Dalt. Trans. 1986, No. 7, 1473. https://doi.org/10.1039/dt9860001473.

(225) Yoshida, T.; Adachi, T.; Ueda, T.; Kaminaka, M.; Sasaki, N.; Higuchi, T.;

Aoshima, T.; Mega, I.; Mizobe, Y.; Hidai, M. N-Arylation AndN,N-Dibenzylation of Coordinated N2 with Organic Halides; Differences in the Reactivity Oftrans[Mo(N2)2(Me8[16]AneS4)] and Its Phosphane Analogues. Angew. Chem. Int. Ed. Engl. 1989, 28 (8), 1040-1042. https://doi.org/10.1002/anie.198910401.

(226) Hidai, M.; Mizobe, Y. Recent Advances in the Chemistry of Dinitrogen Complexes. Chem. Rev. 1995, 95 (4), 1115-1133. https://doi.org/10.1021/cr00036a008.

(227) Aoshima, T.; Tamura, T.; Mizobe, Y.; Hidai, M. Preparation and Properties of Molybdenum and Tungsten Dinitrogen Complexes. J. Organomet. Chem. 1992, 435 (1-2), 85-99. https://doi.org/10.1016/0022-328X(92)83462-Q.

(228) Harada, Y.; Mizobe, Y.; Ishii, Y.; Hidai, M. Syntheses of Tungsten Diazoalkane Complexes from a Dinitrogen Complex and Diketones. Conversion of Molecular Nitrogen into Pyrazoles via the Diazoalkane Complexes as Intermediates. Bull. Chem. Soc. Jpn. 1998, 71 (11), 2701-2708. https://doi.org/10.1246/bcsj.71.2701.

(229) Seino, H.; Ishii, Y.; Hidai, M. Synthesis and Structure Determinations of Complexes Containing a Five-Membered Lactam Structure Based on Organohydrazido(2-) Ligands1. Inorg. Chem. 1997, 36 (2), 161-171. https://doi.org/10.1021/ic960778e.

(230) Curley, J. J.; Sceats, E. L.; Cummins, C. C. A Cycle for Organic Nitrile Synthesis via Dinitrogen Cleavage. J. Am. Chem. Soc. 2006, 128 (43), 14036-14037. 
https://doi.org/10.1021/ja066090a.

(231) Hidai, M.; Komori, K.; Kodama, T.; Jin, D.-M.; Takahashi, T.; Sugiura, S.;

Uchida, Y.; Mizobe, Y. Preparation and Properties of Molybdenum and Tungsten

Dinitrogen Complexes. J. Organomet. Chem. 1984, 272 (2), 155-167.

https://doi.org/10.1016/0022-328X(84)80463-5.

(232) Komori, K.; Oshita, H.; Mizobe, Y.; Hidai, M. Catalytic Conversion of Molecular

Nitrogen into Silylamines Using Molybdenum and Tungsten Dinitrogen

Complexes. J. Am. Chem. Soc. 1989, 111 (5), 1939-1940.

https://doi.org/10.1021/ja00187a092.

(233) Tanaka, H.; Sasada, A.; Kouno, T.; Yuki, M.; Miyake, Y.; Nakanishi, H.;

Nishibayashi, Y.; Yoshizawa, K. Molybdenum-Catalyzed Transformation of

Molecular Dinitrogen into Silylamine: Experimental and DFT Study on the

Remarkable Role of Ferrocenyldiphosphine Ligands. J. Am. Chem. Soc. 2011, 133

(10), 3498-3506. https://doi.org/10.1021/ja109181n.

(234) Tanabe, Y.; Nishibayashi, Y. Catalytic Dinitrogen Fixation to Form Ammonia at Ambient Reaction Conditions Using Transition Metal-Dinitrogen Complexes.

Chem. Rec. 2016, 1549-1577. https://doi.org/10.1002/tcr.201600025.

(235) Ogawa, T.; Kajita, Y.; Wasada-Tsutsui, Y.; Wasada, H.; Masuda, H. Preparation, Characterization, and Reactivity of Dinitrogen Molybdenum Complexes with Bis(Diphenylphosphino)Amine Derivative Ligands That Form a Unique 4Membered P-N-P Chelate Ring. Inorg. Chem. 2013, 52 (1), 182-195. https://doi.org/10.1021/ic301577a.

(236) Liao, Q.; Saffon-Merceron, N.; Mézailles, N. Catalytic Dinitrogen Reduction at the 
Molybdenum Center Promoted by a Bulky Tetradentate Phosphine Ligand. Angew. Chem. Int. Ed. 2014, 53 (51), 14206-14210.

https://doi.org/10.1002/anie.201408664.

(237) Liao, Q.; Saffon-Merceron, N.; Mézailles, N. N2 Reduction into Silylamine at Tridentate Phosphine/Mo Center: Catalysis and Mechanistic Study. ACS Catal. 2015, 5 (11), 6902-6906. https://doi.org/10.1021/acscatal.5b01626.

(238) Duman, L. M.; Sita, L. R. Closing the Loop on Transition-Metal-Mediated Nitrogen Fixation: Chemoselective Production of $\mathrm{HN}(\mathrm{SiMe} 3$ ) 2 from N 2 , Me 3 $\mathrm{SiCl}$, and $\mathrm{X}-\mathrm{OH}(\mathrm{X}=\mathrm{R}, \mathrm{R} 3 \mathrm{Si}$, or Silica Gel). J. Am. Chem. Soc. 2017, 139 (48), 17241-17244. https://doi.org/10.1021/jacs.7b08859.

(239) Ishino, H.; Ishii, Y.; Hidai, M. Synthesis of Boryldiazenido Complexes from Tungsten Dinitrogen Complexes. Chemistry Letters. 1998, pp 677-678. https://doi.org/10.1246/cl.1998.677.

(240) Simonneau, A.; Turrel, R.; Vendier, L.; Etienne, M. Group 6 TransitionMetal/Boron Frustrated Lewis Pair Templates Activate N2and Allow Its Facile Borylation and Silylation. Angew. Chem. Int. Ed. 2017, 56 (40), 12268-12272. https://doi.org/10.1002/anie.201706226.

(241) Coffinet, A.; Specklin, D.; Vendier, L.; Etienne, M.; Simonneau, A. Frustrated Lewis Pair Chemistry Enables N2 Borylation by Formal 1,3-Addition of a B-H Bond in the Coordination Sphere of Tungsten. Chem. - A Eur. J. 2019, 1-5. https://doi.org/10.1002/chem.201904084.

(242) Chatt, J.; Crabtree, R. H.; Jeffery, E. A.; Richards, R. L. The Basic Strengths of Some Dinitrogen Complexes of Molybdenum(o), Tungsten(o), Rhenium(I), and 
Osmium(II). Dalt. Trans. 1973, 1167.

(243) Chatt, J.; Dilworth, J. R.; Leigh, G. J. Dinitrogen Complexes of Rheniurn(1) and Rhenium(I1). J.C.S. Dalt. 1973, No. 612.

(244) Mösch-Zanetti, N. C.; Köpke, S.; Herbst-Irmer, R.; Hewitt, M. Unsymmetrical Tren-Based Ligands: Synthesis and Reactivity of Rhenium Complexes. Inorg. Chem. 2002, 41 (13), 3513-3520. https://doi.org/10.1021/ic025572u.

(245) Kirillov, A. M.; Haukka, M.; Guedes da Silva, M. F. C.; Fraústo da Silva, J. J. R.; Pombeiro, A. J. L. A Picolinate-N2 Complex of Rhenium, the First Dinitrogen Complex Bearing a Carboxylate or a N,O-Ligand. J. Organomet. Chem. 2006, 691 (19), 4153-4158. https://doi.org/10.1016/j.jorganchem.2006.06.015.

(246) Smoleński, P.; Pombeiro, A. J. L. Water-Soluble and Stable Dinitrogen Phosphine Complexes Trans-[ReCl(N 2$)(\mathrm{PTA}-\mathrm{H})$ n (PTA) 4-n ] N+ (n = 0-4), the First with 1,3,5-Triaza-7-Phosphaadamantane. Dalt. Trans. 2008, No. 1, 87-91. https://doi.org/10.1039/b712360d.

(247) Chatt, J.; Dilworth, J. R.; Richards, R. L.; Sanders, J. R. Chemical Evidence Concerning the Function of Molybdenum in Nitrogenase [13]. Nature 1969, 224 (5225), 1201-1202. https://doi.org/10.1038/2241201a0.

(248) Seymore, S. B.; Brown, S. N. Kinetic Effects in Heterometallic Dinitrogen Cleavage. Inorg. Chem. 2006, 45 (23), 9540-9550. https://doi.org/10.1021/ic061153b.

(249) Chomitz, W. A.; Arnold, J. Transition Metal Dinitrogen Complexes Supported by a Versatile Monoanionic [N2P2] Ligand. Chem. Commun. 2007, No. 45, 47974799. https://doi.org/10.1039/b709763h. 
(250) Chomitz, W. A.; Arnold, J. Synthesis and Characterization of Manganese and Iron Complexes Supported by Multidentate [N2P2] Ligands. J. Chem. Soc. Dalt. Trans. 2009, No. 10, 1714-1720. https://doi.org/10.1039/b821954k.

(251) Klopsch, I.; Finger, M.; Würtele, C.; Milde, B.; Werz, D. B.; Schneider, S. Dinitrogen Splitting and Functionalization in the Coordination Sphere of Rhenium. J. Am. Chem. Soc. 2014, 136 (19), 6881-6883. https://doi.org/10.1021/ja502759d.

(252) Klopsch, I.; Kinauer, M.; Finger, M.; Würtele, C.; Schneider, S. Conversion of Dinitrogen into Acetonitrile under Ambient Conditions. Angew. Chem. Int. Ed. 2016, 55 (15), 4786-4789. https://doi.org/10.1002/anie.201600790.

(253) Klopsch, I.; Schendzielorz, F.; Volkmann, C.; Würtele, C.; Schneider, S. Synthesis of Benzonitrile from Dinitrogen. Zeitschrift fur Anorg. und Allg. Chemie 2018, 644 (17), 916-919. https://doi.org/10.1002/zaac.201800181.

(254) Schendzielorz, F.; Finger, M.; Abbenseth, J.; Würtele, C.; Krewald, V.; Schneider, S. Metal-Ligand Cooperative Synthesis of Benzonitrile by Electrochemical Reduction and Photolytic Splitting of Dinitrogen. Angew. Chem. Int. Ed. 2019, 58 (3), 830-834. https://doi.org/10.1002/anie.201812125.

(255) Leigh, G. J.; Jimenez-Tenorio, M. Exchange of Dinitrogen between Iron and Molybdenum Centers and the Reduction of Dinitrogen Bound to Iron: Implications for the Chemistry of Nitrogenases. J. Am. Chem. Soc. 1991, 113 (15), 5862-5863. https://doi.org/10.1021/ja00015a050.

(256) Gilbertson, J. D.; Szymczak, N. K.; Tyler, D. R. H2 Activation in Aqueous Solution: Formation of Trans-[Fe(DMeOPrPE)2H(H2)]+ via the Heterolysis of $\mathrm{H} 2$ in Water. Inorg. Chem. 2004, 43 (11), 3341-3343. 
https://doi.org/10.1021/ic0498642.

(257) Gilbertson, J. D.; Szymczak, N. K.; Tyler, D. R. Reduction of N2 to Ammonia and Hydrazine Utilizing H2 as the Reductant. J. Am. Chem. Soc. 2005, 127 (29), 10184-10185. https://doi.org/10.1021/ja053030g.

(258) Gilbertson, J. D.; Szymczak, N. K.; Crossland, J. L.; Miller, W. K.; Lyon, D. K.; Foxman, B. M.; Davis, J.; Tyler, D. R. Coordination Chemistry of H2 and N2 in Aqueous Solution. Reactivity and Mechanistic Studies Using Trans-FeII(P 2)2X2Type Complexes ( $\mathrm{P} 2$ = a Chelating, Water-Solubilizing Phosphine). Inorg. Chem. 2007, 46 (4), 1205-1214. https://doi.org/10.1021/ic061570o.

(259) Crossland, J. L.; Balesdent, C. G.; Tyler, D. R. Coordination of a Complete Series of $\mathrm{N} 2$ Reduction Intermediates (N 2H 2, N 2H 4, and NH 3) to an Iron Phosphine Scaffold. Inorg. Chem. 2012, 51 (1), 439-445. https://doi.org/10.1021/ic201873a.

(260) Yelle, R. B.; Crossland, J. L.; Szymczak, N. K.; Tyler, D. R. Theoretical Studies of N 2 Reduction to Ammonia in Fe(Dmpe) 2 N 2. Inorg. Chem. 2009, 48 (3), 861871. https://doi.org/10.1021/ic800930t.

(261) Hirano, M.; Akita, M.; Morikita, T.; Kubo, H.; Fukuoka, A.; Komiya, S. Results and Discussion. J. Chem. Soc., Dalt. Trans. 1997, 2, 3453-3458.

(262) Field, L. D.; Hazari, N.; Li, H. L. Nitrogen Fixation Revisited on Iron(0) Dinitrogen Phosphine Complexes. Inorg. Chem. 2015, 54 (10), 4768-4776. https://doi.org/10.1021/acs.inorgchem.5b00211.

(263) Field, L. D.; Li, H. L.; Dalgarno, S. J.; Turner, P. The First Side-on Bound Metal Complex of Diazene, HN=NH. Chem. Commun. 2008, 33 (14), 1680-1682. https://doi.org/10.1039/b802039f. 
(264) Field, L. D.; Li, H. L.; Magill, A. M. Base-Mediated Conversion of Hydrazine to Diazene and Dinitrogen at an Iron Center. Inorg. Chem. 2009, 48 (1), 5-7. https://doi.org/10.1021/ic801856q.

(265) Field, L. D.; Li, H. L.; Dalgarno, S. J. Side-on Bound Diazene and Hydrazine Complexes of Ruthenium. Inorg. Chem. 2010, 49 (13), 6214-6221. https://doi.org/10.1021/ic100821u.

(266) Doyle, L. R.; Hill, P. J.; Wildgoose, G. G.; Ashley, A. E. Teaching Old Compounds New Tricks: Efficient N2 Fixation by Simple Fe(N2)(Diphosphine)2 Complexes. Dalt. Trans. 2016, 45 (18), 7550-7554.

https://doi.org/10.1039/c6dt00884d.

(267) Piascik, A. D.; Hill, P. J.; Crawford, A. D.; Doyle, L. R.; Green, J. C.; Ashley, A. E. Cationic Silyldiazenido Complexes of the Fe(Diphosphine)2(N2) Platform: Structural and Electronic Models for an Elusive First Intermediate in N2 Fixation. Chem. Commun. 2017, 53 (54), 7657-7660. https://doi.org/10.1039/c7cc04188h.

(268) Geri, J. B.; Shanahan, J. P.; Szymczak, N. K. Testing the Push-Pull Hypothesis: Lewis Acid Augmented N2 Activation at Iron. J. Am. Chem. Soc. 2017, 139 (16), 5952-5956. https://doi.org/10.1021/jacs.7b01982.

(269) Heiden, Z. M.; Chen, S.; Mock, M. T.; Dougherty, W. G.; Kassel, W. S.; Rousseau, R.; Bullock, R. M. Protonation of Ferrous Dinitrogen Complexes Containing a Diphosphine Ligand with a Pendent Amine. Inorg. Chem. 2013, 52 (7), 4026-4039. https://doi.org/10.1021/ic4000704.

(270) Heiden, Z. M.; Chen, S.; Labios, L. A.; Bullock, R. M.; Walter, E. D.; Tyson, E. L.; Mock, M. T. Proton and Electron Additions to Iron(II) Dinitrogen Complexes 
Containing Pendant Amines. Organometallics 2014, 33 (6), 1333-1336.

https://doi.org/10.1021/om401089d.

(271) Beach, M. T.; Walker, J. M.; Wang, R.; Spivak, G. J. Ruthenium Piano-Stool Complexes Containing Mono- or Bidentate Pyrrolidinylalkylphosphines and Their Reactions with Small Molecules. J. Organomet. Chem. 2011, 696 (20), 31983205. https://doi.org/10.1016/j.jorganchem.2011.06.037.

(272) Ledger, A. E. W.; Moreno, A.; Ellul, C. E.; Mahon, M. F.; Pregosin, P. S.;

Whittlesey, M. K.; Williams, J. M. J. Pincer Phosphine Complexes of Ruthenium: Formation of Ru(P-O-P)(PPh 3)HCl (P-O-P = Xantphos, DPEphos, (Ph2PCH 2CH2)2O) and $\mathrm{Ru}(\mathrm{Dppf})(\mathrm{PPh} 3) \mathrm{HCl}$ and Characterization of Cationic Dioxygen, Dihydrogen, Dinitrogen, and Arene Coordinated Phosphine Products. Inorg. Chem. 2010, 49 (16), 7244-7256. https://doi.org/10.1021/ic100438d.

(273) Buscagan, T. M.; Oyala, P. H.; Peters, J. C. N2-to-NH3Conversion by a TriphosIron Catalyst and Enhanced Turnover under Photolysis. Angew. Chem. Int. Ed. 2017, 56 (24), 6921-6926. https://doi.org/10.1002/anie.201703244.

(274) Cavaillé, A.; Joyeux, B.; Saffon-Merceron, N.; Nebra, N.; Fustier-Boutignon, M.; Mézailles, N. Triphos-Fe Dinitrogen and Dinitrogen-Hydride Complexes: Relevance to Catalytic N2 Reduction. Chem. Commun. 2018, 54 (84), 1195311956. https://doi.org/10.1039/c8cc07466f.

(275) Schild, D. J.; Peters, J. C. Light Enhanced Fe-Mediated Nitrogen Fixation: Mechanistic Insights Regarding H 2 Elimination, HER, and NH 3 Generation. ACS Catal. 2019, 9 (5), 4286-4295. https://doi.org/10.1021/acscatal.9b00523.

(276) Betley, T. A.; Peters, J. C. Dinitrogen Chemistry from Trigonally Coordinated Iron 
and Cobalt Platforms. J. Am. Chem. Soc. 2003, 125 (36), 10782-10783.

https://doi.org/10.1021/ja036687f.

(277) Betley, T. A.; Peters, J. C. A Tetrahedrally Coordinated L 3 Fe-N x Platform That Accommodates Terminal Nitride and Dinitrogen Ligands. J. Am. Chem. Soc. 2004, 126,6252 .

(278) Saouma, C. T.; Moore, C. E.; Rheingold, A. L.; Peters, J. C. A Five-Coordinate Phosphino / Acetate Iron ( II ) Scaffold That Binds N 2 ,. Inorg. Chem. 2011, 50 (Ii), 11285-11287.

(279) Mankad, N. P.; Whited, M. T.; Peters, J. C. Terminal FeI-N2 and FeII $\cdots H-C$ Interactions Supported by Tris(Phosphino)Silyl Ligands. Angew. Chem. Int. Ed. 2007, 46 (30), 5768-5771. https://doi.org/10.1002/anie.200701188.

(280) Whited, M. T.; Mankad, N. P.; Lee, Y.; Oblad, P. F.; Peters, J. C. Dinitrogen Complexes Supported by Tris(Phosphino)Silyl Ligands. Inorg. Chem. 2009, 48 (6), 2507-2517. https://doi.org/10.1021/ic801855y.

(281) Lee, Y.; Mankad, N. P.; Peters, J. C. Triggering N2 Uptake via Redox-Induced Expulsion of Coordinated NH3 and N2 Silylation at Trigonal Bipyramidal Iron. Nat. Chem. 2010, 2 (7), 558-565. https://doi.org/10.1038/nchem.660.

(282) Mankad, N. P.; Müller, P.; Peters, J. C. Catalytic N-N Coupling of Aryl Azides to Yield Azoarenes via Trigonal Bipyramid Iron-Nitrene Intermediates. J. Am. Chem. Soc. 2010, 132 (12), 4083-4085. https://doi.org/10.1021/ja910224c.

(283) Rittle, J.; Peters, J. C. An Fe-N2 Complex That Generates Hydrazine and Ammonia via $\mathrm{Fe}=\mathrm{NNH} 2$ : Demonstrating a Hybrid Distal-to-Alternating Pathway for N2 Reduction. J. Am. Chem. Soc. 2016, 138 (12), 4243-4248. 

https://doi.org/10.1021/jacs.6b01230.

(284) Rittle, J.; Peters, J. C. Proton-Coupled Reduction of an Iron Cyanide Complex to Methane and Ammonia. Angew. Chem. Int. Ed. 2016, 55 (40), 12262-12265. https://doi.org/10.1002/anie.201606366.

(285) Rittle, J.; Peters, J. C. N-H Bond Dissociation Enthalpies and Facile H Atom Transfers for Early Intermediates of Fe-N2 and Fe-CN Reductions. J. Am. Chem. Soc. 2017, 139 (8), 3161-3170. https://doi.org/10.1021/jacs.6b12861.

(286) Creutz, S. E.; Peters, J. C. Exploring Secondary-Sphere Interactions in Fe-NxHy Complexes Relevant to N2 Fixation. Chem. Sci. 2017, 8 (3), 2321-2328. https://doi.org/10.1039/c6sc04805f.

(287) Takaoka, A.; Gerber, L. C. H.; Peters, J. C. Access to Well-Defined Ruthenium(I) and Osmium(I) Metalloradicals. Angew. Chem. Int. Ed. 2010, 49 (24), 4088-4091. https://doi.org/10.1002/anie.201001199.

(288) Takaoka, A.; Moret, M. E.; Peters, J. C. A Ru(I) Metalloradical That Catalyzes Nitrene Coupling to Azoarenes from Arylazides. J. Am. Chem. Soc. 2012, 134 (15), 6695-6706. https://doi.org/10.1021/ja211603f.

(289) Fajardo, J.; Peters, J. C. Catalytic Nitrogen-to-Ammonia Conversion by Osmium and Ruthenium Complexes. J. Am. Chem. Soc. 2017, 139 (45), 16105-16108. https://doi.org/10.1021/jacs.7b10204.

(290) Rittle, J.; Peters, J. C. Fe- N2/CO Complexes That Model a Possible Role for the Interstitial C Atom of FeMo-Cofactor (FeMoco). Proc. Natl. Acad. Sci. U. S. A. 2013, 110 (40), 15898-15903. https://doi.org/10.1073/pnas.1310153110.

(291) Creutz, S. E.; Peters, J. C. Catalytic Reduction of N2 to NH3 by an Fe-N 2 
Complex Featuring a C-Atom Anchor. J. Am. Chem. Soc. 2014, 136 (3), 1105-

1115. https://doi.org/10.1021/ja4114962.

(292) Moret, M. E.; Peters, J. C. Terminal Iron Dinitrogen and Iron Imide Complexes Supported by a Tris(Phosphino)Borane Ligand. Angew. Chem. Int. Ed. 2011, 50 (9), 2063-2067. https://doi.org/10.1002/anie.201006918.

(293) Moret, M. E.; Peters, J. C. N2 Functionalization at Iron Metallaboratranes. J. Am. Chem. Soc. 2011, 133 (45), 18118-18121. https://doi.org/10.1021/ja208675p.

(294) Anderson, J. S.; Rittle, J.; Peters, J. C. Catalytic Conversion of Nitrogen to Ammonia by an Iron Model Complex. Nature 2013, 501 (7465), 84-87. https://doi.org/10.1038/nature12435.

(295) Anderson, J. S.; Moret, M.-E.; Peters, J. C. Conversion of $\mathrm{Fe}-\mathrm{NH}_{2}$ to $\mathrm{Fe}-\mathrm{N}_{2}$ with Release of $\mathrm{NH}_{3}$. J. Am. Chem. Soc. 2013, 135 (2), 534-537. https://doi.org/10.1021/ja307714m.

(296) Anderson, J. S.; Cutsail, G. E.; Rittle, J.; Connor, B. A.; Gunderson, W. A.; Zhang, L.; Hoffman, B. M.; Peters, J. C. Characterization of an $\mathrm{Fe} \equiv \mathrm{N}-\mathrm{NH} 2$ Intermediate Relevant to Catalytic N2 Reduction to NH3. J. Am. Chem. Soc. 2015, 137 (24), 7803-7809. https://doi.org/10.1021/jacs.5b03432.

(297) Del Castillo, T. J.; Thompson, N. B.; Peters, J. C. A Synthetic Single-Site Fe Nitrogenase: High Turnover, Freeze-Quench57Fe Mössbauer Data, and a Hydride Resting State. J. Am. Chem. Soc. 2016, 138 (16), 5341-5350. https://doi.org/10.1021/jacs.6b01706.

(298) Matson, B. D.; Peters, J. C. Fe-Mediated HER vs N2RR: Exploring Factors That Contribute to Selectivity in P3EFe(N2) $(\mathrm{E}=\mathrm{B}, \mathrm{Si}, \mathrm{C})$ Catalyst Model Systems. 
ACS Catal. 2018, 8 (2), 1448-1455. https://doi.org/10.1021/acscatal.7b03068.

(299) Chalkley, M. J.; Del Castillo, T. J.; Matson, B. D.; Roddy, J. P.; Peters, J. C. Catalytic N2-to-NH3 Conversion by Fe at Lower Driving Force: A Proposed Role for Metallocene-Mediated PCET. ACS Cent. Sci. 2017, 3 (3), 217-223. https://doi.org/10.1021/acscentsci.7b00014.

(300) Chalkley, M. J.; Del Castillo, T. J.; Matson, B. D.; Peters, J. C. Fe-Mediated Nitrogen Fixation with a Metallocene Mediator: Exploring $\mathrm{p}$ K a Effects and Demonstrating Electrocatalysis. J. Am. Chem. Soc. 2018, 140 (19), 6122-6129. https://doi.org/10.1021/jacs.8b02335.

(301) Rudd, P. A.; Liu, S.; Gagliardi, L.; Young, V. G.; Lu, C. C. Metal-Alane Adducts with Zero-Valent Nickel, Cobalt, and Iron. J. Am. Chem. Soc. 2011, 133 (51), 20724-20727. https://doi.org/10.1021/ja2099744.

(302) Rudd, P. A.; Planas, N.; Bill, E.; Gagliardi, L.; Lu, C. C. Dinitrogen Activation at Iron and Cobalt Metallalumatranes. Eur. J. Inorg. Chem. 2013, 2013 (22-23), 3898-3906. https://doi.org/10.1002/ejic.201300272.

(303) Rittle, J.; McCrory, C. C. L.; Peters, J. C. A 106-Fold Enhancement in N2-Binding Affinity of an Fe2( $\mu-\mathrm{H}) 2$ core upon Reduction to a Mixed-Valence FeIIFeIstate. $J$. Am. Chem. Soc. 2014, 136 (39), 13853-13862. https://doi.org/10.1021/ja507217v.

(304) Creutz, S. E.; Peters, J. C. Diiron Bridged-Thiolate Complexes That Bind $\mathrm{N}<$ inf $>2</ \mathrm{Inf}>$ at the $\mathrm{Fe}^{\mathrm{II}} \mathrm{Fe}^{\mathrm{II}}, \mathrm{Fe}^{\mathrm{II}} \mathrm{Fe}^{\mathrm{I}}$, and $\mathrm{Fe}^{\mathrm{I}} \mathrm{Fe}^{\mathrm{I}}$ Redox States. J. Am. Chem. Soc. 2015, 137 (23), 7310-7313. https://doi.org/10.1021/jacs.5b04738.

(305) Takaoka, A.; Mankad, N. P.; Peters, J. C. Dinitrogen Complexes of Sulfur-Ligated Iron. J. Am. Chem. Soc. 2011, 133 (22), 8440-8443. 
https://doi.org/10.1021/ja2020907.

(306) Gu, N. X.; Oyala, P. H.; Peters, J. C. An S = 1 / 2 Iron Complex Featuring N 2, Thiolate, and Hydride Ligands: Reductive Elimination of $\mathrm{H} 2$ and Relevant Thermochemical Fe-H Parameters. J. Am. Chem. Soc. 2018, 140 (20), 6374-6382. https://doi.org/10.1021/jacs.8b02603.

(307) Yuki, M.; Tanaka, H.; Sasaki, K.; Miyake, Y.; Yoshizawa, K.; Nishibayashi, Y. Iron-Catalysed Transformation of Molecular Dinitrogen into Silylamine under Ambient Conditions. Nat. Commun. 2012, 3, 1254-1256. https://doi.org/10.1038/ncomms2264.

(308) Imayoshi, R.; Nakajima, K.; Takaya, J.; Iwasawa, N.; Nishibayashi, Y. Synthesis and Reactivity of Iron- and Cobalt-Dinitrogen Complexes Bearing PSiP-Type Pincer Ligands toward Nitrogen Fixation. Eur. J. Inorg. Chem. 2017, 2017 (32), 3769-3778. https://doi.org/10.1002/ejic.201700569.

(309) Kuriyama, S.; Arashiba, K.; Nakajima, K.; Matsuo, Y.; Tanaka, H.; Ishii, K.; Yoshizawa, K.; Nishibayashi, Y. Catalytic Transformation of Dinitrogen into Ammonia and Hydrazine by Iron-Dinitrogen Complexes Bearing Pincer Ligand. Nat. Commun. 2016, 7, 1-9. https://doi.org/10.1038/ncomms12181.

(310) Sekiguchi, Y.; Kuriyama, S.; Eizawa, A.; Arashiba, K.; Nakajima, K.; Nishibayashi, Y. Bearing Anionic Methyl- and Phenyl-Substituted Catalytic Nitrogen Fixation †. Chem. Commun. 2017, 53, 12040-12043. https://doi.org/10.1039/C7CC06987A.

(311) Higuchi, J.; Kuriyama, S.; Eizawa, A.; Arashiba, K.; Nakajima, K.; Nishibayashi, Y. Preparation and Reactivity of Iron Complexes Bearing Anionic Carbazole- 
Based PNP-Type Pincer Ligands toward Catalytic Nitrogen Fixation. Dalt. Trans. 2018, 47 (Chart 1), 1117-1121. https://doi.org/10.1039/c7dt04327a.

(312) Lee, J. H.; Pink, M.; Tomaszewski, J.; Fan, H.; Caulton, K. G. Facile Hydrogenation of $\mathrm{N} 2 \mathrm{O}$ by an Operationally Unsaturated Osmium Polyhydride. $J$. Am. Chem. Soc. 2007, 129 (28), 8706-8707. https://doi.org/10.1021/ja071452f.

(313) Suzuki, T.; Wasada-Tsutsui, Y.; Ogawa, T.; Inomata, T.; Ozawa, T.; Sakai, Y.; Fryzuk, M. D.; Masuda, H. N<inf $>2</$ Inf $>$ Activation by an Iron Complex with a Strong Electron-Donating Iminophosphorane Ligand. Inorg. Chem. 2015, 54 (19), 9271-9281. https://doi.org/10.1021/acs.inorgchem.5b00536.

(314) MacBeth, C. E.; Harkins, S. B.; Peters, J. C. Synthesis and Characterization of Cationic Iron Complexes Supported by the Neutral Ligands NPi-Pr3, NArPi-Pr3, and NSt-Bu3. Can. J. Chem. 2005, 83 (4), 332-340. https://doi.org/10.1139/v05017.

(315) Field, L. D.; Guest, R. W.; Vuong, K. Q.; Dalgarno, S. J.; Jensen, P. Iron(0) and Ruthenium(0) Complexes of Dinitrogen. Inorg. Chem. 2009, 48 (5), 2246-2253. https://doi.org/10.1021/ic8019827.

(316) Gilbert-Wilson, R.; Field, L. D.; Colbran, S. B.; Bhadbhade, M. M. Low Oxidation State Iron(0), Iron(I), and Ruthenium(0) Dinitrogen Complexes with a Very Bulky Neutral Phosphine Ligand. Inorg. Chem. 2013, 52 (6), 3043-3053. https://doi.org/10.1021/ic3024953.

(317) Field, L. D.; Li, H. L.; Dalgarno, S. J.; McIntosh, R. D. Base-Induced Dehydrogenation of Ruthenium Hydrazine Complexes. Inorg. Chem. 2013, 52 (3), 1570-1583. https://doi.org/10.1021/ic302449n. 
(318) Gilbert-Wilson, R.; Field, L. D.; Bhadbhade, M. Ruthenium Hydrides Containing the Superhindered Polydentate Polyphosphine Ligand $\mathrm{P}(\mathrm{CH} 2 \mathrm{CH} 2 \mathrm{PtBu} 2) 3$. Inorg. Chem. 2014, 53 (23), 12469-12479. https://doi.org/10.1021/ic501895s.

(319) van de Watering, F. F.; van der Vlugt, J. I.; Dzik, W. I.; de Bruin, B.; Reek, J. N. H. Metalloradical Reactivity of RuI and Ru0 Stabilized by an Indole-Based Tripodal Tetraphosphine Ligand. Chem. - A Eur. J. 2017, 23 (52), 12709-12713. https://doi.org/10.1002/chem.201702727.

(320) Prokopchuk, D. E.; Wiedner, E. S.; Walter, E. D.; Popescu, C. V.; Piro, N. A.; Kassel, W. S.; Bullock, R. M.; Mock, M. T. Catalytic N 2 Reduction to Silylamines and Thermodynamics of N 2 Binding at Square Planar Fe. J. Am. Chem. Soc. 2017, 139 (27), 9291-9301. https://doi.org/10.1021/jacs.7b04552.

(321) Araake, R.; Sakadani, K.; Tada, M.; Sakai, Y.; Ohki, Y. [Fe 4 ] and [Fe 6 ] Hydride Clusters Supported by Phosphines: Synthesis, Characterization, and Application in N 2 Reduction. J. Am. Chem. Soc. 2017, 139 (15), 5596-5606. https://doi.org/10.1021/jacs.7b01965.

(322) Lau, S.; Ward, B.; Zhou, X.; White, A. J. P.; Casely, I. J.; MacGregor, S. A.; Crimmin, M. R. Mild Sp2Carbon-Oxygen Bond Activation by an Isolable Ruthenium(II) Bis(Dinitrogen) Complex: Experiment and Theory. Organometallics 2017, 36 (18), 3654-3663. https://doi.org/10.1021/acs.organomet.7b00632.

(323) Bart, S. C.; Lobkovsky, E.; Chirik, P. J. Preparation and Molecular and Electronic Structures of Iron(0) Dinitrogen and Silane Complexes and Their Application to Catalytic Hydrogenation and Hydrosilation. J. Am. Chem. Soc. 2004, 126 (42), 
13794-13807. https://doi.org/10.1021/ja046753t.

(324) Bart, S. C.; Chłopek, K.; Bill, E.; Bouwkamp, M. W.; Lobkovsky, E.; Neese, F.;

Wieghardt, K.; Chirik, P. J. Electronic Structure of Bis(Imino)Pyridine Iron

Dichloride, Monochloride, and Neutral Ligand Complexes: A Combined

Structural, Spectroscopic, and Computational Study. J. Am. Chem. Soc. 2006, 128

(42), 13901-13912. https://doi.org/10.1021/ja064557b.

(325) Bart, S. C.; Lobkovsky, E.; Bill, E.; Chirik, P. J. Synthesis and Hydrogenation of Bis(Imino)Pyridine Iron Imides. J. Am. Chem. Soc. 2006, 128 (16), 5302-5303. https://doi.org/10.1021/ja057165y.

(326) Bart, S. C.; Bowman, A. C.; Lobkovsky, E.; Chirik, P. J. Iron Diazoalkane Chemistry: N-N Bond Hydrogenation and Intramolecular C-H Activation. J. Am. Chem. Soc. 2007, 129 (23), 7212-7213. https://doi.org/10.1021/ja070056u.

(327) Bart, S. C.; Lobkovsky, E.; Bill, E.; Wieghardt, K.; Chirik, P. J. Neutral-Ligand Complexes of Bis(Imino)Pyridine Iron: Synthesis, Structure, and Spectroscopy. Inorg. Chem. 2007, 46 (17), 7055-7063. https://doi.org/10.1021/ic700869h.

(328) Trovitch, R. J.; Lobkovsky, E.; Bill, E.; Chirik, P. J. Functional Group Tolerance and Substrate Scope in Bis(Imino)Pyridine Iron Catalyzed Alkene Hydrogenation. Organometallics 2008, 27 (7), 1470-1478. https://doi.org/10.1021/om701091z.

(329) Sylvester, K. T.; Chirik, P. J. Iron-Catalyzed, Hydrogen-Mediated Reductive Cyclization of 1,6-Enynes and Diynes: Evidence for Bis(Imino)Pyridine Ligand Participation. J. Am. Chem. Soc. 2009, 131 (25), 8772-8774. https://doi.org/10.1021/ja902478p.

(330) Bowman, A. C.; Bart, S. C.; Heinemann, F. W.; Meyer, K.; Chirik, P. J. Synthesis 
of Bis(Imino)Pyridine Iron Amide and Ammonia Compounds from an N-H

Transfer Agent. Inorg. Chem. 2009, 48 (13), 5587-5589.

https://doi.org/10.1021/ic9003017.

(331) Russell, S. K.; Lobkovsky, E.; Chirik, P. J. Iron-Catalyzed Intermolecular [2 $2 \pi$

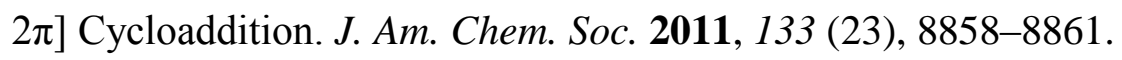
https://doi.org/10.1021/ja202992p.

(332) Stieber, S. C. E.; Milsmann, C.; Hoyt, J. M.; Turner, Z. R.; Finkelstein, K. D.; Wieghardt, K.; Debeer, S.; Chirik, P. J. Bis(Imino)Pyridine Iron Dinitrogen Compounds Revisited: Differences in Electronic Structure between Four- and Five-Coordinate Derivatives. Inorg. Chem. 2012, 51 (6), 3770-3785. https://doi.org/10.1021/ic202750n.

(333) Yu, R. P.; Darmon, J. M.; Hoyt, J. M.; Margulieux, G. W.; Turner, Z. R.; Chirik, P. J. High-Activity Iron Catalysts for the Hydrogenation of Hindered, Unfunctionalized Alkenes. ACS Catal. 2012, 2 (8), 1760-1764. https://doi.org/10.1021/cs300358m.

(334) Darmon, J. M.; Stieber, S. C. E.; Sylvester, K. T.; Fernández, I.; Lobkovsky, E.; Semproni, S. P.; Bill, E.; Wieghardt, K.; Debeer, S.; Chirik, P. J. Oxidative Addition of Carbon-Carbon Bonds with a Redox-Active Bis(Imino)Pyridine Iron Complex. J. Am. Chem. Soc. 2012, 134 (41), 17125-17137. https://doi.org/10.1021/ja306526d.

(335) Atienza, C. C. H.; Tondreau, A. M.; Weller, K. J.; Lewis, K. M.; Cruse, R. W.; Nye, S. A.; Boyer, J. L.; Delis, J. G. P.; Chirik, P. J. High-Selectivity Bis(Imino)Pyridine Iron Catalysts for the Hydrosilylation of 1,2,4- 
Trivinylcyclohexane. ACS Catal. 2012, 2 (10), 2169-2172.

https://doi.org/10.1021/cs300584b.

(336) Tondreau, A. M.; Atienza, C. C. H.; Weller, K. J.; Nye, S. A.; Lewis, K. M.; Delis, J. G. P.; Chirik, P. J. Iron Catalysts for Selective Anti-Markovnikov Alkene Hydrosilylation Using Tertiary Silanes. Science (80-. ). 2012, 335 (6068), $567-$ 570. https://doi.org/10.1126/science.1214451.

(337) Hoyt, J. M.; Sylvester, K. T.; Semproni, S. P.; Chirik, P. J. Synthesis and Electronic Structure of Bis(Imino)Pyridine Iron Metallacyclic Intermediates in Iron-Catalyzed Cyclization Reactions. J. Am. Chem. Soc. 2013, 135 (12), $4862-$ 4877. https://doi.org/10.1021/ja400895j.

(338) Obligacion, J. V.; Chirik, P. J. Highly Selective Bis(Imino)Pyridine Iron-Catalyzed Alkene Hydroboration. Org. Lett. 2013, 15 (11), 2680-2683. https://doi.org/10.1021/ol400990u.

(339) Hoyt, J. M.; Schmidt, V. A.; Tondreau, A. M.; Chirik, P. J. Iron-Catalyzed Intermolecular [2+2] Cycloadditions of Unactivated Alkenes. Science (80-. ). 2015, 349 (6251), 960-963. https://doi.org/10.1126/science.aac7440.

(340) Pony Yu, R.; Hesk, D.; Rivera, N.; Pelczer, I.; Chirik, P. J. Iron-Catalysed Tritiation of Pharmaceuticals. Nature 2016, 529 (7585), 195-199. https://doi.org/10.1038/nature16464.

(341) Scott, J.; Vidyaratne, I.; Korobkov, I.; Gambarotta, S.; Budzelaar, P. H. M. Multiple Pathways for Dinitrogen Activation during the Reduction of an Fe Bis(Iminepyridine) Complex. Inorg. Chem. 2008, 47 (3), 896-911. https://doi.org/10.1021/ic701643d. 
(342) Danopoulos, A. A.; Wright, J. A.; Motherwell, W. B. Molecular N2 Complexes of Iron Stabilised by N-Heterocyclic "pincer" Dicarbene Ligands. Chem. Commun. 2005, No. 6, 784-786. https://doi.org/10.1039/b415562a.

(343) Darmon, J. M.; Yu, R. P.; Semproni, S. P.; Turner, Z. R.; Stieber, S. C. E.; Debeer, S.; Chirik, P. J. Electronic Structure Determination of Pyridine N-Heterocyclic Carbene Iron Dinitrogen Complexes and Neutral Ligand Derivatives. Organometallics 2014, 33 (19), 5423-5433. https://doi.org/10.1021/om500727t.

(344) Yu, R. P.; Darmon, J. M.; Semproni, S. P.; Turner, Z. R.; Chirik, P. J. Synthesis of Iron Hydride Complexes Relevant to Hydrogen Isotope Exchange in Pharmaceuticals. Organometallics 2017, 36 (22), 4341-4343. https://doi.org/10.1021/acs.organomet.7b00398.

(345) Huynh, M. H. V.; El-Samanody, E. S.; Demadis, K. D.; Meyer, T. J.; White, P. S. Oxo-like Reactivity of High Oxidation State Osmium Hydrazido Complexes [13]. J. Am. Chem. Soc. 1999, 121 (6), 1403-1404. https://doi.org/10.1021/ja983290g.

(346) Huynh, M. H. V.; Meyer, T. J.; Hiskey, M. A.; Jameson, D. L. Os(II)-Nitrosyl and Os(II)-Dinitrogen Complexes from Reactions between Os(VI)-Nitrido and Hgdroxylamines and Methoxylamines. J. Am. Chem. Soc. 2004, 126 (11), 36083615. https://doi.org/10.1021/ja030574e.

(347) Kunkely, H.; Vogler, A. Photolysis of Aqueous [(NH3)5Os(??-N 2)Os(NH3)5]5+: Cleavage of Dinitrogen by an Intramolecular Photoredox Reaction. Angew. Chem. Int. Ed. 2010, 49 (9), 1591-1593. https://doi.org/10.1002/anie.200905026.

(348) Namura, K.; Suzuki, H. Synthesis, Structure, and Reactivity of Mixed-Ligand Dinuclear Ruthenium Polyhydrido Complexes Supported by 1,4,7-Trimethyl- 
1,4,7-Triazacyclononane and Bulky Phosphine Ligands. Organometallics 2014, 33 (12), 2968-2983. https://doi.org/10.1021/om500018j.

(349) Smith, J. M.; Lachicotte, R. J.; Pittard, K. A.; Cundari, T. R.; Lukat-Rodgers, G.; Rodgers, K. R.; Holland, P. L. Stepwise Reduction of Dinitrogen Bond Order by a Low-Coordinate Iron Complex [5]. J. Am. Chem. Soc. 2001, 123 (37), 9222-9223. https://doi.org/10.1021/ja016094+.

(350) Eckert, N. A.; Vaddadi, S.; Stoian, S.; Lachicotte, R. J.; Cundari, T. R.; Holland, P. L. Coordination-Number Dependence of Reactivity in an Imidoiron(III) Complex. Angew. Chem. Int. Ed. 2006, 45 (41), 6868-6871.

https://doi.org/10.1002/anie.200601927.

(351) Sadique, A. R.; Brennessel, W. W.; Holland, P. L. Reduction of CO2 to CO Using Low-Coordinate Iron: Formation of a Four-Coordinate Iron Dicarbonyl Complex and a Bridging Carbonate Complex. Inorg. Chem. 2008, 47 (3), 784-786. https://doi.org/10.1021/ic701914m.

(352) Smith, J. M.; Sadique, A. R.; Cundari, T. R.; Rodgers, K. R.; Lukat-Rodgers, G.; Lachicotte, R. J.; Flaschenriem, C. J.; Vela, J.; Holland, P. L. Studies of LowCoordinate Iron Dinitrogen Complexes. J. Am. Chem. Soc. 2006, 128 (3), 756769. https://doi.org/10.1021/ja052707x.

(353) Figg, T. M.; Holland, P. L.; Cundari, T. R. Cooperativity between Low-Valent Iron and Potassium Promoters in Dinitrogen Fixation. Inorg. Chem. 2012, 51 (14), 7546-7550. https://doi.org/10.1021/ic300150u.

(354) Grubel, K.; Brennessel, W. W.; Mercado, B. Q.; Holland, P. L. Alkali Metal Control over N-N Cleavage in Iron Complexes. J. Am. Chem. Soc. 2014, 136 (48), 
16807-16816. https://doi.org/10.1021/ja507442b.

(355) McWilliams, S. F.; Rodgers, K. R.; Lukat-Rodgers, G.; Mercado, B. Q.; Grubel, K.; Holland, P. L. Alkali Metal Variation and Twisting of the FeNNFe Core in Bridging Diiron Dinitrogen Complexes. Inorg. Chem. 2016, 55 (6), 2960-2968. https://doi.org/10.1021/acs.inorgchem.5b02841.

(356) Dugan, T. R.; Macleod, K. C.; Brennessel, W. W.; Holland, P. L. CobaltMagnesium and Iron-Magnesium Complexes with Weakened Dinitrogen Bridges. Eur. J. Inorg. Chem. 2013, No. 22-23, 3891-3897. https://doi.org/10.1002/ejic.201300187.

(357) MacLeod, K. C.; Menges, F. S.; McWilliams, S. F.; Craig, S. M.; Mercado, B. Q.; Johnson, M. A.; Holland, P. L. Alkali-Controlled C-H Cleavage or N-C Bond Formation by N2-Derived Iron Nitrides and Imides. J. Am. Chem. Soc. 2016, 138 (35), 11185-11191. https://doi.org/10.1021/jacs.6b04984.

(358) Rodriguez, M. M.; Bill, E.; Brennessel, W. W.; Holland, P. L. N2 Reduction and Hydrogenation to Ammonia by a Molecular Iron-Potassium Complex. Science (80. ). 2011, 334 (6057), 780-783. https://doi.org/10.1126/science.1211906.

(359) MacLeod, K. C.; McWilliams, S. F.; Mercado, B. Q.; Holland, P. L. Stepwise N-H Bond Formation from N2-Derived Iron Nitride, Imide and Amide Intermediates to Ammonia. Chem. Sci. 2016, 7 (9), 5736-5746. https://doi.org/10.1039/c6sc00423g.

(360) MacLeod, K. C.; Vinyard, D. J.; Holland, P. L. A Multi-Iron System Capable of Rapid N2 Formation and N 2 Cleavage. J. Am. Chem. Soc. 2014, 136 (29), 1022610229. https://doi.org/10.1021/ja505193z. 
(361) Lee, Y.; Sloane, F. T.; Blondin, G.; Abboud, K. A.; García-Serres, R.; Murray, L. J. Dinitrogen Activation upon Reduction of a Triiron(II) Complex. Angew. Chem. Int. Ed. 2015, 54 (5), 1499-1503. https://doi.org/10.1002/anie.201409676.

(362) Ferreira, R. B.; Cook, B. J.; Knight, B. J.; Catalano, V. J.; García-Serres, R.; Murray, L. J. Catalytic Silylation of Dinitrogen by a Family of Triiron Complexes. ACS Catal. 2018, 8 (8), 7208-7212. https://doi.org/10.1021/acscatal.8b02021.

(363) Mcskimming, A.; Harman, W. H. A Terminal N2 Complex of High-Spin Iron(I) in a Weak, Trigonal Ligand Field. J. Am. Chem. Soc. 2015, 137 (28), 8940-8943. https://doi.org/10.1021/jacs.5b06337.

(364) Cummins, D. C.; Yap, G. P. A.; Theopold, K. H. Scorpionates of the "Tetrahedral Enforcer" Variety as Ancillary Ligands for Dinitrogen Complexes of First Row Transition Metals (Cr-Co). Eur. J. Inorg. Chem. 2016, 2016 (15-16), 2349-2356. https://doi.org/10.1002/ejic.201501326.

(365) Stepowska, E.; Jiang, H.; Song, D. Reversible H2 Splitting between Ru(Ii) and a Remote Carbanion in a Zwitterionic Compound. Chem. Commun. 2010, 46 (4), 556-558. https://doi.org/10.1039/b919606d.

(366) Annibale, V. T.; Song, D. Reversible Formal Insertion of CO 2 into a Remote C-H Bond of a Ligand in a Ru(Ii) Complex at Room Temperature. Chem. Commun. 2012, 48 (44), 5416-5418. https://doi.org/10.1039/c2cc17933d.

(367) Kizaki, T.; Matsumoto, T.; Ogo, S. Dissolved N2 Sensing by PH-Dependent Ru Complexes. Dalt. Trans. 2010, 39 (5), 1339-1344. https://doi.org/10.1039/b918940h.

(368) Sellmann, D.; Sutter, J. In Quest of Competitive Catalysts for Nitrogenases and 
Other Metal Sulfur Enzymes. Acc. Chem. Res. 1997, 30 (11), 460-469. https://doi.org/10.1021/ar960158h.

(369) Sellmann, D.; Hautsch, B.; Rsler, A.; Heinemann, F. W. [Ru(N2)(PiPr3)('N2Me2S 2')]: Coordination of Molecular N2 to Metal Thiolate Cores under Mild Conditions. Angew. Chem. Int. Ed. 2001, 40 (8), 1505-1507. https://doi.org/10.1002/1521-3773(20010417)40:8<1505::AIDANIE1505>3.0.CO;2-2.

(370) Sellmann, D.; Hille, A.; Rösler, A.; Heinemann, F. W.; Moll, M.; Brehm, G.; Schneider, S.; Reiher, M.; Hess, B. A.; Bauer, W. Binding N2, N2H2, N2H 4, and NH3 to Transition-Metal Sulfur Sites: Modeling Potential Intermediates of Biological N2 Fixation. Chem. - A Eur. J. 2004, 10 (4), 819-830. https://doi.org/10.1002/chem.200305499.

(371) Čorić, I.; Mercado, B. Q.; Bill, E.; Vinyard, D. J.; Holland, P. L. Binding of Dinitrogen to an Iron-Sulfur-Carbon Site. Nature 2015, 526 (7571), 96-99. https://doi.org/10.1038/nature15246.

(372) Zhang, F.; Song, H.; Zhuang, X.; Tung, C. H.; Wang, W. Iron-Catalyzed 1,2Selective Hydroboration of N-Heteroarenes. J. Am. Chem. Soc. 2017, 139 (49), 17775-17778. https://doi.org/10.1021/jacs.7b11416.

(373) Sunada, Y.; Imaoka, T.; Nagashima, H. Half-Sandwich (H6-Arene)Iron(II) Dinitrogen Complexes Bearing a Disilaferracycle Skeleton as a Precursor for Double Silylation of Ethylene and Alkynes. Organometallics 2010, 29 (23), 61576160. https://doi.org/10.1021/om100889w.

(374) Burling, S.; Häller, L. J. L.; Mas-Marzá, E.; Moreno, A.; Macgregor, S. A.; 
Mahon, M. F.; Pregosin, P. S.; Whittlesey, M. K. The Influence of N-Heterocyclic Carbenes (NHC) on the Reactivity of $[\mathrm{Ru}(\mathrm{NHC}) 4 \mathrm{H}]+$ with $\mathrm{H} 2, \mathrm{~N} 2, \mathrm{CO}$ and $\mathrm{O} 2$.

Chem. - A Eur. J. 2009, 15 (41), 10912-10923.

https://doi.org/10.1002/chem.200901736.

(375) Tskhovrebov, A. G.; Solari, E.; Scopelliti, R.; Severin, K. Activation of Nitrous Oxide by Dinuclear Ruthenium Complexes. Organometallics 2012, 31 (20), 72357240. https://doi.org/10.1021/om300786f.

(376) Liang, Q.; Song, D. Reactivity of Fe and Ru Complexes of Picolyl-Substituted NHeterocyclic Carbene Ligand: Diverse Coordination Modes and Small Molecule Binding. Inorg. Chem. 2017, 56 (19), 11956-11970.

https://doi.org/10.1021/acs.inorgchem.7b01918.

(377) Fernández, F. E.; Puerta, M. C.; Valerga, P. Picolyl-NHC Hydrotris(Pyrazolyl)Borate Ruthenium(II) Complexes: Synthesis, Characterization, and Reactivity with Small Molecules. Inorg. Chem. 2013, 52 (8), 4396-4410. https://doi.org/10.1021/ic302553z.

(378) Ung, G.; Peters, J. C. Low-Temperature N2 Binding to Two-Coordinate L2Fe0 Enables Reductive Trapping of L2FeN2- and NH3 Generation. Angew. Chem. Int. Ed. 2015, 54 (2), 532-535. https://doi.org/10.1002/anie.201409454.

(379) Ouyang, Z.; Cheng, J.; Li, L.; Bao, X.; Deng, L. High-Spin Iron(I) and Iron(0) Dinitrogen Complexes Supported by N-Heterocyclic Carbene Ligands. Chem. - A Eur. J. 2016, 22 (40), 14162-14165. https://doi.org/10.1002/chem.201603390.

(380) Yamamoto, A.; Miura, Y.; Ito, T.; Chen, H. L.; Iri, K.; Ozawa, F.; Miki, K.; Kasai, N.; Sei, T.; Tanaka, N. Preparation, X-Ray Molecular Structure Determination, 
and Chemical Properties of Dinitrogen-Coordinated Cobalt Complexes Containing TriphenyIphosphine Ligands and Alkali Metal or Magnesium. Protonation of the Coordinated Dinitrogen to Ammonia and Hydrazin. Organometallics 1983, 2 (10), 1429-1436. https://doi.org/10.1021/om50004a032.

(381) Cecconi, F. Synthesis, Characterization, and Crystal Structure of the Dimeric, Paramagnetic Cobalt(0) Complex $\{[\mathrm{M} \sim \mathrm{C}(\mathrm{C} \mathrm{H} \sim \mathrm{P} \mathrm{P} \sim \sim) \& \mathrm{O} \mathrm{I} \sim(\sim-\mathrm{N} \sim)$ \}. 1985, No. 1, 731-733.

(382) Suess, D. L. M.; Tsay, C.; Peters, J. C. Dihydrogen Binding to Isostructural S = 1/2 and $\mathrm{S}=0$ Cobalt Complexes. J. Am. Chem. Soc. 2012, 134 (34), 14158-14164. https://doi.org/10.1021/ja305248f.

(383) Del Castillo, T. J.; Thompson, N. B.; Suess, D. L. M.; Ung, G.; Peters, J. C. Evaluating Molecular Cobalt Complexes for the Conversion of N2 to NH3. Inorg. Chem. 2015, 54 (19), 9256-9262. https://doi.org/10.1021/acs.inorgchem.5b00645.

(384) Siedschlag, R. B.; Bernales, V.; Vogiatzis, K. D.; Planas, N.; Clouston, L. J.; Bill, E.; Gagliardi, L.; Lu, C. C. Catalytic Silylation of Dinitrogen with a Dicobalt Complex. J. Am. Chem. Soc. 2015, 137 (14), 4638-4641. https://doi.org/10.1021/jacs.5b01445.

(385) Clouston, L. J.; Bernales, V.; Carlson, R. K.; Gagliardi, L.; Lu, C. C. Bimetallic Cobalt-Dinitrogen Complexes: Impact of the Supporting Metal on N2 Activation. Inorg. Chem. 2015, 54 (19), 9263-9270. https://doi.org/10.1021/acs.inorgchem.5b00983.

(386) Nesbit, M. A.; Suess, D. L. M.; Peters, J. C. E-H Bond Activations and Hydrosilylation Catalysis with Iron and Cobalt Metalloboranes. Organometallics 
2015, 34 (19), 4741-4752. https://doi.org/10.1021/acs.organomet.5b00530.

(387) Greenwood, B. P.; Forman, S. I.; Rowe, G. T.; Chen, C. H.; Foxman, B. M.; Thomas, C. M. Multielectron Redox Activity Facilitated by Metal - Metal Interactions in Early/Late Heterobimetallics: Co/Zr Complexes Supported by Phosphinoamide Ligands. Inorg. Chem. 2009, 48 (13), 6251-6260. https://doi.org/10.1021/ic900552b.

(388) Setty, V. N.; Zhou, W.; Foxman, B. M.; Thomas, C. M. Subtle Differences between $\mathrm{Zr}$ and $\mathrm{Hf}$ in Early/Late Heterobimetallic Complexes with Cobalt. Inorg. Chem. 2011, 50 (10), 4647-4655. https://doi.org/10.1021/ic200445x.

(389) Krogman, J. P.; Gallagher, J. R.; Zhang, G.; Hock, A. S.; Miller, J. T.; Thomas, C. M. Assignment of the Oxidation States of $\mathrm{Zr}$ and Co in a Highly Reactive Heterobimetallic Zr/Co Complex Using X-Ray Absorption Spectroscopy (XANES). Dalt. Trans. 2014, 43 (37), 13852-13857.

https://doi.org/10.1039/c4dt01534g.

(390) Zhou, W.; Saper, N. I.; Krogman, J. P.; Foxman, B. M.; Thomas, C. M. Effect of Ligand Modification on the Reactivity of Phosphinoamide-Bridged Heterobimetallic Zr/Co Complexes. Dalt. Trans. 2014, 43 (5), 1984-1989. https://doi.org/10.1039/c3dt52133h.

(391) Zhou, W.; Marquard, S. L.; Bezpalko, M. W.; Foxman, B. M.; Thomas, C. M. Catalytic Hydrosilylation of Ketones Using a Co/Zr Heterobimetallic Complex: Evidence for an Unusual Mechanism Involving Ketyl Radicals. Organometallics 2013, 32 (6), 1766-1772. https://doi.org/10.1021/om301194g.

(392) Wesley Napoline, J.; Krogman, J. P.; Shi, R.; Kuppuswamy, S.; Bezpalko, M. W.; 
Foxman, B. M.; Thomas, C. M. Activation of E-H and E-E (E = S, O) Bonds by Heterobimetallic Zr/Co Complexes: Evidence for Both One-and Two-Electron Processes. Eur. J. Inorg. Chem. 2013, 2 (22-23), 3874-3882. https://doi.org/10.1002/ejic.201300122.

(393) Marquard, S. L.; Bezpalko, M. W.; Foxman, B. M.; Thomas, C. M. Stoichiometric $\mathrm{C}=\mathrm{O}$ Bond Oxidative Addition of Benzophenone by a Discrete Radical Intermediate to Form a Cobalt(I) Carbene. J. Am. Chem. Soc. 2013, 135 (16), 6018-6021. https://doi.org/10.1021/ja4022683.

(394) Zhou, W.; Napoline, J. W.; Thomas, C. M. A Catalytic Application of Co/Zr Heterobimetallic Complexes: Kumada Coupling of Unactivated Alkyl Halides with Alkyl Grignard Reagents. Eur. J. Inorg. Chem. 2011, No. 13, 2029-2033. https://doi.org/10.1002/ejic.201100109.

(395) Napoline, J. W.; Bezpalko, M. W.; Foxman, B. M.; Thomas, C. M. N-H Activation of Hydrazines by a Heterobimetallic Zr-Co Complex: Promotion of One-Electron Chemistry at Zr. Chem. Commun. 2013, 49 (39), 4388-4390. https://doi.org/10.1039/c2cc35594a.

(396) Krogman, J. P.; Foxman, B. M.; Thomas, C. M. Formation and Subsequent Reactivity of a N2-Stabilized Cobalt-Hydride Complex. Organometallics 2015, 34 (13), 3159-3166. https://doi.org/10.1021/acs.organomet.5b00182.

(397) Wu, B.; Gramigna, K. M.; Bezpalko, M. W.; Foxman, B. M.; Thomas, C. M. Heterobimetallic Ti/Co Complexes That Promote Catalytic N-N Bond Cleavage. Inorg. Chem. 2015, 54 (22), 10909-10917. https://doi.org/10.1021/acs.inorgchem.5b01962. 
(398) Evers, D. A.; Bluestein, A. H.; Foxman, B. M.; Thomas, C. M. Synthesis and Investigation of the Metal-Metal Interactions in Early/Late Heterobimetallic Complexes Linking Group 5 Imido Fragments to Co(I). Dalt. Trans. 2012, 41 (26), 8111. https://doi.org/10.1039/c2dt00034b.

(399) Obligacion, J. V.; Semproni, S. P.; Pappas, I.; Chirik, P. J. Cobalt-Catalyzed C(Sp2)-H Borylation: Mechanistic Insights Inspire Catalyst Design. J. Am. Chem. Soc. 2016, 138 (33), 10645-10653. https://doi.org/10.1021/jacs.6b06144.

(400) Ding, K.; Pierpont, A. W.; Brennessel, W. W.; Lukat-Rodgers, G.; Rodgers, K. R.; Cundari, T. R.; Bill, E.; Holland, P. L. Cobalt-Dinitrogen Complexes with Weakened N-N Bonds. J. Am. Chem. Soc. 2009, 131 (27), 9471-9472. https://doi.org/10.1021/ja808783u.

(401) Spitzer, F.; Graß1, C.; Balázs, G.; Mädl, E.; Keilwerth, M.; Zolnhofer, E. M.; Meyer, K.; Scheer, M. Nacnac-Cobalt-Mediated P4Transformations. Chem. - A Eur. J. 2017, 23 (11), 2716-2721. https://doi.org/10.1002/chem.201605451.

(402) Hojilla Atienza, C. C.; Milsmann, C.; Semproni, S. P.; Turner, Z. R.; Chirik, P. J. Reversible Carbon-Carbon Bond Formation Induced by Oxidation and Reduction at a Redox-Active Cobalt Complex. Inorg. Chem. 2013, 52 (9), 5403-5417. https://doi.org/10.1021/ic400352r.

(403) Bowman, A. C.; Milsmann, C.; Atienza, C. C. H.; Lobkovsky, E.; Wieghardt, K.; Chirik, P. J. Synthesis and Molecular and Electronic Structures of Reduced Bis(Imino)Pyridine Cobalt Dinitrogen Complexes: Ligand versus Metal Reduction. J. Am. Chem. Soc. 2010, 132 (5), 1676-1684. https://doi.org/10.1021/ja908955t. 
(404) Mo, Z.; Chen, D.; Leng, X.; Deng, L. Intramolecular C(Sp 3)-H Bond Activation Reactions of Low-Valent Cobalt Complexes with Coordination Unsaturation. Organometallics 2012, 31 (20), 7040-7043. https://doi.org/10.1021/om300804a.

(405) Gao, Y.; Li, G.; Deng, L. Bis(Dinitrogen)Cobalt(-1) Complexes with NHC Ligation: Synthesis, Characterization, and Their Dinitrogen Functionalization Reactions Affording Side-on Bound Diazene Complexes. J. Am. Chem. Soc. 2018, 140 (6), 2239-2250. https://doi.org/10.1021/jacs.7b11660.

(406) Yu, R. P.; Darmon, J. M.; Milsmann, C.; Margulieux, G. W.; Stieber, S. C. E.; Debeer, S.; Chirik, P. J. Catalytic Hydrogenation Activity and Electronic Structure Determination of Bis(Arylimidazol-2-Ylidene)Pyridine Cobalt Alkyl and Hydride Complexes. J. Am. Chem. Soc. 2013, 135 (35), 13168-13184. https://doi.org/10.1021/ja406608u.

(407) Simler, T.; Braunstein, P.; Danopoulos, A. A. Cobalt PNCNHC "Pincers": Ligand Dearomatisation, Formation of Dinuclear and N2 Complexes and Promotion of CH Activation. Chem. Commun. 2016, 52 (13), 2717-2720. https://doi.org/10.1039/c5cc10121b.

(408) Carpenter, A. E.; Margulieux, G. W.; Millard, M. D.; Moore, C. E.; Weidemann, N.; Rheingold, A. L.; Figueroa, J. S. Zwitterionic Stabilization of a Reactive Cobalt Tris-Isocyanide Monoanion by Cation Coordination. Angew. Chem. Int. Ed. 2012, 51 (37), 9412-9416. https://doi.org/10.1002/anie.201205058.

(409) Mokhtarzadeh, C. C.; Rheingold, A. L.; Figueroa, J. S. Dinitrogen Binding, P4Activation and Aza-Büchner Ring Expansions Mediated by an Isocyano Analogue of the $\mathrm{CpCo}(\mathrm{CO})$ Fragment. Dalt. Trans. 2016, 45 (37), 14561-14569. 
https://doi.org/10.1039/c6dt02789j.

(410) Fout, A. R.; Basuli, F.; Fan, H.; Tomaszewski, J.; Huffman, J. C.; Baik, M. H.; Mindiola, D. J. A Co2N2 Diamond-Core Resting State of Cobalt(I): A ThreeCoordinate CoI Synthon Invoking an Unusual Pincer-Type Rearrangement. Angew. Chem. Int. Ed. 2006, 45 (20), 3291-3295.

https://doi.org/10.1002/anie.200504343.

(411) Ingleson, M.; Fan, H.; Pink, M.; Tomaszewski, J.; Caulton, K. G. ThreeCoordinate Co(I) Provides Access to Unsaturated Dihydrido-Co(III) and SevenCoordinate Co(V). J. Am. Chem. Soc. 2006, 128 (6), 1804-1805. https://doi.org/10.1021/ja0572452.

(412) Rozenel, S. S.; Padilla, R.; Arnold, J. Chemistry of Reduced Monomeric and Dimeric Cobalt Complexes Supported by a PNP Pincer Ligand. Inorg. Chem. 2013, 52 (19), 11544-11550. https://doi.org/10.1021/ic4018882.

(413) Kuriyama, S.; Arashiba, K.; Tanaka, H.; Matsuo, Y.; Nakajima, K.; Yoshizawa, K.; Nishibayashi, Y. Direct Transformation of Molecular Dinitrogen into Ammonia Catalyzed by Cobalt Dinitrogen Complexes Bearing Anionic PNP Pincer Ligands. Angew. Chem. Int. Ed. 2016, 55 (46), 14291-14295. https://doi.org/10.1002/anie.201606090.

(414) Lin, T. P.; Peters, J. C. Boryl-Mediated Reversible H2 Activation at Cobalt: Catalytic Hydrogenation, Dehydrogenation, and Transfer Hydrogenation. J. Am. Chem. Soc. 2013, 135 (41), 15310-15313. https://doi.org/10.1021/ja408397v.

(415) Suzuki, T.; Fujimoto, K.; Takemoto, Y.; Wasada-tsutsui, Y.; Ozawa, T. E Ffi Cient Catalytic Conversion of Dinitrogen to N(SiMe 3 ) 3 Using a Homogeneous 
Mononuclear Cobalt Complex. 2018. https://doi.org/10.1021/acscatal.7b04351.

(416) Ibrahim, A. D.; Tokmic, K.; Brennan, M. R.; Kim, D.; Matson, E. M.; Nilges, M.

J.; Bertke, J. A.; Fout, A. R. Monoanionic Bis(Carbene) Pincer Complexes

Featuring Cobalt(I-III) Oxidation States. Dalt. Trans. 2016, 45 (24), 9805-9811. https://doi.org/10.1039/c5dt04723d.

(417) Tokmic, K.; Markus, C. R.; Zhu, L.; Fout, A. R. Well-Defined Cobalt(I) Dihydrogen Catalyst: Experimental Evidence for a Co(I)/Co(III) Redox Process in Olefin Hydrogenation. J. Am. Chem. Soc. 2016, 138 (36), 11907-11913. https://doi.org/10.1021/jacs.6b07066.

(418) Ibrahim, A. D.; Entsminger, S. W.; Zhu, L.; Fout, A. R. A Highly Chemoselective Cobalt Catalyst for the Hydrosilylation of Alkenes Using Tertiary Silanes and Hydrosiloxanes. ACS Catal. 2016, 6 (6), 3589-3593. https://doi.org/10.1021/acscatal.6b01091.

(419) Sun, J.; Luo, L.; Luo, Y.; Deng, L. An NHC-Silyl-NHC Pincer Ligand for the Oxidative Addition of $\mathrm{C}-\mathrm{H}, \mathrm{N}-\mathrm{H}$, and $\mathrm{O}-\mathrm{H}$ Bonds to Cobalt(I) Complexes. Angew. Chem. Int. Ed. 2017, 56 (10), 2720-2724. https://doi.org/10.1002/anie.201611162.

(420) Hoffman, P. R.; Yoshida, T.; Okano, T.; Otsuka, S.; Ibers, J. A. Crystal and Molecular Structure of Hydrido(Dinitrogen)Bis[Phenyl(Di-Tert-Butyl)Phosphine]Rhodium(I). Inorg. Chem. 1976, 15 (10), 2462-2466. https://doi.org/10.1021/ic50164a030.

(421) Werner, H.; Mahr, N.; Wolf, J.; Fries, A.; Laubender, M.; Bleuel, E.; Garde, R.; Lahuerta, P. Synthesis, Molecular Structure, and Reactivity of Rhodium(I) 
Complexes with Diazoalkanes and Related Substrates as Ligands. Organometallics 2003, 22 (17), 3566-3576. https://doi.org/10.1021/om0302037.

(422) Hanson, S. K.; Heinekey, D. M.; Goldberg, K. I. C-H Bond Activation by Rhodium(I) Phenoxide and Acetate Complexes: Mechanism of H-D Exchange between Arenes and Water. Organometallics 2008, 27 (7), 1454-1463. https://doi.org/10.1021/om7012259.

(423) Adams, G. M.; Chadwick, F. M.; Pike, S. D.; Weller, A. S. A CH2Cl2 Complex of a [Rh(Pincer)]+ Cation. Dalt. Trans. 2015, 44 (14), 6340-6342. https://doi.org/10.1039/c5dt00481k.

(424) Feller, M.; Diskin-Posner, Y.; Shimon, L. J. W.; Ben-Ari, E.; Milstein, D. N-H Activation by $\mathrm{Rh}(\mathrm{I})$ via Metal-Ligand Cooperation. Organometallics 2012, 31 (11), 4083-4101. https://doi.org/10.1021/om300248r.

(425) Schöffel, J.; Šušnjar, N.; Nückel, S.; Sieh, D.; Burger, P. 4d vs. 5d - Reactivity and Fate of Terminal Nitrido Complexes of Rhodium and Iridium. Eur. J. Inorg. Chem. 2010, No. 31, 4911-4915. https://doi.org/10.1002/ejic.201000899.

(426) Salem, H.; Ben-David, Y.; Shimon, L. J. W.; Milstein, D. Exclusive C-C Activation and an Apparent $\alpha$-H Elimination with a Rhodium Phosphinite Pincer Complex. Organometallics 2006, 25 (9), 2292-2300. https://doi.org/10.1021/om060005q.

(427) Cohen, R.; Rybtchinski, B.; Gandelman, M.; Shimon, L. J. W.; Martin, J. M. L.; Milstein, D. Novel Azine Reactivity: Facile N-N Bond Cleavage, C-H Activation, and N-N Coupling Mediated by RhI. Angew. Chem. Int. Ed. 2003, 42 (17), 19491952. https://doi.org/10.1002/anie.200250571. 
(428) Cohen, R.; Rybtchinski, B.; Gandelman, M.; Rozenberg, H.; Martin, J. M. L.; Milstein, D. Metallacarbenes from Diazoalkanes: An Experimental and Computational Study of the Reaction Mechanism. J. Am. Chem. Soc. 2003, 125 (21), 6532-6546. https://doi.org/10.1021/ja028923c.

(429) Gatard, S.; Guo, C.; Foxman, B. M.; Ozerov, O. V. Thioether, Dinitrogen, and Olefin Complexes of (PNP)Rh: Kinetics and Thermodynamics of Exchange and Oxidative Addition Reactions. Organometallics 2007, 26 (25), 6066-6075. https://doi.org/10.1021/om700563k.

(430) Verat, A. Y.; Pink, M.; Fan, H.; Tomaszewski, J.; Caulton, K. G. [( T Bu 2 PCH 2 SiMe 2 ) 2 N]Rh I ? Rapidly Reversible $\mathrm{H}^{-} \mathrm{C}(\mathrm{Sp} 3$ ) and $\mathrm{H}-\mathrm{C}(\mathrm{Sp} 2$ ) Bond Cleavage by Rhodium(I). Organometallics 2008, 27 (2), 166-168. https://doi.org/10.1021/om701165n.

(431) Scheibel, M. G.; Wu, Y.; Stückl, A. C.; Krause, L.; Carl, E.; Stalke, D.; De Bruin, B.; Schneider, S. Synthesis and Reactivity of a Transient, Terminal Nitrido Complex of Rhodium. J. Am. Chem. Soc. 2013, 135 (47), 17719-17722. https://doi.org/10.1021/ja409764j.

(432) Hasegawa, M.; Segawa, Y.; Yamashita, M.; Nozaki, K. Isolation of a PBP-Pincer Rhodium Complex Stabilized by an Intermolecular C-H $\sigma$ Coordination as the Fourth Ligand. Angew. Chem. Int. Ed. 2012, 51 (28), 6956-6960. https://doi.org/10.1002/anie.201201916.

(433) Zenkina, O. V.; Keske, E. C.; Wang, R.; Crudden, C. M. Double Single-Crystal-toSingle-Crystal Transformation and Small-Molecule Activation in Rhodium NHC Complexes. Angew. Chem. Int. Ed. 2011, 50 (35), 8100-8104. 
https://doi.org/10.1002/anie.201103316.

(434) Praetorius, J. M.; Wang, R.; Crudden, C. M. Structure and Reactivity of Dinitrogen Rhodium Complexes Containing N-Heterocyclic Carbene Ligands. Eur. J. Inorg. Chem. 2009, No. 13 SPEC. ISS., 1746-1751. https://doi.org/10.1002/ejic.200801191.

(435) Millard, M. D.; Moore, C. E.; Rheingold, A. L.; Figueroa, J. S. Four-Coordinate Iridium(I) Monohydrides: Reversible Dinitrogen Binding, Bond Activations, and Deprotonations. J. Am. Chem. Soc. 2010, 132 (26), 8921-8923. https://doi.org/10.1021/ja1037808.

(436) Tang, C. Y.; Thompson, A. L.; Aldridge, S. Dehydrogenation of Saturated CC and BN Bonds at Cationic N-Heterocyclic Carbene Stabilized M(III) Centers (M = Rh, Ir). J. Am. Chem. Soc. 2010, 132 (30), 10578-10591. https://doi.org/10.1021/ja1043787.

(437) Tang, C. Y.; Smith, W.; Thompson, A. L.; Vidovic, D.; Aldridge, S. IridiumMediated Borylation of Benzylic C-H Bonds by Borohydride. Angew. Chem. Int. Ed. 2011, 50 (6), 1359-1362. https://doi.org/10.1002/anie.201006320.

(438) Bohle, D. S.; Chua, Z.; Perepichka, I. Facile N-N Activation in Benzotriazole: Capturing the Dimroth Azo/Triazole Intermediate by Complexation to Iridium. Chempluschem 2013, 78 (10), 1304-1310. https://doi.org/10.1002/cplu.201300245.

(439) Yang, W.; Zhang, S.; Ding, Y.; Shi, L.; Song, Q. A Photoluminescent Dinuclear Phenylquinolyl Ir(Ii)-Ir(Ii) Complex Featuring a $\mu-\mathrm{H} 1$ :H2-Phenylquinolyl Bridge and an End-on Dinitrogen Ligand. Chem. Commun. 2011, 47 (18), 5310-5312. 
https://doi.org/10.1039/c1cc11254f.

(440) Ghosh, R.; Kanzelberger, M.; Emge, T. J.; Hall, G. S.; Goldman, A. S. Dinitrogen Complexes of Pincer-Ligated Iridium. Organometallics 2006, 25 (23), 5668-5671. https://doi.org/10.1021/om0607043.

(441) Arunachalampillai, A.; Olsson, D.; Wendt, O. F. Synthesis and Characterisation of PCsp3P Phosphine and Phosphinite Iridium Complexes. Cyclometallation and Dehydrogenation of a Cyclohexyl Ring. Dalt. Trans. 2009, No. 40, 8626-8630. https://doi.org/10.1039/b910798c.

(442) Göttker-Schnetmann, I.; White, P. S.; Brookhart, M. Synthesis and Properties of Iridium Bis(Phosphinite) Pincer Complexes (p-XPCP)IrH 2, (p-XPCP)Ir(CO), (p$\mathrm{XPCP}) \operatorname{Ir}(\mathrm{H})(\mathrm{Aryl})$, and $\{(\mathrm{p}-\mathrm{XPCP}) \operatorname{Ir}\} \mathrm{H} 2\{\mu-\mathrm{N} 2\}$ and Their Relevance in Alkane Transfer Dehydrogenation. Organometallics 2004, 23 (8), 1766-1776. https://doi.org/10.1021/om030670o.

(443) Huang, Z.; White, P. S.; Brookhart, M. Ligand Exchanges and Selective Catalytic Hydrogenation in Molecular Single Crystals. Nature 2010, 465 (7298), 598-601. https://doi.org/10.1038/nature09085.

(444) Fang, H.; Choe, Y. K.; Li, Y.; Shimada, S. Synthesis, Structure, and Reactivity of Hydridoiridium Complexes Bearing a Pincer-Type PSiP Ligand. Chem. - An Asian J. 2011, 6 (9), 2512-2521. https://doi.org/10.1002/asia.201100085.

(445) Conejero, S.; Esqueda, A. C.; Valpuesta, J. E. V.; Álvarez, E.; Maya, C.; Carmona, E. Different Coordination Modes of an Aryl-Substituted Hydrotris(Pyrazolyl) Borate Ligand in Rhodium and Iridium Complexes. Inorganica Chim. Acta 2011, 369 (1), 165-172. https://doi.org/10.1016/j.ica.2010.12.031. 
(446) Bernskoetter, W. H.; Lobkovsky, E.; Chirik, P. J. Synthesis of a $\beta$-Diiminate Iridium Tetrahydride for Arene $\mathrm{C}-\mathrm{H}$ Bond Activation. Chem. Commun. 2004, 4 (7), 764-765. https://doi.org/10.1039/b315817a.

(447) Whited, M. T.; Grubbs, R. H. A Catalytic Cycle for Oxidation of Tert-Butyl Methyl Ether by a Double C-H Activation-Group Transfer Process. J. Am. Chem. Soc. 2008, 130 (49), 16476-16477. https://doi.org/10.1021/ja8071385.

(448) Scheibel, M. G.; Askevold, B.; Heinemann, F. W.; Reijerse, E. J.; De Bruin, B.; Schneider, S. Closed-Shell and Open-Shell Square-Planar Iridium Nitrido Complexes. Nat. Chem. 2012, 4 (7), 552-558. https://doi.org/10.1038/nchem.1368.

(449) Abbenseth, J.; Finger, M.; Würtele, C.; Kasanmascheff, M.; Schneider, S. Coupling of Terminal Iridium Nitrido Complexes. Inorg. Chem. Front. 2016, 3 (4), 469-477. https://doi.org/10.1039/c5qi00267b.

(450) Scheibel, M. G.; Abbenseth, J.; Kinauer, M.; Heinemann, F. W.; Würtele, C.; De Bruin, B.; Schneider, S. Homolytic N-H Activation of Ammonia: Hydrogen Transfer of Parent Iridium Ammine, Amide, Imide, and Nitride Species. Inorg. Chem. 2015, 54 (19), 9290-9302. https://doi.org/10.1021/acs.inorgchem.5b00829.

(451) Beck, R.; Shoshani, M.; Krasinkiewicz, J.; Hatnean, J. A.; Johnson, S. A. Synthesis and Chemistry of Bis(Triisopropylphosphine) Nickel(i) and Nickel(0) Precursors. J. Chem. Soc. Dalt. Trans. 2013, 42 (2), 1461-1475. https://doi.org/10.1039/c2dt32008h.

(452) Waterman, R.; Hillhouse, G. L. Synthesis and Structure of a Terminal Dinitrogen Complex of Nickel. Can. J. Chem. 2005, 83 (4), 328-331. https://doi.org/10.1139/v05-011. 
(453) Kim, Y. E.; Kim, J.; Lee, Y. Formation of a Nickel Carbon Dioxide Adduct and Its Transformation Mediated by a Lewis Acid. Chem. Commun. 2014, 50 (78), 11458-11461. https://doi.org/10.1039/c4cc04800h.

(454) Kim, Y. E.; Oh, S.; Kim, S.; Kim, O.; Kim, J.; Han, S. W.; Lee, Y. PhosphiniteNi(0) Mediated Formation of a Phosphide-Ni(II)-OCOOMe Species via Uncommon Metal-Ligand Cooperation. J. Am. Chem. Soc. 2015, 137 (13), 42804283. https://doi.org/10.1021/ja513112r.

(455) Oh, S.; Kim, S.; Lee, D.; Gwak, J.; Lee, Y. Alkoxide Migration at a Nickel(II) Center Induced by a Ï€-Acidic Ligand: Migratory Insertion versus Metal-Ligand Cooperation. Inorg. Chem. 2016, 55 (24), 12863-12871. https://doi.org/10.1021/acs.inorgchem.6b02226.

(456) Charboneau, D. J.; Balcells, D.; Hazari, N.; Lant, H. M. C.; Mayer, J. M.; Melvin, P. R.; Mercado, B. Q.; Morris, W. D.; Repisky, M.; Suh, H. W. DinitrogenFacilitated Reversible Formation of a Si-H Bond in a Pincer-Supported Ni Complex. Organometallics 2016, 35 (18), 3154-3162. https://doi.org/10.1021/acs.organomet.6b00514.

(457) Harman, W. H.; Lin, T. P.; Peters, J. C. A D10 Ni-(H2) Adduct as an Intermediate in H-H Oxidative Addition across a Ni-B Bond. Angew. Chem. Int. Ed. 2014, 53 (4), 1081-1086. https://doi.org/10.1002/anie.201308175.

(458) Cowie, B. E.; Emslie, D. J. H. Nickel and Palladium Complexes of FerroceneBackbone Bisphosphine-Borane and Trisphosphine Ligands. Organometallics 2015, 34 (16), 4093-4101. https://doi.org/10.1021/acs.organomet.5b00539.

(459) Tsay, C.; Peters, J. C. Thermally Stable N2 and H2 Adducts of Cationic Nickel(II). 
Chem. Sci. 2012, 3 (4), 1313-1318. https://doi.org/10.1039/c2sc01033j.

(460) Cammarota, R. C.; Lu, C. C. Tuning Nickel with Lewis Acidic Group 13 Metalloligands for Catalytic Olefin Hydrogenation. J. Am. Chem. Soc. 2015, 137 (39), 12486-12489. https://doi.org/10.1021/jacs.5b08313.

(461) Pfirrmann, S.; Limberg, C.; Herwig, C.; Stößer, R.; Ziemer, B. A Dinuclear Nickel(i) Dinitrogen Complex and Its Reduction in Single- Electron Steps. Angew. Chem. Int. Ed. 2009, 48 (18), 3357-3361. https://doi.org/10.1002/anie.200805862.

(462) Horn, B.; Pfirrmann, S.; Limberg, C.; Herwig, C.; Braun, B.; Mebs, S.; Metzinger, R. N2 Activation in NiI-NN-NiI Units: The Influence of Alkali Metal Cations and CO Reactivity. Zeitschrift fur Anorg. und Allg. Chemie 2011, 637 (9), 1169-1174. https://doi.org/10.1002/zaac.201100140.

(463) Holze, P.; Horn, B.; Limberg, C.; Matlachowski, C.; Mebs, S. The Activation of Sulfur Hexafluoride at Highly Reduced Low-Coordinate Nickel Dinitrogen Complexes. Angew. Chem. Int. Ed. 2014, 53 (10), 2750-2753. https://doi.org/10.1002/anie.201308270.

(464) Chavan, S.; Bonino, F.; Vitillo, J. G.; Groppo, E.; Lamberti, C.; Dietzel, P. D. C.; Zecchina, A.; Bordiga, S. Response of CPO-27-Ni towards CO, N2 and C2H 4. Phys. Chem. Chem. Phys. 2009, 11 (42), 9811-9822. https://doi.org/10.1039/b907258f.

(465) Murray, L. J.; Weare, W. W.; Shearer, J.; Mitchell, A. D.; Abboud, K. A. Isolation of a (Dinitrogen)Tricopper(I) Complex. J. Am. Chem. Soc. 2014, 136 (39), 1350213505. https://doi.org/10.1021/ja506445d.

(466) Di Francesco, G. N.; Gaillard, A.; Ghiviriga, I.; Abboud, K. A.; Murray, L. J. 
Modeling Biological Copper Clusters: Synthesis of a Tricopper Complex, and Its Chloride- and Sulfide-Bridged Congeners. Inorg. Chem. 2014, 53 (9), 4647-4654. https://doi.org/10.1021/ic500333p.

(467) Zhang, S.; Fallah, H.; Gardner, E. J.; Kundu, S.; Bertke, J. A.; Cundari, T. R.; Warren, T. H. A Dinitrogen Dicopper(I) Complex via a Mixed-Valence Dicopper Hydride. Angew. Chem. Int. Ed. 2016, 55 (34), 9927-9931. https://doi.org/10.1002/anie.201603970.

(468) Hsu, W.; Thapa, K. B.; Yang, X. K.; Chen, K. T.; Chang, H. Y.; Chen, J. Der. Dinitrogen-Supported Coordination Polymers. CrystEngComm 2016, 18 (3), 390393. https://doi.org/10.1039/c5ce02127h.

(469) Welz, E.; Krummenacher, I.; Engels, B.; Braunschweig, H. Reduction At Boron. Science (80-. ). 2018, 900 (February), 896-900.

(470) Légaré, M. A.; Rang, M.; Bélanger-Chabot, G.; Schweizer, J. I.; Krummenacher, I.; Bertermann, R.; Arrowsmith, M.; Holthausen, M. C.; Braunschweig, H. The Reductive Coupling of Dinitrogen. Science (80-. ). 2019, 363 (6433), 1329-1332. https://doi.org/10.1126/science.aav9593.

(471) Sherbow, T. J.; Thompson, E. J.; Arnold, A.; Sayler, R. I.; Britt, R. D.; Berben, L. A. Electrochemical Reduction of N2 to NH3 at Low Potential by a Molecular Aluminum Complex. Chem. - A Eur. J. 2019, 25 (2), 454-458. https://doi.org/10.1002/chem.201804454. 
